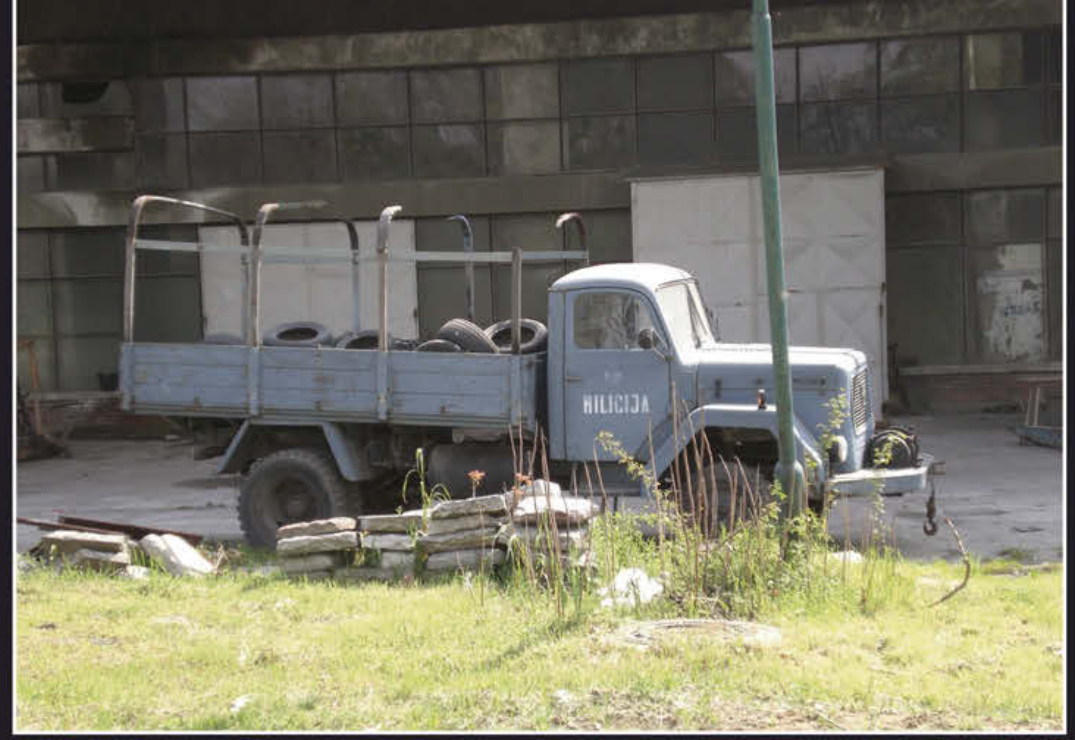

\title{
Daniela Mehler
}

Serbistho

Vergangenheitsaufarbeitung

Normwandel und Deutungskämpfe im Umgang mit Kriegsverbreehen, 1991-2012

[transcript] G 1 oba $/$ s tudies 
Daniela Mehler

Serbische Vergangenheitsaufarbeitung 
Daniela Mehler arbeitet als Referentin in der Präsidialabteilung der Goethe-Universität Frankfurt am Main. 
DANiela Mehler

\section{Serbische Vergangenheitsaufarbeitung}

Normwandel und Deutungskämpfe im Umgang mit Kriegsverbrechen, 1991-2012

[transcript] 


\section{(9) $(1) \Theta \Theta$}

Dieses Werk ist lizenziert unter der Creative Commons Attribution-NonCommercial-NoDerivs 4.0 Lizenz (BY-NC-ND). Diese Lizenz erlaubt die private Nutzung, gestattet aber keine Bearbeitung und keine kommerzielle Nutzung. Weitere Informationen finden Sie unter https://creativecommons.org/licenses/by-nc-nd/4.o/deed.de/. Um Genehmigungen für Adaptionen, Übersetzungen, Derivate oder Wiederverwendung zu kommerziellen Zwecken einzuholen, wenden Sie sich bitte an rights@transcript-verlag.de

\section{(C) 2015 transcript Verlag, Bielefeld}

Die Verwertung der Texte und Bilder ist ohne Zustimmung des Verlages urheberrechtswidrig und strafbar. Das gilt auch für Vervielfältigungen, Übersetzungen, Mikroverfilmungen und für die Verarbeitung mit elektronischen Systemen.

\section{Bibliografische Information der Deutschen Nationalbibliothek}

Die Deutsche Nationalbibliothek verzeichnet diese Publikation in der Deutschen Nationalbibliografie; detaillierte bibliografische Daten sind im Internet über http://dnb.d-nb.de abrufbar.

Umschlagkonzept: Kordula Röckenhaus, Bielefeld

Umschlagabbildung: Ausgesondertes Polizeifahrzeug in Belgrad, 2007 (Daniela Mehler).

Lektorat \& Satz: Jan Wenke, Leipzig

Druck: Majuskel Medienproduktion GmbH, Wetzlar

Print-ISBN 978-3-8376-2850-0

PDF-ISBN 978-3-8394-2850-4

Gedruckt auf alterungsbeständigem Papier mit chlorfrei gebleichtem Zellstoff. Besuchen Sie uns im Internet: http://www.transcript-verlag.de

Bitte fordern Sie unser Gesamtverzeichnis und andere Broschüren an unter: info@transcript-verlag.de 


\section{Inhalt}

Abkürzungsverzeichnis | 7

Danksagung | 9

1. Einleitung | 11

1.1 Forschungsstand, Leerstellen, Innovationen | 13

1.2 Theoretische Einbettung | 21

1.3 Vergangenheitsaufarbeitung | 32

1.4 Analyseschritte und Operationalisierung | 41

1.5 Material | 44

2. Erfahrungsbasierte Vorstellungen des Umgangs mit Kriegsverbrechen | 49

2.1 Der internationale Umgang mit Kriegsverbrechen 49

2.2 Der Umgang mit Kriegsverbrechen in Jugoslawien | 61

2.3 Aufarbeitung $\neq$ Aufarbeitung | 79

3. Vergangenheitsaufarbeitung in Jugoslawien und Serbien 1991-2012 | 83

3.1 Die Aufarbeitung von Kriegsverbrechen im Milošević-Regime | 85

3.2 Die Aufarbeitung von Kriegsverbrechen im demokratischen Serbien | 153

3.3 Normativer Wandel: Normübernahme? | 242

4. Srebrenica erinnern: Narrative und Normen | 251

4.1 Internationale Deklarationen und Deutungsfestschreibungen 1995-2009 | 253

4.2 Deklarationen serbischer Akteure 2005-2010 | 272

4.3 Lexikometrische Analyse des Normwandels in Serbien | 289

4.4 Eine Wahrheit? | 297

5. Fazit $\mid 303$

Literatur/Quellen | 313

Verwendetes Diktionär | 357

Serbische Auslieferungen an das ICTY | 359 



\section{Abkürzungsverzeichnis}

AVNOJ Antifašističko veće narodnog oslobođenja Jugoslavije, Antifaschistischer Rat der Volksbefreiung Jugoslawiens

BdK Bund der Kommunisten

BIA Bezbednosno-informativna agencija, Sicherheitsinformationsdienst, Geheimdienst der Republik Serbien seit 2002

CG Crna Gora, Länderkennung für Montenegro

DHSS Demohrišćanska Stranka Srbije, Christdemokratische Partei Serbiens

DKZ Državna komisija za utvrđivanje zločina okupatora i njegovih pomagača, Staatliche Kommission zur Feststellung von Verbrechen der Okkupanten und ihrer Helfer

DOS Demokratska Opozicija Srbija, Demokratische Opposition Serbiens, Oppositionsbündnis aus 18 Parteien, bestehend 2000-2003

DS Demokratska Stranka, Demokratische Partei

DSS Demokratska Stranka Srbije, Demokratische Partei Serbiens

EU European Union, Europäische Union

EULEX European Union Rule of Law Mission Kosovo, Rechtsstaatlichkeitsmission der Europäischen Union im Kosovo

GSS Građanski savez Srbije, Bürgerbund Serbiens

HR Hrvatska, Länderkennung für Kroatien

ICTY International Criminal Tribunal for the Prosecution of Persons Responsible for Serious Violations of International Humantiarian Law Committed on the Territory of the Former Yugoslavia since 1991, Internationaler Strafgerichtshof für das ehemalige Jugoslawien

JNA Jugoslovenska Narodna Armija, Jugoslawische Volksarmee

JS Jedinstvena Srbija, Einiges Serbien

KNOJ Korpus Narodne Odbrane Jugoslavije, Korpus der Volksverteidigung Jugoslawiens

LDP Liberalno-demokratska Partija, Liberaldemokratische Partei 
LSV Liga Socijaldemokrata Vojvodine, Liga der Sozialdemokraten der Vojvodina

NATO North Atlantic Treaty Organization, Organisation des Nordatlantikvertrags bzw. Atlantisches Bündnis

NDH Nezavisna Država Hrvatska, Unabhängiger Staat Kroatien

NGO non-governmental organization, Nichtregierungsorganisation

NIOD Nederlands Instituut voor Oorlogsdocumentatie, Niederländisches Institut für Kriegsdokumentation

NS Nova Srbija, Neues Serbien

OECD Organisation for Economic Co-operation and Development, Organisation für wirtschaftliche Zusammenarbeit und Entwicklung

OSZE Organization for Security and Co-operation in Europe, Organisation für Sicherheit und Zusammenarbeit

OZNA Organ Zaštite Naroda, Organ des Volksschutzes

PUPS Partija ujedinjenih penzionera Srbije, Partei der vereinigten Pensionäre Serbiens

SDA Stranka Demokratske Akcije, Partei der Demokratischen Aktion

SDP Socijaldemokratska Partija, Sozialdemokratische Partei

SDU Socijaldemokratska unija, Sozialdemokratische Union

SFRJ Socijalistička federativna republika Jugoslavija, Sozialistisch-föderative Republik Jugoslawien

SLO Slovenija, Länderkennung für Slowenien

SNS Srpska Napredna Stranka, Serbische Fortschrittspartei

SPO Srpski Pokret Obnove, Serbische Erneuerungsbewegung

SPS Socijalistička Partija Srbije, Sozialistische Partei Serbiens

SRB Srbija, Länderkennung für Serbien

SRJ Savezne Republike Jugoslavije, Bundesrepublik Jugoslawien

SRS Srpska Radikalna Stranka, Serbische Radikale Partei

SVM Savez vojvođanskih Mađara, Bund der Ungarn der Vojvodina

UÇK Ushtria Çlirimtare e Kosovës, Befreiungsarmee des Kosovo

UN United Nations, Vereinte Nationen

URS Ujedinjeni Regioni Srbije, Vereinigte Regionen Serbiens 


\section{Danksagung}

Der Prozess zu diesem Buch war von vielen Menschen und Begegnungen geprägt. Für die fachliche und persönliche Begleitung auf dem Weg zum Gegenstand danke ich Aleksandar Jakir, Antonija Petričušić, Bosiljka Schedlich sowie Josefina Bajer und Aleksandra Vedernjak, die mich zur Auseinandersetzung mit den Kriegsvergangenheiten ermutigten. Die Reflexion vieler Eindrücke unterstützten Jörn Leonard und Joachim von Puttkamer in einem wissenschaftlichen Kolleg der Studienstiftung des Deutschen Volkes sowie daraus enstehend die langjährige Zusammenarbeit mit Gregor Feindt, Félix Krawatzek, Friedemann Pestel und Rieke Trimçev.

Grundlegend für meine Feldforschungen in Serbien war es, meine Sprachkompetenz mit Hilfe der hervorragenden Vorbereitung von Milica Sabo, Željana Tunić und Biljana Milošević zu erhöhen. Mein Forschungsvorhaben und die Drucklegung wurden durch das DFG-geförderte Graduiertenkolleg »Kulturelle Orientierungen und gesellschaftliche Ordnungsstrukturen in Südosteuropa« unterstützt, das mir eine ideale Infrastruktur, ein regionalspezifisches Diskussionsforum sowie die nötigen Freiräume bereitstellte. Meine beiden Betreuer Olaf Leiße und Thorsten Bonacker unterstützten mich herzlich und pragmatisch.

Während meiner Feldforschungsphasen in Belgrad und Novi Sad begleiteten mich Milica Despotov, Marijana Simu, Iva Kolundžija, Bojan Čimbaljević, Snežana Ilić, Dragan Šljivić, Ksenija Petrović, Elizabeth Salmore, Amrei Walkenhorst, Johannes Rüger, Nora Hasani und Florijana Trpeva liebevoll. Ein besonderer Dank gilt Velimir Čurgus Kazimir, der den Zugang zur digitalen Datenbank von Ebart Consulting ermöglichte.

Nicht vergessen seien die Korrekturleser Jan-Niklas und Anja Mehler, Frank Würzbach, Gösta Neumann, André John, Christian Reumschüssel, Johannes Rüger, Stefanie Wittich und die aufmerksamen Augen von Jan Wenke.

Für Halt und Zuspruch bei jeglichen Berg- und Talfahrten danke ich Hanns Schneider und insbesondere meinem Mann Stefan Würzbach. 



\section{Einleitung}

Sramota mi je, dakle postojim.

[Ich schäme mich, also bin ich.]

Bei einem Spaziergang durch die serbische Hauptstadt Belgrad stolperte ich im September 2011 über dieses Graffito, das sich augenscheinlich an das Postulat ego cogito, ergo sum von René Descartes anlehnt. Diese Analogie verblüffte mich: Während Descartes nach den radikalen Zweifeln an der Erkenntnisfähigkeit aus dem Denken seine Existenzberechtigung ableitete, begründete das Graffito die Existenz mit Scham. Kann Scham der Grund für Existenz sein? Wird schämen hier mit erkennen gleichgesetzt? Was sagt das über die Person, die sich so beschreibt? Oder ist das keine Selbstbeschreibung und damit Identitätsressource, sondern eine Rechtfertigung für die eigene Existenz gegenüber anderen? Der Bezug auf den Umgang der serbischen Politik und Gesellschaft mit den während der Jugoslawienkriege »im Namen der Serben« begangenen Kriegsverbrechen schien mir offensichtlich.

Die Verbindung zwischen Scham und Legitimität ist ein zentrales Motiv serbischer Außenpolitik. Im April 2013 formulierte der serbische Präsident Tomislav Nikolić in einem Interview mit einem bosnischen TV-Sender: »Ich knie und suche um Vergebung für Serbien für das Verbrechen, das in Srebrenica begangen wurde. $\ll^{2}$ Sowohl diese Äußerung als auch das Graffito illustrieren die zugrundeliegende Prämisse dieses Buchs: In der gegenwärtigen Formation internationaler und europäischer Politik muss ein Staat seine Untaten bereuen, um außenpolitische Legitimität zu erhalten. Die zunehmende Zahl von Institutionen,

1 Graffito in der Krunska ulica, Belgrad, vom 22.9.2011.

2 Tanjug: »Nikolić se izvinio zbog zločina i najavio posetu Srebrenici« [Nikolić hat sich wegen des Verbrechens entschuldigt und kündigt Besuch in Srebrenica an], in: politika.rs vom 25.4.2013, http://www.politika.rs/rubrike/Politika/Nikolic-se-izviniozbog-zlocina-i-najavio-posetu-Srebrenici.lt.html vom 25.4.2013. 
Prozessen und nationalen Gesetzgebungen auf dem Feld der transitional justice suggerieren diesen Eindruck. Auch die Schärfe, mit der Staaten, Politiker ${ }^{3}$ oder Prominente, die ein Massenverbrechen oder einen Völkermord leugnen, in öffentlichen Diskursen verurteilt werden, nimmt zu. In den letzten Jahrzehnten scheint sich eine globale Norm der Vergangenheitsaufarbeitung durchgesetzt zu haben, die von einer Vielzahl unterschiedlicher Akteure verfochten wird. Diese neue Norm wird vor allem im Anschluss an internationale Konflikte durchgesetzt. Doch inwieweit funktioniert ein solches Übertragen globaler Normen auf lokale Prozesse? Wie sinnvoll ist eine externe Induzierung von Prozessen der Auseinandersetzung mit Kriegsverbrechen und Menschenrechtsverletzungen in Postkonfliktgesellschaften?

Die Probleme extern induzierter Aufarbeitung und transnationaler Normdiffusionsprozesse werden in dieser theoriegeleiteten Einzelfallstudie am Beispiel Serbien $^{4}$ aufgezeigt. Serbien dient wie andere jugoslawische Nachfolgestaaten als Laboratorium für die Aufarbeitung von Kriegsverbrechen: Hier wurde zum ersten Mal ein internationales Tribunal während eines laufenden Konflikts errichtet, ein regionales System von Sonderstaatsanwälten und -gerichten zur Verfolgung von Kriegsverbrechen eingerichtet, die Aufarbeitung der Kriegsverbrechen und -vergangenheit zu einem Prinzip der Konditionalitätspolitik von Staaten und Internationalen Organisationen gemacht und ein kooperativer Ansatz zur Versöhnung von zivilgesellschaftlichen Initiativen entwickelt. ${ }^{5}$ Zentral für die Auswahl Serbiens ist, dass Material über die Aufarbeitung für einen Zeitraum von ca. zwanzig Jahren vorliegt. Im Verlauf dieser Zeit kann ein starker Wandel in der Aufarbeitung der während der Jugoslawienkriege ${ }^{6}$ begangenen

3 Mit Nennung der männlichen Funktionsbezeichnung ist in diesem Buch, sofern nicht anders gekennzeichnet, immer auch die weibliche Form mitgemeint.

4 Diese Arbeit konzentriert sich auf das Serbien, das die größte Teilrepublik Jugoslawiens war und ab 1992 als Bundesrepublik Jugoslawien dessen Rechtsnachfolge übernahm. 2003 wurde es zur Staatenunion Serbien und Montenegro umgewandelt. Seit der Unabhängigkeit Montenegros 2006 nennt es sich Republik Serbien. 2008 erklärte sich das Kosovo unabhängig von Serbien. Das Kosovo und Montenegro werden im Rahmen der vorliegenden Untersuchung vernachlässigt.

5 Dragović-Soso, Jasna/Gordy, Eric D.: »Coming to Terms with the Past. Transitional Justice and Reconciliation in the Post-Yugoslav Lands«, in: James Ker-Lindsay/ Dejan Djokić (Hg.): New Perspectives on Yugoslavia. Key Issues and Controversies, Milton Park/New York: Routledge 2011, S. 193-213, hier S. 192.

6 Als Jugoslawienkriege werden der Zehn-Tage-Krieg in Slowenien 1991, der Kroatienkrieg 1991-1995 sowie der Bosnienkrieg 1992-1995 bezeichnet. Von der Unter- 
Kriegsverbrechen und Menschenrechtsverletzungen ${ }^{7}$ beobachtet werden. Externe Akteure haben einerseits durch die externe Induzierung einer strafrechtlichen Aufarbeitung von Kriegsverbrechen und andererseits durch Konditionalitätspolitik auf diesen Wandel starken Einfluss genommen.

Betrachtet man den Wandel der serbischen Politik der Aufarbeitung von Kriegsverbrechen, sind die Ambivalenzen augenfällig, die sich sowohl diachron im Verhalten nach außen als auch synchron in der Diskrepanz zwischen innerem und äußerem Verhalten ergeben. Dies verschaffte dem Land auch nach dem Ende des Milošević-Regimes in der internationalen Wahrnehmung ein zweifelhaftes Image.

Aus diesen Überlegungen leiten sich zwei Fragen ab, die im Zentrum der vorliegenden Arbeit stehen: Wie ist der Politikwandel auf dem Feld der Vergangenheitsaufarbeitung, das heißt der Auseinandersetzung mit den während der Jugoslawienkriege begangenen Kriegs- und Menschenrechtsverletzungen, zu erklären? Wie können die Ambivalenzen und Diskrepanzen zwischen dem Verhalten nach innen und außen erklärt werden?

\subsection{FORSCHUNGSSTAND, LEERSTELLEN, INNOVATIONEN}

\section{Forschungsgegenstand}

Die Analyse des Umgangs mit Kriegsverbrechen in Serbien erlangt mit der Transition des Landes im Jahr 2000 Popularität. Ab diesem Zeitpunkt werden regelmäßig zumeist englischsprachige Studien publiziert. Um das Jahr 2008 lässt sich eine Häufung von Artikeln zur Konditionalitätspolitik der Europäischen Union (EU) erkennen. Die Literatur zur Vergangenheitsaufarbeitung in Serbien lässt sich grob in fünf Felder aufteilen. Den ersten und größten Teil nimmt die Literatur zum Internationalen Strafgerichtshof für das ehemalige Jugoslawien ein. Die Autoren widmen sich der Entstehungsgeschichte des Tribunals, den

suchung des Umgangs mit während des Kosovokriegs 1999 begangenen Verbrechen wird aufgrund der Sonderstellung des serbisch-kosovarischen Verhältnisses, der politischen Brisanz der Statusfrage und der nicht anerkannten Unabhängigkeit des Kosovo weitgehend abgesehen.

7 Diese Arbeit kann in ihrem Umfang nicht sämtliche Felder einer möglichen serbischen Vergangenheitsaufarbeitung beleuchten - wie die Auseinandersetzung mit den Geschehnissen auf serbischem Territorium im Zweiten Weltkrieg, den staatlichen Verbrechen unter Tito oder des Milošević-Regimes. 
Problemen bei der Kooperation mit anderen Staaten und bei der Strafverfolgung. Die Prozesse selbst sind breit diskutiert und dokumentiert. Im Zentrum stehen die Analysen des Einflusses des Tribunals auf Serbien, der Wahrnehmung des Tribunals in Serbien und der Kooperation mit dem Internationalen Strafgerichtshof für das ehemalige Jugoslawien. ${ }^{8}$ Ein zweites Feld untersucht Vergangenheitsaufarbeitung als politische Konditionalität der EU. ${ }^{9}$ Das dritte Feld bedienen

8 Vgl. Hagan, John: Justice in the Balkans. Prosecuting War Crimes in the Hague Tribunal, Chicago: University of Chicago Press 2003; Obradović-Wochnik, Jelena: »Strategies of Denial. Resistance to ICTY Cooperation in Serbia«, in: Judy Batt/Jelena Obradović-Wochnik (Hg.): War Crimes, Conditionality and EU Integration in the Western Balkans (=Chaillot Paper 116), Paris: EU Institute for Security Studies 2009, S. 29-47; Rajković, Nikolas Milan: »The Limits of Consequentialism. ICTY Conditionality and (Non)Compliance in Post-Milosevic Serbia«, in: Review of European and Russian Affairs 4 (2008) 1, S. 27-72; Spoerri, Marlene/Freyberg-Inan, Annette: »From Prosecution to Prosecution. Perceptions of the International Criminal Tribunal for the former Yugoslavia (ICTY) in Serbian domestic politics«, in: Journal of International Relations and Development 11 (2008) 4, S. 350-384; Orentlicher, Diane: Shrinking the Space for Denial. The Impact of the ICTY in Serbia, New York: Open Society Institute 2008; Peskin, Victor: International Justice in Rwanda and the Balkans. Virtual Trials and the Struggle for State Cooperation, Cambridge: Cambridge University Press 2008; Lamont, Christopher K.: Coercion, Norms and Atrocity. Explaining State Compliance with International Criminal Tribunal for the former Yugoslavia Arrest and Surrender Orders, Dissertation, Glasgow 2008; McMahon, Patrice C./Forsythe, David P.: »The ICTY's Impact on Serbia. Judicial Romanticism Meets Network Politics«, in: Human Rights Quarterly 30 (2008) 2, S. 412-435.

9 Vgl. J. Batt/J. Obradović-Wochnik (Hg.): War Crimes; Stahl, Bernhard: »Perverted Conditionality. The Stabilisation and Association Agreement between the EU and Serbia«, in: European Foreign Affairs Review 16 (2011) 4, S. 465-487; Dobbels, Mathias: Serbia and the ICTY. An Analysis of EU Conditionality, Masterarbeit, Brügge 2009; allgemeiner zum westlichen Balkan: Noutcheva, Gergana: »Fake, Partial and Imposed Compliance. The Limits of the EU's Normative Power in the Western Balkans«, in: Journal of European Public Policy 16 (2009) 7, S. 1065-1084; Anastasakis, Othon: »The EU's Political Conditionality in the Western Balkans. Towards a More Pragmatic Approach«, in: Southeast European and Black Sea Studies 8 (2008) 4, S. 365-377; Freyburg, Tina/Richter, Solveig: National Identity Matters. The Limited Impact of EU Political Conditionality in the Western Balkans (= NCCR Working Paper 19), Zürich: National Centre of Competence in Research Challenges to Democracy in the 21st Century 2008. 
Autoren der Transitional-justice-Forschung. Sie untersuchen die serbischen Transitional-justice-Prozesse im Vergleich zu anderen Fällen, um die Rahmenbedingungen und Faktoren für den Erfolg oder Misserfolg dieser ${ }^{10}$ oder das spezifische Design unterschiedlicher Instrumente mit Blick auf deren Leistungsfähigkeit zu evaluieren. ${ }^{11}$ Ein viertes Feld befasst sich mit spezifischen Formen der transitional justice in Serbien, zum Beispiel mit lokalen Formen der Strafverfolgung von Kriegsverbrechen ${ }^{12}$, weichen Formen der Vergangenheitsaufarbeitung (Wahrheits- und Versöhnungskommissionen ${ }^{13}$ ) oder symbolischer Politik ${ }^{14}$. Das fünfte und letzte Feld belegen Autoren, die kultur- oder identitätsspezifische Er-

10 Grodsky, Brian: The Costs of Justice: How New Leaders Respond to Previous Rights Abuses (= Contemporary European Politics and Society), Notre Dame: University of Notre Dame Press 2010.

11 Vgl. Fischer, Martina: Friedens- und Versöhnungsprozesse im westlichen Balkan. Von den Schwierigkeiten des Umgangs mit gewaltsamer Vergangenheit (= Berghof Working Paper 4), Berlin: Berghof Conflict Research 2008; Dimitrijević, Nenad: »Serbia After the Criminal Past. What Went Wrong and What Should be Done«, in: The International Journal of Transitional Justice 2 (2008) 1, S. 5-22; Spoerri, Marlene: »Justice Imposed. How Policies of Conditionality Effect Transitional Justice in the Former Yugoslavia«, in: Europe-Asia Studies 63 (2011) 10, S. 1827-1851; Petrović, Vladimir: Gaining the Trust through Facing the Past? Prosecuting War Crimes Committed in the Former Yugoslavia in National and International Legal Context (= CAS Working Paper Series 4), Sofia: Centre for Advanced Study 2008; Horelt, Michael-André: »Durch Symbolik und Recht zur Versöhnung? Ein Vergleich der Versöhnungswirkung des Internationalen Strafgerichtshofs für das ehemalige Jugoslawien (ICTY) und politischer Entschuldigungen im ehemaligen Jugoslawien«, in: Die Friedens-Warte. Journal of International Peace and Organization 86 (2011) 1-2, S. 131-154.

12 Vgl. Đorđe Đorđević: Summary Report Regarding Local, Regional and International Documentation of War Crimes and Human Rights Violations in the Former Yugoslavia, New York: International Center for Transitional Justice 2002; Ivanišević, Bogdan: Against the Current. War Crimes Prosecutions in Serbia (= Prosecution Case Studies Series), Brüssel: International Center for Transitional Justice 2007.

13 Vgl. Grodsky, Brian: »International Prosecution and Domestic Politics. The Use of Truth Commissions as Compromise Justice in Serbia and Croatia«, in: International Studies Review 11 (2009) 4, S. 687-706.

14 Vgl. M.-A. Horelt: »Durch Symbolik und Recht«; Dragović-Soso, Jasna: »Apologising for Srebrenica. The Declaration of the Serbian Parliament, the European Union and the Politics of Compromise«, in: East European Politics and Societies 28 (2012) 2, S. 163-179. 
klärungen für die ausbleibende Aufarbeitung mit Hilfe von Ansätzen aus der Psychologie, der Nationalismus- und der Identitätsforschung suchen. ${ }^{15}$

Besonders hervorheben möchte ich drei neuere Monografien, die zum Teil gleichzeitig mit der vorliegenden entstanden und die durch die unterschiedlichen Ansätze bisweilen als sich ergänzend verstanden werden können. Jelena Obradović-Wochnik befasste sich basierend auf 2005-2007 erhobenen semistrukturierten, qualitativen Interviews mit >gewöhnlichen` serbischen Bürgern mit der individuellen Dimension von transitional justice, also der biografische Kontingenzbewältigung in der Übersetzung von Erfahrung in Erzählung vor dem Hintergrund sich verändernder politischer und normativer Rahmenbedingungen. ${ }^{16}$ In einer vergleichenden Diskursanalyse von Presseartikeln untersuchte die Geisteswissenschaftlerin Katarina Ristic, ${ }^{17}$ wie nationale Eliten und Medien in Bosnien-Herzegowina, Kroatien und Serbien sich die Narrative internationaler Kriegsverbrecherprozesse aneigneten, in ethnonational strukturierte Narrationsbestände einbetteten und zugunsten ihrer Interessen und Normvorstellungen transformierten. ${ }^{18}$ Der Kultursoziologe Eric Gordy verfolgte die öffentliche Debatte über kollektive Erinnerung und Bewertung der Jugoslawienkriege in Serbien von 2000 bis 2012, arbeitete die Bewegungsdynamiken in Reaktion auf die

15 Vgl. Ramet, Sabrina P.: »The Denial Syndrome and its Consequences. Serbian Political Culture since 2000«, in: Communist and Post-Communist Studies 40 (2007) 1, S. 41-58; Shaw, Emily: The Role of Social Identity in Resistance to International Criminal Law. The Case of Serbia and the ICTY (= Berkeley Program in Soviet and Post-Soviet Studies Working Paper Series), Berkeley: University of California 2003; Obradović-Wochnik, Jelena: »Knowledge, Acknowledgment and Denial in Serbia's Responses to the Srebrenica Massacre«, in: Journal of Contemporary European Studies 17 (2009) 1, S. 61-74; Clark, Janine Natalya: »Collective Guilt, Collective Responsibility and the Serbs«, in: East European Politics and Societies 22 (2008) 3, S. 668-692.

16 Obradović-Wochnik, Jelena: Ethnic Conflict and War Crimes in the Balkans. The Narratives of Denial in Post-Conflict Serbia (= International Library of War Studies), London: IB Tauris 2013.

17 Milošević-Ristić, Katarina: Media Discourses on War Crimes Trials in Serbia (= Working papers series 4), Graz: Centre for South East European Studies 2012, http://www. suedosteuropa.uni-graz.at/sites/default/files/publications/0\%20Ristic\%20WP\%204\% 20sept\%202012.pdf.

18 Ristić, Katarina: Imaginary Trials. War Crimes and Memory in Former Yugoslavia (= Global History and International Studies 9), Leipzig: Leipziger Universitätsverlag 2014. 
gegenwärtigen Ereignisse heraus und veranschaulicht und analysiert differenziert die smigration of discourse from denial of facts to dispute over their meaning, and contention over the authority of people who present them «. ${ }^{19}$

Auch wenn es nicht explizit gemacht wird, befassen sich diese Arbeiten alle mit Normdiffusionsprozessen. Sie analysieren in unterschiedlichen Zuschnitten die von außen an Serbien herangetragenen normativen Erwartungen auf dem Feld der transitional justice in Hinblick auf compliance, das heißt auf einen entsprechenden außenpolitischen und innenpolitischen, gesellschaftlichen Wandel, bezíehungsweise untersuchen die Widerstände und Aneignungsprozesse hierauf.

Die serbische Literatur ist deutlich politischer. Eine Vielzahl von Texten, Büchern, Dokumentensammlungen und aus Konferenzen hervorgegangenen Sammelbänden wurde von Aktivisten des Sektors der Nichtregierungsorganisationen (NGOs) in Serbien publiziert, in eigenen Serien ${ }^{20}$, im Buchhandel ${ }^{21}$ oder in der Literaturzeitschrift Reč. Einige NGO-Aktivisten publizieren auch wissenschaftlich für ein überregionales Publikum in englischsprachigen Journalen oder Büchern. Beispiele sind der Jurist und Menschenrechtsaktivist Vojin Dimitrijević vom Belgrader Zentrum für Menschenrechte, der von 1993 bis 2012 konstant über den Internationalen Strafgerichtshof für das ehemalige Jugoslawien

19 Gordy, Eric D.: Guilt, Responsibility, and Denial. The Past at Stake in PostMilošević Serbia (= Pennsylvania Studies in Human Rights), Philadelphia: University of Pennsylvania Press 2013, S. xiii. Zuvor veröffentlichte Gordy bereits umfangreich, vgl. Gordy, Eric D.: »Accounting for a Violent Past by Other than Legal Means«, in: Southeast European and Black Sea Studies 3 (2003) 1, S. 1-24; ders.: »Postwar Guilt and Responsibility in Serbia. The Effort to Confront It and the Effort to Avoid It«, in: Sabrina P. Ramet/Vjeran Pavlaković (Hg.): Serbia since 1989. Politics and Society under Milosević and after (= Jackson School Publication in International Studies), Seattle, Washington: University of Washington Press 2005, S. 166-191; Gordy, Eric D.: »Confronting the Past in Serbia. Obstacles and Opportunities« in: Wolfgang Petritsch/Goran Svilanović/Christophe Solioz (Hg.): Serbia Matters. Domestic Reforms and European Integration (= Southeast European Integration Perspectives 1), Baden-Baden: Nomos 2009, S. 137-141; J. Dragović-Soso/ E. D. Gordy.: »Coming to Terms with the Past«.

20 Hier sind besonders das Helsinki-Komitee für Menschenrechte und das Zentrum für humanitäres Recht zu nennen.

21 Ilić, Dejan/Matić, Veran: Truths, Responsibilities, Reconciliations. The Example of Serbia, Belgrad: Samizdat Free B92 2000. 
$\left(\mathrm{ICTY}^{22}\right)$ und nationale Bemühungen der Strafverfolgung schrieb, ${ }^{23}$ Vesna Nikolić-Ristanović von der Viktimološko Društvo Srbije (Viktimologischen Gesellschaft Serbiens), ${ }^{24}$ die Politikwissenschaftlerin Radmila Nakarada ${ }^{25}$ die an der Fakultet političkih nauka in Belgrad lehrt und Mitglied der serbischen Wahrheits- und Versöhnungskommission war, oder die eher liberal einzuordnende Parlamentarierin Vesna Pešić. ${ }^{26}$ Aus der Perspektive eines Serben, der von außen auf das Land blickt und sich wissenschaftlich mit der Frage des Umgangs mit schuldbehafteter Vergangenheit beschäftigt, intervenierte der an der Central European University in Belgrad lehrende Jurist und Politikwissenschaftler Ne-

22 Der vollständige Name lautet: International Criminal Tribunal for the Prosecution of Persons Responsible for Serious Violations of International Humantiarian Law Committed on the Territory of the Former Yugoslavia since 1991.

23 Zunächst verfasste er kleinere Aufsätze in der Zeitschrift Vreme, später auch in internationalen Fachzeitschriften, vgl. Dimitrijević, Vojin: »The War Crimes Tribunal in the Yugoslav Context«, in: East European Constitutional Review 5 (1996) 4, S. 85-92; ders.: »Ostareli zlikovci i zli starci« [Greise Schurken und böse Alte], in: Reč. Časopis za književnost, kulturu i društvena pitanja 57 (2000) 3, S. 25-27; ders.: »Izgledi za utvrđivanje istine i postizanje pomirenja u Srbiji« [Perspektiven auf die Feststellung der Wahrheit und das Erreichen von Versöhnung in Serbien], in: Reč. Časopis za književnost, kulturu i društvena pitanja 62 (2001) 8, S. 69-74; ders.: »Justice Must be Done and Been Seen to Be Done. The Milosevic Trial«, in: East European Constitutional Review 11 (2002) 1-2, S. 59-62; ders.: »Domestic War Crimes Trials in Serbia, Bosnia-Herzegovina and Croatia«, in: J. Batt/J. ObradovićWochnik (Hg.): War Crimes, S. 83-99; Dimitrijević, Vojin/Hadži-Vidanović, Vidan/ Ivanović, Ivan/Marković, Žarko/Milanović, Marko: Haške nedoumice. Poznato i nepoznato o Međunarodnom krivicnom tribunalu za bivšu Jugoslaviju [Haager Ratlosigkeiten. Bekanntes und Unbekanntes über das ICTY], Belgrad: Beogradski centar za ljudska prava 2010.

24 Nikolic-Ristanovic, Vesna: »Truth and Reconciliation in Serbia«, in: Dennis Sullivan/Larry Tifft (Hg.): Handbook of Restorative Justice: A Global Perspective, London, New York: Routledge 2006, S. 369-386.

25 Nakarada, Radmila: Raspad Jugoslavije. Problemi tumačenja, suočavanja i tranzicije [Zerfall Jugoslawiens. Probleme der Interpretation, der Aufarbeitung und der Transition] (= Vreme Jugoslavije 5), Belgrad: Službeni glasnik 2008.

26 Pešić, Vesna: »Facing the Past. The Prerequisite for Creating a Modern Serbian State«, in: Dragica Vujadinović/Vladimir Goati (Hg.): Between Authoritarianism and Democracy Vol. III. Serbia at the Political Crossroads, Belgrad: Friedrich-EbertStiftung/Centar za demokratsku tranziciju 2009, S. 179-195. 
nad Dimitrijević immer wieder in den serbischen Diskurs. ${ }^{27}$ Andere serbische Autoren, die sich konkret mit dem ICTY oder mit der serbischen Schuld beschäftigen, wirken trotz wissenschaftlichen Anstrichs oftmals wenig objektiv, sondern populistisch. ${ }^{28}$ Im serbischen Buchhandel, in Bibliotheken und im Internet sind eine Vielzahl von wissenschaftlich kaum haltbaren Büchern und Sammelbänden vorhanden, die eine serbisch-nationalistische Deutung der Kriege anbieten. ${ }^{29}$ Besonders auffällig sind die vielen Publikationen, die eine alternative Deutung zum Völkermord in Srebrenica etablieren wollen. ${ }^{30}$ Hier vermischen

27 Dimitrijević, Nenad: »Prošlost, odgovornost, budućnost« [Vergangenheit, Verantwortung, Zukunft], in: Reč. Časopis za književnost, kulturu i društvena pitanja 57 (2000) 9, S. 5-16; ders.: »Serbia After the Criminal Past«; ders.: »Apology Instead of Reconciliation. A View from Serbia«, in: Peščanik.net vom 12.11.2011, http://pescanik.net/2011/11/apology-instead-of-reconciliation-a-view-from-serbia vom 24.11.2011.

28 Vgl. u. a. Simeunović, Dragan: Srpska kolektivna krivica. Srbi i tradicija kolektivne krivice [Die serbische kollektive Schuld. Die Serben und die Tradition kollektiver Schuld], Belgrad: Nolit 2007; Čavoški, Kosta: Hag protiv pravde [Haag gegen die Gerechtigkeit], Belgrad: Centar za srpske studije 1996; ders.: Haški minotaur tom drugi. Hag protiv istine [Haager Minotaurus Teil 2. Haag gegen die Gerechtigkeit], Belgrad: Beoknjiga 2007.

29 Vilić, Dušan/Todorović, Boško: Zašto su optuženi [Warum sie beschuldigt sind], Belgrad: Grafomark 2001; Dimitrijević, Bojan B.: »Slučaj likvidacije zarobljenika posle zauzimanja Srebrenice jula 1995. Problemska pitanja« [Der Fall der Liquidierung Gefangener nach der Einnahme Srebrenicas im Juli 1995. Problemstellungen], in: Istoria 20 (2004) 1, S. 131-156; Vuković, Slobodan: Kako su nas voleli. Antisrpska propaganda i razbijanje Jugoslavije [Wie sie uns liebten. Antiserbische Propaganda und die Zerschlagung Jugoslawiens], Novi Sad: Stylos 2007; ders.: »Ulica Vase Mickina, Markale, Račak. Događaji s obarčem« [Die Vasa Mickina-Straße, Markale, Račak. Ereignisse mit Auslöser], in: Teme. Časopis za društvene nauke 33 (2009) 1, S. 201-214; ders.: Etika zapadnih medija. Antisrpska propaganda devedesetih godina XX veka [Die Ethik der westlichen Medien. Antiserbische Propaganda in den Neunziger Jahren des 20. Jahrhunderts], Sremski Karlovci: Izdavačka Knjižarnica Zorana Stojanovića 2009.

30 Vgl. zum Beispiel Subotić, Momčilo: »Politika (zlo)upotreba zločina« [Politik des Gebrauchs/Missbrauchs von Verbrechen], in: Politička revija 4 (2005) 3, S. 813828; Nedić, Aleksandra/Jeremić, Milovan (Hg.): Da li je bilo sve tako u Srebrenici? [War das alles so in Srebrenica?], Belgrad: Srpska liberalna stranka 2005; Vujadinović, Željko: »Fenomenologija Srebrenice« [Phänomenologie Srebrenicas], in: Istori- 
sich Akteurs- und Beobachterebene. Sie sind meist dem Institut za stradanje Srba u XX. veku (Institut für das Leiden der Serben im 20. Jahrhundert), dem internationalen Srebrenica Historical Project ${ }^{31}$ oder dem Kreis revisionistischnationalistischer Politik zuzuordnen.

\section{Leerstellen der Forschung und Innovation}

Die bisherige Forschung auf dem Feld der transitional justice in Serbien weist einige Leerstellen auf, die diese Arbeit schließt. Erstens nehmen bisherige Studien die Entwicklungsdynamik des Feldes der transitional justice nicht umfassend in den Blick. Sie lösen sich nicht von der Beschränkung auf einzelne Instrumente oder Akteure. Im Gegensatz dazu versteht sich die vorliegende Arbeit als umfassende Untersuchung eines Politikfeldes. Zweitens vernachlässigen bisherige Forschungen die historische Tiefendimension der Auseinandersetzung mit Kriegsverbrechen in Serbien. Diese Arbeit untersucht, auf welche historischen Prägungen und kulturellen Vorerfahrungen diese Auseinandersetzungen aufbauen, und betrachtet institutionelle Kontinuitäten. Drittens wird trotz vieler Studien zur Vergangenheitsaufarbeitung die Übersetzung einer internationalen in eine nationale Norm, also die Frage der Normrezeption, vernachlässigt. Die vorliegende Arbeit schließt diese Lücke, indem sie dieses Problem explizit in den Fokus nimmt. Viertens haben viele empirische Arbeiten zu Serbien und den jugoslawischen Nachfolgestaaten einen affirmativen Charakter gegenüber extern induzierter transitional justice und diskutieren daher nicht die negativen Effekte

ja 20. veka 24 (2006) 2, S. 147-161; Pavić, Aleksanda: Zabranjena istina o Srebrenici. Priručnik zasnovan isključivo na stranim izvorima [Die verbotene Wahrheit über Srebrenica. Handbuch basierend ausschließlich auf ausländischen Quellen], Čačak: Legenda 2007; Ivanišević, Milivoje (Hg.): Srebrenica july 1995. In Search of Truth, Belgrad: Hrišćanska misao 2008; Škrbić, Ratko P.: Srebrenica. Genocid nad istinom [Genozid an der Wahrheit] (= Edicija Dokumenti), Belgrad: Svet knjige 2011.

31 Srebrenica Research Group: Srebrenica and the Politics of War Crimes vom 11.7.2005, http://www.srebrenica-report.com vom 12.11.2010; Simić, Ljubiša: The Martyrdom of Serbian Srebrenica 1992-1995, Belgrad: Istorijski projekat Srebrenice 2010; Karganović, Stephen/Simić, Ljubiša/Herman, Edward/Pumphrey, George/ Maher, J.P/Wilcoxson, Andy: Deconstruction of a Virtual's Genocide: An Intelligent Persons Guide to Srebrenica, Den Haag/Belgrad: Srebrenica Historical Project 2011; Karganović, Stefan (Hg.): Srebrenica. Falsifikovanje istorije [Srebrenica. Fälschung der Geschichte], Belgrad: Pekograf 2012. 
erzwungener Aufarbeitung. ${ }^{32}$ Diese Arbeit macht die Frage nach den Problemen externen Drucks zu einem zentralen Forschungsschwerpunkt. Fünftens vertreten viele Autoren normative Positionen oder ziehen von Dritten an Serbien gestellte Maßstäbe zur Beurteilung der Auseinandersetzung mit Kriegsverbrechen in Serbien heran. So wird zum Beispiel aus der Nichtbefolgung von Konditionalitäten ein fehlender politischer und gesellschaftlicher Wille zur Aufarbeitung. Die vorliegende Arbeit begegnet diesem Problem, indem sie nicht einen angeblichen Erfolg, sondern einen angemessenen Prozess untersucht. Durch eine induktive Annäherung an den Gegenstand kann sie darstellen, wie die jeweiligen Akteure die Auseinandersetzung mit Kriegsverbrechen verstehen und die Situation beschreiben.

\subsection{TheORETISChE EINBETTUNG}

Um die dargestellten Forschungslücken zu schließen, wird eine passende theoretische Einbettung der vorliegenden Arbeit benötigt. Im Folgenden wird das theoretische Gerüst dargestellt, auf dessen Grundlage eine Untersuchung des Fallbeispiels Serbiens erfolgt.

\section{Die Bedingungen serbischer Vergangenheitsaufarbeitung}

Die Aufarbeitung der Vergangenheit in Serbien ist das Ergebnis eines extern induzierten Prozesses. Die Auseinandersetzung mit den Kriegsverbrechen und Menschenrechtsverletzungen, die durch serbische Staatsangehörige verübt wurden, ist maßgeblich durch die Einrichtung des ICTY zu Kriegszeiten angestoßen worden. Zwar gab es auch innerserbische Versuche der Aufarbeitung, sie wurden aber weitgehend nationalistisch und für die Zwecke des Milošević-Regimes instrumentalisiert.

Durch den internationalen Charakter der Jugoslawienkriege und des Tribunals in Den Haag wurde die in erster Linie juristische, später auch symbolische Aufarbeitung der von serbischen Staatsangehörigen begangenen Kriegsverbre-

32 Vgl. allgemein Duthie, Roger: »Afterword. The Consequences of Transitional Justice in Particular Contexts«, in: Alexander Laban Hinton/Stephen E. Bronner/Nela Navarro (Hg.): Transitional Justice. Global Mechanisms and Local Realities after Genocide and Mass Violence, New Brunswick: Rutgers University Press 2010, S. 249-256; auf die postjugoslawische Situation bezogen: M. Spoerri: »Justice Imposed«; T. Freyburg/S. Richter: National Identity Matters. 
chen und Menschenrechtsverletzungen zum Gegenstand internationaler Politik. In Form von Konditionalitätspolitik formulierten verschiedene externe Akteure klare Erwartungen an Serbien hinsichtlich des Umgangs mit der Kriegsvergangenheit. Internationale Akteure und Institutionen wurden zu Akteuren auf einem eigentlich innenpolitischen Politikfeld.

Die engen Verbindungen zwischen internationalen und nationalen Prozessen bauen ein Spannungsfeld für die Aushandlung serbischer Aufarbeitungspolitik auf. Politik wird zwar von serbischen Akteuren betrieben, aber oftmals als Reaktion auf von außen gestellte Konditionen. Analysen der serbischen Vergangenheitsaufarbeitung können mithin nicht nur auf eine der beiden Ebenen, also Innen- oder Außenpolitik (beziehungsweise: politisches System und Internationale Beziehungen), beschränkt bleiben, sondern müssen deren dialektisches Verhältnis zueinander betrachten, zumal sie nur theoretisch voneinander getrennt werden können.

Folgt man dem Gedanken dieser theoretischen Trennung von zwei Ebenen, befinden sich serbische Akteure aufgrund der externen Induzierung des Prozesses in einem Spagat zwischen internationalen und nationalen Erwartungen. So kommt es zu »two-level games $\aleph^{33}$ zwischen internationaler und gesellschaftlicher Ebene. Politikwandel auf dem Feld der Aufarbeitung wird als ein verändertes Verhalten von außenpolitischen Akteuren begriffen, die sich zwischen verschieden Verhaltensoptionen entscheiden. Es bleibt die Frage: Wie kann dieser Politikwandel auf dem Feld der Aufarbeitung in Serbien erklärt werden?

\section{Logiken des Verhaltens außenpolitischer Akteure}

Das Verhalten außenpolitischer Akteure kann mit den Handlungslogiken zweier Theorieschulen der Internationalen Beziehungen erfasst werden. Einen ersten Erklärungsansatz bietet die Kosten-Nutzen-Abwägung der außenpolitischen Akteure. Nach dieser rationalistischen Handlungslogik ist das Ziel jeder Handlung die Nutzenmaximierung. Interessen werden als exogen gegeben betrachtet. Ideen, Werte oder Normen sind folglich »Instrumente für die Durchsetzung oder Rechtfertigung $\aleph^{34}$ dieser Interessen. Die Handlung wird von der Erwartung posi-

33 Vgl. Putnam, Robert: »Diplomacy and Domestic Politics. The Logic of Two-Level Games«, in: International Organization 42 (1988) 3, S. 427-460.

34 Vgl. Boekle, Henning/Rittberger, Volker/Wagner, Wolfgang: »Soziale Normen und normgerechte Außenpolitik. Konstruktivistische Außenpolitiktheorie und deutsche Außenpolitik nach der Vereinigung«, in: Zeitschrift für Politikwissenschaft 11 (2001) 1, S. 71-103, hier S. 74. 
tiver oder der Vermeidung negativer Folgen motiviert. Außenpolitische Akteure vergleichen demnach die Konsequenzen und Kosten bestimmter Handlungsoptionen auf internationaler und staatlicher Ebene und entscheiden rational. In Aussicht gestellte materielle Anreize oder unterschiedliche Formen von Druck wären diesem Ansatz entsprechend vorteilhaft für eine Anpassung oder Übernahme von außen vorgegebener Verhaltens- und Wertvorstellungen. Ein diesen Vorgaben widersprechendes Verhalten würde bestraft. Ein solcher Ansatz kann zwar darlegen, warum sich die serbische Politik bei externem Druck oder Konditionalitäten wandelt. Er kann aber nicht den Wandel ohne externen Druck erklären, der keinen offensichtlichen Nutzen bringt.

Einen zweiten Erklärungsansatz bietet die in der konstruktivistischen $\mathrm{Au}-$ ßenpolitiktheorie verwendete Logik der sozialen Angemessenheit. Sie erweitert die vornehmlich auf Interessen basierte Perspektive um die soziale Eingebundenheit von Akteuren in Strukturen, welche deren Interessen und Identitäten konstituieren. ${ }^{35}$ Dementsprechend wählen Akteure »norm- und regelgeleitet auf dem Hintergrund subjektiver Faktoren, historisch-kultureller Erfahrungen und institutioneller Einbindungen ${ }^{36}{ }^{2}$ zwischen verschiedenen Handlungsoptionen. Angemessen ist dabei, was von einer Gesellschaft oder Gemeinschaft als angemessen erachtet wird. Zentral sind also »nicht die Wertvorstellungen einzelner, sondern die intersubjektiv geteilten, wertegestützten Erwartungen angemessenen Verhaltens ${ }^{37}$. Diese normative Orientierung definiert also Interessen, Identität und Verhalten des Akteurs.

35 Akteure und Strukturen konstruieren und konstituieren sich dabei wechselseitig im Rahmen ihrer Interaktionsprozesse. Vgl. die Akteur-Struktur-Debatte als zentral für die konstruktivistische Wende in der Erforschung der Internationalen Beziehungen, konzise zusammengefasst in Ulbert, Cornelia: »Konstruktivistische Analysen der internationalen Politik: Theoretische Ansätze und methodische Herangehensweisen«, in: dies./Christoph Weller (Hg.): Konstruktivistische Analysen der Internationalen Politik, Wiesbaden: VS Verlag 2005, S. 9-34, hier S. 15 f.

36 Schaber, Thomas/Ulbert, Cornelia: »Reflexivität in den Internationalen Beziehungen. Literaturbericht zum Beitrag kognitiver, reflexiver und interpretativer Ansätze zur dritten Theoriedebatte«, in: Zeitschrift für Internationale Beziehungen 1 (1994) 1, S. 139-169, hier S. 142.

37 Boekle, Henning/Rittberger, Volker/Wagner, Wolfgang: Normen und Außenpolitik. Konstruktivistische Außenpolitiktheorie (= Tübinger Arbeitspapiere zur Internationalen Politik und Friedensforschung 34), Tübingen: Institut für Politikwissenschaft 1999, S. 5, Herv. i. O. 
Neue Mitglieder eines sozialen Gefüges werden im Rahmen eines Sozialisationsprozesses an die geltenden Erwartungen herangeführt. Um diese Überlegung auf das serbische Fallbeispiel anzuwenden, wäre davon auszugehen, dass serbische außenpolitische Akteure in ihrer Normorientierung ohnehin im serbischen Kontext sozialisiert worden sind. Ein verändertes Akteursverhalten wäre dementsprechend entweder durch einen Wandel der Normorientierung in der serbischen Gesellschaft oder durch einen konkurrierenden oder komplementären Normsozialisationsprozess in einem weiteren Referenzsystem zu erklären. Unterschiedliche Bezugseinheiten, im vorliegenden Fall internationale und nationale Ebene, implizieren unterschiedliche Vorstellungen von Angemessenheit. Die veränderte Politik auf dem Feld der Vergangenheitsaufarbeitung würde demnach dadurch zu erklären sein, dass sich die serbischen außenpolitischen Akteure zunehmend als Teil der internationalen Gesellschaft begreifen und sich an den Normen dieses Referenzsystems orientieren. Dieser Ansatz würde auch Verhaltensänderungen erklären, die nicht der Nutzenmaximierung dienen.

Allerdings ist die Intention von Akteuren empirisch nicht feststellbar. Es bleibt unklar, ob sich Akteure aufgrund ihrer Norm- oder aufgrund ihrer Interessenorientierung für ein bestimmtes Verhalten entscheiden. Es ist zudem nicht auszuschließen, dass außenpolitische Akteure ihr Handeln mit normgeleiteten Motiven erklären, obwohl eigentlich Interessen das handlungsleitende Motiv sind, und umgekehrt. Eine analytische Trennung zwischen norm- und interessengeleiteten Motiven ist demnach problematisch. Um diesen Überlegungen Rechnung zu tragen, müssen beide Dimensionen in die Analyse des Wandels der serbischen Vergangenheitsaufarbeitung einbezogen werden.

\section{Politikwandel als Ergebnis von Normsozialisationsprozessen: transnational vs. gesellschaftlich?}

Da Vergangenheitsaufarbeitung als Norm betrachtet werden kann, ist eine Weiterverfolgung des konstruktivistischen Ansatzes vielversprechend. Dieser schreibt Normen gerade in Prozessen politischen Wandels eine zentrale Rolle zu und betrachtet sie als unabhängige Variable für die Erklärung außenpolitischen Verhaltens. ${ }^{38}$

38 Vgl. zum Beispiel Finnemore, Martha/Sikkink, Kathryn: »International Norm Dynamics and Political Change«, in: International Organization 52 (1998) 4, S. 887917. Normen werden definiert durch Intersubjektivität, unmittelbare Verhaltensorientierung, Wertebezug und kontrafaktische Gültigkeit, siehe: H. Boekle/V. Rittberger/W. Wagner, Normen und Außenpolitik, S. 5. Die Autoren verweisen zur 
Transnationale Sozialisation geht von einer verhaltensleitenden Wirkung internationaler Normen innerhalb der internationalen Gesellschaft aus. Als internationale Normen werden vor allem Kodifikationen im Völkerrecht oder in den Rechtsakten und Schlussdokumenten internationaler Organisationen betrachtet. Grundbedingung für dieses Modell ${ }^{39}$ ist, dass ein Staat neues Mitglied in der internationalen Gemeinschaft ist beziehungsweise am Anfang des Integrationsprozesses steht. Die in der internationalen Gesellschaft bestehenden Normen werden im Rahmen von drei idealtypischen Prozessen internalisiert, die in der Regel simultan ablaufen. Der erste Idealtyp ist die Adaptation und das strategische Verhandeln über die Befolgung einer Norm. Normangemessenes Verhalten erfolgt als instrumentelle Anpassung auf ausgeübten Druck. Der zweite Idealtyp ist der argumentative Diskurs, in dem Informationen ausgetauscht werden und die Gültigkeit dieser Informationen verhandelt wird, also Interpretation der Norm, Situationsdefinitionen der am Diskurs beteiligten Akteure und der Gültigkeit der Norm. Unter diesem Punkt können kommunikative Prozesse wie die moralische Bewusstseinsbildung, das sogenannte shaming, aber auch Überzeugungsdiskurse subsumiert werden. Der dritte Idealtyp umfasst die Institutionalisierung und Habitualisierung der Norm. Am Ende aller Prozesse stehen die Internalisierung der Norm und eine freiwillige, eigenständige und selbstverständliche Normbefolgung.

Transnationale Normsozialisationsprozesse wurden bislang vor allem am Beispiel der Menschenrechte untersucht und modelliert. An diesen Prozessen ist eine Vielzahl von Akteuren beteiligt. Das sogenannte Spiralmodell des Menschenrechtswandels besteht aus den fünf Phasen Repression, Leugnung, taktische Konzession, präskriptiver Status und regelgemäßes Verhalten. Das Modell beschreibt den transnationalen Normsozialisationsprozess unter besonderer Berücksichtigung der Interaktion verschiedener Ebenen und des Einflusses transnationaler Interessengruppen. ${ }^{40}$ Dieses Modell verweist auf lokale Aktivisten, die

Unterscheidung zwischen unterschiedlichen Verhaltensanforderungen, denen Akteure ausgesetzt sind, auf die Kriterien Kommunalität und Spezifizität.

39 Das im Folgenden beschriebene Modell stammt aus Risse, Thomas/Sikkink, Kathryn: »The Socialization of International Human Rights Norms into Domestic Practices. Introduction«, in: dies./Stephen C. Ropp (Hg.): The Power of Human Rights. International Norms and Domestic Change (= Cambridge Studies in International Relations), Cambridge/New York/Melbourne: Cambridge University Press 1999, S. 1-38, hier S. $11 \mathrm{ff}$.

40 Ebd., S. 20. Das Spiralmodell baut auf dem von Keck und Sikkink entwickelten boomerang pattern auf, vgl. Keck, Margaret E./Sikkink, Kathryn: Activists Beyond 
sogenannten true norm believers, die den Nukleus jeglicher Normwandel- und Anpassungsprozesse bilden. Sie mobilisieren transnationale Netzwerke oder internationale Institutionen, welche moralischen Druck auf die internationale Staatengemeinschaft ausüben. Dadurch soll die Normverletzung auf die Agenda gesetzt und öffentlich angeprangert werden. Die verschiedenen, dauerhaft beizubehaltenden Formen des internationalen Drucks ${ }^{41}$ auf die nationalen Regierungen und Akteursgruppen sowie die Ausweitung auf die Innenpolitik lösen über die Stadien der Leugnung und taktischen Konzessionen eine Durchsetzung der Norm aus. Durch Wiederholung und Gewohnheit werden internationale Normen und Institutionen mit der Zeit internalisiert und zum Bestandteil alläglicher staatlicher Praxis.

Ausgehend von dieser Perspektive ergibt sich folgende Erklärung für den Wandel der serbischen Politik auf dem Feld der Vergangenheitsaufarbeitung: Die Allianz innergesellschaftlicher und internationaler Akteursgruppen übt Druck auf serbische außenpolitische Akteure aus. Dieser sukzessive Wandel schlägt sich schließlich als Anpassung an die globale Norm der Vergangenheitsaufarbeitung in nationaler Politik nieder. Das vorliegende Modell ist für den serbischen Fall gerade hinsichtlich der Konditionalitätspolitik gegenüber Serbien plausibel. Durch die zunehmende Integration in die internationale Gesellschaft und die Assoziation an die EU wird dieser Prozess verstärkt: Die Möglichkeiten normabweichenden Verhaltens werden geringer. Hier ähnelt der serbische Fall dem der Türkei, denn hier liegen

»defensive Leugnungsstrategien und taktische Zugeständnisse im Erinnerungsdiskurs insbesondere im Vorfeld wichtiger EU-Entscheidungen nahe, d.h., es ist eine Milderung und Anpassung der Leugnung als Reaktion auf außenpolitischen Druck zu erwarten « ${ }^{42}$.

In Bezug auf das serbische Exempel kann allerdings nicht so modellhaft von einem transnationalen Normsozialisationsprozess ausgegangen werden, wie er im Spiralmodell des Menschenrechtswandels modelliert wurde. Es gibt nur we-

Borders. Advocacy Networks in International Politics, Ithaca: Cornell University Press 1998, S. 13.

41 Subotić unterscheidet zwischen Gewaltandrohung, symbolischem und bürokratischem Druck, vgl. Subotić, Jelena: Hijacked Justice. Dealing with the Past in the Balkans, Ithaca: Cornell University Press 2009, S. 8.

42 Diese Erwartungshaltung formulierte für die Türkei Bayraktar, Seyhan: Politik und Erinnerung. Der Diskurs über den Armeniermord in der Türkei zwischen Nationalismus und Europäisierung (= Global Studies), Bielefeld: transcript 2010, S. 78. 
nige und politisch weitgehend marginalisierte gesellschaftliche Kräfte im Land, die den true believers zugerechnet werden könnten und internationalen Druck und Netzwerke mobilisieren könnten, um einen Effekt auf die Regierung hervorzurufen. ${ }^{43}$ Nichtsdestotrotz weisen viele Fälle, in denen es an true believers mangelt, Indikatoren für normangemessenes Verhalten ihrer außenpolitischen Akteure auf. Jelena Subotić schlägt deshalb vor, andere Akteure, die weniger idealistische Motive haben, in die Analyse miteinzubeziehen: norm resisters, instrumental norm adopters sowie international norm promoters. Diese Akteure agieren politisch auch auf innerstaatlicher Ebene. Ein weiterer Kritikpunkt an dem Modell ist, dass sozietale Normen und sozietale Normsozialisation zu wenig beleuchtet bleiben. Dies ist aber zentral, um die Ausgangssituation von möglichen Anpassungs- und Diffusionsprozessen erfassen zu können, denn nur auf dieser Grundlage kann ein Vergleich stattfinden. Auch bleibt aufgrund der Fokussierung auf internationale Normen die Entwicklungsrichtung hin zu einer Universalisierung von Normen in diesem Modell teleologisch. Zudem wird den kulturellen Eigenheiten und fallspezifischen Unterschieden kaum Rechnung getragen: Die Möglichkeit einer synkretistischen Neuausformung von Normen und eines daraufhin tolerierten normabweichenden Verhaltens bleibt ausgeschlossen. Im Rahmen dieser Arbeit wird der sozietalen Normsozialisation deshalb ein entsprechender Platz eingeräumt.

Sozietale Normsozialisation nimmt die Verhaltenserwartung an außenpolitische Akteure auf staatlicher Ebene auf Grundlage von in der Gesellschaft geteilten Normen in den Blick. Dabei wird zwischen expertenzentrierten und gesamtgesellschaftlichen Ansätzen unterschieden. ${ }^{44}$ Erstere analysieren die normativen Erwartungen von Expertengruppen. ${ }^{45}$ Sie können aufgrund ihrer Beratungsfunktion gerade bei sehr speziellen oder komplexen politischen Zusammenhängen, über die Entscheidungsträger schlecht informiert sind, einen relevanten Faktor darstellen. Dies scheint aber für die Vergangenheitsaufarbeitung nicht zuzutref-

43 J. Subotić: Hijacked Justice, S. 7.

44 Vgl. für eine Übersicht der im Folgenden diskutierten Ansätze H. Boekle/V. Rittberger/W. Wagner: Normen und Außenpolitik, S. $18 \mathrm{ff}$.

45 Diese Expertengruppen werden entweder als advocacy coalitions, vgl. Sabatier, Paul: »Advocacy-Koalitionen, Policy-Wandel und Policy-Lernen. Eine Alternative zur Phasenheuristik«, in: Adrienne Héritier (Hg.): Policy-Analyse. Kritik und Neuorientierung (= Politische Vierteljahresschrift Sonderheft 24), Opladen: Westdeutscher Verlag 1993, S. 116-148, oder als epistemic communities konzeptionalisiert, vgl. Haas, Peter: »Introduction. Epistemic Communities and International Policy Coordination«, in: International Organization 46 (1992) 1, S. 1-35. 
fen, da die Debatten darüber meist im öffentlichen Diskurs ausgetragen werden. Zudem ist es im Falle sich widersprechender Erwartungen konkurrierender Expertengruppen unmöglich, Aussagen mit Erklärungskraft zu treffen, weshalb eine ausschließliche Fokussierung auf Experten wenig sinnvoll ist.

Gesamtgesellschaftliche Ansätze identifizieren die politische Kultur oder die nationale Identität einer Gesellschaft als Indikatoren für gesamtgesellschaftlich geteilte Normen. Hierbei wird häufig auf kollektive historische Erfahrungen als Grundlage verwiesen. Problematisch an diesem Vorgehen sind die Operationalisierungen des Indikators »öffentliche Meinung« für gesamtgesellschaftlich geteilte Normen. Diese werden sehr unterschiedlich erhoben: In der quantitativen Umfrageforschung wird Gesellschaft oftmals als Kollektiv gefasst und ist eine Blackbox. Mit der Analyse von Verfassungs- und Rechtsordnungen können Aussagen über in Rechtsform gegossene Normen getroffen werden, allerdings nicht über die tatsächliche Anwendung oder einen sozialen Konsens über diese Normen. Diese Kritik trifft auch auf die Erhebung internationaler Normen über Rechtsakte zu, die der Heterogenität der internationalen Gesellschaft nicht gerecht wird. Analysen der Partei- und Wahlprogramme oder parlamentarischer Debatten reduzieren die gesellschaftliche Pluralität auf die Repräsentanten politischer Parteien. Bei den beschriebenen Ansätzen gilt, dass die Bestimmung einer einzigen gesellschaftlichen Norm nicht mehr möglich wäre, da konkurrierende normative Erwartungen nicht abgebildet werden.

Folglich bleibt unklar, wie der Einfluss von gesellschaftlichen und internationalen Sozialisationsprozessen und die in diesem Referenzsystem geltenden Normen zu hierarchisieren sind. Würden etwa Verhaltenserwartungen vorliegen, deren Norm nur in einem Referenzsystem begründet wäre, führte dies zu einem eindeutigen Einfluss auf die Außenpolitik. Wie aber gezeigt wird, liegen auf internationaler Ebene normative Vorstellungen darüber vor, wie mit Verbrechen und Menschenrechtsverletzungen umzugehen ist (vgl. Kapitel 2). Im Fall Serbiens kann nicht davon ausgegangen werden, dass keine gesellschaftlichen Verhaltenserwartungen hinsichtlich der Vergangenheitsaufarbeitung bestünden. Denn die Auseinandersetzung mit den von Serben begangenen Kriegsverbrechen und Menschenrechtsverletzungen dauern mindestens seit 1992 an. Die beabsichtigten und unbeabsichtigten langfristigen Sozialisationseffekte der im Land eingesetzten Institutionen und angeschobenen Prozesse können aber kaum so qualifiziert werden, dass sie in die Analyse miteinbezogen werden könnten. ${ }^{46}$ Vor

46 Vgl. Kastner, Fatima: »Trojanische Pferde. Universalistische Normen und globaler Wahrheits- und Versöhnungsdiskurs. Zur Evolution der Weltgesellschaft«, in: Hau- 
1992 gemachte Erfahrungen in der Aufarbeitung der Vergangenheit müssen auch berücksichtigen werden, da diese die Normenbildung maßgeblich mit beeinflusst haben können. Dementsprechend ist davon auszugehen, dass auf beiden Ebenen Vorstellungen hinsichtlich der Norm der Vergangenheitsaufarbeitung bestehen.

Folglich ist es zwar möglich, zwischen verschiedenen sozialisierenden Einflussfaktoren zu differenzieren. Es ist auch möglich, unterschiedliche Formen von Druck auf und Erwartungen an serbische außenpolitische Akteure von sozietaler und transnationaler Seite auszumachen. Analytisch lässt sich aber die Wirkung der unterschiedlichen Sozialisationsprozesse auf den außenpolitischen Akteur kaum trennen: Es ist nicht feststellbar, wie oder welche an den Akteur formulierten Erwartungshaltungen tatsächlich in dessen Entscheidungsprozess eine Rolle spielen.

Denkt man allerdings vom Ergebnis des erfolgten Politikwandels her, kann bei Normen, die einander auf internationaler und auf gesellschaftlicher Ebene entsprechen, aufgrund ihrer gegenseitigen Verstärkung von einem normangemessenen Verhalten der Akteure ausgegangen werden. ${ }^{47}$ Die in der Empirie identifizierten Differenzen und Ambivalenzen zwischen den nach innen und außen kommunizierten Normvorstellungen außenpolitischer Akteure würden jedoch einer Entsprechung der Normen auf internationaler und gesellschaftlicher Ebene zunächst widersprechen, legen sie doch unterschiedliche Regeln in unterschiedlichen Referenzsystemen nahe, denen serbische außenpolitische Akteure folgen. Dies würde bedeuten, dass die außenpolitischen Akteure die internationale Norm noch nicht internalisiert, sondern sich lediglich strategisch an sie angepasst haben, was eine symbolische Übernahme der Rhetorik der Norm mit sich bringen könnte. Da der Einfluss der Effekte der unterschiedlichen Normvorstellungen auf das Handeln der Akteure aber nicht erhoben werden kann, soll ein möglicher Anpassungsprozess auf der Grundlage der Analyse der vorhandenen Normvorstellungen in den verschiedenen Bezugssystemen nachgewiesen werden. Dies führt zu einer ersten These, der im Rahmen dieser Arbeit nachgegangen werden soll:

These 1: Die Interpretation der Norm der Vergangenheitsaufarbeitung auf gesellschaftlicher Ebene in Serbien gleicht sich zunehmend den Vorstellungen der internationalen Gesellschaft an.

ke Brunkhorst (Hg.): Demokratie in der Weltgesellschaft (= Soziale Welt 18), Baden-Baden: Nomos 2009, S. 259-276.

47 Vgl. H. Boekle/V. Rittberger/W. Wagner: Soziale Normen und normgerechte AuBenpolitik, S. $77 \mathrm{ff}$. 
Cortell und Davis schlagen zur Analyse der nationalen Auswirkungen internationalen Normen vor, die Faktoren struktureller politischer Kontexte sowie die Salienz der internationalen Norm auf nationaler Ebene in den Blick zu nehmen. ${ }^{48}$ Der strukturelle Kontext kann Akteure im politischen Diskurs entweder privilegieren oder benachteiligen. Die politische Kultur kann transnationale Akteure und die Vermittlung internationaler Normen unterstützen oder behindern. Der domestic impact einer Norm kann anhand einer Art Begriffsgeschichte der Norm im nationalen politischen Diskurs, anhand von institutionellem oder anhand von Policy-Wandel festgemacht werden. Aus diesen Faktoren entwickeln Cortell und Davis eine Skala, anhand derer sie die Salienz bewerten. ${ }^{49}$ Für den Anpassungsprozess sind demnach fünf Punkte relevant: der cultural match von Normen, Rhetorik, nationales Interesse, nationale Institutionen sowie vorhandene Sozialisierungskräfte. Für die Bewertung der Normdiffusion in Serbien (Kapitel 3.3) sollen diese Überlegungen strukturierend sein.

\section{Bleibende Ambivalenzen trotz Anpassung? Zur Deutungsoffenheit von Normen}

Da These 1 die Angleichung der Normvorstellungen auf internationaler und gesellschaftlicher Ebene postuliert, stellt sich die Frage, warum im innerserbischen Diskurs bis heute Aussagen und politisches Verhalten identifiziert werden können, die international geächtet werden. Als Beispiele hierzu können die Leugnung eines Genozids in Srebrenica oder die Verehrung von Kriegsverbrechern gelten. Dieses zunächst irrational scheinende Verhalten lässt sich mit der Deutungsoffenheit der Norm der Vergangenheitsaufarbeitung und den unterschiedlichen Anforderungen an Normen auf internationaler und nationaler Ebene erklären.

Anhand der Menschenrechte beschrieb Thorsten Bonacker, dass Normen mit deutungsoffenem Symbolcharakter integrativ wirkten. In Referenz auf deutungsoffene Symbole können sich Akteure - sowohl auf als auch zwischen den jeweiligen Ebenen - gegenseitig Konsens unterstellen, ohne dass es dafür ein substantielles Fundament gibt, und die Varianz der Akteure überbrücken. ${ }^{50}$

48 Vgl. Cortell, Andrew P./Davis Jr., James W.: »Understanding the Domestic Impact of International Norms. A Research Agenda«, in: International Studies Review 2 (2000) 1, S. 65-87.

49 Ebd., S. 72.

50 Vgl. Bonacker, Thorsten: »Inklusion und Integration durch Menschenrechte. Zur Evolution der Weltgesellschaft«, in: Zeitschrift für Rechtssoziologie 24 (2003) 2, 
»Integration vollzieht sich dadurch, dass etwas mit Unterschiedlichem identifiziert wird. Durch diese Verbindung unterschiedlicher als äquivalente Deutungen wird das deutungsoffene Symbol mit einer solchen Fülle von Deutungen identifiziert, dass es selbst als deutungsoffen erscheint, obwohl es in Wahrheit jeweils spezifisch, aber eben unterschiedlich gedeutet wird. ${ }^{51}$

Dem Anspruch der Deutungsoffenheit wird die internationale Norm der Vergangenheitsaufarbeitung durch die Elastizität ihres Konzepts gerecht. Anders als auf internationaler Ebene müssen Normen aber - obwohl sie auch hier eine integrierende Funktion haben - auf innenpolitischer Ebene geschlossener und spezifischer präsentiert werden. Hier geht es um eine konkrete Politikformulierung. Für gesellschaftliche Akteure ist die konflikthafte Auseinandersetzung über das »Wie« der Normbefolgung und -gestaltung in der Öffentlichkeit eine Ressource im (partei-)politischen Wettbewerb, die sowohl der eigenen Legitimation, der Profilierung als auch der Identitätsbildung dient. Somit würde aber die konkrete Ausgestaltung der Norm Gegenstand innenpolitischer Konflikte, auch wenn die internationale Norm der Vergangenheitsaufarbeitung weitgehend den gesellschaftlichen Vorstellungen entspräche und nach außen ein weitgehend normkonformes Verhalten zeigte. Dieser Umstand bietet subversives Potential für gesellschaftliche und politische Kräfte, die Norm für sich nutzbar machen, indem sie sie rezipieren, aber für ihre Zwecke umdeuten. Daraus ergibt sich eine zweite These, der in der Analyse nachgegangen wird:

These 2: Auch wenn sich Normen auf internationaler und gesellschaftlicher Ebene weitgehend entsprechen und nach außen ein normangemessenes Verhalten zu beobachten ist, kann die Normausdeutung auf gesellschaftlicher Ebene weiterhin Gegenstand des politischen Konflikts sein: Aufgrund des hohen Symbolwerts der Norm für die Legitimität und Identität der gesellschaftlichen Akteure werden Konflikte nicht in Ablehnung der Norm, sondern über die Frage nach deren Deutung und Ausgestaltung ausgetragen.

S. 121-149, sowie ders./Brodocz, André: »Im Namen der Menschenrechte. Zur symbolischen Integration der internationalen Gemeinschaft durch Normen«, in: Zeitschrift für Internationale Beziehungen 8 (2001) 2, S. 178-208.

51 T. Bonacker: »Inklusion und Integration durch Menschenrechte«, S. 131. 


\subsection{VERgANGENHEITSAUFARBEITUNG}

\section{Begriffsklärung}

Die im deutschsprachigen Raum verwendeten Konzepte auf dem Feld des Umgangs mit einer durch Menschenrechtsverletzungen und Kriegsverbrechen gekennzeichneten Vergangenheit sind vielfältig: Vergangenheitsaufarbeitung, -bewältigung, Vergangenheits- und Geschichtspolitik. Diese Begriffe, die ursprünglich nur für den spezifisch deutschen Umgang mit der nationalsozialistischen Vergangenheit verwandt wurden, werden meist synonym benutzt und sind dadurch wenig trennscharf. Allgemein bezeichnen sie einen kritischen Umgang mit der Gewaltvergangenheit.

Der älteste Begriff scheint dabei Vergangenheitsaufarbeitung zu sein. Theodor Adorno schreibt 1963, dass Aufarbeitung der Vergangenheit »von einer Formulierung ausginge, die sich während der letzten Jahre als Schlagwort höchst verdächtig gemacht $\aleph^{52}$ habe - um einen Schlussstrich unter eben jene nationalsozialistische Vergangenheit zu ziehen. Er hingegen setzt diesem Gestus einen aufklärerischen und selbstreflexiven Impetus entgegen, nach welchem eine kontinuierliche »Aufklärung über das Geschehene einem Vergessen entgegenarbeiten ${ }^{53}$ müsse, um ein demokratisches Lernen zu ermöglichen. Gerade im bundesrepublikanischen Fall wird ab den 1960er Jahren die Dimension der intellektuellwissenschaftlichen und pädagogischen Verarbeitung, vor allem im Rahmen der politischen Bildung, als zentral für eine Auseinandersetzung mit der nationalsozialistischen Vergangenheit verstanden.

Vergangenheitsbewältigung umfasst in der gesellschaftlichen Auseinandersetzung in der Bundesrepublik mindestens drei Ebenen: einen Prozess der gesellschaftlichen Verdrängung und Verleugnung, die kritische Auseinandersetzung mit der Vergangenheit und den Kampf um kulturelle Hegemonie. ${ }^{54}$ Die Verwen-

52 Adorno, Theodor W.: »Was bedeutet: Aufarbeitung der Vergangenheit«, in: ders: Eingriffe: Neun kritische Modelle, Frankfurt am Main: Suhrkamp 1963, S. 125-146, hier S. 125.

53 Ebd., S. 141.

54 Vgl. Wöll, Andreas: »Vergangenheitsaufarbeitung in der Gesellschaftsgeschichte der Bundesrepublik. Zur Konfliktlogik eines Streitthemas«, in: Schaal, Gary S./Wöll, Andreas (Hg.): Vergangenheitsbewältigung. Modelle der politischen und sozialen Integration in der bundesdeutschen Nachkriegsgeschichte, Baden-Baden: Nomos 1997, S. 29-42. 
dung des Begriffes als »strategisches Argument für historische Sinndeutung « ${ }^{55}$ in deutschen wissenschaftlichen Diskursen lässt ihn hinsichtlich seines analytischen Potentials als ungeeignet erscheinen. Ab 1990 wird der Begriff in seiner Verwendung auch auf die DDR-Vergangenheit ausgedehnt.

Vergangenheitspolitik hingegen bezeichnet bei Norbert Frei konkret die Amnestierung und Integration von Mitläufern im Nationalsozialismus in Relation zur konsequenten Strafverfolgung von Haupttätern zur normativen Abgrenzung im bundesrepublikanischen Fall. ${ }^{56}$

Ab 1998 werden alle drei Begriffe im deutschsprachigen Diskurs von ihrem Entstehungskontext und dem mit ihm transportierten Konzept gelöst und bisweilen unzulässig stark geweitet. So wird Vergangenheitsbewältigung bei Helmut König zu einem

»Sammelbegriff für jene Aktivitäten [...], mit denen sich demokratische und auf die Menschenrechte verpflichtete politische Systeme und Gesellschaften mit ihren durch Diktatur und Verbrechen gekennzeichneten Vorgängersystemen auseinandersetzen « ${ }^{57}$.

55 Dudek, Peter: "»Vergangenheitsbewältigung〈: Zur Problematik eines umstrittenen Begriffs«, in: Aus Politik und Zeitgeschichte (1992) 1-2, S. 44-53, hier S. 44. Siehe auch: ders.: "Sozialwissenschaften und Nationalsozialismus. Zum Stand der disziplingeschichtlichen >Vergangenheitsbewältigung««, in: Neue Politische Literatur 35 (1990), S. 407-442.

56 Vgl. Frei, Norbert: Vergangenheitspolitik. Die Anfänge der Bundesrepublik und die NS-Vergangenheit, München: Beck 1996.

57 König, Helmut/Kohlstruck, Michael/Wöll, Andreas: »Einleitung«, in: dies. (Hg.): Vergangenheitsbewältigung am Ende des zwanzigsten Jahrhunderts (= Leviathan Sonderhefte 18), Opladen: VS Verlag 1998, S. 7-10, hier S. 7. Eine ausführliche Definition bietet Helmut König am Ende des Bandes: »Unter Vergangenheitsbewältigung ist die Gesamtheit jener Handlungen und jenes Wissens zu verstehen, mit der sich die jeweiligen neuen demokratischen Systeme zu ihren nichtdemokratischen Vorgängerstaaten verhalten. Es geht dabei vor allem um die Frage, wie die neu etablierten Demokratien mit den strukturellen, personellen und mentalen Hinterlassenschaften ihrer Vorgängerstaaten umgehen und wie sie sich in ihrer Selbstdefinition und ihrer politischen Kultur zu ihrer jeweiligen belastenden Geschichte stellen«, vgl. König, Helmut: »Von der Diktatur zur Demokratie oder Was ist Vergangenheitsbewältigung«, in: ders./M. Kohlstruck/A. Wöll (Hg.): Vergangenheitsbewältigung (1998), S. 371-392, hier S. 375. 
Edgar Wolfrum und Petra Bock fokussieren sich unter dem Begriff Geschichtspolitik darauf, »wie nach der Überwindung eines diktatorischen oder autoritären Systems mit dessen unmittelbaren personellen und materiellen Hinterlassenschaften umgegangen wird « ${ }^{58}$. Günther Sandner grenzt Vergangenheitspolitik von dem Überbegriff Geschichtspolitik ab und versteht darunter »den politischen, justiziellen und kulturellen Umgang einer demokratischen Gesellschaft mit ihrer diktatorischen Vergangenheit ${ }^{59}$. Bei Ruth Fuchs und Detlef Nolte ist Vergangenheitspolitik die »staatliche Aufarbeitung der im Kontext von Diktaturen oder Bürgerkriegen begangenen Menschenrechtsverletzungen und Gewalttaten ${ }^{60}$. Diese begrifflichen Unsicherheiten ziehen sich durch die gesamte Literatur zum Gegenstand sowohl im deutschen als auch im englischen Diskurs.

In der Politikwissenschaft ist die systematische Erforschung des Umgangs mit Gewaltvergangenheit in der Transformationsforschung angesiedelt und erlebt im Zuge der dritten Demokratisierungswelle eine erstaunliche Konjunktur. Die Arbeiten von Guillermo A. O'Donnell und Philippe Schmitter ${ }^{61}$ werfen erstmals die Frage der Aufarbeitung von Menschenrechtsverletzungen als Problem des Systemwandels auf. Auch Samuel Huntington identifiziert die Frage des Umgangs mit Tätern des Vorgängerregimes nach der Transition als sogenanntes »torturer problem $\aleph^{62}$. Im Zentrum des Interesses stehen »political decisions made in the immediate aftermath of the transition and directed towards in-

58 Vgl. Bock, Petra/Wolfrum, Edgar: »Einleitung«, in: dies. (Hg.): Umkämpfte Vergangenheit. Geschichtsbilder, Erinnerung und Vergangenheitspolitik im internationalen Vergleich (= Sammlung Vandenhoeck), Göttingen: Vandenhoeck \& Ruprecht 1999, S. 7-14.

59 Sandner, Günther: »Hegemonie und Erinnerung. Zur Konzeption von Geschichtsund Vergangenheitspolitik«, in: Österreichische Zeitschrift für Politikwissenschaft 30 (2001) 1, S. 5-17, hier S. 7.

60 Fuchs, Ruth/Nolte, Detlef: »Politikfeld Vergangenheitspolitik. Zur Analyse der Aufarbeitung von Menschenrechtsverbrechen in Lateinamerika«, in: Lateinamerika Analysen 3 (2004) 9, S. 59-92, hier S. 66.

61 O'Donnell, Guillermo A./Schmitter, Philippe C.: Transitions from Authoritarian Rule. Tentative Conclusions about Uncertain Democracies, Baltimore: Johns Hopkins 1986.

62 Huntington, Samuel P.: The Third Wave. Democratization in the Late Twentieth Century (= Julian J. Rothbaum distinguished lecture series 4), Norman/London: University of Oklahoma Press 1991. 
dividuals on the basis of what they did or what was done to them under the earlier regime $\aleph^{63}$.

Um dieses Untersuchungsfeld eigenständig zu bezeichnen, führte Ruti G. Teitel in den 1990er Jahren den Begriff transitional justice ein. ${ }^{64}$ In der politikwissenschaftlichen Literatur bestehen Diskussionsstränge über die politischen Imperative von Aufarbeitungsprozessen, über die Rahmenbedingungen verschiedener Aufarbeitungsinstrumente sowie über die Frage, ob und wie Aufarbeitungsprozesse auf die Demokratisierung und Demokratieentwicklung zurückwirken. Die skizzierte konzeptionelle Engführung wurde im Laufe der Zeit aufgehoben. Ursprünglich nur für die kurze Periode des politischen Wandels gedacht, wurde das Konzept hinsichtlich seiner zeitlichen Begrenztheit geöffnet und auf nichtstaatliche Verbrechen, über die Staatsgrenzen hinaus sowie auf Nachkriegsgesellschaften ausgeweitet. Neben juristischen (retributive justice) wurden zunehmend nichtjuristische Formen (restorative justice) inkludiert. Transitional justice entwickelte sich sukzessive zu einem Set von allgemeinen Praktiken der Konfliktbewältigung. Dieses Set umfasst juristische Prozesse, Amnestien, Wahrheitskommissionen, Reparationen, Lustrationspolitik - also die Entfernung politisch belasteten Personals aus öffentlichen Positionen nach vorhergehender Überprüfung - sowie Formen symbolischer Politik wie Entschuldigungen oder die Institutionalisierung historischer Narrative in Denkmälern, Schulbüchern oder Gedenkfeiern. ${ }^{65}$

Dem Diskurs über transitional justice liegt seit Ende der 1980er das Streben nach Gerechtigkeit und Wahrheit zugrunde, oftmals wurden auch darüber hinaus

63 Elster, Jon: „Coming to Terms with the Past. A Framework for the Study of Justice in the Transition to Democracy«, in: Archives Européennes de Sociologie 39 (1998) 18, S. 7-48, hier S. 14.

64 Vgl. Hazan, Pierre: Judging War, Judging History. Behind Truth and Reconciliation (= Stanford Studies in Human Rights), Stanford: Stanford University Press 2010, S. 8, sowie Olsen, Tricia D./Payne, Leigh A./Reiter, Andrew G.: Transitional Justice in Balance. Comparing Processes, Weighing Efficacy, Washington: United States Institute of Peace Press 2010, S. 9. Auch im Englischen existieren parallele Begriffsverwendungen wie facing the past, dealing with the past, coming to terms with the past oder mastering the past.

65 Siehe den aktuellen Forschungsstand überblicksartig bei Engert, Stefan/Jetschke, Anja: »Transitional Justice 2.0. Zur konzeptionellen Erweiterung eines noch jungen Forschungsprogramms«, in: Die Friedens-Warte. Journal of International Peace and Organization 86 (2011) 1-2, S. 15-43. 
größere normative Agenden postuliert. ${ }^{66}$ Die hohen Versprechungen, die mit dem Konzept verknüpft werden, reichen von einem postulierten Ende der Straflosigkeit und nachhaltigen Effekten für die politische Kultur über soziale Transformation und Konfliktprävention bis hin zu Frieden und inner- und zwischenstaatlicher Versöhnung. Transitional justice selbst wird nur selten kritisch hinterfragt, da die Zielrichtungen des Konzepts, Demokratisierung und Zivilisierung, allgemein als erstrebenswert gelten. Auch die wissenschaftliche Auseinandersetzung mit dem Gegenstand, die in den letzten Jahren einen regelrechten Boom erlebt hat ${ }^{67}$ ist von diesem normativen bias nicht ausgenommen. Im Zentrum des Forschungsinteresses stehen weitere normative Kategorien: die Frage »nach dem >gerechten` (abhängige Variable: Gerechtigkeit) beziehungsweise dem >richtigen` oder >effektiven` (abhängige Variable: nachhaltige Befriedung) Umgang mit Schuld ${ }^{68}$.

Gerade diese inhärente Normativität birgt Konfliktpotential, da durch sie sowohl von Akteuren als auch von Forschenden das Konzept dichotomisch, hierarchisch und teleologisch gedeutet wird: Es wird zwischen einem babarischen »Davor« und einem modernen »Danach« unterschieden, wobei die Praktiken der Aufarbeitung eine symbolischen Reinigung - »from a contaminating state of conflict and illiberalism to a condition of liberal democratic purity ${ }^{69}$ - anzeigen und als Übergangsritus von einer zu einer anderen Phase dienen. Diese führen dabei idealisiert zu einem

"'post< state of liberalism defined by a cluster of key terms, such as >rule of law<, >civil

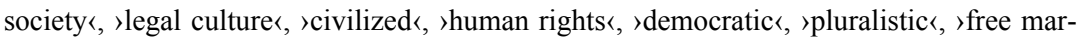
ket $\iota$, and $>$ liberal $\ll^{70}$.

Transitional justice konstituiert folglich neue liberale, demokratische Identitäten, Subjekte und Narrative. Die normativen Implikationen des Konzepts verleihen

66 Siehe ausführlich Crocker, David A.: »Transitional Justice and International Civil Society. Toward a Normative Framework«, in: Constellations 5 (1998) 4, S. 492517, hier S. 496.

67 Wie eine steigende Zahl von Seminaren, Konferenzen und working groups belegen, wächst das Forschungsfeld rasant. Seit 2007 erscheint auch das International Journal of Transitional Justice bei Oxford Journals.

68 S. Engert/A. Jetschke: »Transitional Justice 2.0«, S. $24 \mathrm{f}$.

69 Vgl. Hinton, Alexander Laban: »Introduction. Toward an Anthropology of Transitional Justice«, in: ders./S. E. Bronner/N. Navarro (Hg.): Transitional Justice, S. 1-22.

70 Ebd., S. 6 f. 
seinen Initiatoren und Anhängern Legitimität, während seine Gegner sowie die Repräsentanten des Vorgängerregimes disqualifiziert werden. Ein weiteres Problem ist das postulierte Ziel der Wahrheit und/oder Gerechtigkeit, das die naturgegebene Richtigkeit einer Interpretation impliziert. Sowohl die Vorstellung normativer Überlegenheit des Konzepts an sich, die Qualifizierungen in gut/ böse oder Täter/Opfer, als auch das richtige Bild der Geschichte implizieren Machtkämpfe um normative Dominanz. Diese Konfliktivität und Politizität bleiben allerdings bislang - vor allem in empirischen Studien - weitgehend ausgeblendet.

Das Problem der dargelegten Konzepte ist ihre Heterogenität: Weder gibt es einen einheitlichen Begriff noch ist der Untersuchungsgegenstand klar umrissen. Mal wird ein normatives Konzept, mal eine konkrete Praxis oder ein konkreter Diskurs, mal ein Politikfeld bezeichnet. Zumeist wird staatliches Handeln benannt, doch zunehmend werden auch zivilgesellschaftliche Aktivitäten einbezogen. Unklar bleibt zudem, ob staatliche oder individuelle Verbrechen im Vordergrund stehen sollten. Im Wust von Begriffen und Definitionen, die bisweilen synonym füreinander verwendet werden, wenig trennscharf und häufig normativ stark aufgeladenen sind, bemerken Olsen et al. treffend:

»Definition and measurement problems plague the study of transitional justice. Multiple and often conflicting definitions confound understanding of the goals themselves. >Truth<,

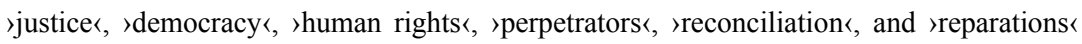
all hold different meanings for different social actors and social scientists. $\ll^{71}$

Diese begrifflichen und definitorischen Unschärfen stellen vielfältige Probleme für empirische Arbeiten dar. Im Folgenden soll diese Unbestimmtheit und Vagheit des Begriffsfelds als Ausgangspunkt genommen und nicht als normatives Konzept verwendet werden. Statt dessen wird Vergangenheitsaufarbeitung als analytische Chiffre für die verschiedenen Vorstellungen und Möglichkeiten eines Umgangs mit Kriegsverbrechen verschiedener Akteure dienen.

Natürlich könnte auch der Terminus transitional justice verwendet werden, wovon aber aufgrund der irreführenden Semantik und der problematischen Übersetzung (transitionale Gerechtigkeit) abgesehen wird. Zudem ist Vergangenheitsaufarbeitung der am häufigsten verwendeten serbischen Bezeichnung am nächsten: součavanje za prošlošću - das Konfrontieren, die Auseinandersetzung mit der Vergangenheit. Zwar sind auch andere Bezeichnungen im Serbischen zu finden, um Prozesse der Vergangenheitsaufarbeitung zu bezeich-

71 T. D. Olsen/L. A. Payne/A. G. Reiter: Transitional Justice in Balance, S. 131. 
nen, wie savladavanje prošlosti (das Überwinden der Vergangenheit) oder preispitivanje prošlosti (Überprüfung der Vergangenheit), allerdings sind beide Termini sehr selten und beziehen sich auf Spezialdebatten.

\section{Vergangenheitsaufarbeitung als symbolischer Kampf um Deutungshoheit}

Die Vergangenheit aufzuarbeiten ist per se politisch: Bisher konsensual und kollektiv geltende Bedeutungen, Identitäten und Strukturen werden als Ergebnisse kontingenter Entscheidungen und Festlegungen offenbar und mit Alternativen konfrontiert und neu verhandelt. Ein zentrales Anliegen dieser Arbeit ist es, diesen politischen Charakter und die damit verbundenen symbolischen Kämpfe und Aushandlungsprozesse herauszustellen.

$\mathrm{Zu}$ diesem Zweck wird im Folgenden als Heuristik die diskursanalytische Hegemonietheorie verwendet, die von Ernesto Laclau und Chantal Mouffe gemeinsam veröffentlicht und von Laclau weiter konzeptionalisiert wurde. ${ }^{72}$ Beiden ging es darum, den politischen Charakter gesellschaftlicher Strukturen als Ergebnisse kontingenter Entscheidungen, von Aushandlungsprozessen der dahinterstehenden Machtverhältnisse zu begreifen.

Leitend in den Überlegungen von Laclau und Mouffe ist die Vorstellung, dass erst durch das In-Beziehung-Setzen im Moment einer Artikulation einem Element vorübergehend eine Bedeutung zukommt. Bedeutung lässt sich grundsätzlich nur in Differenz, also in Abgrenzung, konstituieren. Artikulationen um-

72 Vgl. Laclau, Ernesto/Mouffe, Chantal: Hegemonie und radikale Demokratie. Zur Dekonstruktion des Marxismus, Wien/München: Passagen Verlag 2006. Ausführlicher zum Diskursbegriff von Laclau und Mouffe, vor allem in Abgrenzung zum normativen Diskursbegriff von Jürgen Habermas siehe Nonhoff, Martin: »Diskurs«, in: Gerhard Göhler/Matthias Iser/Ina Kerner (Hg.): Politische Theorie. 22 umkämpfte Begriffe zur Einführung (= Politische Theorie 2594), Wiesbaden: VS Verlag 2004, S. 65-82, allgemeiner Nonhoff, Martin: »Chantal Mouffe und Ernesto Laclau. Konfliktivität und Dynamik des Politischen«, in: Ulrich Bröckling/Robert Fenstel (Hg.): Das Politische denken. Zeitgenössische Positionen, Bielefeld: transcript 2010, S. 33-57. Zu Laclaus hegemonie- und kulturtheoretischen Überlegungen siehe Reckwitz, Andreas: »Ernesto Laclau. Diskurse, Hegemonien, Antagonismen«, in: Stephan Moebius/Dirk Quadflieg (Hg.): Kultur. Theorien der Gegenwart, Wiesbaden: VS Verlag 2006, S. 339-349, und Dyrberg, Torben Bech: »Diskursanalyse als postmoderne politische Theorie«, in: Oliver Marchart (Hg.): Das Undarstellbare der Politik. Zur Hegemonietheorie Ernesto Laclaus, Wien: Turia + Kant 1998, S. 23-65. 
fassen sämtliche relationale Praktiken, auch nichtsprachliche, symbolische oder materielle Referenzen. Erst diskursive Routinen und Wiederholungen - die aber immer auch eine Andersheit der Wiederholung implizieren - machen eine gewisse Eindeutigkeit möglich. So entstehen »schier unendliche, differenzbasierte Verweisungsräume $\aleph^{73}$, deren »strukturierte Totalität « ${ }^{74}$ einen Diskurs ergeben.

Der diskursiven Instabilität treten »hegemoniale Projekte« als komplexe diskursiv-materielle Beziehungsgeflechte entgegen, die darauf abzielen, die Vorherrschaft über die Sinnzuweisung zu erringen und die von ihnen vorgenommenen Zuordnungen als einzig mögliche und allgemeine zu präsentieren. Ideologisch sind sie insofern, als sie durch die Universalisierung ihrer partikularen Interessen und Interpretationen eine Schließung des kulturellen Horizonts anstreben. Dies gelingt ihnen, indem sie Elemente äquivalent setzen, somit Differenzen überformen und Identität herstellen. Sogenannte leere Signifikanten ${ }^{75}$ dienen als Knotenpunkte, die durch ihre Deutungsoffenheit symbolisch die Identität der Gemeinschaft oder das Allgemeine zum Ausdruck bringen. Gleichzeitig werden Ausschließungen vorgenommen, also als Differenz oder verworfenes Außen markiert, wer oder was nicht zur Diskursformation des hegemonialen Projekts gehört. Da sich dieses verworfene Außen nicht integrieren lässt, ist der Universalitätsanspruch eines hegemonialen Projekts per se unterminiert.

Laclau und Mouffe selbst haben keine Operationalisierung ihrer Diskurstheorie zur konkreten Analyse empirischen Materials vorgenommen. Dementsprechend wurde kritisch angemerkt, dass eine in ihrer Semantik vorgenommene Schilderung konkreter Beispiele vor allem illustrativ bleibe, auch würden sie die analysierten Daten nicht zur Einbindung in die Theoriebildung berücksichtigen. $^{76}$

Diese Kritik mag für das wissenschaftliche Schaffen von Laclau und Mouffe, die beide im Bereich der politischen Theorie verhaftet blieben, berechtigt sein.

73 M. Nonhoff: »Chantal Mouffe und Ernesto Laclau«, S. 37.

74 E. Laclau/C. Mouffe: Hegemonie und radikale Demokratie, S. 141.

75 Vgl. ideengebend Laclau, Ernesto: »Was haben leere Signifikanten mit Politik zu tun?«, in: ders.: Emanzipation und Differenz, Wien/München: Turia + Kant 2007, S. 65-78. Ausführlich zum leeren Signifikanten vgl. Nonhoff, Martin: Politischer Diskurs und Hegemonie. Das Projekt Projekt `Soziale Marktwirtschaftı (= Sozialtheorie), Bielefeld: transcript 2006, S. $124 \mathrm{ff}$.

76 Vgl. Keller, Reiner: Wissenssoziologische Diskursanalyse. Grundlegung eines Forschungsprogramms, Wiesbaden: VS Verlag 2005, S. 165, oder Kiel, Sören: State Bonus und Social Credit. Zwei frühe Grundeinkommensvorschläge in diskurstheoretischer Perspektive, Diplomarbeit, Hamburg 2008, S. 15. 
Einige jüngere Arbeiten haben allerdings ihren Ansatz fruchtbar rezipiert und konstruktiv operationalisiert. Er kann genutzt werden, um einerseits Diskurse und Interaktionen von Akteuren unter Offenlegung der Machtverhältnisse und des Konstruktionscharakters von Kategorien zu beschreiben; andererseits können auf ihrer Basis Artikulationen, Signifikanten oder diskursive Strategien operationalisiert und analysiert werden. Georg Glasze schlägt hierzu ein rein induktives, korpusbasiertes Verfahren vor und trianguliert lexikometrische Verfahren wie Frequenzanalyse und Kookurrenzanalyse mit der Analyse narrativer Muster. ${ }^{77}$ Anhand von vier unterschiedlichen, geschlossenen Teilkorpora untersucht er die Konstitution der Frankophonie über einen längeren Zeitraum. Mittels Frequenzanalyse zeigt er Dynamiken und Verschiebungen in der Verwendung bestimmter Signifikanten auf, die er durch die Analyse narrativer Muster zu erklären versucht. An den zweiten Schritt der Untersuchung der semantischen Beziehungen in der Verwendung eines Signifikanten schließt auch Judith Renner ${ }^{78}$ an, die die Gebrauchsmuster von Versöhnung in unterschiedlichen Kontexten analysiert. Martin Nonhoff operationalisiert die Diskurstheorie von Laclau und Mouffe mit einem anderen Fokus: Sein Interesse gilt der Frage, wie sich hegemoniale Projekte in bestimmten Kontexten konstituieren. Dazu leitet er neun Strategeme aus den Überlegungen von Laclau und Mouffe ab, mit denen hegemoniale Projekte diskursive Vorherrschaft anstreben. Diese überzeugende und innovative theoretische Weiterentwicklung, die ein großes analytisches Potential zu entfalten verspricht, versucht er dann anhand zentraler Texte aus der Anfangsphase der sozialen Marktwirtschaft in der Bundesrepublik Deutschland zu rekonstruieren. ${ }^{79}$

Aufbauend auf diesen Erfahrungen möchte die vorliegende Arbeit die Vorzüge der Möglichkeiten kombinieren, die aus der Diskurstheorie von Laclau und Mouffe und ihren Operationalisierungen ableitbar sind.

77 Vgl. Glasze, Georg: »Vorschläge zur Operationalisierung der Diskurstheorie von Laclau und Mouffe in einer Triangulation von lexikometrischen und interpretativen Methoden«, in: Historical Social Research 33 (2008) 1, S. 185-223.

78 Renner, Judith: ")Versöhnung〈 als leerer Signifikant im Kontext politischer Transformationen. Eine diskursanalytische Konzeptualisierung«, in: Die Friedens-Warte. Journal of International Peace and Organization 86 (2011) 1-2, S. 245-270, hier S. $251 \mathrm{ff}$.

79 Vgl. M. Nonhoff, Politischer Diskurs und Hegemonie. 


\subsection{ANALYSESCHRITTE UND OPERATIONALISIERUNG}

Um der angesprochenen Pluralität von Norminterpretationen einzelner Akteure innerhalb der beiden Referenzsysteme gerecht zu werden, reicht es nicht aus, nur die in Kodifizierungen bereits festgeschriebenen Normen als Indikator für sozial geteilte Normvorstellungen zu nehmen. Das würde einerseits eine Homogenität sowohl der internationalen als auch der serbischen Gesellschaft als Akteure suggerieren und andererseits ein Bestehen »fertiger« sozial geteilter Normen implizieren, von welchen nicht einfach so ausgegangen werden kann. Damit würden die Kontingenz, der Konstruktcharakter der Norm sowie die Reichweite der unterschiedlichen Normvorstellungen in den jeweiligen Referenzsystemen ausgeblendet.

Deshalb soll Vergangenheitsaufarbeitung als analytische Kategorie verwendet werden, die die durchaus sehr unterschiedlichen Vorstellungen verschiedener Akteure auf den beiden Ebenen über den Umgang mit Kriegsverbrechen und Menschenrechtsverletzungen bezeichnet. Theoretisch müssten die Normvorstellungen in den Äußerungen jeglicher am Prozess beteiligten Akteure zunächst einzeln synchron und diachron untersucht werden. Ein inhalts- oder diskursanalytisches Vorgehen liegt hierbei nahe. Da ein inhaltsanalytisches Verfahren implizieren würde, dass die relevanten, am Prozess beteiligten Akteure bereits identifiziert worden wären, soll ein rekonstruktives diskursanalytisches Verfahren gewählt werden, das die Äußerungen auf einem bestimmten Feld, dem Politikfeld der Vergangenheitsaufarbeitung, in den Blick nimmt. Daraufhin müssten diese Äußerungen synchron und diachron verglichen werden, um eine Differenz bestimmen und Wandel aufzeigen zu können. Die vorliegende Arbeit möchte diesem Anspruch gerecht werden, muss sich aber auch begrenzen, da eine Untersuchung in dieser Tiefe und Breite empirisch kaum im Rahmen einer einzelnen Arbeit geleistet werden kann. Dementsprechend wird ein mehrstufiges Vorgehen für die Analyse gewählt, das verschiedene Analyseverfahren miteinander kombiniert und somit synchrone und diachrone Schnitte durch die Diskurse ermöglicht.

In einem ersten Schritt soll den grundsätzlichen Vorstellungen über den Umgang mit Kriegsverbrechen und Menschenrechtsverletzungen in der internationalen und in der serbischen Gesellschaft nachgegangen werden (Kapitel 2). Dazu werden die historischen Erfahrungen mit Vergangenheitsaufarbeitung in dem jeweiligen Referenzsystem zum Ausgangspunkt gemacht, die in erster Linie über konkrete Festschreibungen der Norm beschrieben werden können. So kann eine Art Genealogie der Normen nachgezeichnet werden. 
Zum Zweiten wird der Politikwandel im serbischen Umgang mit begangenen Kriegsverbrechen und Menschenrechtsverletzungen während der Jugoslawienkriege betrachtet (Kapitel 3). Hier steht neben dem Verhalten der außenpolitischen Akteure die konkrete Umsetzung in Form von Initiativen oder der Einrichtung von Institutionen im Vordergrund. Hinsichtlich der angenommenen unterschiedlichen normativen Referenzsysteme wird ein besonderes Augenmerk auf Konflikte und Interaktionsmuster wie die Konditionalitätspolitik und deren (Nicht-) Befolgung sowie auf Strategien gelegt, die als taktische Konzessionen oder Ausweichstrategien gewertet werden.

Ein dritter Schritt wählt die Diskussion über die Verurteilung des Massakers von Srebrenica als Beispiel, um die Normvorstellungen und Verhaltenserwartungen von Akteuren auf beiden Ebenen tiefergehend in den Blick zu nehmen (Kapitel 4). Die Auseinandersetzungen um Deutungsfestschreibungen werden als diskursive Kristallisationspunkte gewertet, da sie besonders konflikthaft zu sein scheinen und somit die Pluralität an Deutungsangeboten auf den verschiedenen Ebenen sichtbar macht. Zur Analyse der Vorstellungen auf internationaler Ebene werden Deutungsfestschreibungen seit 1995 in den Fokus gestellt, die einerseits die Berichte und Deklarationen von staatlichen Akteuren wie Frankreich oder den Niederlanden, andererseits die von nichtstaatlichen Akteuren wie den Vereinten Nationen, des ICTY, dem Internationalen Gerichtshof oder schließlich der EU berücksichtigen. Die hinsichtlich des Massakers von Srebrenica verfassten Berichte, Deklarationen und Urteile sollen in die Analyse miteinbezogen werden.

Die Auseinandersetzung mit Srebrenica erscheint auch als besonders aussagekräftig für die serbische Vergangenheitsaufarbeitung, da die Frage der Verurteilung des Massakers in Form einer Deklaration der Nationalversammlung 2005 und 2010 jeweils über mehrere Monate öffentlich diskutiert wurde und sich sämtliche relevanten politischen und gesellschaftlichen Akteure an der Auseinandersetzung beteiligten. Hierzu werden 13 Deklarationsvorschläge analysiert, die zwischen 2005 und 2010 von verschiedenen Parteien und NGOs vorgelegt wurden. Gerade die Beobachtung über mehrere Jahre kann graduelle Veränderungen aufzeigen, da die zum Teil monatelangen Debatten eine Perspektive auf ein Spektrum von politischen Meinungen im Land eröffnen. So können die Evolution eines Diskurses über die Vergangenheit und die Faktoren, die das staatliche Handeln erklären, nachvollzogen werden. Aus den Deklarationsvorschlägen können konkrete Verhaltenserwartungen und Normvorstellungen abgeleitet werden. Um die öffentlichen Diskurse über die eine Deklaration zu Srebrenica in den Jahren 2005 und 2010 zu rekonstruieren, wurde die Berichterstattung serbi- 
scher Tages- und Wochenzeitungen vom ersten Auftauchen des Themas bis etwa eine Woche nach Beendigung der jeweiligen Debatte analysiert.

Diese Korpora können auch Hinweise darauf geben, inwieweit sich in der vergleichsweise kurzen Zeitspanne von etwa einem halben Jahrzehnt die Normvorstellungen über den Umgang mit Kriegsverbrechen und Menschenrechtsverletzungen im öffentlichen Diskurs verändert haben. Falls im Material von 2010 zunehmend Semantiken oder Themen des zuvor dem internationalen Repertoire zugeordneten Spektrums identifiziert werden können, wäre das ein Beleg für eine zunehmende Entsprechung beziehungsweise Annäherung beider Normen.

Um einen möglichen diskursiven Wandel zu belegen, werden die Zeitungskorpora zunächst lexikometrisch untersucht und so die Häufigkeit der token ${ }^{80}$ im vorliegenden Material ermittelt. Ursprünglich war daraufhin eine weitere ausführliche qualitative Analyse von zuvor identifizierten extremen Ausschlägen vorgesehen, um den konkreten Gebrauch bestimmter Begriffe zu fassen. Diese Methode erwies sich aber als vergleichsweise unergiebig für den zu betreibenden Aufwand und brachte kaum neue Einsichten, so dass die qualitative Analyse nicht bis zum Ende durchgeführt wurde. Die Ergebnisse der Explorationsphase der qualitativen Untersuchung wurden berücksichtigt und können die festgestellten diskursiven Verschiebungen teilweise erklären.

Aus den Positionen serbischer politischer Akteure heraus kann abgeleitet werden, ob eine Ablehnung der Norm der Vergangenheitsaufarbeitung (noch) als möglich erachtet wird. Denn nachdem die Norm akzeptiert wurde, würden Konflikte über den Umgang mit Kriegsverbrechen und Menschenrechtsverletzungen nicht mehr über die Frage der Aufarbeitung an sich ausgetragen, sondern über die konkrete Ausdeutung der Norm. Die konkrete Politikformulierung würde dann zu einem Teil des politischen Wettbewerbs.

In einem schlussfolgernden Kapitel sollen die gebildeten Hypothesen auf Grundlage der Ergebnisse der Analyseschritte verifiziert oder falsifiziert sowie die Befunde und die gewählte Methode mit Blick auf die einschlägige Literatur reflektiert werden.

Da die Vielzahl von Namen, die Komplexität staatlicher Desintegration sowie das volatile Parteiensystem von Autor und Leser große Aufmerksamkeit erfordern, wird zum Nachschlagen in der Anlage eine chronologische Übersicht der serbischen Auslieferungen an das ICTY sowie der Staatsoberhäupter und Regierungschefs Jugoslawiens und Serbiens 1989-2014 vorgehalten.

80 Token und type unterscheiden in der Linguistik zwischen einem einzelnen Vorkommnis und einem Vorkommnistyp. 


\subsection{MATERIAL}

Das dieser Arbeit zugrundeliegende empirische Material beruht auf Sekundärund Primärliteratur. Zu seiner Erhebung wurden die Bestände und Datenbankzugänge der Universitäten Jena, Marburg, Frankfurt und Hamburg genutzt. Schwerer greifbare Journalartikel konnten über die Universität Oxford erreicht werden. Während mehrmonatiger Forschungsaufenthalte 2010 und 2011 in Belgrad und Novi Sad wurden die Bibliotheken der Universitäten, des Belgrader Institute of International Politics and Economics sowie der Matica Srpska genutzt. Dies ermöglichte den Zugriff auf nur lokal verfügbare wissenschaftliche Literatur und Originalquellen.

2009 wurden in der Bibliothek des Südostinstituts Regensburg die dort vorgehaltenen serbischen Wochenzeitungen Vreme und NIN für den Zeitraum 1991 bis 2002 gesichtet, um auf dieser Grundlage Tendenzen für die Medienberichterstattung über Kriegsverbrechen im Milošević-Regime und in der Zeit direkt nach der Transition auszumachen. Andrej Ivanij, Redakteur bei Vreme, ermöglichte einen Zugang zum Onlinearchiv der Zeitung. Dank Velimir Čurgus Kazimir, einem Belgrader NGO- und Medienaktivisten, konnte das digitale Medienarchiv arhiv.rs genutzt werden, in dem seit 2003 systematisch die Artikel der Printausgaben von Zeitungen kooperierender Verlage gesammelt werden.

Die Zeitungsartikel ermöglichen die exemplarische Untersuchung zweier vergleichbarer Ereignisse im Abstand von fünf Jahren: die öffentliche Debatte über eine parlamentarische Verurteilung des Massakers von Srebrenica 2005 und 2010. Die Zeitungsberichterstattung kann Aufschluss geben über Schwerpunkte der Auseinandersetzungen, die Positionierung einzelner Akteure und über gesellschaftliche Mobilisierungen. Aufgrund der Spanne von sechs Jahren kann auch ein Wandel der Diskurse in diesem vergleichsweise kurzen Zeitraum nachvollzogen werden. Um eine solche Untersuchung zu ermöglichen, wurden 2010 und 2011 über die Datenbank von arhiv.rs zwei Datenkorpora aus neun Tageszeitungen (Blic, Danas, Dnevnik, Glas Javnosti, Kurir, Politika, Press, Večernje Novosti, ab 2007 auch: Pravda) und zwei Wochenzeitungen (NIN, Vreme) erhoben. Die Auswahl der Zeitungen ist einerseits mit der Verfügbarkeit in der Datenbank zu begründen, andererseits mit dem Versuch, das ganze politische Spektrum der Printöffentlichkeit des Landes abzudecken. Während Danas, Dnevnik und Vreme eher dem linksliberalen, proeuropäischen Lager zuzuordnen sind, nehmen Blic, Glas Javnosti, Politika und Press eher Positionen der politischen Mitte ein. $\mathrm{Ku}$ rir, NIN und Večernje Novosti gehören eher dem rechtskonservativen, nationalen Lager an. Die Pravda markiert den rechten Rand. Dnevnik ist die einzige Zeitung mit einem nichtzentralistischen Anspruch, sie gilt als regionalspezifische 
Zeitung der Vojvodina. Die Traditionszeitungen Politika und Večernje Novosti sind noch immer zu großen Teilen in Staatsbesitz. Blic, Kurir, Pravda und Press sind Tabloidblätter, also boulevardistisch ausgerichtet.

Zur Auflagenstärke dieser Zeitungen können keine gesicherten Aussagen getroffen werden, da sie von den Verlagshäusern nicht öffentlich gemacht werden. Erst seit Oktober 2006 gibt es mit ABC-Audit Bureaux of Circulations eine kostenpflichtige Agentur, die die Auflagenzahlen der Printmedien erhebt. ${ }^{81}$ Die folgenden Angaben wurden einem Bericht entnommen, dessen Verfasser Zugriff auf die Daten dieser Agentur hatte. Demnach zirkulierten 2010 täglich etwa 600.000 Tageszeitungen in Serbien, wovon etwa drei Viertel von dem Tabloid Blic und den Traditionsblättern Večernje Novosti und Politika eingenommen wurden. ${ }^{82}$ Danach folgten die Tabloids Alo! - die nicht von arhiv.rs erhoben wird - mit ca. 115.000 und Press mit unter 100.000 Ausgaben. Alle anderen Blätter erscheinen in einer vergleichsweise niedrigen Auflage, ihre Reichweite in der Gesellschaft kann dementsprechend auch als relativ gering angesehen werden. Die Auflage der Wochenzeitungen Vreme und NIN liegt bei ca. 20.000 bis 25.000 Exemplaren.

Durch die Digitalisierung erfuhr auch der serbische Tageszeitungsmarkt seit Mitte der 2000er Jahre starke Umstrukturierungen. Bei fast allen Tageszeitungen sank die Auflage um 15 bis dreißig Prozent. Der Marktführer Blic verlor in nur vier Jahren ein Viertel seiner Auflage: Sie sank von 200.0002007 auf 150.000 Ausgaben 2010. Die Auflage von Press ging um 31,5 Prozent, die von Večernje Novosti um dreißig Prozent zurück. Im Zuge der Zeitungskrise schlossen auch einige Tageszeitungen, so stellte die Glas Javnosti im Januar 2010 komplett auf ein Onlineangebot um, das nicht mehr von arhiv.rs erfasst wird. Gleichzeitig nahm die Popularität von digitalen Nachrichtenseiten, zum Teil auch derjenigen der Zeitungen, zu. Trotzdem positionierten sich seit 2007 einige Tabloidblätter auf dem serbischen Markt wie die rechtspopulistische Pravda oder das überaus erfolgreiche Skandalblatt Alo!, dessen Auflage trotz der Zeitungskrise stieg. Angesichts von Digitalisierung und Wirtschaftskrise konnten sich die neuen Tabloids aber nicht auf dem Markt halten. Mit Press beendete im November 2012

81 Vgl. Salamurović, Aleksandra: Wie viele Gesichter hat Deutschland? Das Deutschlandbild in der serbischen Presse, Wiesbaden: Harrassowitz 2013, S. 59. Darin wird auch die Entwicklung und das Spektrum der serbischen Presselandschaft ausführlicher dargestellt, ebd., S. 57-67.

82 Vgl. hier und im Weiteren die Studie von Sučurlija, Jelena/Pavlović, Biljana/ Jovanović Padejski, Đurđa: Mapping Digital Media: Serbia, London: Open Society Foundations 2011, S. 19. 
eines der erfolgreichsten Boulevardblätter die Printausgabe. Auch die erst 2007 gegründete rechtspopulistische Pravda stellte ihre Printtätigkeit zum Juni 2012 ein, seitdem ist sie nur noch im Internet verfügbar.

Das für die Erhebung relevanter Artikel herangezogene Medienarchiv arhiv.rs nimmt durch Verschlagwortung eine Vorstrukturierung vor, die bei der Erstellung des Korpus hilfreich war. So wurden als Referenzort »Srebrenica«, als Rubrik »Gesellschaft« und als Thema »Kriegsverbrechen 1990-2000« angewählt. Die Suchzeiträume wurden begrenzt auf das Datum der ersten Nennung einer Deklaration zur Verurteilung von Srebrenica in den gewählten Periodika bis zu den Reaktionen auf das Scheitern oder den Erfolg einer Deklaration. 2005 stand dementsprechend die Periode 22. April bis 18. Juni 2005 im Fokus der Untersuchung, 2010 die Zeit vom 12. Januar bis zum 3. April 2010. Bedingungen für die Auswahl in die Korpora waren ein direkter Zusammenhang mit der serbischen Diskussion um eine Srebrenica-Resolution und die Frage des politischen und moralischen Umgangs mit Kriegsverbrechen. Artikel, in denen auf außerserbische Akteure verwiesen wurde (wie beispielsweise eine unkommentierte Äußerung des EU-Erweiterungskommissars) oder Kontextinformationen, die sich nicht direkt auf die Debatte bezogen, wurden nicht in den Korpus aufgenommen. Auf diese Weise konnten für 2005251 und für 2010435 Texte und somit insgesamt 686 Artikel erhoben, im RTF-Dateiformat gespeichert und in MAXQDA bearbeitet werden. Auf dieser Grundlage wurde eine Rekonstruktion der vergleichbaren Diskurse in den Jahren 2005 und 2010 über eine parlamentarische Verurteilung des Massakers von Srebrenica vorgenommen.

Auf die untersuchten internationalen Deklarationen war zumeist ein digitaler Zugriff möglich. Die serbischen Deklarationsvorschläge hingegen konnten nicht immer vollständig rekonstruiert werden. Das untersuchte Material lag zum größten Teil in Form von PDFs der Orginaldokumente vor. Mit Hilfe einer Mitarbeiterin von G17plus, einer Fraktion des serbischen Parlaments, konnten noch drei Originale von Deklarationsvorschlägen zugänglich gemacht werden. Drei Resolutionsentwürfe konnte ich nicht im Original recherchieren, obwohl ich die Belgrader Parteizentralen kontaktiert habe. ${ }^{83}$ Auch im Parlament sind sie nicht dokumentiert und archiviert worden, da die Entwürfe es nicht auf die Tagesordnung geschafft hatten. In diesen Fällen behalf ich mir mit der Medienbericht-

83 Hierbei handelt es sich um die Resolutionsentwürfe von Predrag Marković (G17plus, 2004-2007 Parlamentspräsident Serbiens), der Demokratska Stranka (Demokratische Partei) und der Srpska Radikalna Stranka (Serbische Radikale Partei), 2005. 
erstattung oder Teilabdrucken der Vorschläge in den Publikationen von Parteien oder NGOs.

Der Informationsservice des Parlaments stellte darüber hinaus die Protokolle der Parlamentssitzungen vom 31. März 2010 und vom 14. Oktober 2010 digital zur Verfügung, in denen die Verabschiedung einer Deklaration zur Verurteilung von Srebrenica und die Verabschiedung einer Deklaration zu den Verbrechen an der serbischen Bevölkerung debattiert wurden.

Als weitere Quellen dienten zehn Berichte der jugoslawischen Regierung, genauer: der interministeriellen Arbeitsgruppe beziehungsweise des 1993 gegründeten Komitees für die Sammlung von Daten über begangene Verbrechen gegen die Menschlichkeit und das internationale Recht. Diese übergab der permanente Repräsentant der Bundesregierung Jugoslawien zunächst an den Generalsekretär der Vereinten Nationen, der sie an die 1992 von der UN eingerichtete Expertenkommission weiterreichte. Auch nachdem diese Expertenkommission ihre Arbeit beendet und der von der Regierung der Bundesrepublik Jugoslawien nicht anerkannte ICTY seine Tätigkeit aufgenommen hatte, wurden weitere Berichte an die Expertenkommission gesandt beziehungsweise veröffentlicht. Welche Reichweite und Öffentlichkeitswirksamkeit die Berichte sowohl innerhalb Serbiens als auch auf internationaler Ebene hatten, ist bislang nicht hinreichend geklärt.

Es war nicht möglich, Zugang zu den gedruckten Berichten im Archiv des Komitees für die Sammlung von Daten über begangene Verbrechen gegen die Menschlichkeit und das internationale Recht zu erlangen, dessen Archiv mittlerweile in der Kammer für Kriegsverbrechen am Bezirksgericht Belgrad angesiedelt ist. ${ }^{84}$ Auch der UN-Informationsdienst konnte keine Auskunft über die an die Expertenkommission und an andere UN-Organisationen gesandten Berichte der Bundesrepublik Jugoslawien erteilen. Die Berichte des Landes, die bei der UN eingegangen seien, seien »wie gewohnt « gehandhabt worden, wobei es nicht üblich sei, sie als »offizielles Dokument« öffentlich zugänglich zu machen. ${ }^{85}$ Lediglich die Berichte 5 bis 8 konnten in den online zugänglichen UN-Archiven lokalisiert werden, da sie der Generalversammlung als Diskussionsgrundlage gedient hatten. Alle anderen Berichte sind bis heute digital unter »Dokumente« auf http://www.slobodan-milosevic.org/hague/research.htm verfügbar. Die zunächst zweifelhaft erscheinende Homepage enthält Dokumente zu Kriegsverbrechen während der Jugoslawienkriege sowie zwei Weißbücher zu Verbrechen während

84 E-Mail des Büros des serbischen Staatsanwalts für Kriegsverbrechen vom 2.11.2012. 
der Bombardierung Jugoslawiens 1999, zuletzt wurde die Seite am 15. Februar 2009 aktualisiert. Die Website wurde von Unterstützern Slobodan Milošević' während seines Prozesses am ICTY erstellt. Die dort online gestellten Dateien konnten mit Dokumenten abgeglichen wurden, die auf der ehemaligen Homepage des Komitees selbst standen. Das Büro des serbischen Staatsanwalts für Kriegsverbrechen stellte Dateien von einer Diskette des Komitees zur Verfügung, die von August 2000 datieren und belegen, dass es sich bei den Dokumenten um eine direkte Übernahme von der Homepage des Komitees handelt. ${ }^{86}$

Die Berichte des Komitees wurden ohne weitere Quellennachweise abgetippt, enthalten zum Teil Rechtschreibfehler und bisweilen fehlen die Einleitung oder die in der Einleitung angekündigten Annexe. Teilweise sind die serbische und englische Version der Berichte verfügbar, meist fehlen Angaben über den Verfasser oder das Datum. In ihrer Einbindung auf der Homepage sind die Berichte - zu finden unter dem Menüpunkt $»$ Kriegsverbrechen im ehemaligen Jugoslawien«-zwar tendenziös im Sinne einer sehr einseitigen Parteinahme, allerdings besteht kein Anlass, Manipulationen zwischen den Originalberichten und denen auf der Homepage zu vermuten. Die Berichte erlauben einen einzigartigen Einblick in die Selbstsicht und -darstellung der jugoslawischen Regierung hinsichtlich des Umgangs mit Kriegsverbrechen und der Deutung der Konflikte gegenüber der internationalen Öffentlichkeit. Sie bilden ab, was die jugoslawische Regierung zeigen, wie sie wahrgenommen werden wollte, und geben Aufschluss über die serbische Wahrnehmung der (außenpolitischen) Situation, über normative Einstellungen im Umgang mit Kriegsverbrechen und über die dabei vorgenommene Themenauswahl. Aufgrund dessen werden diese Berichte in der folgenden Darstellung einbezogen, aber in den Kontext von Dokumenten mit größerer Validität gesetzt.

86 E-Mail des Büros des serbischen Staatsanwalts für Kriegsverbrechen vom 1.3.2012. 


\section{Erfahrungsbasierte Vorstellungen des Umgangs mit Kriegsverbrechen}

Gesellschaftliche Normen, Rechtskodifizierungen und Institutionen über die Frage, was ein Kriegsverbrechen ist und wie mit ihm umgegangen wird, sind kontingent und verändern sich. In diesem Kapitel wird gezeigt, dass der Umgang mit Kriegsverbrechen erfahrungsgeleitet und erlernt ist. Dazu werden die Erfahrungen im Umgang mit Kriegsverbrechen auf internationaler und auf serbischer Ebene nachgezeichnet und ausgehend von den unterschiedlichen Erfahrungen Ähnlichkeiten und Unterschiede herausgearbeitet.

\subsection{DeR INTERNATIONALE UMGANG MIT KRIEGSVERBRECHEN}

Seit der antiken Geschichtsschreibung sind unterschiedliche Formen des Umgangs mit Kriegen und den in ihrem Verlauf begangenen Verbrechen bekannt. Lange war das Gebot des Vergessens von Verbrechen dominant, das eine gesellschaftliche (Re-)Integration nach Konflikten ermöglichte. ${ }^{1}$ Sowohl durch das Entstehen einer übernationalen Öffentlichkeit als auch durch den historischen Kontext von Aufklärung, Humanismus und der zunehmenden Erosion dynastischer Herrschaft wurde dieses Gebot aufgeweicht. Ideen von weltumspannenden Rechtsräumen für Staats-, Bürger- und Menschenrechte kamen auf. In diesem Zusammenhang grundlegend war Immanuel Kant, der bereits 1795 eine weltumspannende Solidarität bei Rechtsbrüchen konstatierte,

1 Meier, Christian: Das Gebot zu vergessen und die Unabweisbarkeit des Erinnerns. Vom öffentlichen Umgang mit schlimmer Vergangenheit, München: Siedler 2010. 
»[d]a es nun mit der unter den Völkern der Erde einmal durchgängig überhand genommenen (engeren oder weiteren) Gemeinschaft so weit gekommen ist, daß die Rechtsverletzung an einem Platz der Erde an allen gefühlt wird «².

Dieser Idee und dem Paradigma der Regelbar- und Einhegbarkeit von Krieg und Frieden durch Verträge folgend, wurden im 19. Jahrhundert als Reaktion auf konkrete Kriegsfälle mit der Genfer Konvention 1864, der Brüsseler Konferenz 1874 und der 1899 verfassten Haager Landkriegsordnung sukzessiv übernational geltende Standards für das Führen von Kriegen entwickelt. Auf dieser Grundlage konnten Verstöße gegen diese Standards geächtet und geahndet werden. Für die Bewältigung der Massenverbrechen der beiden Weltkriege wurden schließlich von den alliierten Siegermächten im 20. Jahrhundert justizielle Mechanismen angestoßen beziehungsweise entwickelt, die den Umgang mit Kriegsverbrechen durch Recht regeln sollten. In Reaktion auf den Ersten Weltkrieg erwuchs das Völkerstrafrecht, das die Verletzung völkerrechtlicher Normen auf individueller Ebene unter Strafe stellte. In diesem Kontext veränderte sich über die direkte Strafbarkeit hinaus die Vorstellung davon, wie mit Kriegsverbrechen institutionell sowohl auf internationaler als auch auf nationaler Ebene umgegangen werden sollte.

Die Berichte über jungtürkische Massaker an der armenischen Bevölkerung sensibilisierten die europäische und internationale Öffentlichkeit für Verbrechen gegen die Zivilbevölkerung. Die Zeitungen im Deutschen Reich rezipierten die Veröffentlichungen des deutschen Missionars Johannes Lepsius, der die Gräueltaten dokumentierte und als Völkermord beschrieb - als eine absichtliche, staatliche Vernichtungspolitik gegen ein ganzes Volk, das sich hinsichtlich der nationalen und religiösen Zugehörigkeit von den Tätern, hier den Jungtürken, unterschied. ${ }^{3}$ Die Verbrechen an der armenischen Bevölkerung veranlassten Frankreich, Großbritannien und Russland bereits am 24. Mai 1915, eine diplomatische Protestnote an die Hohe Pforte zu senden und auf die Feststellung der Verantwortlichen für die Massaker zu drängen. In der Protestnote verurteilte die Triple Entente diese Verbrechen gegen die Menschlichkeit und gegen die Zivili-

2 Kant, Immanuel: Zum ewigen Frieden. Ein philosophischer Entwurf, Nachdr., Stuttgart: Reclam 1981, S. 24, Herv. i. O.

3 Vgl. Werkmeister, Christian: »Johannes Lepsius und die Verbrechen an den Armeniern. Die Vorgeschichte der UN-Genozidkonvention«, in: Fritz Bauer Institut/ Sybille Steinbacher (Hg.): Holocaust und Völkermorde. Die Reichweite des Vergleichs (= Jahrbuch zur Geschichte und Wirkung des Holocausts Bd. 16, Frankfurt am Main: Campus Verlag 2012, S. 83-104. 
sation, die nach Ende des Krieges verfolgt würden. ${ }^{4}$ Unter dem Druck dieser drei Staaten, die von der britischen Vorstellung eines internationalen Tribunals zwischenzeitlich abgekommen waren, ordnete Sultan Mehmed VI. im Dezember 1918 die Strafverfolgung gegen die verantwortlichen jungtürkischen Funktionäre an. Nach einer Konferenz in London, die die Verfahrensgrundsätze geregelt hatte, begannen im Februar 1919 die Istanbuler Prozesse. Diese stellten erstmals den Versuch dar, Staats- und Kriegsverbrechen auf Regierungsebene zu ahnden. Es wurden sowohl zahlreiche Minister, die dem jungtürkischen Komitee für Einheit und Fortschritt angehörten, als auch lokale Beamte angeklagt. Während die Bevölkerung und nationale Kreise im Sommer 1919 empört auf die ersten Urteile reagierten, erachtete die Regierung die Prozesse als Voraussetzung, um ihre Forderung nach staatlicher Souveränität gegenüber den Ententemächten durchsetzen zu können. Allerdings schwand das Engagement der türkischen Regierung für die Prozesse angesichts des beginnenden griechisch-türkischen Kriegs und der kleinasiatischen Katastrophe rasch. Verdächtige wurden freigelassen, und trotz der britischen Bemühungen kam die Türkei aufgrund der veränderten Mächteverhältnissen - ein Vorteil für die eigene Verhandlungsposition durch die Strafverfolgung war nicht mehr auszumachen - den Forderungen nicht weiter nach. Offiziell dauerten die Prozesse dennoch bis März 1923 an, als Sultan Mehmed VI. schließlich eine Generalamnestie erließ.

Nach dem Ende des Ersten Weltkriegs erachteten die Alliierten allerdings nicht nur wegen des Völkermordes an den Armeniern juristische Mittel als notwendig. Anstatt, wie bis dahin üblich, eine für alle Kriegsparteien geltende Amnestie zu verhängen, wurde im Versailler Friedensvertrag die alleinige Schuld am Ersten Weltkrieg Deutschland zugesprochen. ${ }^{5}$ Auch sollte im Rahmen von Gerichtsprozessen die durch Deutschland verübten Kriegsverbrechen geahndet werden. Diese Absicht stellte ein absolutes Novum in den internationalen Beziehungen dar. Artikel 227 bis 230 des Versailler Vertrags forderten die Ausliefe-

4 Diese und die folgenden Ausführungen beziehen sich auf die Darstellungen von Bass, Gary Jonathan: Stay the Hand of Vengeance. The Politics of War Crimes Tribunals (= Princeton Studies in International History and Politics), Princeton: Princeton University Press 2000, S. 106-146, und Akçam, Taner: Armenien und der Völkermord. Die Istanbuler Prozesse und die türkische Nationalbewegung, Hamburg: Hamburger Edition 2004.

5 Vgl. Hankel, Gerd: Die Leipziger Prozesse. Deutsche Kriegsverbrechen und ihre strafrechtliche Verfolgung nach dem Ersten Weltkrieg, Hamburg/Bremen: Hamburger Edition 2003. 
rung des Kaisers sowie weiterer noch zu benennende Personen. ${ }^{6}$ Sie sollten vor ein alliiertes internationales Militärgericht gestellt werden beziehungsweise vor ein Gericht, das alliierte Gesetzesvorgaben anwenden würde. Im Zuge der deutschen Revisionsbemühungen und der Uneinigkeiten der Alliierten darüber fiel erst 1920 die Entscheidung, die Kriegsverbrechen nicht vor einem alliierten Gericht zu ahnden, sondern dem deutschen Wunsch zu entsprechen, das Reichsgericht in Leipzig mit der Aufgabe zu betrauen. Die Alliierten forderten Prozesse gegen eine stark verkürzte Liste von Anzuklagenden - weitgehend ohne prominente Namen - und verzichteten im Gegenzug auf Auslieferungsforderungen sowie eine Einmischung in die Prozesse. In der Weimarer Republik selbst erfuhr die Ahndung deutscher Kriegsverbrechen nur geringe Unterstützung. Die mangelnde Zusammenarbeit von Institutionen und Bevölkerung erschwerte die Ermittlungen, viele Anklagen mussten aufgrund fehlender Beweise fallen gelassen werden. Ab 1922 stellte das Reichsgericht die Kooperation mit den Alliierten gänzlich ein. Die Prozesse fanden zudem nunmehr unter Ausschluss der Öffentlichkeit statt. Die meisten Verfahren wurden bald nicht weiter verfolgt, etwa 1700 Fälle wurden zu den Akten gelegt. Die Alliierten kritisierten das Reichsgericht vehement für die voreingenommen Prozesse, Konsequenzen allerdings blieben aus - lediglich Belgien und Frankreich reagierten mit Abwesenheitsprozessen gegen deutsche Staatsbürger, die nicht ausgeliefert wurden. Von 1921 bis 1927 fanden nur 17 Prozesse vor dem Reichsgericht in Leipzig statt. Die meisten endeten mit Freisprüchen oder milden Urteilen.

Trotz des Scheiterns der Auseinandersetzung mit den von deutschen Staatsangehörigen im Ersten Weltkrieg begangenen Kriegsverbrechen wurde auch in der Weimarer Republik ein Bewusstsein für die Unrechtmäßigkeit von Verbrechen an der Zivilgesellschaft zum Ausdruck gebracht. Hinsichtlich der jungtürkischen Verbrechen solidarisierten sich nach den Berichten von Lepsius viele Bürger mit den christlichen Armeniern, wenngleich sich das nicht in außenpolitischem Handeln niederschlug. In einem 1921 in Berlin stattfindenden Prozess, bei dem sich der Armenier Soghomon Tehlirian wegen Mordes am ehemaligen türkischen Innenminister Talaat Pascha verantworten musste, übernahm die Strafbehörde die Deutung des einflussreichen Zeugen Lepsius. Erstmals prangerte ein Gericht einen Völkermord an und verurteilte diesen moralisch, indem die Tat Tehlirians als notwendige Sühne interpretiert wurde. Er wurde freigesprochen. $^{7}$

6 Vgl. Friedensvertrag von Versailles, 28.6.1919, http://www.documentarchiv.de/wr/ vv.html vom 14.9.2012, Teil IV. Strafbestimmungen.

Vgl. C. Werkmeister, »Johannes Lepsius«, S. 98 ff. 
Sowohl die Istanbuler als auch die Leipziger Prozesse waren zentral dafür, eine neue Norm auszubilden, nämlich nach den Verantwortlichen für Verbrechen zu suchen und diese Verbrechen klar als Kriegsverbrechen zu qualifizieren. Die Idee dahinter war »der Versuch, einer zivilisatorischen Errungenschaft - die rechtliche Begrenzung der Kriegsgewalt - post festum zur Anwendung zu verhelfen, um eine Wiederholung der Rechtsverletzung zu verhindern « ${ }^{8}$.

Zwar scheiterten beide Umsetzungsversuche, allerdings wurde mit den Prozessen erstens das Paradigma des Legalismus in die internationalen Beziehungen eingeführt, zweitens der Begriff des »Kriegsverbrechens« und das Prinzip entsprechender Verantwortlichkeit geschärft und drittens aus dem Scheitern bei der Entwicklung von Vorgehen und Instrumentarium für die Zukunft gelernt. Die Anstöße aus den gesammelten Erfahrungen wurden insbesondere in der Arbeit des Völkerbundes und in juristischen Kreisen aufgenommen und dort weiterentwickelt. Auch erschien es nicht sinnvoll, nach Normbrüchen auf die Strafverfolgung und Bestrafung in den »Täter«-Ländern zu hoffen, auch wenn die Auseinandersetzung mit den Rechtsverletzungen für das politische System und die Gesellschaften dieser Ländern lehrreich schien. Aber die Bereitschaft zur unvoreingenommenen, konsequenten Konfrontation mit den Verbrechen konnte nicht vorausgesetzt werden, zumal die Nachkriegsgesellschaften auch eine entsprechende politische Instabilität aufwiesen. Nur eine Strafverfolgung und Ahndung von Rechtsverletzungen auf internationaler Ebene schien Gerechtigkeit sicherstellen zu können.

So wurde insbesondere auch das Scheitern der Leipziger Prozesse argumentativ von den Alliierten unter amerikanischer Führung für die Gründung der United Nations War Crimes Commission 1942 genutzt. Im Rahmen dieser Kommission sollten die von Deutschland und Japan begangenen Verbrechen dokumentiert werden, um eine spätere Ahndung zu ermöglichen. Damit wollte man auch der Rechtslosigkeit während des Kriegsverlaufs begegnen und das durch den Zusammenbruch der Rechtsstaaten entstandene Vakuum mit einem internationalen Instrument füllen. Die Kriegsverbrechenskommission der Vereinten Nationen nahm 1943 ihre Arbeit in London auf. Sie bestand aus den Vertretern von 17 Nationen, die jeweils nationale Büros für Kriegsverbrechen einsetzten und Anklagen an die Kommission weiterreichten. Die Grundlage der Strafverfolgung bildete das Londoner Viermächteabkommen und dessen Anlage, die Ordnung und Verfahrensweisen des zu errichtenden Internationalen Militärtribunals regel- 
te. ${ }^{9}$ Vor dem ad hoc eingesetzten Gerichtshof wurden nur die größten Prozesse verhandelt, in denen die Anführer und Hauptverantwortlichen vor allierten Richtern in Nürnberg wegen Verbrechen gegen den Frieden, Kriegsverbrechen und Verbrechen gegen die Menschheitverantworten mussten. Prozesse gegen Anführer und Täter aus den nachgeordneten Führungsriegen wurden vor nationalen Gerichten geführt. Mit dem Internationalen Militärtribunal für den Fernen Osten in Tokio wurde eine Parallelorganisation geschaffen. Das Statut des Tribunals in Tokio nahm die Prinzipien aus London auf. ${ }^{10}$

Die Einführung von Verfahren und Verfahrensregeln im Umgang mit Kriegsverbrechen auf supranationaler Ebene nahmen sowohl nach dem Ersten als auch nach dem Zweiten Weltkrieg die alliierten Siegermächte vor. 1942 ergriff US-Präsident Roosevelt die Initiative, um eine Organisation zur künftigen Sicherung des internationalen Friedens zu schaffen. Am Ende eines von den Alliierten und ihren Verbündeten unterstützten Prozesses stand die Konferenz von San Francisco, in deren Verlauf im Juni 1945 die Gründungscharta der Vereinten Nationen (United Nations, UN) von 51 Staaten unterzeichnet wurde. Internationales Recht wurde nach dem Zweiten Weltkrieg als Modernisierungsinstrument verstanden. Insbesondere nach der globalen Kriegserfahrung wurde einem universellen Geltungsanspruch von Justiz und dem Wunsch von global einzuhaltenden Mindeststandards große Aufmerksamkeit geschenkt. Die Schaffung gemeinsamer Verbindlichkeiten und Regeln in Form von Rechtsregimen sollte neuen Kriegen und Kriegsverbrechen vorbeugen, indem sie abschreckten. Basierend auf den formulierten Ansprüchen bestätigte die Generalversammlung der neu gegründeten UN die im UN-Statut und den Urteilen des Nürnberger Gerichtshofes angelegten Grundsätze des Völkerrechts und beauftragte eine Kommission damit, Verbrechen gegen den Frieden und die Sicherheit der Menschheit beziehungsweise ein internationales Strafgesetzbuch zu kodifizieren. ${ }^{11}$

9 Vgl. United Nations: Agreement for the prosecution and punishment of the major war criminals of the European Axis (»London Agreement«), 8.8.1945, 82 U.N.T.C. 280, http://www.refworld.org/docid/47fdfb34d.html vom 5.2.2012.

10 Vgl. Supreme Commander for the Allied Powers at Tokyo: Special proclamation. Establishment of an International Military Tribunal for the Far East Charter, 19.1.1946, http://www.loc.gov/law/help/us-treaties/bevans/m-ust000004-0020.pdf vom 23.3.2012. In der Anlage wurde per Dekret die Satzung des Tribunals kommuniziert.

11 United Nations General Assembly: Affirmation of the Principles of International Law recognized by the Charter of the Nürnberg Tribunal, UN-Dok. A/RES/I/95 vom 11.12.1946. 
Im Dezember 1948 verabschiedete die UN-Generalversammlung die Konvention zur Verhütung und Bestrafung von Völkermord. Mit der Kodifikation eines vornehmlich von dem polnischen Anwalt Raphael Lemkin definierten Genozids, aus der deutlich die Rezeption Johannes Lepsius' Schriften über den Völkermord an den Armeniern hervorscheint ${ }^{12}$, wurde einer der Hauptstrafbestände der Nürnberger Prozesse allgemein unter Strafe gestellt. Über die Anwendbarkeit der Konvention sollte ein Internationaler Gerichtshof wachen, der aber nie eingerichtet wurde. ${ }^{13}$ Im gleichen Monat verabschiedete die UNGeneralversammlung mit der Allgemeinen Erklärung der Menschenrechte eine weitere Konvention, die die Rechte des Individuums unter besonderen Schutz stellen sollte. In den folgenden Jahren wurden mit den Erweiterungen der Genfer Konventionen weitere Dokumente erarbeitet, um in Konflikt- und Kriegssituationen ganze Personengruppen durch einheitliche Rechtsregime über Grenzen hinweg zu schützen. Hierzu zählen die Konvention zur Verbesserung des Loses der Verwundeten und Kranken im Feld und der Schiffsbrüchigen auf See, die Konvention über die Behandlung von Kriegsgefangenen und die Konvention über den Schutz von Zivilisten zu Kriegszeiten, die sich direkt auf die Vermeidung von ethnischen Säuberungen bezieht. Auch in den folgenden Jahrzehnten wurden die Vereinbarungen zur Kriegsführung und damit auch darüber, was als Kriegsverbrechen gilt, aus den Erfahrungen mit zeitgenössischen Konflikten und Kriegsgräueln kontinuierlich in internationalen Regimen zum Humanitären Völkerrecht weiterentwickelt. Dabei fanden neben den Beschränkungen von Waffenarten auch der Schutz kollektiven Eigentums wie Kultur und Natur zunehmende Berücksichtigung. Weitere Regeln zur Kriegsführung wurden mit der Haager Konvention von 1954, die den Schutz kulturellen Eigentums während bewaffneter Konflikte betont, und der Biowaffenkonvention von 1971 verabschiedet. 1977 wurden die Genfer Konventionen um zwei Protokolle hinsichtlich des Schutzes von Opfern internationaler und nichtinternationaler bewaffneter Konflikte erweitert. Weiterhin wurde 1980 das Umweltkriegsübereinkommen getroffen und im Jahr 1993 die Chemiewaffenkonvention verabschiedet. 1997 verbot eine weitere Konvention den Einsatz von Antipersonenminen, 2008 wurde schließlich auch die Verwendung von Streuminen untersagt.

Parallel zur Ausbildung rechtlicher Grundlagen auf internationaler Ebene entwickelten einzelne Länder weitere Modi und Instrumente, wie mit Kriegsverbrechen und -schuld umzugehen sei. Besonders dem deutschen Modell der Ver-

12 So lautet die zentrale These in C. Werkmeister: »Johannes Lepsius«.

13 Vgl. United Nations General Assembly: Convention on the Prevention and Punishment of the Crime of Genocide, UN-Dok. A/RES/III/260 vom 9.12.1948. 
gangenheitsbewältigung nach der von den allierten Besatzern durchgeführten Entnazifizierungs- und Säuberungsphase wurde große Aufmerksamkeit zuteil. Die spätere Politik Konrad Adenauers, in der Reparationszahlungen, die deutliche Distanzierung von den Normen des Vorgängerregimes und das Eingeständnis von im Namen des deutschen Volkes begangenen Verbrechen zentral waren, führte eine neue (Symbol-)Sprache im Umgang mit Schuld und Menschenrechtsverbrechen ein. Gleichzeitig fand eine Reintegration in die internationale Gemeinschaft und eine Wiederaufnahme von Beziehungen zu den ehemaligen Kriegsgegnern statt. ${ }^{14}$ Der Fokus verschob sich zunehmend von der Auseinandersetzung mit Kriegsverbrechen hin zu einer Innenschau, einer Auseinandersetzung mit dem autoritären nationalsozialistischen System und dessen Verbrechen - auch außerhalb des Krieges.

Im Nachhall der Demokratisierungswelle der 1970er und 1980er Jahre in Lateinamerika, Südeuropa, Süd- und Ostasien befassten sich auch in diesen Ländern die neuen Regierungen mit den Verbrechen der Vorgängerregime. Deren Menschenrechtsverletzungen ahndeten die betroffenen Staaten selbst. Die Bestrafung von Menschenrechtsverbrechen diente als Legitimations- und Souveränitätsquelle für die neuen politischen Systeme. Hier stand nicht immer die retributive Justiz im Vordergrund, sondern vermehrt die Idee einer restorativen Justiz, mit der durch Wahrheitsfindung eine innerstaatliche Versöhnung und nachhaltiger Friede erreicht werden sollte. Während bis dato Gerechtigkeit das zentrale Ziel der Prozesse war, wurden nun die Geschichten der Opfer und die Anerkennung ihres Leidens über die Bestrafung gestellt: Diese Phase war von der Abwesenheit internationaler Tribunale sowie einer Privatisierung und Hybridisierung von Recht geprägt. Außerrechtliche Formen des Umgangs mit Kriegsund Menschenrechtsverbrechen wie Wahrheits- und Versöhungskommissionen ${ }^{15}$ und symbolische Entschuldigungen wurden zunehmend populär.

14 Vgl. P. Hazan: Judging War, S. 13-22.

15 Weitere Kommissionen mit unterschiedlichen Schwerpunktsetzungen und Öffentlichkeitsgraden waren beziehungsweise sind die Untersuchungskommission über Menschenrechtsverletzungen in Uganda 1986-1994, die Untersuchungskommission des Justizministeriums von Tschad über die Verbrechen des Regimes von Hissène Habré 1990, die Rettig-Kommission in Chile 1990-1991, die Untersuchungskommission zur Suche nach Verschwundenen während der autokratischen Periode in Nepal 1990-1991, die Enquête-Kommission zur Aufarbeitung von Geschichte und Folgen der SED-Diktatur in Deutschland 1992-1995, die Wahrheitskommission für El Salvador 1992-1993, die Kommission zur Aufklärung der Geschichte in Guatemala 1994-1999, die Nationale Kommission für Wahrheit und Gerechtigkeit in Haiti 
In der Folge der politischen Umwälzungen in Europa 1989 wurden häufig unterschiedliche Ausprägungen retroaktiver Justiz eingesetzt, um die autoritären sozialistischen Regime aufzuarbeiten. Lustrations- und Rehabilitationsgesetzgebungen, das Öffnen von Geheimdienstakten sowie Schulbuch- und Historikerkommissionen waren der Regelfall, um die Vergangenheit neu zu bewerten und die neuen politischen Systeme zu entlasten sowie die Geschichte kritisch und neu zu bewerten. Die Aufarbeitung der Vergangenheit wurde zum »grand narrative of recent times « ${ }^{16}$, das Erinnern an Menschenrechtsverstöße zum globalen Erinnerungsimperativ. ${ }^{17}$

Doch auch retributive Formen der Vergangenheitsaufarbeitung behielten ihren Stellenwert und wurden vor allem auf internationaler Ebene vorangetrieben, nachdem die UN-Völkerrechtskommission mit dem Ende des Kalten Krieges, auf Initiative von Trinidad und Tobago hin, die Arbeit am Statut eines Internationalen Gerichtshofs wieder aufnahm. Die Strafverfolgung von Kriegsverbrechern und politisch Verantwortlichen wurde als internationales Instrument der Abschreckung - auch in noch laufenden Konflikten - bewertet. ${ }^{18} 1993$ und 1994

1994, die südafrikanische Wahrheits- und Versöhnungskommission 1995-1998, die Justizkommission für die Untersuchung von Menschenrechtsverletzungen in Nigeria 1999, die Kommission für Wahrheit und Versöhnung in Peru 2001-2003, die Valech-Kommission in Chile 2001-2005, die Nationale Versöhnungskommission Ghana 2002-2005, die Kommission für Wahrheit und Versöhnung in der Bundesrepublik Jugoslawien 2002-2003, die Wahrheits- und Versöhnungskommission in Sierra Leone 2002-2004, die Wahrheitskommission in Marokko ab 2004, die Wahrheitskommission in Liberia ab 2005, die Kommission für Wahrheit und Versöhnung in Südkorea ab 2005, die Wahrheits- und Freundschaftskommission in Osttimor 20072008, die Kommission für gelernte Lektionen und Versöhnung in Sri Lanka ab 2010, die Wahrheits- und Versöhnungskommission in der Elfenbeinküste ab 2011 und die brasilianische Wahrheitskommission ab 2011.

16 Misztal, Barbara A.: »Collective Memory in a Global Age. Learning How and What to Remember«, in: Current Sociology 58 (2010) 1, S. 24-44, hier S. 28.

17 Levy, Daniel/Sznaier, Natan: Human Rights and Memory. Essays on Human Rights, University Park: Pennsylvania State University Press 2010.

18 Die Wirksamkeit und inhärente Problematik dieser Instrumente wie die Delegitimierung von Tribunalen durch den Vorwurf von Siegerjustiz und Kulturimperialismus, mangelnde Durchsetzungsfähigkeit aufgrund fehlender Exekutive oder auch Destabilisierung der Konfliktparteien und damit Unkontrollierbarkeit von Konfliktdynamiken wurde auch von Zeitgenossen thematisiert, die aber gleichsam sehr hoffnungsvoll hinsichtlich möglicher positiver Effekte waren, vgl. anlässlich der 
wurden mit dem ICTY und dem Internationalen Strafgerichtshof für Ruanda zwei internationale Ad-hoc-Tribunale geschaffen, die Kriegsverbrechen, Völkermord und Verbrechen gegen die Menschlichkeit anklagten.

Die Grundprinzipien des London-Statuts wurden in den Statuten der neuen Tribunale genauso aufgenommen wie die seitdem verabschiedeten Konventionen und die Arbeit der Völkerrechtskommission. Dementsprechend wurde auch die Definition dessen, was als Kriegsverbrechen gilt, an die Neuerungen angepasst. Die Zuständigkeit der Tribunale war örtlich und zeitlich begrenzt. Trotz ihrer starken Stellung konnten die Anklagebehörden oft nur beschwerlich arbeiten, da sie sowohl hinsichtlich der Beweisbeschaffung als auch in Bezug auf die Exekutive von der Kooperation der betroffenen Konfliktparteien abhängig waren, die durch den Eingriff in ihre nationale Souveränität ein lediglich begrenztes Interesse an der Zusammenarbeit hatten. Es gab nicht nur Kritik, dass das Gericht ein politisches Tribunal sei und Siegerjustiz ausübe, sondern auch die Öffentlichkeitswirkung und damit die Reichweite in die exjugoslawischen Gesellschaften war begrenzt.

Ab Mitte der 1990er Jahre wurde die Möglichkeit extraterritorialer Rechtsprechung ausgeweitet. Bis dahin war Rechtsprechung eng an die nationale Souveränität gebunden. Es gab nur wenige Ausnahmeregelungen - etwa, wenn ein Täter oder ein Opfer die Nationalität des Landes hatte, dessen Institution das Verbrechen anklagt, oder ein Verbrechen Effekte für das entsprechende Land hatte oder dessen Interessen direkt betroffen waren. ${ }^{19}$ Die kontrovers diskutierte Idee, einigen Normen universelle Geltung zuzusprechen und deren Verstoßauch unabhängig vom Ort des Verbrechens - zu ahnden und dies moralisch verpflichtend festzulegen, wurde von Menschenrechtsaktivisten aufgegriffen. Das belgische Parlament verabschiedete 1993 ein umstrittenes Gesetz zur universellen Rechtsprechung, um damit ruandische Staatsbürger wegen des Tatbestands des Völkermords zu bestrafen. Auch im Fall des ehemaligen argentinischen Generals Augusto Pinochet engagierten sich einzelne Juristen in Spanien und Großbritannien ab 1996 und nahmen dabei die Möglichkeit zur universellen Rechtsprechung im Rahmen des Völkergewohnheitsrechts und dessen Pflege in Anspruch. In Folge der Jugoslawienkriege nutzte Deutschland die universelle Ju-

Einführung des ICTY Pearl, Elizabeth L.: »Punishing Balkan War Criminals. Could the End of Yugoslavia Provide an End to Victors' Justice?«, in: American Criminal Law Review 30 (1992/1993) 4, S. 1373-1414.

19 Sriram, Chandra Lekha: »Revolutions in Accountability. The Approaches to Past Abuses«, in: American University International Law Review 19 (2003) 21, S. 301429, hier S. 306. 
risdiktion, um serbische Kriegsverbrecher zu verfolgen. Universelle Jurisdiktion wurde sukzessive immer häufiger in immer mehr Ländern genutzt, um Verletzungen des Humanitären Völkerrechts zu ahnden. Die Modalitäten sind dabei unterschiedliche: In manchen Ländern werden internationale Konventionen automatisch zu nationalem Recht, in anderen müssen diese Vertragsverpflichtungen ratifiziert oder durch zusätzliche nationale Provisionen implementiert werden. Diese Dynamik der $»$ Globalisierung von Strafverfolgung $\aleph^{20}$, die Erfahrungen mit den Ad-hoc-Tribunalen für Jugoslawien und Ruanda und der nun vorhandene, breite politische Wille beförderte auch die Entwicklung einer permanenten internationalen Institution: 1996 verabschiedete die Völkerrechtskommission einen Entwurf des internationalen Strafgesetzbuchs, 1998 wird das Statut des Internationalen Strafgerichtshofs in Rom angenommen, seit 2003 arbeitet er.

Die Etablierung des Internationalen Strafgerichtshofes hat auch dazu beigetragen, dass staatliche Strafgerichte und Strafverfolgungsbehörden universelle Jurisdiktion ausüben. Dabei nehmen nationale Institutionen die Befugnis wahr, Völkerrechtsverbrechen unabhängig von Ort, Täter und Opfer zu verfolgen. In Deutschland wurde beispielsweise 2002 mit dem Völkerstrafgesetzbuch eine Grundlage für die Verfolgung von Völkermord, Verbrechen gegen die Menschlichkeit und Kriegsverbrechen geschaffen. Aufgrund der festgelegten Bestimmungen sind deutsche Strafverfolgungsbehörden und -gerichte auch dann zuständig, wenn die Tat im Ausland begangen wurde und keinen Bezug zu Deutschland aufweist. ${ }^{21}$

Auch in der jüngsten Vergangenheit wurde das Humanitäre Völkerrecht erweitert: Nachdem Vergewaltigungen als Mittel der Kriegsführung seit dem Bosnienkrieg verstärkte Aufmerksamkeit erlangt haben, wurden Vergewaltigungen während Konflikten 2008 in einer UN-Resolution zum Straftatbestand erklärt. ${ }^{22}$

Nach der Jahrtausendwende wurden hybride Sondertribunale, also nationale Tribunale mit internationaler Unterstützung, die sowohl nach nationalem als

\section{Ebd.}

21 Die Entwicklungen in Deutschland zeigt Sriram am Beispiel der gescheiterten Strafverfolgung im Fall Pinochet in Deutschland und führt die Implementierung anhand der Strafverfolgung von Verbrechen aus, die im ehemaligen Jugoslawien begangen wurden, vgl. ebd., S. 330, $341 \mathrm{ff}$.

22 Vgl. United Nations Security Council: Resolution 1820, UN-Dok. S/RES/1820 vom 19.6.2008. Die Resolution engagiert sich besonders für den Schutz von Frauen und Mädchen, wertet aber sexuelle Gewalt im Allgemeinen - und damit auch unabhängig von Geschlecht oder sexueller Orientierung - als Verbrechen. 
auch nach Völkerrecht urteilen, in Osttimor (2000), Sierra Leone (2002), Kambodscha (2003) und Libanon (2005) eingerichtet. Ein besonderer Vorteil hybrider Tribunale ist die Einbindung in das staatliche Gerichtssystem und lokale Strukturen, wodurch das Gericht eine höhere Legitimität in der Bevölkerung erreicht. Gleichzeitig kann mit internationaler Expertise eine gewisse Objektivität gewahrt und der Aufbau von Ressourcen und Strukturen auf lokaler Ebene vorangetrieben werden. Deutlich unkomplizierter als bei internationalen Tribunalen sind die Gerichtslogistik, die Kommunikation und die Handhabung des outreach.

All diese Entwicklungen sorgten dafür, dass sich die Vergangenheitsaufarbeitung als zunehmend akzeptierte Norm in der Weltgesellschaft durchsetzte. ${ }^{23}$ Am Ende des 20. Jahrhunderts hat sich so mit der Expansion und der Normalisierung der zumeist justiziellen Aufarbeitung von massiven Kriegs- und Menschenrechtsverbrechen durch diverse internationale Institutionen eine »steadystate transitional justice«, eine globale Rechtsstaatlichkeit sowie eine geteilte »language of universal morality « etabliert. ${ }^{24}$ Der Maßnahmenkatalog ist breit, wie dessen Definition in der Handreichung des Generalsekretärs der UN belegt:

»the full range of processes and mechanisms associated with a society's attempt to come to terms with a legacy of large-scale past abuses, in order to ensure accountability, serve justice and achieve reconciliation $\aleph^{25}$.

Wie Rosemary Nagy treffend formulierte, ist die Notwendigkeit des Umgangs mit begangenen Verbrechen als ein $»$ globales Projekt $\aleph^{26}$ zu charakterisieren, so

23 Als eine Art Präventivinstrument schließt sich hier die Responsibility to Protect an, die mit dem klarer definierten Konzept der Schutzverantwortung die humanitäre Intervention ablöst. Es versteht sich als Lehre aus begangenen Verbrechen und legitimiert die Verletzung nationaler Souveränität, um einen Genozid, Kriegsverbrechen, ethnische Säuberungen und Verbrechen gegen die Menschlichkeit abzuwenden. Das Konzept der Responsibility to Protect wurde von einer Ad-hoc-Kommission auf Initiative Kanadas erarbeitet, 2005 auf dem UN-Weltgipfel anerkannt und in UNResolution 1674 auch völkerrechtlich verbindlich bestätigt. Vgl. International Commission on Intervention and State Sovereignty: The Responsibility to Protect, Dezember 2001, http://responsibilitytoprotect.org/ICISS Report.pdf vom 13.5.2013.

24 Teitel, Ruti G.: »Transitional Justice Genealogy«, in: Harvard Human Rights Journal 69 (2003) 16, S. 69-94, hier S. 92.

25 United Nations (Hg.): United Nations Approach to Transitional Justice: Guidance Note of the Secretary-General vom März 2010, http://www.unrol.org/files/TJ Guidance_Note_March_2010final.pdf vom 25.10.2010. 
dass nicht mehr die Frage der Aufarbeitung selbst thematisiert wird, sondern lediglich noch die Frage nach dem Wie. Zwar gibt es bislang keine international kodifizierte Norm, doch deutliche Anzeichen für eine Hegemonialisierung: Die Aufarbeitung von Kriegs- und Menschenrechtsverbrechen gehört nunmehr zu einem festen Bestand an normativen Standards, internationalen Vereinbarungen und Recht auf internationaler und nationaler Ebene.

\subsection{DeR Umgang mit KRIEgsverbReChen IN JUGOSLAWIEN}

In diesem Unterkapitel gilt es, die Frage zu beantworten, mit welchen Erfahrungen im Umgang mit Kriegsverbrechen jugoslawische und serbische Akteure in den Prozess der Aufarbeitung ab 1991 gegangen sind. Im Folgenden wird dazu auf die staatlichen und gesellschaftlichen Erfahrungen im Umgang mit Kriegsverbrechen geblickt.

\section{Keine Kriegsverbrechen? Balkankriege und der Erste Weltkrieg}

Das Königreich Serbien gehörte zu den Unterzeichnern der Haager Landkriegsordnung zugunsten einer zivilivierten Kriegsführung von 1899, trat allerdings nicht der geringfügig überarbeiteten Fassung von 1907 bei. Im ersten und zweiten Balkankrieg 1912/13 kämpften serbische Truppen im Balkanbund gegen die Herrschaft des Osmanischen Reichs und für die `Befreiung`der slawischen Völker auf der Balkaninsel. Die Kriege waren Beginn an von großer Brutalität gegen die muslimische Zivilbevölkerung geprägt, die misshandelt, massenhaft vertrieben und unverhältnismäßiger Gewalt ausgesetzt wurde. ${ }^{27}$ Auch im Kosovo eskalierte die Gewalt der serbischen Truppen gegen die albanische Bevölkerung und sollte noch jahrelang anhalten. Internationale Beobachter kritisierten die Kriegsführung gegen Zivilisten und erregten mit ihrer Berichterstattung in der europäischen Öffentlichkeit Aufmerksamkeit. Auch die kriegsführenden Balkanstaaten dokumentierten vereinzelt Verbrechen und rechneten diese propagandistisch gegeneinander auf. Im August 1913 nahm die international zusammengesetzte

26 Nagy, Rosemary: »Transitional Justice as Global Project. Critical Reflections«, in: Third World Quaterly 29 (2008) 2, S. 275-289, hier S. 276.

27 Vgl. bis Ende dieses Absatzes: Boeck, Katrin: Von den Balkankriegen zum Ersten Weltkrieg (= Südosteuropäische Arbeiten 97), München: Oldenbourg 1996, S. 365377. 
und privat finanzierte Carnegie-Kommission Untersuchungen zu den Kriegsgräueln und den wirtschaftlichen Folgen auf. Serbien akzeptierte zunächst die Kommission, forderte allerdings vor Ort den Auschluss eines Mitglieds, das als voreingenommen gewertet wurde. Der serbische Ministerpräsident verweigerte dem russischen Duma-Abgeordneten, der zuvor für eine makedonischen Unabhängigkeit und zugunsten damit bulgarischer Interessen votiert hatte, sogar ein Treffen, Studenten demonstrierten gegen ihn, auch die Einreise nach Neuserbien, das das in etwa das heutie Kosovo und große Teile Mazedoniens umfasste, wurde ihm nicht gestattet. ${ }^{28}$ Vom Beginn des Ersten Weltkriegs überschattet, erfuhr der Bericht der Carnegie-Kommission im Sommer 1914 nur wenig Aufmerksamkeit.

Das Königreich Serbien ging erstarkt mit großen Bevölkerungs- und Gebietsgewinnen aus dem Zweiten Balkankrieg hervor. Finanziell und kräftemäßig geschwächt konnte es sich im anschließenden Ersten Weltkrieg gegen die österreich-ungarischen Offensiven, die mit schweren Übergriffen gegen die serbische Zivilbevölkerung einhergingen, und den Feldzug der Mittelmächte nur bis Herbst 1915 behaupten. König, Regierung und Armee mussten sich schließlich über Albanien nach Korfu zurückziehen. Insgesamt verlor das Königreich Serbien im Ersten Weltkrieg durch die Kämpfe, Vertreibung, Typhus und Hunger etwa ein Viertel seiner Bevölkerung, auch die materiellen Schäden waren enorm. Auch in den anderen Teilen des Ende 1918 neu proklamierten Königreichs der Serben, Kroaten und Slowenen waren hohe Opferzahlen zu beklagen. Die Frage von Kriegschuld und der Kriegsverbrechen schienen durch Friedensvertrag von Saint-Germain 1920 geklärt, in dem Österreich zu Reparationszahlungen verpflichtet worden war. Ohnehin wurde der Staatsaufbau nach der Vereinigung mit den südslawischen Gebieten der Habsburgermonarchie als vorrangig betrachtet und als Sieg über Habsburg nationalistisch ausgedeutet. Eine Befassung mit Kriegsverbrechen fand darüber hinaus nicht statt, einerseits da der Begriff noch nicht eindeutig geklärt war, andererseits, da allen Seiten gegen die geltenden Regeln des Kriegsrechts verstoßen hatten.

Während der Balkankriege und des Ersten Weltkriegs wurde die Rolle als Märtyrer und Opfer der serbischen Nation mythisch weiterentwickelt: Auf die triumphale und altruistische >Befreiung \ der slawischen Brudervölker vom türkischen Joch folgte das `Golgotha<, das Leiden und die Opferung zugunsten der Widerauferstehung in einem gemeinsamen südslawischen Staat. 


\section{Die selektive Bearbeitung von Kriegsverbrechen des Zweiten Weltkriegs}

Nach dem Belgrader Putsch im April 1941, der den kurz zuvor unterzeichneten Beitritt der deutschfreundlichen Regierung Jugoslawiens zum Dreimächtepakt unsicher erscheinen ließ, wurde das Königreich Jugoslawien zerschlagen und besetzt. Die jugoslawische Königsfamilie und die Regierung flohen nach London. Serbien blieb als Vasallenstaat von der Wehrmacht okkupiert und die Besatzer installierten ein Marionettenregime: General Milan Nedić wurde als Ministerpräsident der »Regierung der nationalen Rettung« eingesetzt und von der faschistischen jugoslawischen Nationalbewegung Zbor (Versammlung, Zusammenkunft) Dimitrije Ljotić' unterstützt. Slowenien wurde dreigeteilt zwischen Deutschland, Italien und Ungarn. Die slowenische domobranstvo (nationale Heimwehr) kollaborierte mit den Besatzern. Kroatien und Bosnien-Herzegowina wurden unter dem Führer der faschistischen Bewegung der ustaše (der Aufständischen), Ante Pavelić, zum kollaborierenden Nezavisna Država Hrvatska (Unabhängigen Staat Kroatien, NDH). Montenegro, das Kosovo und Mazedonien wurden italienisch besetzte Vasallenstaaten. Gegen die Besatzer und die kollaborierenden Regime kämpften die aus einem Bündnis verschiedener Gruppen und Parteien bestehende, kommunistisch dominierte Volksbefreiungsarmee ${ }^{29}$ Josip Broz Titos sowie die četnici (Mitglieder einer četa, d.h. einer militärischen Kompanie, Truppe, Schar, Rotte), eine Gruppe von monarchistischen, antikommunistischen und volkstümlichen Freischärlern unter der Führung von Draža Mihailjović. Trotz der gemeinsamen Gegner bekämpften sich Volksbefreiungsarmee und četnici auch gegenseitig.

Das Präsidium des Antifašističko veće narodnog oslobođenja Jugoslavije (Antifaschistischen Rats der Volksbefreiung Jugoslawiens, AVNOJ) beschloss am 29. November 1943 eine neue Föderation südslawischer Völker unter der

29 Die Volksbefreiungsarmee änderte während ihres Bestehens mehrfach den Namen. Dieser Umstand kann durch die Aufnahmen neuer Gruppen und Kampfverbände erklärt werden, wodurch die Volksbefreiungsarmee größer wurde und auch organisatorische Umstrukturierungen vonnöten wurden. Von Juni 1941 bis Januar 1942 wurde die Bezeichnung Narodnooslobodilački partizanski odredi Jugoslavije (Volksbefreiende Partisanenabteilungen Jugoslawiens) verwendet, von Januar 1942 bis November 1942 Narodnooslobodilačka partizanska i dobrovoljačka vojska Jugoslavije (Volksbefreiende Partisanen- und Freiwilligenarmee Jugoslawiens) und von November 1942 bis zum März 1945 Narodnooslobodilačka vojska i partizanski odredi Jugoslavije (Volksbefreiungsarmee und Partisanenabteilungen Jugoslawiens). 
Führung der Kommunistischen Partei Jugoslawiens. Der jugoslawischen Exilregierung wurde die Anerkennung entzogen und die Rückkehr verboten. Der von den Westmächten ausgehandelte Vertrag von Vis vom 16. Juni 1944 erkannte eine Koalitionsregierung aus Teilen der Exilregierung unter Führung von Ivan Šubašić und den die befreiten Gebiete tatsächlich kontrollierenden Partisanen unter Führung von Josip Broz Tito als legitime Regierung des Demokratischen Föderativen Jugoslawien an. Das Belgrader Abkommen vom 1. November 1944 regelte eine Interimsregierung bis zu den ersten Wahlen am 29. November 1945, nach denen schließlich offiziell die Föderative Volksrepublik Jugoslawien proklamiert wurde.

Wie ging die jugoslawische Regierung mit Verbrechen um, die während des Zweiten Weltkrieges auf dem Territorium ihres Landes begangen wurden? Obwohl es von 1941 bis 1945 keinen jugoslawischen Staat mit Machtmonopol gab, lässt sich eine personale und quasiinstitutionelle Kontinuität von der Volksbefreiungsbewegung bis zur Föderativen Volksrepublik Jugoslawien feststellen.

Schon bei der ersten Tagung des AVNOJ 1942 in Bihać wurde deutlich, welche Personen und Personengruppen nach einem Sieg der Volksbefreiungsarmee bestraft werden sollten: die einheimischen »Volksverräter« Pavelić, Nedić und Mihailović, die meisten Parteien und Organisationen aus dem königlichen Jugoslawien inklusive der Exilregierung in London, die Mitglieder des nicht die Volksbefreiungsbewegung unterstützenden Flügels der kroatischen Bauernpartei, ein Großteil der Offiziere und fast der gesamte Verwaltungsapparat. ${ }^{30}$ In diesem Rahmen fand eine selektive Strafverfolgung von Kriegsverbrechen statt, die unter Anführung des »Volkswillens« legitimiert wurde und klar politisch motiviert war.

Den Partisanenverbänden stellte sich konkret die Frage, wie man mit Kollaborateuren der Besatzer, mit Kriegsgegnern, Deserteuren oder mit sogenannten Volksfeinden umgehen sollte. Eine Verordnung des Obersten Stabes der Volksbefreiungsarmee und der Partisanenverbände legte im Winter 1941/1942 fest, dass alle Partisanenabteilungen dreiköpfige Militärgerichte einrichten sollten, die Straftaten im Zusammenhang mit Spionagetätigkeit, Verrat am Volksbefreiungskampf, Desertion, Plünderung, Mord und Behinderung der militärischen Einheiten an der Ausführung ihrer Pflichten zu ahnden hatten. Die Rechtsprechung war oftmals vergleichsweise primitiv, zum Teil willkürlich und politisch,

30 Vgl. Portmann, Michael: Kommunistische Abrechnung mit Kriegsverbrechern, Kollaborateuren, »Volksfeinden « und »Verrätern« in Jugoslawien während des Zweiten Weltkriegs und unmittelbar danach (1943-1950), Diplomarbeit, München/Ravensburg: Grin 2002, S. 49 f. 
die Verfahren wurden meist schnell abgehalten. Um diesen Missständen zu begegnen, wurden die sehr unterschiedlichen Praktiken der Militärgerichte im Mai 1944 mit einer Anweisung vereinheitlicht, welche die Zuständigkeit für Kriegsverbrechen, Taten der Volksfeinde und Straftaten von Militärpersonen und Kriegsgefangenen regeln sollten. Hier wurden erstmals die Begriffe »Kriegsverbrechen« und »Volksfeind « definiert. ${ }^{31}$ Gerade der Paragraph zu den »Volksfeinden« ließ großen Interpretationsspielraum und machte es möglich, mit missliebigen politischen Gegnern abzurechnen. Generell wurden auch die bereits seit 1929 geltenden Gesetze großzügig ausgelegt, so galt zum Beispiel jeder, der den militärischen Verbänden des Unabhängigen Staats Kroatien angehört hatte, als Deserteur und musste bei Gefangennahme durch die Partisanen mit Bestrafung rechnen.

31 »Artikel 13: Als Kriegsverbrecher werden betrachtet (seien sie Bürger Jugoslawiens, Bürger der Okkupationsländer oder anderer Länder): Anführer, Organisatoren, Befehlsgeber und Helfer sowie unmittelbare Vollstrecker von Massentötungen, Folter, Zwangsaussiedlungen, Lagertransporten und Transporten zur Zwangsarbeit, im weiteren von Brandstiftung, Vernichtung und Plünderung des Volks- und Staatsbesitzes, alle Guts- und Fabrikbesitzer in Jugoslawien, den Besatzungsländern und anderen Ländern, die auf unmenschliche Art die Arbeitskraft der verschleppten Zwangsarbeiter ausgebeutet haben, Funktionäre des terroristischen Apparats und terroristischer bewaffneter Formationen des Besatzers oder in seinem Dienste, welche die Mobilisierung unseres Volkes für die feindliche Armee ausgeführt haben.

Artikel 14: Als Volksfeinde werden betrachtet: Alle aktiven Ustaše, Četnici und Angehörige anderer bewaffneter Formationen im Dienste des Feindes sowie seine Organisatoren und Helfer; all diejenigen, die in irgendeiner Form im Dienste des Feindes stehen: Als Spione, Zusteller, Kuriere, Agitatoren und ähnliche; jene, die das Volks gezwungen haben, den Okkupanten Waffen zu übergeben; all jene, die den Volkskampf verraten haben und mit dem Feind paktiert haben; all jene, die sich von der Volksregierung abwenden und gegen sie arbeiten; all jene, die die Volksarmee zerstören oder auf eine andere Art den Okkupanten geholfen haben oder helfen; all jene, welche schwere Fälle von Mord, Plünderung und ähnlichem ausführen.« Vrhovni štab NOV i POJ, maj 1944., Uredba o vojnim sudovima [Oberster Stab der NOV und POJ, im Mai 1994, Verordnung über Kriegsgerichte], aus: Nešović, Slobodan: Stvaranje nove Jugoslavije 1941-1945. Jubilarno izdanje povodom 40godišnjice narodnog ustanka i revolucije 1941-1945 [Die Schaffung des neuen Jugoslawien 1941-1945. Jubiläumsausgabe anlässlich des 40. Jahrestags des Volksaufstands und der Befreiung 1941-1945], Belgrad: Beogradski izdavačko-grafički za$\operatorname{vod} 1981$, S. 412-420, hier S. $414 \mathrm{f}$. 
Die 1943 gemäß den AVNOJ-Beschlüssen zudem eingerichtete Državna komisija za utvrđivanje zločina okupatora i njegovih pomagača iz drugog svetskog rata (Staatliche Kommission zur Feststellung von Verbrechen der Okkupanten und ihrer Helfer, DKZ) folgte weitgehend sowjetischem Vorbild. ${ }^{32}$ Die DKZ mit Sitz in Belgrad hatte den Auftrag, die Verantwortlichkeiten für Kriegsverbrechen festzustellen sowie Informationen über und Zeugenaussagen zu Straftatbeständen wie Mord, Körperverletzung, Raub, Bombardierung von Zivilisten, Beschaffung von Mitteln zur Durchführung von Verbrechen, Vertreibung und Aussiedlung von Zivilisten zu sammeln. Ihr zum Teil zuarbeitende Unterkommissionen auf Ebene der Teilrepubliken vervollständigten die DKZ. Ihre zentrale Aufgabe bestand darin, sogenannte Entscheide anzufertigen, welche die Personalien von Verdächtigen, die Namen ihrer Opfer, eine Beschreibung der begangenen Verbrechen und Beweise dafür festhielten.

Parallel zu diesem formalisierten Verfahren ordnete Tito im Mai 1944 in einer streng vertraulichen Anordnung die Gründung einer gesamtjugoslawischen Geheimpolizei an. Die Abteilungen und angegliederten bewaffneten Einheiten des Organ Zaštite Naroda (Organ des Volksschutzes, OZNA) hatten die Aufgabe, politische Gegner, die unter die Kategorien Kriegsverbrecher, Kollaborateure, Volksfeinde und Verräter fielen, aufzuspüren, zu verhören, zu verhaften und zu liquidieren. ${ }^{33}$ Im August 1944 begründete ein Beschluss des AVNOJ die Spezialeinheit Korpus Narodne Odbrane Jugoslavije (Korpus der Volksverteidigung Jugoslawiens, KNOJ) für den Kampf gegen abtrünnige Gruppen. Die Spezialeinheit sollte das befreite Territorium von Spionen und Fünfkolonisten säubern,

32 Katrin Boekh wies auf die Nachahmung der am 2. November 1942 gegründeten, sowjetischen »Außerordentlichen Staatlichen Kommission für die Feststellung des Schadens und der Verbrechen, die von den deutschen faschistischen Eindringlingen und ihren Helfershelfern begangen wurden«, hin, vgl. Boekh, Katrin: »Zur Religionsverfolgung in Jugoslawien 1944-1953. Stalinistische Anleihen unter Tito«, in: Konrad Clewing/Oliver Jens Schmitt (Hg.): Südosteuropa. Von vormoderner Vielfalt und nationalstaatlicher Vereinheitlichung, München: Oldenbourg 2005, S. 431462, hier S. 440.

33 Zur Gründung der OZNA in Serbien und Belgrad und die Verfolgung von »Volksfeinden« 1944 vgl. Nikolić, Kosta/Dimitrijević, Bojan B.: »Formiranje OZN-e u Srbije i Beogradu i likvidacije >narodnih neprijatelja 1944« [Die Bildung der OZNA in Serbien und Belgrad und die Liquidierung der »Volksfeinde« 1944], in: Istoria 20. veka (2010) 2, S. 9-28. 1946 wurde die OZNA in Uprava državne bezbednosti (Staatssicherheitsdienst) umbenannt, nachdem die militärischen Aufgaben ausgelagert wurden. 
Deserteure ergreifen und Aufgaben des OZNA ausführen. Ende Januar 1945 betonte Tito in einem Befehl an die KNOJ ein hartes Vorgehen gegen bewaffnete Einheiten bis zur »vollständigen Vernichtung und bedingungslosen Kapitulation $\aleph^{34}$. Ein geheimer Befehl des Leiters der OZNA, Aleksandar Ranković, vom 9. April 1945 bekräftigte die Vernichtungspolitik.

Schon ab Ende 1944 wurden Gesetze und Erlasse zur Konfiskation von Eigentum, zur Enteignung wegen Kollaboration, wegen Wirtschaftssabotage und schließlich über Wählerlisten veröffentlicht, die ebenso auf vermeintliche Kollaborateure und Verräter angewandt wurden. Die Vertreibung von Angehörigen der deutschen und italienischen Minderheiten wurde legalisiert.

Widersprüchlich zu diesen Maßnahmen erscheint, dass Tito ab November 1944 in der Bevölkerung der befreiten Gebiete um ein Amnestiegesetz warb, das diejenigen entlasten sollte, die ihre Hände nicht »mit dem unschuldigen Blut des Volkes $«{ }^{35}$ besudelt hätten: Sie sollten keine Bestrafung erfahren, rehabilitiert, umerzogen und somit in die Volksbefreiungsbewegung integriert werden. Während die vom AVNOJ erlassene allgemeine Amnestie für četnici sowie für die kroatischen und slowenischen domobrani (Angehörige der Heimwehr) - ausgenommen waren Personen, die Verbrechen begangen hatten - nach außen als Akt der Großzügigkeit erschien, ist sie vielmehr als Maßnahme psychologischer Kriegsführung zu verstehen: Zur Gewährung der Amnestie musste man sich binnen kurzer Frist der Partisanenbewegung stellen. ${ }^{36}$

Trotz der Versuche, einen Umgang mit Kriegsverbrechen auf rechtsstaatlicher Basis einzuleiten, richteten sich gewaltsame, wilde Racheakte oft pauschal gegen die Angehörigen der uniformierten Verbände - und häufig auch gegen Zivilisten, soweit sie den Besatzern angehörten oder mit ihnen kollaborierten. Hierunter fielen auch die deutsche und italienische Minderheit. Die in den letzten beiden Kriegsjahren erstarkte Partisanenbewegung übte brutal Vergeltung. ${ }^{37}$

34 Vgl. M. Portmann: Kommunistische Abrechnung, S. 65.

35 Ferhadbegović, Sabina: »Von `Volksfeinden` und `Volkshelden২. Die jugoslawischen Kriegsverbrecherprozesse nach dem Zweiten Weltkrieg und heute«, Vortrag an der Humboldt-Universität Berlin am 8.6.2011.

36 Vgl. Völkl, Ekkehard: »Abrechnungsfuror in Kroatien«, in: Klaus-Dietmar Henke und Hanns Woller (Hg.): Politische Säuberung in Europa. Die Abrechnung mit Faschismus und Kollaboration nach dem Zweiten Weltkrieg, München: Deutscher Taschenbuch Verlag 1991, S. 358-394, hier S. 374. Zum Wortlaut der Amnestieentscheidung des AVNOJ sowie zur Rede von Tito über den von ihm eingebrachten Vorschlag siehe S. Nešović: Stvaranje nove Jugoslavije, S. 575-578.

37 Vgl. ausführlich dazu M. Portmann: Kommunistische Abrechnung. 
Gegen Kriegsende organisierten OZNA und KNOJ gemeinsam mit den Partisanenverbänden großangelegte Vergeltungsmaßnahmen, als nach dem Fall Zagrebs am 6. Mai 1945 kroatische Streitkräfte, Ustaša-Angehörige, Muslime aus Bosnien-Herzegowina sowie die deutsche Wehrmacht und ihre Hilfstruppen vor den vorstoßenden Partisanen nach Norden flüchteten. Nach der bedingungslosen Kapitulation der ustaše im österreichischen Bleiburg lieferte die britische Besatzungsmacht alle »Bürger Jugoslawiens« an die Volksbefreiungsarmee zur »Repatriierung« aus. Obwohl Partisanenverbände rund um Bleiburg schon Kollaborateure töteten, sicherte man den Briten die Einhaltung von internationalen Bestimmungen für die Behandlung von Zivilisten und den Umgang mit Kriegsverbrechern zu. Nach der Übergabe wurden die Gefangenen auf Todesmärschen in Lager in Slowenien und im nördlichen Kroatien verbracht und aufgeteilt, bevor die Überlebenden von Mitgliedern von OZNA, KNOJ und Partisanenverbänden in Massenexekutionen getötet wurden. ${ }^{38}$

Vermutlich um die Situation nicht weiter eskalieren zu lassen, forderte Tito in einer Rundfunkrede dazu auf, die Tötungen zu beenden. ${ }^{39}$ Allerdings erscheinen die Ansprache Titos und ihre Intention im Kontext der Äußerungen von Milovan Đilas ambivalent:

»Niemand weiß, ob Tito direkte Befehle gegeben hat oder nicht. Doch er war sicher für eine radikale Lösung, genau wie die Briten pragmatische Gründe hatten, diese Flüchtlinge zurückzuschicken. Jugoslawien befand sich im Zustand des Chaos und der Zerstörung. Eine Zivilverwaltung gab es praktisch nicht. Es gab keine ordentlichen Gerichte. Es gab keine Möglichkeit, die 20.000 bis 30.000 Fälle zuverlässig zu untersuchen. So war der einfachste Ausweg, sie alle zu erschießen und damit das Problem los zu sein. ${ }^{40}$

Am 15. August 1945 wurde das »Gesetz über Straftaten gegen das Volk und den Staat« verabschiedet, welches auch rückwirkend angewandt wurde. Es bot erneut einen großen Interpretationsspielraum darüber, welche Straftaten überhaupt geahndet wurden, wer als Volksfeind galt, und legalisierte die Verfolgung politisch unliebsamer Personengruppen in den Anfängen des sozialistischen Jugoslawien. ${ }^{41}$

38 Vgl. ebd., S. $111 \mathrm{ff}$.

39 Vgl. Tolstoy, Nikolai: The Minister and the Massacres, London: Hutchinson 1986, S. 389 .

40 Urban, George: Gespräche mit Zeitgenossen, Weinheim: Beltz 1982, S. 201.

41 Vgl. Mitrović, Momčilo, »Narodni i državni neprijatelji u Srbiji posle Drugoga svetskog rata« [Volks- und Staatsfeinde in Serbien nach dem Zweiten Weltkrieg], in: Hans-Georg Fleck/Igor Graovac (Hg.): Dijalog povjesničara - istoričara 4 [Dia- 
All diese Maßnahmen schwächten auch politisch oppositionelle Gruppen mit Blick auf die geplanten Wahlen im November 1945.

Schließlich wurde, auch im August 1945, eine großzügige »Verordnung über eine allgemeine Amnestie und Begnadigung « erlassen, mit der »Verführte« wieder in die Gesellschaft integriert werden sollten. ${ }^{42}$ Hiervon ausgenommen waren nachgewiesenermaßen Beteiligte an Verbrechen, Mitglieder des volksdeutschen Kulturbundes, Mitarbeiter der Gestapo und anderer Polizeiorganisationen, Angehörige der kroatischen Ustaša-, der serbischen profaschistischen LjotićBewegung, des russischen Freiwilligenkorps, höhere Offiziere und Personen, die sich einem Gerichtsverfahren entzogen hatten. Waren aber diese Gruppen nach dem 1. Januar 1942 zwangsmobilisiert worden, fielen sie ebenfalls unter die Amnestie.

Bei der DKZ gingen bis zu ihrer Auflösung 1948 insgesamt über 900.000 Anzeigen über Kriegsverbrechen ein. Alle Landeskommissionen zusammen nahmen ca. 550.000 Zeugenaussagen auf und trafen auf dieser Grundlage 120.000 Entscheidungen. Dabei identifizierten sie $65.000 »$ Kriegsverbrecher, Verräter und Volksfeinde«, etwa 50.000 davon waren einheimische »Verräter «. ${ }^{43}$ Auf Grundlage der DKZ-Entscheide erhoben die bereits genannten Militärgerichte bis Mai 1945 Anklage, später wurden deren Kompetenzen schrittweise an zivile Volksgerichte übertragen. Die Prozesse gegen Kriegsverbrecher und Volksfeinde fanden 1945/1946 ihren Höhepunkt und liefen bis 1950 weitgehend aus. ${ }^{44}$ Gerade die Prozesse gegen Führungsfiguren des kollaborierenden Unabhängigen Staates Kroatiens wurden sehr öffentlichkeitswirksam geführt.

Auch auf internationaler Ebene beteiligte sich Jugoslawien an den Bemühungen, Kriegsverbrecher für ihre Taten zu bestrafen. Die jugoslawische Exilregierung war Gründungsmitglied der United Nations War Crimes Commission, die am 20. Oktober 1943 in London gegründet wurde und bis Ende März 1948 bestand. Eine bei den UN akkreditierte jugoslawische Delegation hatte den Auftrag, auf Grundlage der lokal vorliegenden Informationen Anklageschriften gegen ausländische Kriegsverbrecher zu formulieren. ${ }^{45}$ Die jugoslawische Dele-

log kroatischer und serbischer Historiker], Zagreb: Friedrich Naumann Stiftung 2000, S. 249-266, siehe auch E. Völkl: »Abrechnungsfuror in Kroatien«, S. 386 f.

42 Vgl. ebd.

43 Vgl. S. Ferhadbegović: »Von >Volksfeinden〈 und >Volkshelden««.

44 Der letzte Kriegsverbrecherprozess in Jugoslawien fand im April 1986 gegen Andrija Artuković, den Innenminister des Unabhängigen Staats Kroatien, statt.

45 Unter der Interimsregierung wurde 1944 die jugoslawische Delegation der Kommission für Kriegsverbrechen bei den UN personell ausgetauscht. Nachdem in den von 
gation reichte 4800 Anträge zu mutmaßlichen Kriegsverbrechern ein, 2868 davon wurden bei der UN-Kommission auch als solche registriert. Zur Diskrepanz zwischen der vergleichsweise niedrigen Anzahl der in London gestellten Anträge und der hohen Zahl der bei den jugoslawischen Staats- und Landeskommissionen ausgestellten »Entscheidungen« über ausländische Kriegsverbrecher erklärt Michael Portmann, dass die Masse an vorliegenden Entscheidungen für die jugoslawische Delegation in London kaum zu bewältigen war. Deshalb haben sowohl die DKZ als auch die Delegation nur die schwersten und aussichtsreichsten Fälle ausgewählt. Da die Regierungen Ungarns, Bulgariens und Albaniens ihre Kriegsverbrecher selbst vor Gericht stellen wollten, seien zudem in London von Staatsangehörigen dieser Staaten keine Registrierungen mehr vorgenommen worden. Portmann mutmaßt, dass der DKZ bewusst war, dass ihre Maßstäbe den internationalen Anforderungen nicht immer genügten. ${ }^{46}$

Zusammenfassend lässt sich feststellen, dass es schon seit den ersten Kriegsmonaten eine Bestrafung von Kriegsverbrechen der Besatzer und Kollaborateure gab, die zunehmend legalisiert wurde. Dieser rechtsstaatliche Anschein, die DKZ und die ihren Ermittlungen nachgelagerten Prozesse verliehen der Volksbefreiungsbewegung Legitimität. In erster Linie dienten die ergriffenen Maßnahmen aber der Rache, der Vergeltung und der Benachteiligung politischer Gegner. Aufgrund ihrer Selektivität müssen die Strafverfolgung und die Prozesse als politisch und als eine Form von Siegerjustiz gewertet werden. Sie kamen einer Abrechnung mit politischen Feinden zugunsten des Machtausbaus der Partisanen gleich, denen der Bezug auf eine angebliche verräterische Rolle der Bestraften im Krieg Vorwand bot, um politische Opponenten zu diskreditieren. Von einer Vergangenheitsaufarbeitung, die den Vorstellungen einer neutralen Rolle der Justiz in der Bewertung der Fälle unter Berücksichtigung aller Umstände und der Offenlegung sämtlicher Fakten folgt, kann hier keineswegs die Rede sein, sondern vielmehr von einer politischen Interpretation des Krieges und einer Instrumentalisierung der Prozesse. Selbst das politische Führungspersonal des jungen sozialistischen Jugoslawien ordnete die gewalttätige Abrechnung als gängig ein und betrachtete sie als eine Art Tradition in der konfliktreichen Region:

den Briten beaufsichtigten ersten Wahlen 1945 die kommunistische Partei Titos klar als Wahlsieger hervorging, traten die oppositionellen, noch vom König eingesetzten Politiker der Exilregierung zurück. Am 29. November 1945 wurde schließlich die Föderative Volksrepublik Jugoslawien proklamiert.

Vgl. M. Portmann: Kommunistische Abrechnung, S. 71. 
»[Dieses] Prinzip [der Abrechnung, D. M.] ist weder ausschließlich kommunistisch noch jugoslawisch. Auf dem Balkan hat Abtrünnigen und Aufrührern schon immer solch ein Schicksal geblüht. Und das ist auch anderswo so - seltener in Europa, denn dort sind auch die Rebellen und Aufstände seltener. ${ }^{47}$

In der Interpretation der Geschichte unterschieden sozialistische Politiker und Institutionen zwischen den guten, heldenhaften Partisanen, den »Volksfeinden« sowie den »Helfern der Okkupanten« oder versagenden bourgeoisen Kräften, die moralische Ächtung und politische Ausgrenzung erfuhren. Um dieses ideologische Narrativ aufrechtzuerhalten, wurden die gewalttätige Abrechnung mit politischen Gegnern während des Kriegstreibens und die Racheaktionen der Partisanen in der Öffentlichkeit beschwiegen und nicht verfolgt. Die interethnischen Verbrechen waren ebenfalls tabuisiert und wurden ethnisch »neutralisiert «. ${ }^{48}$ In den Jahren nach Kriegsende schrieb die staatliche Politik, zunehmend aber auch lokale Veteraneninitiativen die schon seit 1943 festgelegten dichotomen Großnarrative in oftmals monumentalen Denkmälern fest. ${ }^{49}$ Dabei wurden die Verbrechen der Nazis stets in ihrer vollen Grausamkeit und Unmenschlichkeit und die Kämpfe der antifaschistischen Partisanen als besonders heldenhaft dargestellt. Die doppelte Dichotomisierung in gut/böse und innen/außen diente so dazu, den Bürgerkrieg und die nationalistische Verfolgung zwischen den verschiedenen Volksgruppen zu überformen, um eine einheitliche sozialistische Gesellschaft in »Brüderlichkeit und Einheit« zu ermöglichen.

In scharfem Kontrast zu den von der jugoslawischen Führung befohlenen und geduldeten Kriegsverbrechen an politischen Gegnern 1945 gestaltet sich das außenpolitische Verhalten Jugoslawiens in den folgenden Jahren: Das Land ratifizierte wenig später die wichtigsten internationalen Rechtsregime des Humanitären Völkerrechts. Diese Normübernahme kann nicht als bewusste Abgrenzung zu einem früheren Fehlverhalten gewertet werden, da dieses ja nicht öffentlich thematisiert werden durfte. Allerdings teilte die politische Führung des Landes nach den beiden Weltkriegen und den daraus für die Bevölkerung auf dem Ge-

47 Đilas, Milovan: Der Krieg der Partisanen. Memoiren, 1941-1945, Weinheim: Fritz Molden 1978, S. 570.

48 Vgl. Höpken, Wolfgang: »Vergangenheitspolitik im sozialistischen Vielvölkerstaat: Jugoslawien 1944-1991«, in: P. Bock/E. Wolfrum (Hg.): Umkämpfte Vergangenheit, S. 210-243.

49 Siehe hierzu ausführlich Karge, Heike: Steinerne Erinnerung - versteinerte Erinnerung? Kriegsgedenken in Jugoslawien (1947-1970) (= Balkanologische Veröffentlichungen 49), Wiesbaden: Harrassowitz 2010. 
biet Jugoslawiens und auch für die Staatsorganisation verheerenden Folgen die Hoffnung der Zivilisierung von Kriegen. Im Dezember 1948 unterzeichnete Jugoslawien die Genozidkonvention, 1950 traten die vier Abkommen der Genfer Konventionen in Kraft. 1970 ratifizierte es die Konvention über die Nichtanwendbarkeit der Verjährung auf Kriegsverbrechen und Verbrechen gegen die Menschlichkeit. Die beiden Zusatzprotokolle zu den Genfer Konventionen traten 1978 in Kraft.

\section{Genoziddiskurs und Umdeutung des Zweiten Weltkriegs}

$\mathrm{Ab}$ den 1970er Jahren ist eine schrittweise Umdeutung der Bewertung des Zweiten Weltkriegs in Jugoslawien zu beobachten. Die Inanspruchnahme der internationalen Genozidkonvention und damit des Völkermordbegriffs hielt in die jugoslawische Historiographie Einzug. Wie die Monographie von Tea Sindbæk aufzeigte, nutzte die jugoslawische Geschichtsschreibung das Wort genocid bis 1970 nur sehr selten in völkerrechtlichen Fragen oder in Anwendung auf die nationalsozialistischen Verbrechen, auch im politischen Diskurs wurde der Begriff lediglich in Fragen der Außenpolitik verwandt. ${ }^{50}$ Zentral für eine breitere Verwendung des Genozidbegriffs war eine einzelne einflussreiche Person, die das Völkermordthema in den politischen Diskurs des sozialistischen Jugoslawien transportierte: Vladimir Dedijer, Partisan, ausgebildeter Jurist, jugoslawischer Politiker und Vertrauter von Tito. Bereits 1942 arbeitete er in einer Kommission der Partisanen unter Führung von Moše Pijade mit, die Beweise für Kriegsverbrechen und Völkermord, vor allem an Serben, rund um Bihać sammelte. Im Vorwort eines Buches machte er deutlich, dass ihn die Zeit als Partisan erschütterte, nach Verbrechen wie der Bombardierung Belgrads, des Massakers von Kragujevac, den unzähligen Opfern in den Höhlen des Unabhängigen Kroatischen Staates, dem Konzentrationslager Jasenovac und den vielen Opfern der Schlacht von Sutješka sei die Frage des Völkermords für ihn nicht nur eine juristische Angelegenheit gewesen. ${ }^{51} 1948$ nahm Dedijer für Jugoslawien an den Verhandlungen zur Genozidkonvention teil. Später war er Mitglied des privat organisierten, ersten Russell-Tribunals, das 1966/1967 die amerikanischen Kriegsverbrechen in Vietnam untersuchte und einstimmig die US-Führung für den Genozid am vietnamesischen Volk schuldig sprach. In der von Dedijer mit-

50 Vgl. Sindbæk, Tea: Usable History? Second World War Massacres and the Theme of Genocide in Yugoslav Historical Culture, 1945-2002, Aarhus: University Press 2013.

51 Vgl. das Vorwort in Dedijer, Vladimir: Vatikan i Jasenovac. Dokumenti [Der Vatikan und Jasenovac. Dokumente], Belgrad: Izdavačka radna organizacija »Rad« 1987. 
herausgegebenen populären Geschichte Jugoslawiens ${ }^{52}$ hielt die Kategorie Genozid 1972 in die Neubewertung des Zweiten Weltkriegs Einzug. Ihm lagen nationale Deutungen fern, allerdings ging er von einem Konzept des Völkermords deutscher Prägung aus, dessen Methoden lokale Kollaborateure rezipiert und gegen andere Volksgruppen angewandt hätten: im Falle der ustaša und kollaborierender Bosnier und Albaner ${ }^{53}$ gegen Serben, im Falle der četnici, der militärischen und paramilitärischen Kräfte der serbischen Kollaborationsregierung gegen Muslime und Kroaten. Dedijer betonte immer wieder, dass Kriegsverbrechen und Völkermord von allen Kriegsparteien verübt wurden - wovon die Partisanen aber auch bei ihm ausgenommen blieben. Besonders hob er die unterbeleuchtete Rolle des Vatikan und der katholischen Kirche im Unabhängigen Staat Kroatien hervor. Der monumentale Sammelband ${ }^{54}$ und die in ihm transportierten Deutungen wurde von der Öffentlichkeit breit rezipiert, der wegen seiner Kontakte zu Intellektuellen wie Jean-Paul Satre und seiner Mitarbeit im RussellTribunal im Bund der Kommunisten Serbiens umstrittene Dedijer schließlich sogar in die Serbische Akademie der Wissenschaften und Künste aufgenommen.

Die mehr kulturelle und nationale Autonomie fordernde Bewegung des »kroatischen Frühlings« strahlte in den späten 60er und frühen 70er Jahren auch in die anderen Teilrepubliken und die Diaspora aus. Die gesellschaftliche Mobilisierung gegen die Einhegung nationaler Freiräume und gegen die sozialistische Deutungshoheit schaffte die Voraussetzung für eine nationale Pluralisierung von Kriegsnarrativen von unten, die die jugoslawischen Staatsnarrative von Brüderlichkeit und Einigkeit kontrastierten. Vor allem in der USA wurden Erinnerungserzählungen über den Zweiten Weltkrieg gesammelt, was in Jugoslawien bis dato »unerwünscht« war, da sie das sozialistische Narrativ und dessen Geltungsanspruch unterminierten. ${ }^{55}$

52 Božić, Ivan/Cir-Kovit, Sima/Ekmetić, Milorad/Dedijer, Vladimir (Hg.): Istorija Jugoslavije [Geschichte Jugoslawiens], Belgrad: Prosveta 1972.

53 Hierunter fallen die vorwiegend aus bosnischen Muslimen bestehenden Waffen-SSDivisionen Handžar und Kama (türk., benannt nach Dolcharten) sowie die WaffenGebirgsdivision der SS Skanderbeg, die vor allem aus (kosovo-)albanischen Angehörigen bestand.

54 Vgl. Božić, Ivan et.al.: Istorija Jugoslavije.

55 Siehe zum Beispiel Hečimović, Joseph: In Tito's Death Marches and Extermination Camps, New York: Carlton Press 1962; Karapandžić, Bor: Kočevje: Tito’s Bloodiest Crime, Cleveland 1965, oder Prcela, John/Guldescu, Stanko (Hg.): Operation Slaughterhouse. Eyewitness Accounts of Postwar Massacres in Yugoslavia, Philadelphia: Dorrance Publications 1970. Eine erneute Welle ausländischer Publikatio- 
In Bezug auf den Ersten Weltkrieg öffnete sich die Kommunistische Partei Mitte der 60er Jahre den serbischen Veteranenverbänden, deren heroische Erzählungen der Periode von 1913 bis 1918 mit der Perspektive der makedonischen Partei auf diese Jahre unvereinbar waren, die diese Zeit als nationale Katastrophe deutete. ${ }^{56}$ Die Udruženje nosilaca Albanske spomenice (Vereinigung der Träger der Albanischen Gedenkplakette ${ }^{57}$ ), die im sozialistischen Jugoslawien verboten war, veröffentlichten 1971 den Sammelband Golgota i Vaskrs 1916-1918 (Golgotha und Auferstehung). In ihm wurde in serbisch-nationaler Perspektive die heroische »Opferung« von Angehörigen des serbischen Volks im Ersten Weltkrieg als Leidensweg beschrieben, dem die Auferstehung der Nation folgte. ${ }^{58}$ Sie erinnerten damit an den Rückzug der serbischen Armee nach der Besatzung Serbiens im Winter 1915/1916 aus Albanien über die Insel Korfu, die auch Sitz der Exilregierung wurde, aber auch an die Kriegserfahrung der darauf folgenden Jahre, als Soldaten an der Salonikifront und später mit französischer Unterstützung für die Rückeroberung Serbiens kämpften. Bereits 1917 wurde in der Deklaration von Korfu die Absicht der Gründung eines jugoslawischen Staates formuliert. Wie Nenad Stefanov aufzeigte, spielt der Titel des Buchs auf eine Arbeit um die Jahrhundertwende an, die sich auf den ersten serbischen Aufstand

nen zu den Verbrechen der Tito-Partisanen wurde zeitgleich zum jugoslawischen Genoziddiskurs ab ca. 1985 veröffentlicht.

56 Vgl. Stefanov, Nenad: »Geschichte als Religion: Anmerkungen zur gesellschaftlichen Genese der historisierenden Opfermythologie im serbischen Ethnonationalismus«, in: Ulf Brunnbauer/Andreas Helmedach/Stefan Troebst (Hg.): Schnittstellen. Gesellschaft, Nation, Konflikt und Erinnerung in Südosteuropa: Festschrift für Holm Sundhaussen zum 65. Geburtstag (= Südosteuropäische Arbeiten 133), München: Oldenbourg 2007, S. 449-460, hier S. 453.

57 Die Medalja za spomen na povlačenje srpske vojske preko Albanije [Medaille zum Andenken an den Rückzug der serbischen Armee durch Albanien] wurde den Soldaten 1920 von Prinzregent Aleksandar Karađorđević verliehen.

58 Todorović, Kosta/Velimirović, Milutin (Hg.), Golgota i vaskrs Srbije 1916-1918 [Golgatha und Auferstehung Serbiens 1916-1918], Belgrad: Udruženje nosilaca albanske spomenice 1915-1916/Beogradski izdavačko-grafički zavod 1971. Vervollständigt wurde das Narrativ einige Jahre später durch eine weitere Publikation, welche die Zeit des gesamten Ersten Weltkriegs abdeckte, vgl. Đurić, Silvija/ Stevanović, Vidosav: Golgota i vaskrs Srbije 1914-1918 [Golgatha und Auferstehen Serbiens 1914-1915] (= Istorijsko-memoarska dela [Historisch-autobiographische Werke]), 2 Bd., Belgrad: Beogradski izdavačko-grafički zavod/Partizanska knjiga 1986. 
bezog. Sie schreibt diese Erhebung in eine Kontinuitätslinie mit dem mittelalterlichen serbischen Großreich von Stefan Nemanja und Stefan Dušans ein, das mit den Niederlagen gegen die Osmanen endete. ${ }^{59}$ An der Erosion und vor allem einer Nationalisierung der geltenden Kriegsnarrative arbeitete auch der Schriftsteller Dobrica Ćosić mit. Er war nach seinem Ausschluss aus der Kommunistischen Partei 1968 aufgrund der von ihm postulierten »kosovarischen Wahrheit« wegen seiner schriftstellerischen Erfolge 1978 nunmehr zum ordentlichen Mitglied der serbischen Akademie der Wissenschaften ernannt worden und propagierte einen Blick auf das weite Panorama des serbischen Leidens in der Geschichte im Allgemeinen und im 20. Jahrhundert im Besonderen ${ }^{60}$. In seiner von 1972 bis 1979 veröffentlichten Romanserie Vreme smrti (Zeit des Todes) widmete er sich der Zeit des Ersten Weltkriegs, etwa zeitgleich wurden auch im Ausland erste biographische Berichte veröffentlicht. ${ }^{61}$

Im Zuge der Reformen, die mit Liberalisierung, Demokratisierung und stärkerer Föderalisierung einhergingen, reagierte der Bund der Kommunisten Jugoslawiens auf die innenpolitischen Krisendynamiken im Kontext des kroatischen Frühlings. 1973 wurden auch Kriegsverbrecher im Ausland und 1977 politische Gefangene amnestiert. Der Straferlass ermöglichte die Rückkehr von antisozialistischen und nationalistisch orientierten Exilanten und ihrer Narrative nach Jugoslawien. Im Zuge der Nationalisierung des jugoslawischen politischen Diskurses nach Titos Tod 1980 wurde somit schließlich auch das hegemoniale sozialistische Narrativ des Zweiten Weltkriegs und des Nationalen Befreiungskampfes zunehmend aufgebrochen und national pluralisiert. In Serbien thematisierten national gesinnte Schriftsteller wie beispielsweise Vuk Drašković die beschwiegenen Verbrechen und Konfliktlinien während des Zweiten Weltkrieges zwischen den in Jugoslawien lebenden Volksgruppen. Trotz - oder wegen - der

59 Stefanov verweist auf Novaković, Stojan: Vaskrs Države Srpske. Političko-istorijska studija o prvom srpskom ustanku 1804-1813 [Die Wiedergeburt des serbischen Staates. Politisch-historische Studie über den ersten serbischen Aufstand 18041813], Belgrad: Državna štamparija Kraljevine Srbije 1903, vgl. N. Stefanov: »Geschichte als Religion«, S. 452.

60 Ders.: Wissenschaft als nationaler Beruf. Die Serbische Akademie der Wissenschaften 1944-1992. Tradierung und Modifizierung nationaler Ideologie (= Balkanologische Veröffentlichungen Geschichte - Gesellschaft - Kultur 52), Wiesbaden: Harrassowitz 2011, S. 279.

61 Exemplarisch Vuković-Birčanin, Momčilo/Vuković, Dragoljub T.: Golgota i vaskrs Srbije. Očev dnevnik I. Svetskog rata [Golgatha und Auferstehung Serbiens. Vaters Tagebuch des Ersten Weltkriegs], München: Izdanje pisca 1979. 
kommunistischen Zensur wurden ihre Romane durch die Berichterstattung populär. Kollaborateuren, »Volksfeinden« und »Verrätern« verlieh man nun nicht mehr politische, sondern nationale Präfixe. Diese Entwicklung wurde von wissenschaftlicher Seite untermauert, gerade die Arbeiten von Mitgliedern der Serbischen Akademie der Wissenschaften wie Vladimir Dedijer und Veselin Đuretić bewerteten den Volksbefreiungskampf neu. ${ }^{62}$ Leiden und Widerstand des serbischen Volkes erhielten Anerkennung, auch wurde der existentielle Abwehrkampf des serbischen Volkes gewürdigt und die serbischen Widerstandsbewegungen unter Milan Nedić und Draža Mihailović rehabilitiert.

An der Serbischen Akademie der Wissenschaften und Künste wurde der $O d$ bor za sakupljanje građe o genocidu protiv srpskog i drugih naroda Jugoslavije $u X X$ veku (Ausschuss zur Sammlung von Material über den Genozid am serbischen Volk und an anderen jugoslawischen Völkern im 20. Jahrhundert) eingerichtet. $^{63}$ Der unter dem Vorsitz von Vladimir Dedijer arbeitende Ausschuss nahm die Verbrechen zwischen den jugoslawischen Volksgruppen während des Zweiten Weltkrieges in den Fokus, die unter Titos Herrschaft völlig tabuisiert wurden, auch sollte die Zahl der Kriegsopfer ermittelt werden. Der Ausschuss wurde 1985 in mehrere Unterkomitees aufgeteilt und sollte insgesamt 21 Studien und Quellensammlungen veröffentlichen. Bis 1990 wurden elf Bände veröffentlicht, in zehn davon stellten Serben die größte Opfergruppe dar. ${ }^{64}$ Der Ausschuss

62 Đuretić, Veselin: Saveznici i jugoslovenska ratna drama [Die Alliierten und das jugoslawische Kriegsdrama], Belgrad: Narodna knjiga/Balkanološki institut SANU 1985.

63 Parallel arbeitete an der Serbischen Akademie für Wissenschaft und Künste ab Sommer 1985 ein Komitee zur Vorbereitung eines Memorandums über aktuelle soziale Fragen, das nach der Vorabveröffentlichung eines Auszugs in der Zeitung Večernje novosti am 25./26. September 1986 sowohl innerhalb Jugoslawiens als auch in den Folgejahren international für Furore sorgte, da in diesem ein (groß-)serbisches nationalistisches Programm skizziert wurde. An der Person Vasilije Krestić kann die Gleichzeitigkeit der beiden Themen gut aufgezeigt werden: Während er am Memorandum mitschrieb, veröffentlichte er parallel einen Artikel über den Hintergrund des Völkermords an Serben im Unabhängigen Staat Kroatien, vgl. Krestić, Vasilije: »O genezi genocida nad Srbima u NDH« [Über die Genese des Völkermords an den Serben im Unabhängigen Staat Kroatien], in: Književne novine vom 15.9.1986, S. 1-4.

64 T. Sindbæk: Usable History?, S. 155. Beispiele für die veröffentlichten Titel sind V. Dedijer: Vatikan i Jasenovac; ders./Miletić, Antun: Proterivanje Srba sa ognjišta 1941-1944. Svedočanstva [Die Verbannung der Serben von der Feuerstelle 1941- 
platzierte mit seinem Fokus auf Völkermord den Begriff prominent im öffentlichen Diskurs, der mit der politischen Dynamik national gestimmter Kreise und der Erosion des jugoslawischen Staates massiv an Konjunktur gewann. Die zum Teil problematischen Quelleneditionen und Sammlungen von »Zeugenaussagen« für Verbrechen legten die Basis für eine polemische Medienberichterstattung.

Ein besonderer Schwerpunkt lag auf der bis dahin unterbeleuchteten Geschichte des kroatischen Lagers Jasenovac, in dem Juden, Serben und Roma umkamen, sowie auf den Kollaborations- und Unterstützungsstrukturen von Deutschen, Kroaten und kirchlichen Würdenträgern im katholischen Kroatien, also des Vatikans. Zunächst beförderte der Vorwurf der nur mangelhaften Auseinandersetzung mit Jasenovac und den Hintergründen einen Legitimationsverlust der sozialistischen Strukturen, die die Kroaten schützten und die Serben zu doppelten Opfern machten. Die de facto unzureichende Forschung sorgte dafür, dass Mythisierungen und Übertreibungen die Runde machten. Die populäre dritte Auflage des 1948 erstmals veröffentlichten und bis dato kaum beachteten $\mathrm{Ma}$ gnum Crimen von Viktor Novak, das die Verwicklungen der katholischen Kirche im Unabhängigen Staat Kroatien beschrieb, sowie die es ergänzende Publikation Barbarei im Namen Christis, die die "völkermordende Maschinerie der Ustaša« thematisierte, befeuerten eine eindeutige Geschichtsinterpretation: ${ }^{65}$ Die nunmehr national »aufgearbeitete« Geschichte skizzierte eine Trias von Deutschen, Kroaten und dem Vatikan als verantwortlich für einen Völkermord an den Serben. Serben wurden hierin ausnahmslos als Opfer dargestellt, die eigene Kollaborationsgeschichte oder die von der eigenen ethnischen Gruppe verübten Verbrechen blieben unthematisiert.

Die Auseinandersetzung mit Jasenovac wurde auch innerhalb der jugoslawischen Beziehungen zu einem Problem, da ausgehend von den historiographischen Veröffentlichungen ein regelrechter Zahlenkrieg um die Höhe der Opfer

1944. Zeugnisse], Belgrad: Prosveta 1989; dies.: Genocid nad Muslimanima 19411945. Zbornik dokumenata i svedočenja [Genozid an den Muslimen 1941-1945. Sammlung von Dokumenten und Bezeugungen] (= Biblioteka $>$ Refleksi $<$ ), Sarajevo: Svjetlost 1990; dies.: Protiv zaborava i tabua. Jasenovac 1941-1991 [Gegen das Vergessen und das Tabu. Jasenovac 1941-1991], Sarajevo: Pregres 1991. 1994 wurde die Arbeit des Komitees eingestellt.

65 Novak, Viktor: Magnum crimen. Pola vijeka klerikalizma u Hrvatskoj [Magnum crimen. Ein halbes Jahrhundert des Klerikalismus in Kroatien], Belgrad: Nova knjiga 1986; Živojinović, Dragoljub R./Lučić, Dejan V.: Varvarstvo u ime Hristovo. Prilozi za Magnum crimen [Barbarbei im Namen Christi. Beiträge zum Magnum crimen], Belgrad: Nova knjiga 1988. 
des Zweiten Weltkriegs in den nationalen Öffentlichkeiten ausbrach. Gegen Jasenovac als Ort serbischen Leidens führten die Kroaten Bleiburg als Ort des Massenmords der von Serben dominierten Partisanen an Kroaten an. ${ }^{66}$ Holocaustanalogien und sprachliche Anleihen waren in beiden nationalen Diskursen populär.

Unter dem Eindruck der nationalen Erzählungen über Jasenovac reaktualisierten sich im serbischen öffentlichen Diskurs Feind-Freund-Schemata. Deutschland, Kroatien und der Vatikan seien antiserbisch. Das gemeinsame Schicksal als Opfer im kroatischen Lager Jasenovac parallelisierte in der öffentlichen Rezeption das serbische und das jüdische Leiden. Die Gründung der Gesellschaft serbisch-jüdischer Freundschaft 1987 erscheint vor diesem Hintergrund nicht zufällig.

Im November 1988 hielt die Serbische Akademie für Wissenschaften und Künste eine große Konferenz zu Jasenovac ab, der große mediale Aufmerksamkeit zukam. Auch die serbisch-orthodoxe Kirche griff das Thema Jasenovac auf, vor allem ab 1991 war sie sehr aktiv und inszenierte in aufwändigen feierlichen Zeremonien die Umbettung von serbischen Opfern.

Bereits seit 1980 wurde das Genozidthema auch im Zuge der Kosovokrise von serbischen Geistlichen aufgegriffen, um damit nationales Opfertum zu markieren. Sie verwiesen auf die problematische Situation der Serben im Kosovo und forderten deren Schutz und den ihrer heiligen Stätten. Im Oktober 1985 reichten schließlich 2016 Serben aus dem Kosovo eine Petition beim Bundesund Republiksparlament ein, der sich danach Tausende Mitunterzeichner anschlossen. Sie blieb politisch weitgehend unbeantwortet. Im Januar 1986 richtete sich ein Appell von 212 Belgrader Intellektuellen an das Bundes- und Republiksparlament gegen den »Genozid an den Serben im Kosovo«. Er beschrieb das Ausmaß der Situation. So seien in den vergangenen zwanzig Jahren mehr als 200.000 Serben aus über 700 Gemeinden gezogen, das Kosovo und Metohija würden aufgrund der albanischen Agression »ethnisch sauber«. Die Unterzeichner forderten ein politisches Bewusstsein und die entsprechenden Maßnahmen, um

»die Geschichte eines langen, verheerenden Völkermordes auf europäischem Boden zu beenden. Wie man aus der Geschichtswissenschaft und dem noch nicht erloschenen Gedächtnis weiß, dauert die Vertreibung der serbischen Bevölkerung aus Kosovo und Meto-

66 Vgl. dazu zum Beispiel Calic, Marie-Janine: Geschichte Jugoslawiens im 20. Jahrhundert (=Europäische Geschichte im 20. Jahrhundert), München: C. H. Beck 2010, $287 \mathrm{ff}$. 
chien schon drei Jahrhunderte an. Verändert haben sich nur die Beschützer der Täter, statt des Osmanischen Reiches, der Habsburger Monarchie, dem faschistischen Italien und Nazi-Deutschland - der albanischen Staat und die regierenden Institutionen Kosovos. Anstatt einer gewaltsamen Islamisierung und Faschismus - stalinisierter Chauvinismus. Neu ist einzig die Verknüpfung von Stammesrache und dem Völkermord des verkleideten Marxismus. ${ }^{67}$

Sie warnen vor den Folgen einer solchen Politik, fordern aber auch gleichzeitig die Beendigung der drakonischen Bestrafungen junger Albaner. Sie rufen zu demokratischen Rechten, Gleichheit des serbischen und der anderen Völker im Kosovo und zu tiefgreifenden sozialen und politischen Veränderungen auf. Das in diesem Appell skizzierte Narrativ zeigt am Beispiel des Kosovo deutlich, wie sehr das Genozidthema Eingang in die Deutung historischer Ereignisse gefunden hat und dass aktuelle politische Ereignisse auf dieser Interpretationsfolie gedeutet werden: Die Geschichte scheint sich zu wiederholen beziehungsweise kontinuierlich die gleiche Entwicklungsrichtung zu haben. Die damit verbundenen Deutungsmuster, Feindbilder und Ängste und ein vermeintliches Wissen darum, welchen Ausgang die Geschichte habe, werden im medialen und politischen Diskurs meinungsbildend.

\subsection{Aufarbeitung $\neq$ Aufarbeitung}

Während auf der internationalen Ebene der Umgang mit Kriegsverbrechen schon frühzeitig reflektiert wurde und auf eine breite Forschungsliteratur zurückgegriffen werden konnte, scheint im jugoslawischen Fall erst mit dem sozialistischen Jugoslawien ein staatlicher Umgang mit Kriegsverbrechen zu beginnen. An den jugoslawischen Erfahrungen wird deutlich, wie sehr die Aufarbeitung von Kriegsverbrechen ein politisches Konzept und Teil symbolischer Kämpfe ist: Geschichte und Politik werden neu verbunden, um gegenwärtige Interessen zu legitimieren. So wurden die nationalen Vorzeichen der Deutung des Zweiten Weltkriegs in der Region Ende der 1940er und in den 50er Jahren durch politische ersetzt. An der Strafverfolgung von Kriegsverbrechen der Achsenmächte

67 Zit. nach Helsinški odbor za ljudska prava u Srbiji (Hg.): Kovanje antijugoslovenske zavere [Das Schmieden der antijugoslawischen Verschwörung] (= Biblioteka Svedočanstva 26), 2 Bd., Belgrad: Helsinški odbor za ljudska prava u Srbiji 2006, hier Bd. 1, S. 113 f.. (So nicht anders angegeben, wurden alle Übersetzungen von der Autorin vorgenommen.) 
und ihrer Verbündeten wurde sowohl auf nationaler als auch auf internationaler Ebene gearbeitet, wobei diese innenpolitisch aufgrund schwammiger Definitionen auch als Mittel zur Marginalisierung und Unterdrückung politischer Gegner instrumentalisiert wurde. Gleichzeitig wurden die staatlicherseits unterstützten und geduldeten Verbrechen der Partisanen, der OZNA und der KNOJ nicht thematisiert und blieben gänzlich unbearbeitet.

Die aus dem Zweiten Weltkrieg entstandenen Zivilisierungsversuche durch internationale Rechtsregime unterstützte Jugoslawien von Beginn an, ohne aber die in diesen Regimen postulierten normativen Prämissen auch in Bezug auf die eigene Vergangenheit zu reflektieren oder einen öffentlichen Diskurs dazu zuzulassen.

$\mathrm{Ab}$ den 80er Jahren brach das staatliche Narrativ über den Zweiten Weltkrieg auf, und mit Hilfe von Interventionen aus Wissenschaft und Kultur wurden die komplizierten politischen und nationalen Konfliktlinien des Zweiten Weltkriegs erneut mit nunmehr rein nationalen Interpretationen überformt, welche die politischen Akteure in Serbien und die serbisch-orthodoxe Kirche dankbar aufnahmen. Diese Auseinandersetzung mit den Kriegsverbrechen des Zweiten Weltkriegs durch Dissidenten, Literaten und Historiker kann nichtsdestotrotz als eine kritische Aufarbeitung des sozialistischen Narrativs verstanden werden. Da eine nationale Perspektive nach der anationalen sozialistischen Politik unter Tito nun als zentrales demokratisches Recht verstanden wurde, legte die Aufarbeitung der Kriegsverbrechen den Fokus auf die eigenen Opfer und forderte eine Anerkennung der nationalen Leidens- und Opfergeschichte. Die Thematisierung der verschwiegenen Verbrechen brach die nach politischen Vorzeichen selektierende sozialistische Aufarbeitung auf. Kollaborateure wurden wegen ihres Leids und ihrer Zugehörigkeit zur Nation rehabilitiert, während die Partisanen aufgrund des beschwiegenen Jasenovac und anderer Verbrechen sowie der von Partisanen selbst begangenen Gräuel - hier sei nur stellvertretend das Massaker von Bleiburg zu nennen - doppelt delegitimiert wurden. Das integrative Narrativ der Volksbefreiungsbewegung verlor endgültig seinen Geltungsanspruch, gleichzeitig verschärften sich in der Berichterstattung die nationalistischen Töne und der Gebrauch von Kollektiva: »Die Serben« beschuldigten »die Kroaten« wegen des Völkermords in Jasenovac, während »die Kroaten« »die Serben« äquivalent mit den Tätern von Bleiburg setzten und ausblendeten, dass die politisch motivierten Vergeltungsmaßnahmen nicht nach ethnischen Kriterien verliefen.

Auch semantisch wurden durch starke moralische Normen, Totemismen, Symbole und die scheinbar allgegenwärtige Holocaustanalogie emotionale und dichotome Interpretationen von Vergangenheit und gegenwärtigen Entwicklun- 
gen unterstützt. ${ }^{68}$ Wie Höpken treffend formulierte, wurden so beispielsweise Jasenovac und das Kosovo zur »Abbreviatur einer Geschichtsnarration, die das vermeintliche Schicksal von Bedrohung und genozidaler Gefährdung zur zentralen Achse und einer \Konstante der serbischen Geschichte [...] stilisierte «"

Eine Referenz auf internationale Konventionen und Begriffe folgte in erster Linie in Bezug auf die Völkermordkonvention. Zentral für die Aufarbeitungsdiskurse in den 80er Jahren war die Inanspruchnahme des Terminus Genozid und der damit verbundenen moralischen und politischen Implikationen. Sie wurden mit lokalen Prozessen und Erfahrungen während des Zweiten Weltkriegs und der Gegenwart verbunden. Die Selbstdefinition als Opfer wies anderen die Rolle der Täter oder Feinde zu und lieferte einen Deutungsrahmen politischer Entwicklungen im Erosionsprozess Jugolawiens, die diesen noch befeuerte.

Während zeitgleich in anderen Ländern die Ausbildung neuer moralischpolitischer Verantwortungen unterschiedliche Formen retributiver und restorativer Praktiken abbildeten, fanden diese Diskurse über einen geregelten Umgang mit Kriegsverbrechen im sozialistischen Jugoslawien keine Anschlussfähigkeit. Da der Großteil der politischen Eliten Jugoslawiens nach dem Tod Titos kein Interesse an einer Auseinandersetzung mit Kriegsverbrechen mit der Perspektive einer Versöhnung hatten, sondern selbst im Wettbewerb um Vorherrschaft im destabilisierten politischen System standen, transformierten sie, unterstützt von den Kirchen und den sensationsgeleiteten Medien, den Diskurs über Kriegsverbrechen in einen Diskurs über nationale Opfer, der weiter zur nationalistischen Mobilisierung und zur Desintegration des politischen Systems beitrug. Zumindest der serbische Diskurs koppelte sich von dem internationalen Diskurs über Kriegsverbrechen ab beziehungsweise nutzten serbische Wissenschaftler und politische Organe die internationalen Diskurse über Kriegsverbrechen und den Umgang mit ihnen nur noch selektiv, das heißt dann, wenn sie von nationalem Interesse und Nutzen waren.

Daniel Levy und Natan Sznaider konstatierten in ihren Überlegungen zur Rekonfiguration neuer Erinnerungskulturen nach 1989, dass sich der Umgang mit belasteter Vergangenheit neu formierte. Es habe eine Abkehr von der für die Abgrenzung konstitutiven Unterscheidung zwischen Täter- und Opfererinnerung

68 Ausführlich hierzu siehe Bugarski, Ranko: Jezik od mira do rata [Die Sprache vom Frieden zum Krieg] (= Biblioteka XX vek 81), Belgrad: Slovograf 1995.

69 Höpken, Wolfgang: »Jasenovac - Bleiburg - Kočevski rog. Erinnerungsorte als Identitätssymbole in (Post-)Jugoslavien«, in: Angela Richter/Barbara Beyer (Hg.): Geschichte (ge-)brauchen. Literatur und Geschichtskultur im Staatssozialismus: Jugoslavien und Bulgarien, Berlin: Frank \& Timme 2006, S. 401-432, hier S. 412 f. 
der ersten Moderne gegeben, in der Mitte/Ende des 20. Jahrunderts beginnenden zweiten Moderne mache die gegenseitige Anerkennung der Geschichte des Anderen die Versöhnung zum zentralen Erinnerungserlebnis. ${ }^{70}$ Diese erinnerungskulturelle Transformation vollzog Jugoslawien nicht mit. Stattdessen wurden ab den 80er Jahren Elemente der Ersten Moderne und eine Selbstdefinition als Opfer verstärkt, während Täternarrative keinen Eingang in die neuen serbischen Selbstbeschreibungen fanden. Um es mit den Begrifflichkeiten der Diskurstheorie auszudrücken: Während die Wahrnehmung als Opfer hegemonial wurde, projizierte man die Rolle des Täters konsequent in ein verworfenes Außen.

70 Vgl. Levy, Daniel/Sznaider, Natan: Erinnerung im globalen Zeitalter: der Holocaust (= Suhrkamp Taschenbuch 3870), Frankfurt am Main: Suhrkamp 2007, S. 241-248. 


\section{Vergangenheitsaufarbeitung in Jugoslawien und Serbien 1991-2012}

In diesem Kapitel wird untersucht, wie sich der Umgang mit Kriegsverbrechen und Menschenrechtsverletzungen in Serbien seit Beginn der 1990er Jahre gewandelt hat und wie er ausgestaltet wurde. Um die These eines transnationalen Lernprozesses zu überprüfen, werden Konflikte und Interaktionsmuster zwischen der nationalen und der internationalen Ebene, wie beispielsweise Konditionalitätspolitik und deren (Nicht-)Befolgung, sowie nationale Strategien, die als taktische Konzessionen oder Ausweichstrategien gewertet werden, besonders berücksichtigt.

Aufgrund der doppelten politischen Transition Serbiens ${ }^{1}$ - einmal 1990, einmal 2000 - und ihres ausgehandelten Charakters kann im serbischen Fall nicht von einer idealtypischen transitional justice ausgegangen werden, die direkt auf eine Transition folgen würde und einen klaren Bruch mit der Vergangenheit und dem vorhergehenden Regime markieren soll.

Im serbischen Diskurs blieb lange unklar, was genau der Gegenstand einer Aufarbeitung sein sollte. Nach dem Tod Titos und der zunehmenden Erosion der sozialistischen Legitimität in den letzten Jahren des sozialistischen Jugoslawien drängte sich eine Auseinandersetzung mit dem bis dato nur partiell beleuchteten Zweiten Weltkrieg und mit den Verbrechen des sozialistischen Regimes auf. Während und nach Ende der Jugoslawienkriege wäre eine kritische Auseinandersetzung mit den Verbrechen des Krieges angebracht gewesen, nach Ende des Milošević-Regimes eine Aufarbeitung der Verbrechen des semiautoritären Regimes. Insgesamt standen und stehen also vier Themenkomplexe, der Zweite

1 Diamandouros, Nikiforos P./Larrabee, Stephen F.: Democratization in Southeastern Europe. Theoretical Considerations and Evolving Trends (= Working Paper 129), Madrid: Juan March Institute 1999. 
Weltkrieg, das sozialistische Jugoslawien, die Jugoslawienkriege und das autoritäre Milošević-Regime, im Raum. Diese wurden und werden von verschiedenen politischen und zivilgesellschaftlichen Akteuren auf unterschiedlichen Ebenen, aus unterschiedlichen Interessen und Motiven heraus instrumentalisiert und treten oftmals gemeinsam auf. Aufgrund dieser Verbundenheit zueinander sind sie auch in der Analyse kaum voneinander zu trennen und stellen offenbar Kontinuitäten zumindest in ihren Deutungsmustern beziehungsweise in ihrer Funktion dar.

Als Material werden neben Sekundärliteratur Resolutionstexte und Korrespondenzen zwischen der jugoslawischen/serbischen und der internationalen Ebene einbezogen. Zudem wurden, um den innerserbischen Diskurs zum Umgang mit den Jugoslawienkriegen besser durchdringen und illustrieren zu können, Artikel aus den Wochenzeitungen Vreme und NIN herangezogen, die Kriegsverbrechen behandeln. Während die NIN gerade während des MiloševićRegimes als konservativ und regimenah galt, ist die Vreme eher als repräsentativ für einen alternativen Diskurs zu werten.

In der Darstellung auf den nächsten Seiten werden die 1990er Jahre aufgrund der Materiallage und der Ausrichtung dieser Studie oberflächlicher behandelt als die Zeit nach der zweiten Transition Serbiens. Zudem wurden Kriegsverbrechen sowohl aufgrund des mangelnden zeitlichen Abstands als auch wegen der fehlenden Distanzierung der Regierungsparteien von den Konfliktparteien nicht kritisch aufgearbeitet. Ich werde zeigen, dass es einen Diskurs über universelle Normen des Umgangs mit Kriegsverbrechen gab und dass eine bestimmte Vorstellung über eine angemessene Behandlung ausgebildet wurde. Es wurden konkrete Institutionen geschaffen, die Kriegsverbrechen dokumentierten und die nicht per se und schon in ihrer Anlage als Teil der nationalistischen Politik des Milošević-Regimes gewertet werden können. Sie schlossen zwar in den verwendeten Deutungsmustern an die nationale Lesart der späten 80er Jahre an, konnten aber erst vor dem Hintergrund der veränderten internationalen Lage von Seiten des Milošević-Regimes instrumentalisiert werden.

Ein echter Bruch vollzog sich zu dem Zeitpunkt, als sich die in den 80er Jahren als Gegenentwurf zur jugoslawischen Geschichtserzählung über den Zweiten Weltkrieg entwickelte serbische Deutung der eigenen Vergangenheit - durch die gegenwärtigen Ereignisse als bestätigt und als kontinuierlich gewertet - mit der Interpretation des Bosnienkriegs konfrontiert sah, welche die Vertreter der westlichen Presse, die internationalen advocacy coalitions und schließlich auch Regierungsvertreter heranzogen. Beide Parteien verwendeten die selben Deutungsmuster der Holocausterinnerung - nur mit diametral entgegengesetzten Rollenzuweisungen: Während die Serben als unschuldige Opfer und Deutsche, 
Kroaten und Muslime als Nazis und deren Handlanger konstruiert wurden, wurden »den Serben« auf internationaler Ebene die Rolle der Nazis, des abgrundtief Bösen, zugewiesen. Im serbischen Diskurs ließ sich die antagonistische Rollenzuweisung, gleichzeitig Täter und Opfer, nicht auflösen, da die aktuellen Geschehnisse die Richtigkeit der serbischen Perspektive zu bestätigen schienen.

Im internationalen Diskurs wurden die bosnischen Muslime als unschuldige Opfer stilisiert, die der Hilfe und Unterstützung bedurften. Aufgrund der kroatischen Beteiligung im Bosnienkrieg blieb die Rolle der Kroaten teilweise ambivalent, im kroatisch-serbischen Verhältnis wurden sie aber aus internationaler Sicht als Opfer wahrgenommen. Die Sichtbarmachung serbischer Opfer von Kriegsverbrechen war hingegen nicht anschlussfähig.

Es wird offensichtlich, dass der Umgang mit Kriegsverbrechen zu einer Verhandlungsmasse und dadurch seiner normativen Grundlage beraubt wurde, als die Einrichtung eines Internationalen Tribunals für das ehemalige Jugoslawien näher rückte. Dieses Funktionalisieren der Aufarbeitung von Kriegsverbrechen, die Annahme, dass eine wie auch immer geartete Bearbeitung von Kriegsverbrechen eine zukünftig ungünstige Situation des Landes verhindern oder eine günstigere Situation herbeiführen könnte, setzt sich bis in die Gegenwart fort. Damit verbunden ist eine Übernahme der Formen der Aufarbeitung in die Sprache und Symbole, aber ohne eine Übernahme des Inhalts.

\subsection{Die Aufarbeitung Von Kriegsverbrechen IM MILOŠEVIĆ-REgIME}

\section{Nürnberg jetzt!}

Nach Beginn der ersten Kampfhandlungen in Kroatien und zwei Monate vor Beginn des Zehn-Tage-Krieges in Slowenien forderte der Journalist Mirko Klarin in einem Leitartikel der serbischen Zeitung Borba die Einrichtung eines »balkanisches Nürnberg «. ${ }^{2}$ Klarin zeigte sich überzeugt davon, dass ein internationales neutrales Tribunal Vorbereitungen für Verbrechen gegen den Frieden und ethnischer Hetze Einhalt gebieten würde, so es die Verantwortlichkeiten der Handelnden feststelle und Rechtsbrüche ahnde. Er sah die abschreckende Wirkung eines Tribunals als Mittel zur Deeskalation an, zur Kriegsprävention. Zwar verhallte seine Forderung weitgehend ungehört, die Unrechtmäßigkeit des Handelns

2 Vgl. Klarin, Mirko: »Nirnberg sada« [Nürnberg jetzt], in: Borba vom 16.5.1991, S. 3 . 
von Politikern wurde aber weiterhin thematisiert. So behandelten Experten in der Wochenzeitung Vreme Anfang September 1991, also während der Belagerung von Vukovar, die Frage, inwieweit es möglich wäre oder gegen internationale Bestimmungen verstoßen würde, die Präsidenten Jugoslawiens und Kroatiens als Kriegsverbrecher zu verurteilen. ${ }^{3}$ Initiiert vor allem von den Menschenrechtsund Antikriegsaktivisten von Žene u crnom (Frauen in Schwarz), Centar za antiratnu akciju (Zentrum für Antikriegsaktion) und des Beogradski krug (Belgrader Kreis) protestierten täglich Bürger gegen die Belagerung Vukovars vor dem serbischen Präsidentensitz, auch wurde in Petitionen eine Amnestie von Deserteuren gefordert. Die Antikriegsaktivisten identifizierten sich als explizit nichtethnonationalistisch, städtisch, kosmopolitisch und weitgehend als panjugoslawisch. ${ }^{4}$

Mit der weiteren Eskalation des Kroatienkriegs wurden zunehmend auch Kriegsverbrechen an der Zivilbevölkerung zum Thema, gerade im nationalisierten Serbien wurden Fragen nach dem Schicksal der serbischen Bevölkerung in Kroatien laut. Das serbische Parlament gab um den Jahreswechsel 1991/1992 bekannt, eine parlamentarische Kommission einzurichten, die Daten über Kriegsopfer und Verbrechen an serbischen Bürgern sammeln solle. Die Bundesebene, nunmehr nur noch die Interessen der Republiken Serbien und Montenegro vertretend, gab die serbischen Befürchtungen an die internationale Öffentlichkeit weiter. Die jugoslawische Regierung sandte Ende Januar 1992 ein »Memorandum über das Verbrechen des Völkermords in Kroatien und über die Schändung des Gedenkortes Jasenovac « an die UN und andere internationale Organisationen, in dem sie den kroatischen Regierungsorganen und ihren "paramilitärischen, rebellischen bewaffneten Banden« vorwarf, »zum zweiten Mal in einem halben Jahrhundert einen Völkermord am serbischen Volk in Kroatien « zu begehen. ${ }^{5}$ Die aktuellen Kriegshandlungen wurden als Wiederholung der Gewalterfahrung und der Akteurskonstellationen des Zweiten Weltkriegs gedeutet.

3 Vgl. Ninčić, Roksanda: »Po slovu zakona. Balkanski Nirnberg« [Dem Gesetz nach. Balkanisches Nürnberg], in: Vreme vom 1.3.1993, S. 22 f.

4 Vgl. Dević, Ana: »Anti-war Initiatives and the Unmaking of Civic Identities in the Former Yugoslav Republics«, in: Journal of Historical Sociology 10 (1997) 2, S. 127-156.

5 Vgl. Milošević, Milan: »Haški sud: Između Unprofora i Interpola« [Das Haager Gericht: Zwischen Unprofor und Interpol], in: Vreme vom 14.11.1994, S. 22 f. 


\section{Die Staatskommission für Kriegsverbrechen und Völkermordverbrechen}

Im März 1992 beschloss das jugoslawische Bundesparlament die Einrichtung der parlamentarischen Komisija za prikupljanje podataka radi utvrđivanja zločina protiv čovječnosti $i$ međunarodnog prava koji su počinjeni nad stanovništvom srpske $i$ drughi nacionalnosti u vrijeme oružanij sukoba u Hrvatskoj $i$ drugim djelovima zemlje (Kommission zur Sammlung von Informationen hinsichtlich der Feststellung von Verbrechen gegen die Menschlichkeit und das internationale Recht, begangen an der Bevölkerung serbischer und anderer Nationalität während des bewaffneten Konflikts in Kroatien und in anderen Teilen des Landes). ${ }^{6}$ Die 41-köpfige Kommission bestand aus Wissenschaftlern, Parlamentariern, Intellektuellen sowie aus Mitgliedern des Genozidausschusses der Serbischen Akademie für Wissenschaften und Künste, an dessen Arbeit sie hinsichtlich der verwendeten Rhetorik und Deutungsmuster direkt anschloss. Die Staatskommission war ein regierungsnahes Prestigeprojekt, mit dem man dem Drängen auf nationaler und internationaler Ebene nachgab, die Kriegsverbrechen während des Kroatienkrieges und des beginnenden Bosnienkriegs zu thematisieren, zu dokumentieren und sich dazu zu positionieren. Vor allem war die Kommission aber ein politisches Instrument, um serbische Positionen in Zeiten der Krise als legitim zu kommunizieren. Trotz der Staatstransformation im April 1992 und einer offiziellen Distanzierung von den bosnischen Einheiten der Jugoslawischen Volksarmee begann im Mai 1992 mit dem Abzug von Botschaftern und dem Ausschluss aus internationalen Organisationen eine harte internationale Sanktionspolitik gegen die Bundesrepublik Jugoslawien.

Die Ernsthaftigkeit, mit der die Kommission eingesetzt wurde, kann bezweifelt werden. So wurde die Arbeit des Organs schon kurz nach seiner Einrichtung durch diverse Hürden erschwert, wie zum Beispiel den unklaren Rechtsstatus gemäß der neuen Verfassung im April 1992, wonach sie ohne Vorsitzenden ver-

6 Bundesparlament der Bundesrepublik Jugoslawien: Zakon o osnivanju Komisiju za prikupljanje podataka radi utvrđivanja zločina genocida i drugih zločina protiv čovečnosti i međunarodnog prava koji su počinjeni nad stanovništvom srpske i drugih nacionalnosti u vreme oružanih sukoba u Hrvatskoj i drugim delovima zemlje [Gesetz über die Errichtung einer Kommission zur Sammlung von Daten zur Feststellung der Verbrechen des Völkermords und anderer Verbrechen gegen die Menschlichkeit, die an der serbischen Bevölkerung und anderen Nationalitäten in der Zeit des bewaffneten Konflikts in Kroatien und in anderen Teilen des Landes begangen wurden], in: Službeni list 18 (1992). 
blieb. Noch bevor sie wirklich zu arbeiten begann, löste sich die Kommission wenige Wochen nach ihrer Gründung schleichend wieder auf, ohne dass die Öffentlichkeit davon in Kenntnis gesetzt wurde. Obwohl sie in ihrem Titel ankündigte, sich mit Kriegsverbrechen zu befassen, die über die serbische Nationalität hinausgingen, blieb ihre konkrete Arbeit von Beginn an auf Verbrechen an der serbischen Zivilbevölkerung beschränkt und legitimierte weitgehend die Positionen der Regierung, indem sie diese wissenschaftlich unterfütterte. So schloss sie direkt an das Memorandum der Bundesregierung über »Verbrechen des Völkermords in Kroatien und über die Schändung des Gedenkortes Jasenovac« an und veröffentlichte im Mai 1992 ihren einzigen Bericht über

»[d]ie Systematisierung der Methoden der Tötung, des Folterns, der Misshandlung, Erniedrigung, Einschüchterung und Erpressung der Serben, angewendet in den UstašaLagern und darüber hinaus auf dem Gebiet der Bosanska Posavina und der Republik Kroatien«?

Staatspräsident und Mitglied der Serbischen Akademie für Wissenschaften und Künste, Dobrica Čosić, sah in der Kommission eine willkommene Möglichkeit, um die internationale Außenwirkung Jugoslawiens nach den im Frühjahr verhängten Sanktionen gegen das Land zu verbessern. Zur Vorbereitung eines Treffens mit der Jugoslawienkontaktgruppe, einer informellen Gruppe aus Großbritannien, Frankreich, Deutschland, Italien und den USA, die eine Regelung zwischen den Konfliktparteien im Bosnienkrieg vermitteln wollten, initiierte Čosić eine »wissenschaftliche Beratung«, organisiert von der Kommission gemeinsam mit dem Ausschuss zur »Erforschung des Genozids am serbischen Volk und anderer Nationalitäten« an der Serbischen Akademie für Wissenschaften und Künste. Mit der Konferenz über »Kriegsverbrechen und Genozid 1991-1992« in Belgrad sollte gezeigt werden, dass man sich mit Kriegsverbrechen befasste, sie dokumentierte und verurteilte, zudem konnten die Verbrechen an den Serben auf diesem Weg stärker in das Licht der Öffentlichkeit gerückt werden. ${ }^{8}$ Innenpolitisch hatte die Tagung noch eine weitere Funktion: Sie fand weniger als ein Jahr nach der vom Ausschuss der Serbischen Akademie der Wissenschaften und Künste organisierten Konferenz zum »Genozid an den Serben im Zweiten Weltkrieg« statt und markierte somit eine eindrucksvolle Parallele zwischen dem Völkermord an den Serben im Zweiten Weltkrieg durch den Unabhängigen Staat Kroatien und den Kampfhandlungen im Kroatienkrieg 1991/1992.

$7 \quad$ M. Milošević: »Haški sud«.

8 N. Stefanov, Wissenschaft als nationaler Beruf, S. 365. 
Trotz ihres übernationalen Anspruchs standen auf dieser Konferenz die Verbrechen an serbischen Bürgern im Vordergrund. Auffällig ist auch die inflationäre Verwendung des Terminus Völkermord. ${ }^{9}$ Deutlich wird das anhand des Konferenzprogramms, das sich in der Struktur des Tagungsbandes abbildet und den deklaratorischen Charakter der »wissenschaftlichen Beratungen« - so der Untertitel des Bandes - belegt. ${ }^{10}$ Nach einer Einleitung behandelt Kapitel zwei »Die Vertreibung der serbischen Bevölkerung von ihrer Feuerstelle « ${ }^{11}$; in Kapitel drei werden nach der Vorstellung des bereits erwähnten Memorandums der Bundesregierung zum »Verbrechen des Völkermords von 1991 in Kroatien und die Schändung des Gedenkortes Jasenovac« deren Hintergründe und Aspekte thematisiert. In Kapitel vier werden unter dem Titel »Verbrechen während der bewaffneten Konflikte 1991-1992« zunächst ein Memorandum »über die genozidale Politik Kroatiens gegen das serbische Volk in Westslawonien« und dann ein »Memorandum über die dramatische Situation der serbischen Bevölkerung auf dem Gebiet Gorski Kotar und Appell an die UN und andere internationale Organisationen« präsentiert. Die folgenden Beiträge befassen sich ausschließlich mit Verbrechen gegen die serbische Zivilbevölkerung. Kapitel fünf thematisiert die Zerstörung von serbischen Häusern, Kirchen und Denkmälern; weiterhin gehen die Kapitel vier und fünf auf juristische Überlegungen und die völkerrechtliche Einordnung der Verbrechen im Kroatien- und Bosnienkrieg ein. Hier wird ein weiteres Memorandum »über das Engagement der Republik Kroatien in den kriegerischen Konflikten in Bosnien-Herzegowina « präsentiert, in dem Kroatien als Aggressor identifiziert wird. Das achte Kapitel behandelt internationale Faktoren, die Rolle von Verantwortung und Propaganda sowie die Möglichkeiten

9 Jevremović, Pavle: »An Examination of War Crimes Comitted in the Former Yugoslavia«, in: Međunarodni problemi 46 (1994) 1, S. 39-73.

10 Vgl. bis zum Ende des Absatzes Bulajić, Milan/Samardžić, Radovan (Hg.): Ratni zločini i zločini genocida 1991-1992.: Naučno savetovanje Odbora SANU za sakupljanje građe o genocidu protiv srpskog naroda i drugih naroda Jugoslavije $u$ XX veku i Državne komisije za ratne zločine i zločine genocida, održano od 6. do 8 . avgusta 1992. godine u Beogradu [Kriegsverbrechen und Verbrechen des Genozids 1991-1992. Wissenschaftliche Beratung des SANU-Komitees zur Sammlung von Materialien über den Genozid am serbischen Volk und anderen Völkern Jugoslawiens im 20. Jahrhundert und der Staatskommission für Kriegsverbrechen und Verbrechen des Genozids, abgehalten 6.-8.8.1992], Belgrad: Srpska akademija nauka i umetnosti 1993.

11 Im serbischen Original ist von ognište die Rede. Der Totemismus bezeichnet die offene Feuerstelle im traditionellen Haushalt. 
internationalen Handelns zur Vermeidung von Völkermord. Abschließend werden Studienprojekte zu und Beweise für Verbrechen des Völkermords vorgestellt und Schlussüberlegungen diskutiert.

Die Konferenz kann als Versuch eingeordnet werden, Aufmerksamkeit für Verbrechen an Serben zu erzeugen und die kroatische Regierung für diese Verbrechen verantwortlich zu machen. Sie sollte ein Gegennarrativ zur internationalen Wahrnehmung der Jugoslawienkriege darstellen und die aus serbischer Sicht falsche Perzeption korrigieren, dass im Kroatienkrieg ausschließlich Serben Täter und Aggressoren gewesen seien, wie auch die Memoranden belegen. Die Verbrechen von serbischer Seite werden nicht thematisiert-abgesehen von Dragan Zgonjanins Beitrag, der die »Wahrheit« über die in Vukovar begangenen Frevel verspricht. Die serbische Belagerung der Stadt und die dabei verübten Verbrechen analysierte er allerdings nicht - nur wenige Monate später wird ein UN-Forensiker auf das Massengrab in Ovčara aufmerksam machen. Zgonjanjin dokumentiert hingegen nach

»strafgesetzlicher Methode [...] Kriegsverbrechen und Verbrechen des Völkermords, begangen auf dem Gebiet Vukovars in der Periode seit Mai 1990, aus der die erste genozidale Aktion der HDZ [Hrvatska demokratska zajednica, Kroatische Demokratische Union] datiert, bis zum Schluss der Vukovar-Operation beziehungsweise der Befreiung Ostslawoniens, der Baranja und des Westsrems von den Angehörigen der bewaffneten Formationen Kroatiens ${ }^{12}$.

Seinen Ausführungen nach legten die bestätigten Opferzahlen nahe, dass die Mehrheit der bei den Auseinandersetzungen auf dem Gebiet Vukovars im Untersuchungszeitraum getöteten Zivilisten serbischer Nationalität gewesen seien. Mit seiner Studie rechtfertigt und legitimiert Zgonjanin die angewendete Gewalt implizit, da sie notwendig gewesen sei, um die serbische Bevölkerung zu befreien und damit zu schützen.

In einem Schlusswort erklärte Milan Bulajić, stellvertretender Präsident der Kommission für Kriegsverbrechen und Verbrechen des Genozids und Sekretär des Ausschusses an der Serbischen Akademie der Wissenschaften und Künste, dass Informationen zu Kriegs- und Völkermordverbrechen auf Basis von Fragebögen auf dem Territorium der Bundesrepublik Jugoslawien und in der Krajina gesammelt werden müssten. Unter Einsatz der UN bot er vergleichbaren Institu-

12 Zgonjanin, Dragan: »Istina o zločinima u Vukovaru« [Die Wahrheit über die Verbrechen in Vukovar], in: M. Bulajić/R. Samardžić (Hg.): Ratni zločini (1993), S. 205-208, hier S. 205. 
tionen in Kroatien und Bosnien-Herzegowina eine Zusammenarbeit an, auch sollten weitere Experten einbezogen werden.

Dieser Ankündigung folgten allerdings keine Taten. 1993 beschrieb ein Journalist der Vreme die Kommission für Kriegsverbrechen und Verbrechen des Genozids wegen ihrer Unsichtbarkeit und Untätigkeit als "phantomgleich «. ${ }^{13}$ Das Dilemma zwischen Ideal und Wirklichkeit zeigt sich in der 1995 veröffentlichten Sammlung über die Arbeit der Kommission während ihres Tätigkeitszeitraums von etwas mehr als einem Jahr. ${ }^{14}$ In der Einleitung verortete und beschrieb Milan Bulajić seine Situationswahrnehmung. So parallelisierte er die Erfahrung des Auseinanderbrechens Jugoslawiens 1991/1992 mit der Zerschlagung Jugoslawiens 1941 und vertrat die Auffassung, dass sich die Geschichte nun wiederhole. Demnach bedienten sich externe Aggressoren der unterschiedlichen Autonomieinteressen der jugoslawischen Völker, um sie gegeneinander auszuspielen und ihre geopolitischen Großmachtinteressen durchzusetzen. Am Ende dieses Prozesses stünde die Tragödie des serbischen Volkes. Für diese Tragödie gelte es, die Schuldigen zu identifizieren. Bulajić betont zuvorderst die serbisch-nationale Ausrichtung bei der Strafverfolgung, fordert aber ein Primat von Gerechtigkeit und der Gleichheit aller vor Gericht. Gemäß seinen Ausführungen stellt ein juristisches Verfahren, das Gerechtigkeit herstellt, das einzige Mittel dar, um neuer Gewalt vorzubeugen. Es scheint so, als verstehe Bulajić die unterbliebene Auseinandersetzung mit den Verbrechen während des Zweiten Weltkriegs als Ursache für die gegenwärtigen Verbrechen. In einer anderen Passage der Einleitung empört er sich über die abweichende Methode des UNSicherheitsrates, Kriegsverbrechen festzustellen, die daher von der Bundesregierung zu Recht nicht anerkannt würden. Sowohl die Ursachen und die Genese der Jugoslawienkriege als auch eine Vielzahl von Kriegsverbrechen würden dadurch ignoriert. Während der Autor bis hierhin weitgehend den Positionen des Milošević-Regimes folgte, wies er an anderer Stelle klar auf die Probleme der

13 Vasilijević, Vladan: »Sveti princip pravde. Međunarodni krivični sud: zablude i fakta« [Das internationale Gerechtigkeitsprinzip. Das Internationale Strafgericht: Missverständnisse und Fakten], in: Vreme vom 8.3.1993, S. 25-28.

14 Komisija za prikupljanje podataka radi utvrđivanja zločina protiv čovječnosti i međunarodnog prava koji su počinjeni nad stanovništvom srpske i drughi nacionalnosti u vrijeme oružanij sukoba u Hrvatskoj i drugim djelovima zemlj (Hg.): Zbornik o radu državne komisije za ratne zločine i zločine genocida (od 20. marta 1992 do 23. jula 1993) [Sammlung über die Arbeit der Staatskomission für Kriegsverbrechen und Verbrechen des Genozids (20.3.1992-23.7.1993)], Belgrad: Muzej žrtava genocida 1995. 
Arbeit und die Überforderung der Kommission hin und verdeutlichte die dadurch entstehenden blinden Flecken. Dafür macht er ohne Umschweife die politischen Stellen und Funktionsträger verantwortlich:

»Am tragischsten ist die Tatsache, dass das Sammeln der Daten über Kriegsverbrechen und Verbrechen des Völkermords nicht als nationale Aufgabe verstanden wird, als Priorität des Bundesparlaments, der Bundesregierung und deren Organe und Institutionen, sondern nur durch das Wissen der Staatskommission, Unterausschüsse und Komitees gelöst wird. Die Folge ist, dass den zahlreichen Beschuldigungen der Bundesregierung Jugoslawien und des serbischen Volkes keine dokumentierten Tatsachenanalysen entgegenstehen, das der Bericht des State Departments der USA, des Sonderberichterstatters der Vereinten Nationen Mazowieski, die Untersuchungen und Bücher von Hunderten von Seiten von Helsinki Watch nicht analysiert sind, und reden wir nicht über die Untersuchungen des kroatischen >Veritas〈-Professors Zvonimir Šeparović, der bosnisch-muslimischen Zentren und der bezahlten, starken Medienzentren. Die Zuständigen werden erklären müssen, warum man Ende 1994 nicht weiß, zur Zeit des Beginns des Internationalen Gerichts für Kriegsverbrechen auf dem Boden des ehemaligen Jugoslawien in Den Haag, wie viele Serben seit 1991 gestorben sind, nicht in Tausenden! « ${ }^{15}$

Da der politische Wille nicht vorhanden gewesen sei, könne man nun den Angriffen auf Serbien auch nichts entgegenstellen. Zudem warf Bulajić den politisch Verantwortlichen vor, ihrer Pflicht nicht nachgekommen zu sein, sich angemessen um die serbischen Opfer zu kümmern. Dieser Vorwurf zeigt, dass das Thema Aufarbeitung auch im Rahmen nationalistischer Argumentationen Verwendung findet, die zur Kritik der Regierungspolitik von rechts dient.

\section{Zivilgesellschaftliche Initiativen}

Die Ignoranz und Tatenlosigkeit der jugoslawischen und der serbischen Regierung im Umgang mit Kriegsverbrechen mobilisierte die Gründung zivilgesellschaftlicher Initiativen. Um die Leerstelle auszufüllen, die aufgrund der mangelnden Unterstützung von Seiten der Regierung entstand, richtete Milan Bulajić 1992 den Fonds za istraživanje genocida (Fond für die Erforschung des Genozids) und das Muzej žrtava genocida (Museum für die Opfer des Genozids) ein. Als hochrangiger Diplomat und Jurist war Bulajić Vertreter Jugoslawiens bei den Prozessen gegen den ehemaligen Innenminister im NDH-Staat Andrija Artuković, als parteiischer Sachverständiger (amicus curiae) beim Prozess gegen 
Adolf Eichmann sowie Zeuge in verschiedenen Prozessen gegen Angehörige der Ustaša gewesen und widmete sich bereits seit Jahren der Dokumentation und Strafverfolgung von Verbrechen im Konzentrationslager Jasenovac. Das Museum für die Opfer des Genozids, das ein Forschungs- und Dokumentationszentrum umfasst und keine Ausstellungsräumlichkeiten hat, nahm seine Arbeit 1995 auf und sammelt seitdem Daten zu Kriegsverbrechen und Opfern von Genoziden auf dem Territorium des ehemaligen Jugoslawien - sowohl aus der Periode des Zweiten Weltkriegs als auch aus den Kriegsjahren 1991-1995. Da Milivoje Ivanišević bereits seit 1991 auf eigene Faust Kriegsverbrechen gegen Serben dokumentierte, gründete der Kulturschaffende ebenfalls 1992 das Centar za istraživanje zločina nad srpskim narodom (Institut zur Erforschung der Verbrechen am serbischen Volk), das die Dokumentation von an Serben begangenen Verbrechen in Kroatien und Bosnien-Herzegowina in den Mittelpunkt stellte. ${ }^{16}$

Im gleichen Jahr gründete die Menschenrechtsaktivistin Nataša Kandić den Fond za humanitarno pravo (Fonds für Völkerrecht), eine weitgehend aus dem Ausland finanzierte NGO, die sich die Dokumentation von Menschenrechtsverletzungen und Kriegsverbrechen während der Jugoslawienkriege zum Ziel setzte. Ihre Datenbank wurde später zur Grundlage vieler Prozesse auf internationaler und nationaler Ebene. Auch die Antikriegsaktivisten beschäftigten sich zunehmend mit dem Thema Kriegsverbrechen und deren möglicher Bearbeitung. So setzte die ehemalige Diplomatin, Beraterin im Außenministerium und Oppositionelle Sonja Biserko zwischen 1992 und 1994 im Rahmen des Center za antiratnu akciju (Zentrum für Antikriegsaktion) in Belgrad ein Projekt zu den Möglichkeiten eines internationalen Tribunals zur Strafverfolgung von Kriegsverbrechen um. Die Belgrader NGO-Szene grenzte sich ab 1992 zunehmend vom Milošević-Regime und der nationalistischen Opposition des Landes ab. Mit der Bezeichnung Druga Srbija (anderes Serbien), erstmals verwendet 1992 von Mitgliedern des Beogradski krug (Belgrader Kreis), sollte eine Alternative zum nationalistischen Serbien einen Namen, einen Slogan erhalten. Zeitweise stand sie auch für eine Art paralleles Serbien, da sich die dahinter versammelnden Akteure aus der Öffentlichkeit zurückzogen, um »[a]us[zu]weichen vor der einheitlichen nationalen Front ${ }^{17}{ }^{17}$. In den folgenden Jahren entwickelte sich das »andere Serbien« zum Synonym für die regimekritische, alternative serbische Zivilge-

162008 unbenannt in Institut za istraživanje srpskih stradanja $u$ XX. veku (Institut für das serbische Leiden im 20. Jahrhundert).

17 Savić, Obrad: »Parallele Welt. Die Belgrader NGO-Szene«, in: Šlosar, Irina (Hg.): Verschwiegenes Serbien: Stimmen für die Zukunft?, Klagenfurt/Salzburg: Wieser 1997, S. 41-54. 
sellschaft, zu der unter anderem das Zentrum für Antikriegsaktion, Žene u crnom (Frauen in Schwarz), Helsinški odbor za ljudska prava (Helsinki-Komitee für Menschenrechte), der Belgrader Kreis, das Centar za kulturnu dekontaminaciju (Zentrum für kulturelle Dekontamination), der Fond für Völkerrecht, das Forum za etničke odnose (Forum für ethnische Beziehungen), das Centar za ženske studije (Zentrum für Frauenstudien) und viele mehr gehörten.

\section{Berichte der jugoslawischen Bundesregierung über Kriegsverbrechen}

Seit Anfang September 1992 tagte die Genfer Jugoslawienkonferenz, die unter dem Vorsitz von Europäischer Gemeinschaft und UN mit Unterbrechungen über ein für alle am Bosnienkrieg beteiligten Parteien annehmbares Friedensabkommen verhandelte. Am 22. September verwehrte die UN-Generalversammlung Jugoslawien die Rechtsnachfolge der Sozialistischen Föderativen Republik Jugoslawien, wodurch das Land seinen Sitz in der UN-Generalversammlung nicht wahrnehmen konnte. Die jugoslawische Regierung weigerte sich, diese Entscheidung zu akzeptieren. Weiterhin richtete der UN-Sicherheitsrat mit der Resolution 780 im Oktober 1992 eine fünfköpfige Expertenkommission ein, die die begangenen Verbrechen in der Region beurteilen sollte. ${ }^{18}$ Als Grundlage für deren Arbeit wurde allen Mitgliedsstaaten und UN-Organisationen, internationalen und anderen Organisationen sowie Individuen vorab die Möglichkeit gegeben, innerhalb von dreißig Tagen »substantielle Informationen « - und nicht Beweise - über Kriegsverbrechen auf dem Territorium des ehemaligen Jugoslawien seit 1991 vorzulegen. ${ }^{19}$ Die Expertenkommission unter Vorsitz des niederländischen Juristen Frits Kalshoven sollte diese dann bewerten.

Die ad hoc eingerichtete Expertenkommission war für die Bundesrepublik Jugoslawien auch ohne UN-Mitgliedschaft

18 United Nations Security Council: Resolution 780, UN-Dok. S/RES/780 vom 6.10.1992.

19 In der Behandlung der Expertenkommission, der es anfänglich an finanzieller und technischer Unterstützung fehlte, die dann durch freiwilliges Engagement und Finanzierung durch den internationalen NGO-Sektor ausgeglichen wurde, drückte sich die lange Ambivalenz »des Westens« gegenüber internationaler Justiz aus. Vgl. V. Peskin: International Justice, S. 40. Später unternahm die Expertenkommission auch Untersuchungsmissionen in den Ländern des ehemaligen Jugoslawiens. Insgesamt tagte die Expertenkommission zwölf Mal. 1993 veröffentlichte sie zwei Zwischenberichte. 
»a chance to present facts about crimes committed against the Serbian population, thus perhaps contributing to the relevant international factors taking a more balanced attitude towards the sides in the conflict and the settlement of the crisis as a whole. [...] In other words the Federal Republic of Yugoslavia was given the opportunity of answering, with good arguments, many serious accusations and of defending its legitimate national interests before an international political audience and, on a wider scale, the general public. ${ }^{20}$

Diese Aufgabe wurde einer Arbeitsgruppe übertragen, die sich aus Vertretern des Justiz-, Außen-, Verteidigungs- und Innenministeriums sowie des Ministeriums für Menschenrechte und Minderheiten zusammensetzte. Überfordert von der kurzen Zeitspanne, in der der Bericht angefertigt werden sollte, und aufgrund institutioneller Unzulänglichkeiten trug die Arbeitsgruppe lediglich bereits vorliegende Informationen von anderen Organen, NGOs und Agenturmeldungen zusammen und editierte sie.

In einem ersten von der Arbeitsgruppe verfassten Bericht über Kriegsverbrechen auf dem Territorium des ehemaligen Jugoslawien an die Expertenkommission von Ende November 1992 begrüßt die Bundesregierung Jugoslawiens die Einrichtung des Gremiums. Auch verdeutlicht sie ihre normativen Zielsetzungen,

»dass es, um die politische Krise in der ehemaligen jugoslawischen Region zu lösen, von zentraler Bedeutung ist, alle relevanten Fakten im Zusammenhang mit den bewaffneten Konflikten und der Gewalt, insbesondere in Bezug auf schwerwiegende Verstöße gegen das humanitäre Völkerrecht, und dem Krieg zu etablieren. Für die künftige Stabilität in der Region, die Beziehungen zwischen den neuen Bundesländern, geschaffen durch die Sezession von Jugoslawien, sowie die Beziehungen zwischen ihren Völkern ist die erste und grundlegende Voraussetzung, die Verantwortung für Gewalttaten, Zerstörung, Leid und den gewaltsamen Tod vieler Menschen zu bestimmen. ${ }^{21}$

Die Bundesregierung sprach sich deutlich für eine juristische Aufarbeitung aus, indem sie forderte, Verantwortliche festzustellen und Rechtsbrüche zu ahnden. Gleichzeitig setzte sie einen Schwerpunkt auf die Wahrheitsfindung. Der Wille zur Kooperation mit der Expertenkommission wurde klar ausgedrückt. Die Zeit

20 P. Jevremović: »An Examination«.

21 Bundesregierung der Republik Jugoslawien: Izveštaj komisiji eksperata ustanovljenoj na osnovi rezolucije Saveta Bezbednosti 780 (1992) [Bericht an die Expertenkommission auf Grundlage der Resolution des Sicherheitsrates 780 (1992)] 1992, http://www.slobodan-milosevic.org/documents/reports/Serbian/1-izv.htm vom 3.1.2013. 
zur Zusammenstellung der Informationen sei knapp gewesen und der Gegenstand komplex, nichtsdestotrotz habe man die größtmögliche Anzahl von Fällen mit den Namen der Opfer und, wenn möglich, der Täter aufgelistet. In Übereinstimmung mit internationalem und nationalem Recht habe man dementsprechend Daten über Kriegsverbrechen aufbereitet, die gegen die Genfer Konvention von 1949 und ihre Zusatzprotokolle von 1977, gegen die Völkermordkonvention sowie die Haager Konvention zum Schutz von Kulturgut bei bewaffneten Konflikten von 1954 verstießen. Die Liste der konkreten Straftatbestände enthielt:

- die vorsätzliche Tötung von Zivilisten,

- die vorsätzliche Tötung von Gefangenen und Kriegsgefangenen,

- die inhumane Behandlung von Zivilisten,

- die inhumane Behandlung von Gefangenen und Kriegsgefangenen,

- die vorsätzliche Tötung und die inhumane Behandlung von Verwundeten und Kranken,

- Geiselnahme und die Errichtung von Lagern,

- die Zerstörung von zivilen Objekten ohne militärische Notwendigkeit,

- die Zerstörung von Kultstätten, Friedhöfen, kulturellen und historischen Denkmälern und

- ethnische Säuberung.

Der Tatbestand der ethnischen Säuberung wurde von der Genfer Konvention zum Schutz der Zivilbevölkerung in Kriegszeiten abgeleitet und auch retrospektiv gewendet:

»Der grundlegende Maßstab [für ethnische Säuberungen, D. M.] war die ethnische Zugehörigkeit der ehemaligen Bewohner, und dort wiederholt sich, was im Zweiten Weltkrieg unter der Herrschaft des NDH begonnen hat, außer dass nun neben Serben auch Muslime, Kroaten und andere bedroht sind. ${ }^{22}$

Trotz dieser Einordnung war der kurzfristig zusammengestellte Bericht in erster Linie für Experten und Juristen geschrieben und ist nicht als Instrument der Propaganda einzuordnen. Zwar waren die meisten angeführten Verbrechen an Serben begangen worden und nur wenige verzeichnet, in denen ethnische Serben als Täter angeführt wurden. Dies kann aber auch auf die nach Serbien und Montenegro Geflüchteten und deren Aussagen über Gewalterfahrungen zurückgeführt werden. Ohne Frage bestand bei den Verfassern die Absicht, auf Verbrechen und 
Leiden der serbischen Bevölkerung zu verweisen, gerade auch, weil die Regierungen in der Republika Srpska und in der Republika Srpska Krajina keine entsprechenden Gremien geschaffen hatten, die die Verbrechen an der serbischen Bevölkerung dokumentierten. Allerdings wurde in dem Bericht von Seiten der Bundesregierung ebenfalls deutlich gemacht, dass zukünftige Berichte genauso auch Verbrechen mit nichtserbischen Opfern und serbischen Tätern aufführen würden.

Der Bericht der Bundesregierung an die Expertenkommission löste in der Republik Serbien öffentlichen Unmut aus. Insbesondere die von der serbischen Regierung kontrollierte Berichterstattung des staatlichen Fernsehensenders RTS und einiger Zeitungen vermittelte unverblümt, dass eine objektive, professionelle und systematische Dokumentation von Kriegsverbrechen, vor allem nach den Richtlinien des internationalen Rechts, nicht erwünscht sei. ${ }^{23}$ Hierin drückte sich die unterschiedliche Ausrichtung der beiden Regierungen aus, wobei die serbische erkennbar nationalistischere Töne anschlug und von internationaler Seite antiserbische Propaganda und Verurteilung fürchtete. Die offene Kritik an dem Bericht von serbischer Seite stand bereits im Zeichen der Präsidenten- und Parlamentswahlen vom Dezember 1992 und kann als Versuch des serbischen Präsidenten Milošević gelesen werden, den damals erst kurze Zeit amtierenden jugoslawischen Ministerpräsidenten Milan Panić zu disqualifizieren, der bei den serbischen Präsidentenwahlen gegen ihn antreten sollte.

\section{Übernahme starker Symbole: Ein zweiter Holocaust und ein zweites Nürnberg}

Im Herbst 1992 nahm der Druck von außen auf Jugoslawien zu. Schon im Sommer hatte die internationale Berichterstattung über serbische Lager ${ }^{24}$ eine Parallele zwischen den Verbrechen an den Juden im Holocaust und den gegenwärtig begangenen Gräueln an den bosnischen Muslimen gezogen. Diesen Bezug auf eine universale moralische Norm stellten zunächst Journalisten her, nach kurzer Zeit griffen ihn jüdische Lobbyorganisationen auf, die sich aus der eigenen Opfererfahrung heraus, die in der Lagersymbolik reaktualisiert wurde, als Pressure-

23 P. Jevremović: »An Examination«.

24 Als Erster berichtete der amerikanische Journalist Roy Gutman am 2. August in der US-Tageszeitung Newsday über Massenmord in von Serben betriebenen Internierungslagern, vgl. D. Levy/N. Sznaider: Erinnerung im globalen Zeitalter, S. 186. Kurz darauf teilte das Internationale Rote Kreuz mit, alle drei Konfliktparteien betrieben Internierungslager. 
groups für die Anliegen der bosnischen Muslime einsetzten. Am 5. August 1992 veröffentlichten das American Jewish Committee, der American Jewish Congress und die Anti-Defamation League eine ganzseitige Anzeige in der New York Times, welche die Verbindung von Holocaust und Bosnien explizierte. ${ }^{25}$ Eine Vielzahl von NGOs in den USA und Europa übernahm die Idee einer Parallelisierung von Holocaust und Bosnienkrieg in Rhetorik und Symbolik. Die komplexen Ursachen der Jugoslawienkriege, bestehend aus einem ethnisierten sozioökonomischen Konflikt, dem Machtstreben Einzelner und der Problematik der Internationalisierung wurden damit auf ein einfaches binäres Schema reduziert und damit entpolitisiert: Die Übertragung des Holocaust auf den Konflikt in Bosnien machte aus Serben böse Nazis und aus Muslimen unschuldige Opfer. Zudem gerieten politische Akteure und Institutionen durch die der Holocausterinnerung implizite und moralisch ultimativ begründete Handlungsanweisung, in einen Krieg einzugreifen, öffentlich unter Handlungsdruck. Gegen »die Nazis« aktiv zu werden erwies sich zunehmend als Gradmesser für politische Legitimation. Statt militärisch zu intervenieren zog die internationale Gemeinschaft als Reaktion auf die Verbrechen alle Register politischer Aktion und Vermittlungsversuche.

Auf der Genfer Friedenskonferenz hielt der amerikanische UN-Gesandte Lawrence Eagleburger im Dezember 1992 eine Rede, in der er die Namen von zehn Personen nannte, die er vor ein internationales Tribunal zu stellen beabsichtigte. Damit zielte er besonders auf die Einschüchterung von politischen Führungsfiguren und militärisch Verantwortlichen ab. Das serbische Volk müsse verstehen, dass »a second Nuremberg awaits the practitioners of ethnic clean-

25 » $\mathrm{Zu}$ den blutigen Namen von Auschwitz, Treblinka und anderen Nazi-Todeslagern scheinen die Namen von Omarska und Brčko hinzuzufügen zu sein [...] Ist es möglich, daß fünfzig Jahre nach dem Holocaust die Nationen der Welt, unserer eingeschlossen, passiv dastehen und nichts tun und vorgeben, hilflos zu sein? [...] Es sei hier betont, daß wir jeden notwendigen Schritt tun werden, inklusive den der Gewalt, um diesem Wahnsinn und dem Blutvergießen ein Ende zu setzen.«Zit. nach ebd., S. 187. Auch über die Anzeige hinaus blieben die jüdischen Lobbygruppen, vor allem im Kontext der Einweihung des Holocaust Memorial Museum, sehr aktiv. Der Buchenwald-Überlebende Elie Wiesel besuchte im November 1992 Belgrad, Sarajevo, Banja Luka und das Manjača-Konzentrationslager und zieht öffentlich Parallelen zu seinen Erfahrungen in Buchenwald. Er versuchte erfolglos, die BushAdministration von der moralischen Notwendigkeit zu überzeugen, sich gegen den geschehenden Völkermord auszusprechen. Anlässlich der Eröffnung des Holocaust Memorial Museum am 22. April 1993 rief Wiesel den neuen Präsidenten Bill Clinton öffentlich dazu auf, den bosnischen Völkermord zu thematisieren. 
sing, and that the judgment and opprobrium of history awaits the people in whose name their crimes were committed $\aleph^{26}$.

Die Parallelisierung serbischer Politiker und Militärs mit den Naziverbrechern, die in den Nürnberger Prozessen verurteilt wurden, und des serbischen Volks als Tätervolk nutzte die Propaganda des Milošević-Regimes für sich aus, indem sie sie umkehrte. Sie stilisierte die USA und den Westen als serbenfeindlich und rekurrierte auf das erneute historische Unrecht, dass dem unschuldigen serbischen Volk widerfahre. Somit konnten die USA in die Logik einer nunmehr internationalen antiserbischen Verschwörung eingegliedert und in die Reihe der »Feinde der Serben« einsortiert werden - dort standen sie neben den Kroaten und den Deutschen sowie deren Helfern, den Muslimen, also Bosniaken und Albanern, und dem Vatikan. Als besonders dreist galt, dass man die unschuldigen Opfer als Urheber des Bösen bezeichnete und ihnen mit Bestrafung drohte. Die Absicht der USA, auf der Grundlage von Siegerjustiz auch den Balkan einer amerikanisch dominierten Weltordnung zu unterwerfen, galt als durchschaut. Dieser amerikanische Imperialismus und die daraus abgeleiteten geopolitischen Ziele der USA schlossen nicht nur an nationalistische Narrative an, sondern reaktualisierten vor allem alte sozialistische Feindbilder.

Milošević gewann die Präsidentschaftswahl im Dezember 1992 und konnte nun auch auf Bundesebene seine Macht weiter ausbauen. So übernahm das Personal des serbischen Innenministeriums, unter Vorgabe eines Streits über das Gebäude, teilweise das Bundesinnenministerium. Vielen Aufgaben auf Bundesebene wurde wegen dieses Konflikts nicht nachgekommen. Dadurch verspätete sich der zweite Bericht über Kriegsverbrechen auf dem Territorium des ehemaligen Jugoslawien an die Expertenkommission der UN, der erst Mitte 1993 versandt wurde. ${ }^{27}$ In ihm erklärte die jugoslawische Regierung erneut, dass sie »immer noch zur Zusammenarbeit mit den UN und ihren Organen zur Verfolgung und Bestrafung von Kriegsverbrechen, unabhängig ihrer nationalen oder religiösen Zugehörigkeit, bereit ist ${ }^{28}$.

Wie im ersten Bericht ist in den Ausführungen der Bundesregierung eine Parteinahme für die serbische Bevölkerung zu erkennen. Mit einigen Zeilen

26 Zit. nach V. Peskin: International Justice, S. 31.

27 Vgl. P. Jevremović: »An Examination«.

28 Bundesregierung der Republik Jugoslawien: »Drugi izveštaj komisiji eksperata ustanovljenoj na osnovi rezolucije Saveta Bezebdnosti 780 (1992)« [Zweiter Bericht an die Expertenkommission auf Grundlage der Resolution des Sicherheitsrates 780 (1992)], http://www.slobodan-milosevic.org/documents/reports/Serbian/2-izv-u.htm vom 3.1.2013. 
werden vier Anhänge beschrieben, einer zur Gewalt an Frauen und drei zu Verbrechen an Serben in verschiedenen Regionen und Orten. Die Notwendigkeit einer Strafverfolgung wurde stark betont, besonders verurteile man

»scharf alle Arten von Gewalt gegen die Zivilbevölkerung, vor allem an Frauen, und findet, dass in allen Fällen die Täter identifiziert und für ihre Untaten verantwortlich gemacht werden müssen, ohne Rücksicht darauf, welche Seite im Konflikt sie beging « ${ }^{29}$.

Weiterhin wird ausgeführt, dass die Untersuchung des Srpski sabor (serbischer Rat) der Verfolgung des serbischen Volkes in Kroatien und der ethnischen Säuberung in Westslawonien bewiesen habe, dass schon in den ersten Phasen des bewaffneten Konfliktes ethnische Säuberungen als Teil der Sezessionspolitik Kroatiens verbreitet gewesen seien. Die einseitige Schuldzuweisung an die kroatische Regierung wird hier expliziert und von den folgenden beiden Anhängen verstärkt, in denen kroatische Einheiten für mehrere als Völkermord qualifizierte Verbrechen verantwortlich gemacht werden. Aus dem Bezirk Metković werden »neue Verbrechen des Völkermords" gemeldet, hier sei die lokale serbische Bevölkerung praktisch vertrieben; auch das Verbrechen in Bradin im Gebiet Konjica wird als »neuer Genozid an den Serben« beschrieben. ${ }^{30}$

Der Sicherheitsrat der UN war nach den erfolglosen Versuchen von europäischer Seite, Friedensgespräche mit den Konfliktparteien zu führen, nach zahlreichen gebrochenen Waffenstillstandsregelungen und bis dato wirkungslosen Resolutionen zu Beginn 1993 fest entschlossen, ein Ad-hoc-Tribunal einzurichten, um die Verantwortlichen für die seit 1991 auf dem Gebiet des ehemaligen Jugoslawien begangenen Kriegsverbrechen vor Gericht zu stellen. Bereits in den Monaten zuvor wurde die inhärente Problematik eines solchen neuen Instruments thematisiert und erörtert, ob der Eindruck von kulturellem Imperialismus und Siegerjustiz entstehen und damit die Legitimität des Gerichts in Frage gestellt werden könnte, wie mit der großen Anzahl von Tätern umzugehen sei und ob die Stabilität in der Region und die Konfliktdynamiken beinflusst würden. Die fehlende Kooperation der Exekutive galt es gegen die Dringlichkeit einer juristischen Intervention und die Notwendigkeit eines Instruments zur Abschreckung abzuwägen. ${ }^{31}$ Schließlich verabschiedete der UN-Sicherheitsrat die Resolution 808, die festhielt, dass die Kriegshandlungen auf dem Gebiet des ehemaligen Jugoslawien den internationalen Frieden und die Sicherheit bedrohen. Der Rat

29 Ebd.

30 Ebd.

31 Vgl. E. L. Pearl: »Punishing Balkan War Criminals«. 
prüfte, ein Tribunal einzurichten, das erstmals Verbrechen während eines laufenden Konflikts ahnden und dessen primäre Ziele Sühne und Abschreckung sein sollten. ${ }^{32}$

In Serbien reichten die Reaktionen auf die Pläne des Sicherheitsrats von moderaten Bedenken bis zu lauter Empörung. Gerade die Tatsache, dass die Prozesse in Nürnberg und Tokio nach dem Zweiten Weltkrieg, die Ausdruck von Siegerjustiz waren, als Vorbild für die Errichtung des neuen Tribunals dienten, sorgte für Diskussion. Vladan Vasilijević, der Ratspräsident des Fonds für Völkerrecht, bemühte sich in der Zeitschrift Vreme im Kontext der Berichterstattung und Einordnung des ICTY immer wieder um sachliche Richtigstellungen. Er beschrieb mit Verweis auf die konkreten Zeitungsartikel und TV-Sender die Berichterstattung über die Einrichtung eines Tribunals für das ehemalige Jugoslawien, die von moderaten Tönen reichte

»bis zu sehr schweren Anklagen, dass man mit diesem Entschluss der Weltorganisation Serbien und der SR Jugoslawien Schaden beibringen möchte im Sinne einer unverdienten und teilweisen Bestrafung für eine Schuld, die es nicht gibt. Es ging so weit, dass man in der Errichtung des Gerichts den Fall einer Neubewertung nur einer Seite der Konflikte auf dem Boden des ehemaligen Jugoslawien (Večernje novosti, 26.2.) und die bösartigen Bemühungen der USA sah, um jeden Preis die Serben in den Augen der Weltöffentlichkeit zu diskreditieren (NTV Studio B, NTV-Paket, 26.2.). ${ }^{33}$

Die Regierung lancierte im staatlichen Fernsehsender RTS und in der Zeitung Politika eine Informationskampagne gegen ein zukünftiges Tribunal, die dieses schon vor seiner tatsächlichen Einrichtung mit einem Angriff auf und einer Schuldzuweisung an die Bundesrepublik Jugoslawien beziehungsweise »die Serben« gleichsetzte, da sich die Vertreter der internationalen Gemeinschaft für die Unabhängigkeit der Kroaten und der Bosnier beziehungsweise als Beschützer der Opfer dieser Volksgruppen engagierten. Die Nürnberger Prozesse, die Rolle der Amerikaner und anderer internationaler Vertreter nach dem Zweiten Weltkrieg und in der Gegenwart wurden dementsprechend für parteiisch erachtet.

Nur einzelne Stimmen bezogen Gegenposition zu der nationalistischen Deutung des ICTY. Vladan Vasilijević rief ins Gedächtnis, dass sich Jugoslawien vertraglich dazu verpflichtet hat, das Völkerrecht zu achten, und die jugoslawische Regierung dies am 27. November 1991 mit Vertretern der kroatischen Re-

32 Vgl. United Nations Security Council: Resolution 808, UN-Dok. S/RES/808 vom 22.2.1993.

33 Vgl. V. Vasilijević: »Sveti princip pravde«. 
gierung sowie am 3. Mai 1992 mit Vertretern der kroatischen und der bosniakischen Regierung in Vereinbarungen bekräftigt habe. Jugoslawien sei als Mitunterzeichner an die Einhaltung der völkerrechtlichen Abkommen gebunden, die von dem zu schaffenden Tribunal überprüft würden. Irritierend wirkt aus heutiger Sicht Vasilijević' Argumentation, dass Jugoslawien verpflichtet sei, auch wenn es »nicht einen Moment lang Konfliktteilnehmer war ${ }^{34}$. Diese Einschätzung entsprach allerdings der Mehrheitsmeinung der serbischen Öffentlichkeit. Zentral für diese Bewertung war die immer wieder wiederholte Äußerung serbischer Politiker, Serbien befinde sich nicht im Krieg. Tatsächlich war die Armee der Republik Jugoslawiens formell kein Kriegsteilnehmer.

\section{Die Rolle der Jugoslawischen Volksarmee und der Armee der Republik Jugoslawiens}

Die Jugoslovenska narodna armija (Jugoslawische Volksarmee, JNA) wurde aus den Partisaneneinheiten gegründet. Sie war zwar traditionell multiethnisch und sozialistisch und verstand sich als Beschützerin des sozialistisch-förderativen Jugoslawien, musste aber in ihrem Inneren vor allem seit dem Tod Titos 1980 ethnische und politische Spannungen aushalten. Innerhalb der Armee gab es ein Ungleichgewicht zugunsten der serbischen Bevölkerung, die etwa 36 Prozent der Gesamtbevölkerung ausmachten. So waren 1985 waren ca. 58 Prozent der Armeeangehörigen Serben, in den höheren Rängen war der Anteil noch höher. ${ }^{35}$ Innerhalb der Armeeführung war folglich eine gewisse proserbische Tendenz dominant, sie unterstützte zudem jede Maßnahme, die dazu beitrug, Jugoslawien zu erhalten, dessen Auflösung auch das Ende der JNA bedeutet hätte.

Im März 1991 beantragte die JNA beim Präsidium Jugoslawiens, den Ausnahmezustand zu verhängen, um gegen die Unruhen in Kroatien und Slowenien vorzugehen. Serbien, Montenegro, die Vojvodina und das Kosovo befürworteten den Antrag, während Slowenien, Kroatien, Bosnien-Herzegowina und Mazedonien ihn ablehnten. ${ }^{36}$ Kurz darauf gab die Regierung Serbiens der Armee freie

\section{Ebd.}

35 Vgl. Bieber, Florian: »The Role of the Yugoslav People's Army in the Dissolution of Yugoslavia«, in: Jasna Dragović-Soso/Lenard Cohen (Hg.): State Collapse in South-Eastern Europe. New Perspectives on Yugoslavia's Disintegration (= Central European Studies), West Lafayette: Purdue University Press 2007, S. 301-332, hier S. $306 \mathrm{f}$.

36 Ausführlich zur genannten Präsidiumssitzung und den Entwicklungen in der JNA bis dahin vgl. ebd. 
Hand zu agieren, als sie erklärte, sie fühle sich nicht mehr an die Weisung des Präsidiums gebunden. Tatsächlich versuchte die JNA in Kroatien, die Bildung kroatischer Verbände zu verhindern und kämpfende Parteien durch die Einrichtung von Pufferzonen voneinander zu trennen. Am 25. Juni übernahm die Territorialverteidigung Sloweniens die Sicherung der slowenischen Grenzen. Die JNA war völlig unvorbereitet und die slowenischen Streitkräfte blockierten die Einheiten schnell. Aufgrund der Unterstützung Kroatiens, das selbst nach Unabhängigkeit strebte, konnten kaum JNA-Einheiten aus Bosnien-Herzegowina oder Serbien nachrücken. Nach zehn Tagen vereinbarten die Konfliktparteien einen Waffenstillstand. Durch die Umbildung der Verteidigung in Slowenien und Kroatien, später in Bosnien-Herzegowina, war die "Armee aller Jugoslawen« praktisch gelähmt und in Auflösung begriffen. Im Juli eskalierten die Kampfhandlungen in der kroatischen Krajina. Aufgrund eines Beschlusses des jugoslawischen Präsidiums griff die JNA zunächst nicht ein, unterstützte aber serbische Verbände logistisch gegen die separatistischen Bestrebungen der Kroaten. Als die aus Sicht der JNA illegitime kroatische Regierung eine Blockade der JNA-Kasernen beabsichtigte, begann sich die JNA im September 1991 aktiv in den Konflikt einzumischen. ${ }^{37}$ Der serbische Verteidigungsminister General Tomislav Simović erklärte der Öffentlichkeit, dass nur so Personal, Material und technisches Gerät aus den umzingelten Kasernen in Kroatien evakuiert und vor allem ein Völkermord an den serbischen Bewohnern dieser Republik durch paramilitärische Einheiten verhindert werden könne. ${ }^{38}$ Auch der jugoslawische Bundesverteidigungsminister rechtfertigte den Militäreinsatz, der gegen die »Neonazis« in Kroatien vorgehen, die Kontrolle über die Krisengebiete erlangen und die serbischen Zivilisten sowie die JNA-Angehörigen und ihre Familien befreien sollte. ${ }^{39}$

37 Zur Rechtfertigung des Militäreinsatzes der JNA 1991 wurden keine tiefergehenden Recherchen vorgenommen. Die folgenden Ausführungen bezieht sich kritisch auf: Marijan, Davor: »The Yugoslav National Army Role in the Aggression Against the Republic of Croatia 1990 to 1992 «, in: National Security and the Future 2 (2001) 34, S. 143-178, hier S. 162.

38 Vgl. Simović, Tomislav: »Strategija domina« [Domino-Strategie], in: Narodna armija vom 2.10.1991, S. 10, zit. nach D. Marijan: »The Yugoslav National Army«, S. 174.

39 Vgl. Kadijević, Veljko: »Neonacisti na radu u Hrvatskoj« [Neonazis am Werk in Kroatien], in: Narodna armija vom 5.10.1991, S. 5, zit. nach D. Marijan: »The Yugoslav National Army«, S. 162. 
Die JNA stilisierte sich als Beschützerin der Serben in Kroatien, die von kroatischer Seite angegriffen würden, unterstützte diese in ihrer militärischen Organisation, damit sie sich verteidigen könnten, und bereitete sich darauf vor, Selbstverteidigung zu üben, so man angegriffen werde. ${ }^{40}$ Präventive Militäraktionen galten als moralisch gerechtfertigt. Die politische und militärische Führung teilte das gleiche Narrativ der Verteidigung Jugoslawiens und der nun entstehenden serbischen Minderheit gegen das sezessionistische, nationalistische, illegitime Kroatien. Gegenläufige Deutungen, die eine serbische Rebellion gegen eine legitime Regierung erkannten, wie sie die kroatische Seite vertrat, wurden nicht zugelassen. Auch thematisierte niemand die zuvor getroffenen militärischen Maßnahmen, die auf eine aggressive Politik von Seiten Belgrads hinwiesen. $^{41}$

Da die Mobilmachung der Reservisten der JNA im Herbst 1991 nur sehr mäBigen Erfolg hatte, akzeptierte die Armee auch Freiwillige in ihren Reihen, die sich der Einhaltung von Bundesgesetzen verpflichteten. Die JNA öffnete sich damit paramilitärischen serbischen Verbänden. In den folgenden Wochen beteiligte sie sich an den Kampfhandlungen, zum Teil gemeinsam mit paramilitärischen Einheiten, vor allem am Beschuss von Vukovar, Osijek und Dubrovnik und blockierte die Adriahäfen. Unter internationalem Druck einigten sich die kroatische Regierung und Vertreter der JNA am 18. November 1991 auf den freien Rückzug der JNA von kroatischem Gebiet, der am 30. Dezember abgeschlossen wurde.

Mit der Gründung der Bundesrepublik Jugoslawien im April 1992 wurde aus der JNA die Armee Jugoslawiens. Nachdem der UN-Sicherheitsrat im Mai die neuen Republiken auf dem Gebiet des ehemaligen sozialistisch-föderativen Jugoslawien anerkannt hatte, musste sich die Armee Jugoslawiens aus den nunmehr souveränen Staaten Kroatien und Bosnien-Herzegowina zurückziehen. Die Reste der JNA wurden aufgeteilt, das heißt, der Teil der Einheiten ohne Einwohner der jeweiligen Staaten zog sich zurück. Segmente der in Bosnien-Herzegowina stationierten Verbände bildeten die Armee der Serbischen Republik. Damit

40 Kadijević, Veljko: Moje viđenje raspada [Meine Sicht auf den Zerfall], Belgrad: Politika 1993, S. 172.

41 Die Vorbereitungen zu einem Waffeneinsatz begannen mit einer Reorganisation der JNA-Strukturen in Kroatien möglicherweise schon im Mai 1990, also nur einen Monat nach den ersten demokratischen Wahlen in Slowenien und Kroatien. Der Befehl dazu wurde am Tag nach dem Befehl zur Konfiszierung der Waffen der kroatischen Territorialverteidigung gegeben, vgl. D. Marijan: »The Yugoslav National Army Role«, S. 172. 
verblieb das größte Kontingent der Bewaffnung der JNA unter serbischer Kontrolle. Im Oktober 1992 bildete sich die Serbische Armee der Republik Serbische Krajina aus den Verbänden der Territorialverteidigung der Krajina. Nach der Auflösung der JNA waren so zwar serbische Verbände Kriegsparteien, allerdings gehörten sie offiziell nicht zur Bundesrepublik Jugoslawien.

\section{Ein international anerkannter Völkermord?}

Nachdem der Sicherheitsrat mit der Prüfung der Einrichtung eines Tribunals eine Justifizierung der Jugoslawienkriege angekündigt hatte, strengte die bosniakische Regierung im März 1993 ebenfalls ein juristisches Verfahren an, indem sie beim Internationalen Gerichtshof beantragten zu prüfen, ob die »Konvention zur Verhütung und Bestrafung des Verbrechen des Völkermord« gegen die Bundesrepublik Jugoslawien angewandt werden kann. Es war das erste Mal in seiner Geschichte, dass das Gericht über die Anwendung der Völkermordkonvention befinden sollte, zudem noch in einem laufenden Konflikt. Der Internationale Gerichtshof als Appellationsinstanz ist eine mächtige Institution, da er in einem Urteil Definitionsmacht hat und damit Legitimität zuweisen kann und über die Rollenzuweisung von Täter und Opfer, innerhalb eines laufenden Konflikts über (moralische) Sieger und Besiegte, Recht und Unrecht und in der Folge auch über mögliche Kompensationszahlungen entscheidet. Die Inanspruchnahme einer universellen Norm und deren Legitimierung durch einen von allen akzeptierten, unparteiischen Dritten ermöglicht somit, ein partikulares Narrativ zu universalisieren und diese Deutung zu institutionalisieren.

Der Antrag Bosnien-Herzegowinas leitet damit ein, im Anschluss an den Diskurs in der internationalen Öffentlichkeit zum Bosnienkrieg eine Analogie zum Holocaust herzustellen und eine bevorstehende Wiederholung der Geschichte, einen erneuten Völkermord, nun am bosniakischen Volk, anzudeuten. Der Autor formuliert pathetisch:

»Not since the end of the Second World War and the revelations of the horrors of Nazi Germany's >Final Solution 〈 has Europe witnessed the utter destruction of a People, for no other reason than they belong sto a particular national ethnical, racial, and religious group as such. The abominable crimes taking place in the Republic of Bosnia-Herzegovina at this time can be called by only one name: genocide. Genocide is the most evil crime a State or human being can inflict upon another State or human being. The sheer enormity 
of this crime requires that the nations of the world stand together as one, and with a single voice stop the destruction of the Bosnian People. ${ }^{42}$

Dem bosnischen Volk sei das internationale Verbrechen des Völkermords von Jugoslawien, seinen Vertretern und Stellvertretern zugefügt worden. Die Anhänge verwiesen auf Zeitungsberichterstattung und Zeugenaussagen, die Kriegsverbrechen belegen sollten.

Als Reaktion auf die Klageschrift beschuldigte die Bundesrepublik Jugoslawien in ihrem Antrag auf provisorische Maßnahmen vom 1. April 1993 ihrerseits Bosnien-Herzegowina, die Genozidkonvention gebrochen und Verbrechen des Völkermords gegen Kroaten und Serben auf von Bosnien-Herzegowina kontrolliertem Gebiet nicht unterbunden oder durch staatliche Organe begangen zu haben. So wird gefordert, dass die Regierung »of the so-called Republic of Bosnia and Herzegovina should immediately [...] take all measures within its power to prevent commission of the crime of genocide against the Serb ethnic group « ${ }^{43}$.

Der Antrag geht auf die historischen Parallelen der gegenwärtig verübten Verbrechen zum Zweiten Weltkrieg und auf das Konzentrationslager Jasenovac ein und verweist auf die für die Expertenkommission verfassten Berichte sowie auf das zu diesem Zeitpunkt bereits eingereichte, aber erst im Juni 1993 vom Menschenrechtsberichterstatter der UN-Generalversammlung vorgestellte $» \mathrm{Me}$ morandum über Kriegsverbrechen und Völkermord in Ostbosnien (Kommunen Bratunac, Skelani und Srebrenica), begangen gegen die serbische Bevölkerung zwischen April 1992 und April 1993 « ${ }^{44}$.

42 International Court of Justice: Application of the Convention on the Prevention and Punishment of the Crime of Genocide (Bosnia and Herzegovina v. Yugoslavia). Application Instituting Proceedings vom 20.3.1993.

43 International Court of Justice: Application of the Convention on the Prevention and Punishment of the Crime of Genocide (Bosnia and Herzegovina v. Yugoslavia). Request for the Indication of Provisional Measures made by the Federal Republic of Yugoslavia vom 10.8.1993.

44 United Nations General Assembly: Human Rights Questions: Human Rights Situation and Reports of Special Rapporteurs and Representatives. Letter dated 24 May 1993 from the Chargé d'affaires a.i. of the Permanent Mission of Yugoslavia to the United Nations addressed to the Secretary-General, 48th session, Annex, Agenda item $115 \mathrm{c}, 2.6 .1993$. 


\section{Werben um internationale Unterstützung}

Die sich innerhalb von kurzer Zeit zuspitzenden internationalen Entwicklungen setzten die Politiker in der Bundesrepublik Jugoslawien enorm unter Druck, und auch innenpolitisch schwand die Machtbasis der Regierungen angesichts einer am Boden liegenden Wirtschaft und einer Bevölkerung, deren Leben angesichts von Krieg, Hyperinflation und internationaler Sanktionspolitik zunehmend schwieriger wurde. Milošević unterstützte den von der Genfer Bosnienkonferenz vermittelten Vance-Owen-Plan, der Bosnien-Herzegowina in elf Kantone aufteilen sollte, und versuchte Einfluss auf die Politiker der bosnischen Serben zu nehmen. Nachdem die Vermittlung des Vance-Owen-Plans zu gelingen schien nur die Unterschrift des Führers der bosnischen Serben Radovan Karadžić stand noch aus - und vor dem Hintergrund des kurz zuvor geschlossenen Europaabkommens mit Rumänien und Bulgarien, warb Serbien international um Unterstützung. Dazu hielt der serbische Präsident Dobrica Ćosić am 30. März 1993 eine Rede vor dem Außenausschuss des Europäischen Parlaments. Darin ging er nicht, wie der Bericht über seine Ansprache in der serbischen Zeitschrift NIN betitelt wurde, auf »Die Krise und ihre Schuldigen« ein, sondern er warb um die Unterstützung des Balkans und eine objektivere Wahrnehmung der Serben. Er betonte, die Wahrheit gegenüber den Unwahrheiten und Lügen zu berichten und dass die Serben mit Stereotypen des Rassenhasses belegt würden, die sie als Barbaren und Verbrecher darstellten. Ćosić forderte Differenziertheit, blieb dabei aber nicht frei von Relativierungen und Übersteigerungen:

»Die serbischen nationalistischen Extremen dürfen sie nicht als Repräsentanten der serbischen nationalen Ideologie betrachten und sie gleichsetzen mit dem ganzen serbischen Volk. Sie wissen gut, dass es in allen europäischen Nationen heute Nationalextreme und chauvinistische Stimmungen gibt. Obwohl wir in Umzingelung chauvinistischer Ideologien und Regime leben, obwohl wir im 20. Jahrhundert drei Völkermorde überlebt haben, obwohl wir auch heute dem genozidalen Terror in Kroatien und dem Genozid von Seiten fanatisierter Muslime ausgesetzt sind, ist das serbische Volk im Wesen ethisch, freiheitsliebend, offen für Verständigung und Freundschaft mit anderen Nationen und respektiert den Anderen. ${ }^{45}$

Im Weiteren beschrieb er den Krieg gegen die Serben, die Folgen von Inflation, Isolation und Sanktionen. Kriegsverbrechen oder das Verhältnis der serbischen

45 Ćosić, Dobrica: »Kriza i krivci« [Krise und Schuldige], in: NIN vom 9.4.1993, S. 51 ff., hier S. 52. 
Regierung zu den kämpfenden Verbänden in Bosnien-Herzegowina wurden mit keinem Wort erwähnt. Zum Ende eröffnete er eine Perspektive für eine friedliche Zukunft, für die er um Unterstützung warb: für eine Europäisierung des Balkans in Form von wirtschaftlichem Aufbau und der Vermittlung von bilateralen Vereinbarungen zum Schutz der Minderheiten. Wegen der noch ausstehenden Zustimmung Karadžić' zum Vance-Owen-Plan verschärfte der europäische Ministerrat allerdings weniger als eine Woche später die Sanktionen gegen die Bundesrepublik Jugoslawien. Die Flugsverbotszone über dem Luftraum Bosnien-Herzegowinas wurde am 31. März gemäß UN-Beschluss ausgeweitet, woraufhin die North Atlantic Treaty Organization (NATO) am 8. April beschloss, die Flugverbotszone mit einem eigenen Einsatz durchzusetzen. Ab dem 12. April flogen Düsenjäger aus Frankreich, den Niederlanden und den USA die Operation Deny Flight. Am 2. Mai unterzeichnete Karadžić schließlich den Vance-OwenPlan - unter Vorbehalt der Zustimmung des Parlamentes der bosnischen Serben. Ohne eine parlamentarische Entscheidung abzuwarten, wies Karadžić weniger als zwei Wochen später den Vance-Owen-Plan zurück.

\section{Beschlossene Sache: Der ICTY}

Am 25. Mai 1993 beschloss der UN-Sicherheitsrat mit Resolution 827 die Errichtung des International Tribunal for the Prosecution of Persons Responsible for Serious Violations of International Humanitarian Law Committed in the Territory of the Former Yugoslavia (ICTY), ${ }^{46}$ das nach den internationalen Tribunalen in Nürnberg und Tokio erst das dritte internationale Strafgericht darstellte. Dem Statut gemäß umfasste die Zuständigkeit des Tribunals alle seit 1991 auf dem Territorium des bis 1992 bestehenden Jugoslawien begangenen Verstöße gegen die Genfer Konventionen von 1949, Verletzungen des Kriegs- und des Kriegsgewohnheitsrechts, Völkermord und Verbrechen gegen die Menschlichkeit. Mit der Ernennung des Leiters der Anklagebehörde sollte die Arbeit der Expertenkommission beendet werden.

Aufgrund des zunehmenden äußeren Drucks mit Blick auf die Expertenkommission und das im Entstehen begriffene Tribunal verabschiedete das jugoslawische Bundesparlament im Mai 1993 ein neues Gesetz. ${ }^{47}$ Dieses überführte

46 So die Ursprungsbezeichnung des ICTY, siehe United Nations Security Council: Resolution 827, UN-Dok. S/RES/827 vom 25.5.1993.

47 Vgl. Bundesparlament der Bundesrepublik Jugoslawien: Zakon o prikupljanju i dostavljanju podataka o izvršenim zločinima protiv čovečnosti i međunarodnog prava [Gesetz über das Sammeln und Dokumentieren von Informationen über begangene 
die gescheiterte Staatskommission noch im gleichen Monat in das Komitet za prikupljanje podataka o izvršenim zločinima protiv čovečnosti i međunarodnog prava (Komitee für die Sammlung von Daten über begangene Verbrechen gegen die Menschlichkeit und das internationale Recht), um die Verbrechen zu untersuchen, die seit 1990 auf dem ganzen Territorium der Föderativen Republik Jugoslawien begangen worden waren. ${ }^{48}$ Die von der Bundesregierung benannten Kommissionsmitglieder sollten explizit Beweise für die Strafverfolgung von Tätern sammeln, auch wurden sie beauftragt, direkt mit internationalen Organisationen und Institutionen im Rahmen ihres Zuständigkeitsbereiches zusammenzuarbeiten. Das Gesetz klärte die Kompetenzen und gewährte weitreichenden Aktenund Archivzugang. Allerdings fehlte der Kommission die politische Unterstützung, es blieb unklar, welche Funktion sie genau einnehmen sollte, und es war nicht geregelt, inwieweit Einsicht in Akten möglich war, die unter Geheimhaltung standen. Mit entsprechendem politischem Rückhalt von hoher Stelle hätte die Kommission ihre weitreichenden Befugnisse nutzen können, um auch im Land selbst Untersuchungen gegen die Inhaber hoher Staatsämter einzuleiten.

Auch die Zivilgesellschaft in Serbien formierte sich zunehmend und mit internationaler Unterstützung. Im schweizerischen Fribourg fand im Sommer 1993 das internationale Symposium zu »Kriegsverbrechen und Kriegstribunal« statt, gemeinsam organisiert vom Institut für Föderalismus der Universität der Stadt und dem Belgrader Centar za antiratnu akciju, hier war Sonja Biserko federführend. Finanziert wurde die Konferenz mit Unterstützung des National Endowment for Democracy. Anlässlich des Symposiums beschrieb Vladan Vasilijević in der Vreme, wie Kriegsverbrechen während der Jugoslawienkriege gerechtfertigt würden. Demnach gäbe es ein »Recht auf Verbrechen«, die Regierungen aller drei an den Kriegen beteiligten Staaten hätten das Verbrechen als "größten Akt der Ergebenheit gegenüber ihrem Volk» ausgerufen. Die schlimmsten Verbrecher seien häufig die konsequentesten Kämpfer für das nationale Interesse; es sei so weit gekommen, dass mit der Fürsprache ihrer Glaubensgemeinschaft nun alle Wertesysteme ungültig seien. Dadurch genössen die Täter eine Art Immunität, ihre strafrechtliche Verfolgung sei praktisch unmöglich. In einer großen Zahl der Fälle würde diese Immunität durch die Wahl der Verbrecher in die Parlamente der einzelnen Länder legalisiert. ${ }^{49}$

Verbrechen gegen die Menschlichkeit und das internationale Recht], in: Službeni list SRJ 37 (1993).

48 Ebd.

49 Vasilijević, Vladan: »Pravo na zločin« [Recht auf Verbrechen], in: Vreme vom 12.6.1993, S. $34 \mathrm{f}$. 
Um diesem Eindruck entgegenzutreten, löste Milošević im Herbst 1993 die informelle Koalition mit der Srpska Radikalna Stranka (Serbische Radikale Partei, SRS), die die Socijalistička Partija Srbije (Sozialistische Partei Serbiens, SPS) Milošević' bislang aus "patriotischen« Gründen auch ohne Anspruch auf einen Ministerposten unterstützte, und distanzierte sich von deren nationalistischem Kurs. Nur durch eine moderatere Politik schien seine prekäre Position so weit stabilisierbar, um auch bei den angekündigten Neuwahlen die Stammwählerschaft zu mobilisieren und mit internationaler Rückendeckung ein Ende der Sanktionen zu erreichen. Auch in den Medien vollzog sich diese Wende. Im Zuge der größten Säuberungswelle verschwanden »patriotische« Moderatoren aus dem staatlichen Rundfunksender RTS. ${ }^{50}$ Nun begann die SPS auch Kriegsverbrechen während der Jugoslawienkriege zu erwähnen und legte nahe, dass »some Serbs, supposedly not supported by him or the party, had committed war crimes « ${ }^{51}$. Milošević und der Parteichef der SRS Vojislav Šešelj beschuldigten sich während des Wahlkampfes vor den serbischen Parlamentswahlen im Dezember 1993 gegenseitig der Unterstützung von Kriegsverbrechen. In den Medien berichtete man, dass Milošević die Strafverfolgung von gut vierzig Kampfgefährten Šešeljs wegen Vergewaltigung und Kriegsverbrechen befohlen habe. ${ }^{52}$ Der öffentliche serbische Diskurs thematisierte von Serben begangene Kriegsverbrechen nun offen und polarisierte zwischen den Lagern der »Patriotischen« und dem Belgrader NGO-Sektor beziehungsweise oppositionellen Gruppen, die sich aber nicht auf eine klare Position festlegten. Die Frage der Positionierung zu Kriegsverbrechen wurde zu einer Frage der Positionierung zur Nation.

Polemisch kanzelte Željko »Arkan« Ražnatović, Führer einer paramilitärischen Gruppe und seit 1992 Abgeordneter im kosovarischen Parlament ${ }^{53}$, in einem Interview der Zeitschrift NIN die Vorwürfe gegen die serbische Seite ab. Jovial kommentierte er, es sei »jetzt Mode geworden, Serben, zum ersten Mal in

50 Vgl. Nadjivan, Silvia: Wohl geplante Spontaneität. Der Sturz des MiloševićRegimes als politisch inszenierte Massendemonstration in Serbien, Frankfurt am Main: Lang 2008, S. 48 f.

51 V. Peskin: International Justice, S. 37.

52 United Nations Security Council: Letter dated 24 May 1994 from the SecretaryGeneral to the President of the Security Council, UN-Dok. S/1994/674 vom 27.5.1994, S. 76.

531994 kandidierte er mit seiner Partei Stranka Srpskog Jedinstva (Partei der serbischen Einigkeit) erfolgreich für das Bundesparlament. 
ihrer Geschichte, der Kriegsverbrechen zu beschuldigen « ${ }^{54}$. Aber natürlich könne man im Krieg nicht alle Kriminellen und Banden kontrollieren. Auf die Kriegsverbrechen von Muslimen gegen Muslime (!) verweisend, stellte er den Anschuldigungen gegen Serben seine Kriegserfahrung entgegen:

»Ich bin durch diesen ganzen Krieg gegangen und nicht in einem Moment habe ich gesehen, dass auch nur ein Serbe auch nur ein Kriegsverbrechen begangen hat! Das kann ich versichern! Ihnen, allen und vor Gott. Aber ich sage nicht, dass nicht auch Serben das ge$\tan$ haben. $\ll^{55}$

Weiterhin gab er sein Wort, dass rückkehrende Kämpfer nichts außer Respekt verlangen würden, keine Privilegien. Gleichsam verlangte er eine Art Straffreiheit für sie, da sie nur ihrer patriotischen Pflicht nachgekommen seien: »[u]nd dass sie sie nicht verfolgen, weil sie ihr Volk verteidigt haben, weil es kein Verbrechen ist, sein Volk zu verteidigen! « ${ }^{56}$

Eine gegenteilige Position nahmen Vertreter der Zivilgesellschaft ein, die sich auf die Seite des internationalen Rechts stellten und offen die Strafverfolgung von bekannten Kriegsverbrechern forderten. Ihre Position reflektiert der Artikel des Vreme-Redakteurs Aleksandar Ćirić anlässlich des Fundes des Massengrabs in Ovčara bei Vukovar, der der Behauptung Milošević' widerspricht, es gebe in Serbien keine paramilitärischen Einheiten. Ćirić verweist auf die Führung der radikalen Partei als Verantwortliche und fordert die Strafverfolgung von eindeutig identifizierten Kriegsverbrechern:

»Kriminelle haben einen Namen. Und einen Vornamen. Vom Standpunkt des internationalen Rechts aus - das, nebenbei bemerkt, nicht das Produkt von Vučelić ${ }^{57}$ neuer Weltordnung ist, sondern das in Nürnberg etabliert wurde, und Jugoslawien war Mitunterzeichner und Mitbegründer dieses Tribunals - sind Name und Vorname genug. ${ }^{58}$

54 Jovanović Cupa, Zoran: »Željko Ražnatović Arkan: Zločin je ne braniti svoj narod« [Željko Ražnatović Arkan: Ein Verbrechen ist es, sein Volk nicht zu verteidigen], in: NIN vom 5.11.1993, S. 30 f.

55 Ebd., S. 30.

56 Ebd., S. 31.

57 Gemeint ist Milorad Vučelić, Direktor des staatlichen Senders Radio-Televizija Srbi$j a$, SPS-Politiker und Vertrauter Milošević'. Als Chefredakteur der Wochenzeitung

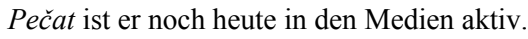

58 Ćirić, Aleksandar: »Ratni zločini. Balkanska arheologija« [Kriegsverbrechen. Balkanische Archäologie], in: Vreme vom 15.11.1993, S. 26 f., hier S. 27. 


\section{Komitee, Kommission und Tribunal}

Im Februar 1994 begann das neu geschaffene ICTY mit seiner Arbeit. Parallel dazu gründete Sonja Biserko das Helsinki-Komitee für Menschenrechte, das sich ähnlich wie der Fonds für Völkerrecht der Dokumentation von Kriegsverbrechen und Menschenrechtsverletzungen widmete und sich um Opfer kümmerte. Beide NGOs arbeiteten von Beginn an eng mit dem ICTY zusammen.

Zwei Monate, nachdem das Tribunal seine Arbeit aufgenommen hatte, beendete die Expertenkommission, die durch das Tribunal nun ersetzt werden sollte, mit einem abschließenden Bericht ihre Tätigkeit. In ihm wird deutlich, dass die Kommission die von außen an sie gestellten hohen normativen Erwartungen auch zu den eigenen Handlungsmaximen und denen des Tribunals erklärte. Demnach sei zwangsläufig, dass ein zukünftiger Frieden Gerechtigkeit erfordere, die wiederum mit der Wahrheitsfindung beginne. ${ }^{59}$ Die größte Herausforderung leitete die Kommission aus der selektiven Wahrnehmung der einzelnen Konfliktparteien ab, wonach jede Seite nur die eigene Viktimisierung sehe und nicht, »what their side has done to others $\ll^{60}$.

Die Unvereinbarkeit der Wahrheit der Expertenkommission mit der serbischen Perspektive zeigte sich noch im selben Monat. Während der Bericht der Expertenkommission die Kriegsverbrechen als Resultat einer Strategie wertete und neben Verbindungen zwischen der JNA und anderen serbischen militärischen Formationen auch konstatierte, dass es einen starken "political, diplomatic and military influence ${ }^{61}$ Jugoslawiens auf die Politik der serbischen Führungen in Bosnien-Herzegowina und der Republika Srpska Krajina gebe, zeigt der dritte Bericht der jugoslawischen Bundesregierung ein völlig abweichendes Narrativ. Darin wird Jugoslawien implizit als unschuldig und Slowenien, Kroatien, die Bosniaken und die internationale Gemeinschaft als verantwortlich für die Jugoslawienkriege dargestellt:

59 United Nations Security Council: Letter dated 24 May 1994, S. 72. Als »established truth« gelten hier zunächst die von der Expertenkommission ermittelten Fakten. Der Abschlussbericht behandelt Kriegsverbrechen in der Region Prijedor, die Schlacht und Belagerung von Sarajevo, Kriegsverbrechen in Sarajevo, Kriegsverbrechen während der Operation Medački đep (Medak-Tasche), die von allen Kriegsparteien betriebenen Lager, Vergewaltigung und sexuelle Übergriffe, die Massengräber in Ovčara bei Vukovar und bei Pakračka poljana, Verbrechen gegen kulturelle Güter sowie Kriegsverbrechen bei der Bombardierung von Dubrovnik.

60 Ebd.

61 Ebd., S. 36. 
»Die verfassungsfeindliche Sezession der Teilrepubliken der ehemaligen SFRJ [sozialistisch-föderativen Republik Jugoslawien, D. M.] in Verbindung mit den Aktivitäten einer Vielzahl von internationalen Faktoren, die zur Eskalation des Kriegs beigetragen haben, waren die Grundursachen des Kriegs, was nicht im Geringsten Kriegsverbrecher von ihrer individuellen Verantwortung befreit, unabhängig davon, auf welcher Seite sie oder ihre Opfer waren. ${ }^{62}$

Dieser Bericht grenzte sich deutlich von den vorherigen beiden ab, da er als erstes Ergebnis des neuen Komitees für die Sammlung von Daten über begangeneVerbrechen gegen die Menschlichkeit und das internationale Recht systematisch erhobene Fakten präsentierte und die Dokumentation von Zeugenaussagen als Methode in den Fokus rückte. In den Bemerkungen zur Materialauswahl räumten die Verfasser ein, dass es schwierig sei, Beweise für Verbrechen in Territorien außerhalb der Kompetenz der Bundesrepublik zu erlangen, in denen Krieg geführt werde.

Die Bundesregierung verband im Weiteren ihre entschiedene Kritik am neu geschaffenen Tribunal mit der Versicherung, selbst Wert auf Strafverfolgung zu legen, und zeigte deutliche Grenzen auf. Die Verfassung des Landes verbiete die Auslieferung von jugoslawischen Staatsbürgern. Gleichzeitig bekräftigte die Bundesregierung aber ihre volle Bereitschaft, sämtlichen internationalen Verpflichtungen nachzukommen. Hinsichtlich der Verfolgung und Bestrafung von Personen, die Verbrechen begangen oder die gegen das Völkerrecht verstoßen hätten, bestünden keine »Dilemmata«: Innerhalb des Territoriums der Bundesrepublik würden die jugoslawischen Behörden jeden Täter, dessen Schuld nachgewiesen werde, verfolgen und bestrafen. ${ }^{63}$ Weiterhin wird zwischen den - vom Statut des ICTY nicht abgedeckten - schwerer gewichteten Verbrechen gegen den Frieden, begangen von einzelnen Personen, die die Desintegration Jugoslawiens vorangetrieben haben, und der individuellen Verantwortung von Personen unterschieden, die in den Konflikten Verbrechen gegen die Menschlichkeit oder das Völkerrecht verübt haben. Auch in Zukunft wolle man mit der Expertenkommission und »anderen UN-Institutionen« zusammenarbeiten. Wie eine weitere Berichtspraxis mit einem nicht mehr arbeitenden Gremium aussehen sollte,

62 Bundesregierung der Republik Jugoslawien: Treći izveštaj vlade SRJ o počinjenim ratnim zločinima na prodručju bivše SFRJ 1994 [Dritter Bericht der Regierung Jugoslawiens über begangene Kriegsverbrechen auf dem Territorium der ehemaligen SFRJ 1994], April 1994, http://www.slobodan-milosevic.org/documents/reports/Ser bian/3-izv.htm vom 16.1.2013.

Ebd. 
blieb ungeklärt wie auch die Frage der Zusammenarbeit mit dem Tribunal jenseits der Auslieferungen von Angeklagten.

Die im Bericht erwähnte Verfassungswidrigkeit der Überstellung serbischer Staatsbürger an das internationale Tribunal wurde vom jugoslawischen Bundesjustizminister mit Verweis auf Artikel 17 der jugoslawischen Verfassung begründet, nach der eine Auslieferung an andere Staaten untersagt sei - auch wenn dieser Artikel keine Konkretisierung für den Fall einer Auslieferung an internationale Organisationen beinhaltete. Schwerwiegender für die Weigerung waren dagegen politische Gründe, wie die zeitgenössische Einschätzung von Pavle Jevremović, bis 1992 außenpolitischer Berater des Bundespräsidiums und dann Berater im Bundesaußenministerium der Bundesrepublik, verdeutlicht:

»The preliminary collection of data on war crimes conducted to date has already shown the extent to which this subject matter has been exploited politically and propaganda-wise, primarily against Serbs. Many influential factors, certain countries and international bodies, pay no heed to the fact that the nature and >quality< of the crimes committed by all three parties to the conflict are pretty much the same. If, from the point of view of quantity, they are mostly being ascribed to Serbs, this should not mean that the other warring parties are free of responsibility for the crimes that are being committed against the Serbian population. Bearing in mind the hitherto preliminary stage of collecting initial information it is justified to doubt that the trials and other deliberations before the International Tribunal will be fair, free of political pressures and propaganda objectives. ${ }^{64}$

Diese Kritik richtete sich nicht gegen das Tribunal oder die Idee eines unabhängigen Strafverfolgungsorgans an sich, sondern gegen die Polarisierung in der internationalen Gemeinschaft und speziell innerhalb des UN-Sicherheitsrats in Bezug auf die Jugoslawienkriege, die der Schaffung des Tribunals vorausgingen und nach serbischer Auslegung vom Tribunal institutionalisiert wurde. Der Solidarisierung europäischer Staaten mit kroatischen und muslimischen Opfern stand man kritisch gegenüber, nachdem die Sezession von Kroatien und BosnienHerzegowina unterstützt worden war. Gerade die Rolle der USA, die fast alle UN-Resolutionen Jugoslawien betreffend initiierten und in ihren Berichten an die Expertenkommission in den meisten Fällen auf serbische Täter verwiesen, wurde skeptisch betrachtet. Auch transnationale NGOs und Lobbygruppen nahmen in ihrem Engagement eine klare Dichotomisierung von kroatischen und bosniakischen Opfern auf der einen und bosnisch-serbischen Tätern auf der anderen Seite vor. Da alle diese Akteure das Tribunal unterstützten, konnte es aus 
Sicht regimenaher oder national orientierter serbischer Kräfte nicht objektiv sein. Menschenrechts-NGOs und die Vreme, die auch zuvor über die Berichte der Expertenkommission informiert hatten, begrüßten das Tribunal und die Einsetzung des erfahrenen Richard Goldstone als Chefankläger. Allerdings war die Kluft zwischen internationalen und nationalen Konfliktwahrnehmungen und Gerechtigkeitsvorstellungen groß. Vreme-Redakteur Stojan Cerović kommentierte:

»Wir können keine Moral und kein Gesetz haben, die das Gegenteil von dem des Rests der Welt sind; wir können nicht als Heldentat verkünden, was sie überall als Verbrechen betrachten, und dabei Teil der gleichen Welt sein. [Das Tribunal in, D. M.] Den Haag bietet uns die Möglichkeit, uns wieder an die internationalen Normen zu erinnern, die uns mit Spott serviert wurden, als wir mit großen nationalen Angelegenheiten beschäftigt waren. ${ }^{65}$

\section{Gemäßigter Kurse}

Ab Mitte 1994 führten der von der Kontaktgruppe vorgelegte Friedensplan und das mit einem Fortdauern des Kriegs für Jugoslawien zunehmend schlechter werdende internationale Klima dazu, dass Milošević erneut versuchte, sich international als gemäßigt zu präsentieren. Während er für die Annahme des Plans der Kontaktgruppe plädierte, distanzierte er sich von der sich weigernden radikalen Führungselite der bosnischen Serben. Im August verhängte er sogar durch eine Blockade von Wirtschafts- und Militärgütern eigene Sanktionen gegen die Republika Srpska.

Mit Blick auf die Auseinandersetzung mit Kriegsverbrechen sah der VremeRedakteur Milan Milošević aber keinen neuen Kurs. Zwar habe die jugoslawische Regierung im Laufe des Jahres in der Kommunikation über das ICTY seltener »die Verurteilung von Verbrechen mit der Verurteilung des serbischen Volks gleichgesetzt ${ }^{66}{ }^{6}$, allerdings versuche sie weiter der Zusammenarbeit mit dem internationalen Tribunal auszuweichen. Auch bliebe trotz der Erwähnung von Serben begangener Kriegsverbrechen und der Lokalisierung von Kriegsverbrechern in Serbien unklar, wie ernst es die SPS Milošević' mit der Auseinandersetzung mit Kriegsverbrechen meine. Bislang habe es keine ernsthaften Signale der zuständigen Organe gegeben, systematische Untersuchungen zu er-

65 Ćerović, Stojan: »Haški pitomci« [Haager Zöglinge], in: Vreme vom 17.10.1994, S. $8 \mathrm{f}$. 
wägen. Auch seien die an die internationalen Institutionen versandten Berichte »unsystematisch, nicht fachlich und ideologisiert ${ }^{67}$.

Ende Oktober 1994 veröffentlichte die Bundesregierung der Republik Jugoslawien den vierten Bericht über »begangene Verbrechen gegen die Menschlichkeit und das Völkerrecht «. ${ }^{68}$ Die Verfasser erklärten in der Einleitung, dass dieser Bericht

»die Kontinuität fortführt, die nationale und der ausländische Öffentlichkeit sowie die Vereinten Nationen über begangene Straftaten gegen die Menschlichkeit und internationales Recht aufzuklären « ${ }^{69}$.

Erneut wurde die Untersuchungsmethode erläutert, mit der am Ort des Verbrechens Beweise gesichert und Zeugenaussagen aufgenommen würden. Aus Gründen der Sicherheit der Zeugen könne man aber nicht immer deren Namen preisgeben. Der Anhang des Berichts listete, anders als die vorherigen, erstmals zusätzlich nicht nur einzelne Fälle auf, sondern setzte auch Schwerpunkte in Form von thematischen Untersuchungen. Ein Anhang umfasste eine Liste von ausländischen Söldnern, die für die kroatische Armee beziehungsweise die Armee Bosnien-Herzegowinas kämpften. Während in der Mehrzahl der Fälle Söldner namentlich, inklusive persönlicher Merkmale beziehungsweise einer Personenbeschreibung, aufgeführt waren, wurde in anderen Fällen von bezahlten ausländischen Soldaten berichtet, die teilweise nur auf Basis von Hörensagen, den Vermerk »NN«, »sprach kein serbisch« oder »Ägypter« erhielten oder einer Einheit zugehörig oder an einem Ort aufgetaucht seien. Der zweite Anhang listete Ortsnamen auf, zum Teil mit konkreter Benennung von Gebäuden oder Gebäudekomplexen, in denen sich Gefangenenlager für Serben befänden. Auf der Liste waren 152 Lager in Bosnien-Herzegowina, 47 in Kroatien und 15 in Slowenien verzeichnet.

Um das Argument zu entkräften, ein internationales Tribunal sei nötig, damit die Kultur der Straflosigkeit in der Region und vor allem auf serbischer Seite be-

67 Ebd.

68 Bundesregierung der Republik Jugoslawien: Četvrti izveštaj vlade SRJ o počinjenim zločinima protiv čovečnosti i međunarodnog prava na području bivše SFRJ [Vierter Bericht der Regierung der Bundesrepublik Jugoslawien über begangene Verbrechen gegen die Menschlichkeit und das internationale Recht auf dem Boden der ehemaligen SFRJ] von1995, http://www.slobodan-milosevic.org/documents/reports/Serbian/ 4-izv-u.htm vom 17.1.2013.

69 Ebd. 
endet würde, setzte das Milošević-Regime auch auf juristischem Feld ein Zeichen. Schon im Mai 1994 hatte die Staatsanwaltschaft Šabac Anklage gegen die Brüder Dušan und Vojin Vučković wegen Kriegsverbrechen erhoben, Ende November wurde der Prozess gegen sie unter großem Medieninteresse eröffnet. ${ }^{70}$ Den Anführern der von der SRS ins Leben gerufenen und unterstützten paramilitärischen Einheit Žuta osa (Gelbe Wespen) wurden Gräueltaten im bosnischen Zvornik zur Last gelegt. Im Fokus der Anklage stand das sogenannte VidovdanMassaker im Juni 1992. Die Staatsanwaltschaft beschuldigte Dušan der Verbrechen gegen Zivilisten, der Vergewaltigung und des Raubes, Vojin wurde wegen betrügerischen Auftretens und des illegalen Besitzes von Waffen und Sprengstoff angeklagt. Auffällig war für Beobachter, dass die Angeklagten in ihren Aussagen der Polizei gegenüber schwerere Verbrechen und größere Zahlen von Tötungen gestanden, als die Anklage ihnen vorwarf. Für ihre freigiebigen Erstaussagen führten die Beschuldigten unterschiedliche Gründe an: In einer Version hatte die Polizei ihnen angeblich versprochen, sie würden nicht verhaftet werden, ${ }^{71}$ in einer anderen behauptete Dušan Vučković, er sei zur Unterschrift eines Geständnisses gezwungen worden, da er fürchten musste, die Geheimpolizei würde seine Familie töten. ${ }^{72}$ Das Gericht unterließ es, die Beteiligung der SRS und des serbischen Innenministeriums sowohl im Zuge der Verbrechen selbst als auch im Ermittlungsverlauf zu untersuchen, obwohl die Aussagen der Brüder darauf verwiesen. Das Gericht schloss offenbar jede Art eines Involviertseins Serbiens in den Bosnienkrieg von vornherein aus. Vielleicht erklärt das auch, warum die weiteren militärischen »Erfolge«, mit denen sich die Brüder Vučković brüsteten, von der Staatsanwaltschaft gänzlich unbeachtet blieben. Denn somit musste sie keine entsprechenden Verbindungen zugeben. Der Verteidiger von Dušan Vučković gab trotz der Aussage des Richters, es gebe keinerlei politischen Druck auf das Verfahren, die Einschätzung seines Mandanten wieder, wonach die serbische Regierung den Fall aus zwei Gründen nutze:

70 Cohen, Roger: »Serbs Put a Serb On Trial for War Crimes«, in: The New York Times vom 12.7.1994, http://www.nytimes.com/1994/06/12/world/serbs-put-a-serbon-trial-for-war-crimes.html vom 8.4.2011.

71 Vgl. o. V.: »Vidovdanski masakr« [Vidovdan-Massaker], in: NIN vom 12.7.2001, S. 20 .

72 Human Rights Watch: War Crimes Trials in the Former Yugoslavia, Report vom 1.6.1995, http://www.unhcr.org/refworld/docid/3ae6a7ed0.html vom 16.8.2011. 
»To distance itself from war crimes in Bosnia by showing that such crimes will be punished in Serbia, and to pre-empt international war crimes trials that could target the political leaders found to be responsible for what happened. ${ }^{73}$

Der Verdacht, der Prozess sei außenpolitisch motiviert und solle lediglich zeigen, dass eine Strafverfolgung von Kriegsverbrechen in der Bundesrepublik Jugoslawien stattfinde und dass somit keine Einmischung von außen oder Auslieferungen an das internationale Tribunal nötig seien, erhärtete sich schnell. In der Vreme äußerte Jovan Dulović Erstaunen über das Verfahren gegen den ersten serbischen Freiwilligen und fragt mit Blick auf ein Urteil:

»Wie würde [...] ein Serbe für Kriegsverbrechen verurteilt, wenn die patriotische hocherfreute Obrigkeit der Regierung beharrlich wiederholt, dass im vergangenen Konflikt in Kroatien und Bosnien-Herzegowina Serben ausschließlich Opfer und Kroaten und Muslime Täter waren? « ${ }^{74}$

Dulović spielte auf eine Äußerung von Zoran Stojanović ${ }^{75}$, jugoslawischer Bundesjustizminister und Präsident des Komitees zur Sammlung von Daten über begangene Verbrechen gegen die Menschlichkeit und das internationale Recht, an, dessen Darstellung eine rein dichotomische Konfliktwahrnehmung nahelegt. Auch die ausländischen Journalisten hätten schnell begriffen, dass die Anklage eigentlich ein »Propagandaflyer [sei, D. M.], mit dem sie die echte Wahrheit über Serbien begreifen ${ }^{76}$. Der Prozess sei ein sehr offensichtliches Propagandainstrument. Schon am dritten Verhandlungstag vertagte sich das Gericht auf unbestimmte Zeit. Erst im Juli 1996 wurde der Prozess wiederaufgenommen, ein Urteil gesprochen und Dušan Vučković zu sieben Jahren Gefängnis verurteilt.

73 R. Cohen: »Serbs Put a Serb«.

74 Dulović, Jovan: »Šabačka posla« [Šabačker Angelegenheiten], in: Vreme vom 26.12.1994, S. 23.

75 Tatsächlich war im Artikel fälschlicherweise von »Dr. Stojan Stojanović« mit der entsprechenden Berufsbeschreibung die Rede. Zoran Stojanović war 1993/1994 jugoslawischer Bundesjustizminister und leitete das und Bereitstellung von Daten über begangene Verbrechen gegen die Menschlichkeit und das internationale Recht. Er gilt als renommierter Experte auf dem Gebiet des Strafrechts, publizierte umfangreich in seinem Fachgebiet und verteidigte auch in den späten 90er Jahren seine Perspektive auf die Jugoslawienkriege und den ICTY. Im November 2012 wurde er vom Parlament in den Obersten Justizrat Serbiens gewählt.

76 Ebd. 
Nach der Berufung gegen das Urteil verhängte der Oberste Gerichtshof Serbiens 1998 eine Strafe von zehn Jahren Gefängnis gegen Dušan Vučković, Vojin Vučković wurde mit vier Monaten Freiheitsentzug bestraft.

\section{Völkermordvorwurf und Friedensverhandlungen}

Der fünfte Bericht der Regierung der Bundesrepublik Jugoslawien vom Mai 1995 verwies darauf, dass weit mehr Daten vorlägen, als Eingang in den Bericht gefunden hätten, diese harrten aber noch der Verifizierung. Ein Themenbericht ging gesondert auf Verbrechen der bosniakischen Partei Stranka Demokratske Akcije (Partei der Demokratischen Aktion, SDA) und der von ihr kontrollierten militärischen Verbände gegen Serben im Bezirk Goražde ein, viele dieser Straftaten würden alle Kriterien eines Völkermords erfüllen. Ein zweiter Teil trug die forensischen und psychiatrischen Untersuchungsergebnisse von 92 ehemaligen serbischen Gefangenen zusammen, die in von Kroaten und Muslimen betriebenen Lagern gefoltert worden seien. ${ }^{77}$

Am 25. Juni veröffentlichte der Chefankläger des ICTY, Richard Goldstone, eine erste Liste mit 21 Namen von Personen, die er diverser Verbrechen beschuldigte und gegen die er Anklagen vorbereitete. Da die Liste nur ethnische Serben enthielt, gab sie der polemischen Diskussion um die Objektivität des Tribunals zusätzlich Feuer. ${ }^{78}$ Die jugoslawische Regierung boykottierte das Tribunal weiterhin und die serbischen Gerichte - sowohl in der Bundesrepublik Jugoslawien als auch in anderen serbisch dominierten Gebieten-verfolgten die rechtlich verankerten Straftatbestände aufgrund mangelnden Willens und der politischen Nähe zu den Tätern nicht angemessen, so dass Vreme-Redakteur Dejan Anastasijević hoffnungslos resümierte: »Was die Serben betrifft, werden wir vermutlich noch in fünfzig Jahren bitter diskutieren, ob Karadžić ein Held oder ein Verbrecher war, den jüngsten Tag und göttliche Gerechtigkeit erwartend. « ${ }^{79}$

Im Juli 1995 griffen bosnisch-serbische Verbände in den Militäroperationen Krivaja '95 und Stupčanica '95 die Armee Bosnien-Herzegowinas in Ostbosnien an und marschierten auf die Stadt Srebrenica zu, in der mehr als 50.000 muslimische Flüchtlinge nach militärischen Auseinandersetzungen 1992/1993 Zuflucht

77 United Nations General Assembly: Letter dated 22 May 1995 from the Chargé d'affaires a.i. of the Permanent Mission of Yugoslavia to the United Nations addressed to the Secretary-General, UN-Dok. A/50/187 vom 12.6.1995.

78 Vgl. zum Beispiel Anastasijević, Dejan: »Bombaški procesi« [Bombenprozesse], in: Vreme vom 31.7.1995, S. $16 \mathrm{f}$.

Ebd. 
gefunden hatten und die von bosnisch-serbischen Truppen belagert blieb. Der UN-Sicherheitsrat forderte als Reaktion auf diese Berohung in einer EntschlieBung, Srebrenica und die umliegende Region als Schutzzone einzurichten, auf die jeder Angriff oder anderer unfreundliche Akt unterbleiben müsse. ${ }^{80}$ Schutztruppen der UN sollten die Einhaltung dieser Schutzzonen überwachen und die Zivilbevölkerung schützen, hierzu wurde das eigentlich völlig passive Mandat der Blauhelme sogar - für Zwecke der Selbstverteidigung - auf die Anwendung von Waffengewalt ausgeweitet. ${ }^{81}$

Die serbische Öffentlichkeit verfolgte das Vordringen der Einheiten unter dem Kommando von General Ratko Mladić auf Srebrenica aufmerksam. Nicht nur, aber vor allem die staatliche Berichterstattung vermittelte dabei den Eindruck, es handle sich um eine legitime Reaktion zum Schutz der von Gewalt bedrohten serbischen Bevölkerung vor »Terroristen« aus Srebrenica. Argumentativ wurde dabei auf die Gewalterfahrungen der serbischen Bevölkerungen in und um Srebrenica, von der Zeit der osmanischen Herrschaft bis zu den Angriffen von Einheiten des bosniakischen Kommandanten der Enklave Srebrenica, Naser Orić, auf die umliegenden serbischen Dörfer 1992 und 1993, zurückgegriffen. So wurde die Einnahme der Enklave als »Befreiung von den Muslimen« gedeutet. Am Tag der Eroberung Srebrenicas am 11. Juli 1995 verwies Mladić in einer Ansprache für die serbischen Medien auf die historische Dimension: Er und seine Truppen schenkten dem serbischen Volk Srebrenica. Nun, nach dem Aufstand gegen die dahije, sei endlich der Zeitpunkt gekommen, sich an den Türken in der Region zu rächen. ${ }^{82}$ Mit der Referenz auf die dahije bezieht er sich auf die Führer der osmanischen Janitschareneinheiten, gegen die sich im gescheiterten ersten serbischen Aufstand 1804-1813 die serbischen Anführer erhoben. Srebrenica war für einige Jahre Teil des von der osmanischen Herrschaft befreiten serbischen Gebiets, allerdings gelang es den Osmanen, die Revolte niederzuschlagen. Aus Sicht von Mladić wiederholte sich die Geschichte, die nationalmythisch aufgeladene Projektion verwandelte die militärische Auseinandersetzung zu einem Kampf zur Befreiung der vom muslimischen Joch unterdrückten Ser-

80 United Nations Security Council: Resolution 819, UN-Dok. S/RES/819 vom 16.4.1993.

81 United Nations Security Council: Resolution 836, UN-Dok. S/RES/836 vom 4.6.1993.

82 Zit. nach Duijzings, Ger: »Commemorating Srebrenica. Histories of Violence and the Politics of Memory in Eastern Bosnia«, in: ders./Xavier Bougarel/Elissa Helms (Hg.): The New Bosnian Mosaic. Identities, Memories and Moral Claims in a PostWar Society, Farnham/Burlington: Ashgate 2007, S. 141-166, hier S. 142. 
ben, Rache und auch Wiedergutmachung für die erlittene Schmach standen augenscheinlich im Vordergrund.

In Folge der Einnahme der Enklave wurden muslimische Frauen, Kinder und Alte deportiert und in dem mehrere Tage andauernden Massaker von Srebrenica ca. 8000 Männer und Jungen, die nicht fliehen konnten, ermordet. Bereits wenige Tage nach dem Fall der Enklave protestierten Vertreterinnen der Frauen in Schwarz auf dem Platz der Republik in Belgrad gegen die Militäraktion, einzelne NGOs wie das Helsinki-Komitee für Menschenrechte verurteilten sie. Die Massaker wurden der Öffentlichkeit zunächst nicht bekannt, erst nach mehreren Wochen und aufgrund des Einflusses von transnationalen advocacy coalitions wurden die Verbrechen an Zivilisten und ihre Ausmaße offenbar. ${ }^{83}$ Von den Gräueltaten in Folge der »Befreiung « Srebrenicas berichtete die serbische Presse erst spät. Während in der zweiten Julihälfte und im August 1995 in den westlichen Medien erste Berichte und Stellungnahmen zu dem Massaker veröffentlicht wurden und die Weltöffentlichkeit über die Verbrechen rund um die ostbosnische Stadt berichtete, dominierte in Serbien und in der Republika Srpska ein anderes Thema die Berichterstattung: Im August 1995 gelang es der kroatischen Armee im Rahmen der Militäroperation Oluja (Sturm), die seit 1991 serbisch besetzten und unter die Kontrolle der Serbischen Republik Krajina gestellten Gebiete auf dem Territorium Kroatiens zurückzugewinnen. Dabei wurden bis zu 200.000 serbische Zivilisten vertrieben, über deren Schicksal breit berichtet wurde und die nach Serbien drängten.

Erst diese schweren Massenverbrechen, das Massaker von Sebrenica und die ethnischen Säuberungen im Zuge der Operation Oluja, erhöhten den diplomatischen Druck auf die Konfliktparteien und somit die Bereitschaft zu Friedensgesprächen. Da die Führung der bosnischen Serben aufgrund der zunemenden Landgewinne der anderen Kriegsparteien und der Anklage des ICTY gegen Radovan Karadžić von den Friedensverhandlungen ausgeschlossen, der Krieg aber unvermindert weitergeführt wurde, bombardierten die USA und die NATO zeitgleich bosnisch-serbische Stellungen. Im September 1995 konnte eine Grundsatzeinigung zwischen den Präsidenten Bosnien-Herzegowinas, Serbiens und Kroatiens im Rahmen der Genfer Bosnienkonferenz erzielt werden. Die Frage

83 Ausführlich zur konflikthaften Erinnerung an Srebrenica und vor allem zur serbischen Deutung vgl. Mehler, Daniela: »Srebrenica und das Problem der einen Wahrheit«, in: Feindt, Gregor/Krawatzek, Félix/Mehler, Daniela/Pestel, Friedemann/ Trimçev, Rieke (Hg.): Europäische Erinnerung als verflochtene Erinnerung. Vielstimmige und vielschichtige Vergangenheitsdeutungen jenseits der Nation (=Formen der Erinnerung 55), Göttingen: V \& R unipress 2014, S. 205-234. 
des Umgangs mit Kriegsverbrechen und mit der Balance zwischen Frieden und Gerechtigkeit war allerdings für die Vermittler sehr sensibel, da man die kriegführenden Mächte weiter am Prozess beteiligen, sich aber auch nicht auf Amnestierungen einlassen wollte. Die vom ICTY erhobenen Anklagen machten es unmöglich, mit extrem nationalistischen Politikern wie Radovan Karadžić über einen Frieden zu verhandeln, die nunmehr als illegitime Gesprächspartner galten. Vertreter der amerikanischen Regierung spielten folglich die Rolle Milošević' in den Jugoslawienkriegen herunter, um ihn als legitimen Verhandlungspartner zu erhalten. ${ }^{84}$

Nach der Anklageerhebung gegen drei hochrangige Angehörige des jugoslawischen Militärapparats durch das ICTY Ende Oktober ${ }^{85}$ wurde auch die den Friedensgesprächen in Dayton vorausgehende internationale Debatte um Srebrenica reflektiert. Obwohl im innerserbischen Diskurs weiterhin die Verteidigung der eigenen Volksgruppe und die berechtigte Angst vor Kriegsverbrechen als legitime Rechtfertigung galten, wurden Kriegsverbrechen, begangen von Angehörigen der gleichen Nation oder von Angehörigen des jugoslawischen Staates, zumindest in der Gegenöffentlichkeit zunehmend kritisch thematisiert. VremeAutor Dragan Todorović klagte an, dass die von den serbischen Offiziellen genannten »verbliebenen und übrigen Kräfte« bosnisch-muslimischer Kämpfer, gegen die serbische Einheiten rund um Srebrenica nach dem Fall der Enklave kämpften, vermutlich durch die Wälder fliehende Zivilisten gewesen seien. Die Befreier Bosniens - hiermit sind die UN und die Amerikaner gemeint - betrachteten »die Aktion der >Befreiung < [der Serben, D. M.] aber als Völkermord gemäß der $\mathrm{UN} \ll{ }^{86}$

Im November 1995 wurde schließlich das Abkommen von Erdut geschlossen, das den Kroatienkrieg beendete, im Dezember besiegelte der Friedensvertrag von Dayton den Bosnienkrieg. Der Vertrag verpflichtet alle unterzeichnenden Parteien-also auch die Bundesrepublik Jugoslawien unter Slobodan Milošević - zur Kooperation mit dem ICTY.

84 Vgl. V. Peskin: International Justice, S. $40 \mathrm{ff}$.

85 Mile Mrkšić, Miroslav Radić und Veselin Šlivančanin, die Kommandierenden der JNA während der Schlacht um Vukovar, wurden schwere Verletzungen der Genfer Konventionen, Kriegsverbrechen und Verbrechen gegen die Menschlichkeit vorgeworfen.

86 Todorović, Dragan: »Zaostale i ostale snage« [Verbliebene und andere Kräfte], in: Vreme vom 6.11.1995, S. 13. 


\section{Zwischen Verweigerung und verstärkter Kooperation}

Der sechste Bericht der Bundesrepublik Jugoslawien über Kriegsverbrechen wurde am 26. Januar 1996 vom Ständigen Gesandten der Bundesrepublik Jugoslawien bei den UN an den UN-Generalsekretär versandt und von ihm an die Generalversammlung als Dokument zum Tagungsordnungspunkt »Bericht des ICTY « und an den Sicherheitsrat weitergereicht. ${ }^{87}$ Seine Verfasser vom Komitee zur Sammlung von Daten über begangene Verbrechen gegen die Menschlichkeit und das internationale Recht wiesen darauf hin, dass das Komitee über eine weit größere Menge an Beweisen, Dokumentationen und Zeugenaussagen über Kriegsverbrechen verfüge, als aufgeführt wurden. Dieser sechste Bericht und die angehangenen Dokumente weichen stilistisch von den fünf vorhergehenden $a b$. Er enthielt keine reine Auflistung von Kriegsverbrechen mehr, sondern nur noch spezifische Untersuchungsberichte über größeren Verbrechenszusammenhängen. Im Fokus dieses sechsten Rapports, der als Antwort auf den Antrag von Bosnien-Herzegowina verstanden werden kann, vor dem Internationalen Gerichtshof die Völkermordkonvention anzuwenden, steht die Qualifizierung der Verbrechen gegen Serben als Genozid. In einem Untersuchungsbericht wird ohne konkrete Ortsnennung allgemein von einem »Genozid und Handlungen gegen Serben im ehemaligen Bosnien-Herzegowina« gesprochen, in einem zweiten konkret der »Genozid an Serben in Mostar« dokumentiert. Darüber hinaus wurden 395 Lager für Serben in Bosnien-Herzegowina, 162 in Kroatien und 21 in Slowenien lokalisiert - und konsequent als »Konzentrationslager« bezeichnet.

Auch wenn er nun auf internationalem Parkett als Friedensvermittler angesehen wurde, vermied Milošević eine offene Kooperation mit dem ICTY. Er geriet zunehmend unter den Druck der ultranationalistischen Opposition, die ihm aufgrund der Unterzeichnung des Friedensvertrags Verrat am serbischen Volk vorwarf. Zwar hatte die Unterzeichnung des Dayton-Vertrags auch die Bundesrepublik Jugoslawien zur Kooperation mit dem ICTY verpflichtet, allerdings ignorierte die Regierung die Anklagen gegen Bürger der Republik Serbien zunächst schlichtweg.

Offiziell wurde an der Interpretation festgehalten, dass eine Auslieferung von jugoslawischen Staatsbürgern juristisch unzulässig sei. Darüber hinaus diskre-

87 Das gleiche Verfahren lässt sich für die Berichte 6 bis 8 feststellen, die alle im UNArchiv vorliegen. Vgl. bis Ende des Absatzes United Nations General Assembly: Letter dated 26 January 1996 from the Chargé d'affaires a.i. of the Permanent Mission of Yugoslavia to the United Nations addressed to the Secretary-General, UNDok. A/51/61 vom 30.1.1996. 
ditierten der Bundesjustizminister und vor allem die Nationalisten der SRS das Gericht als politisch motiviert, einseitig und antiserbisch. Handfeste Argumentationsgrundlagen lieferten nationalistisch gesinnte Vertreter der Rechtswissenschaft. ${ }^{88}$ Sie kritisierten die Ad-hoc-Natur des Gerichts und einen Verstoß gegen das Rückwirkungsverbot, also dass das Tribunal etwas bestrafen würde, für das es zum Zeitpunkt des Verbrechens kein Gesetz gab. Falls eine internationale Gerichtsbarkeit eingerichtet werden müsste, wäre ein permanentes Tribunal notwendig. Das ICTY sei ohnehin illegitim, da es per Beschluss des UNSicherheitsrats errichtet worden sei, der kein legislatives Organ darstelle. Das prominenteste Argument im innerserbischen Diskurs war allerdings, dass das Tribunal als eine gegen Serben gerichtete Institution geschaffen worden sei. Es verstoße durch diese Partialität gegen den Gleichheitsgrundsatz vor dem Recht. Da die Anklagen des ICTY bis zu diesem Zeitpunkt ausnahmslos gegen Angehörige der serbischen Nationalität erhoben worden waren, wurde dieser Umstand als Bestätigung des Vorwurfs mangelnder Objektivität und Parteilichkeit gewertet. Den ICTY-Kritikern gelang es, eine Atmosphäre zu schaffen, in der die serbische Bevölkerung »undoubtedly fear[ed] the Tribunal as a remote and mysterious punitive institution, attached to great powers ${ }^{89}$.

Um neuen Problemen auf internationaler Ebene aus dem Weg zu gehen, erachtete die jugoslawische Regierung die Kooperation mit dem Tribunal in Den Haag, dem nach dem Massaker von Srebrenica große Unterstützung von Seiten der USA zuteil geworden war, allerdings zunehmend als relevant. Dazu trug auch der neu entwickelte, Ende Februar 1996 vorgestellte Regionalansatz der EU bei, der eine Förderung der politischen Stabilität und der wirtschaftlichen Entwicklung in der Region auf Basis bilateraler Verträge und finanzieller Förderung vorsah. Um die Beziehungen zu verbessern, formulierte der Europäische Rat in jährlichen Berichten zu überprüfende Ziele, denen gemäß die Länder demokratisiert weden sollten. ${ }^{90}$ Die vergleichsweise niedrigschwellige Konditionalität, die eine Einhaltung allgemeiner demokratischer Standards, der Friedensabkommen sowie die Förderung der regionalen Kooperation umfasste, fand aber keine direkte Umsetzung im Milošević-Regime. Dennoch weichte die absolut ablehnen-

88 Vgl. den prominentesten Kritiker des ICTY in Serbien: K. Čavoški: Hag protiv pravde.

89 V. Dimitrijević: »The War Crimes Tribunal«, S. 88.

90 Vgl. ausführlicher Ratiu, Camelia Elena: EU Soft Power at Its Best. Zur Leistungsfähigkeit der Europäischen Union als Demokratieförderer in Transformationsstaaten, Hamburg: Dr. Kovač 2011, S. 130 f. 
de Haltung gegenüber dem ICTY auf und wurden Zugeständnisse gemacht. ${ }^{91}$ Eine Vereinbarung mit dem Büro der Chefanklage des Tribunals ermöglichte dem ICTY die Eröffnung eines Büros in Belgrad, die uneingeschränkte Bewegungsfreiheit von Personal, Equipment, Eigentum und Transportmitteln in Serbien, Zugang zu allen öffentlichen Archiven und Dokumenten, die Befragung von bereitwillig aussagenden Zeugen auch außerhalb des Büros und den Transfer von gesammelten Daten und Informationen. ${ }^{92}$ Während seitens der Regierung in Belgrad gegenüber der Öffentlichkeit weiterhin das Bild der Nichtkooperation mit dem Tribunal gezeichnet wurde, unterhielt das Anklagebüro des ICTY ab August 1996 (bis März 1999) auch ein Büro in der Belgrader Innenstadt. ${ }^{93}$

Ende März 1996 lieferten die jugoslawischen Behörden Dražen Erdemović und Radoslav Kremenović, die beide am Massaker von Srebrenica beteiligt waren, für Vernehmungen an das ICTY aus. ${ }^{94}$ Da sie auf jugoslawischem Staatsterritorium festgenommen wurden, aber keine jugoslawische Staatsbürgerschaft besaßen, konnten die Auslieferungen vollzogen werden, ohne die bisher vertretene Position der Nichtauslieferung räumen zu müssen. In einer in Belgrad organisierten Pressekonferenz freute sich der stellvertretende ICTY-Chefankläger Graham Blewitt öffentlich über »the new beginning of cooperation « ${ }^{95}$. Innerhalb Serbiens wurde die Auslieferung aber kaum thematisiert, wie der serbische Staatsanwalt für Kriegsverbrechen, Vladimir Vukčević, 2010 konstatierte:

»Diesem Urteil wurde in Serbien zu wenig Öffentlichkeit zuteil. 1996 passierte alles im medialen Nebel, als die Verbrecher Patrioten waren und Dražen Erdemović mit Patriotismus vor den Augen der Öffentlichkeit versteckt wurde. ${ }^{96}$

Hinsichtlich jugoslawischer Staatsbürger unterstützten die jugoslawischen Behörden weder Ermittlungen noch Auslieferungen. So beschwerte sich ICTYPräsident Antonio Cassese drei Mal, im April, Mai und Juli 1996, beim UN-

91 V. Dimitrijević: »The War Crimes Tribunal«.

92 Vgl. Republik Serbien (Hg.): Answers to the European Commision's Questionnaire vom 31.1.2011, http://www.seio.gov.rs/upload/documents/upitnik/aswers_ro_the_ec_ questionnaire.zip vom 17.4.2013, S. 537.

93 Vgl. International Criminal Tribunal for the Former Yugoslavia: ICTY Weekly Press Briefing vom 15.11.2000, http://www.icty.org/sid/3448 vom 15.11.2010.

94 Vgl. J. Hagan: Justice in the Balkans, S. $75 \mathrm{ff}$.

95 Vgl. ebd., S. $77 \mathrm{f}$.

96 Vukčević, Vladimir: »Jedinstvena prilika za poruku pomirenja« [Einzigartige Möglichkeit für eine Botschaft der Versöhnung], in: Vreme vom 11.2.2010, S. 14. 
Sicherheitsrat über die mangelnde Kooperation Jugoslawiens mit dem ICTY in den Fällen der Vukovar Three (Mile Mrkšić, Veselin Slivančanin, Miroslav Radić), Radovan Karadžić' sowie Ratko Mladić', die sich alle auf dem Gebiet Jugoslawiens aufhalten würden. Währenddessen veröffentlichte im Juni eine Gruppe von 24 serbischen Intellektuellen eine Deklaration zur Aussetzung der Strafverfolgung von Radovan Karadžić, da eine Stabilisierung des Friedens in Bosnien-Herzegowina ohne die Vertretung der serbischen Interessen durch den "wahren Führer aller Serben« nicht möglich wäre. ${ }^{97}$

Der Internationale Gerichtshof nahm im Juli, ein Jahr nach dem Massaker von Srebrenica, den Antrag Bosnien-Herzegowinas auf Anwendung der Völkermordkonvention an. Ebenfalls nur ein Jahr nach der kroatischen Militäroperation Oluja schlossen die Regierungen Kroatiens und Jugoslawiens ein Normalisierungsabkommen ihrer beiden Länder.

Im September 1996 sandte die jugoslawische Bundesregierung den siebten Bericht über Kriegsverbrechen und Vergehen gegen das Völkerrecht an die UN. In ihm standen Untersuchungen über das Konzentrationslager für Serben in Ćelebići, über kroatische Verbrechen auf der Straße von Okucani nach Stara Gradiška sowie der kroatischen Armee auf der Straße von Srbobran nach Jajce und über Verbrechen von kroatischen Soldaten und Polizeikräften in der Krajina im Fokus. ${ }^{98}$

1996 verlegte die zweiwöchig erscheinende Zeitschrift Republika ${ }^{99}$ den umfangreichen Sammelband Srpska strana rata (Die serbische Seite des Kriegs). Die darin vorgenommenen wissenschaftlichen Analysen, die teilweise vorab in der Zeitschrift veröffentlicht worden waren, bilden den Bezugspunkt für sämtliche gesellschaftlichen Akteure, die sich nicht dem Milošević-Regime zurechne-

97 Raljić, Prvoslav (Hg.): Bela knijga. Istina o Haškom tribunalu. Apel za ukidanje Haškog tribunala [Weißbuch. Die Wahrheit über das Haager Tribunal. Appell zur Abschaffung des Haager Tribunals], Belgrad: Sova 2001, S. 177.

98 United Nations General Assembly: Letter dated 20 September 1996 from the Chargé d'affaires a.i. of the Permanent Mission of Yugoslavia to the United Nations addressed to the Secretary-General, UN-Dok. A/51/397 vom 24.9.1996.

99 Die Republika wurde von der gleichen Gruppe Intellektueller, die kurz zuvor die Udruženje za jugoslovensku demokratsku inicijativu (Vereinigung für eine jugoslawische demokratische Initiative) gegründet hatten, im März 1989 als »Zeitschrift der zivilgesellschaftlichen Selbstbefreiuung«, die sich gegen »Elemente von Angst, Hass und Gewalt« richten sollte, ins Leben gerufen, vgl. http://www.republika. co.rs/o_nama/srpski.html vom 13.4.2013. 
ten. Auch im Ausland wurde das Buch rezipiert. ${ }^{100}$ In über zweijähriger Arbeit hatten sich unabhängige Intellektuelle ${ }^{101}$ zum Novi srpski forum (Neuen serbischen Forum), das als alternativer Diskursraum dienen sollte, zusammengefunden, um den Weg Serbiens in den Krieg von allen Seiten zu analysieren. Unter dem Vorsitz der Politikwissenschaftlerin Latinka Perović diskutierten die Autoren in zweiwöchentlichem Rhythmus ihre Ideen und Beiträge. Die Arbeit am Buch und dessen Finanzierung wurde durch das Centar za antiratnu akciju (Zentrum für Antikriegsaktion) und die Heinrich-Böll-Stiftung ermöglicht. Herausgeber Nebojša Popov, ein zur Praxisgruppe ${ }^{102}$ gehörender Soziologe, erklärte im Vorwort der englischen Ausgabe des Buchs, die Autoren befänden sich in der gleichen Situation wie diejenigen, die nach den Gräueln des Zweiten Weltkriegs versucht hätten, ihren Verstand zu behalten. ${ }^{103}$ Die Beiträge behandeln die Schaffung der militanten, nationalistischen Ideologie, die Zerstörung von Bil-

100 Es wurde zunächst in stark gekürzter Fassung ins Deutsche, dann vollständig ins Englische übersetzt, vgl. Bremer, Thomas/Stobbe, Heinz-Günther (Hg.): Serbiens Weg in den Krieg. Kollektive Erinnerung, nationale Formierung und ideologische Aufrüstung, Berlin: Berlin-Verlag Spitz 1998; Popov, Nebojša/Gojković, Drinka (Hg.): The Road to War in Serbia. Trauma and Catharsis, Budapest/New York: Central European University Press 2000.

$101 \mathrm{Zu}$ den Autoren gehörten Vesna Pešic, Olivera Milosavljević, Nebojsa Popov, Sreten Vujović, Srđan Bogosavljević, Ljubomir Madžar, Marina Blagojević, Vojin Dimitrijević, Bojana Šušak, Miroslav Hadžić, Rade Veljanovski, Aleksandar Nenadović, Zoran Marković, Snježana Milivojević, Dubravka Stojanović (alle Universität Belgrad), Latinka Perovic, Radmila Radić, Marija Obradović (Institut für Zeitgeschichte), Olga Žirojević, Ivan Čolović, Mirko Đorđević (Serbische Akademie für Wissenschaft und Künste) sowie Drinka Gojković.

102 Die Praxisgruppe bestand aus jugoslawische Philosophen und Sozialwissenschaftlern, die in den 1960er und 1970er Jahren in scharfer Abgrenzung zum Stalinismus einen humanistischen, undogmatischen und schöpferischen Sozialismus propagierten und mit ihrer offenen Gesellschaftskritik in zum Teil offenen Konflikt zu den Positionen des Bundes der Kommunisten und staatlicher Einrichtungen traten. $\mathrm{Ab}$ 1963-1975 veranstalteten sie (außer 1966) eine Somerschule auf der Insel Korçula, weiterhin veröffentlichten sie neben einer jugoslawischen auch eine internationale Zeitschrift. 1975 wurden die Mitglieder der Praxisgruppe aus der Universität Belgrad ausgeschlossen, die jährliche Sommerschule und die Zeitschrift verboten.

103 Popov, Nebojša/Gojković, Drinka (Hg.): The Road to War in Serbia. Trauma and Catharsis, Budapest/New York: Central European University Press 2000, S. 3. 
dungsinstitutionen, Kultur und Politik sowie die Konsequenzen dieses Prozesses für die serbische Gesellschaft.

Im November 1996 entschied die jugoslawische Bundesregierung, dass kein spezielles Gesetz für eine Zusammenarbeit mit dem Tribunal notwendig sei. Nur einige Tage später wählten die Bürger der Republik Serbien in zweiter Runde ihre kommunalen Vertreter. Nach dem Vorwurf großflächiger Wahlfälschung zugunsten des Machterhalts von Milošević' SPS riefen Vertreter der Oppositionsparteien zum Protest auf. Der Widerstand gegen die Wahlfälschungen und das Milošević-Regime, an denen sich auch die Studierenden mit einem zeitlich parallelen, aber räumlich getrennten Protest beteiligten, sollten dreieinhalb Monate andauern. Die Kriege der Vorjahre und die währenddessen begangenen Kriegsverbrechen blieben in ihrem Verlauf allerdings gänzlich unerwähnt.

\section{Amtswechsel und die Wahrheit des serbischen Opfers}

Die Anerkennung der Wahlerfolge der Opposition beendeten die Antiregimeproteste im Februar, nur die Studierenden gaben ihren Protest erst drei Wochen später auf. ${ }^{104}$ Milošević' Macht in Serbien erodierte nun langsam, nachdem in großen, einflussreichen Städten wie Belgrad, Pirot, Kraljevo, Užice, Smederavske Palanke, Vršac, Sokobanji, Kragujevac, Pančevo, Jagodina, Niš, Zrenjanin, Lapovo und Šabac Oppositionspolitiker die Wahl gewonnen hatten.

Im März 1997 sandte die jugoslawische Bundesregierung erneut einen Bericht über Kriegsverbrechen an die UN. Dieser achte Report beinhaltete diesmal keine Einleitung, sondern begann sofort mit einem der insgesamt sechs zusammengestellten Untersuchungsberichte. Drei von ihnen fokussierten auf Verbrechen kroatischer Einheiten an Serben - die Verbrechen gegen die Bevölkerung der Gemeinde Mrkonić-Stadt, den Völkermord gegen Zivilisten der Republika Srpska Krajina und auf vermisste Personen aus diesem Gebiet. ${ }^{105}$ Die anderen drei dokumentierten Kriegsverbrechen während des Bosnienkriegs, den Missbrauch medizinischer Einrichtungen für militärische Nutzung in Sarajevo sowie die Vorgänge im Silos-Lager im ostbosnischen Tarčin.

Nicht nur die Politik stellte die Serben als unschuldige Opfer dar. Mit dem Segen von Patriarch Pavle forderten sechzig Intellektuelle und Personen des öf-

104 Sie forderten zudem einen Führungswechsel in der Universitätsleitung und die Wiederherstellung der Unabhängigkeit der Hochschule.

105 United Nations General Assembly: Letter dated 28 February 1997 from the Chargé d'affaires a.i. of the Permanent Mission of Yugoslavia to the United Nations addressed to the Secretary General, UN-Dok. A/52/83 vom 3.3.1997. 
fentlichen Lebens ${ }^{106}$ - unter anderem ICTY-Kritiker Kosta Čavoski und Oppositionsführer Zoran Đinđić - an Ostern 1997, den Völkermord am serbischen Volk und dessen Exodus während der Jugoslawienkriege anzuerkennen und zu verurteilen. Der »Aufruf an das Gewissen der ganzen Welt«, wurde in sieben Sprachen unter anderem an die UN-Generalsversammlung, den UN-Sicherheitsrat, die Organisation für wirtschaftliche Zusammenarbeit und Entwicklung (OECD), den Europarat und das Europäische Parlament versandt. Mit der Deklaration forderten die Unterzeichner, den Genozid am und den Exodus des serbischen Volks im letzten Krieg anzuerkennen und zu verurteilen. In dem Schreiben wurde das Narrativ der serbischen Geschichte rekonstruiert, nach dem diese bis heute Opfer von Völkermorden und Vertreibungen aus ihren Ländern seien:

»Die Geschichte der serbischen Länder als Teil des Balkans und Europas ist ein Beispiel des Genozids an den Serben und des Exodus, dem sie ausgesetzt waren. Die Vernichtungsprozesse der Serben haben auf unterschiedlichste und grausamste Weise kontinuierlich angehalten. [...] Der Exodus des serbischen Volkes dauert auch heute fort, am Ende des 20. Jahrhunderts. Der Prozess der Zerstörung Jugoslawiens ließ den Serben das größte Leiden und die Verbannung aus ihrem historischen Lebensraum in Kroatien und Bosnien und Herzegowina ertragen. ${ }^{107}$

106 Marko Radulović, Ivan Maksimović, Dragoslav Mihajlović, Nikola Milošević, Miodrag Jovičić, Dragan Nedeljković, Kosta Bradić, der Bischof der Bačka Irinej, Kosta Cavoški, Nada Miloš-Đorđević, Zoran Stanojević, Milos Blagojević, Rade Mihaljčić, Milorad Ekmečić, Boško Petrović, der Bischof der Šumadija Sava, Vladan Batić, Ljubomir Tadić, Enriko Josif, Professor Bartabedijan, Slavenko Teržić, Nikša Stipčević, Mihajlo Marković, Vojislav Korać, Mihajlo Đurić, Slavko Gavrilović, Dinko Davidov, Nikola R. Ćelebić, Novica Petković, Mihajlo Pavlović, Cedomir Popov, Dragan Kijuk, Ljubivoje Prvulović, Kosta Mihajlović, Dragoljub Simović, Miroslav Pantić, Vladimir Grečić, der dalmatische Bischof Longin, Zoran Živković, Rados Ljušić, Slobodan Mileušnić, Pavle Ivić, Smilja Avramov, Slobodan Rakitić, Danko Popović, Vasilije Krestić, Čadik Danon, Vlado Stugar, Bogdan Jamedžija, Milan Vujin, Zoran Đinđic, der Bischof von Niš Irinej, Tadija Ivanović, Dragan Kuburović, Nikola Božinović, Vladimir Umeljić, Miodrag Perišić und Zoran Konstantinović.

107 O.V.: »Apel svetu da zaštiti Srbe. Deklaracija protiv genocida nad srpskim narodom« [Appell an die Welt um die Serben zu schützen. Erklärung gegen den Genozid am serbischen Volk], in: Blic vom 22.4.1997, S. 3. 
Die Erfahrung von Völkermord, Exodus, Leiden und Verbannung wird hierbei als Erfahrungswelt der Serben stilisiert. Besonders betont werden das Leiden und die Ungerechtigkeit, die an Serben in den zwei Weltkriegen begangen worden seien. Außerdem appellierten die Unterzeichner »an das Gewissen der Menschheit« für eine angemessene Erinnerung an

»die schrecklichen Fälle von Völkermord an Serben und deren Exodus im letzten Krieg [...]. Die große Zahl an Beispielen für körperliche und geistige Zerstörung des serbischen Volkes, die weltweit bekannt sind, möge erwähnt werden. Dies ist ein Aufruf, dass all jene schrecklichen Beispiele von Völkermord und Exodus einen Platz nicht nur vor dem Gericht der Geschichte finden, sondern auch vor unparteiischen und qualifizierten Richtern in der heutigen Welt. Um fair zu sein, kann all dieses Richten nicht vorbeigehen am gerechten Zeugnis des leidenden serbischen Volkes. $\ll^{108}$

Das Schreiben reflektierte die Enttäuschung über eine falsche Darstellung der Rolle der Serben und der Geschichte auf internationalem Parkett und den daraus resultierenden Eindruck von Ungerechtigkeit, der mit einem Vertrauensverlust in Institutionen einhergeht. Hoffnung bietet nur noch das »Gericht der Geschichte«. Nicht nur wurde eine Anklage zugleich gegen die kroatischen und bosniakischen Konfliktgegner wegen des Völkermords an den Serben und deren Vertreibung, gegen die Richter wegen mangelnder Qualifizierung und Parteilichkeit sowie gegen die gewissenlose Welt formuliert, sondern auch mit starken Adjektiven, emotionaler Sprache und Moralisierung aus dem Opferstatus heraus ein Anspruch auf einen angemessenen Platz in der Weltgeschichte erhoben. Indem der Apell die Völkermordkategorie verwendete, analogisierte er die serbische Opferschaft mit anderen Opfern von Genoziden, und man erhoffte sich somit unter Berufung auf die Wahrheit eine gleiche Behandlung:

»Die Wahrheit, eine klare Äußerung des Völkermords, verstanden im weitesten Sinne des Wortes, ist auch in der Betrachtung der unmenschlichen Beziehungen gegenüber den Juden, Armeniern und anderen gegenwärtig. ${ }^{109}$

108 Ebd.

109 Tašić, Jelana: »Poziv savesti (celog sveta). Šta sadrži Deklaracija protiv genocida nad srpskim narodom « [Aufruf an das Gewissen (der ganzen Welt). Was die Erklärung gegen den Genozid am serbischen Volk enthält], in: Naša Borba vom 25.4.1997, http://www.yurope.com/nasa-borba/arhiva/Apr97/2504/2504_25.HTM vom 12.7.2014. 
Implizit wurden so all diejenigen, die nicht den Völkermord an den Serben bezeugten, mit Leugnern des Holocaust gleichgestellt, was durch die Verletzung dieser Konvention des gesellschaftlichen Grundkonsenses mit einer moralischen und sozialen Ächtung verbunden ist. Andere Wahrheiten als diese innerserbisch wahrgenommene »Wahrheit des serbischen Opfers" galten dementsprechend als illegitim und wurden als Angriff gewertet, so auch die Anklagen des ICTY gegen Serben. Sicherlich nicht in dieses Bild passten Äußerungen wie die von Sonja Biserko, die auf einer Konferenz in Berkley die Nationalisierung der serbischen Gesellschaft seit den späten 1980er Jahren beschrieb und die serbische Regierung des Genozids in Srebrenica beschuldigte. Sie machte deutlich, dass der serbische Nationalismus nicht mit dem Vertrag von Dayton beendet sei, vielmehr habe er eine neue, »more sophisticated form ${ }^{110}$ angenommen. Da es militärisch nicht besiegt worden sei, sei es für das Land objektiv nicht möglich, sich mit den wahren Gründen des Kriegs, seinen Absichten und Folgen auseinanderzusetzen. Deswegen plädiere sie dafür, enorme Anstrengungen zu unternehmen, um eine Denazifizierung zu beginnen. ${ }^{111}$

Die Position der Bundesregierung gegenüber Auslieferungen an das ICTY war nach wie vor unverändert, als die amerikanische Außenministerin Madeleine Albright im Juni 1997 Slobodan Milošević öffentlichkeitswirksam mit den Anklagen des ICTY und Nachweisen darüber konfrontierte, dass sich zahlreiche Angeklagte in Serbien befänden. Dieses Treffen markierte das Ende des amerikanischen Kuschelkurses gegenüber Milošević, der nun zunehmend unter Druck der politischen Unterstützerin des Tribunals geraten sollte. ${ }^{12}$ Nach den Kommunalwahlen war seine Machtbasis auch innerhalb Serbiens instabil geworden. Da er ohnehin als Präsident Serbiens nicht hätte wiedergewählt werden können, trat Slobodan Milošević am 23. Juli 1997 zurück - um sich am gleichen Tag von der sozialistischen Mehrheit des jugoslawischen Bundesparlaments zum Präsidenten der Bundesrepublik Jugoslawien wählen zu lassen.

Zur Verteidigung gegen die Genozidklage Bosnien-Herzegowinas sandte die jugoslawische Bundesregierung ein umfassendes Counter-Memorial an den Internationalen Gerichtshof. Auf mehr als eintausend Seiten wurden die gegen die Bundesrepublik Jugoslawien vorgebrachten Vorwürfe entkräftet und Bewei-

110 Biserko, Sonja: »Reporting from the Writing Fields, or: How to Prepare Genocide in Five Years«, Vortrag an der University of California in Berkeley bei der Konferenz »Reporting from the Killing Fields« vom 11.4.1997, http://www.nettime.org/ListsArchives/nettime-1-9705/msg00066.html vom 5.4.2013.

111 Ebd.

112 V. Peskin: International Justice, S. $50 \mathrm{f}$. 
se für einen an Serben begangenen Völkermord dargelegt. Der Bericht schlussfolgert, dass keine der in der Genozidkonvention aufgeführten Verbrechen an Muslimen und Kroaten begangen worden seien beziehungsweise dass diese nicht als Völkermord qualifiziert werden könnten. Die Vorwürfe oder Anklagen, die gegen Jugoslawien vorgebracht würden, seien weder durch Organe der Bundesrepublik Jugoslawien noch unter deren Befehl oder auf deren Territorium begangen worden. Hingegen sei Bosnien-Herzegowina verantwortlich für Verbrechen des Genozids an der serbischen Bevölkerung in Bosnien-Herzegowina. Dementsprechend müssten die Verantwortlichen bestraft und Maßnahmen ergriffen werden, die solche Verbrechen in Zukunft unterbinden, zudem sei Kompensation zu leisten. ${ }^{113}$

Auch ohne die Debatte um erneute »Völkermordkonkurrenz« nach der Logik »Nicht wir haben einen Völkermord an euch begangen, sondern ihr an uns! « gab die serbisch dominierte Politik auf serbischer und jugoslawischer Ebene ausreichend Anlass zur Kritik. Mirko Tepavac, ehemaliger jugoslawische Politiker und Herausgeber der Politika, beschrieb die Widersprüchlichkeit von Worten und Taten und schloss dabei auch die oftmals nicht weniger nationalistisch gesinnte, verzagte Opposition mit ein:

»Wenn wir Dayton wirklich akzeptieren, warum unterstützen wir dann die Illusion Pales über einen souveränen serbischen Staat auf der anderen Seite der Drina, warum senden wir nicht >unsere〈 Kriegsverbrecher nach Den Haag, die sicherlich nicht unsere sein müssen, falls sie Verbrecher sind, zumal fast alle Kriegsprofiteure und Kriminelle sind. Warum erschweren wir die Reformen in Montenegro, anstatt sie selbst zu ergreifen? Die Regierung will der Wahrheit nicht ins Auge sehen, und auch die Opposition scheint das nicht einfach zu genießen. ${ }^{114}$

\section{Erneut im Krieg: das Kosovo}

Im Winter 1998 eskalierte die Lage im Kosovo, wo die paramilitärische Ushtria Çlirimtare e Kosovës (UÇK, Befreiungsarmee des Kosovo) schon seit 1996 ge-

113 International Court of Justice: Application of the Convention on the Prevention and Punishment of the Crime of Genocide (Bosnia and Herzegovina v. Yugoslavia). Counter-Memorial of the Federal Republic of Yugoslavia vom 23.7.1997, S. $1083 \mathrm{ff}$.

114 Tepavac, Mirko: »Srbija na kori od banane« [Serbien auf der Bananenschale], in: ders.: Države, državnici i stradalnici. Ogledi iz Republike (1991-2008) [Länder, Staatsmänner und Verunglückte. Ansichten aus der Republik (1991-2008)] (= Edicija PUBLIKUS 18), Belgrad: Službeni glasnik 2009, S. 167-170, hier S. 167. 
walttätig für die Unabhängigkeit des Kosovo kämpfte. Auf eine lokale UÇKOffensive im Februar, bei der vier serbische Polizisten getötet worden waren, folgte ab Anfang März eine Offensive von Spezialkräften der serbischen Polizei im Drenica-Gebiet. Direkt nach der Eskalation ${ }^{115}$ organisierte sich die im Bosnienkrieg eingerichtete Balkankontaktgruppe erneut, um zwischen den Konfliktparteien zu vermitteln. Der UN-Sicherheitsrat verurteilte die Gewalt auf beiden Seiten, mahnte zu einer politischen Konfliktlösung unter Vermittlung der Kontaktgruppe und verhängte ein Waffenembargo gegen die Bundesrepublik Jugoslawien. Zudem wurde das Mandat des ICTY auf das Kosovo ausgeweitet und erneut konstatiert, dass eine Verpflichtung der Bundesrepublik Jugoslawien zur Kooperation mit dem ICTY bestünde. ${ }^{116}$

Diese Pflicht zur Zusammenarbeit wurde auf innerjugoslawischer Ebene neu thematisiert, nachdem sich ICTY-Chefanklägerin Louise Arbour im Februar 1998 in Podgorica mit dem Landesstaatsanwalt Montenegros, Vladimir Šušović, und montenegrinischen Oppositionellen getroffen hatte. Die montenegrinische sozialdemokratische Partei SDP insistierte bei einer anschließenden Pressekonferenz darauf, dass der Fall Štrpci ${ }^{117}$ vor dem ICTY verhandelt werden müsse, da eine Strafverfolgung in Montenegro und ganz Jugoslawien ausbleibe und diese Länder so zum Zufluchtsort für Verbrecher würden. ${ }^{118}$ Auf die vergleichsweise frühe innerjugoslawische Kritik reagierte Bundesstaatsanwalt Vukašin Jokanović, Milošević-Vertrauter und ehemaliger Bundesinnenminister, barsch. Er wies die Oppositionellen in Montenegro in die Schranken und machte in einem

115 Eine Anti-Terrorismus-Spezialeinheit des serbischen Innenministeriums griff am 5. März 1998 den Ort Prekaz an, angeblich, um Terroristen gefangen zu nehmen. Tatsächlich wurden die Verdächtigen, UÇK-Führer Adem Jashari und sein Bruder, und über 60 ihrer Familienmitglieder in einem Massaker getötet. Der Massenmord führte zu einer massiven Popularisierung der UÇK und viele lokale Milizen gründeten sich. Adem Jashari wird heute im Kosovo als Freiheitskämpfer verehrt.

116 Vgl. United Nations Security Council: Resolution 1160, UN-Dok. S/RES/1160 vom 31.3.1998.

117 Beim Massaker von Štrpci wurden 19 nichtserbische Fahrgäste beim Halt des Zugs, der auf der Strecke Belgrad-Bar über bosnisches Territorium fuhr, im Februar 1993 entführt, ausgeraubt, gefoltert und ermordet. Ihre Leichen wurden bis heute nicht gefunden, das Verbrechen blieb weitgehend unaufgeklärt und es fand keine umfassende Strafverfolgung statt.

118 O. V.: Slucaj Strpci - za Haski tribunal [Fall Strpci - für das Haager Tribunal], in: Naša Borba vom 14.2.1998, http://www.yurope.com/nasa-borba/arhiva/Feb98/1402/ 1402 _. htm vom 25.1.2013. 
Machtwort die Kompetenzen deutlich: »Einzig ich bin bevollmächtigt, Verpflichtungen zu übernehmen, wenn es um die Zusammenarbeit mit dem Haager Tribunal geht. $\ll^{119}$

Zeitgleich veröffentlichte die Literaturwissenschaftlerin Drinka Gojković, die dem »anderen Serbien« angehörte und schon seit 1996 kritisch über den Nationalismus in der serbischen Demokratie schrieb, ${ }^{120}$ den innerserbisch vielbeachteten Aufsatz Za početak, skica (Für den Anfang, eine Skizze), in der sie die fehlende Differenz der Oppositionsparteien zum Milošević-Regime für das Scheitern der Antiregimeproteste verantwortlich machte. ${ }^{121}$ Statt lediglich eine Anerkennung der Wahlergebnisse zu fordern und gegen das Regime zu sein, fehle es den Oppositionsparteien an einem gemeinsamen Ziel, das »in der Klärung des Nebels von Nationalismus und Krieg « ${ }^{122}$ liegen müsse. Dies bedeute allerdings auch eine deutliche Abgrenzung zum Milošević-Regime. In ihrer Analyse prägte sie den Begriff eines »kognitiven Blocks«, einer mentalen Verschlossenheit, die es unmöglich mache, auf die Realität und ihre Herausforderungen zu reagieren. Sowohl die Führer des Protests als auch das Regime seien nicht in der Lage, sich

»der Realität der serbischen Verantwortung für den Zerfall Jugoslawiens und die Kriege, die danach ausbrachen, zu stellen. Genau dieses Unvermögen hindert die Opposition im demokratischen Wandel Serbiens, da die Demokratie im Wesentlichen auf dem Prinzip der Verantwortung basiert. $\ll^{123}$

Implizit unterstellte sie den Oppositionsparteien eine Nähe zum serbischen Nationalismus und die fehlende Bereitschaft zum Bruch mit dem Regime.

Im April sandte die Bundesregierung erneut einen Bericht über begangene Kriegsverbrechen an die UN. Dieser neunte Bericht, namentlich unterzeichnet vom Vorsitzenden des Komitees, Professor Dr. Zoran Stojanović, umfasste fünf Studien, die sich mehrheitlich mit bosniakischen Verbrechen an Serben während des Bosnienkriegs beschäftigten und auf den Nachweis eines Völkermords an Serben abzielten. Das geht eindeutig aus den Titeln der Berichte hervor, die vom

119 O.V.: »Izjave godine« [Äußerungen des Jahres], in: Vreme vom 2.1.1999, S. 34 f., hier S. 34.

120 N. Popov/D. Gojković: Srpska strana rata.

121 Gojković, Drinka: »Za početak, skica« [Für den Anfang, eine Skizze], in: Reč. Časopis za književnost, kulturu i društvena pitanja 35 (1998) 2, S. 135-141.

122 Ebd., S. 137.

123 Ebd. 
»Genozid gegen Serben in der Gemeinde Konjić«, »Genozid gegen Serben im Bezirk Bosanska Posavina« und dem »organisierten Charakter des Genozids gegen Serben in Sarajevo« lauten. ${ }^{124}$ Darüber hinaus wurde ein Bericht über ein militärisches Lager der sogenannten Mujaheddin erstellt, muslimischer Freiwilliger und Söldner, die den Kampf ihrer Glaubensbrüder unterstützten, und ein weiterer über die Sprengung der Kirche St. Nikolaj im kroatischen Vukovar. Besonders hob Stojanović die ersten drei Dossiers hervor, die »unter Priorität fallen, da sie auf Antrag der Anklägerin des Internationalen Tribunals angefertigt wurden, so wie ihnen das Tribunal Priorität gegeben habe ${ }^{125}$. Neu in diesem Bericht sind der dialogische Charakter und die erstmalige direkte Bezugnahme auf Ermittlungen der Anklage des ICTY. Es ist fraglich, ob man damit zeigen wollte, dass man der Kooperationsverpflichtung nachkommt, oder ob man die Ermittlungen des ICTY nur dann zu unterstützen beabsichtigte, wenn es im eigenen Interesse wäre. Von einer echten Kooperation konnte keinesfalls die Rede sein, da die Unterstützung bei der Verfolgung serbischer Staatsbürger weiter gänzlich ausblieb.

Während die Verhandlungen zwischen Vertretern der kosovo-albanischen und der serbischen Seite ergebnislos blieben, schien auf internationaler Ebene der Konflikt schon interpretiert worden zu sein: Die NATO beschloss Ende Mai, militärische Handlungsoptionen gegen die Bundesrepublik Jugoslawien zu planen. Anfang Juni verhängten die EU und die USA Sanktionen gegen Jugoslawien. Anfang Juni stationierten die UN die Kosovo Diplomatic Observer Mission im Kosovo. Im Sommer weitete sich der zunächst im Nordkosovo ausgetragene Konflikt auf die ganze Region aus, die UÇK ging von einer Guerillataktik sukzessive zur regulären Kriegsführung über, auf serbischer Seite unterstützte nun die Armee die Polizeikräfte.

Die Bundesrepublik Jugoslawien versuchte weiterhin, im Rahmen der UN internationale Unterstützung im Kampf gegen die »internationalen Terrorristen« der UÇK zu erlangen. Der jugoslawische Botschafter sandte regelmäßig kurze

124 Bundesregierung der Republik Jugoslawien: Deveti izveštaj Vlade SRJ o izvršenim ratnim zločinima na području prethodne Jugoslavije pripremljen od strane Komiteta za prikupljanje podataka o izvršenim zločinima protiv čovečnosti i međunarodnog prava [Neunter Bericht der Regierung der SRJ über begangene Kriegsverbrechen auf dem Gebiet des früheren Jugoslawien, angefertigt vom Komitee für die Sammlung von Daten über begangene Verbrechen gegen die Menschlichkeit und das internationale Recht] vom 2.4.1998, http://www.slobodan-milosevic.org/documents/reports/Ser bian/9-uvod.htm vom 21.1.2013.

125 Ebd. 
Berichte über die Konfliktlage an den Generalsekretär. Ausführlicher hingegen fiel das an die Generalversammlung übersandte Statement des jugoslawischen Außenministeriums über die brutale Ermordung von 22 entführten Serben in Klečka aus. Besonders drastisch erwähnte der Bericht, dass die Örtlichkeiten einer Zitronenfabrik als eine Art Krematorium zum Verbrennen der Leichen genutzt worden waren. Diese Art der Leichenbeseitigung wurde zum Anlass genommen, die Täter mit Nazis und die Tötung der Serben dementsprechend mit dem industrialisierten Massenmord an den Juden gleichzusetzen:

»This most serious and brutal of the discovered crimes committed by terrorists thus far has been done following a Nazi recipe. It proves that the killers were brutal and that they not only killed, kidnapped, raped, burned people's homes and destroyed their property and carried out subversive acts, but also went so far, in their crazed Nazi obsession, to commit the cowardly act of burning the bodies of their victims. ${ }^{126}$

In einer Stellungnahme forderte das jugoslawische Außenministerium die UNMitgliedsstaaten einzeln auf, diese Verbrechen klar zu verurteilen und den »legitimen Kampf gegen den Terrorismus « ${ }^{127}$ zu unterstützen, indem man die gleichen Standards wie in anderen Fällen anwende. Zudem ersuchte es darum, jegliche Unterstützung der UÇK zu unterbinden, und forderte ein gemeinsames Handeln aller Länder und internationaler Faktoren im Kampf gegen »this universal evil facing mankind today « ${ }^{128}$. Zwar verurteilten einzelne Vertreter der internationalen Gemeinschaft und internationaler Organisationen das Verbrechen von Klečka, eine breite Solidarisierung mit den Serben blieb allerdings aus. In Serbien führte das Verbrechen von Klečka dazu, die These vom albanischen Genozid an den Serben bestätigt zu sehen. Das seit den 1980ern konstruierte Narrativ wurde in den Medien reaktualisiert und radikalisiert.

Da vor allem die USA eine prokosovarische Rolle einnahmen - der amerikanische Sondergesandte Richard Holbrooke traf sich demonstrativ mit Vertretern der UÇK, Vertreter der USA wiederholten die von George Bush senior 1992 erstmals verwendete Christmas warning, der gemäß die USA militärisch auf einen serbischen Vorstoß ins Kosovo reagieren würden -, verschlechterten sich die Beziehungen Jugoslawiens zu den USA zunehmend, was sich in der Presse

126 United Nations General Assembly: Letter dated 29 August 1998 from the Chargé d'affaires a.i. of the Permanent Mission of Yugoslavia to the United Nations addressed to the Secretary-General, UN-Dok. A/53/300 vom 31.8.1998.

127 Ebd.

128 Ebd. 
widerspiegelte. Ein Beispiel dafür ist der Politika-Artikel »Warum brach der Krieg gegen Albanien erst in Hollywood aus?«. In ihm zieht Milan V. Petković, ehemals Leiter des Fachbereichs Militärschulen der JNA, Parallelen zwischen den Ereignissen in der Region und dem 1997 erschienenen amerikanische Satirefilm Wag the Dog, in dem ein US-Präsident einen Krieg gegen ein unbedeutendes Land inszenieren lässt, um im Wahlkampf von der Belästigung einer Minderjährigen abzulenken. Mit Blick auf die amerikanische Militärdoktrin, psychopsychologische Kriegsführung und Propaganda resümiert er, dass zentral sei, welches Land »Freiheit und Demokratie« und welches »Totalitarismus« unterstützen würde. Der Artikel wurde vom serbischen Informationsministerium ins Englische übersetzt und im Internet lanciert. ${ }^{129}$

Parallel zur weiteren Eskalation des Kosovokriegs, die mit einer ersten Mobilisierung der NATO und der Einrichtung einer Verifizierungsmission der Organisation für Sicherheit und Zusammenarbeit (OSZE) in Europa im Kosovo einherging, verstärkte sich auch hinsichtlich der Frage des Umgangs mit Kriegsverbrechen der Druck auf Jugoslawien. Ab September 1998 reichte die Präsidentin des ICTY, Gabrielle Kirk MacDonald, über einen Zeitraum von drei Monaten fünf offizielle Beschwerden gegen die Bundesrepublik Jugoslawien beim UNSicherheitsrat ein. Dabei formulierte sie vor allem Kritik an der weiterhin ausbleibenden Kooperation der serbischen Behörden, aber auch Enttäuschung über den UN-Sicherheitsrat, der das Problem mit den serbischen Behörden zwar zur Kenntnis nehme, aber nicht weiter handle. ${ }^{130}$ Hier kann vermutet werden, dass zusätzlicher Druck nicht als hilfreich angesehen wurde, um eine friedliche Lösung für den Kosovokonflikt zu erzielen. Erst im November, und auch nur symbolisch, reagierte der Sicherheitsrat auf die Beschwerden der ICTY-Präsidentin mit Verabschiedung von Resolution 1207, in der die Bundesrepublik Jugoslawien dazu aufgefordert wurde, alle notwendigen Maßnahmen zu ergreifen, um gesetzlich eine Zusammenarbeit mit dem ICTY zu ermöglichen und nicht weiter das nationale Recht als Rechtfertigung dafür zu verwenden, den internationalen Verpflichtungen nicht nachkommen zu brauchen. Zudem ruft der Sicherheitsrat die Regierung dazu auf, sofort die Verhaftungen auszuführen, die vom Tribunal erwartet würden, und das Tribunal auch hinsichtlich der Ermittlungen bezüglich des Kosovo zu unterstützen.

129 Knezević, Darko: »Why Did the >War in Albania First Erupt in Hollywood?«, in: Politika vom 13.10.1998 (Übersetzung des serbischen Informationsministeriums: http://www.ex-yupress.com/politika/politika7.html vom 8.5.2012).

Vgl. V. Peskin: International Justice, S. 56 f. 
Der zehnte Bericht über Kriegsverbrechen der Jugoslawischen Bundesregierung an die UN vom Dezember 1998 weist gravierende stilistische Änderungen auf. Er umfasst keine Einleitung mehr und ist auch nicht mehr als »10. Bericht « gekennzeichnet, sondern besteht direkt aus einer Anklageschrift gegen Alija Izetbegović, muslimisch-bosniakischer Aktivist, politischer Gefangener im sozialistischen Jugoslawien, Mitgründer der bosniakischen SDA und erster Präsident des unabhängigen Bosnien-Herzegowina. ${ }^{131}$ Die Verfasser erklären das ICTY für einen Prozess gegen Alija Izetbegović zuständig und führen Beweise für Kriegsverbrechen in Ćelebići und auf dem Gebiet Konjic an. Besonders wird die Verantwortung für Vorgesetzte in der Befehlskette gemäß ICTY-Statut betont. Spätestens dieser Hinweis zeigt auf, dass der zehnte und ebenso der vorhergehende Bericht als Versuche gewertet werden können, das Tribunal auch für eigene Zwecke politisch nutzbar zu machen. Weiterhin besteht der Rapport aus fünf Unterberichten über Völkermorde an Serben im Lager Lora in Split, den Völkermord an der serbischen Bevölkerung von Kupres, die Tötung der Zivilbevölkerung in Kozarska Dubica, das Leiden der Serben im Lager Dretelj und das Lager der ehemaligen JNA-Kaserne 27. Juli in Bihać. ${ }^{132}$

\section{Der Kosovokrieg und die Bombardierung Jugoslawiens}

Nach dem vermeintlichen Massaker von Raçak, wo internationale Beobachter die Leichen von 45 kosovo-albanischen Zivilisten gefunden zu haben glaubten ${ }^{133}$ nahm der internationale Druck auf die Bundesrepublik Jugoslawien mas-

131 Bundesregierung der Republik Jugoslawien: Odgovornost Alije Izetbegovića za ratne zločine u logoru Čelebići i na području Konjica [Die Verantwortung Alija Izetbegović' für Kriegsverbrechen im Lager Ćelebići und auf dem Gebiet Konjic], 1998, http://www.slobodan-milosevic.org/documents/reports/Serbian/alija.htm vom 21.1.2013.

132 Ebd.

133 »Deutlich ist zumindest, dass weder im Januar 1999 noch zu Beginn der NATOBombardements klar war, was in Račak/Reçak wirklich passiert war. Und anscheinend ist es bis heute nicht geklärt. Es hat den Anschein, dass sowohl die serbische als auch die OSZE-Seite einiges zu verbergen beziehungsweise ein Interesse an einem bestimmten Bild der Vorgänge hatte. So viel scheint klar: Der befestigte Ort ist umkämpft gewesen, die Grenze zwischen UÇK-Kämpfern und Zivilisten ist im Nachhinein schwer zu ziehen, aber es sind offenbar Zivilisten getötet worden. Ob sie allerdings ermordet wurden oder im Verlauf der Kämpfe versehentlich getötet wurden, ließ sich bisher nicht feststellen. Durch die enge Verbindung der Dorfbevölkerung zur UÇK sind deren Äußerungen mit Skepsis zu behandeln, was eine Aufklärung zusätz- 
siv zu. Während sich der öffentliche Diskurs in den Mitgliedsländern der NATO in Richtung einer Intervention bewegte, für die das Massaker von Račak als Rechtfertigung herangezogen wurde, ${ }^{134}$ blieben die weiterhin geführten Friedensverhandlungen ergebnislos. Zeitgleich führte das Büro der ICTY-Chefanklägerin Louise Arbour eine großangelegte Kampagne gegen die Bundesrepublik Jugoslawien, um auf die Nichtkooperation des Landes mit dem Tribunal aufmerksam zu machen.

Im Februar 1999 reichte Jugoslawien erneut eine Erwiderung beim Internationalen Gerichtshof in der Genozidklage Bosnien-Herzegowinas ein. Während die für das Gericht formulierten Vorlagen denen des Counter-Memorial von 1997 entsprechen, hielten die Schlussfolgerungen nun fest, dass der Antragsteller die Genozidkonvention verletze. Die Zerstörung der Serben als Gruppe sei ein Element des radikalen Islamismus. Weiterhin sei die Absicht, einen Völkermord zu begehen, von bosniakischen Tätern verbal ausgedrückt worden. Auf dem Territorium der Bundesrepublik Jugoslawien und durch seine Organe seien keine Verbrechen, wie in der Genozidkonvention beschrieben, verübt worden in Bosnien-Herzegowina hingegen träfe beides zu. Bosnien-Herzegowina sei demnach sowohl direkt als auch indirekt das Verbrechen des Völkermords anzulasten. $^{135}$

Im März scheiterten schließlich die Friedensverhandlungen von Rambouillet. Bis kurz vor der Unterzeichnung wurden die Kapitel 7 und 8 sowie Anhang B des Vertrages vor der serbischen Delegation geheim gehalten, die die freie Beweglichkeit und völlige Immunität der NATO in Jugoslawien umfassten und den Vertrag somit für die serbische Seite unannehmbar machten, da dies einer Kapitulation gleichgekommen wäre. ${ }^{136}$ Die Nichtunterzeichnung des

lich erschwert.« Polónyi, Carl: Heil und Zerstörung. Nationale Mythen und Krieg am Beispiel Jugoslawiens 1980-2004, Berlin: Berliner Wissenschafts-Verlag 2010, S. 348.

134 Vgl. Schwab-Trapp, Michael: Kriegsdiskurse: Die politische Kultur des Krieges im Wandel 1991-1999, Opladen: Leske + Budrich, 2002.

135 International Court of Justice: Application of the Convention on the Prevention and Punishment of the Crime of Genocide (Bosnia and Herzegovina v. Yugoslavia). Rejoinder of the Government of the Federal Republic of Yugoslavia vom 22.2.1999.

136 Aus serbischer Sicht drängten sich im unannehmbaren Vertragsentwurf von Rambouillet Parallelen zum Ultimatum Österreich-Ungarns 1914 an Serbien auf, das mit der Delegierung von Organen der K.u.k.-Regierung in der Untersuchung und Unterdrückung gegen die territoriale Integrität der Monarchie gerichteter »subversiver 
Vertrags durch die serbische Seite diente der NATO als Begründung für die am 24. März begonnene Bombardierung Jugoslawiens, die bis zum 3. Juni andauern sollte.

Im Kontext der Kriegshandlungen im Kosovo wurde am ICTY im Mai 1999 Anklage gegen den jugoslawischen Präsidenten Slobodan Milošević wegen Kriegsverbrechen, Verbrechen gegen die Menschlichkeit und Völkermords erhoben. Gleichzeitig richtetet sich die Anklaege wegen Verbrechen gegen die Menschlichkeit und Verletzungen von Kriegskonventionen auch gegen Milan Milutinović, Präsident Serbiens, Nikola Šainović, Premierminister Jugoslawiens, General Dragoljub Ojdanić, Generalstabschef der Armee der Bundesrepublik Jugoslawien, und Vlajko Stojilković, den Innenminister Serbiens. Damit wurde die gesamte Führungsriege des Landes von einem internationalen Gericht schwerster Verbrechen beschuldigt. In Reaktion auf die Anklageerhebung bezeichnete der jugoslawische Außenminister das ICTY als Tribunal der NATO und als Instrument der US-Außenpolitik.

Entsprechend verwundert es kaum, dass seit Beginn der NATO-Bombardierung neben Protesten ${ }^{137}$ gegen das Militärbündnis nicht nur unzählige Schriften veröffentlicht wurden, die sich gegen die NATO wendeten, ${ }^{138}$ sondern auch das ICTY in den Fokus nahmen. In dem von der Vereinigung der Serben aus Bosnien-Herzegowina in Serbien und dem Literaten Duško M. Petrović herausgegebenen Sammelband »NATO $i \mathrm{Hag}$ " (NATO und Haag = NATO und das ICTY), der im Mai/Juni 1999 veröffentlicht wurde, ist vom Missbrauch des internationalen Rechts, der Verurteilung durch »übergeordnete Völker«, kriegerischer Aggression als Geschäft, dem Gesetz des Dschungels, also des Stärkeren, und der »Fabrik der Unwahrheit« zu lesen. Aus den Beiträgen spricht Verbitterung und Enttäuschung über Institutionen wie das Recht und die Verwehrung von Gleichbehandlung. Während die eigene Position der Wahrheit entspricht,

Bewegungen« eine ähnliche Beschneidung staatlicher Souveränität auf serbischem Territorium forderte. Vgl. den Text des Ultimatums im Schreiben von Graf Berchtold an Freiherrn von Giesl in Belgrad vom 20. Juli 1914, in: Staatsamt für Äußeres in Wien (Hg.): Die Österreichisch-Ungarischen Dokumente zum Kriegsausbruch, Wien: Europäischer Geschichtsverlag 2012, S. 53.

137 Vgl. zu den Anti-NATO-Protesten Jansen, Stef: »Victims, Underdogs and Rebels. Discursive Practices of Resistance in Serbian Protest«, in: Critique of Anthropology 20 (2000) 4, S. 393-420.

138 Eine vom serbischen Informationsministerium zusammengestellte Liste von englischsprachiger Literatur vom Dezember 1999 findet sich auf http://nointervention.com/ archive/Yugoslavia/www.serbia-info.com/news/2000-01/05/16625.html vom 13.5.2013. 
gilt die Lüge des Anderen als Mittel des Stärkeren zur widerrechtlichen und unmoralischen Durchsetzung seiner Interessen mit Gewalt. Das ICTY wird in diesem Kontext zum Instrument der NATO beziehungsweise der USA, zur rechtlich-moralischen Legitimation ihrer Absichten. Weiterhin verweist der Band skandalisierend darauf, dass Jugoslawien mit uranhaltiger Munition bombardiert worden sei, und spekuliert, ob es nicht bereits seit Oktober 1998 Überfallspläne der NATO auf Jugoslawien gegeben habe. ${ }^{139}$

Während und kurz nach der NATO-Bombardierung der Bundesrepublik Jugoslawien 1999 veröffentlichte das Bundesaußenministerium auf englisch zwei Weißbücher über die Verbrechen der NATO in Jugoslawien, die die Zerstörungen, Schäden, Verletzten und Todesopfer des Bombardements in Bild und Wort dokumentierten und einordneten. Band eins umfasst Vorkommnisse vom Beginn der Bombardierungen am 24. März bis zum 24. April, Band zwei die Periode bis zum Ende der Bombardierungen am 10. Juni. Rodoljub Etinski, Chefjurist im Bundesaußenministerium, ${ }^{140}$ erklärte im Vorwort zum zweiten Band klar die Sicht der Regierung auf die NATO-Bombardierung, die ein Mittel zur Durchsetzung der Interessen der NATO-Mitgliedsstaaten gewesen sei:

»The committed crimes cannot be justified at all. Those were premeditated crimes. The aggression against the FR of Yugoslavia had been planned several months in advance. The targets were selected a few months before. Furthermore, by presenting an unacceptable text for the alleged Rambouillet Agreement which implied an occupation of all of the FR of Yugoslavia (Chapters II, V and VII), anti-Serb and anti-Yugoslav propaganda in the most influential media provided the needed excuse for the impending aggression. It is more than obvious today that the true reason for NATO aggression was geo-strategic expansion of NATO interests and those of some of its Member States, i. e. the setting of a precedent for aggression, for the use of force contrary to the Charter of the United Nations and without the authorization of the UN Security Council. There is no statute of limitations for the committed crimes in a legal and moral sense. Those responsible for them should not be exonerated. This White Book testifies to their responsibility. ${ }^{141}$

139 Petrović, Duško M. (Hg.): NATO i Hag [Die NATO und das ICTY] (= Edicija Tribina 1), Belgrad: Udruženje Srba iz BiH u Srbiji 1999.

140 Rodoljub Etinski war schon seit der Klage Bosnien-Herzegowinas vor dem Internationalen Gerichtshof als juristischer Vertreter des Milošević-Regimes auf internationaler Ebene in Erscheinung getreten.

141 Federal Ministry of Foreign Affairs of the Federal Republic of Yugoslavia: NATO crimes in Yugoslavia: Documentary evidence, 25 April-10 June 1999, Bd. 2, 
Nach außen zeigte sich die jugoslawische Regierung weiterhin wehrhaft und reichte Ende April Klage vor dem Internationalen Strafgerichtshof gegen die NATO-Mitgliedsstaaten USA, Großbritannien, Spanien, Portugal, Niederlande, Italien, Deutschland, Frankreich, Kanada und Belgien ein, um die Legalität der Gewaltanwendung gegen Jugoslawien überprüfen zu lassen. Mit den recht knapp formulierten und auf das juristisch Nötigste beschränkten Klagen war ein Antrag auf eine einstweilige Verfügung verbunden, jegliche Gewaltanwendung sofort zu unterbinden, bis ein Urteil gefällt worden sei. ${ }^{142}$

In der innerserbischen Öffentlichkeit erfuhr der alternative Diskurs der Elite des »anderen Serbien« im Zuge der nunmehr drei Monate dauernden Bombardierung des Landes eine gewisse Aufmerksamkeit. Diese Vorreiter in der kritischen Auseinandersetzung mit der autoritären Herrschaft des Milošević-Regimes bezogen seit Jahren Position gegen die nationalistische Politik und für die Aufarbeitung von Kriegsverbrechen und traten nun wieder verstärkt in die Öffentlichkeit. 27 von ihnen organisierten sich in einem »Appell besorgter serbischer Bürger« und riefen alle Konfliktparteien dazu auf, Zivilität vorherrschen zu lassen und jegliche Gewaltwendung einzustellen. ${ }^{143}$ In einem Appell an die Regierungen und Parlamente Jugoslawiens, Serbiens und Montenegros forderten 22 Organisationen der Zivilgesellschaft ${ }^{144}$ eine friedliche Lösung des Kosovokriegs und zeichneten eine andere Zukunftsvision Serbiens als das Milošević-Regime:

Belgrad: Federal Ministry of Foreign Affairs of the Federal Republic of Yugoslavia 1999, S. 5.

142 Durch neue Provisorien wurde das Mandat des Komitees für die Sammlung von Daten über begangene Verbrechen gegen die Menschlichkeit und das internationale Recht passend zu der neuen Klage erweitert. Der Untersuchungszeitraum wurde bis 1999 ausgedehnt, nun sollte auch die »die Vorbereitung, Anstiftung, Unterstützung und Aufrechterhaltung der NATO-Aggression gegen die Bundesrepublik Jugoslawien « in den Blick genommen werden. Der Ausschuss arbeitete offiziell bis zu seiner Abschaffung im Jahr 2003. Im April 2009 wurde das Archiv der Kommission an die für die Verfolgung von Kriegsverbrechen zuständige Staatsanwaltschaft übergeben. Vgl. Bekan, Milan: »Dekontaminacija vredne dokumentacije« [Dekontaminierung einer wertvollen Dokumentation], in: Pravda u tranziciji 5 (2009) 13, http://www. tuzilastvorz.org.rs/html_trz/\%28CASOPIS\%29/SRP/SRP13/2191.pdf vom 10.9.2010.

143 Vgl. o. V.: O. V.: Let Civility Prevail. A Statement of Concerned Serbian Citizens, in: balkansnet.org vom 16.4.1999, http://balkansnet.org/wib/stats/civility.html vom 30.1.2013.

144 Darunter waren der Verein der Bürger für Demokratie, soziale Gerechtigkeit und die Unterstützung für Gewerkschaften, die Vereinigte Branchengewerkschaft Nezavis- 
»Extreme positions and radicalisation of the conflict will only lead to more suffering. It is high time that from the vantage of political realism and wisdom solutions be found which would make possible a European future for Yugoslav society and its peoples. That is Serbia's only national interest. ${ }^{145}$

Ende Mai veröffentlichte Vreme ein Gespräch von Borka Pavićević vom Zentrum für kulturelle Dekontamination mit der kroatischen Autorin Slavenka Drakulić über ihre Verantwortung für die Kriege in den 90ern, in dem sie die aus ihrer Sicht konkreten gegenwärtigen Probleme und Notwendigkeiten benannten. Pavićević sagte darin: »So wie du für die Serben in der Krajina Verantwortung fühlst, so fühle ich mich verantwortlich für Sarajevo und Vukovar. " ${ }^{146}$ Drakulić bezeichnete die Albaner als moderne Juden, Pavićević sah einzig in der Anerkennung der Aussage »Ich bin mitverantwortlich für das hier « ${ }^{147}$ eine Möglichkeit zur Lösung. Die Kroatin räumte ein, dass man am Beispiel der Deutschen sehe, dass man dafür fünfzig Jahre brauche. Pavićević kritisierte die Identifizierung der Nation mit dem Staat, wie sie die Politik betreibe, und die Gewaltanwendung, die diese Politik nur verlängern würde. Ihrer Meinung nach müsste man die zehnjährige Geschichte des Landes »kathastasieren«. Drakulić zog erneut den deutschen Fall heran - auch hier habe nur Gewalt in Form von Bombardierung und Besetzung eine Denazifizierung einleiten können. Implizit wird hier ein ähnlicher Verlauf des serbischen Falls erhofft. Die von den beiden Intellektuellen verwendeten Konzepte einer Aufarbeitung der Vergangenheit und

nost [Unabhängigkeit], die Europäische Bewegung in Serbien, die Bürgerlichen Initiativen, das Forum für ethnische Beziehungen, das Zentrum für die Transition zur Demokratie, das Centrum für Demokratie und freie Wahlen, Distrikt 0230 (Kikinda), das Helsinki-Komitee für Menschenrechte, Frauen in Schwarz, das Belgrader Zentrum für Menschenrechte, die Studierendenunion Serbiens, VIN - Wöchentliche Video-Nachrichten, die Gruppe 484, Anwaltskomittee für Menschenrechte, die Stiftung für Frieden und Krisenmanagement, Urban Inn (Novi Pazar), der Belgrader Zirkel, die Union für die Wahrheit über den Antifaschistischen Widerstand, die Friedensgruppe Sombor, die Gesellschaft für Frieden und Toleranz (Bačka Palanka) und das Alternative Akademische Bildungsnetzwerk.

145 O. V.: To the Governments of the FRY, Serbia and Montenegro; To the Parliaments of the FRY, Serbia and Montenegro, in: balkansnet.org vom 10.5.1999, http://balkansnet. org/wib/stats/tofry.html vom 30.1.2013.

146 Pavićević, Borka/Drakulić, Slavenka: »Sučeljavanja. Dželati i žrtve« [Die Debatten. Henker und Opfer], in: Vreme vom 29.5.1999, S. 10.

147 Ebd. 
des Umgangs mit Schuld zeigen deutlich den immer wieder hergestellten Bezug auf das deutsche Beispiel. Neben den Schlüssen aus der Analyse der unterschiedlichen Fälle übernahmen sie die Parallelisierungen der Opfer als Juden und der Täter als Nazis aus dem internationalen Diskurs.

Am 2. Juni wies der Internationale Gerichtshof die Klage der Bundesrepublik Jugoslawien gegen die USA mit der Begründung ab, dass er nicht bevollmächtigt sei. Den Antrag einer einstweiligen Verfügung zur Einstellung der Gewaltanwendung lehnte er in allen Fällen ebenfalls aufgrund mangelnder Entscheidungsbefugnis ab. Das Gericht begründete, eine Zuständigkeit prima facie träfe hier nicht zu, da unklar sei, ob beide Konfliktparteien auch unter der UN-Charter und damit dem Statut des Internationalen Gerichtshofs handelten. Während die Richter 1999 in Frage stellten, ob die NATO-Mitgliedsstaaten, da sie ohne UNMandat handelten, unter dem Statut agierten, prüften sie nur in den Fällen, in denen auch die Beklagten volles Mitglied der Völkermordkonvention waren, die Klage weiter. 2004 befand der Internationale Gerichtshof, zugebend, dass sich seine Meinung geändert habe, dass er schon 1999 keine Zuständigkeit gehabt hätte, da die Bundesrepublik Jugoslawien zu dem Zeitpunkt, als der Antrag gestellt wurde, ohnehin kein Mitglied der UN und damit des Statuts gewesen sei.

Am 3. Juni, einen Tag nach der Abweisung der Zuständigkeit seitens des Internationalen Gerichtshofs und nach drei Monaten Bombardierung durch die NATO, stimmten die jugoslawische Regierung und das serbische Parlament einem Friedensplan zu. Das militärtechnische Abkommen von Kumanovo regelte den Abzug der jugoslawischen und serbischen Einheiten aus dem Kosovo. Am 10. Juni endete die Bombardierung Jugoslawiens. Entgegen der augenscheinlichen Realität erklärte Milošević den Sieg gegen die NATO, ignorierte die UNResolution 1244, der zufolge das Kosovo formal Teil Jugoslawiens blieb, aber unter die Verwaltung der UN gestellt wurde, und kündigte ein umfassendes Wiederaufbauprogramm an.

In der Folge des Kosovokriegs und der NATO-Bombardierung wurden in der jugoslawischen Öffentlichkeit die Tragödie »Kosovo« und die Frage nach ihren Verursachern diskutiert. Miloš Minić, der nach der Befreiung von der deutschen Okkupation die Geheimpolizei OZNA in Belgrad leitete, die auch für die Verfolgung und Liquidierung von Kriegsverbrechern zuständig war, und der später jugoslawischer Außenminister wurde, forderte in einem über die Nachrichtenagentur Beta verbreiteten offenen Brief den Rücktritt der Regierungen Serbiens und Jugoslawiens und ihrer Präsidenten sowie eine rigorose Aufklärung der im Kosovo begangenen Kriegsverbrechen. Er wandte sich direkt an Milošević, der das bestinformierte Individuum bezüglich all dieser Fragen sei. Keine Autorität hätte das Recht, die Frage nach Kriegsverbrechen und -verbrechern abzuwehren, 
auch müssten jugoslawische Gerichte diese Verbrechen behandeln, bevor es das das Tribunal in Den Haag täte. Er beschuldigte Milošević, »das Ergebnis Ihres großserbischen Hegemonismus ist das präzedenzlose Leiden der Menschen in unserem glücklosen Land « ${ }^{148}$. Minić führt fort,

»in den Augen der Kosovo-Albaner, der Welt und der europäischen Öffentlichkeit, wird das ganze serbische Volk schuldig sein, bis diejenigen, die Kriegsverbrechen befohlen und ausgeführt haben, aufgespürt und verurteilt sind « ${ }^{149}$.

Auch Kroatien forderte Gerechtigkeit für die von der Bundesrepublik Jugoslawien zu verantwortenden Kriegsverbrechen während des Kroatienkrieges. Es reichte seinerseits Klage bezüglich der Anwendung der Genozidkonvention beim Internationalen Gerichtshof ein.

Im Oktober erschien nach achtmonatiger Pause die angesehene Literaturzeitschrift Reč (Wort) wieder. Wie in ihrer Onlineausgabe bereits angekündigt worden war, nahm sie den Kosovokrieg und die Bombardierung der Bundesrepublik Jugoslawien zum Anlass, einen Kurswechsel vorzunehmen. Indem nunmehr die sozialen Themen in den Mittelpunkt gestellt würden, wolle man einen Diskurs eröffnen, in dem die zentralen Fragen nach der Zukunft des Lebens und Wirkens von Schriftstellern, Lesern und der serbischen Gesellschaft Raum fänden. ${ }^{150}$ Gleich die erste Ausgabe titelte hoffnungsvoll mit »Ende des serbischen Unglücks?«. In ihr reflektierten serbische Autoren darüber, wie man aus diesem Krieg herauskommen könne, was man für eine erfolgreiche Transition brauche, darüber, was man im Krieg gemacht habe und wie eine Denationalisierung aussehen könne. Ausländische Intellektuelle wie Vaclav Havel, Susan Sontag, Daniel Goldhagen, Jürgen Habermas, Maria Todorova und Edward Said meldeten sich zu Wort. In ähnlicher Manier wurden in den folgenden Ausgaben der nunmehr halbjährlich erscheinenden Zeitschrift die Themen Geschichtsschreibung, Schuld und Verantwortung, Identität und Wahrheit in den Mittelpunkt der Auseinandersetzung gestellt und bereiteten intellektuell die Transition des Landes vor. Auch das Helsinki-Komitee für Menschenrechte nahm das Programm Sou-

148 Minić, Miloš: »Who Caused Kosovo Tragedy. Open letter from Milos Minic to Slobodan Milosevic«, in: Pobjeda vom 24.6.1999, http://www.ex-yupress.com/pobjeda/ pobjeda3.html vom 6.5.2013.

149 Ebd.

150 Ilić, Dejan: »Zašto »Reč«, ponovo?« [Warum erneut >Reč^?], in: Reč. Časopis za književnost, kulturu i društvena pitanja, Online-Ausgabe vom Mai/Juni 1999, http://www.b92.net/casopis_rec/arhiva/ilic.html vom 29.1.2013. 
čavanje sa prošlošču/istinom (Konfrontation mit der Vergangenheit/Wahrheit) auf, das in den folgenden Jahren zu seinem Arbeitsschwerpunkt wurde. Es zielt darauf, ein öffentliches Bewusstsein zu schaffen für die Ursachen und Folgen des Zerfalls Jugoslawiens, die Strafwürdigkeit der Verbrechen, die im Namen der Nation begangen wurden, Lustration und die Notwendigkeit, ein »moralisches Minimum « für die Normalisierung und Bereitschaft der Gesellschaft zu erreichen, das Erbe des Regimes und des Nationalismus zu überwinden. ${ }^{151}$

In diesem Rahmen veröffentlichte das Komitee regelmäßig die Helsinška povelja (Helsinki-Bulletins), hielt regelmäßig Podiumsdiskussionen ab und verlegte zahlreiche Bücher und Filme.

Nach den Luftschlägen der NATO, erneuten Sanktionen und dem Verlust des Kosovo, angesichts des negativen internationalen Ansehens des Landes und insbesondere aufgrund der schlechten sozioökonomischen Lage äußerten breite Teile der serbischen Bevölkerung ihre Enttäuschung und ihren Unmut zunehmend lauter, auch die Beiträge der nicht vom Regime kontrollierten Medien wurden zunehmend kritischer. Die Legitimationskrise Milošević' nutzten die Vertreter der Opposition und organisierten ab September 1999 Proteste gegen das Regime auf den Straßen Belgrads, die im Dezember langsam abebbten.

Dem in diese Zeit fallenden zehnten Jahrestag der Regierung Slobodan Milošević' auf serbischer und jugoslawischer Ebene widmete die Wochenzeitschrift Vreme Ende November einen zynischen Artikel. Redakteur Dragoslav Grujić beschrieb darin die widersprüchlichen Realitäten, mit denen er sich konfrontiert sah:

»Helden, Verbrecher und Verräter: Slobodan Milošević ist der erste Staatschef, der der Kriegsverbrechen beschuldigt wird, während er sich noch in seiner Funktion befindet. Während die Beamten des Haager Tribunals die Erweiterung der Anklage ankündigen, schlagen die einheimischen Verteidiger Milošević als nationalen Helden vor. Die Patrioten betonen, dass ihr oberster Kommandant diese große Anerkennung mit seinem außerordentlichen Mut und seiner staatsmännischen Weisheit in der Verteidigung der territorialen Integrität und Souveränität der Bundesrepublik Jugoslawien verdient‘, der sich `als würdiger Nachfahre der ruhmvollen Helden und Heroen des Befreiungskrieges heroisch gegen die Babaren der NATO gestellt hat, geführt von den Schurken Amerikas und des Westens.$^{152}$

151 Helsinški odbor za ljudska prava u Srbiji: Helsinški odbor. Misija i strategija [Helsinki-Komitee. Mission und Strategie], http://www.helsinki.org.rs/serbian/onama. html vom 11.4.2013.

152 Grujić, Dragoslav: »Godina bombardovanja, heroja i izdajnika« [Die Jahre der Bombardierungen, Helden und Verräter], in: Vreme vom 27.11.1999, S. 18 f. 
Als eine Art ambivalenter Beleg des »heroischen Kampfes« wurde im Dezember 1999 eine Ausstellung zur NATO-Bombardierung im Jugoslawischen Luftfahrtmuseum eröffnet.

\section{Denazifizierung?}

Im Winter 2000 wurde das Schlagwort der »Denazifizierung« zunehmend salonfähig im öffentlichen Diskurs Serbiens. Sonja Biserko vom Helsinki-Komitee für Menschenrechte in Serbien formulierte sogar den Eindruck, als sei

»die Frage der Denazifizierung in der letzten Zeit irgendwie ein Hit in Belgrad. An diesem Projekt arbeiten schon Radio B2-92, darüber spricht man sogar bereits in der NIN, und auch Đinđić hat vor einigen Tagen in Amerika über Schuld gesprochen. « ${ }^{153}$

Anfang März organisierten Radio B2-92, die Heinrich-Böll-Stiftung und das Büro der OSZE die internationale Konferenz Istine, odgovornosti i pomirenja. Srbija pred izazovom suočavanja s proslošću (Wahrheiten, Verantwortungen und Versöhnungen. Serbien vor der Herausforderung der Vergangenheitsaufarbeitung) im montenegrinischen Ulcinj. Über sechzig Teilnehmer aus der ganzen Welt und allen Ländern der Region versammelten sich, um über die Wahrheit der Kriege 1991-1999 auf dem Gebiet des ehemaligen Jugoslawien und die in dieser Zeit begangenen Verbrechen, die Verantwortung und Schuld der Gesellschaften und des Einzelnen für diese Kriege und Verbrechen zu sprechen, über die Möglichkeit einer Normalisierung des Lebens in der Region sowie über die Bedingungen für eine mögliche Versöhnung zwischen den Völkern des ehemaligen Jugoslawien. ${ }^{154}$ In Serbien wurde die Tagung zunächst zum Anlass genom-

153 Ninčić, Roksanda: »Intervju: Sonja Biserko: O vlasti, opoziciji, crkvi i denacifikaciji« [Interview: Sonja Biserko: Über die Regierung, die Opposition, die Kirche und Denazifizierung], in: Vreme vom 12.2.2000, S. 23 ff.

154 Vgl. ausführlicher den Tagungsbericht: Gojković, Drinka: Istine, odgovornosti i pomirenja [Wahrheiten, Verantwortungen und Versöhnungen], in: Republika XII (2000) 235, http://www.yurope.com/zines/republika/arhiva/2000/235/235_21.html vom 30.1.2013. Die Konferenzhomepage existiert weiterhin und hält auch die Sonderausgabe der Reč unter dem Titel »Krivica i odgovornost« [Schuld und Verantwortung] vor, vgl. B92: Istina, odgovornosti i pomirenja: Srbija pred izazovom suočavanja s prošlošću [Wahrheiten, Verantwortungen und Versöhnungen. Serbien vor der Herausforderung der Vergangenheitsaufarbeitung], Homepage der Konferenz vom 17.-19.3.2000 in Ulcinj, http://www.b92.net/trr/trr.html vom 11.5.2013. 
men, um die Bevölkerung für die Notwendigkeit einer Auseinandersetzung mit diesen Themen zu sensibilisieren:

»Eine öffentliche Debatte in Serbien über die Verbrechen in den vergangenen Kriegen gibt es nicht. In dieser Hinsicht, wie jemand sagt, ist Serbien ein Land voller Verwirrung: Halbwahrheiten, Wahrheiten, Lügen. Wie sehr sind wir verantwortlich, dass wir geschwiegen haben über Sarajevo, Ovčara, die Dörfer rund um Prizren? Das Regime hat jegliche Verantwortung für die Gewalt, den Terror und die Zerstörung verweigert, die offizielle Version ist immer gleich: Serbische Kräfte verteidigen nur das serbische Volk. « ${ }^{155}$

Dementsprechend fand im Mai 2000 eine an die Konferenz von Ulcinj anschließende zweite internationale Konferenz in Belgrad statt, die unter dem Thema $U$ potrazi za istinom i odovornošću - ka demokratskoj budućnosti (Auf der Suche nach Wahrheit und Verantwortung-der demokratischen Zukunft entgegen) stand und auf der die Beispiele erfolgreicher Wahrheits- und Versöhnungskommissionen diskutiert wurden. ${ }^{156}$ Auf beiden Konferenzen waren auch Aktivisten, wie der Architekt der südafrikanischen Wahrheits- und Versöhnungskommission Alex Borraine, anwesend. Die Zeitschrift Reč widmete den Vorträgen und Ergebnissen der Konferenz ihre März- und Oktoberausgabe mit dem Schwerpunkt Schuld und Verantwortung. In ihnen wurden auch Originaltexte von Hannah Arendt (Organisierte Schuld und universelle Verantwortung und Auszüge aus Eichmann in Jerusalem) und Theodor W. Adorno (Was heißt: Aufarbeitung der Vergangenheit?) abgedruckt, B92 verlegte begleitend in der Edition Samiszdat Karl Jaspers Schuldfrage.

Die gegenläufige Einstellung zur Bearbeitung von Kriegsverbrechen wurde in den Äußerungen des Vertreters des Milošević-Regimes gegenüber dem ICTY deutlich, das sich nur noch durch Repressionen und aggressives Auftreten nach innen an der Macht halten konnte. Auf einen Brief der Chefanklägerin Carla Del Ponte an den jugoslawischen Justizminister von der SRS, in dem sie ihn um die Unterstützung bei der Strafverfolgung und um behördliche Zusammenarbeit bat, bekam sie am 24. Mai schriftlich eine ganz und gar undiplomatische Antwort,

155 Ast, Slobodanka: »Istina - odgovornost - pomirenje. Da li su Srbi krivi?« [Wahrheit Verantwortung - Versöhnung. Sind die Serben schuld?], in: Vreme vom 25.3.2000, S. 11-14.

156 Vgl. die Konferenzdokumentation unter http://www.b92.net/trr/eng/index.html. Auch aus dieser Konferenz ging eine Sonderausgabe der Reč unter dem Titel »Viđenje istine u Srbiji« [Das Sehen der Wahrheit in Serbien] hervor, zudem ein Buch, vgl. D. Ilić/V. Matić: Truths, Responsibilities, Reconciliations. 
die die Beziehungen des Milošević-Regimes zum ICTY zu dieser Zeit zu charakterisieren vermag. Darin sah sich Petar Jojić auf der Seite des Rechts, während er die Chefanklägerin des Unrechts und der Unmoral bezichtigte, da sie »heimtückische Absichten« habe:

»Im Unterschied zu Ihnen respektiere ich das Völkerrecht, insbesondere die Verantwortung für internationale Verbrechen; ich möchte Sie davon in Kenntnis setzen, dass es Menschen gibt, die sich nicht kaufen lassen und nicht mit Füßen treten, was sie auf der Universität gelernt haben, die an Gott glauben und nicht das Blut unschuldiger Opfer an [den, D. M.] Händen haben. Die Brutstätte, die Sie leiten, die Brutstätte, in der Sie sich wie eine billige Hure an die Amerikaner verkauft haben, die Brutstätte, in die Sie, nicht einmal vor Mord zurückschreckend, mit Gewalt unschuldige Serben verschleppen, das sogenannte Haager Tribunal, ist eine illegale Institution, gegründet unter Missachtung der Bestimmungen der Charta der Vereinten Nationen und des gesamten Völkerrechts [...]. Früher oder später werden auch Sie der Wahrheit ins Gesicht sehen müssen, Ihre Taten werden ans Licht kommen, und Sie werden den Rest Ihres verdorbenen Lebens hinter Gittern verbringen. ${ }^{157}$

Der Brief endete mit dem Apell, die für die NATO-Bombardierung Verantwortlichen vor Gericht zu stellen. Jojić forderte damit eine objektive Strafverfolgung, die auch den illegitimen Gewalteinsatz der Operation Allied Force umfassen sollte und damit die den Einsatz unterstützenden Staatschefs, insbesondere Bill Clinton und Tony Blair, vor Gericht zu stellen.

Im Sommer 2000 schwand die Unterstützung für Milošević in der jugoslawischen Bevölkerung zusehends. Nachdem eigentlich seine Amtszeit als Präsident Jugoslawiens auslaufen sollte, veränderte er die Regeln, um seine Wiederwahl zu ermöglichen.

Die vorgezogenen Präsidentschaftswahlen fanden gemeinsam mit den Wahlen für das Oberhaus des Bundesparlaments und den Lokalwahlen statt. Der Bundeswahlausschuss stellte bei den Wahlen am 24. September allerdings fest, dass kein Kandidat für die Präsidentschaftswahl über die erforderlichen fünfzig Prozent der Stimmen gekommen und damit eine Stichwahl zwischen Milošević und dem Kandidaten der Opposition Vojislav Koštunica ${ }^{158}$ von der Demokratska

157 Zit. nach Del Ponte, Carla: Im Namen der Anklage. Meine Jagd auf Kriegsverbrecher und die Suche nach Gerechtigkeit, Frankfurt am Main: S. Fischer 2009, S. 84 f.

158 Die Demokratische Opposition Serbiens hatte sich unter amerikanischer Beratung auf Koštunica als aussichtsreichsten Konsenskandidaten für die Wahl gegen Milošević geeinigt. Vuk Drašković und Zoran Đinđić ordneten sich dem unter. 
Stranka Srbije (Demokratischen Partei Serbiens, DSS) nötig sei. Die Diskrepanz zwischen den offiziellen Ergebnissen und den Ergebnissen unabhängiger NGOs, die sich der Wahlbeobachtung verpflichtet hatten, sorgten für großangelegte öffentliche Proteste. Die sogenannte Baggerrevolution ${ }^{159}$ am 5. Oktober 2000 erzwang schließlich den Rücktritt von Slobodan Milošević. ${ }^{160}$

\section{Zwischenfazit}

Bevor der Charakter der Transition 2000 thematisiert wird, um die Voraussetzungen für die verschiedenen Instrumente der Vergangenheitsaufarbeitung nach der Transition zu beleuchten, fasse ich zuvor die wichtigsten Erkenntnisse der Aufarbeitungsbemühungen im Milošević-Regime zusammen.

Während die jugoslawische Regierung mit der Einrichtung der Kommission zur Sammlung von Daten zur Feststellung der Verbrechen des Völkermords und anderer Verbrechen gegen die Menschlichkeit, begangen an der Bevölkerung serbischer und anderer Nationalitäten in der Zeit des bewaffneten Konflikts in Kroatien und in anderen Teilen des Landes zunächst versuchte, mit der Kommission auf Bundesebene ein ethnisch neutrales Medium einzurichten, wurde sie schnell als strategisches Instrument verstanden. Wo noch Ende 1992 die Milošević treuen Medien den ersten Bericht der Kommission im Wahlkampf skandalisierten, wurde die Kommission vor dem Hintergrund der sich verändernden Konfliktdynamik, der Serbisierung des Innenministeriums, mit der Präsidentschaft Dobrica Ćosić' sowie der personellen und ideologischen Kontinuität der Arbeit des Genozid-Komitees an der Serbischen Akademie für Wissenschaft und Künste im weiteren Verlauf genutzt, um das serbische Opfertum zu untermauern, ein Gegennarrativ herzustellen und mit Verweis auf die Kriegsverbrechen der »Anderen « die serbische Konfliktdeutung und damit auch serbische Kampfhandlungen zu legitimieren. Dieses Muster erhielt sich bis zum letzten Bericht 1999 aufrecht. Der strategische Charakter der Berichte wird auch dadurch deutlich, dass sie mit fortschreitender Zeit vom Chefjuristen des Außenministeriums unterzeichnet wurden. Instrumente der Aufarbeitungsbemühungen, wie die Konferenz 1993 oder auch die Strafverfolgung von verdächtigten Kriegsverbrechern

159 Am 5. Oktober stürmten Tausende Demonstranten das Gebäude des Staatsfernsehens RTS in Belgrad, ein Symbol des Milošević-Regimes. Voran fuhr Ljubisav Đokić mit einem Schaufellader und bahnte der Menge den Weg. Đokić räumte die Betonblockaden vor dem Parlamentsgebäude zur Seite und hob dort Demonstranten in der Schaufel in den ersten Stock. Die Bilder gingen um die Welt.

160 Vgl. zur Transition 2000 insbesondere S. Nadjivan: Wohl geplante Spontaneität. 
1994, sollten auf internationaler Ebene den Eindruck von Normbefolgung erzeugen, blieben aber symbolischer Natur und selektiv in ihrem nationalisierten Gerechtigkeitsverständnis. Obwohl sich die jugoslawische Regierung im Duktus und ihrer Berichtspolitik an die Regeln der UN hielt und es auch eine - wenn auch sehr beschränkte - Kooperation mit dem ICTY gab, gelang es der serbischen Regierung und den Vertretern einer nationalistischen Politik nicht, das Thema der serbischen Opfer zu internationalisieren und die außerhalb des Balkans dominante Wahrnehmung der Jugoslawienkriege zu brechen. Zentrale Deutungsmuster auf internationaler Ebene waren vor allem die Völkermordklage Bosnien-Herzegowinas, die Berichte über serbische Lager und Vertreibungen durch Serben, die an die Erfahrungen aus dem Zweiten Weltkrieg anknüpften, das Massaker von Srebrenica sowie die ersten Urteile des ICTY. Auf die genozidale Dimension der Konflikte nahmen Politiker und Vertreter aus der Zivilgesellschaft teleologisch auch bei der Deutung der Kosovokrise Bezug.

Innenpolitisch wurden Ideen eines justiziellen, abschreckenden Aufarbeitungsinstruments schon in den Monaten der ersten Kriegshandlungen thematisiert. Und auch später nahm die serbische Presse Aufarbeitungsthemen wie durch Serben begangene Kriegsverbrechen, der Bericht der Expertenkommission oder die Entwicklungen zum und am ICTY wahr. Entsprechend ihrer Ausrichtungen berichtete Vreme erwartungsgemäß mehr und kritischer oder objektiver über solche Themen als zum Beispiel die vom Regime kontrollierten Medien. Doch auch in anderen Zeitungen fanden sich immer wieder kritischere Stimmen.

Wie auch die politische Elite positionierten sich Menschen- und Bürgerrechtsaktivisten der erst kurz zuvor gegründeten Organisation des zivilgesellschaftlichen Sektors schnell für oder gegen den serbischen Nationalismus und damit für oder gegen Krieg. Somit waren diejenigen, die Kriegsverbrechen dokumentierten und für eine Aufarbeitung plädierten, in unterschiedliche ideologische Lager aufgeteilt: diejenigen, die sich für die serbischen Opfer einsetzten, und diejenigen, die sich für die Opfer serbischer Gewalt engagierten. Während die erste Gruppe vor dem Hintergrund des Milošević-Regimes eine weithin legitime Position einnahm, war die zweite Gruppe zahlenmäßig marginal und phasenweise öffentlichen und staatlichen Repressionen ausgesetzt. In ihrer völligen Ablehnung des serbischen Nationalismus, der Regierung und ihrer Vertreter war jegliche Kooperation zwischen ihnen und Vertretern des Regimes oder auch nur gemäßigt nationalistischen Bürgern unmöglich. Sie verstanden sich als Radikalopposition und reproduzierten die dichotomische Konfliktwahrnehmung der internationalen außenpolitischen Diskurse. So wurden die im Ausland und von einheimischen zivilgesellschaftlichen Akteuren vertretenen Aufarbeitungskonzepte und -instrumente in den hegemonialen Deutungen im serbischen öffentli- 
chen Diskurs als Mittel des politischen Gegners und als dessen Instrument der Machtausübung dargestellt. Während die lokalen Aktivisten an internationale Diskurse über Vergangenheitsaufarbeitung anschlossen, trugen sie aufgrund ihres Rückzugs aus der Öffentlichkeit - oftmals gingen sie ins innere Exil oder zogen sich ins Ausland zurück - auch mit dazu bei, dass ihre Forderungen und Inhalte nicht breiter rezipiert wurden.

Erst im Zuge der Mobilisierung der Opposition und des Protests bildete sich ab 1997 eine breitere Gegenöffentlichkeit aus, die in der Schlussphase des Milošević-Regimes einen breiteren, gesamtgesellschaftlich aber immer noch nur auf Eliten beschränkten, Aufarbeitungsdiskurs etablierten. Vreme, Danas, $B 92$ und Reč widmeten internationalen Entwicklungen, Berichten aus nichtserbischer Perspektive und den zivilgesellschaftlichen Akteuren Raum, die sich mit anderen Fällen der Aufarbeitung von Krieg und autoritären Regimen befassten.

Die »Revolution« im Oktober richtete sich nicht per se gegen das MiloševićRegime oder gegen die Kriegsvergangenheit, sondern gegen die Person Milošević an sich, der für die schlechte ökonomische Lage und die erneute außenpolitische Isolierung sowie für die zunehmenden innenpolitischen Repressionen verantwortlich gemacht wurde. Die als Studentenorganisation begonnene NGO Otpor! (Widerstand!) wurde im Frühjahr 1999 zu einer Art allparteilichen Volksbewegung, der sogar der ehemalige Präsident Dobrica Ćosić, ein langjähriger Unterstützer Milošević', beitrat. Die Proteste waren hinsichtlich einer Positionierung gegenüber den Kriegen unpolitisch, so dass sowohl diejenigen Milošević' Rücktritt forderten, die ihm die nationalistische Politik und die blutigen Kriege in den Nachbarländern vorwarfen, als auch diejenigen, die ihm übel nahmen, als Verlierer aus den Kriegen hervorgegangen zu sein. Auch die Transition selbst war ausgehandelt, im Vorlauf des 5. Oktober gab es Absprachen zwischen führenden Politikern der Opposition und Vertretern der zentralen Machtbasen des Regimes, wie dem Militär, dem Geheimdienst und einer Spezialeinheit des Innenministeriums, den Crvene beretke (Roten Baretten). Vesna Pešić stellte zum zehnjährigen Jahrestag des 5. Oktobers 2010 sogar offen die Frage, ob es sich um eine Revolution oder einen Putsch der ehemaligen das Regime unterstützenden Kräfte gehandelt habe. ${ }^{161}$ Sie identifiziert drei Faktoren als zentral für die ausbleibende Modernisierung und demokratische Konsolidierung des Lan-

161 Pešić, Vesna: »Revolucija ili puč. Rekonstrukcija petooktobarskih zbivanja na osnovu memoarske i stručne literature« [Revolution oder Putsch. Rekonstruktion des Geschehens am 5. Oktober auf der Grundlage von Erinnerungs- und Forschungsliteratur], in: Republika XXII (2010) 490-491, http://www.republika.co.rs/490-491/20. html\#f16 vom 13.5.2013. 
des, die alle eine Kontinuität zu den 1990er Jahren darstellen. So sei es dem Wahlbündnis Demokratska Opozicija Srbije (Demokratischen Opposition Serbiens) auch als Regierungspartei nicht gelungen, eine klare Position zu Milošević und dessen Politik des Nationalismus und Kriegs zu definieren. Der Kampf zwischen den Oppositionsparteien um die neue Regierung habe das hybride autoritäre Regime in eine Mehrparteiendiktatur verwandelt, in der nicht das öffentliche Interesse oder eine neutrale Verwaltung im Vordergrund stünden, sondern die Interessen der Parteiführung und der Finanziers der Parteien. Darüber hinaus bildeten die nichttransformierten Staatsapparate, vor allem die Geheimdienste, ein intransparentes, informelles Zentrum der Macht. ${ }^{162}$

\subsection{Die Aufarbeitung von Kriegsverbrechen IM DEMOKRATISCHEN SERBIEN}

\section{Transitional Justice?}

Nach dem Rücktritt Milošević' wurde von den neuen, demokratischen Machthabern eine völlige Kooperation mit dem ICTY erwartet, obwohl die Regierung auch nach der »Revolution« noch bis zu den Parlamentswahlen Anfang Dezember in der Hand des alten Regimes lag. Schon bei seinem ersten Auftritt im Fernsehen am 6. Oktober 2000 machte der neue Präsident Vojislav Koštunica, der NATO und ICTY sehr kritisch gegenüberstand und ohne diese Positionen vermutlich nicht mehrheitsfähig gewesen wäre, deutlich, dass er die Verpflichtung, Staatsbürger der Bundesrepublik Jugoslawien an das Tribunal auszuliefern, als »Mittel der Ausübung des amerikanischen Einflusses und der Präsenz der NATO auf dem Balkan ${ }^{163}$ betrachtete. Für ihn sei das ICTY »das fünfte Rad am Wagen ${ }^{164}$. In einem Interview mit dem amerikanischen Sender CBS erklärte

162 Ebd.

163 Zit. nach Dimitrijević, Vojin: »Od pijanca i plota do devete rupe na svirali. Ljudska prava u Jugoslaviji i Srbiji, pre i posle novembra 1989. godine« [Vom Betrunkenen, der Umzäunung bis zum neunten Loch auf der Flöte. Menschenrechte in Jugoslawien und Serbien, vor und nach November 1989], in: Ivan Čolovićv (Hg.): Zid je mrtav, živeli zidovi! Pad Berlinskog zida i raspad Jugoslavije [Die Mauer ist tot, es leben die Mauern! Der Fall der Berliner Mauer und der Zerfall Jugoslawiens], Belgrad: Biblioteka XX vek 2009, S. 107-128, hier S. $121 \mathrm{f}$.

164 Im Original: »je deveta rupa na svirali«, wörtlich übersetzt: das neunte Loch auf der Flöte. 
Koštunica, dass die Kooperation mit dem ICTY eine Gefahr für die Demokratie und die Stabilität Serbiens sei. Allerdings zeigte er ein Bewusstsein für die Verbrechen während der Kriege: »I am ready to accept the guilt for all those people who have been killed. [...] For what Milošević had done, and as a Serb, I will take responsibility for many of these crimes. ${ }^{165}$

Erstmalig räumte ein serbischer Politiker ein, dass serbische Kräfte im Kosovo Verbrechen begangen hätten. Allerdings betonte Koštunica, dass es auch eine Menge Verbrechen auf der anderen Seite gegeben habe und dass »die Serben« getötet worden seien.

Eine kurz darauf durchgeführte Telefonumfrage der Zeitschrift NIN über das zukünftige Schicksal von Slobodan Milošević ergab, dass 53 Prozent der Befragten der Meinung waren, er müsse nicht vor Gericht gestellt werden, während ihn dreißig Prozent in Jugoslawien und neun Prozent in Den Haag vor Gericht sehen wollten. Gleichzeitig waren fast 68 Prozent überzeugt, dass er in kriminelle Aktivitäten verwickelt sei. 75 Prozent gingen fest davon aus, dass Milošević ein schlechter Präsident gewesen sei, und 81,5 Prozent befürworteten seinen Rückzug aus der Politik. ${ }^{166}$

Nur wenige Tage nach der erneuten Aufnahme Jugoslawiens in die UN äuBerte sich der jugoslawische Justizminister Momčilo Grubač über die Zusammenarbeit mit dem ICTY. Das Gericht sei objektiv, die Anklage hingegen ein politisches Instrument. Er erklärte, in einen politischen Dialog mit der Anklage treten zu wollen, um auch eigene politische Ziele zu erreichen. ${ }^{167}$ Konkret meinte er hier die Strafverfolgung von Kriegsverbrechen während der NATO-Bombardierung und solcher, die gegen die Genozidklagen Bosnien-Herzegowinas und Kroatiens nutzbar erschienen.

Der Journalist Batić Bačević griff in einem Artikel in der NIN die herbstliche Debatte zwischen »Humanisten und Nationalisten « auf, die entbrannt war, nachdem der zur Demokratischen Opposition gehörende Politiker Nenad Čanak äuBerte, ein balkanischer Willy Brandt sei nötig, »da sich Serbien nicht aufrichten

165 O. V.: »Kostunica admits Kosovo guilt«, in: BBC News online vom 24.10.2000, http://news.bbc.co.uk/2/hi/europe/988602.stm vom 13.2.2013.

166 Marković, Zoran M.: »Sudbina poraženog. Telefonska anketa: Šta sa Slobodanom Miloševićem?« [Das Schicksal des Besiegten. Telefonumfrage: Was wird aus Slobodan Milošević?], in: NIN vom 19.10.2000, S. 12 ff.

167 Boarov, Dimitrije: »Intervju: prof. dr. Momčilo Grubač, minister pravde SRJ: Samo se zakonu može robovati« [Interview: Prof. Dr. Momčilo Grubač, Justizminister: Nur dem Gesetz kann man frönen], in: Vreme vom 9.11.2000, S. 12 ff., hier S. 14. 
wird, bis jemand in Vukovar knien wird « ${ }^{168}$. Anschließend diskutierte Bačević die Frage, wer sich sich nun bei wem entschuldigen solle. Der »ultrabürgerliche« Teil, das heißt Intellektuelle und Vertreter der Zivilgesellschaft, habe auf Parallelen mit dem deutschen Fall hingewiesen, die Historiker nicht sähen. Auch habe der kroatische Präsident gefordert, Serbien solle sich offiziell bei Kroaten, Muslimen und Albanern entschuldigen und in den Anträgen dazu die Wörter Genozid, Holocaust und Agressionen nennen. Der Autor verweist auf die ausgebliebenen Entschuldigungen der amerikanischen Regierung nach dem Vietnamkrieg und der türkischen Regierung für den Völkermord an den Armeniern und die unterschiedlichen normativen Standards: Serbien gegenüber würden die Konzepte der kollektiven Verantwortung und Katharsis verwandt. Präsident Koštunica wies diese Einseitigkeit zurück, betonte die gemeinsame Vergangenheit der jugoslawischen Völker gegenüber den vergangnene zehn Jahren und betonte: »Ich unterscheide weder Verbrechen, noch Opfer oder menschliches Leiden danach, woher sie stammen. Uns befreit nur die Wahrheit, die sehr komplex ist. «" ${ }^{169}$

Zoran Đinđić, der sich gerade im Wahlkampf um das Amt des serbischen Premiers befand, urteilte, dass die Serben genug bezahlt hätten. Jetzt würde eine Linie gezogen und eine abschließende Rechnung aufgemacht, und die Serben als die Schuldigen für alles ausgemacht. Für ihn sei eine Entschuldigung im Trioalso der Vertreter Kroatiens, Bosnien-Herzegowinas und Jugoslawiens - vorstellbar, die man sich gegenseitig ausspreche und bei der man gleichzeitig die Entschuldigungen der anderen annehme. Der Autor Batić Bačević selbst vertrat die Meinung, dass die Entschuldigungen nicht unbedingt ein Auftakt seien, der zu einer neuen Art der balkanischen Politik der früheren Brudervölker ${ }^{170}$ führe, son-

168 Bačević, Batić: »Ko če se kome izviniti? « [Wer wird sich bei wem entschuldigen?], in: NIN vom 30.11.2000, S. 16 f., hier S. 16.

169 Ebd., S. 17.

170 Diese Bezeichnung weist nicht nur auf die früheren, positiven Beziehungen zwischen den ehemaligen Kriegsparteien hin, sondern impliziert die Annahme, dass es zwischen Serben, Kroaten und Bosniern vor der Christianisierung und Islamisierung nur rudimentäre Unterschiede gegeben habe. Zu Beginn des 19. Jahrhunderts entstand die romantische Vorstellung einer kulturellen, religiösen und politischen Einheit aller Slawen, die von Ljudevit Gaj und Franjo Rački lokal aufgenommen wurde und die in der illyrischen Nationalbewegung die enge Verwandtschaft zwischen den südslawischen, Völkern betonte. Diese Idee wurde im Königreich der Serben, Kroaten und Slowenen Doktrin, das sich als Staat eines (!) dreinamigen Volkes verstand. Im sozialistischen Jugoslawien wurde an der Grundidee der Verwandtschaft festgehalten, allerdings einigte man sich auf die Sprachregelung einer Gemeinschaft von 
dern vielmehr zu einer Feststellung, wer in den Kriegen gewonnen und wer verloren habe. Er fasste zusammen, was für ihn das Grundproblem in Serbien darstellte:

»Die bisherige linke Propaganda behauptete, dass die SR Jugoslawien und ihre weise Führung aus allen bisherigen Kriegen als Sieger hervorgegangen ist, aber es ist nicht klar, warum alle von uns eine Entschuldigung fordern, da die Geschichte nicht belegt, dass irgendein Staat in irgendeinem Krieg gewonnen und dann die kollektive Verantwortung übernommen hat. ${ }^{171}$

Eine Voraussetzung für ein künftiges Zusammenleben der ehemaligen Kriegsparteien, die die nationalistischen Erzählungen fortgesetzt hätten, die man 1945 unterbrochen hatte, sah er in der »Überprüfung unserer, ihrer und der gemeinsamen Vergangenheit ${ }^{172}$.

Das Wahlbündnis Demokratische Opposition Serbiens mit Zoran Đinđić an der Spitze kündigte noch vor der Wahl an, mit vier Gesetzen zur Denationalisierung - das heißt zur Aufhebung von Enteignungen, Privatisierung, Lustration und Rehabilitation - Säulen für die Demokratie zu schaffen. Nach ihrem Wahlsieg folgten darauf keine direkten Taten im Sinne von Gesetzesgrundlagen. Zwar wurde nur wenige Monate nach dem Regimewechsel ein Dekret erlassen, welches die Vertraulichkeitsregelung änderte und Betroffenen und ihren Angehörigen Zugang zu ihren Geheimdienstakten einräumen sollte. Allerdings hatte das Dekret keine Rechtsbasis und wurde nach kurzer Zeit vom Verfassungsgericht wieder aufgehoben. Nur einige wenige Personen erlangten in den wenigen Tagen, in denen die Regelung in Kraft war, Einsicht in ihre Geheimdienstakten. Die NGO Zentrum für Antikriegsaktion, später in Zentrum für Frieden und Demokratieentwicklung umbenannt, schlug daraufhin ein Modell zur Öffnung der Akten der Bezbednosno-informativna agencija (Sicherheitsinformationsdienst, BIA) und der Državne bezbednosti (Staatssicherheit) vor.

Dem Milošević-Regime entzog die neue Regierung eher indirekt einige der ehemaligen Machtbasen, ohne auf die kriminellen Machenschaften und Menschenrechtsverletzungen von Funktionsträgern und Staatsorganen hinzuweisen.

fünf Völkern (Serben, Kroaten, Slowenen, Montenegrinern und Mazedonen), die entsprechend der Formel »Einheit und Brüderlichkeit« miteinander leben sollten. Bosniaken und Kosovo-Albaner wurden nicht als eigene Nationen anerkannt, als Ausweichkategorie wurden 1971 muslimani (Muslime) als sechstes konstitutives Staatsvolk eingeführt.

171 Ebd.

172 Ebd. 
Innerhalb der ersten drei Wochen seiner Amtszeit wechselte der neue Innenminister Dušan Mihajlović alle 13 Leitungspersonen auf Direktorialebene der Polizei aus, nach sechs Monaten waren auch 60 Prozent der Leitungspositionen auf Territorialebene ausgetauscht. Weitere Maßnahmen auf unterer Ebene wurden den neuen Verantwortlichen überlassen. Ziel dieser »Depolitisierung" sei es, gegen Korruption und Inkompetenz vorzugehen. ${ }^{173}$ Entgegen dieser Politik wurde General Sreten Lukić 2001 zum stellvertretenden Innenminister ernannt, der zwar unter Milošević die serbische Polizei im Kosovo führte und in dieser Funktion für zahlreiche Kriegsverbrechen verantwortlich war, aber eine gewisse Stabilität und Loyalität des Polizeiapparats garantieren konnte. ${ }^{174}$ Brian Grodsky beschreibt dieses selektive Aufräumenmit den alten Machteliten als Kompromiss »between fighting for human rights and fighting against corruption ${ }{ }^{175}$.

\section{Das Ringen um die Verhaftung und Auslieferung Milošević'}

Innerhalb der neuen demokratischen Regierung trat schnell der Konflikt zwischen den ICTY-Skeptikern und -Befürwortern deutlich zu Tage. Die Partei des jugoslawischen Präsidenten Vojislav Koštunica, DSS, die auch der Demokratischen Opposition Serbiens angehörte, sollte in den darauf folgenden Monaten eine Zusammenarbeit mit dem Tribunal und die Auslieferung von Angeklagten durch eine Politik des Rechtsprimats und der Technisierung konsequent blockieren. Der Präsident gab vor, nur zu kooperieren, wenn dies verfassungsgemäß möglich sei. Zudem sah Koštunica die Schuld an der Situation des Landes allein bei Milošević und seinen Unterstützern, deren größte Fehler allerdings nicht ihre Taten gewesen seien, sondern darin gelegen haben, zu viel unterlassen und so Spielraum für Kriminelle und Radikale ermöglicht zu haben. Er zielte auf eine Strafverfolgung von Kriegsverbrechen in Serbien ab und vertrat die Meinung, dass die Verantwortung für den Zerfall Jugoslawiens und die damit verbundenen Verbrechen geteilt werden müssten. Ein großer Teil der Verantwortung lag seiner Ansicht nach bei der internationalen Gemeinschaft. In der von ihm vertretenen Geschichtsdeutung war das serbische Volk ein hilfloses Opfer der Umstände, die es nicht hatte beeinflussen können. ${ }^{176}$ Darüber hinaus forderte Koštunica

173 B. Grodsky: The Costs of Justice, S. 136.

174 Er wurde 2009 vom ICTY zu 22 Jahren Haft verurteilt.

175 Ebd.

176 Vgl. Stojanović, Dubravka: »Demokratska opozicija Srbije - otvaranje traumatičnog kruga? (2000-2002)« [Die Demokratische Opposition Serbiens - Öffnen eines traumatischen Kreises?], in: dies.: Ulje na vodi. Ogledi iz istorije sadašnjosti Srbije [Öl 
eine strikte Anwendung des Grundsatzes der Eigenverantwortung und der individuellen Schuld. ${ }^{177}$ Das ICTY wurde von ihm und seiner DSS als »nicht objektives, kontroverses, irrelevantes politisches Gericht [dargestellt, D. M.], welches selektive Gerechtigkeit anwenden würde « ${ }^{178}$. Die bürgerlichen Parteien des Oppositionsbündnisses hingegen sahen ein unbedingtes Erfordernis in der Zusammenarbeit mit dem Tribunal. Sie vertraten damit ihre Positionen aus den 90er Jahren weitgehend weiter. Die Demokratska Stranka (Demokratische Partei, DS) des serbischen Premiers Đinđić oszillierte dabei zwischen beiden Standpunkten und machte bisweilen diffuse Aussagen, wie sich in der politischen Praxis deutlich zeigen sollte. Von der Notwendigkeit einer wie auch immer gearteten tiefgreifenden Auseinandersetzung mit den Ursachen für die Verbrechen unter dem und durch das Regime Milošević' war Đinđić allerdings fest überzeugt:

»Milošević ist nicht vom Himmel gefallen. Er trat zu uns, wie Hitler in Deutschland, wegen der Schwäche der Gesellschaft - der Opposition, der orthodoxen Kirche, der Intellektuellen. Wir sind dafür verantwortlich, dass er so lange regiert hat. ${ }^{179}$

Während Koštunica kein Gebot für die Übernahme von Verantwortung auf Seiten der serbischen Gesellschaft erkannte und bisweilen sogar Verständnis für das Milošević-Regime zeigte, schloss sich Đinđić der Position von Belgrader Menschenrechts-NGOs an, die - wie viele im internationalen Diskurs - die Milošević-Hitler-Analogie bemühten und sich an einem deutschen Modell von Vergangenheitsaufarbeitung orientierten, in dem eine Auseinandersetzung mit der gesellschaftlichen Schuld zentral wäre. Dementsprechend divergierend waren die politischen Handlungen der Regierung in den ersten sechs Monaten nach ihrem Amtsantritt, zumal während dieser Zeit die Frage des Umgangs mit der Vergangenheit unter den legacies des Milošević-Regimes bearbeitet werden musste.

Kurz nach Amtsantritt der neuen serbischen Regierung im Januar 2001 besuchte die Chefanklägerin des ICTY, Carla Del Ponte, für drei Tage Belgrad. Staatspräsident Koštunica weigerte sich zunächst, sich mit ihr zu treffen, und begründete dies damit, dass solche Zusammenkünfte nicht in seinen Zuständigkeitsbereich fielen. Schließlich kam es doch zu einer Besprechung, auf der sie

auf dem Wasser. Ansichten aus der Zeitgeschichte Serbiens], Belgrad: Čigoja štampa 2010, S. 212-255, hier S. $238 \mathrm{ff}$.

177 Vgl. ebd., S. 241.

178 Vgl. ebd.

179 Ebd., S. 250. 
die Auslieferung Milošević' nach Den Haag debattierten. ${ }^{180}$ Koštunica hatte sich schon im Vorfeld dagegen ausgesprochen und beharrte auf seiner Position, nach der das Tribunal als anti-serbisch und von der US-Regierung manipuliert einzuschätzen sei. Auch Đinđić zögerte hinsichtlich einer Auslieferung des ehemaligen Staatspräsidenten und äußerte Besorgnis über die Reaktionen von engen Verbündeten Milošević' im Sicherheits- und Militärapparat. Über das Thema Milošević hinaus kritisierte Koštunica die Praxis der geheimen Anklagen und bemängelte die fehlende Bereitschaft des Tribunals, die Bombenangriffe der NATO und die Verwendung von Uranmunition zu untersuchen. Auch erklärte er, das ICTY verhänge eine Kollektivschuld über die bosnischen Serben, weshalb die Serben das Tribunal so negativ beurteilten. Das Tribunal dürfe sich nicht zum Richter über die Geschichte aufschwingen. ${ }^{181} \mathrm{Zu}$ einer Kooperation mit dem Tribunal müsse die jugoslawische Nationalversammlung und Regierung noch Gesetze über Auslieferung und Zusammenarbeit verabschieden. Eine Wahrheits- und Versöhungskommission erschien ihm als »wissenschaftlichere, systematischere und analytischere Methode der Aussöhnung « ${ }^{182}$. Weiterhin besprach Zoran Stanković, der Präsident des Komitees für die Sammlung von Daten über Kriegsverbrechen, das trotz der Transition keine personellen Veränderungen erfahren hatte, mit der Chefanklägerin, wie eine Beweisführung für eine mögliche Anklageerhebung der Verbrechen der NATO in Jugoslawien 1999 aussehen könne. ${ }^{183}$

Del Ponte traf sich gesondert mit dem serbischen Premier Zoran Đinđić, der die Wichtigkeit einer strafrechtlichen Aufarbeit betonte. Er erklärte die mangelnde Kontrolle über die Exekutive, die reformiert werden müsste. Es hätte verheerende Folgen, die Kooperation mit dem ICTY als erstes Thema zu behandeln. Weiterhin wies er darauf hin, dass er Beweise für die Verwicklung des serbischen Staats in Kriegsverbrechen habe. ${ }^{184}$ Zudem traf Del Ponte Momčilo Grubač, den Justizminister der Bundesrepublik Jugoslawien. Dieser erklärte, dass sein Ministerium zunächst die Zusammenarbeit mit dem ICTY koordinierte, es

180 Cvijanović, Željko: »Del Ponte in Belgrade. Hague Tribunal Prosecutor Carla Del Ponte Storms out of Meeting with President Kostunica«, in: Institute for War \& Peace Reporting online vom 23.1.2001, http://iwpr.net/print/report-news/del-pontebelgrade vom 15.9.2010.

181 Vgl. C. Del Ponte: Im Namen der Anklage, S. 134.

182 Ebd., S. 133.

183 Er habe dem ICTY Beweismaterial für Kriegsverbrechen in Varvarin, Novi Pazar, Aleksinc und Surdelica übergeben. 2003 wurde das Vorhaben abgewiesen

184 Ebd., S. 136. 
aber bald ein gesondertes Gremium für diesen Zweck geben sollte. Die ihm übergebenen Anklageschriften des Tribunals wollte er an das serbische Ministerium weitergeben, da die Bundesebene hier nicht zuständig sei. Del Ponte und ihr Begleiter sprachen ihn desweiteren auf die Obstruktionen in der Auslieferungspolitik an:

»Als wir Grubač fragten, wie es möglich gewesen sei, dass die Vorgängerregierung ohne Gesetzesänderung zwei gesuchte Personen überstellt hätte, antwortete er: ১Milošević hat sich eben nie an die Gesetze gehalten. $\ll^{185}$

Wenige Tage nach Del Pontes Besuch trat Ende Januar Milošević' Chef für Staatssicherheit, Radomir Marković, zurück. Währenddessen wurde auch in der serbischen Politik und Gesellschaft eine mögliche Verurteilung des ehemaligen Staatschefs in Serbien breit diskutiert, wo Milošević wegen Verbrechen gegen das serbische Volk angeklagt werden sollte. Von Regierungsvertretern lag schließlich ein Beschluss vor, wonach ein Befehl zur Verhaftung Milošević' gegen die Unabhängigkeit der Strafverfolgung verstoßen würde.

Das Außenministerium und die Regierung arbeiteten emsig daran, ihr Land in internationale Organisationen zu reintegrieren und das Ansehen Jugoslawiens zu verbessern. Innerhalb kürzester Zeit erfolgte die Wiederaufnahme in die UN sowie von Beziehungen mit den Ländern des Sicherheitsrats der UN und den Nachbarländern. Jugoslawien wurde wieder Mitglied des Internationalen Währungsfonds, der Weltbank, des NATO-Partnership-for-Peace-Programms und der OECD. Auch hinsichtlich der Prozesse, die gegen die Bundesrepublik Jugoslawien vor dem Internationalen Gerichtshof geführt wurden, schlug das jugoslawische Außenministerium nach der Transition nun deutlich versöhnlichere Töne an. Nur drei Monate nach dem Antritt der neuen Regierung unterzeichnete der serbische Premier Đinđić den ersten und zweiten Menschenrechtspakt, die Folterkonvention, die Völkermordkonvention sowie die Konvention gegen rassische Diskriminierung und bekannte sich damit deutlich zu den Menschenrechten, ohne dies explizit mit den Verstößen in der Vergangenheit in Verbindung zu bringen.

Đinđić verhandelte zudem über die Festnahme Milošević', den er als potentielle Oppositionsfigur weiter für gefährlich hielt. In zwei Treffen mit Chefanklägerin Del Ponte im März erörterte er die Möglichkeiten einer Verhaftung und Auslieferung. Für eine Kooperation mit dem Tribunal bräuchte er entsprechende Finanzhilfen und die Unterstützung der USA. Zudem schlug er ein Gesetz vor, 
mit dem gefördert werden sollte, dass sich Angeklagte freiwillig stellen. Hinsichtlich einer Verhaftung Mladić' blieb er pessimistisch, dieser sei durch die Armee geschützt. ${ }^{186}$ Offenbar war Đinđić' Plan erfolgreich, da das amerikanische Außenministerium tatsächlich für eine Zertifizierung von Finanzhilfen eine Liste mit elf Punkten formulierte, die unter anderem die Verhaftung des ehemaligen Regierungspräsidenten, die Verhaftung und Überstellung von mindestens einem Angeklagten, Zugang zu Akten und die Verabschiedung eines Gesetzes über die Zusammenarbeit mit dem Tribunal vorsahen. Als Frist wurde die erste Aprilwoche gesetzt. ${ }^{187}$

Die unterschiedlichen Vorstellungen über die Zusammenarbeit mit dem ICTY zeigten sich auch als am 23. März 2001 in Belgrad Milomir Stakić verhaftet wurde, der Kommandant der Lager Omarska und Keraterm, dessen Verhaftung und Auslieferung nach Den Haag Koštunica als illegal kritisierte.

Koštunica plädierte für eine Bearbeitung der Kriegsverbrechen auf nationaler Ebene. Dazu veröffentlichte er am 30. März 2001 ein Präsidentendekret zur Schaffung einer Komisija za istinu i pomirenje (Kommission für Wahrheit und Versöhnung). ${ }^{188}$ Die Idee für eine solche Kommission war von Vertretern aus Zivilgesellschaft und Wissenschaft im Kontext der Konferenzen in Ulcinj und Belgrad immer wieder ins Gespräch gebracht worden. ${ }^{189}$ Die Fürsprecher sahen in dem Instrument die Möglichkeit, die Gesellschaft in ihrer Breite mit der Wahrheit über den Staatszerfall und die Kriege zu konfrontieren. Koštunicas Initiative schloss aber nicht direkt an diese Diskurse an, sondern nahm einen Vorschlag von Außenminister Goran Svilanović auf. Auch war der inhaltliche Schwerpunkt der Kommission anders gelagert, die Forschung betreiben und Beweise erbringen sollte »über soziale, interethnische und politische Konflikte, die zum Krieg führten, und die kausalen Zusammenhänge zwischen diesen Ereignissen beleuchten ${ }^{190}$ sollte. Im Fokus standen also nicht die verübten Verbrechen, sondern die Gründe und Prozesse, die zu ihnen führten. Für innenpolitische Diskussion sorgte aber zunächst nicht die inhaltliche Ausrichtung, sondern die Tatsache, dass das Dekret Koštunicas quasi über Nacht kam. Selbst der jugoslawi-

186 Ebd., S. $142 \mathrm{ff}$.

187 Vgl. ebd., S. $147 \mathrm{f}$.

188 Präsident der Republik Serbien Vojislav Koštunica: Odluka o osnivanju Komisije za istinu i pomirenje [Entschließung über die Errichtung einer Kommission für Wahrheit und Versöhnung], in: Službeni list SRJ 15 (2001).

189 Vgl. N. Dimitrijević: »Prošlost, odgovornost, budućnost«, und V. Dimitrijević: »Izgledi za utvrđivanje«.

190 Präsident der Republik Serbien Vojislav Koštunica: Odluka o osnivanju. 
sche Justizminister war nicht darüber informiert. ${ }^{191}$ International brüstete sich der Präsident damit, die erste Wahrheits- und Versöhnungskommission der Region eingerichtet und den Südafrikaner Alex Borraine als Berater engagiert zu haben.

Während Koštunica auf einem Gipfel in Genf gegenüber dem französischen Präsidenten Jaques Chirac behauptete, eine Verhaftung Milošević' stünde nicht bevor, ${ }^{192}$ wurde der ehemalige Präsident auf Befehl von Regierungschef Đinđić angesichts der näherrückenden Frist für die amerikanische Zertifizierung in der Nacht vom 30. März auf den 1. April in seinem Haus im Belgrader Stadtteil Dedinje festgenommen. Zunächst hatte sich Milošević der Verhaftung widersetzt und gefordert, nicht an das ICTY ausgeliefert zu werden. Am Tag nach der Verhaftung herrschte aus Angst vor Reaktionen und aus Erklärungsnot vorerst bei allen politischen Akteuren in Serbien Stille. Đinđić behauptete sogar, nichts von dem konkreten Vorgang am betreffenden Abend gewusst zu haben, er habe zu Hause den Hollywoodfilm Gladiator geschaut. ${ }^{193}$ Nach seiner Rückkehr legitimierte der von den Ereignissen überraschte Koštunica die Verhaftung unter der Voraussetzung, dass es keine Auslieferung von Milošević nach Den Haag gebe. Innenpolitisch wurde die Festnahme nun mit dem Tatbestand des Machtsmissbrauches begründet. ${ }^{194}$ Es blieb zunächst unklar, ob Milošević in Serbien oder wegen der seit 1999 bestehenden Anklage des ICTY wegen Kriegsverbrechen in Den Haag vor Gericht gestellt werden sollte - oder beides. Während seitens der das ICTY unterstützenden Staaten signalisiert wurde, dass man Milošević in Den Haag sehen wolle, dominierte in Serbien die Vorstellung, ihn vor ein nationales Gericht zu stellen.

Schon nach dem ersten Treffen der 19 von Präsidenten benannten MItlgieder der Kommission für Wahrheit und Versöhnung traten mit dem Menschenrechtsaktivisten Vojin Dimitrijević und der kritischen Historikerin Latinka Perović zwei prominente Mitglieder zurück. Sie sahen die Ziele und Aufgaben der ohnehin in ihren Kompetenzen sehr begrenzten Kommission überstrapaziert, da diese auf nationaler Basis über die gesamtjugoslawischen Entwicklungen forschen und

191 B. Grodsky: »International Prosecutions«, S. $696 \mathrm{ff}$.

192 C. Del Ponte: Im Namen der Anklage, S. 147.

193 E. D. Gordy: »Accounting for a Violent Past «, S. 8.

194 Milošević selbst reagierte auf diese Vorwürfe, indem er sich verteidigte, »that he had not stolen money from the state - rather, he claimed, he had ordered money diverted from the state budget to finance paramilitaries in Croatia and Bosnia and Hercegovina.« Zit. nach ebd., S. 14. 
eine Art historischen Bericht mit Fokus auf die Zeit vor dem Zerfall Jugoslawiens als Endprodukt der Arbeit vorlegen sollte. ${ }^{195}$

Im April 2001 zweifelte der neue Chefjurist des Auswärtigen Amts, Tibor Varady, die Zuständigkeit des Internationalen Gerichtshofs hinsichtlich der von Bosnien-Herzegowina geführten Klage auf Anwendung der Völkermordkonvention an und verwies darauf, dass die Bundesrepublik Jugoslawien zum Zeitpunkt der Antragsstellung kein UN-Mitglied gewesen sei und damit auch nicht Mitglied des Statuts des Internationalen Gerichtshofs. Zeitgleich zog Varady die Gegenklage gegen Bosnien-Herzegowina zurück. ${ }^{196}$ Er begründete, man müsse die Periode der Konflikte hinter sich lassen und sich einer Ära der Kooperation und der freundschaftlichen Lösung von bestehenden Auseinandersetzungen entgegen bewegen. Weiterhin äußerte er, dass die neue Regierung der Ansicht sei, dass

»the tragedies of Bosniacs, Serbs, Croats and others in Bosnia and Herzegovina do require a response of the machinery of justice, but it might be more appropriate to seek justice through national and international proceedings, which would yield punishment of individual perpetrators, rather than punishment of the collectives to which the perpetrators belong ${ }^{197}$.

Auch wenn sie die Notwendigkeit der Strafverfolgung einzelner Täter deutlich macht, wird in dieser Formulierung die Ablehnung von kollektiv angewendeten Konzepten von »Bestrafung« jedweder Art offensichtlich, wobei unklar bleibt, ob aus fehlendem Bewusstsein für die eigene Verantwortung oder aufgrund der Sorge vor der Destruktivität, die eine Debatte um kollektive Verantwortung in sich tragen könnte. Die Bezeichnung »Tragödie« allerdings impliziert eine Schicksalhaftigkeit der Kriege, die man nicht verhindern hätte können. Die Frage nach Tätern, Schuld und Verantwortung kann bei Verwendung dieser Bezeichnung nicht mehr gestellt werden.

Das nationalistische Lager versuchte nach der Festnahme Milošević' Stimmung gegen das ICTY und gegen die Behandlung Milošević' zu machen. In dem

195 Ilić, Dejan: »The Yugoslav Truth and Reconciliation Commission: Overcoming Cognitive Blocks«, in: Eurozine vom 23.4.2004, http://www.eurozine.com/articles/ 2004-04-23-ilic-en.html vom 30.8.2010.

196 International Court of Justice: Application of the Convention on the Prevention and Punishment of the Crime of Genocide (Bosnia and Herzegovina v. Yugoslavia). Withdrawal of Counter-claims by the Federal Republic of Yugoslavia vom 20.4.2001. 
im Mai 2001 veröffentlichten Weißbuch Die Wahrheit über das Haager Tribunal. Apell zur Aufhebung des Haager Tribunals stellte es in Aufsätzen wie Grünes Licht für Den Haag, Ende der serbischen Geschichte die Legitimität des Tribunals auf polemische Art und Weise in Frage. Das Gericht sei politisch motiviert und illegitim, es benutze unlautere Methoden, werde von den »Feinden« Serbiens finanziert und sei lediglich ein Instrument des politischen Drucks auf Serbien und das ganze serbische Volk, das durch das Tribunal satanisiert werde. ${ }^{198}$ Im Anhang des Sammelbands finden sich einige Apelle, wie der von 45 Intellektuellen unterzeichnete und weit zirkulierte »Appell zur Aufhebung des Haager Tribunals«, ein Appell der Ärzte und der Abgeordneten des serbischen und des jugoslawischen Parlaments an die Führer Serbiens und der Bundesrepublik sowie die allgemeine und medizinische Öffentlichkeit, in dem vor einem »leisen Mord « an Milošević gewarnt wird und man »für eine adäquate Behandlung Slobodan Milošević' und die Bereitstellung eines Ambientes, in der diese realisiert werden könne«, warb. ${ }^{199}$ Auch wird in mehreren Dokumenten auf die Solidarisierung anderer Länder verwiesen. So habe sich ein russisches Komitee für die Verteidigung von Slobodan Milošević gegründet und Mitglieder des Rats der Russischen Förderation sowie die Ukrainische Bauernpartei unterstützten Milošević.

In diesem Klima schlug Präsident Koštunica Ende Mai dem jugoslawischen Parlament ein Gesetz zur Regulierung der Zusammenarbeit mit dem ICTY vor. Dieses sollte eine Auslieferung von Serben nach Den Haag ermöglichen, allerdings erst nachdem lokale Gerichte die fraglichen Fälle überprüft hätten. Sein Vorschlag erhielt keine Mehrheit im Parlament. Etwa zeitgleich erklärte Zoran Đinđić, dass die Auslieferung von Milošević zwingend weiter von der Verabschiedung eines Gesetzes zur Zusammenarbeit mit dem Tribunal abhänge, da sie sich sonst innenpolitisch nicht vertreten ließe, es über ein entsprechendes Gesetz

198 Vgl. R. Prvoslav (Hg.): Bela knijga (2001).

199 O. V.: »Apel lekara, republičkih i saveznik poslanika, rukovodstvu Republike Srbije i Savezne Republike Jugoslavije, medicinskoj i najširoj javnosti za adekvatno lečenje Slobodana Miloševića i za obezbedivanje ambijenta u kom će se ono realizovati. Sprečite fatalan ishod Miloševićeve bolesti i ne budite saučesnici u njegovom tihom ubistvu« [Appell an die Ärzte, die Republiks- und Bundesabgeordneten, die Regierung der Republik Serbien und der Bundesrepublik Jugoslawien, die medizinische und weiteste Öffentlichkeit für eine adäquate Behandlung Slobodan Milošević' und für die Bereitstellung einer Umgebung, in der die sich realisieren lässt. Vermeiden Sie einen fatalen Ausgang der Krankheiten Milošević' und seien Sie keine Komplizen an seinem leisen Mord], in: ebd., S. 165-170. 
aber weiterhin keinen Kompromiss gebe. Darüber hinaus legte er ICTY-Chefanklägerin Del Ponte Beweise für die direkte Beteiligung des Milošević-Regimes und der JNA an serbischen Kriegsverbrechen im Kosovo vor: ${ }^{200} \mathrm{Nach} \mathrm{Be}-$ ginn der NATO-Bombardierung 1999 vertuschten serbische Einheiten auf Anweisung des Innenministeriums Kriegsverbrechen, indem sie die Leichen von getöteten Kosovo-Albanern wieder ausgruben, in Kühlwagen nach Serbien fuhren und dort vergruben oder versenkten. Bereits 1999 entdeckten Anwohner einen ersten Kühlwagen mit achtzig Leichen in der Donau in der Nähe von Zaječar, was aber nicht öffentlich wurde. Die Deutung des serbischen Polizeiministers Dušan Mihajlović, der in einer Pressekonferenz am 5. Juni den Fund eines Massengrabs mit ca. 800 Leichen auf einem Flugplatz der Specijalnih antiterorističkih jedinica 13. maja (Antiterror-Sondereinheit 13. Mai) publik machte und auf das Milošević-Regime und die Kriegsverbrechen im Kosovo verwies, war sehr konkret. Auch wurde von Beginn an die Einbeziehung von Ermittlern des ICTY zugesagt. Der serbische Polizeiminister sagte, die Öffentlichkeit solle nicht interessieren, wer den Hinweis auf das Massengrab gab, sondern,

»wer das befohlen, organisiert hat und wer es zum Staatsgeheimnis erklärt hat. Die Aufklärung der einzelnen Täter der Verbrechen [an den Toten, D. M.] aus den Kühlwagen und aller anderen nimmt die kollektive Verantwortung von den Bürgern unseres Landes und den von Tausenden unschuldigen Polizisten und Soldaten, die im Kosovo eingesetzt waren. $\ll^{201}$

200 C. Del Ponte: Im Namen der Anklage, S. 158-163.

201 A.A.: »Nepoznat broj tela. MUP Srbije potvrdio da se grobnica nalazi kod Batajnice« [Unbekannte Zahl Körper. Innenministerium bestätigt Massengrab bei Batajnica], in: Blic online vom 14.6.2001, http://www.blic.rs/stara_arhiva/hronika/4180/Nepoznatbrojtela vom 22.4.2013. In Folge dieser Entdeckungen versprach die Regierung eine Aufklärung dieser Verbrechen. Ausgrabungen wurden ab Juni 2001 und 2002 durchgeführt, nachdem Bundesjustizminister Momčilo Grubač ein Abkommen mit dem International Committee for Missing Persons getroffen hatte. Bei weiteren Ermittlungen und Ausgrabungen fand man insgesamt ca. 800 Leichen in Batajnica, weitere 77 Leichen auf dem Gelände des Trainingszentrums derselben Einheit in Petrovo Selo und die Überreste von ca. siebzig Personen im See Perućac bei Bajna Bašta. Für die Ermordung von fünfzig Personen in einem Massaker im kosovarischen Suva Reka, die in Batajnica abgelegt wurden, wurde ab 2005 acht Polizisten an der Belgrader Kammer für Kriegsverbrechen der Prozess gemacht, vier von ihnen wurden verurteilt. Darüber hinaus wurden keine Prozesse eingeleitet. Zu Batajnica vgl. Kron, Ana: »Determining the Fate of Missing Persons in Post-Conflict Society. 
Er dementierte weiterhin, dass der Fall der Kühlwagen nur ausgedacht sei, um Druck auf die Öffentlichkeit hinsichtlich eines Gesetzes zur Zusammenarbeit mit dem ICTY auszuüben. Die Terminierung der Veröffentlichung allerdings war im Kontext der politischen Situation sicherlich nicht zufällig. Für eine internationale Geberkonferenz am 29. Juni hatten die USA bereits die Auslieferung Milošević' gefordert, und auch Deutschland und Frankreich engagierten sich in diesem Rahmen nun als pressure states.

Bereits direkt nach der Transition hatte die EU bedingungslos die Wirtschaftsbeziehungen zu Jugoslawien wieder aufgenommen. Mit dem Stabilisierungs- und Assoziierungsprozess hatte der Europäische Rat schon sein Interesse an vertieften Beziehungen zwischen der Bundesrepublik Jugoslawien und der EU bekundet, war aber noch nicht konkreter geworden. Im Juni 2001 erklärte die Europäische Kommission in einem Länderstrategiepapier nun auch grundsätzlich ihre Reformprioritäten gesondert für Serbien und Montenegro im Rahmen des Stabilisierungs- und Assoziierungsprozesses. Demgemäß soll das Mittel der politischen Konditionalität angewendet werden, das heißt, wenn die formulierten Bedingungen nicht erfüllt würden, führe das zu Krisen oder zu Rückschritten in den bilateralen Beziehungen. Als Schlüsselelemente wurden Minderheitenrechte, interethnische Versöhnung und die Beachtung von internationalen Verpflichtungen wie die Kooperation mit dem ICTY angeführt. Als weitere Bedingungen sah die Europäische Kommission eine Neuordnung der Kompetenzen innerhalb der Föderation, die Reform von Verwaltung, Justiz und Polizei, die Bekämpfung der organisierten Kriminalität, eine Stärkung der Zivilgesellschaft und die Rückkehr von Flüchtlingen vor. ${ }^{202}$ Zur Überprüfung der Reformfortschritte, für die die EU finanzielle Hilfen und technische Unterstützung zur Verfügung stellte, ${ }^{203}$ sollten jährliche Stabilisierungs- und Assoziierungsberichte verfasst werden. Neben der politischen Konditionalität wurden die Beziehungen zwischen der EU und der Bundesrepublik Jugoslawien durch die Implikationen der Kosovofrage belastet.

Role of Judiciary, ad hoc Bodies, and International actors. Case study«, in: Justice in Transition 2 (2006) 7, http://www.tuzilastvorz.org.rs/html_trz/\%28casopis\%29/eng/ eng07/1620.pdf vom 3.3.2013, und die Dokumente zu Suva Reka bei der Kammer für Kriegsverbrechen Belgrad. 2010 wurden erneut Überreste von mehr als 250 Personen in Rudnica gefunden.

202 European Commission: Federal Republic of Yugoslavia. Country Strategic Paper 20022006, http://ec.europa.eu/enlargement/pdf/financial_assistance/cards/publications/fry_stra tegy_paper_en.pdf vom 11.4.2013.

203 Vgl. C. E. Ratiu: EU Soft Power, S. 134 f. 
Am 23. Juni veranlasste Präsident Koštunica ein Dekret des Bundesparlaments zur Zusammenarbeit mit dem ICTY, dass nunmehr das Parlament bevollmächtigte, über die Auslieferung von Verdächtigen des ICTY zu entscheiden. Darüber hinaus eröffnete es ICTY-Verurteilten auch die Möglichkeit, ihre Strafe in Jugoslawien zu verbüßen. Milošević' Anwälte legten wegen Verfahrensfehlern Einspruch gegen das Dekret ein, das Verfassungsgericht ordnete am 28. Juni seine Aussetzung an. ${ }^{204}$ Nur wenige Stunden später verabschiedete die Regierung Serbiens eine sofort in Kraft tretende Entscheidung, die eine Kooperation mit dem ICTY autorisierte. ${ }^{205}$ Der Konflikt zwischen Đinđić und Koštunica war vorprogrammiert. Noch am gleichen Tag, dem symbolträchtigen Vidovdan, ${ }^{206}$ wurde Slobodan Milošević nach Den Haag ausgeliefert. Der serbischen Bevölkerung wurde die Auslieferung ihres früheren Präsidenten als notwendige Bedingung für amerikanische und europäische Finanzhilfe kommuniziert. Eine 100Millionen-Dollar-Finanzhilfe der amerikanischen Regierung sei im Vorlauf einer Geberkonferenz von der Auslieferung abhängig gemacht worden. ${ }^{207}$ Demnach waren die wichtigsten Motive für die Auslieferung »eine Geberkonferenz, die

204 Am 6. November 2001 urteilte das Verfassungsgericht schließlich, dass das Dekret nicht mit der jugoslawischen Verfassung und dem jugoslawischen Strafrecht vereinbar sei.

205 Vgl. Magliveras, Konstantinos D.: »The Interplay between the Transfer of Slobodan Milosevic to the ICTY and Yugoslav Constitutional Law«, in: European Journal of International Law 13 (2002) 3, S. 661-677.

206 Der Vidovdan, der Tag des heiligen Veit, hat in Serbien eine besondere Mythologie. Der heilige Veit ersetzte in der Zeit der Christianisierung den heidnischen Gott Svantovit, den viele Slawen verehrten. In der panslawischen Bewegung gewann er erneut an nationaler Bedeutung. Er wird nach dem julianischen Kalender am 15., nach dem gregorianischen am 28. Juni gefeiert. Für die serbische Nationalmythologie ist der 28. Juni auch deshalb symbolisch aufgeladen, da an ihm vermeintlich besonders schicksalhafte Ereignisse stattgefunden hätten wie die Schlacht auf dem Amselfeld 1389. Bisweilen werden politisch relevante Handlungen aber auch bewusst in den Traditionskontext des Vidovdan gestellt wie die Erschießung des österreichischen Thronfolgers Franz Ferdinand durch den serbischen Nationalisten Gavrilo Princip, die Verabschiedung der Verfassung des Königreichs der Serben, Kroaten und Slowenen 1921, die Verabschiedung der KP-Resolution, die Titos Bruch mit Stalin 1948 offiziell machte, Milošević' Rede auf dem Amselfeld zur 600-Jahr-Feier 1989 oder die Konstituierung des Parallelparlaments der nordkosovarischen Serben 2008.

207 V. Peskin: International Justice, S. 70. 
Umschuldung der Schulden, eine Stand-by-Vereinbarung und die Sicherung des Standortes Jugoslawien für den Internationalen Währungsfonds « ${ }^{208}$.

Sehr interessant ist in diesem Zusammenhang die mystische Deutung des Tages und die moralische Selbstglorifizierung einiger Akteure - ohne über das ICTY oder die Auslieferung an sich zu sprechen. Boris Tadić, der damalige jugoslawische Telekommunikationsminister, markierte auf einer Pressekonferenz am Tag der Auslieferung den Unterschied zu Milošević' Politik und verwies auf dessen Rede anlässlich der 600-Jahr-Feier der Schlacht auf dem Amselfeld 1989:

»Vor genau zwölf Jahren, an genau diesem Tag, an einem der größten serbischen Feiertage, Vidovdan, hat Slobodan Milošević unser Volk aufgerufen, zu erkennen, was er als die Ideale des himmlischen Serbien bezeichnete. Die serbische Regierung ist jetzt verpflichtet, die Ideale des irdischen Serbien zu wahren, nicht so sehr für uns und unsere Eltern, sondern zum Wohle unserer Kinder. $\aleph^{209}$

Am 29. Juni ermöglichte die internationale Geberkonferenz für die Bundesrepublik Jugoslawien schließlich Hilfen in Höhe von 1,3 Milliarden Euro.

Die Auslieferung Milošević' zog einen schweren Konflikt mit der Partei Koštunicas und schließlich ein Ausscheren der DSS aus dem Oppositionsbündnis Demokratische Opposition Serbiens und damit auch aus der Regierungskoalition nach sich. Die erste Regierung nach der Transition in Serbien scheiterte nach weniger als einem Jahr. Auch wurde die Debatte um ein Für und Wider der nationalen und der internationalen Strafverfolgung fortgesetzt. Um die ambivalenten serbischen Bemühungen der Strafverfolgung herauszustellen, verwies die Zeitschrift NIN auf den Prozess gegen Dušan Vučković, der 1996 vom Bezirksgericht in Sabač verurteilt worden war und auch in der Revision vom Obersten Gerichtshof eine Strafe von zehn Jahren erhielt. ${ }^{210}$ Nach der symbolträchtigen Auslieferung des ehemaligen Präsidenten im Juni 2001 versprach die serbische Regierung die Kooperation mit dem ICTY nach außen und den Schutz seiner Bürger - auch der vom ICTY gesuchten Kriegsverbrecher - nach innen. Immer noch galt die Auslieferung von serbischen Staatsbürgern als verfassungswidrig.

Auf diplomatischer Ebene wurde durch symbolische Politik an einer Wiederaufnahme und der Verbesserungen der Beziehungen zu den Nachbarstaaten gearbeitet. Bereits im November 2001 drückte der jugoslawische Außenminister

208 Đinđić in der Politika vom 29.6.2001, zit. nach D. Stojanović: »Demokratska opozicija Srbije«, S. 254.

209 Tadić in der Politika vom 29.6.2001, zit. nach ebd., S. 250.

210 Vgl. o. V.: »Vidovdanski masakr«. 
Goran Svilanović bei einem Staatsbesuch in Kroatien sein tiefes Bedauern über das Leiden der Bürger Kroatiens, der Kroaten wie der Serben, sowie der Bürger Jugoslawiens in den vergangenen Jahren aus. Auf die kroatische Erwartung einer Entschuldigung für die begangenen Verbrechen angesprochen äußerte Svilanović sein Bedauern über alle Kriegsopfer und fügte hinzu, dass Vukovar für immer im Herzen aller Kroaten bleibe. Allerdings müsse man auch für die Serben Verständnis haben, bei denen sich die Erinnerung an Jasenovac und andere Richtstätten stark eingeprägt habe und die tatsächlich in großer Zahl Angst davor hatten, dass sich einige Kroaten zu Verbrechen verleiten ließen. Noch war die jugoslawische Führung offenbar nicht für formale Entschuldigungen bereit, eröffnete aber einen Dialog über Kriegsverbrechen und sicherte zu, Kriegsverbrechen zu verfolgen und an der Erneuerung der bilateralen Beziehungen zu arbeiten, ungeachtet der Tatsache, »dass sich alle den Traumata der jüngsten Vergangenheit bewusst sind ${ }^{211}$.

\section{Grenzen der Aufarbeitung auf nationaler Ebene}

Im Dezember 2001 veröffentlichte die Wahrheits- und Versöhnungskommission nach zwei Treffen schließlich ihre Arbeitsprinzipien, wonach sie durch eine Auseinandersetzung mit der Wahrheit über die Konflikte im ehemaligen Jugoslawien und in seinen Nachfolgestaaten zur allgemeinen Versöhnung innerhalb Jugoslawiens und zwischen dem Land und seinen Nachbarnationen beitragen wolle. Ihr Ziel sei es, die Gründe und Entwicklungen, die zur Desintegration des früheren Staates und zum Krieg geführt hatten, zu ermitteln und zu untersuchen. In den darauf folgenden Monaten wurde sie vor allem von Menschenrechtsaktivisten dafür kritisiert, in »internationalen Faktoren« Rechtfertigungen für die Kriege und Kriegsverbrechen zu suchen, auch wurde ihre Inaktivität und die Unterbeleuchtung der Kriegsverbrechen und Verletzungen des Völkerrechts bemängelt. ${ }^{212}$ Im Frühling 2002 forderte ein breites Bündnis von NGOs und Bürgern, angeführt von der liberalen Partei Građanski Savez Srbije (GSS, Bürgerliche Allianz Serbiens) ein Gesetz zur Lustration und die Ahndung von Menschenrechtsverletzungen durch staatliche Amtsträger. Diese Forderung blieb aber von der Politik ungehört.

211 O. V.: Svilanović u poseti u Hrvatskoj [Svilanović auf Besuch in Kroatien], in: b92.net vom 14.12.2001, http://www.b92.net/info/vesti/index.php?yyy=2001\&mm= $12 \& d d=14 \&$ nav_category=1\&nav_id=54979 vom 13.2.2013.

212 D. Ilić: »The Yugoslav Truth«. 
Trotz der geschlossenen Kooperationsvereinbarung wurde erst im April 2002, wieder im Zusammenhang mit der Zusage von amerikanischen Geldern und auf Initiative der montenegrinischen Politik hin, ein Gesetz zur Zusammenarbeit mit Den Haag verabschiedet. ${ }^{213}$ Dieses Gesetz missachtete aber den Gesetzesvorrang des ICTY-Statuts, indem es auf nationale Prozesse nach einem Urteil des ICTY bestand und nur auf Anklagen angewendet werden konnte, die bereits vor Verabschiedung des Gesetzes erhoben wurden. Zudem wurde als Vermittlungsinstanz zwischen dem ICTY und den serbischen Behörden ein Nationaler Rat zur Koordinierung zwischen Den Haag und der Regierung gegründet. ${ }^{214}$ Der Nationale Koordinierungsrat sollte aus einem Vorsitzenden, der aus der Ministerriege gewählt werden sollte, und je einem Vertreter von Verteidigungs-, Innen-, Justiz- und Außenministerium bestehen. Bis der Rat tatsächlich arbeitete, dauerte es aber noch. Erst 2004 übernahm Rasim Ljajić die Präsidentschaft des Rates und führte Verfahrensregeln zur Koordination ein, und erst 2007 wurde ein Büro für den Koordinierungsrat eröffnet, das als besonderer Dienst der Regierung mit Expertise zur Seite stehen sollte. ${ }^{215}$

ICTY-Chefanklägerin Carla Del Ponte wandte sich im Juli 2002 an den UNSicherheitsrat, um deren Mitglieder dazu zu bringen, über den politischen und finanziellen Druck, den sie auf Serbien ausüben könnten, eine Zusammenarbeit mit dem Tribunal zu erzwingen. Die USA machten weiterhin ihren Einfluss geltend und banden finanzielle Zuwendungen an die Zusammenarbeit mit dem ICTY. In den folgenden Monaten verlief die Kooperation mit dem Tribunal nach dem immer gleichen Muster:

»[T] he government would promise never to arrest Serbian >heroes` and would pledge to provide them with all the support they needed, and then days before an international dead-

213 Vgl. Bundesparlament der Bundesrepublik Jugoslawien: Zakon o saradnji Srbije i Crne Gore sa međunarodnim tribunalom za krivično gonjenje lica odgovornih za teška kršejna međunarodnog humanitarnog prava počinjena na teritoriji bivše Jugoslavije od 1991. godine [Gesetz über die Zusammenarbeit Serbien und Montenegros mit dem Internationalen Tribunal für die Strafverfolgung von verantwortlichen Personen für auf dem Territorium des ehemaligen Jugoslawien seit 1991 begangene schwere Verletzungen des Internationalen Völkerrechts], in: Službeni list SRJ 18 (2002) sowie in: Službeni list SCG 16 (2003).

214 Ebd.

215 Republik Serbien (Hg.): Answers to the European Commision's Questionnaire, S. 539. 
line that usually involved financial or membership sanctions, the heroes would reluctantly but regularly shipped off to The Hague $\ll^{216}$.

Hinsichtlich der Armee waren die Positionen von DS und DSS unterschiedlich, 2002 schien aber ein Kompromiss erreicht, nachdem 70 Prozent aller Generäle in Rente geschickt wurden - auch Generalstabschef Nebojša Pavković, der 2009 für Verbrechen gegen die Menschlichkeit und Kriegsverbrechen im Kosovokrieg verurteilt wurde.

\section{Der Milošević-Prozess und ein Streit des »anderen Serbien« über moralische Verantwortung}

In Den Haag stilisierte sich Slobodan Milošević anfänglich einem globalen $\mathrm{Pu}-$ blikum gegenüber als Märtyrer im Kampf gegen den amerikanischen und europäischen Imperialismus und reihte sich nach dem 11. September 2001 in das Narrativ des immer währenden Kampfes gegen den islamischen Terrorismus ein. Nach Beginn des Prozesses am 12. Februar 2002 gestaltete er seine Verteidigung so, als stünden Serbien und die Serben vor Gericht. Diese Überidentifikation unterstützte die Wahrnehmung der Serben als Opfer und von Milošević als lebendem Märtyrer für sein Volk. ${ }^{217}$ Als Schuldige identifizierte er eine Verschwörung von westlichen Staaten, die Jugoslawien zerschlagen und neokolonialistisch mit Hilfe der abtrünnigen Republiken ihre Interessen durchsetzen wollten. Von Serbien sei keine Aggression ausgegangen, man habe sich nur verteidigt. Auch hinsichtlich des Massakers von Srebrenica vermutete er eine französischmuslimische Konspiration. ${ }^{218}$ Zwar liegen zur medialen Berichterstattung über den Milošević-Prozess in Serbien noch keine Studien vor, es kann allerdings nicht von einer objektiven Berichterstattung ausgegangen werden, worauf die Untersuchungen von Katarina Ristić zum allgemeinen Mediendiskurs über Kriegsverbrechen hinweisen. ${ }^{219}$ Wurde den TV-Übertragungen des Prozesses an-

216 J. Subotić: Hijacked Justice, S. 48.

217 Vgl. Osland, Kari M.: »The Trial of Slobodan Milošević«, in: S. P. Ramet/V. Pavlakovic (Hg.): Serbia since 1989, S. 227-251, hier S. 238.

218 Vgl. Ramet, Sabrina P.: »Martyr in his own Mind. The Trial and Tribulations of Slobodan Milošević«, in: Wolfgang Höpken/Holm Sundhaussen (Hg.): Serbia, Croatia and Slovenia at Peace and at War. Selected Writings, 1983-2007 (= Studien zur Geschichte, Kultur und Gesellschaft Südosteuropas 7), München/Zürich: LIT 2008, S. 111-134.

219 Vgl. K. Milošević-Ristić: Media Discourses. 
fänglich noch große Aufmerksamkeit zuteil, verloren sowohl viele Bürger als auch die mediale Öffentlichkeit mit der Zeit das Interesse daran, das Verfahren zu verfolgen. Dennoch mobilisierten SRS und SPS weiter gegen das Tribunal und für Milošević. Den Prozess in Den Haag kommentierte und dokumentierte in Serbien auch das Helsinki-Komitee für Menschenrechte, das auch Zeugenaussagen von serbischen Protagonisten der 90er Jahre übersetzte und veröffentlichte und so einem breiteren serbischen Publikum Informationen über deren Rolle und die historischen Zusammenhänge verfügbar machte. ${ }^{220}$

Im Herbst 2002 entbrannte, ausgehend von der Berichterstattung über Kriegsverbrechen und die Prozesse am ICTY, eine heftige Kontroverse, die zwischen den Vertretern der Zivilgesellschaft und der Zeitung Vreme geführt und weit über die Vreme hinaus ausgetragen wurde. ${ }^{221}$ Sie dauerte ununterbrochen insgesamt 15 Wochen und umfasste 78 Artikel. Insgesamt schrieben fünfzig Autoren an der Debatte mit, von denen 15 zusammen 43 Briefe verfassten, während 35 Personen sich mit jeweils einem Artikel beteiligten. Der Jurist Srđa Popović, Gründer der Vreme, zeichnete für neun Artikel verantwortlich. Die Autoren können in zwei Lager eingeteilt werden, auf der einen Seite die Zeitschrift Vreme und ihre Verteidiger und auf der anderen Seite deren Kritiker. Auf Seiten der Zeitschrift Vreme wurden genauso viele Artikel geschrieben wie von Seiten der Kritiker. Die Debatte begann mit dem scharfen Angriff des Vreme-Journalisten Dragoljub Žarković, der in seinem Artikel Dehelsinkizacija gospođe Biserko (Die Dehelsinkisierung von Frau Biserko) auf einen Angriff der Menschenrechtsaktivistin Sonja Biserko antwortete und seine Zeitung verteidigte. Biserko hatte unter anderem der Vreme und $B 92$ als unabhängigen Medien vorgeworfen, mit einer vermeintlich objektiven und wertungsfreien Berichterstattung über die während der 90er Jahre im Namen der Serben begangenen Kriegsverbrechen zur Art und Weise beizutragen, mit der die serbische Elite eine Relativierung und Deethnisierung dieser Verbrechen vorantreibe. Diese neue Wahrheit sei genauso totalitär wie der Nationalismus, der zu seiner Zeit die Kriegsmaschinerie angetrieben habe. Žarković stritt diese Vorwürfe ab und behauptete: »Wir tun das Beste in dem Glauben, dass Kriminelle einen Namen haben und dass jede

220 Vgl. Biserko, Sonja (Hg.): Milošević vs. Jugoslavija [Milošević gegen Jugoslawien] (= Biblioteka Svedočanstva 20), 2 Bd., Belgrad: Zagorac 2004.

221 Sämtliche Artikel, die zur Debatte gehörten, sind versammelt in Helsinški odbor za ljudska prava u Srbiji (Hg.): Tačka razlaza. Povodom polemike vođene na stranicama lista Vreme od 1. avgusta do 21. novembra 2002 [Punkte der Trennung. Anlässlich der auf den Seiten der Zeitung Vreme geführten Polemik vom 1. August bis zum 21. November 2002] (= Helsinške sveske 16), Belgrad: Zagorac 2003. 
Denkweise, die bereit ist, ein ganzes Volk für ein Verbrechen anzuklagen, totalitär ist. $\ll^{222}$

Für die harsche persönliche Kritik und die mangelnde Kritikfähigkeit wurde die Vreme in der Folge sowohl im Rahmen von Leserbriefen als auch durch Stellungnahmen von Vertretern des »anderen Serbien« unter Beschuss genommen. ${ }^{223}$ Im Zentrum stand dabei die unzulässige Vermischung von kollektiver Schuld und kollektiver Verantwortung. Die Gegner der Position Žarković' konstatierten, dass es nicht möglich sei, ethnische Säuberung zu deethnisieren und dass die moralische Verantwortung bestünde, sich der kollektiven Verantwortung für die begangenen Verbrechen zu stellen. Die Kontroverse erstreckte sich darüber hinaus auf Nebenthemen wie die Berichterstattung aus Den Haag, das ICTY, die NATO-Intervention, den 5. Oktober, die Finanzierung der NGOs und ihrer Projekte und bewertete die Akteure und deren Handeln. Sie offenbarte in der Frage, wie eine Aufarbeitung der Vergangenheit aussehen müsse, unterschiedliche Denkschulen, die sich in ihrer Beziehung zur jüngsten Vergangenheit gegenseitig ausschließen. Die Debatte endete auf Intervention der Vreme, ohne dass es zu einer wirklichen Annäherung der unterschiedlichen Positionen gekommen wäre.

Anlässlich der Vreme-Kontroverse erschien in der NIN der Artikel Kollektivni nevini (Kollektiv unschuldig), ${ }^{24}$ in der Autor Srboljub Bogdanović mit Biljana Kovačević-Vučo und Nenad Lekić vom Ethik-Lehrstuhl der Philosophischen Fakultät der Universität Belgrad die Fragen diskutierten, inwieweit eine Denazifizierung der Serben notwendig sei, ob die Serben am meisten schuld seien, ob das ICTY Siegerjustiz ausübe, wo der Unterschied zwischen der Belagerung Sarajevos und der NATO-Bombardierung liege, ob eine Lustration nach dem Ende des Milošević-Regime nötig sei und ob die unabhängigen Medien das MiloševićRegime unterstützten, als sie ein Ende der Bombardierungen forderten. All diese Fragen drückten eine normative Verunsicherung aus, die sich auf die Bereiche Geschichte, Politik, individuelle und kollektive Identität bezogen und von Seiten der politischen Handlungsträgern nicht abschließend diskutiert wurden. Die fehlende normative Positionierung von Seiten der politischen Institutionen wertete der Chefredakteur der Vreme, Dragoljub Žarković, als Leerstelle und als Aus-

222 Vgl. Žarković, Dragoljub: »Dehelsinkizacija gospođe Biserko« [Die Dehelsinkisierung von Frau Biserko], in: Vreme vom 1.8.2002, http://www.vreme.com/cms/view. php?id=319354 vom 15.7.2014.

223 Weder Sonja Biserko noch $B 92$ nahmen aktiv an der Debatte teil.

224 Bogdanović, Srboljub: »Kolektivno nevini« [Kollektiv unschuldig], in: NIN vom 31.10.2002, S. 22-25. 
druck fehlender Entwicklung: »In zivilisierten Ländern würde diese Arbeit im Parlament gemacht. $\ll^{225}$

\section{Das Attentat auf Premierminister Đinđić als Katalysator der Aufarbeitung}

Bei einer Parteiversammlung der SRS verkündete deren Parteichef Vojislav Šešelj, dass er das ICTY besiegen wolle, und stellte sich am 24. Februar 2003 freiwillig dem Gericht in Den Haag. Er wollte das Tribunal als »antiserbisches Instrument« entlarven und benutzte seine Selbstauslieferung als politische Ressource. Ähnlich wie Slobodan Milošević nutzt er die Auftritte vor dem Haager Tribunal als politische Bühne und vor allem für innenpolitische Agitation und Instrumentalisierung. In seinen Auftritten vor dem ICTY stilisiert er sich als Märtyrer für die serbische Nation und beschreibt Serbien als Opfer der internationalen Politik. Seine Ansichten propagiert er auch über eine Homepage und zahlreiche Publikationen in der serbischen Öffentlichkeit. ${ }^{226}$

Etwa zeitgleich äußerte Premierminister Zoran Đinđić gegenüber ICTYChefanklägerin Del Ponte, bei weiteren Anklageschriften gegen Verantwortliche in der Befehlskette für Kriegsverbrechen im Kosovo müsse die Regierung die Kooperation mit dem Tribunal beenden, da sie sonst befürchte, die Unterstützung der Polizei zu verlieren. ${ }^{227}$

Eine Gruppe von Parlamentsabgeordneten der liberalen GSS $^{228}$ brachte Anfang 2003 einen Gesetzesvorschlag für eine Regelung hinsichtlich der Öffnung von Archiven und der Lustration von politisch belasteten Staatsbeamten ins Parlament ein. Ihren Vorstellungen gemäß sollte das Gesetz auf von serbischen Amtsträgern begangene Menschenrechtsverletzungen seit dem 23. März 1976 angewandt werden, dem Tag, an dem der Internationale Pakt über bürgerliche und politische Rechte in Kraft trat. Um die Verletzung dieser Rechte durch staatliche Behörden zu überprüfen, sollten, so sah es der Gesetzesvorschlag vor, Geheimdienstakten für eine Kontrollkommission sowie für die Betroffenen geöffnet

225 Ebd., S. 22.

226 Vgl. seine Homepage und exemplarisch Šešelj, Vojislav: Suočavanje za haškim inkvizitorima [Konfrontation mit den Haager Inquisitoren], Belgrad: SRS 2003, oder ders.: Afera Hrtkovci i ustaška kurva Nataša Kandić [Die Affäre Hrtkovci und die Ustaša-Hure Nataša Kandić], Belgrad: SRS 2007.

227 C. Del Ponte: Im Namen der Anklage, S. 234.

228 Im Einzelnen waren das Nataša Mičić, Dr. Dragor Hiber, Dr. Miloš Lučić, Ljubiša Kesić, Sandor Melank und Sima Radulović. 
werden. Ziel war es, Inhaber von und Bewerber um zentrale staatliche Positionen auf ihre Tätigkeiten in der Vergangenheit hin zu überprüfen und sie, wenn sie sich der Verletzung von Menschenrechten schuldig gemacht haben sollten, von verantwortungsvollen Positionen in staatlichen Institutionen auszuschließen. ${ }^{229}$

Am 12. März 2003 fiel der serbische Premierminister Zoran Đinđić einem Attentat zum Opfer. Infolge des Mordanschlags wurde in Serbien der Ausnahmezustand verhängt und im Rahmen der großangelegten Polizeioperation Sablja (Säbel) wurden über 7000 Menschen festgenommen. Die Untersuchungen brachten Verbindungen des organisierten Verbrechens, (para-)militärischer Einheiten, der Geheimdienste und nationalistischer Parteien ans Licht, die den Tod Đinđić' als Symbol einer Art »counter-revolution $«{ }^{230}$ zum Reformkurs der Regierung betrachteten. Schon wenig später wurden Angehörige der Jedinica za specialne operacije (Einheit für Spezialoperationen, auch »Rote Barette«), die in den 90er Jahren für das serbische Innenministerium tätig waren und zahlreiche Kriegsverbrechen in den Jugoslawienkriegen verübt hatten, ${ }^{231}$ für die Ermordung Đinđić' verantwortlich gemacht. Die »Roten Barette« wurden aufgelöst. ${ }^{232}$ Die serbische Politik deutete das Attentat als Warnung vor einer weiteren Verfolgung von Kriegsverbrechern, es brachte aber gleichzeitig die dringende Notwendigkeit einer Aufarbeitung der autoritären Vergangenheit und von Kriegsverbrechen offen zu Tage. Besonders machte es deutlich, wie viele Profiteure des MiloševićRegimes $^{233}$ und Kriminelle ${ }^{234}$ gegenwärtig noch in einflussreichen Positionen

229 Vgl. Cakić, Milan: »Lustracija u Evropi i Srbiji. Motivacija za donošenje zakona o lustraciji i njihove društvene funkcije« [Lustration in Europa und in Serbien. Motivation für die Gesetzgebung zu Lustration und ihre gesellschaftlichen Funktionen], in: Sociologija. Časopis za sociologiju, socijalnu psihologiju i socijalnu antropologiju 52 (2010) 3, S. 285-306.

230 Pavlaković, Vjeran: »Serbia Transformed?«, in: S. P. Ramet/ders. (Hg.): Serbia since 1989, S. 13-54, hier S. 39.

231 International Criminal Tribunal for the Former Yugoslavia: The Prosecutor v. Jovica Stanišić and Franko Simatović. Third Amended Indictment, Fall Nr. IT-03-69-PT vom 10.7.2008.

232 Denjenigen Mitgliedern, denen keine Verbrechen oder kriminellen Aktivitäten nachgewiesen wurden, wurden Positionen in anderen Polizeieinheiten angeboten. Vgl. Shentov, Ognian/Todorov, Boyko/Stoyanov, Aleksander: »Partners in Crime. The Risk of Symbiosis between the Security Sector and Organized Crime in Southeast Europe« (= CSD Report 13), Sofia: Center for the Study of Democracy 2004.

233 Miljković, Maja/Hoare, Marko Attila: »Crime and the Economy under Milošević and his Successors«, in: S. P. Ramet/V. Pavlaković (Hg.): Serbia since 1989, S. 192-226. 
waren beziehungsweise im Grenzbereich von Staat und Kriminalität eine Gegenmacht zur Regierung bildeten und den demokratischen Kurs des Landes bedrohten.

Obwohl der Chefanklägerin des ICTY noch wenige Tage zuvor der Besuch des Staatsbegräbnisses als »ungebetener Gast« verwehrt wurde -

»Svilanović und Konsorten waren offenbar übereingekommen, die Ermordung Đinđić’ zur Rechtfertigung ihrer mangelnden Kooperationsbemüungen zu nutzen, indem sie nun behaupteten, Đinđić sei genau deswegen getötet worden, weil er kooperiert hatte ${ }^{235}$-,

fand am 2. April ein inoffizielles Treffen zwischen Außenminister Svilanović und Carla Del Ponte statt. Die serbische Regierung ersuchte nun sogar die schnelle Bearbeitung der Anklagen von Jovica Stanišić, dem Chef des Staatssicherheitsdienstes im Innenministerium, der als zweiter Mann im MiloševićRegime galt, und Franko Simatović, dem Kommandeur der Einheit für Sondereinsätze, vor dem ICTY. Gleichzeitig räumte die serbische Regierung eine neue Strategie ein, wonach sie aus politischen Gründen in Zukunft keine Anklagen akzeptieren würde, die auf der »Verantwortlichkeit als Befehlshaber«, also einer indirekten Verantwortlichkeit für Kriegsverbrechen, aufbauen würden. ${ }^{236}$

Unter dem Eindruck des Attentats und der Ermittlungen danach veröffentlichten 29 NGOs einen Appell, in dem sie noch einen Schritt weiter gingen als das vorgeschlagene Lustrationsgesetz: Sie forderten von der Regierung, »alle Maßnahmen zu ergreifen, um all diejenigen aus der Legislative und den Regierungsbehörden zu entfernen, die in ihrem Tun oder Nichttun Kriegsverbrecher schützen $\aleph^{237}$. Besonders beschuldigten sie Präsident Vojislav Koštunica, die Führung der Sicherheitsapparate und der Armee zu schützen und die Serben dazu aufzurufen, mit den wegen Kriegsverbrechen in Den Haag Angeklagten zu sympathisieren. Am 13. Mai verhaftete die serbische Polizei Jovica Stanišić und Franko Simatović.

In dieser aufgeheizten und polarisierten Atmosphäre fand Ende Mai 2003 im serbischen Parlament die Debatte über ein Lustrationsgesetz statt, dessen Verab-

234 Zum historischen Hintergrund zwischen jugoslawischen beziehungsweise serbischen Strukturen der Sicherheitsapparate und dem organisierten Verbrechen siehe O. Shentov/B. Todorov/A. Stoyanov, »Partners in Crime«, S. 7 ff.

235 C. Del Ponte: Im Namen der Anklage, S. 257.

236 Ebd., S. 259.

237 Außenministerium der Republik Serbien: Daily Survey vom 26.3.2005, http://www. mfa.gov.rs/Bilteni/Engleski/b260303_e.html\#N11 vom 6.2.2013. 
schiedung unter dem Eindruck der aktuellen Ereignisse vorgezogen wurde. Im Parlament argumentierte die Regierungskoalition, dass man mit einem solchen Gesetz die autoritäre Vergangenheit bewältigen und die neue Demokratie stärken könne. Gerade unter dem Eindruck des Attentats auf Đinđić verwies sie darauf, dass die Verquickung zwischen staatlichen Institutionen und organisierter Kriminalität so effektiver bekämpft werden könne. Zudem benannte sie eine Lustrationsregelung als Bedingung für eine zukünftige Aufnahme Serbiens in die EU. Die Oppositionsparteien, die in den 90er Jahren an der Regierung beteiligt waren, positionierten sich gegen das Gesetz und bezeichneten es als ein Instrument, das auf die Schwächung politischer Gegner abziele. So bestünde die Gefahr, dass »unerwünschte« Personen aus den Geheimdiensten, der Polizei, dem Generalstab der Armee und der militärischen Aufklärung aus politischen Gründen entfernt und durch politische Freunde ersetzt werden könnten. Außerdem sei das vorgeschlagene Lustrationsgesetz unvereinbar mit der serbischen Gesetzgebung, da es selektiv und retroaktiv sei und gegen die Unschuldsvermutung verstoße. ${ }^{238}$ Während der Abstimmung befanden sich nur 127 von 250 Abgeordneten im Parlament. Die Radikale Partei boykottierte die Abstimmung und die Mitglieder der nationalkonservativen DSS verließen aus Loyalität gegenüber den ehemaligen Machthabern den Saal. Die als reformfreundlicher einzuschätzenden Parteien DS, GSS, Socijaldemokratska Unjia (Sozialdemokratische Union, SDU), Demohrišćanske Stranka Srbije (Christdemokratische Partei Serbiens, DHSS) und die unabhängigen Abgeordneten stimmten für das Gesetz, die Sozialistische Partei stimmte erwartungsgemäß dagegen. Schließlich wurde das »Gesetz über die Verantwortung für Menschenrechtsverletzungen « ${ }^{239}$ mit 111 Stimmen, einer Gegenstimme und 15 Enthaltungen vom Parlament verabschiedet. Der Weg für eine Öffnung der Geheimdienstakten schien frei. Nur zehn Monate nach der Verabschiedung dieses Gesetzes äußerte sich der Jurist Jovica Trkulja, Herausgeber der am Centar za unapređivanje pravnih studija (Zentrum für die Förderung juristischer Studien) erscheinenden Zeitschrift Hereticus. Časopis za preispitivanje prošlosti (Zeitschrift für die Überprüfung der Vergangenheit), im Vorwort der Themenausgabe Kontroverze oko lustracije (Kontroversen um die Lustration) dahingehend, dass das Gesetz nur ein »toter Buchstabe auf dem

238 Vgl. zur Parlamentsdebatte M. Cakić: »Lustracija u Evropi i Srbiji«.

239 Vgl. Volksversammlung der Republik Serbien: Zakon o odgovornosti za kršenje ljudskih prava [Gesetz über die Verantwortung für die Verletzung der Menschenrechte], in: Službeni glasnik RS 58 (2003). 
Papier « sei. ${ }^{240}$ Tatsächlich wurde das Lustrationsgesetz nie implementiert. Acht von neun erforderlichen Mitgliedern einer zukünftigen Lustrationskommission waren benannt worden, doch auf ein neuntes konnte man sich nicht einigen, und so nahm die Kommission ihre Arbeit nie auf.

Nachdem die Aufarbeitung von Kriegsverbrechen und vor allem die Zusammenarbeit mit dem ICTY öffentlich als sehr riskant gedeutet wurden, meldete sich die von Präsident Koštunica eingerichtete nationale Alternative zu Wort: Ebenfalls im Mai 2003 legten auch die Mitglieder der Wahrheits- und Versöhnungskommission ein Grundsatzdokument für die Arbeit der Kommission vor. Darin erklärten sie, ihr primärer Fokus läge auf den massiven Menschenrechtsverletzungen und Kriegsverbrechen während der Jugoslawienkriege. Als sekundären Arbeitsauftrag nannten sie darüber hinaus die Erforschung der Ursachen für die Konflikte in einer historischen Analyse, für die eine erstaunliche Zeitspanne, beginnend mit der Gründung des Königreichs der Serben, Kroaten und Slowenen 1918, angesetzt wurde. Nach der Präsentation des Grundsatzdokuments verschwand die Kommission, ohne dass sie je effektiv zum Arbeiten gekommen war. Die Streitereien über ihre Besetzung, ${ }^{241}$ Obstruktionen wie ein fehlendes Büro und mangelnde Finanzierung sowie das unklare Mandat-die unvereinbaren Positionen der Mitglieder schwankten zwischen der Perspektive der Opfer und der Gründe für diese, zwischen partieller und totalitärer Wahrheit - machten eine Arbeit unmöglich. Dejan Ilić vermutet in seiner Analyse, dass Präsident Koštunica und der jugoslawische Außenminister Svilanović mit der Kommission versuchten, sowohl eine Versöhnung der nationalen als auch der internationalen Perspektive zu forcieren, dies aber nicht nur an der Unmöglichkeit der Aufgabe, sondern vor allem an der Widerspenstigkeit von Mitgliedern wie Vojin Dimitrijević und Latinka Perović scheiterte. ${ }^{242}$ Die Kommission

240 Vgl. Trkulja, Jovica: »Uvodne napomene« [Einführende Bemerkungen], in: Hereticus. Časopis za preispitivanje prošlosti 1 (2003) 2, http://www.hereticus.org/ arhiva/2003-2/uvodne-napomene.html vom 6.2.2013.

241 Vgl. Freeman, Mark: Serbia and Montenegro. Selected Developments in Transitional Justice, International Center for Transitional Justice Briefing Paper vom 1.10.2004, http://www.ictj.org/images/content/1/1/117.pdf vom 16.9.2010, S. 7 ff. Im November 2002, nachdem auch Tibor Varadi sein Amt niedergelegt hatte und Bischof Sava verstorben war, sollte Koštunica vier neue Mitglieder nachbenennen. Er nominierte gleich mehrere neue Personen: Mira Bleham, Đorđe Vukadinović, Miomir Dašić, Mustafa Jusufspahić, Andrija Kopilović, Emir Kusturica, Ljubiša Lazarević, Slobodan Reljić und Ljiljana Smajlović.

242 Ilić, Dejan: »The Yugoslav Truth«. 
»designed to fail $\aleph^{243}$ kann als Schachzug Koštunicas gewertet werden, das ICTY zu delegitimieren und inländische Kritiker ruhig zu stellen, indem er eine Alternative im Land verfügbar machte. ${ }^{244}$ Gleichzeitig diente es als Mittel, um durch eine Suche nach Ursachen und Verursachern der Jugoslawienkonflikte die Verantwortung für Menschenrechtsverletzungen und Kriegsverbrechen bei anderen zu suchen. Serbische Täter konnten auf dieser Basis als Opfer dargestellt beziehungsweise die Anwendung von Gewalt gerechtfertigt und vernünftig begründet werden.

Auf nationaler Ebene blieben Kriegsverbrechen bis 2003 weitgehend unbearbeitet. Einem Untersuchungsbericht der OSZE zufolge wurden in der Bundesrepublik Jugoslawien von 1996 bis 2003 lediglich Ermittlungen in neun Fällen wegen des Verdachts auf Kriegsverbrechen eingeleitet. ${ }^{245}$ Auffällig sei, dass die Verwicklungen des Staates und der Sicherheitsorgane und die Untersuchung von Befehlsketten bei der Strafverfolgung unbetrachtet blieben. Auch die Unabhängigkeit und Rechtsstaatlichkeit der Gerichte sei aufgrund ausgebliebener Reformen im Justizwesen des Landes nicht garantiert. Bei den näher betrachteten Fällen konstatierten die Analysten Unzulänglichkeiten im Verfahren.

Erst in den Nachwehen des Attentats auf Premierminister Đinđić und dessen Untersuchung beschloss das serbische Parlament die Einrichtung von spezialisierten Gerichtskammern für besondere Straftaten - einerseits ein Sondergericht zur Ermittlung des Attentats und eine Kammer für organisierte Kriminalität und andererseits eine Kammer für Kriegsverbrechen. ${ }^{246}$ Mit dem »Gesetz zur Organisation und Zuständigkeit der Behörden für strafrechtliche Verfolgung von Kriegs-

243 J. Subotić: Hijacked Justice, S. 52.

244 Vgl. M. Fischer: Friedens- und Versöhnungsprozesse.

245 Vgl. OSCE Mission to Serbia and Montenegro: War Crimes Before Domestic Courts. OSCE Monitoring and Empowering of the Domestic Courts to Deal with War Crimes, Belgrad: OSCE 2003. Die erwähnten neun Fälle waren: Žuta osa am Bezirksgericht Sabač 1996, Kapitän Petrović et al. am Militärgericht in Niš, Orahovač vor dem Bezirksgericht Požarevac, Ivan Nikolić in Prokuplje 2001/2002, Štrpcil 2002 am Oberen Gericht Bijelo Polje, Montenegro, Mančić et al. am Obersten Militärgericht 2002, Podujevo erst am Bezirksgericht Prokuplje, dann am Bezirksgericht Belgrad 2007, Sjeverin am Bezirksgericht Belgrad 2002 und Ovčara am Bezirksgericht Novi Sad 2003.

246 Die Kammer für Kriegsverbrechen ist mit einem gesonderten Staatsanwalt für Kriegsverbrechen, einem eigenen Arrestbereich und einer eigenen Abteilung im Innenministerium zur Ermittlung von Kriegsverbrechen ausgestattet. 
verbrechen ${ }^{247}$ wurde im Juli des Jahres 2003 eine nationale Institution zur Strafverfolgung von Kriegsverbrechen am Bezirksgericht von Belgrad geschaffen. Die Kammer arbeitet eng mit dem ICTY zusammen, da »kleinere« Fälle an die nationalen Gerichte delegiert werden. Nach Abschluss der Arbeit und des Mandats des ICTY soll dann die Strafverfolgung gegen Kriegsverbrecher ganz von den nationalen Behörden übernommen werden. Die Kammer für Kriegsverbrechen hatte immense Anlaufschwierigkeiten und erhielt in den ersten Monaten und Jahren ihrer Arbeit kaum Unterstützung aus der Politik.

Im Oktober 2003 besuchte ICTY-Chefanklägerin Del Ponte Belgrad. Sie konstatierte, dass die serbische Regierung nur auf den massiven Druck der amerikanischen oder europäischen Konditionalitätspolitik hin kooperiere. $\mathrm{Zu}$ diesem Zeitpunkt bestand ihrer Ansicht nach die serbische »Strategie« darin,

»Mladić dem Tribunal auszuliefern, damit es ihm wegen des Völkermords in BosnienHerzegowina den Prozess machen konnte, und parallel dazu die bosnische Regierung zu bewegen, ihre Völkermord-Klage vor dem Internationalen Gerichtshof fallenzulassen ${ }^{248}$.

Hinsichtlich der Verbesserung der Beziehungen zu den Nachbarländern benutzte der Präsident der Staatsunion Serbien und Montenegro, Svetozar Marović, das Mittel symbolischer Entschuldigungen. Während eines Besuchs seines kroatischen Amtskollegen Stipe Mesić in Belgrad entschuldigte sich der Präsident »für alles Unheil, das Bürger Montenegros oder Serbiens in Kroatien verübt, angerichtet oder jemandem angetan haben ${ }^{249}{ }^{29}$. Er wolle sich nicht entschuldigen, weil er denke, dass beide Völker schuld seien oder weil es nötig wäre, dass sie sich entschuldigen, sondern um daran zu arbeiten, »dass jeder, der schuldig ist, sich stellt und sich vor dem Gesetz verantwortet $\aleph^{250}$. Dies sei eine der größten Verpflichtungen der Zusammenarbeit mit dem ICTY. Stipe Mesić bedankte sich für die Geste und erwiderte die Entschuldigung mit ähnlichem Wortlaut. Zwei Mo-

247 Volksversammlung der Republik Serbien: Zakon o organizaciji i nadležnosti državnih organa u postupku protiv učinilaca ratnih zločina [Gesetz über die Organisation und Kompetenzen von Staatsorganen im Verfahren gegen Täter von Kriegsverbrechen], in: Službeni glasnik RS 67 (2003).

248 C. Del Ponte: Im Namen der Anklage.

249 B92: »Marović i Mesić razmenili izvinjenja građanima Hrvatske i SCG« [Marović und Mesić tauschen Entschuldigungen bei den Bürgern Kroatiens und Serbien-Montenegros aus], in: b92.net vom 10.9.2003, http:/www.b92.net/info/vesti/index.php?yyyy= $2003 \& \mathrm{~mm}=09 \&$ dd $=10 \&$ nav_category=11\&nav_id=119131 vom 4.4.2013. 
nate später entschuldigte sich Marović bei einem Besuch in Sarajevo auch mit Blick auf den Bosnienkrieg:

»Ich entschuldige mich für alles Böse und Unglück, das jemand in Bosnien und Herzegowina durch jemanden aus Serbien und Montenegro erlitten hat. Ich sage, dass die Völker im Unrecht sind und nicht die Schuld und das Böse erdulden sollten, das Einzelne verursacht haben. ${ }^{251}$

\section{Koštunica als serbischer Premierminister}

Am 3. März 2004 wurde Vojislav Koštunica, der als einer der größten Kritiker des ICTY gilt, serbischer Premierminister. Seiner Meinung nach sollten serbische Angeklagte sich - wenn überhaupt - nur freiwillig dazu entscheiden, sich vor dem Gericht in Den Haag zu verantworten. Mit einer Zusammenarbeit mit dem ICTY würde man den nationalistischen Kräften im Land in die Hände spielen, dies bedrohe die innenpolitische Stabilität. Koštunica gab vor, einen »legalistischen ${ }^{252}$ Reformkurs zu vertreten, mit dem er zwar Đinđić' Politik der West- und EU-Integration fortsetzte, allerdings kam er den Forderungen der seine Regierung tolerierenden SPS nach, was bedeutete, die in Den Haag Inhaftierten zu unterstützten und keine weiteren Auslieferungen zuzulassen. Dementsprechend unkooperativ war die Zusammenarbeit mit dem ICTY 2003/2004.

Ende März 2004 verabschiedete das serbische Parlament das »Gesetz über die Rechte von Angeklagten in Gewahrsam des Internationalen Strafgerichtshofs für das ehemalige Jugoslawien und ihrer Familienangehörigen $«,{ }^{253}$ das nicht nur - wie bereits zuvor praktiziert - jenen Angeklagten in Den Haag, die sich

251 Beta: »Marović se u Sarajevu izvinio za zla počinjena BIH«, in: b92.net vom 13.11. 2003, http://www.b92.net/info/vesti/index.php?yyyy=2003\&mm=11\&dd=13\&nav\& nav_category=11\&nav_id=124553 vom 4.4.2013.

$252 »$ Legalism in post-Milosevic Serbia stands for the ideological basis for a practice in which personalized, partial and irresponsible state authority creates the conditions for socio-political insecurity and the routine violation of basic rights. In Serbia, legalists are those who identify themselves as defenders of the legal system in a political context in which the law is corrupted by the practices of illegal behaviour«, N. Dimitrijević: »Serbia after the Criminal Past«, S. 13.

253 Volksversammlung der Republik Serbien: Zakon o pravima optuženog u pritvoru međunarodnog krivičnog tribunala i članova njegove porodice [Gesetz über die Rechte Angeklagter im Arrest des Internationalen Strafgerichtshofs und ihrer Familienmitglieder], in: Službeni glasnik RS 35 (2004). 
freiwillig gestellt hatten, Hilfen zusagte, sondern auch auf Angeklagte wie Slobodan Milošević ausgedehnt wurde. Vorgeblich wolle man so die Kooperation mit Den Haag stärken und nicht Kriminelle finanzieren, wie von Seiten der Opposition und von internationalen Akteuren kritisiert wurde. Direkt nach Erlass des Gesetzes wurde zum 30. März 2004 eine US-Finanzhilfe in Höhe von 25 Millionen Dollar eingefroren. ${ }^{254}$

Gegen die kontraproduktive Haltung der Regierung hinsichtlich der Aufarbeitung von Kriegsverbrechen engagierten sich die Aktivisten des »anderen Serbien«. Eines der größten Projekte im Bildungsbereich war die Rubrik Hag među nama (Den Haag unter uns), in der die Tageszeitung Danas vom 9. April 2004 bis zum 9. Juni 2005 im wöchentlich Turnus eine Serie von Artikeln veröffentlichte, die sich mit Kriegsverbrechen und dem Umgang mit ihnen befasste. Die Reihe, die aus einer Kooperation zwischen Kandić' Fonds für Völkerrecht und der Danas entstand, versammelte Dokumentationen zu Kriegsverbrechen und kontroversen Fragen wie »War Serbien im Krieg?« sowie Artikel von Juristen, Publizisten, Schriftstellern, Historikern und Experten nationaler und internationaler Organisationen, die sich mit Fragen der transitional justice beschäftigten. Aus Sicht der Initiatoren aus dem Fonds für Völkerrecht steckte hinter der Serie die Idee, ein Klima zu ermöglichen, in dem sich Fragen der Verantwortung und des Rechts hinsichtlich Kriegsverbrechen als "prioritäre Frage der serbischen Gesellschaft« stellen ließen. Sie seien eine

»Antwort auf das Schweigen und die Leugnung der schrecklichsten Verbrechen, für die serbische Kräfte verantwortlich sind [...] sowie auf die entgegengesetzte offizielle Propaganda, die ständig wiederholt, dass es das Ziel des Haager Tribunals sei, das ganze serbische Volk auf die Anklagebank zu bringen ${ }^{255}$.

Die Texte der Rubrik zielten darauf ab, Gerechtigkeit für die Opfer von Kriegsverbrechen einzufordern und sich einer auf die Kriegsverbrechen der anderen Konfliktparteien verweisenden Relativierung von Kriegsverbrechen entgegenzustellen.

254 Grubanović, Saša: »Serbia \& Montenegro. Helping and Unhelpful«, in: Transitions online vom 6.4.2004, http://www.tol.org/client/article/11840-helping-and-unhelpful. $\mathrm{html}$.

255 Fond za humanitarno pravo (Hg.): Škorpioni. Od zločina do pravde [Die Skorpione. Vom Verbrechen zur Gerechtigkeit] (=Edicija: Dokumenti), Belgrad: Publikum 2007, S. 3. 
Auch der Europäische Rat reagierte auf die Haltung der serbischen Regierung, als er erneut Reformprioritäten und politische Kriterien im Rahmen einer europäischen Partnerschaft mit Serbien-Montenegro formulierte. Darin wurden Reformen in den Bereichen Verfassungsrecht, Institutionen, öffentliche Verwaltung, Justiz, Korruptionsbekämpfung, Menschenrechte, Minderheitenschutz, internationale Verpflichtungen und regionale Zusammenarbeit gefordert. Die Einhaltung internationaler Verpflichtungen meinte vor allem die Kooperation mit dem ICTY. Für die Aufarbeitung von Kriegsverbrechen sollte darüber hinaus die angemahnte Reform des Justizwesens zentral sein, die dessen Unabhängigkeit stärken sollte, sowie eine bessere Ausstattung der Gerichte und der zuständigen Staatsanwälte, die Kriegsverbrechen verfolgten. Außerdem forderte der Rat den Ausbau der nachbarschaftlichen Beziehungen in bilateralen Abkommen. Der Reformbedarf sollte erneut regelmäßig überprüft werden. ${ }^{256}$

Obwohl die Signale der amerikanischen Regierung und des Europäischen Rats eindeutig waren, verfolgte Präsident Koštunica den Kurs der Zugeständnisse an die national orientierte Klientel weiter. Im Juli ernannte er den in der Diplomatie erfahrenen, Milošević-loyalen SPS-Politiker Nebojša Vujović als Sonderbeauftragten für die Beziehungen zum Tribunal. Wirklich sicher, nicht verhaftet und ausgeliefert zu werden, konnten vom ICTY Gesuchte aber nicht sein. Goran Hadžić, der ehemalige Präsident der Republika Srpska Krajina, floh in Reaktion auf die Anklageerhebung in Den Haag aus Novi Sad und tauchte unter. Auch nachdem Boris Tadić das seit 2002 vakante Amt des serbischen Präsidenten einnahm, änderte sich zunächst nichts am Verhältnis zum Tribunal.

Diesen Umstand nahm auch die parlamentarische Versammlung des Europäischen Rats im Oktober 2004 zum Anlass für eine erste Resolution bezüglich Serbien und Montenegro. Zwar hob sie die nach dem Attentat auf Đinđić eingeleiteten Reformen als positiv heraus, die Haltung führender Politiker gegenüber und deren Kampagnen gegen das ICTY schätzte sie hingegen als Hindernisse für die Zukunft des politisch volatilen Landes ein. Bezüglich der Kammern für organisiertes Verbrechen und für Kriegsverbrechen rief sie dazu auf, jegliche politische Einmischung in die Prozesse zu unterlassen. Hinsichtlich der Verpflichtungen gegenüber dem ICTY forderte die parlamentarische Versammlung zur

256 European Council: Council Decision of 14 June 2004 on the principles, priorities and conditions contained in the European Partnership with Serbia and Montenegro including Kosovo as defined by the United Nations Security Council Resolution 1244 of 10 June 1999, in: Official Journal of the European Union L 227 vom 26.6.2004. 2006 und 2008 wurde die europäische Partnerschaft jeweils erneuert, ohne aber die vom Land geforderten Reformprioritäten weitreichend zu ändern. 
sofortigen und bedingungslosen Kooperation auf. Auch auf nationaler Ebene sollte Personen, die man verdächtigte, Kriegsverbrechen begangen zu haben, der Prozess gemacht werden, und insbesondere war die Strafverfolgung gegen die Mörder der über 800 Kosovo-Albaner voranzutreiben, die in Massengräbern in Batajnica und an anderen Stellen auf serbischem Territorium gefunden worden waren. Zudem sollte die Öffentlichkeit in einer Kampagne über die Verbrechen des Milošević-Regimes informiert und die Einstellungen der Politiker gegenüber dem ICTY einem Wandel unterzogen werden. ${ }^{257}$

Im Dezember 2004 attestierte ICTY-Chefanklägerin Del Ponte Serbien in ihrem Bericht an den UN-Sicherheitsrat eine Verschlechterung der Zusammenarbeit. Statt die Zusammenarbeit mit dem Tribunal zu verbessern, wurde der Präsident des Landes erneut mit Symbolpolitik aktiv. Weniger als ein halbes Jahr nach seinem Amtsantritt entschuldigte er sich während eines Staatsbesuchs in Sarajevo:

"Ich entschuldige mich bei allen, gegen die ein Verbrechen im Namen des serbischen Volks verübt wurde, aber diese hat nicht das serbische Volk begangen, sondern Verbrecher und Einzelne. Es ist unmöglich, ein ganzes Volk anzuklagen. Die gleichen Verbrechen wurden auch gegen unser Volk ausgeführt und in diesem Sinn schulden wir uns alle eine Entschuldigung. Falls ich der Erste sein muss, der beginnt - bitte, hier bin ich. Um Vertrauen herzustellen, ist es für mich entscheidend, dass alle Verbrecher sich für die Verbrechen verantworten, dass es keinen einseitigen Ansatz den Verbrechen gegenüber gibt und dass es keine Protektion gibt, wenn Verbrechen gegen Bosniaken, Kroaten oder Serben zur Debatte stehen. ${ }^{258}$

Die Reaktionen in Belgrad fielen gemischt aus. Während ein Vertreter der DSS sagte, Worte seien weniger wichtig als Taten, äußerte ein SPS-Abgeordneter Unverständnis über die Frage, warum sich die Serben für Verbrechen entschuldigen müssten, die auf dem Gebiet Bosnien-Herzegowinas begangen worden waren. Tomislav Nikolić von der Radikalen Partei kritisierte die Entschuldigung des Präsidenten, da unklar sei, für wen er spreche und wovon: »Im Namen wel-

257 Parliamentary Assembly of the Council of Europe: Functioning of Democratic Institutions in Serbia and Montenegro, Resolution Nr. 1397 vom 5.10.2004.

258 B92: »Tadić: Svi dugujemo izvinjenje« [Tadić: Alle schulden eine Entschuldigung], in: b92.net vom 6.12.2004, http://www.b92.net/info/vesti/index.php?yyyy=2004\&mm $=12 \& \mathrm{dd}=06 \&$ nav_category $=11 \&$ nav_id=157274 vom 21.2.2013. 
ches Serben hat sich Tadić entschuldigt und welcher Serbe hat Kriegsverbrechen begangen? « ${ }^{259}$

Aufgrund der ausbleibenden Kooperation mit dem ICTY erklärte der amerikanische Außenminister im Januar 2005, dass Serbien die vom US-Kongress aufgestellten Bedingungen nicht erfülle; der amerikanische Botschafter in Serbien kündigte an, bereits gewährte Hilfsmittel würden gestrichen und technische Berater abgezogen. Schließlich froren die USA Finanzhilfen in Höhe von 40 Millionen Dollar ein. Auch die EU erklärte nun die Kooperation mit dem ICTY zur höchsten Priorität in den Beziehungen mit Serbien, indem EUErweiterungskommissar Olli Rehn signalisierte, Belgrads Verweigerungshaltung sei ein Hindernis für Serbien auf dem Weg in die EU.

Auf diese konzertierten Maßnahmen reagierte die Regierung Koštunica mit der Strategie der »freiwilligen Auslieferung«, einer Politik, die schon der kroatische Premierminister Sanader praktizierte. ${ }^{260}$ Den vom ICTY Angeklagten wurde Straffreiheit nach ihrer Rückkehr nach Serbien zugesagt, wenn sie sich im Gegenzug freiwillig dem ICTY stellten. Durch öffentlichen, moralischen Druck in den Medien und auch der serbisch-orthodoxen Kirche wurden sie zur Selbstauslieferung gedrängt. Zudem lockte der Staat Familienangehörige mit finanzieller Unterstützung. ${ }^{261}$ Die Selbstauslieferung wurde zu einem Opfer für das Vorwärtskommen Serbiens, die Auslieferungen als Bedingung der internationalen Gemeinschaft hierfür dargesetellt. ${ }^{262}$ Die Inhalte der Anklagen wurden nicht thematisiert. Die Regierung und die Kirche konnte die für die Erfüllung von Konditionalitäten erforderliche Kooperation diskursiv so transformieren, dass es für die Angeklagten zu einer patriotischen Pflicht wurde, sich selbst auszuliefern. Dieser Akt der Selbstopferung ermöglichte ein Deutungsmuster, nach dem angeklagte serbische »Kriegshelden« sich nun erneut für das Kollektiv hingaben und somit zu einer Art Märtyrer der eigenen ethnischen Gruppe wurden. Die eigentliche Intention des Tribunals oder eine Auseinandersetzung mit der Vergangenheit aus moralischen Gründen wurde nicht thematisiert.

Kurz vor der Machbarkeitsstudie für die Aufnahme von Verhandlungen über ein Stabilisierungs- und Assoziationsabkommen der Europäischen Kommission konnten durch die Politik der freiwilligen Auslieferung bis April 2005 sogar 14 (!) Namen auf den Fahndungslisten des ICTY als freiwillig gestellt verzeichnet

259 Ebd.

260 V. Peskin: International Justice, S. 84.

261 Vgl. Volksversammlung der Republik Serbien: Zakon o pravima optuženog.

262 Vgl. V. Peskin: International Justice, S. 84. 
werden. ${ }^{263}$ Auf dieser Grundlage fiel die Machbarkeitsstudie positiv aus und Verhandlungen stand nun nichts mehr im Wege. Die Kommission bewertete die Zusammenarbeit mit dem ICTY aber durchaus kritisch. So bezog sie sich auf den negativen Bericht der Chefanklägerin im Vorjahr. Zwar räumte sie ein, dass der Nationale Rat die Zusammenarbeit mit dem ICTY bessere koordinierte, stellte aber fest, dass dessen Beschlüsse von Personen in den Behörden oder in der Armee obstruiert würden. Trotz der freiwilligen Selbstauslieferung sei noch eine große Anzahl gesuchter Personen in Freiheit, weshalb die Regierung Maßnahmen ergreifen müsse. Die nationalen Gerichte würden gut mit dem ICTY zusammenarbeiten, auch wenn es noch an Kapazitäten mangele. Die Kommission gab allerdings weiterhin zu bedenken, dass »the overall political climate is such that there is no guarantee that any high profile war crimes trails could be conducted in a fair and transparent manner ${ }^{264}$.

\section{Debatte über eine Deklaration zur Verurteilung Srebrenicas}

Der bevorstehende 10. Jahrestag des Massakers von Srebrenica triggerte eine Mobilisierung von serbischen zivilgesellschaftlichen Akteuren, die für bestimmte Formen der Vergangenheitsaufarbeitung stehen und unterschiedliche Interessen verfolgten. Das Helsinki-Komitee, das Komitet pravnika za ljudka prava (Anwaltskomitee für Menschenrechte), der Belgrader Kreis, die Frauen in Schwarz, die Initiative Junger für Menschenrechte, die Bürgerliche Initiative, das Zentrum für kulturelle Dekontamination und der Fonds für Völkerrecht setzten sich für eine Verurteilung des Kriegsverbrechens von offizieller Seite ein. Sie veröffentlichten Ende April einen offenen Brief an Präsident Tadić und Premierminister Koštunica, den sie darüber hinaus an die Botschaften der USA, Kanadas, Russlands, an das Büro des Europarates und an die Delegationen der EU sandten. Wenige Wochen darauf fand an der Belgrader Rechtsfakultät anlässlich des 10. Jahrestags der »Befreiung« von Srebrenica eine vom studentischen, reli-

263 Freiwillig lieferten sich aus: Dragomir Milošević, Vladimir Lazarević, Milan Gvero, Radivoje Miletić, Momčilo Perišić, Mićo Stanišić, Gojko Janković, Vinko Pandurević, Ljubomir Borovčanin, Sreten Lukić, Vujadin Popović und Nebojša Pavković.

264 European Commission: Report on the Preparedness of Serbia and Montenegro to negotiate a Stabilisation and Association Agreement with the European Union. Commission Staff Working paper, EU-Dok. SEC (2005) 478 final vom 12.4.2005, S. 11. 
giös-nationalistischen Verein Nomokanon ${ }^{265}$ veranstaltete Podiumsdiskussion statt, die nach ersten Protesten in »Die Wahrheit über Srebrenica« umbenannt wurde. Auf dem Podium saßen der pensionierte General Radovan Radinović, die Journalistin Liljana Bulatović, Milivoje Ivanišević vom Zentrum für die Erforschung der Verbrechen am serbischen Volk sowie der Rechtsanwalt Dragoslav Ognjanović, der dem Verteidigerteam von Slobodan Milošević angehörte. Bei der Diskussion trafen die Organisatoren und protestierende Gegner der Veranstaltung aufeinander, aufgrund der vielfachen Leugnungen des Verbrechens wurde die Veranstaltung zu einem Eklat und Politikum. In der Folge äußerten sich ungewöhnlich viele Akteure öffentlich. Vertreter des NGO-Sektors verurteilten die Leugnung von Srebrenica, Professoren und der Dekan der Rechtsfakultät distanzierten sich von der Veranstaltung. Die Organisatoren von Nomokanon rechtfertigten sich damit, dass die Podiumsdiskussion eine akademische Konferenz gewesen sei, und verwiesen auf die akademische Freiheit. Auch Präsident Tadić verteidigte die Veranstaltung mit der Meinungsfreiheit, woran sich eine Debatte über die Frage anschloss, ob die akademische Freiheit und die Meinungsfreiheit der Leugnung von Kriegsverbrechen Vorschub leisteten.

Nur wenige Tage später veranstaltete das Zentrum für Antikriegsaktion im Zentrum für kulturelle Dekontamination die Podiumsdiskussion »Unser Verhältnis zu Srebrenica«. Hier saßen mit Nataša Kandić, Milan St. Protić, Žarko Korać, Vladimir Beba Popović und Vesna Pešić Vertreter des NGO-Sektors und liberale, reformunterstützende Politiker auf dem Podium. Nataša Kandić identifizierte die JNA, die Organe der Staatssicherheit und paramilitärische Einheiten als Schuldige für das Massaker und betonte damit die serbische Verantwortung. Die Parlamentsabgeordneten Nataša Minčić (GSS) und Žarko Korać (SDU) kündigten an, einen Vorschlag für eine Resolution zur Verurteilung von Srebrenica ins Parlament einzubringen, die von acht NGOs verfasst und von 50 NGOs unterstützt worden war. Auch die Internationale Helsinki-Föderation für Menschenrechte, die Europäische Bewegung in Serbien und die Igmanska Inicijativa, eine Schirmorganisation von NGO-Vertretern, Politik- und Wirtschaftsanalysten, Medien und Regierungsvertretern, riefen zu einer Unterstützung der Deklaration auf.

Am 1. Juni 2005 strahlten die serbischen Fernsehsendern B92 und RTS das sogenannte Škorpioni-Video aus, nachdem es kurz zuvor im Rahmen einer Ver-

265 Nomokanon bezeichnet in der Orthodoxie eine spezielle Art der Rechtskodifizerung, die aus dem Staatskirchenrecht (nomos) und dem Synodalrecht (kanon) besteht. Die Studentenorganisation bezieht sich auf die Lehre des im 12. Jahrhundert verstorbenen serbischen Heiligen Sava. 
handlung in Den Haag gezeigt wurde. Es war Nataša Kandić zugespielt worden, die das Video an das ICTY weitergeleitet hatte. ${ }^{266}$ Der kurze Ausschnitt, der im serbischen Fernsehen zu sehen war, zeigte die Minuten vor der Erschießung sechs bosnischer Muslime durch serbische Paramilitärs in der Nähe von Srebrenica im Juli 1995. Die Einheit der »Skorpione« bestand aus serbischen Staatsbürgern und unterstand nach Informationen des ICTY dem serbischen Innenministerium. Das Video sorgte für Furore und wurde in sämtlichen Medien tagelang breit thematisiert und diskutiert. ${ }^{267}$ Erstmals wurde der breiten Öffentlichkeit in Serbien deutlich, dass serbische Staatsbürger an Kriegsverbrechen beteiligt waren und dass man nicht mit der Behauptung, auf dem Territorium des serbischen Staates habe kein Krieg stattgefunden, auf andere Tätergruppen verweisen konnte. Zum Zeitpunkt der Ausstrahlung in Serbien war auch Carla Del Ponte in Belgrad, die die Erwartung formulierte, dass Ratko Mladić bis zum 11. Juli verhaftet würde. Noch am Tag der Sendung des Videos kündigte der Sonderbeauftragte für die Kooperation mit dem ICTY, Rasim Ljajić, an, dass das Verbrechen, das von Einzelnen begangen worden sei, von der Staatsanwaltschaft der nationalen Kammer für Kriegsverbrechen am Bezirksgericht Belgrad untersucht werden würde. Bereits am nächsten Tag wurde verkündet, dass zehn Mitglieder der Skorpione verhaftet worden seien. Nach einigen Tagen lautete das von Politik und Medien offiziell kommunizierte Deutungsmuster über das Video, dass diese Verbrechen als »individual crimes of obviously deranged individuals $\ll^{268}$ zu werten sei. Die Verstrickungen der Skorpione mit Staatsorganen, die Befehls- und Entscheidungsstrukturen hinter dem Verbrechen thematisierten die Offiziellen nicht. Nachdem die Frage der Strafverfolgung geregelt schien, ebbte das mediale Interesse schnell ab, ohne dass ein nachhaltiger öffentlicher Diskurs über die Frage der serbischen Kriegsverbrechen geführt wurde, wie Vertreter von NGOs gehofft hatten.

Noch immer stand die Frage einer serbischen Deklaration aus, die nach der Veröffentlichung des Videos von allen politischen Kräften aufgenommen wurde. Der serbische Außenminister Drašković deutete die Erschießungen durch die Skorpione patriotisch um, statt Verbrechen gegen die muslimische Bevölkerung seien dies auch Verbrechen gegen das serbische und montenegrinische Volk gewesen. Repräsentanten der amerikanischen Botschaft drohten wegen der mangelnden Kooperation Serbiens mit dem ICTY einen negativen Bericht über Serbien im US-Kongress an. Zudem gab Rasim Ljajić, Minister für Minderheiten

266 Vgl. Fond za humanitarno pravo: Škorpioni, S. 7 ff.

267 Ebd.

268 J. Subotić: Hijacked Justice, S. 63. 
und Vorsitzender des Rats für die Zusammenarbeit mit dem ICTY, bekannt, dass der US-Kongress eine Resolution zu verabschieden beabsichtige, in welcher der Völkermord von Srebrenica verurteilt und der 11. Juli als Gedenktag eingerichtet werden soll. ${ }^{269}$ Er mutmaßte nach einem mehrtägigen Besuch in Washington zudem öffentlich, dass der vom Kongress vorbereitete Bericht »über uns« nach dem Fall der Skorpione ohnehin negativ ausfallen werde, da seine Glaubwürdigkeit und die Serbien-Montenegros durch das Video und die Berichterstattung darüber in Frage gestellt worden sei. ${ }^{270}$ Der Staat dürfe sich nicht weiter nur verteidigen, sondern müsse nun schnell und entschlossen reagieren:

»Es ist besser anzuerkennen, dass sich das Verbrechen ereignet hat. Dieses Verbrechen haben Serbien und Montenegro nicht als Staat begangen, die Schuld muss man individualisieren, die Schuldigen müssen vor Gericht, müssen sich verantworten, und ich denke, das ist vor allem im Interesse Serbiens und Montenegros. Im Gegenteil, wir werden als Staat, der nicht bereit ist, sich mit seiner jüngsten Vergangenheit auseinanderzusetzen, ständigem Druck ausgesetzt sein. « ${ }^{271}$

Weiterhin versicherte Ljajić, es werde eine Ministerratserklärung geben, falls keine adäquate und entschiedene Reaktion der Regierung und der ganzen Öffentlichkeit zustande käme, um Srebrenica zu verurteilen. ${ }^{272}$

Die Frage, ob es eine Deklaration über Srebrenica geben solle, entfachte zwischen den im Parlament vertretenen Parteien eine Kontroverse, die von großer Polemik geprägt war. Breit wurde diskutiert, ob eine solche Deklaration den Interessen Serbiens und dem Land schade. In der nationalen Öffentlichkeit, aber auch im Ausland, entstand so zwangsläufig der Eindruck von mangelnder Kons-

269 Der Hinweis darauf kam von Rasim Ljajić, vgl. Anastasijević, Dejan: »Srebrenica za početnike« [Srebrenica für Anfänger], in: Vreme vom 2.6.2005, S. 18. Daraus gingen hervor: United States Senate: A Resolution Expressing the Sense of the Senate Regarding the Massacre at Srebrenica in July 1995, S.Res. 134 vom 22.6.2005, sowie United States House of Representatives: Expressing the Sense of the House of Representatives Regarding the Massacre at Srebrenica in July 1995, HRES 199 EH vom 27.6.2005.

270 O. V.: »Rasim Ljajić«, in: Blic vom 3.6.2005, S. 5.

271 O. V.: »Srbija hapsi ubice iz `Škorpionaく. Srebrenica, deset godina posle: součavanje sa zločinom « [Serbien verhaftet die Mörder der »Skorpione«. Srebrenica, zehn Jahre danach: Auseinandersetzung mit dem Verbrechen], in: Dnevnik vom 3.6.2005, S. 14.

272 Preneto: »Ameri zgroženi« [Amerika angewidert], in: Kurir vom 3.6.2005, S. 4. 
truktivität und Ernsthaftigkeit im Umgang mit Kriegsverbrechen, die einen anderen politischen Modus hätte erwarten lassen, wie eine kollektive Verurteilung durch alle politischen Kräfte. Nachdem zunächst alle Fraktionen des Parlaments signalisiert hatten, sie würden Srebrenica verurteilen, wurde schnell deutlich, dass die vorgeschlagene Resolution der NGOs aus vorgeschobenen formalen Gründen nicht übertragen werden sollte und nicht von allen Fraktionen mitgetragen wurde. Zwischen den Fraktionen entwickelten sich Konflikte um den konkreten Inhalt einer Resolution, da sie die Verurteilung Srebrenicas zum Anlass nahmen, um im Allgemeinen die Frage der "Wahrheit« über die Kriege, des Umgangs mit Kriegsverbrechen und der Verantwortung zu thematisieren. Während die nationalistischen Kräfte auf der serbischen Opferposition beharrten, räumten reformorientierte Fraktionen eine Verantwortung von serbischen Staatsbürgern und des serbischen Staats unter Milošević ein. Allen gemeinsam war eine Distanzierung von dem Verbrechen. DS, Srpski Pokret Obnove (Serbische Erneuerungsbewegung, SPO) und Sozialdemokraten strebten eine Verurteilung Srebrenicas in einer gesonderten Resolution an, während sich SRS, SPS und DSS dagegen stellten und eine gemeinsame Verurteilung aller Kriegsverbrechen forderten. Während der polemischen Auseinandersetzung der Parteien positionierten sich auch andere gesellschaftliche Akteure.

Nach tagelangem Schweigen äußerte sich die serbisch-orthodoxe Kirche in einer Pressemitteilung zu dem im Skorpion-Video gezeigten Pater Gavrilo, der die Täter gesegnet hatte. Unter dem Titel »Herr, lass es nicht wieder geschehen!« verurteilte sie die Erschießungen, bewertete das Verhalten der Täter als beschämend und zivilisierten Menschen unwürdig und drückte ihre Anteilnahme am Leiden der unschuldigen Zivilisten aus. Pater Gavrilo nahm sie hingegen in Schutz, indem sie auf den getrennten Charakter von Segnung und Erschießung hinwies und anführte, dass es »wirklich nicht leicht ist, abzuschätzen oder im Voraus zu beurteilen, was nach einem gemeinsamen Gebet geschieht, vor dem Aufbruch der Soldaten auf das Schlachtfeld ${ }^{273}$. Die Kirche erklärte, sie sei bereit, alles Nötige zu tun, damit sich eine solche Szene nicht wiederhole, und rief weiterhin dazu auf, die Schuldzuweisungen zu unterlassen. ${ }^{274}$

Die Jugend der DS protestierte in Reaktion auf die parteipolitische Auseinandersetzung gegen die Relativierung von Kriegsverbrechen und der Fonds für Völkerrecht veranstaltete gemeinsam mit dem Belgrader Büro des ICTY im $\mathrm{Sa}$ -

273 O. V.: »SPC osudila zločin Škorpiona« [Serbisch-orthodoxe Kirche verurteilt das Verbrechen der Skorpione], in: Glas Javnosti vom 11.6.2005, S. 2.

274 Tašić, Jelena: »Gospode, ne ponovilo se« [Herr, lass es nicht wieder geschehen!], in: Danas vom 11.6.2005, S. 4. 
va Centar die große Konferenz Srebrenica - izvan osnovane sumnje (Srebrenica - ohne grundlegende Zweifel), ${ }^{275}$ die einen Dialog verschiedener Seiten ermöglichte. Neben den Organisatoren, Nataša Kandić und Alseksandra Milenov, sprachen Mirsad Tokać vom Istraživački-dokumentacioni centar (ForschungsDokumentationszentrum) in Sarajevo, das die Arbeit der Kommission zur Sammlung von Daten über Kriegsverbrechen der Präsidentschaft BosnienHerzegowinas seit 2004 als NGO fortsetzt, der Journalist Emir Suljagić, der als Dolmetscher für die Blauhelmsoldaten Srebrenica überlebte, die serbische Landwirtschaftsministerin Ivana Dulić-Marković, die als Bürgerin Serbiens sprach, der Politiker und Historiker Milan St. Protić, Behara Husanović als Zeugin und direkt vom Massaker Betroffene, die drei Familienmitglieder verlor, sowie Amor Mašović von der Stiftung für ein Gedenkzentrum in SrebrenicaPotočari.

Auch das nationalistische Lager organisierte sich. Erste Anzeichen waren Graffiti in der Innenstadt Belgrads mit den Slogans »Befreites Srebrenica« und »Skorpione-serbische Helden«, das Sava Centar wurde vor der Konferenz »Srebrenica - Ohne grundlegenden Zweifel« mit Graffiti besprüht, die Ratko Mladić ehrten, ähnliche Graffiti tauchten gemeinsam mit faschistischen Symbolen auch in Niš auf. ${ }^{276}$ Nationalistische Positionen wurden vor allem von Personen aus der Republika Srpska geäußert und von Opferverbänden vertreten. Slavko Jovičić, der stellvertretende Vorsitzende des Koordinationszentrums von elf NGOs aus der Republika Srpska, beschrieb die Konferenz im Sava Centar als einseitig, man habe nur die eine, antiserbische Wahrheit gehört, auch sei keine Organisation aus der Republika Srpska eingeladen worden. Es gäbe keine kleinen und keine großen Verbrechen, Verbrechen sei Verbrechen:

»Bei Verbrechen gibt es keinen Kompromiss, sie passieren oder sie passieren nicht, und wie bekannt ist, sind sie in Bosnien-Herzegowina auf allen Seiten passiert. Mit einem selektiven Zugang und der Herstellung von Lügen, wie man sie in Belgrad hörte, wird nie die Wahrheit herausgefunden, die die einzige Voraussetzung für eine Versöhnung der Völker in Bosnien-Herzegowina ist. Bei den Organisatoren und Teilnehmern an der Kon-

275 Vgl. Torov, Ivan: »Zatrpavani zločini. Između dve nedelje« [Verschüttete Verbrechen. Zwischen zwei Sonntagen], in: Politika vom 12.6.2005, S. A8; Tončić, Bojan: $»$ Dok predsednik Tadić ne prizna zločin ne možemo dalje. Konferencija ১Srebrenica: Van osnovane sumnje« « [Solange Präsident Tadić das Verbrechen nicht anerkennt, können wir nicht weiter. Konferenz »Srebrenica: Ohne grundlegende Zweifel«], in: Danas vom 13.6.2005, S. 4.

276 Vgl. ebd. 
ferenz handelt es sich um eine antiserbische Lobby, die aus dem serbischen Volk Unglückliche machen. $\ll^{277}$

Weit diplomatischer war der Präsident der Republika Srpska, Dragan Čavić, einige Tage zuvor, als er das Verbrechen der Skorpione verurteilte. Er interpretierte Kriegsverbrechen als Verbrechen gegen das eigene Volk. So habe, wer ein Verbrechen im Namen seines Volkes begangen habe, ein Verbrechen gegen sein Volk begangen. Mehr als 20.000 Serben hätten ihr Leben im Kampf für ihr Volk verloren, aber die Verbrecher hätten ihr Gesicht verloren, da sie es nicht erwarten könnten, dass das ganze serbische Volk wegen ihnen leide. Allerdings könnten nur die Serben die Wahrheit darüber herausfinden, was sich während des Krieges ereignet habe, ohne Rücksicht darauf, wie hässlich diese Wahrheit sei. ${ }^{278}$ Damit kritisierte er implizit die Wahrheitsfindung durch das ICTY.

Der Odbor porodica žrtava rata (Rat der Familien von Kriegsopfern) und der Savez logoraša i boračkih organizacija (Bund der Lagerinsassen und Veteranenorganisationen) veröffentlichten gemeinsam mit dem Zentrum für die Erforschung der Verbrechen am serbischen Volk einen Artikel mit der Aussage, dass auf dem Gebiet um Srebrenica von 1992 bis 19953277 Serben »gelitten haben «, also getötet wurden. ${ }^{279}$

Gerade die national orientierten Parteien nahmen Argumente aus der Republika Srpska und der Opfergruppen auf. Die SRS ging sogar noch einen Schritt weiter und sagte, man müsse alle Verbrechen gleichermaßen verurteilen, um mit der offenen antiserbischen Hysterie und den Beschuldigungen auf Kosten des serbischen Volkes und des serbischen Staats zu brechen. Heute sei völlig klar, dass viele in und außerhalb Serbiens um jeden Preis die Schuld für alle Verbrechen Serbien zur Last legten, seiner damaligen politischen Führung, aber auch des serbischen Volks in Serbien, der Republika Srpska und der Republika Srpska Krajina. Die Anschuldigungen gegen Serbien und das serbische Volk hälfen den Kampagnen zur Aufhebung der Republika Srpska und der Auslösung des Kosovo aus Serbien. ${ }^{280}$

277 O. V.: »Čula se samo antisrpska istina« [Man hört nur die antiserbische Wahrheit], in: Glas Javnosti vom 13.6.2005, S. 2.

278 O.V: »Dragan Čavić osudio zločin« [Dragan Čavić verurteilt Verbrechen], in: Glas Javnosti vom 11.6.2005, S. 4.

279 O. V.: »Ubijeno 3277 Srba!« [3277 Serben getötet!], in: Večernje Novosti vom 13.6.2005, S. 7.

280 Preneto: »SRS: Antisrpska histerija « [SRS: Antiserbische Hysterie], in: Politika vom 12.6.2005, S. A7. 
Bojan Kostreš von der Liberaldemokratischen Partei der Vojvodina kündigte eine Resolution im Regionalparlament der Vojvodina an, falls es keine Deklaration auf Landesebene geben sollte. Auch die Resolution in der Vojvodina sollte später scheitern. ${ }^{281}$ Journalisten schürten mit Blick auf das noch ausstehende Urteil des Internationalen Gerichtshofs Angst vor Reparationszahlungen. ${ }^{282}$

Schließlich kam keine gemeinsame Deklaration zustande, da sich die Fraktionen nicht auf einen gemeinsamen Text einigen konnten. Die Folge war wie Obrad Savić treffend formulierte eine »bizarre hyperinflation of declarations $\aleph^{283}$ : Alle Fraktionen verfassten eigene Deklarationen, die jeweils die eigene Lesart zu Srebrenica und den Jugoslawienkriegen widerspiegelten und auf die an anderer Stelle ausführlich eingegangen wird.

In Reaktion auf das Scheitern eines gemeinsamen serbischen Papiers aller Fraktionen kündigte die montenegrinische Regierung eine eigene Deklaration an für etwas, das sie nicht begangen hätten, aber auch sie seien Teil der Kriegsmaschinerie Milošević' gewesen und müssten andere Verbrechen aufarbeiten. ${ }^{284}$ Schließlich verurteilte, wie von Ljajić zugesagt wurde, der Ministerrat von Serbien-Montenegro Srebrenica auf das Schärfste. Die SPS kritisierte, diese Erklärung des Ministerrats habe gegen die Interessen der Staatenunion verstoßen. ${ }^{285}$

Nach knapp zwei Wochen intensiver Diskussion flaute die Debatte über Srebrenica ab, die Medien reflektierten konkrete Ereignisse und die Frage, ob Präsident Tadić zur Gedenkfeier nach Srebrenica fahren soll, in deutlich kleinerem Umfang. Die DS veranstalte eine Podiumsdiskussion unter dem Titel »10 Jahre danach - Wir verlangen Verantwortung «. Sie bekräftigte, dass es eine Deklaration geben müsse, um die Diskontinuität mit dem Milošević-Regime zu mar-

281 O. V.: »Ako neće Srbija hoće Vojvodina. Bojan Kostreš o Deklaraciji o Srebrenici« [Wenn nicht Serbien, will die Vojvodina. Bojan Kostreš über die Deklaration über Srebrenica], in: Večernje Novosti vom 10.6.2005, S. 4.

282 Vgl. Smajlović, Liljana: »Srebrenica kao sudbina« [Srebrenica als Schicksal], in: NIN vom 2.6.2005, S. 16.

283 Savić, Obrad: »Srebrenica. Between Denial and Recognition«, in: Eurozine vom 8.7.2005, http://www.eurozine.com/articles/2005-07-08-savic-en.html vom 26.5.2010.

284 Preneto: »Izvinjenje i Podgorice« [Entschuldigung auch aus Podgorica], in: Večernje Novosti vom 15.6.2005, S. 15.

285 Preneto: »Šteti državnim interesima. SPS protiv izjave Saveta ministara« [Schadet staatlichen Interessen. SPS gegen die Äußerung des Ministerrats], in: Politika vom 17.6.2005, S. A5. 
kieren, und dass Präsident Tadić nach Srebrenica fahren würde. ${ }^{286}$ Gleichzeitig äußerte der serbische Innenminister Dragan Jočić, dass die Skorpione in keiner Verbindung zum Innenministerium gestanden hätten, und manifestierte damit für die Öffentlichkeit, dass es keine staatliche Verwicklung in das Kriegsverbrechen gab. ${ }^{287}$

Wenige Tage vor dem Jahrestag des Massakers veranstaltete die SRS ein öffentliches Meeting unter dem Titel Istina (Wahrheit). Über 5000 Besucher, unter ihnen auch viele Politiker und hochrangige Personen des öffentlichen Lebens wie Patriarch Pavle, hörten eine Rede des stellvertretenden Parteivorsitzenden Tomislav Nikolić, bevor sie den Film Istina sahen, der mit einer Kompilation von Kriegsverbrechen gegen Serben auf dem Territorium des ganzen ehemaligen Jugoslawien ein Gegennarrativ zum »Versuch der Satanisierung der Serben ${ }^{288}$ zeigen sollte. Ebenfalls mit den visuellen Mitteln der Konfrontation mit Kriegsverbrechen arbeitete die Initiative Junger für Menschenrechte, die in Belgrad, Novi Sad, Čačak und Niš vierzig große Werbetafeln mit Fotos aus Srebrenica beklebte. Die Plakate bildeten zumeist Gräber und exhumierte Leichen ab und waren mit der Aufschrift Srebrenica 1995-2005. Da vidiš, da znaš, da pamtiš. (Srebrenica 1995-2005. Dass du es siehst, es weißt, es dir merkst.) versehen. Innerhalb von drei Tagen wurden sämtliche Tafeln in Belgrad zerstört. ${ }^{289}$ Erst kurz vor dem Jahrestag verurteilte die serbische Regierung in einer Erklärung die Massenverbrechen sowohl in Srebrenica als auch in Bratunac. Es sei von größter Wichtigkeit, bei der Verurteilung von Kriegsverbrechen keinen Unterschied zwischen unschuldigen Opfern auf Grundlage ihrer Nationalität oder ihres Glaubens zu machen. Weiterhin rief sie zur Aufklärung und Strafverfolgung aller Kriegsverbrechen auf und betonte das besondere Interesse des serbischen Volkes daran. ${ }^{290}$

286 Jasmina Čolak: »Mnoge patriote pokazaće se kao zločinci« [Viele Patrioten werden sich als Verbrecher herausstellen], in: Danas vom 18.6.2005, S. 7.

287 Zveržhanovski, Ivan: »Watching War Crimes. The Srebrenica Video and the Serbian Attitudes to the 1995 Srebrenica Massacre«, in: Southeast European and Black Sea Studies 7 (2007) 3, S. 417-430, hier S. 427.

288 Kostić, Slobodan: »Zaboravljeno vojvodstvo. Film Srpske radikalne stranke« [Vergessenes Herzogtum. Film der Serbischen Radikalen Partei], in: Vreme vom 13.7.2005, http://www.vreme.com/cms/view.php?id=421886 vom 12.7.2013

289 Nosov, Andrej (Hg.): Srbija i Srebrenica 1995-2005. Serbia and Srebrenica 19952005, Belgrad: Inicijativa mladih za ljudska prava 2006.

290 Beta: »Vlada izjednačeno osudila zločine« [Regierung verurteilte Verbrechen ausgeglichen], in: b92.net vom 7.7.2005, http://www.b92.net/info/vesti/index.php?yyyy $=2005 \& \mathrm{~mm}=07 \& \mathrm{dd}=07 \&$ nav_category=11\&nav_id=172193 vom 25.8.2011. 
2005 wohnte Präsident Tadić erstmals den Gedenkfeierlichkeiten an das Massaker von Srebrenica bei, was sowohl in der serbischen als auch in der bosniakischen Öffentlichkeit hoch umstritten war. Nach der durch das ŠkorpioniVideo ausgelösten öffentlichen Aufmerksamkeit im Vorlauf des 10. Jahrestags des Massakers, das eindeutig die Beteiligung von serbischen Staatsbürgern an Erschießungen zeigte, bestand Tadić auf dem Besuch in Srebrenica und begründete dies in einer Pressemitteilung:

»Ich gehe nach Srebrenica, um den unschuldigen Opfern des Verbrechens, das sich dort ereignet hat, Respekt zu erweisen. Ich gehe, damit ich als Präsident Serbiens zeige, wie sich Serbien gegenüber am bosniakischen Volk begangenen Kriegsverbrechen verhält. Der erste Grund ist menschlich und muss nicht weiter erklärt werden. Der zweite Grund sind die Bürger Serbiens. Wir haben nicht hinter den Verbrechen gestanden. Wir müssen Distanz wahren zwischen Bürgern und Verbrechern. Davon hängt die Zukunft Serbiens ab. Der dritte Grund ist die Notwendigkeit der Wiederherstellung von vollem Vertrauen und der Zusammenarbeit zwischen den Ländern in unserer Region. Ich gehe nach Srebrenica, denkend an die regionale Zusammenarbeit und an die Verantwortung für alles, was auf dem Gebiet des ehemaligen Jugoslawien geschehen ist. Wir müssen den Teufelskreis des Bösen auf dem Balkan durchbrechen. Am serbischen Volk wurden ebenfalls viele Verbrechen begangen. Die Verurteilung auch dieser Verbrechen ist selbstverständlich. Allerdings ist das Verurteilen von Verbrechen, die in unserem Namen an einem anderen Volk begangen wurde, Tugend und Stärke. Darum gehe ich nach Srebrenica.« ${ }^{291}$

Tadić verzichtete darauf, sich auf der Gedenkfeier zu äußern. Sein Sprecher betonte aber gegenüber der Inlandspresse, dass Tadić' Besuch und seine Gespräche mit Medienvertretern über Srebrenica eine eindeutige Botschaft gesendet hätten. Diese solle zeigen und beweisen, dass die Bürger Serbiens nicht hinter den Verbrechen ständen, solle eine Distanz zwischen Verbrechern und Bürgern schaffen und auf diese Weise die Interessen Serbiens verteidigen. ${ }^{292}$

Die Begründung, mit dieser Symbolpolitik die Interessen Serbiens zu verteidige, die Distanzierung von dem Verbrechen und die Reduzierung der Verant-

291 Präsident der Republik Serbien Boris Tadić: Obraćanje naciji povodom desete godišnjice zločina u Srebrenici [Ansprache an die Nation anlässlich des zehnten Jahrestags des Verbrechens in Srebrenica], http://www.predsednik.rs/mwc/pic/50/20061 224125233/srebrenica_256K_Stream.wmv vom 13.5.2013.

292 B92: »Srebrenica: 10 godina od zločina« [Srebrenica: zehn Jahre seit dem Verbrechen], in: b92.net vom 11.7.2005, http://www.b92.net/info/vesti/index.php?yyyy=20 $05 \& \mathrm{~mm}=07 \& \mathrm{dd}=11 \&$ nav_category=12\&nav_id=172392 vom 21.2.2013. 
wortung auf einzelne Schuldige machen die Begrenztheit sowie den ambivalenten Charakter dieser Symbolpolitik deutlich. Dies zeigt auch die Relativierung, die das serbische Parlament vornahm, als es zu Sitzungsbeginn eine Schweigeminute als Zeichen des Respekts für alle Opfer von Skelani, Srebrenica und Bratunac und für die Opfer des terroristischen Angriffes in London abhielt. Am 7. Oktober schließlich erhob die nationale Kammer für Kriegsverbrechen Anklage gegen fünf Mitglieder der Skorpione.

Obwohl mit dem Video eine gewisse Faktizität der Beteiligung von serbischen Staatsbürgern und staatlichen Organen belegt war, zweifelten große Teile der serbischen Gesellschaft weiterhin an der Echtheit des Videos. ${ }^{293}$ Allerdings war es ab 2005 zumindest von Seiten offizieller Akteure nicht mehr legitim, das Massaker von Srebrenica zu leugnen. Gleichzeitig mit der Anerkennung des Massakers und der Kriegsverbrechen, die »im Namen des serbischen Volkes" begangen wurden, wurde allerdings die Schuldfrage weiterhin externalisiert, auf ungenannte Akteure abgewälzt und gänzlich individualisiert. Die öffentliche Beschäftigung war mit der einsetzenden juristischen Strafverfolgung einzelner Täter - die allerdings weitgehend als richtig akzeptiert wurde - vorerst beendet. Durch die Betonung des serbischen Opfers und Analogisierungen mit anderen Kriegsverbrechen wurde der serbische Opferdiskurs erneut reaktualisiert. Zugleich relativierte man und distanzierte sich von Kriegsverbrechen, vor allem von Srebrenica. Auch Jelena Subotić schlussfolgerte in ihrer Untersuchung, dass die serbische politische Elite den Diskurs über die Frage des Umgangs mit Srebrenica 2005 nutzte, »to further pursue its ideological agenda, which focused on advancing the narrative of Serbia's victimization, suffering, and unfair international condemnation $\aleph^{294}$.

\section{Abhängig von externer Bewertung: Erfolg und Krise in der Annäherung an die EU}

Trotz der problematischen Debatte über den Umgang mit Srebrenica zeigte sich die Europäische Kommission mit der Symbolpolitik zufrieden und eröffnete, in erster Linie als Ergebnis der positiven Machbarkeitsstudie vom April, am 10. Oktober 2005 die Verhandlungen mit Serbien über ein Stabilisierungs- und Assoziierungsabkommen. ${ }^{295}$ Javier Solana, der Hohe Vertreter der Gemeinsamen

293 Vgl. I. Zveržhanovski: »Watching War Crimes«, S. 427.

294 J. Subotić: Hijacked Justice, S. 66.

295 Das Wechselspiel von Bedingtheiten zwischen der EU, Serbien und dem ICTY thematisieren J. Obradović-Wochnik: »Strategies of Denial«; Hartmann, Florence: 
Außen- und Sicherheitspolitik der EU, lobte sogar die serbische Zusammenarbeit mit dem ICTY.

Im November veröffentlichte die Europäische Kommission einen Fortschrittsbericht ${ }^{296}$, der die Grenzen der Politik der freiwilligen Selbstauslieferung betonte und auf der Auslieferung der restlichen Angeklagten, vor allem von Ratko Mladić und Radovan Karadzić, bestand. Die Arbeit des Rats zur Zusammenarbeit mit dem ICTY hinsichtlich der Freistellung von Zeugen und des Zugangs zu Dokumenten wurde gelobt, auch wenn es Obstruktionen durch das Personal in den Behörden oder durch die Armee gebe. Zwar läge dem Parlament der Staatenunion ein Gesetzesvorschlag vor, demgemäß das Vermögen von flüchtigen Kriegsverbrechern eingefroren werden könne, und habe die serbische Justiz mit einem Erlass eine Zwischenlösung ermöglicht, allerdings komme SerbienMontenegro damit noch nicht der Entscheidung des Europäischen Rats nach. ${ }^{297}$ Die nationalen Gerichte wurden gelobt, hier seien Fortschritte beim Ausbau der Kapazitäten erzielt worden, die aber noch immer nicht ausreichen würden. Zum Strafgesetzbuch seien mit Verbrechen gegen die Menschlichkeit und Völkermord neue Straftatbestände hinzugefügt worden, allerdings sei hierbei die Befehlsverantwortung nur teilweise berücksichtigt worden. Noch immer seien Strafverfolgungsbehörden und ihre Exekutive großem politischen Druck ausgesetzt. $^{298}$

Im Januar 2006 allerdings gab die Sprecherin der Chefanklägerin des ICTY bekannt, einer vertrauenswürdigen Quelle nach verstecke sich Ratko Mladić

»The ICTY and EU conditionality«, in: J. Batt/J. Obradović-Wochnik (Hg.): War Crimes, S. 67-82, sowie M. Dobbels: Serbia and the ICTY.

296 European Commission: Serbia 2005 Progress Report, EU-Dok. SEC (2005) 1428 vom 9.11.2005.

297 Der Europäische Rat hatte im Oktober 2004 eine gemeinsame Position über die Maßnahmen zur Unterstützung des ICTY beschlossen, die vorsah, die Vermögen von Radovan Karadzić, Ratko Mladić und Ante Gotovina einzufrieren. Diese Position sollte in allen Mitgliedsländern und Anwärterländern auf eine Mitgliedschaft umgesetzt werden. Vgl. European Council: Council Common Position on Further Measures in Support of the Effective Implementation of the Mandate of the International Criminal Tribunal for the Former Yugoslavia, Dok. 2004/694/CFSP, in: Official Journal of the European Union L 315/52 vom 14.10.2004.

298 European Commission: Serbia 2005 Progress Report, EU-Dok. SEC (2005) 1428 vom 9.11.2005, S. 23. 
weiterhin in serbischen Militärkasernen. ${ }^{299}$ Dieser Vorwurf sorgte für eine breite Berichterstattung in den serbischen Medien und forderte Erklärungen von Regierungsvertretern. Der Verteidigungsminister der Staatenunion Zoran Stanković dementierte, dass Mladić vom Militär versteckt oder unterstützt würde. Er räumte aber ein, dass es einen »Fehler« hinsichtlich der Pensionszahlungen gegeben habe, die Mladić noch bis November erhalten habe. Auch sie waren erst wenige Wochen zuvor publik geworden. ${ }^{300}$ Als Reaktion auf den nun entstehenden Druck auf das Land durch Vertreter der EU und der USA verabschiedete das Bundesparlament ein Gesetz über das Eigentum von Personen, die vom ICTY angeklagt wurden, das die Konten flüchtiger Kriegsverbrecher einfror. ${ }^{301} \mathrm{Im}$ März erließ der Ministerrat nach einer Korrespondenz zwischen dem Ministerratspräsidenten und der Chefanklägerin des ICTY des Weiteren einen Beschluss über die Modalitäten, unter denen den Ermittlern des ICTY Zugang zu den staatlichen Archiven gewährt werden sollte.

Am 11. März verstarb jedoch der in Scheveningen inhaftierte Slobodan Milošević an Herzversagen. Das lieferte seinen Unterstützern einen Anlass, in der serbischen Öffentlichkeit Spekulationen über die Ursache seines Todes und die Frage, ob Milošević die nötige ärztliche Hilfe zugekommen war, zu schüren. Konservative serbische Analysten vermuteten, dass das ICTY spätestens mit Milošević' Tod unter diesen Umständen die letzte Glaubwürdigkeit in der Bevölkerung und die aufrichtige Unterstützung sogar der bis dahin für das ICTY

299 Fonet: »Mladić u kasarnama u Srbiji« [Mladić in Kasernen in Serbien], in: b92.net vom 3.1.2006, http://www.b92.net/info/vesti/index.php?yyyy $=2006 \& m m=01 \& d d=0$ $3 \&$ nav_id $=184139$ vom 16.4.2013.

300 Ebd.

301 So geht es zumindest aus dem Bericht der Europäischen Kommission und den Antworten auf den Fragebogen der Republik Serbien hervor, der auf eine Veröffentlichung des Gesetzes »Act on measures considerate to the property of the persons indicted for war crimes before the International Tribunal for the prosecution of persons responsible for serious violations of international humanitarian law committed in the territory of the former Yugoslavia since 1991, who are at large « im Bundesanzeiger der Staatenunion 15/2006 verweist. Vgl. Republik Serbien: »Answers to Additional Questions« vom 22.4.2011, http:/www.seio.gov.rs/upload/documents/ upitnik/answers_to_additional_questions.zip vom 22.4.2013, S. 96. Die Berichte der Kommission sprechen nach 2006 vom »unklaren Status« des Gesetzes - das dem Parlament Serbien und Montenegros nur als Entwurf vorgelegt worden sei, vgl. European Commission: Serbia 2006 Progress Report, EU-Dok. SEC (2006) 1389 vom 8.11.2006, S. 16 . 
eingestellten Politiker verloren hätte. ${ }^{302}$ Präsident Koštunica ermöglichte Milošević ein Staatsbegräbnis und zeigte damit erneut seinen Unwillen, sich vom Vorgängerregime zu distanzieren. Die Medien zeichneten ein weitgehend positives Bild des ehemaligen Staatschefs. In der entpolitisierten und unkritischen Berichterstattung herrschten Wir-Identifizierungen vor, die Milošević miteinschlossen, auch wurden oft Bezeichnungen verwandt, die ihn als Held oder Verteidiger charakterisierten. ${ }^{303}$ Entsprechend distanziert war auch das Verhältnis der Regierung zum ICTY.

Vertreter der EU hatten von Serbien-Montenegro gefordert, bis zum 30. April Ratko Mladić an das ICTY auszuliefern. Da das Land ihn nicht auslieferte, habe es hinsichtlich einer vollen Kooperation mit dem ICTY versagt, und die Europäische Kommission suspendierte am 6. Mai die Verhandlungen über ein Stabilisierungs- und Assoziationsabkommen wieder. Kurz darauf öffneten das Innen- und das Verteidigungsministerium des Staatenbundes und der serbische Präsident ihre Archive für die Ermittler.

Anfang Juni 2006 erklärte Montenegro mit einem Referendum seine Unabhängigkeit von Serbien. Ziel der Unabhängigkeitsbestrebung war in erster Linie ein schneller Beitritt zur EU. Mit Resolution 1514 reagierte die parlamentarische Versammlung des Europarats auf das montenegrinische Referendum, um die Vertragsnachfolge der Mitgliedschaft zu regeln. In ihr mahnte sie sowohl von Serbien als auch von Montenegro eine volle Kooperation mit dem ICTY sowie die Durchführung von Programmen an, die darauf abzielen sollten, die Öffentlichkeit über die Ziele des Tribunals aufzuklären, um damit seine gesellschaftliche Akzeptanz zu verbessern. Auch sollte durch Bildungsmaßnahmen das Bewusstsein für die Verbrechen des Milošević-Regimes erhöht werden. Weiterhin sagte die parlamentarische Versammlung, wobei sie sich sensibel für die innenpolitischen Spannungen zeigte, Serbien die volle Unterstützung des Europarats $\mathrm{zu}$,

302 Fatić, Aleksandar/Bulatović, Aleksandra: »Justice and Reconciliation in the International Criminal Tribunal for the Former Yugoslavia«, in: Međunarodni problemi 60 (2008) 1, S. 31-46, hier S. 39.

303 Vgl. Erjavec, Karmen/Volčič, Zala: »Rehabilitating Milošević. Posthumous Coverage of the Milošević Regime in Serbian Newspapers«, in: Social Semotics 19 (2009) 2, S. 125-143. 
»where there is a risk that the multiple challenges that it [Serbien, D. M.] is currently facing in a climate of political instability would further increase the feeling of isolation and frustration amongst Serbian citizens and the support for radical nationalist forces. $\ll^{304}$

Für die serbische Politik bedeuteten der Tod Milošević', das Aussetzen der Verhandlungen mit der EU sowie die Unabhängigkeit von Montenegro eine dreifache Niederlage. Auch veränderte sich die Einstellung zum Jugoslawien-Tribunal im Kontext der Konditionalitäten und Ereignisse so weit, dass von Regierungsseite jede politische Unterstützung von Auslieferungen vorerst ausblieb, da, wie BIA-Chef Rade Bulatović gegenüber Del Ponte einräumte, »das JugoslawienTribunal ein politisches Instrument sei, mit dem man Druck auf Serbien ausüben wolle $\ll^{305}$.

Wie auch ein Jahr zuvor forderten die NGOs der Frauen in Schwarz, das Centar za regionalizam (Zentrum für Regionalismus), das Helsinki-Komitee für Menschenrechte, das Anwaltskomitee für Menschenrechte und der Fonds für Völkerrecht erneut eine klare parlamentarische Verurteilung Srebrenicas. Ihren Resolutionsentwurf, der gleiche wie 2005, griffen die Parteien aber nicht auf.

Um die aufgestellten Bedingungen im Rahmen des Stabilisierungs- und Assoziierungsprozesses zu erfüllen, präsentierte die serbische Regierung im Juli 2006 einen Aktionsplan zur Verhaftung von Ratko Mladić. Das dreiseitige Konzept stellte eine Medienkampagne in Aussicht, um die Öffentlichkeit über die Anklage gegen Mladić zu informieren. Zudem sollte die Koordination von Armee, Polizei, Geheimdiensten und Justiz sowohl für die Festnahme der Flüchtigen als auch zur Kooperation mit dem ICTY verbessert werden und es sah sogar die Verabschiedung einiger spezifischer Gesetze vor. Darüber hinaus war ein Team für die Implementierung des Aktionsplans unter Vorsitz des serbischen Premierministers intendiert. Der Staatsanwalt für Kriegsverbrechen sollte als Koordinator fungieren und die entsprechenden Abteilungen des Innenministeriums und der Geheimdienste operativ steuern. Bei den Treffen des Teams sollten auch Vertreter des ICTY-Büros anwesend sein. ${ }^{306}$ EU-Vertreter begrüßten den Aktionsplan, während Kritiker skeptisch blieben, hatten sie solche Verspre-

304 Parliamentary Assembly of the Council of Europe: Consequences of the Referendum in Montenegro, Resolution Nr. 1514 vom 29.6.2006.

305 C. Del Ponte: Im Namen der Anklage, S. 435.

306 Für eine konkrete Beschreibung vgl. Republik Serbien: »Answers to the European Commission's Questionnaire«, S. 539. 
chungen doch schon zu oft gehört. ${ }^{307}$ Der Vorsitzende des Nationalen Rates zur Zusammenarbeit mit dem ICTY hingegen gab an, man wolle bis September Beweise für den Erfolg des Aktionsplans erbringen. ${ }^{308}$ Diese blieb er allerdings, zumindest für die breite Öffentlichkeit, schuldig. Am 17. Oktober 2006 schloss die Republik Serbien ein Abkommen zur Kooperation bei der Verfolgung von Kriegsverbrechen mit Kroatien ab. Darüber hinaus zeigte die Regierung Koštunica wenig Interesse an einer aktiven Intensivierung der Zusammenarbeit mit dem Tribunal. Zeitgleich begannen die offiziellen Verhandlungen um den Status des Kosovo. Im November 2006 erschien der nächste Fortschrittsbericht der Europäischen Kommission, der die ausbleibende volle Implementierung des Aktionsplans zur Ergreifung von Ratko Mladić kritisierte, vor allem fehle eine Koordination zwischen den Geheimdiensten und den Strafverfolgungsbehörden. Die Weiterentwicklung des Gesetzesrahmens zu Kriegsverbrechen und die Arbeit der nationalen Gerichte mit Blick auf die Verfahren zu Ovčara und der Škorpioni hingegen wurden positiv bewertet. Deren Arbeit werde allerdings durch einen »major lack of political will to establish accountability « ${ }^{309}$ unterminiert, der Druck und die Verunglimpfungen - auch durch Politiker - auf die Staatsanwälte und Richter in diesem Bereich habe zugenommen. ${ }^{310}$

\section{Eine Mehrheit für den europäischen Kurs}

Bei den Parlamentswahlen im Januar 2007 gelang es der SRS zwar, die Stimmen der meisten Wähler auf sich zu vereinigen, doch zwei Drittel der Sitze im Parlament ging an Parteien, die einen proeuropäischen Kurs verfolgten. Die Koalitionsverhandlungen zwischen ihnen dauerten mehrere Monate an. Im Februar 2007 fällte der Internationale Strafgerichtshof das Urteil im Fall der Klage Bosnien-Herzegowinas gegen Serbien. Demnach sei das Massaker von Srebrenica als Genozid zu werten. Serbien sei zwar anzulasten, nichts gegen das Morden unternommen zu haben, aber keine direkte Verantwortung für das Verbrechen

307 Deutsche Welle/AFP : »EU Welcomes Serbia War Crimes Action Plan, Awaits Results«, in: Deutsche Welle online vom 18.7.2006, http://www.dw.de/eu-welcomesserbia-war-crimes-action-plan-awaits-results/a-2099346 vom 28.4.2013.

308 O. V.: Evidence on Mladić by mid-September, in: b92.net vom 21.8.2006, http:// www.b92.net/eng/news/politics.php?yyyy $=2006 \& \mathrm{~mm}=08 \& \mathrm{dd}=21 \&$ nav_id $=36235 \mathrm{vom}$ 16.4.2013.

309 European Commission: Serbia 2006 Progress Report, S. 16.

310 Ebd. 
nachweisbar. ${ }^{311}$ Das Urteil des Internationalen Strafgerichtshof wurde in Serbien von den Medien aufgegriffen und breit diskutiert. Die Liberaldemokratische Partei nahm es zum Anlass, erneut eine parlamentarische Resolution zu Srebrenica zu fordern, und brachte einen Vorschlag ein, der Serbiens völkerrechtliche Verpflichtungen betonte, allerdings keine breitere Unterstützung fand. ${ }^{312}$ Schon wenige Tage nach dem Urteil und den vergleichsweise gemäßigten Reaktionen darauf einigten sich die EU-Außenminister im Februar 2007 darauf, dass die Gespräche mit Serbien im Falle einer besseren Kooperation mit Den Haag wieder aufgenommen werden könnten.

Am 10. April urteilte die Kammer für Kriegsverbrechen im Fall der Mitglieder der paramilitärischen Einheit der Skorpione. Es verurteilte vier Angeklagte zu insgesamt 57 Jahren Haft, während einer freigelassen wurde. Einen sechsten veruteilte ein kroatisches Gericht. Die Belgrader Kammer für Kriegsverbrechen klassifizierte den Bosnienkrieg als Bürgerkrieg und bestätigte, dass die Skorpione eine paramilitärische Einheit aus Belgrad waren, es sah es allerdings nicht als eindeutig erwiesen an, dass die Opfer aus Srebrenica nach Trnovo, dem Ort ihrer Erschießung, deportiert worden seien. Trotz kontrafaktischer Zeugenaussagen, nach denen die Skorpione innerhalb der regulären Einheiten der bosnischserbischen Armee agierten, deutete das Gericht die Erschießungen als isolierte Taten, die nicht in einen Gesamtzusammenhang mit dem Massaker in Srebrenica gestellt wurden. Diese Interpretation kritisierten Sonja Biserko und Biljana Kovačević-Vučo, die dem Gericht vorwarfen, den Opfern keine Gerechtigkeit verschafft zu haben, und das Urteil als politisch motiviert einordneten. ${ }^{313}$

Im April 2007 nutzte Präsident Boris Tadić während eines Interviews im kroatischen Fernsehen die Gelegenheit für eine symbolische Entschuldigung: »Allen Bürgern Kroatiens und allen Angehörigen des kroatischen Volks, denen Angehörige meines Volks Unglück angetan haben, sende ich eine Entschuldi-

311 International Court of Justice: Application of the Convention on the Prevention and Punishment of the Crime of Genocide (Bosnia and Herzegovina v. Serbia and Montenegro). Judgement vom 26.2.2007.

312 Čanak, Nenad: »Antiratni aktivisti su jedini pravi heroji« [Antikriegsaktivisten sind die einzigen wahren Helden], in: Slobodna Vojvodina 10 (2007) 19, S. 2.

313 Jovanović, Igor/Alić, Anes: »Serbia sentences its Scorpions«, in: ISN Security Watch vom 17.5.2007, http://www.isn.ethz.ch/Digital-Library/Articles/Detail?lng=en\& id=53124 vom 22.4.2013. 
gung und übernehme dafür die Verantwortung. « $^{314}$ Tadić betonte, dass er nicht einen Fall vernachlässige, in dem Personen, während sie offiziell irgendwelchen Angelegenheiten im Namen des serbischen Volks oder des serbischen Staats nachgingen, Menschen einer anderen Nation oder Religion das Leben nahmen. Gleichsam vergesse er aber niemals die Tatsache, dass derartige Taten auch gegen sein Volk begangen wurden. Er würde sich wünschen, dass alle Politiker auf dem Balkan etwas weniger stolz wären und häufiger selbst Verantwortung übernehmen würden.

Für seine Äußerungen erhielt Tadić in Serbien viel Anerkennung, sie seien ernsthaft und ausbalanciert gewesen, allerdings würden Worte nicht ausreichen. Lediglich die SRS bewertete Tadić’ Auftritt als »Skandal und Schande ${ }^{315}$ sowie als größten Schaden für Serbien und seine nationalen Interessen. Aleksandar Vučić beschuldigte Tadić, Serbien direkt für die Kriegsprovokation auf dem Gebiet des ehemaligen Jugoslawien verantwortlich gemacht und sich bei den Kroaten für die Tötung und die Vertreibung der Serben »von Ante Pavelić bis Franjo Tuđman« entschuldigt zu haben, wofür »Hunderttausende Serben abgeschlachtet und Millionen Serben von ihren Feuerstellen vertrieben ${ }^{316}$ worden seien.

Erst nach dreimonatiger Verhandlung konnte am 15. Mai eine neue Regierung gebildet werden, die im Parlament eine Mehrheit von zwei Dritteln der Sitze umfasste. ${ }^{317}$ Sie richtete nur zwei Wochen später den bereits im Januar 2006 beschlossenen Nacionalni savet za bezbednost (Nationalen Sicherheitsrat) ein. ${ }^{318}$

314 B92/Beta: »Tadić se izvinio građanima Hrvatske« [Tadić entschuldigt sich bei den Bürgern Kroatiens], in: B92.net vom 24.6.2007, http://www.b92.net/info/vesti/index. php?yyy $=2007 \& \mathrm{~mm}=06 \& d d=24 \&$ nav_category=11\&nav_id=252551 vom 23.2.2013.

315 Ebd.

316 Ebd.

317 Im Mai 2007 übernahm Serbien den Vorsitz des Ministerkomitees des Europarats, wogegen beispielsweise Human Rights Watch protestierte, da somit ein Land, dass immer noch in der Überprüfungsprozedur für die Mitgliedschaft sei und das flüchtige Kriegsverbrecher nicht ausliefere, nun dem größten Menschenrechtsregime vorstände, vgl. Human Rights Watch: Council of Europe: Hold Serbia to Account, Pressemitteilung vom 6.5.2007, http://www.hrw.org/news/2007/05/06/council-europehold-serbia-account vom 16.4.2013.

318 Allerdings waren auch schon die vorherigen Gründungsanläufe eines solchen Gremiums - auf Bundesebene 2000, auf Länderebene per Verordnung während der Regierung von Zoran Đinđić und 2006 durch die Regierung Koštunica - im Sande verlaufen. Auch diesen Versuch hielten Analysten nach knapp zwei Jahren, in denen 
In ihm sollten die Zusammenarbeit und Kommunikation zwischen den verschiedenen Akteuren auf dem Feld der Sicherheitspolitik besser koordiniert werden, vor allem, um die Flüchtigen zu verhaften. Sein Vorsitzender, der Präsident der Republik, ist verantwortlich für die Koordination der militärischen und zivilen Geheimdienste. Zeitgleich wurde ein Gesetz zur Neurordnung der Struktur der Geheimdienste entworfen, das dem Nationalen Sicherheitsrat weitreichende Kompetenzen einräumte. ${ }^{319}$ Am gleichen Tag wurden außerdem die neuen Mitglieder des per Regierungsbeschluss ${ }^{320}$ neu eingesetzten nationalen Rats zur Zusammenarbeit mit dem ICTY ernannt. Ebenfalls an diesem Tag half die serbische Polizei bei der Verhaftung und Auslieferung von Zdravko Tolimir, der als ein Stellvertreter von Ratko Mladić in der bosnisch-serbischen Armee das Massaker von Srebrenica mitzuverantworten hatte und an einem Grenzübergang zwischen Bosnien-Herzegowina und Serbien gefasst werden konnte. Serbische Behörden waren auch an der Verhaftung von Vlastimir Đorđević beteiligt, der bis 2001 stellvertretender Innenminister und für Kriegsverbrechen im Kosovo verantwortlich war und am 17. Juni im montenegrinischen Budva gestellt werden konnte. Dementsprechend hoffte man auf einen positiven Bericht der Chefanklägerin, die am Tag darauf vor dem UN-Sicherheitsrat sprechen sollte.

In Resolution 1564 bekräftigte die parlamentarische Versammlung des Europarats ihre Unterstützung des ICTY und forderte die Verfolgung aller Straftaten, die in die Rechtsprechung dieses Gerichtes fallen. Die Verhaftungen und Auslieferungen von Zdravko Tolimir und Vlastimir Đorđević führte sie auf die Forderungen der EU zurück, weshalb sie die EU einlud, weiterhin die serbische Zusammenarbeit mit dem ICTY als Voraussetzung für die Unterzeichnung eines

auf die Verordnung keinerlei Aktivität folgte, für gescheitert. Vgl. Popović, Đorđe: Savet za nacionalnu bezbednost Republike Srbije, http://www.bezbednost.org/upload/ document/popovic_2009_savet_za_nacionalnu_bezbednost.pdf vom 13.5.2013.

319 Volksversammlung der Republik Serbien: Zakon o osnovama uređenja službi bezbednosti [Gesetz über die grundlegende Ordnung der Sicherheitsdienste], Službeni glasnik RS 116 (2007).

320 Regierung der Republik Serbien: Odluka o osnivanju nacionalnog saveta za saradnju sa međunarodnim tribunalom za krivično gonjenje lica odgovornih za teška kršenja međunarodnog humanitarnog prava počinjena na teritoriji bivše Jugoslavijie od 1991. godine [Entschließung über die Einrichtung eines nationalen Rats für die $\mathrm{Zu}$ sammenarbeit mit dem Internationalen Tribunal für die Strafverfolgung von verantwortlichen Personen für auf dem Territorium des ehemaligen Jugoslawien begangene schwere Menschenrechtsverbrechen seit 1991], in: Službeni glasnik RS 50 (2007). 
Stabilisierungs- und Assoziierungsabkommens zu fordern. Besonders rief sie die Staaten des ehemaligen Jugoslawien auf, ihre nationale Gesetzgebung anzupassen, so dass eine volle Kooperation möglich sei. Des Weiteren forderte sie eine Verbesserung der bilateralen justiziellen Zusammenarbeit, da aufgrund des Verbots der Auslieferung von Staatsangehörigen in der nationalen Gesetzgebung Kriegsverbrecher oftmals in absentia verurteilt werden müssten. In elf Punkten listete sie Reformbedarf für die Verfolgung von Kriegsverbrechen auf nationaler Ebene auf. ${ }^{321}$

Im September 2007 sprach das ICTY mit Veselin Šljivančanin, Mile Mrkšić und Miroslav Radić, alle Offiziere der JNA, erstmals hochrangiges Personal wegen der Verbrechen in Vukovar für schuldig. Zudem war damit deutlich, dass die JNA in Kroatien für Kriegsverbrechen verantwortlich ist. Die These der JNA als Defensivarmee, die in den 90er Jahren an Popularität gewann, wurde somit unhaltbar. Im Oktober stellte die serbische Regierung ein Kopfgeld für die Ergreifung von Ratko Mladić in Höhe von einer Million Euro in Aussicht, für Goran Hadžić 250.000 Euro. Zudem richtete sie unter 9191 eine Telefonnummer ein, die 24 Stunden am Tag besetzt ist und unter der Bürger Informationen über die Lokalisierung der beiden Angeklagten oder über deren Helfer an die Polizei weitergeben konnten.

Ein am 6. November 2007 veröffentlichter Fortschrittsbericht der Europäischen Kommission konstatierte Serbien Fortschritte hinsichtlich seiner Verpflichtungen gegenüber dem ICTY, besonders durch die Verhaftungen im Mai und Juni 2007, die eine enge regionale Kooperation der Geheimdienste offenbarten. Es wurde zur Kenntnis genommen, dass die Kammer für Kriegsverbrechen drei weitere Urteile in Fällen von Kriegsverbrechen gesprochen hat. Kritisiert wurde der unklare Status des Gesetzes über das Einfrieren des Vermögens flüchtiger Angeklagter. Mit den neuen Programmen habe die Regierung jedoch gezeigt, dass sie eine volle Kooperation anstrebe. Diese sei aber erst erreicht, wenn alle vier noch flüchtigen Angeklagten des ICTY gefasst seien. ${ }^{322}$ Auf dieser Grundlage initiierten Erweiterungskommissar Olli Rehn, der stellvertretende Premierminister Serbiens Božidar Đelić und Präsident Tadić tags darauf das Stabilisierungs- und Assoziierungsabkommen mit Serbien.

321 Parliamentary Assembly of the Council of Europe: Prosecution of offences falling within the jurisdiction of the International Criminal Tribunal for the former Yugoslavia (ICTY), Resolution Nr. 1564 vom 28.6.2007.

322 European Commission: Serbia 2007 Progress Report, EU-Dok. SEC (2007) 1435 vom 6.11.2007. 
In ihrer Abschiedsrede vor dem UN-Sicherheitsrat im Dezember 2007 machte Carla Del Ponte allerdings deutlich, dass es entgegen der Anzeichen für Optimismus keine Fortschritte in der Unterstützung der serbischen Regierung bei der Ergreifung der vier verbliebenen Flüchtigen gebe. Sie forderte die EU auf, die Unterzeichnung des Stabilisierungs- und Assoziierungsabkommens von der Ergreifung Ratko Mladić' abhängig zu machen. ${ }^{323}$

\section{8: Im Zeichen der politischen Krise}

Im Januar 2008 bemängelte auch ihr Nachfolger Serge Brammertz die mangelnde Kooperation Serbiens mit dem ICTY. Zwei Tage später gaben Vertreter der Niederlande und Belgiens bekannt, dass sie das Stabilisierungs- und Assoziierungsabkommen so lange nicht unterzeichnen würden, bis eine volle Kooperation mit dem Tribunal in Den Haag erfolge, also alle noch flüchtigen Kriegsverbrecher an das Tribunal ausgeliefert seien. ${ }^{324}$ Auf die Unabhängigkeitserklärung des Kosovo am 17. Februar 2008 folgte eine innenpolitischen Krise in Serbien, die ein Zerwürfnis der serbischen Regierung zur Folge hatte. Im Parlament hatte die DSS gemeinsam mit der SRS und der SPS einen Beschluss gefasst, der einen Abbruch sämtlicher Beziehungen zur EU und den Staaten vorsah, die das Kosovo anerkannten. Die anderen Regierungsparteien hingegen forderten eine Fortsetzung der Verhandlungen zum Stabilisierungs- und Assoziierungsabkommen. Daraufhin kündigte Ministerpräsident Koštunica seinen Rücktritt an. Vorgezogene Parlamentswahlen wurden nötig. In den Wahlkampf fiel die Unterzeichnung des Stabilisierungs- und Assoziierungsabkommens am 29. April 2008, das als eine Art frühes Wahlgeschenk galt. Aus Sicht der EU-Offiziellen sollte es eine Wahlentscheidung zugunsten eines Kurses Richtung Europa und damit zugunsten der DS und Boris Tadić' befördern. Nach der Wahl, bei der die proeuropäischen Kräfte dem nationalistischen Lager knapp überlegen waren, begannen zähe Koalitionsverhandlungen. Erstaunlicherweise einigte sich die ehemalige

323 Beta: »Del Ponte submits negative report«, in: b92.net vom 10.12.2007, http:// www.b92.net/eng/news/crimes-article.php?yyyy $=2007 \& m m=12 \& d d=10 \& n a v \_i d=46$ 080 vom 19.4.2013.

324 Insbesondere die niederländische Regierung fühlte sich zu diesem Schritt verpflichtet, da es sich um niederländischen Blauhelmsoldaten handelte, unter deren Augen das Massaker von Srebrenica begangen wurde. Anlässlich einer Studie des Niederländischen Instituts für Kriegsdokumentation trat das Kabinett unter Premierminister Wim Kok 2002 geschlossen zurück, um die politische Verantwortung für die Operation der UN-Mission zu übernehmen. 
Partei von Slobodan Milošević, die eine Wahlallianz anführte und mit zwanzig Sitzen im neuen Parlament vertreten war, mit den proeuropäischen Kräften um die DS auf einen europafreundlichen Kurs, was der bis dahin vertretenen Politik der SPS widersprach, aber eine proeuropäische Regierungskoalition unter Führung der DS ermöglichte. Wenige Monate später, im Oktober 2008, verabschiedeten die DS und die SPS ein historisches Sporazum o pomirenju (Versöhnungsabkommen) - immerhin hatten sich ihre Parteiführungen und Mitglieder in den 90er Jahren erbittert gegenüber gestanden -, in dem sie für die Zukunft einen gemeinsamen proeuropäischen Kurs festlegten. ${ }^{325}$ Von nun an erfüllte Serbien die geforderten, bisweilen unpopulären Konditionen und setzte sich dabei auch gegen Widerstände und die öffentliche Meinung durch, wenngleich bisweilen erst nach langen politischen Manövern, in denen versucht wurde, die Verteidigung der nationalen Interessen in den Vordergrund zu stellen.

Mit der Festnahme des wegen Kriegsverbrechen gesuchten ehemaligen Präsidenten der Republika Srpska Radovan Karadžić (a.k.a. Dragan Dabić) in Belgrad am 21. Juli 2008 - kurz nach einem Personalwechsel an der Spitze des Geheimdienstes BIA - wurde der Mythos des serbischen Kriegshelden in der serbischen Öffentlichkeit entzaubert. Das Narrativ der Selbstopferung des Helden für die Nation konnte in Anbetracht der Umstände des Lebens von Dr. Dragan Dabić, der als Wunderheiler ein esoterisches Leben in Wohlstand und vor allem in aller Öffentlichkeit in Belgrad führte, kaum aufrechterhalten werden. Als Zäsur für den Prozess der Vergangenheitsaufarbeitung in Serbien ist die Tatsache zu betrachten, dass die Dekonstruktion des Mythos des Kriegshelden Karadžić von innen erfolgte. Jelena Obradović-Wochnik geht sogar so weit, die Verhaftung Karadžić' als zaghaften Anfang eines kulturellen und politischen Wandels in Serbien zu betrachten. ${ }^{326}$ Die Unterstützung für Kriegsverbrecher schien deutlich nachzulassen, auch nahm die innenpolitische Relevanz des Themas ab. ${ }^{327}$

Auch EU-Erweiterungskommissar Olli Rehn erweckte nach der Verhaftung Karadžić' den Eindruck, sich des Mittels der Konditionalitätspolitik gegenüber Serbien lediglich noch im Rahmen von Symbolpolitik zu bedienen, ein weiteres

325 O. V.: »Deklaracija o pomirenju DS-a i SPS-a« [Versöhnungserklärung der DS und der SPS] in: Politika online vom 21.10.2008, http://www.politika.rs/rubrike/Politika/ Deklaracija-o-pomirenju-DS-a-i-SPS-a.lt.html vom 11.5.2013.

326 J. Batt/J. Obradović-Wochnik: War Crimes, S. 45 f.

327 Vgl. Bieber, Florian: „Serbien zwischen Europa und Kosovo. Politische Entwicklungen seit der Unabhängigkeitserklärung«, in: Südosteuropa 56 (2008) 3, S. 318335, hier S. 321. 
Drohen mit Sanktionen blieb aus. Natürlich forderten er und das Personal der Anklage des Tribunals weiterhin bei jedem Besuch in Belgrad die Verhaftung der letzten zwei verbliebenen flüchtigen Kriegsverbrecher, Ratko Mladić und Goran Hadžić.

In ihrem Monitoringbericht 2008 lobt die parlamentarische Versammlung des Europarats die Auslieferungen an das ICTY und stellte sehr explizite Forderungen. So verlangte sie die Auslieferung der verbliebenen Angeklagten, die Verfügbarmachung aller relevanten Dokumente des Verteidigungsministeriums und der Geheimdienste für die Untersuchungen des ICTY, die Unterzeichnung und Ratifizierung der Europäischen Übereinkommen über die Unverjährbarkeit von Verbrechen gegen die Menschlichkeit und Kriegsverbrechen sowie über die Entschädigung der Opfer von Gewalt und die prompte Ergreifung und Auslieferung von Ratko Mladić and Goran Hadžić. ${ }^{328}$

Auch die Europäische Kommission bekräftigte, dass Serbien signifikante Fortschritte in der Zusammenarbeit mit dem ICTY erzielt habe und führte dazu besonders die Festnahmen von Stojan Župljanin und von Radovan Karadžić an. Neben der Notwendigkeit, alles in der Macht der Regierung Liegende für die Verhaftung und Auslieferung der verbliebenen beiden Flüchtigen zu tun, mahnte die Kommission in diesem Kontext eine gesetzliche Grundlage für das Einfrieren des Vermögens von flüchtigen Personen an, da das angewendete Verfahren kompliziert sei und zahlreiche Schlupflöcher ermögliche. Mit Blick auf die nationale Verfolgung von Kriegsverbrechen zog die Kommission Bilanz. Demnach führte die Kammer für Kriegsverbrechen seit ihrer Gründung 2003 gegen 123 Verdächtige Prozesse, gegen 111 Personen wurden Untersuchungen eingeleitet und gegen 57 Personen Anklagen erhoben. Die Kommission monierte aber die weiterhin recht limitierten Kapazitäten und kritisierte die wiederholten Drohungen gegen den Staatsanwalt für Kriegsverbrechen und den Präsidenten der Kammer für Kriegsverbrechen. ${ }^{329}$

\section{9: Europaweiter Gedenktag und Beitrittsantrag}

Am 24. März 2009 jährte sich der Beginn der mehr als drei Monate dauernden Bombardierung Serbiens durch die NATO zum zehnten Mal und gab Anlass für zahlreiche Gedenkpraktiken. Die klerikal-nationalistische Organisation Dveri

328 Parliamentary Assembly of the Council of Europe: The Honouring of Obligations and Commitments by Serbia, Report Nr. 11701 vom 15.9.2008.

329 European Commission: Serbia 2008 Progress Report, EU-Dok. SEC (2008) 2698/F vom 5.11.2008, S. 22 . 
(Tore) veröffentlichte eine Sonderausgabe ihrer Zeitschrift Dveri srpske (serbische Tore) mit dem Thema »NATO-Genozid am serbischen Volk«. Laut der Herausgeber sei dieses Themenheft

»ein Kampf für den wahrhaften Humanismus der menschlichen Zivilisation, der Versuch eines kleinen Volkes, das mit der Wahrheit, auf die es sich in der Fülle der Unmoral, der Unmenschlichkeit und der Destruktivität der Quasihumanisten und Quasigerechten beruft, auch weiter seine historische Bereitschaft zeigt, für die Freiheit, das Gute und den christlichen Sinn des menschlichen Volks zu kämpfen«. ${ }^{330}$

In dem ausführlichen Themenheft werden in verschiedenen Artikeln die NATOStaaten als illegitime Aggressoren, das serbische Volk als Opfer von Kriegsverbrechen dargestellt und besonders die Verwendung von uranhaltiger Munition angeprangert.

Die parlamentarische Versammlung des Europäischen Rats wiederholte im April 2009 in einer Resolution die Ergebnisse des Berichts von 2008 nahezu wortgleich. Zudem rief sie die serbische Regierung zu einer vollen Kooperation mit den zuständigen Behörden und der Rechtsstaatlichkeitsmission der EU im Kosovo (EULEX) auf, um das Schicksal und den Verbleib aller Opfer von Entführungen und erzwungenen Verschwindens zu ermitteln. Darüber hinaus forderte sie den Ausbau der Kapazitäten und Ressourcen der Kammer für Kriegsverbrechen, des dafür zuständigen ermittelnden Staaatsanwalts und der ihm zuarbeitenden Ermittlungsbehörde für Kriegsverbrechen im Innenministerium. ${ }^{331}$

Nach einer positiven Evaluation der Bereiche Dokumentensicherheit, illegale Einwanderung, öffentliche Sicherheit und Ordnung, Außenbeziehungen und Grundrechte stellte der Europäische Rat Mitte Juni 2009 unter anderem Serbien die visafreie Einreise seiner Bürger in die Staaten der EU in Aussicht.

330 Nešić, Branimir: »Uvodna reč. O sirenama, preciznosti i pečenom mesu [Einleitende Worte. Von Sirenen, Genauigkeiten und verbranntem Fleisch], in: ders./Boško Obradović (Hg.): 1999-2000. NATO genocid nad srpskim narodom: Deset godina od bombardovanja Srbije [1999-2000. NATO-Genozid am serbischen Volk: Zehn Jahre nach der Bombardierung Serbiens] (= Dveri srpske 41), Belgrad: Dveri srpske 2009, S. 2 f., hier S. 2.

331 Vgl. Parliamentary Assembly of the Council of Europe: The Honouring of Obligations and Commitments by Serbia, Resolution Nr. 1661 vom 28.4.2009. 
Seitdem das Europäische Parlament im Januar 2009 den 11. Juni zum europaweiten Gedenktag für das Massaker in Srebrenica erklärt hatte, ${ }^{332}$ demonstrierten die Frauen in Schwarz, das Helsinki-Komitee für Menschenrechte, die Initiative Junger für Menschenrechte, der Fonds für Völkerrecht und das Centar za unapređivanje pravnih studija (Zentrum für die Weiterentwicklung juristischer Studien) vor dem Sitz des Präsidenten. Sie verlangten, er solle seiner Pflicht nachkommen und die Resolution des Europäischen Parlaments auch in Serbien mittels der Verabschiedung einer parlamentarischen Resolution umsetzen. Die Forderungen nach einem Treffen und einer Deklaration wurden monatlich vorgebracht, letztmalig am 10. Juli 2009 und unterstützt von insgesamt 100 serbischen NGOs. Das Anliegen der zivilgesellschaftlichen Gruppen blieb vom Präsidenten ungehört. Am Tag vor dem Gedenktag des Massakers von Srebrenica veröffentlichte die SDU einen neuen Vorschlag einer Resolution, der auf den Schutz der Rechte der Opfer von Kriegsverbrechen, vor allem des Verbrechens in Srebrenica, abzielte. ${ }^{333}$ Diese Initiative ignorierte die Regierungskoalition ebenso, wie der Präsident nicht auf die Forderungen der zivilgesellschaftlichen Gruppen reagierte. Der Jahrestag des Massakers wurde mit einer Gedenkaktion der Frauen in Schwarz in der Innenstadt Belgrads begangen. ${ }^{334}$ Nur einige Wochen später verwies eine Kampagne von Amnesty International auf die kontinuierlichen Anfeindungen und Übergriffe gegenüber den in der Öffentlichkeit be-

332 Europäisches Parlament: 11. Juli: Tag des Gedenkens an die Opfer des Massakers von Srebenica. Entschließung des Europäischen Parlaments, EP-Dok. P6_TA (2009)0028 vom 15.1.2009.

333 SDU: Deklaracija o obavezama države Srbije da preduzme sve mere zaštite prava žrtava ratnih zločina, a posenbno žrtava genocida u Srebrenici [Deklaration über die Verpflichtungen des Staates Serbien zur Ergreifung aller Maßnahmen zum Schutz der Rechte der Opfer von Kriegsverbrechen, besonders des Völkermords in Srebrenica] vom 10.7.2009, http://www.sdo.org.rs/cms/documents/SDU\%20\%20deklaraci ja\%20o\%20srebrenici.pdf vom 26.8.2011.

334 YUCOM: Attitudes in Serbia Regarding the Demand by one Hundred NGOs for July 11 to be Proclaimed as Remembrance Day of the Srebrenica Genocide, Human Rights and Democracy Violation Early Warning Weekly Newsletter 41 vom 24.7.2009, http://www.yucom.org.rs/upload/vestgalerija_61_18/1253790310_GS0_EWS41-English24072009.pdf vom 12.7.2015. 
kanntesten Aktivistinnen für eine umfassende Vergangenheitsaufarbeitung in Serbien, Nataša Kandić, Sonja Biserko und Biljana Kovačević-Vučo. ${ }^{335}$

Im November 2009 veröffentlichte die Europäische Kommission ihren Fortschrittsbericht zu Serbien. Demnach habe sich dem Bericht des Chefanklägers gemäß die Zusammenarbeit mit dem ICTY weiter verbessert, auch wenn Mladić und Hadžić noch immer nicht gefasst seien. Bedenklich seien allerdings die negativen Aussagen von Regierungsvertretern über die Urteile des Tribunals. Weiterhin monierte die Kommission den unklaren Status des Gesetzes über das Einfrieren von Vermögen Flüchtiger und die somit schwierige und juristisch uneindeutige Situation. Sie lobte die Strafverfolgung von Kriegsverbrechen auf nationaler Ebene, wo das Büro des Staatsanwalts für Kriegsverbrechen gegen 100 Verdächtige ermittle und trotz begrenzter Ressourcen und einer politisch schwierigen Lage effizient arbeite, so dass zum Zeitpunkt der Veröffentlichung des Berichts zwölf Prozesse geführt wurden. ${ }^{336}$

Seit dem 19. Dezember 2009 dürfen die Bürger Serbiens visafrei in den Schengen-Raum einreisen. Am 22. Dezember 2009 stellte Serbien einen Antrag auf Mitgliedschaft in der EU.

\section{0: Drei Monate Debatte. Von bosnischen und serbischen Opfern}

Nur wenige Tage nachdem Serbien bei der schwedischen EU-Ratspräsidentschaft einen Antrag auf EU-Mitgliedschaft gestellt hatte, schlug Präsident Tadić in einem Interview während eines Besuch in Banja Luka in der Republika Srpska selbst vor, eine parlamentarische Deklaration zur Verurteilung des Verbrechens von Srebrenica zu verabschieden. Er argumentierte, eine Verurteilung des Massakers sei eine Verpflichtung, die aus dem Urteil des Internationalen Gerichtshofs hervorgehe und dass man mit einer Politik des Respekts für ausländische Opfer Glaubwürdigkeit für die Verfolgung von nationaler Politik auf internationaler Ebene erreichen könne. ${ }^{337}$ Ein Korrespondent der Zeitung Dnevnik kommentierte später, dass es die Intention Belgrads sei, dem Internationalen Ge-

335 Amnesty International: Serbia: Human Rights Defenders at Risk, Bericht vom 14.9.2009, https://www.amnesty.org/download/Documents/48000/eur700142009en.pdf vom 22.8.2011.

336 European Commission: Serbia 2009 Progress Report, EU-Dok. SEC (2009) 1339 vom 14.10.2009.

337 Preneto: »Tadić: Rezolucija o Srebrenici je naša obaveza« [Tadić: Die Erklärung über Srebrenica ist unsere Verpflichtung], in: Politika vom 11.1.2010, S. 2. 
richtshof in Den Haag Respekt zu erweisen, bevor es zu einer Entscheidung über die Legitimität der einseitigen Unabhängigkeitserklärung des Kosovo käme. ${ }^{338}$ Sicherlich schadeten Zeichen der Versöhnung nicht der Außenpolitik und der Zeitpunkt erschien mit Blick auf die anstehende Entscheidung günstig. Die Äußerungen des Präsidenten lassen auf ein strategisches Verhalten schließen, das gerade angesichts des Umstands, seine Symbolpolitik der Entschuldigungen mit der Verteidigung serbischer Interessen zu begründen, völlig kohärent erscheint.

$\mathrm{Zu}$ einer Verurteilung von Srebrenica bezogen in kürzester Zeit sämtliche politischen Kräfte des Landes Stellung, die im Wesentlichen die Positionen von 2005 umfassten. Nur drei Tage nach seiner Aufforderung kündigte der Präsident zwei getrennte Resolutionen an, eine zur Verurteilung aller Kriegsverbrechen, über die Konsens zwischen den Parlamentsfraktionen bestand, und eine weitere zur Verurteilung von Srebrenica, die die DSS, die SPS und die Srpska Napredna Stranka (Serbische Fortschrittspartei, SNS) strikt ablehnten. Diese Parteien beharrten auf einer Gleichstellung, wenn nicht sogar besonderen Betonung der serbischen Opfer der Kriege. Selbst Tadić' eigene Partei war hinsichtlich einer separaten Deklaration für Srebrenica gespalten. ${ }^{339}$ Wie 2005 diskutierten die Vertreter der Parteien erneut extensiv darüber, ob man Srebrenica als schwerstes Verbrechen gesondert herausstellen sollte. Im Zuge dieser Kontroverse bemühten die politischen Vertreter die gleichen Argumente wie 2005 und teilweise sogar die gleichen Resolutionsvorschläge, die schon fünf Jahre zuvor eingereicht worden waren. So forderte die DSS, nun gemeinsam mit Abgeordneten von Nova Srbija, erneut eine allgemeine »Verurteilung von Kriegsverbrechen auf dem Territorium des ehemaligen Jugoslawien « und dabei sogar eine Referenz auf die serbischen Toten aus den Kriegen des 20. Jahrhunderts. ${ }^{340}$

338 Pantelić, Željko: »Osuda zločina zbog suda u Hagu. Eksklusivno: Kako EU vidi pokušaj suočavanja Srbije s genocidom u Srebrenici« [Verurteilung der Verbechen wegen des Gerichts in Den Haag. Exklusiv: Wie die EU den Versuch Serbiens sieht, den Genozid in Srebrenica aufzuarbeiten], in: Dnevnik vom 1.2.2010, S. 2.

339 Karge macht das an Aussagen von DS-Sprecherin Jelena Trivan fest, vgl. Karge, Heike: »Nie wieder Srebrenica. Eine Dokumentation der Srebrenica-Erklärungen und ihrer Wirkungen«, in: Südosteuropa 59 (2011) 1, S. 128-167, hier S. 141 f.

340 Vgl. Koštunica, Vojislav: Predlog Deklaracije o osudi ratnih zločina na prostoru nekadašnje Jugoslavije. Predlog 30 poslanike DSSa i Nove Srbije [Deklarationsvorschlag über die Verurteilung von Kriegsverbrechen im Raum des ehemaligen Jugoslawien. Vorschlag von dreißig Abgeordneten der Fraktionen der DSS und Nova Srbija] vom 1.2.2010, Belgrad: Narodna Skupština Republike Srbije 2010. 
Für weitere Polemiken sorgten die Fragen, wie die Rolle Serbiens in den Jugoslawienkriegen und deren Wahrnehmung genau bezeichnet werden soll und inwieweit Srebrenica als Genozid zu werten sei. Beide Punkte implizierten unterschiedliche Grade der staatlichen oder kollektiven Nähe zu Verbrechen und dessen Tätern und drohten gegebenenfalls das Ansehen des Landes und der »serbischen Identität« zu beschädigen. Zentral war die Frage, inwieweit serbische Opfer den gleichen Wert hätten wie bosnische, die nun nicht nur durch die internationale Gemeinschaft, sondern auch durch das serbische Parlament eine besondere Aufmerksamkeit erfahren sollten. In diesem Kontext wurde auch gemutmaßt, dass die Resolution Ergebnis externer Induzierung und Konditionalität sei. Die Regierungsseite wies diesen Vorwurf von sich.

Doch nicht nur die im Parlament vertretenen Parteien, auch die Zivilgesellschaft bezog in der Debatte Position. Weiterhin demonstrierten NGOs monatlich vor dem Sitz des Präsidenten, um auf die Einrichtung des 11. Juli als Gedenktag an Srebrenica zu drängen, wie es die Resolution des Europäischen Parlaments forderte. Auf der anderen Seite mobilisierten die nationalistischen Kräfte ebenso gegen eine Resolution. Im Stadtzentrum Belgrads war ein Graffito zu lesen, dass die bosniakische Gewalt an den rund um Srebrenica getöteten Serben beklagte: »Sarajevoer Genozid an 6530 Serben ${ }^{341}$. Vom 11. Januar bis zur Verabschiedung der Deklaration Ende März organisierten nationalistische NGOs eine Kampagne, die Dveri srpske als die größte des »patriotischen« zivilgesellschaftlichen Sektors bezeichnete. ${ }^{342}$ Mehr als achtzig serbische zivilgesellschaftliche Akteure und über 200 Persönlichkeiten aus der Region und der Diaspora appellierten, organisiert von der »Initiative Bürger für die Wahrheit über Srebrenica«, unter dem Titel »Serbische Opfer sind nicht weniger wichtig« gegen die SrebrenicaResolution. ${ }^{343}$ Zwar müsse jedes Verbrechen verurteilt werden, allerdings kritisiert der Appel die Etablierung eines »antiserbischen, mythischen Symbols« und die Politisierung, die mit der Srebrenica-Resolution einherginge-»um so

341 Preneto: »Grafit o genocidu nad Srbima« [Graffitti über den Genozid an den Serben], in: Glas Javnosti vom 15.1.2010, S. 3.

342 Vgl. Dveri srpske (Hg.): »Skupštinska deklaracija o Srebrenici« [Die parlamentarische Deklaration über Srebrenica], http://www.dverisrpske.com/tekst/1791741 vom 4.3.2011.

343 Vgl. bis zum Ende des Absatzes Inicijativa građana za istinu o Srebrenici: »Apel više od 80 srpskih nevladinih organizacija povodom tvz. Rezolucije o Srebrenici« vom 11.2.2010 [Appell von mehr als achtzig serbischen NGOs anlässlich der sogenannten Resolution über Srebrenica], http://inicijativagis.wordpress.com/2010/02/11/ апел-више-од-80-српских-невладиних-орган vom 6.7.2011. 
schlimmer, da sie mit menschlichen Opfern manipulierte«. Mit der Verabschiedung der Srebrenica-Resolution würde die »historische Wahrheit« derer anerkannt, die 1995 und 1999 »unser Volk« bombardiert hätten. Zudem würde sie den Kampf für die Republika Srpska untergraben und die serbischen Opfer erniedrigen. Noch heute würde über den vielfachen Genozid am serbischen Volk geschwiegen. Statt diese Erinnerung auch in der Außenpolitik des Landes auszudrücken, käme eine Resolution zur Verurteilung von Srebrenica der Auslöschung des eigenen Volkes aus der Geschichte gleich. Für sie zu stimmen stelle für jeden Abgeordneten die größte Schande dar, die er noch dazu mit dem eigenen Namen unterschreiben würde.

Auch ausländische Intellektuelle aus Amerika, Russland, Deutschland, Belgien und anderen westlichen Ländern unterschrieben einen vom Srebrenica Historical Project verfassten Appell, der den serbischen Präsidenten und das Parlament dazu aufforderte, nicht mit der Zukunft ihres Landes zu spielen. ${ }^{344}$ Sie vertraten die Position, es habe in Srebrenica keinen Genozid gegeben. Nach ihrer Deutung seien nach der Übernahme der Stadt durch die bosnischen Serben innerhalb von drei Tagen genauso viele muslimische Gefangene getötet worden, wie die Muslime in den drei Jahren zuvor Serben umgebracht hätten. Ihre Lesart unterscheidet sich maßgeblich von der offiziellen des ICTY. So ist von keiner serbischen Beteiligung oder von Paramilitärs die Rede, die Getöteten werden als Gefangene und nicht als unschuldige Zivilisten qualifiziert und ihre Zahl der Getöteten liegt deutlich niedriger als die ca. 8000 Personen, die das ICTY führt. Die Unterzeichner räumen ein, dass der Disput darüber, was in Srebrenica passiert sei, noch keine Klärung erfahren hätte. Das Verbrechen in Srebrenica sei zwar ein grausames Kriegsverbrechen gewesen, allerdings bestünde kein Anlass, ein Kriegsverbrechen gegenüber einem anderen zu privilegieren. Die akzeptierte Version sei auf die Kriegspropaganda zurückzuführen. Sie befürchten eine weitere Politisierung des menschlichen Leidens und eine Relativierung der Völkermorde, die bislang als solche qualifiziert wurden, sollte Srebrenica als Völkermord von Serbien anerkannt werden. Zudem führten sie die dann drohenden

$344 \mathrm{Zu}$ den Unterzeichnern gehörten neben vielen anderen Edward Herman, Jürgen Elsässer, Diana Johnstone, Germinal Civikov und Patrick Barriot, vgl. hier und bis zum Ende des Absatzes Srebrenica Historical Project (Hg.): »Appeal to President Boris Tadić and the Serbian Parliament. Do Not Gamble With Your Country's Future! No to the Srebrenica Resolution!« vom 6.2.2010, http:/www.srebrenicaproject.com/index.php?option=com_content\&view=article\&id=83:appeal-to-presidentboris-tadi-and-the-serbian-parliament-do-not-gamble-with-your-countrys-future-noto-the-srebrenica-resolution\&catid=12:2009-01-25-02-01-02 vom 20.3.2013. 
Konsequenzen auf: dass Serbien in eine Liga mit Nazideutschland gestellt würde, dass die Perspektive Unterstützung fände, die Republika Srpska baue auf einem Völkermord auf und leiste somit einer Zentralisierung Bosniens Vorschub, dass dem serbischen Steuerzahler hohe Kompensationszahlungen drohten.

Die amerikanische Stiftung Studenica forderte regionale Deklarationen, die alle Parlamente der Region zeitgleich verabschieden sollten. Anfang März umfasste die Gruppe »Stoppt die Resolution über Srebrenica!« auf Facebook über 12.000 Mitglieder. In Belgrad fand die Podiumsdiskussion »Wohin führt die Resolution über Srebrenica?« statt, an deren Ende die Teilnehmer Milivoje Ivanišević vom Institut za istraživanje srpskih stradanja u 20. veku (Institut zur Erforschung des serbischen Leidens im 20. Jahrhundert), der Jurist und ICTYGegner Kosta Čavoški sowie zwei offizielle Repräsentanten der Gemeinde Srebrenica in der Republika Srpska zu dem Ergebnis kamen, dass die SrebrenicaResolution ein amerikanisches Projekt sei, um den Bürgerkrieg in BosnienHerzegowina in eine Aggression zu transformieren und um einen einheitlichen islamischen Staat in Bosnien-Herzegowina zu errichten. Auch der Premier der Republika Srpska, Milorad Dodik, kritisierte die Logik, dass »alle anderen, die gelitten haben, unwichtige Menschen sind, wichtig ist nur Srebrenica. Das dient der politischen Propaganda der Bosniaken [...] Was ist mit den ca. 30.000 Serben, die im Bosnienkrieg gelitten haben? $\ll^{345}$

Die Koordination der serbischen Vereinigungen der Familien der Verschwundenen auf dem Gebiet des ehemaligen Jugoslawien rief dazu auf, nicht zwischen Opfern zu unterscheiden.

Mitte März wurde eine im Januar durchgeführte Meinungsumfrage unter 1000 serbischen Bürgern veröffentlicht, nach der sich 46,2 Prozent der Befragten für die Verabschiedung einer Deklaration aussprachen, die alle Kriegsverbrechen verurteilt, die auf dem Boden des ehemaligen Jugoslawien begangen wurden. Demgegenüber waren 20,6 Prozent dafür, eine Deklaration zur Verurteilung Srebrenicas und eine für alle Kriegsverbrechen anzunehmen, während ebenfalls 20,6 Prozent gegen irgendeine Deklaration des Parlaments votierten. 12,7 Prozent enthielten sich der Meinungsäußerung. ${ }^{346}$

345 Marić, Boro: »Dodik: Srebrenica nije jedino mesto zločina u BiH« [Dodik: Srebrenica ist nicht der einzige Ort eines Verbrechens in Bosnien-Herzegowina], in: Politika vom 22.3.2005, S. 1.

346 Agentur Politikum: »Istraživanje stavova građana Srbije na temu Haga i rezolucije o Srebrenici« [Untersuchung der Standpunkte der Bürger Serbiens zum Thema ICTY und Srebrenica-Resolution], in: Nova srpska politička misao vom 18.3.2010, 
Die Schwierigkeit eines mehrheitsfähigen Deklarationsvorschlags reflektierte sich auch darin, dass die Regierungskoalition ihren Vorschlag erst drei Tage vor der Debatte vorlegte. Die Fortschrittspartei und die Liberaldemokratische Partei reichten ihrerseits Vorschläge ein, die aber ihrerseits nicht mehrheitsfähig waren.

Nach 13-stündiger, höchst kontroverser Parlamentsdebatte ${ }^{347}$ wurde am 30. März 2010 schließlich die Deklaration der Regierungskoalition mit einer Mehrheit von lediglich 24 Abgeordneten verabschiedet. Es waren nur 149 Abgeordnete im Saal, die Abgeordneten der Fraktionen der SNS, SRS und der Liberalnodemokratska Partija (Liberaldemokratische Partei, LDP) boykottierten die Abstimmung gänzlich. 127 Abgeordnete der Liste »Für ein europäisches Serbien«, die mit ihr koalierende SPS, die populistische, aber europafreundliche Jedinstvena Srbija (Einiges Serbien, JS) und die Partija ujedinjenih penzionera Srbije (Partei der vereinigten Pensionäre Serbiens, PUPS) votierten für die Deklaration, während sich die 21 Abgeordneten der DSS und von Nova Srbija (Neues Serbien, NS) dagegen aussprachen. Ein Abgeordneter enthielt sich. ${ }^{348}$

Das serbische Parlament verurteilte in der Parlamentsresolution das Massaker von Srebrenica, der Begriff des Völkermords oder ein Verweis auf das Urteil des Internationalen Gerichtshofs vermied es allerdings. Weltweit erntete Serbien positive Reaktionen für diesen »Schritt in die Zukunft«, während bosniakische Vertreter die schwachen Formulierungen und die fehlende Qualifizierung als Genozid kritisierten. ${ }^{349}$ Gegenüber dem Parlament kommentierte ein Graffito »Dies schwere Wort Genozid «. ${ }^{350}$ Am Tag nach der Verabschiedung titelten die serbischen Zeitungen nicht mit der Verabschiedung der Deklaration, sondern mit einem nicht gezeigten Fußballspiel. Da die im Fernsehen übertragene Parlamentsdebatte so lange gedauert hatte, wurde nun gefragt, wer nun für den durch

http://www.nspm.rs/istrazivanja-javnog-mnjenja/agencija-politikum-istrazivanje-stavovagradjana-srbije-na-temu-haga-i-rezolucije-o-srebrenici-januar-2010.html?alphabet=l vom 23.4.2013.

347 Vgl. hierzu Mehler, Daniela: »Understanding Normative Gaps in Transitional Justice. The Serbian Discourse on the Srebrenica Declaration 2010«, in: Journal on Ethnopolitics and Minority Issues in Europe 11 (2012) 4, S. 127-156.

348 Čekerevac, Mirjana: »Usvojena deklaracija o Srebrenici« [Deklaration zu Srebrenica verabschiedet], in: Politika vom 31.3.2010, S. A1.

349 O. V.: »Ključni potez za pomirenje u čitavom regionu« [Entscheidender Zug für die Versöhnung in der ganzen Region], in: Večernje Novosti vom 1.4.2010, S. 2.

350 Dobromirović, Milan/ Šaronjić, Ivana: »Jaja i grafiti ispred Skupštine« [Eier und Grafitti vor dem Parlament], in: Kurir vom 2.4.2010, S. 2. 
die abgesagte Ausstrahlung entstandenen Schaden aufkommen würde. ${ }^{351}$ Auf den Mittelseiten der Blätter wurde auf die Reaktionen der Welt eingegangen und kaum auf die Resolution und deren Bedeutung selbst.

Am 11. Juli 2010 nahm der serbische Präsident erneut an der offiziellen Gedenkfeier in Srebrenica-Potočari teil. Er sagte über das Massaker von Srebrenica, dass diese Tragödie nicht vergessen werden könne. Bei seinem Besuch in Potočari betonte Tadić, dass die Verfolgung von General Mladić nicht aufgegeben würde, und skizzierte eine eher naive Vision von Versöhnung der ehemaligen Kriegsparteien:

»Ich werde denken, dass ich einen Teil meiner Arbeit beendet habe, wenn er vor Gericht gebracht wird. Danach ist es erforderlich, dass die Völker sich einander die Hände reichen und weiter leben, wie wir einst lebten. ${ }^{352}$

Einige Stunden nach Beginn der offiziellen Gedenkfeier in Potočari fand in Bratunac eine Gedenkfeier an die ca. 3500 serbischen Opfer statt, die in Bratunac und seiner Umgebung von den Einheiten Naser Orić', der von 1992 bis 1995 Kommandant der bosnischen Enklave Srebrenica war, getötet wurden. Lediglich ein Gesandter Tadić' legte einen Kranz nieder. Die Sprecher der Oppositionsparteien SNS, NS und DSS beschwerten sich nach den Gedenkfeiern in der Öffentlichkeit lautstark darüber, dass Tadić nicht auch den serbischen Opfern gedacht hatte: »Schämt er sich der serbischen Opfer?«, fragte der stellvertretende Vorsitzende der SNS Aleksandar Vučić, während der Vorsitzende der NS Velimir Ilić dessen Verhalten wie folgt kommentierte:

»Tadić besucht Srebrenica, wo er mit Pfiffen erwartet wurde, und mit seiner Abwesenheit in Bratunac trampelt er auf allen serbischen Opfern herum. Ich weiß nicht, wie weit er den Staat und die Menschen noch demütigen wird, wie lange er sich noch entschuldigen wird, während die andere Seite weiter schweigt. Eine Schande! « ${ }^{353}$

351 Tanjug: »RTS traži odštetu od Skupštine« [RTS verlangt Schadenersatz vom Parlament], in: Glas Javnosti online vom 1.4.2010, http://www.glas-javnosti.rs/clanak/ politika/glas-javnosti-01-04-2010/rts-trazi-odstetu-od-skupstine vom 1.4.2014.

352 B. Marić: »Dodik«.

353 Vojinović, Svetlana.: »Opozicija tvrdi da je Tadić morao da ode i u Bratunac« [Die Opposition behauptet, Tadić hätte auch nach Bratunac gehen müssen], in: Press vom 14.7.2010, http://www.pressonline.co.rs/sr/vesti/vesti_dana/story/125434/Opozicija+tv rdi+da+je+Tadi\%C4\%87+morao+da+ode+i+u+Bratunac.html vom 22.8.2010. 
In diesen Auszügen wird deutlich, dass vom serbischen Präsidenten eine unbedingte Bevorzugung der serbischen Opfer erwartet wurde. Gleichermaßen wurde nur wenig Verständnis für das vermeintlich unnötige Verhalten Tadić' aufgebracht: Warum soll der serbische Präsident der muslimischen Opfer gedenken, wenn die Muslime nicht der serbischen gedachten? Sind serbische Opfer weniger wert als die der Anderen? Hier wurde das Bedürfnis nach Anerkennung der eigenen Opfererfahrungen und ein Unverständnis für die vergleichsweise große Aufmerksamkeit gegenüber den Opfererfahrungen anderer ethnonationaler Gruppen zum Ausdruck gebracht und dem serbischen Präsidenten vor diesem Hintergrund vorgeworfen, nicht seiner patriotischen Pflicht nachgekommen zu sein, zuallererst der serbischen Opfer zu gedenken. Ein echtes Verantwortungsgefühl für die Geschehnisse in Srebrenica ist in den Äußerungen der oppositionellen Vertreter der Parteienlandschaft nicht zu finden, vielmehr gehören sie zu den Stimmen des Landes, die das Verbrechen von Srebrenica nicht nur durch das Fokussieren auf die serbischen Opfer in Bratunac relativieren, sondern auch der Interpretation anhängen, dass Srebrenica eine - bisweilen als legitim qualifizierte - Reaktion auf die bosniakischen Verbrechen an der serbischen Zivilbevölkerung gewesen sei.

In erster Linie zur innenpolitischen Aussöhnung wurde im Oktober 2010, wie zu Beginn der Debatte um die Srebrenica-Deklaration angekündigt, eine weitere Resolution behandelt. Statt alle Kriegsverbrechen zu verurteilen, die während der Jugoslawienkriege begangen wurden, verabschiedete das serbische Parlament gesondert eine $»$ Verurteilung der an den Angehörigen des serbischen Volkes begangenen Verbrechen «. ${ }^{354}$ Für die Deklaration votierten die 133 Abgeordneten der Koalition »Für ein Europäisches Serbien«, der SPS, JS, G17, PUPS, Liga Socijaldemokrata Vojvodine (Liga der Sozialdemokraten der Vojvodina, LSV) und LDP. Den Vertretern der SRS, DSS, NS und SNS war die Deklaration nicht weitreichend genug und zu schwach formuliert, weshalb sie vor der Abstimmung den Saal aus Protest verließen. ${ }^{355}$

354 Vgl. bis zum Ende des Absatzes Volksversammlung der Republik Serbien: Deklaracija Narodne Skupštine Republike Srbije o osudi zločina učinjenih nad pripadnicima srpskog naroda i građanima Srbije [Deklaration der Volksversammlung der Republik Serbien über die Verurteilung der an den Angehörigen des serbischen Volkes und den Bürgern Serbiens begangenen Verbrechen] vom 14.10.2010, http://www.parlament. gov.rs/upload/archive/files/lat/pdf/ostala_akta/2010/Rs31-10Lat.zip vom 28.4.2013.

355 Vgl. Rovčanin, Snzežana/Babović, Milan: »Osuđeni i zločini nad Srbima« [Auch Verbrechen an Serben verurteilt], in: Večernje Novosti vom 15.10.2010, S. 3. 
Ende Oktober 2010 erhöhte das Parlament der Republik Serbien die Belohnung für Informationen, die zur Lokalisierung und Verhaftung von Ratko Mladić führen würde, auf zehn Millionen Euro und auf eine Million Euro für Goran Hadžić.

Im November 2010 besuchten der serbischen Präsident Boris Tadić und der kroatische Präsident Ivo Josipović gemeinsam zwei Gedenkstätten für Kriegsverbrechen bei Vukovar. Von August bis November 1991 hatten die JNA und paramilitärische Verbände die Stadt Vukovar belagert. Ca. 400 kroatische Zivilisten wurden aus dem Vukovarer Krankenhaus verschleppt, 200 von ihnen auf dem Gelände einer ehemaligen Schweinefarm im nahegelegenen Ovčara ermordet. In Paulin Dvor tötete die 130. Brigade der kroatischen Armee 18 serbische Zivilisten. In Ovčara legte Tadić den »unschuldigen Opfern« zu Ehren einen Kranz nieder und sagte:

»Mit dem Anerkennen von Verbrechen, dem Entschuldigen und Trauern schaffen sich Möglichkeiten für Verzeihung und Versöhnung. Wenn sich unsere Völker aussöhnen, eröffnet sich eine neue Zukunft, und deshalb finde ich, dass alles, was zwischen Kroaten und Serben im 20. Jahrhundert passiert ist, in ein Buch der Vergangenheit geschlossen werden muss und dieser Weg das Schaffen und Schreiben eines neuen Buchs der Zukunft darstellt. ${ }^{356}$

Weiterhin erklärte er, ihm müsse man nicht sagen, wie man sich gegenüber Kriegsverbrechen und dem Gedenken zu verhalten habe, dies sei die moralische Verpflichtung des Bürgers Boris Tadić. Diejenigen, die Verbrechen und Opferzahlen verglichen, würden sich tief versündigen. Er und Josipović würden keine Mathematik, sondern eine »gerade« Ethik verfolgen. Ein anderes Vorgehen wäre falsch, da das zu Auszählungen führe, die kein Ende nähmen. ${ }^{357}$

Tadić' Geste blieb innerhalb der serbischen Politik erstaunlicherweise völlig unkommentiert, in den Medien waren die Reaktionen überwiegend positiv, aber durchaus unterschiedlich. Die Danas machte mit dem Titel »Ende des Kriegs $«{ }^{358}$ auf und blickte wie die Politika verstärkt auch auf die internationalen Reaktionen auf die historische Geste, ${ }^{359}$ allerdings blieben in deren Berichterstattung auch die nationalistischen T-Shirts einiger kroatischer Angehöriger nicht unerwähnt.

356 Bilbija, Bojan: »Poklonjenje žrtvama na Ovčari« [Das Ehren der Opfer in Ovčara], in: Politika vom 5.11.2010, S. A5.

357 Vgl. ebd.

358 Cvetićanin, Radivoj: »Kraj rata« [Ende des Kriegs], in: Danas vom 5.11.2010, S. 6.

359 B. Bilbija: »Poklonjenje žrtvama na Ovčari«. 
Während die kroatische Politikerin Vesna Pusić und die serbische Wochenzeitung Vreme die Geste Tadić' mit dem Kniefall Willy Brandts verglichen, ${ }^{360}$ bemerkte der Gründer des Dokumentations- und Informationszentrums Veritas und ehemalige Informationsminister der Republika Srpska Krajina, Savo Štrbac, in der Pravda, die Frage der serbischen Flüchtlinge sei wichtiger als Entschuldigungen. ${ }^{361}$ In der Danas wurde der Besuch in Vukovar kontextualisiert: Er sei wichtig gewesen, da die politische Elite das Kriegsverbrechen über zwanzig Jahre lang negiert, relativiert oder in den größeren Zusammenhang des Zerfalls gestellt habe, in dem die Serben ausschließlich Opfer gewesen seien. Allerdings sei die Symbolpolitik nicht genug. Sonja Biserko machte deutlich, dass der »wahre Prozess der Auseinandersetzung ${ }^{362}$ noch nicht begonnen habe. Die serbische Elite sei nicht bereit, sich in einer adäquaten Weise in einen Prozess der Aufarbeitung zu begeben, vor allem da Teile von ihr das Projekt Milošević' unterstützt habe. Bislang habe sich die serbische Politik darauf konzentriert, sich gegen die Anschuldigung als Aggressor zu verteidigen. Eine Aufarbeitung umfasse eine Distanzierung von der Ideologie des Milošević-Regimes, ein Ende der Politik des Vergessens, die Anerkennung der Urteile des ICTY als grundlegende Wahrheit und die Identifizierung der Opfer und ihrer Grabstätten. Der kroatische Politikwissenschaftler und Menschenrechtsaktivist Žarko Puhovski wertete die Geste Tadić' als paradigmatisches Beispiel eines staatsmännischen Ansatzes: Etwas zu tun, wofür die gesellschaftliche Mehrheit nicht bereit sei, es aber nicht vor dem Wähler zu verstecken, sondern ihm einen Weg zu weisen. ${ }^{363}$

Ende Oktober 2010 leiteten die EU-Außenminister den serbischen Antrag auf Mitgliedschaft in der EU an die Kommission weiter. Sie betonten aber gleichzeitig, dass die umfassende Kooperation mit dem ICTY die grundlegende Bedingung für eine Mitgliedschaft sei. In einem weiteren Fortschrittsbericht zeigte sich die Kommission, basierend auf dem Bericht des ICTY-Chefanklä-

360 Vgl. Miladinović, Veljko: »Veliko izvinite i mala isprika« [Große Entschuldigung und kleine Ausreden], in: Press vom 5.11.2010, S. 3, sowie Ivanji, Andrej: »Sa Ovčara do Kablara« [Vom Ovčar zum Kablar], in: Vreme vom 11.11.2010, http://www. vreme.com/cms/view.php?id=960456 vom 12.7.2014.

361 Štrbac, Savo: »Pitanje izbeglih važnije od izvinjenja« [Die Flüchtlingsfrage ist wichtiger als Entschuldigungen], in: Pravda vom 5.11.2010, S. 4.

362 Čongradin, Snežana: »Izvinjenje zbog zločina, uz skrivanje grobnica žrtava: Nakon posete Borisa Tadića u Vukovaru« [Entschuldigung wegen der Verbrechen, nebst dem Verstecken von Opfergräber. Nach dem Besuch Boris Tadić' in Vukovar], in: Danas vom 6.11.2010.

363 Ebd. 
gers, zufrieden mit der Kooperation Serbiens mit dem Tribunal. Die Zusammenarbeit funktioniere problemlos und sei professionell, allerdings müsse das Land die Strategie zur Ergreifung von Ratko Mladić und Goran Hadžić überprüfen, wozu ein rigoroserer und multidisziplinärer Ansatz notwendig sei. Zudem wurde moniert, dass der Status des Gesetzes über das Einfrieren des Vermögens von Flüchtigen weiterhin unklar sei. ${ }^{364}$

Einige Tage darauf überreichte Erweiterungskommissar Stefan Füle der serbischen Regierung den Beitrittsfragebogen, der im Fall Serbiens insgesamt 2483 Fragen enthielt. Die Antworten Serbiens auf den Beitrittsfragebogen konnten bereits am 31. Januar 2011 übergeben werden, da ministerielle Arbeitsgruppen unter Koordination des Büros für Europäische Integration die Antworten schon seit 2007 vorbereiteten.

\section{1: Verhaftungen, zivilgesellschaftliche Initiativen und EU-Annäherung}

Am 26. Januar 2011 verabschiedete die parlamentarische Versammlung des Europarats eine gesonderte Resolution über die Versöhnung und den politischen Dialog zwischen den Ländern des ehemaligen Jugoslawien, in der sie die gegenwärtigen Konsequenzen der Jugoslawienkriege verdeutlichte. Demnach lebten über 300.000 Personen als Binnenvertriebene, 120.000 seien weiterhin Flüchtlinge und 14.000 Personen gelten immer noch als vermisst. Zunächst lobte die Versammlung die Bereitschaft zur Zusammenarbeit und zur Aufarbeitung der Vergangenheit in bilateralen Erklärungen ${ }^{365}$ und im Rahmen von Symbolpolitik. Explizit stellte sie die zivilgesellschaftliche Initative für eine regionale Kommission heraus. Die Reformen der Regierungen der Staaten des ehemaligen Jugoslawien und die konkreten Implementierungen bi- und multilateraler Abkommen hingegen variierten sehr und würden oftmals hinter den Erwartungen zurückbleiben. Zur Bewältigung der Kriegsfolgen, zur Strafverfolgung von Kriegsverbrechen und zur Ergreifung von Maßnahmen zur Versöhnung forderte eine Intensivierung der regionalen Beziehungen und listete konkrete Maßnahmen auf. Darüber hinaus kam in der Resolution die Besorgnis darüber zum Aus-

364 European Commission: Serbia 2010 Progress Report, EU-Dok. SEC (2010) 1330 vom 9.11.2010, S. 19.

365 Hier wurden der Palić-Prozess, die Istanbuler Erklärung zwischen Serbien, BosnienHerzegowina und der Türkei 2010 und die Regionalkonferenz über die Probleme von Flüchtlingen und Binnenvertriebenen in Belgrad im November 2011 sowie der Brdo-Prozess aufgelistet. 
druck, dass sich die öffentlichen Diskurse über die Jugoslawienkriege und ihre Folgen in den Ländern des ehemaligen Jugoslawien unterschieden, was als potentielle Quelle für Hass und Konflikte gewertet wurde, der die politischen Führer gezielt entgegentreten müssten. ${ }^{366}$

Im Mai 2011 verhaftete die serbische Polizei schließlich Ratko Mladić und lieferte ihn an das ICTY aus. Die Regierung kommunizierte die Verhaftung als Erfüllung der an Serbien gestellten Konditionen, ohne die Verbrechen, wegen der Mladić gesucht wurde, breiter zu thematisieren. Die Medien berichteten in erster Linie über die Umstände der Verhaftung, über die prekären Lebensverhältnisse des Untergetauchten, seine familiäre Situation, den gesundheitlichen Zustand und über außenpolitische Reaktionen auf die Festnahme. Eine kritische Auseinandersetzung mit den begangenen Kriegsverbrechen blieb aus. Hingegen klang sowohl in den Äußerungen von Politikern als auch in der medialen Berichterstattung mit Referenz auf die Notwendigkeit der Kooperation mit dem ICTY immer wieder eine Art Entschuldigung für die Verhaftung durch. In den Worten des Juristen Srđa Popović sei das Narrativ über die Ergreifung Mladić' gewesen, dass man »dieses unsere Generälchen, diesen Opa, angesehen und hoch geachtet im Volk [...] eingeholt von den Umständen, wegen denen uns dieses Den Haag, diese Europäische Union und Kathrin Ashton jagen, verhaften musste ${ }^{367}$.

Zwischen der Festnahme Mladić' und der im Juli folgenden von Goran Hadžić sollte im Juni 2011 die Veröffentlichung des Buches Zloupotrebljene institucije: Ko je bio ko u Srbiji 1987-2000 (Mißbrauchte Institutionen: Wer war wer in Serbien 1987-2000) ${ }^{368}$ die serbische Gesellschaft erschüttern. Das Buch listet 1400 Namen von Personen aus verschiedenen gesellschaftlichen Sphären von Politik und Wissenschaft über Kirche und Armee bis zu den Medien und der Kultur - auf, über die Slobodan Milošević seine politischen Ziele verwirklicht hatte. Es ging auf die dreijährige Forschung von Biljana Kovačević-Vučo und Dušan Bogdanović zurück und wurde vom Fond Biljana Kovačević-Vučo veröffentlicht. Die Publikation wurde von Podiumsdiskussionen zum Leben in den

366 Parliamentary Assembly of the Council of Europe: Reconciliation and political dialogue between the countries of the former Yugoslavia, Resolution Nr. 1786 vom 26.1.2011.

367 Lukić, Svetlana: Reakcije na hapšenje Ratka Mladić [Reaktionen auf die Verhaftung von Ratko Mladić], Radiosendung Peščanik vom 27.5.2011, http://pescanik.net/ 2011/05/reakcije-na-hapsenje-ratka-mladica vom 14.2.2013.

368 Bogdanović, Dušan/Kovačević-Vučo, Biljana: Zloupotrebljene institucije: Ko je bio ko u Srbiji 1987.-2000. godine [Mißbrauchte Institutionen. Wer war wer in Serbien 1987-2000], Belgrad: Fond Biljana Kovačević-Vučo 2011. 
Neunzigern und zum Wandel seit 2000 sowie von zwei Ausstellungen begleitet. $\mathrm{Zu}$ den Podiumsdiskussionen waren als Gesprächspartner neben dem Autor Dušan Bogdanović die Menschenrechtsaktivistin Sonja Biserko vom HelsinkiKomitee und der Politiker Žarko Korać eingeladen, der sich in den 90er Jahren in der demokratischen Opposition des Landes engagiert hatte und aktiv für eine Aufarbeitung dieser Periode einsetzt. Die interaktive, multimediale Ausstellung Glasačka mašina (Wahlmaschine) stellte eine Retrospektive der Wahlkampagnen im Mehrparteiensystem Serbiens von 1990 bis 1997 dar. Dokumente der 90er Jahre zeigen, neu zusammengestellt, das politische Marketing des Milošević-Regimes und dessen Elemente der politischen Manipulation, des ideologischen Fanatismus und der ethnischen Perversion auf. ${ }^{369}$ Die Ausstellung Muzej objekata (Museum der Objekte) hingegen lädt bis heute die Bürger Serbiens dazu ein, ihre persönliche Erinnerung an die 90er Jahre zu teilen und Gegenstände für die Ausstellung zu spenden. Die Buchvorstellung, Podiumsdiskussionen und Ausstellungen reisten in den Monaten nach der Erstveröffentlichung durch das ganze Land. Öffentlich sollte so die Frage thematisiert werden, wo Milošević' Leute und ihre politischen Ziele in der Gegenwart seien und welche Rolle sie spielten. Die Auseinandersetzung mit dem Buch sollte deutlich machen, dass es in den Biographien vieler einflussreicher Personen trotz des Regimewechsels keinerlei Bruch gab. Statt eines erwarteten Sturms erfolgte auf das Buch und die konzertierte Aktion aber kaum eine öffentliche Reaktion, vielmehr wurden sie sowohl von der breiten Öffentlichkeit als auch von den im Buch aufgeführten Personen einfach ignoriert. Auch von Aufarbeitungsbefürwortern wie dem Peščanik ${ }^{370}$-Autor Saša Ilić wurde das Buch kritisiert, da es keinen Aufschluss

369 Der zentrale, 32-minütige Film der Ausstellung kann online gefunden werden, siehe Medijska arheologija: »Glasačka mašina« [Die Wahlmaschine], http://www. youtube.com/watch?v=ucBVRRk4tcc vom 11.5.2013. Idee und Realisierung gehen auf den Fonds Biljana Kovačević-Vučo, Medijska arheologija, Kiosk, das Zentrum für kulturelle Dekontamination und die Heinrich-Böll-Stiftung zurück, während die finanzielle Unterstützung vom Fond za otvoreno društvo [Fonds für eine offene Gesellschaft] kam.

370 Peščanik (Sanduhr) wurde 2006 als NGO gegründet und wird durch Mittel der Civil Rights Defenders, des National Endowment for Democracy, der Heinrich-BöllStiftung, der Europäischen Union, der norwegischen Botschaft und der Niederlande unterstützt. Sie produzierte zunächst eine Radiosendung, die von 2000 bis 2011 auf B92 ausgestrahlt wurde. Mittlerweile wird die Sendung auf 15 Radio- und TVSendern in Serbien, Montenegro, Bosnien-Herzegowina und im Kosovo ausgestrahlt. Seit 2007 hält die Sendung eine Homepage mit nunmehr 15.000 Artikeln 
über den Missbrauch von Institutionen gebe. Es fehlten Analysen über die Machtverteilung und über Entscheidungsstrukturen sowie Quellennachweise und Bibliographien der Akteure des nationalistischen Projekts. Darüber hinaus sei es wissenschaftlich schlecht gemacht, die Autoren hätten schlecht recherchiert und nicht nachvollziehbare Gewichtungen vorgenommen. Ilić schließt:

»Alles wird jedoch der mündlichen Überlieferung und Erinnerung von Zeitgenossen überlassen, und es ist bekannt, dass die mündliche Überlieferung das greifbarste Instrument für die Revision der Vergangenheit in Serbien ist. Schade. Dieses Buch hätte wirklich der Beginn der Bewältigung der Vergangenheit sein können, so bleibt es ein weiteres Halbfabrikat ${ }^{371}$.

Die Verhaftung von Goran Hadžić im Juli 2011 schlug deutlich weniger Wellen in der serbischen Öffentlichkeit als die von Mladić. Nach dem dieser dingfest gemacht worden war, schien sie ohnehin nur noch eine Frage der Zeit zu sein. Präsident Tadić erklärte bei der Pressekonferenz, Serbien habe das schwerste Kapitel in der Zusammenarbeit mit dem ICTY beendet und werde die Erfüllung seiner internationalen Verpflichtungen fortsetzen. Mit der Verhaftung Hadžić' seien die gesetzlichen Aufgaben erfüllt und die moralische Schuldigkeit beglichen. Weiterhin erklärte er die »finsteren Seiten unserer Geschichte« für been$\operatorname{det}^{372}$

Im Sommer 2011 trat die Iniciative za REKOM (Initiative für eine regionale Kommission) im öffentlichen Diskurs Serbiens zu Tage, die mittels einer Unterschriftenkampagne zur Gründung einer regionalen Wahrheitskommission aufrief. Bereits Mitte der 2000er Jahre schlossen sich die Aufarbeitungsaktivisten Nataša Kandić vom Fonds für Völkerrecht in Belgrad, Vesna Teršelič von Documenta in Zagreb und Mirsad Tokača vom Informativno-dokumentacioni centar in Sarajevo zusammen und stellten in einem allen interessierten Organisationen und Einzelpersonen offenen Prozess die Idee einer regionalen Wahrheitskommission zur Diskussion. Die daraus entstandene Initiative versteht sich als

vor. Ihre Autoren und Vorstandsmitglieder sind kritische Intellektuelle, Künstler, Vertreter der Zivilgesellschaft.

371 Ilić, Saša: »Danak konzervativnoj metodi« [Tribut den konservativen Methoden], in: Peščanik.net vom 29.7.2011, http://pescanik.net/2011/07/danak-konzervativnoj-metodi vom 13.5.2013.

372 RTV, RTS, Beta, Tanjug, Fonet: Hadžić se neće žaliti na izručenje Hagu [Hadžić wird sich nicht über Auslieferung nach den Haag beklagen], in: RTV.rs vom 20.7.2011, http://www.rtv.rs/sr_lat/hronika/pocelo-saslusanje-hadzica-u-specijalnomsudu_264597.html vom 20.7.2011. 
koordinierte, aber plurale, explizit nicht politische, zivilgesellschaftliche Bewegung und setzt sich für eine unabhängige, überregionale Kommission zur Feststellung der Fakten über alle Opfer von Kriegsverbrechen und anderen schweren Menschenrechtsverletzungen ein, die zwischen 1991 und 2001 auf dem Gebiet des ehemaligen Jugoslawien begangen wurden. Neu waren der Regionalansatz, der alle Verbrechen während aller jugoslawischen Nachfolgekonflikte miteinbezieht, also auch den albanischen Aufstand in Mazedonien 2001, sowie die Idee absoluter Unabhängigkeit von politischem Einfluss und von staatlichen Institutionen. Der Initiative, die im Februar 2013 mehr als 1800 zivilgesellschaftliche Organisationen und Einzelpersonen aus den jugoslawischen Nachfolgestaaten umfasste, liegt ein Bottom-up-Ansatz zugrunde. In dreijähriger zivilgesellschaftlicher Debatte, an der sich fast 6200 Vertreter von NGOs, Opfer- und Veteranenverbänden sowie Individuen beteiligten, wurde nach einem effizienten und sinnvollen Versöhnungskonzept für die ganze Region gesucht. Dabei einigte man sich auf zwei Hauptziele: Einerseits sollte den Opfern eine öffentliche Plattform gegeben, andererseits die Wahrheit beziehungsweise die Fakten festgestellt und Einigkeit über die Fakten hergestellt werden. Die Initiative wurde institutionalisiert, im Mai 2009 wurde REKOM als Verein eingetragen, dessen Sekretariat in Belgrad sitzt. In Serbien unterstützen ein Großteil des alternativen NGOSektors die Initiative, aber auch Vertreter des »dritten Wegs« der Aufarbeitung wie die Viktimologische Gesellschaft Serbiens. Präsident Tadić empfing im Oktober 2009 Vertreter von REKOM und sagte ihnen Unterstützung zu. Im März $2011 \mathrm{nahm}$ die Mitgliederversammlung der Initiative einen Vorschlag für das Statut einer zukünftigen regionalen Kommission ${ }^{373}$ mit Sitz in Sarajevo an, die 16 Mitglieder aus Bosnien-Herzegowina, Kroatien, Serbien, dem Kosovo, Mazedonien, Slowenien und Montenegro umfasst. Innerhalb von drei Jahren soll sie Informationen zusammentragen und analysieren und-zum Teil öffentlichZeugenaussagen hören, bevor sie schließlich einen Abschlussbericht vorlegt. Im Sommer 2011 setzte sich eine öffentliche Unterschriftenaktion für die im Statut beschriebene Kommission ein, an der sich ca. 122.000 Bürger in BosnienHerzegowina, 20.000 in Kroatien und über 250.000 in Serbien beteiligten. Die führenden Tageszeitungen der Region veröffentlichten einen Brief von 155

373 Koalicija za REKOM: Predlog statuta regionalne komisije za utvrđivanje činjenica o ratnim zločinima i drugim kršenjima ljudskih prava na području nakadašnje SFRJ [Vorschlag eines Statuts der regionalen Kommission zur Feststellung von Tatsachen über Kriegsverbrechen und andere Verletzungen der Menschenrechte auf dem Gebiet der ehemaligen SFRJ] vom 26.3.2011, http://www.recom.link/wp-content/uploads/ 2012/01/Predlog-Statuta.pdf vom 11.2.2015. 
Künstlern und Intellektuellen, die ebenfalls ihre Unterstützung zusicherten und die Staatsoberhäupter dazu aufforderten, diese Kommission gemeinsam zu errichten. Im Anschluss daran bereitete eine Expertenkommission einen Gesetzestext vor, der nun einen politischen Prozess anstoßen soll, um in ein multinationales Abkommen zu münden. Dafür soll jedes Land seine eigene REKOMOrganisation gründen, die nach der Arbeitsphase einen Bericht verfasst. Dieser soll dem Parlament vorgelegt und dann angenommen werden.

Der Vorstoß stieß nicht überall auf Zustimmung, wie die auf der REKOMHomepage gesammelten polemischen Artikel und Kontroversen zeigen. ${ }^{374}$ Kurz nach der Veröffentlichung des Statuts schrieben einige Autoren auf der populistischen, nationalkonservativen Plattform Nova srpska politička misao (Neuer serbischer politischer Gedanke) gegen das Projekt an. In nahezu allen Medien der Region gab es vereinzelte kritische Berichte über die Initiative. Ihr wurde vorgeworfen eine Minderheitenposition zu vertreten. Das Ziel der Versöhnung wurde skeptisch betrachtet, man vermutete, dass die Konflikte durch die Offenlegung in einer solchen Kommission wieder angeheizt werden könnten. Die mangelnde Komplementarität einer neuen Kommission wurde kritisiert, da viele Fakten durch die bisherigen Prozesse und die bereits arbeitenden staatlichen Institutionen schon vorliegen würden. Auch wurde der überregionale und unabhängige Status der Kommission bemängelt, die so über bereits vorhandenen staatlichen Organisationen stünde. Das vorgeschlagene Statut würde gegen die Verfassungen der Länder verstoßen. Den Aktivisten wurde mangelnder Realitätssinn nachgesagt, da die Parteien und Politiker in der Region die Realisierung einer regionalen Kommission sicher nicht unterstützen würden. Unberechtigterweise wurde ihnen vorgeworfen, Spenden veruntreut zu haben, immer wieder wurde verlautbart, dass der REKOM-Prozess gescheitert sei. ${ }^{375}$ Auch andere serbische zivilgesellschaftliche Akteure übten Kritik, wie die weitgehend frei von Argumenten vorgetragenen Polemiken von Miljenko Dereta und Dragan Popović von der Građanske iniciative (Bürgerlichen Initiative) zeigen. Sie beschuldigten Nataša Kandić, das regionale Projekt privatisiert zu haben und willkürlich Millionen zu verschleudern. ${ }^{376}$ Kandić wehrte sich in einer Gegendarstellung und

374 Vgl. die Übersicht von Presseartikeln auf http://www.recom.link/sr/category/info-sr/ kritika-i-polemike-sr vom 11.5.2013.

375 Vgl. ebd.

376 Vgl. o. V.: »REKOM osuđen na propast« [REKOM zum Untergang verurteilt], in: Politika vom 24.10.2012, S. 5; Tanjug: »Statut REKOM-a protiv dobre ideje« [Das Statut von REKOM gegen eine gute Idee], in: b92.net vom 23.10.2011, 
entkräftete die vorgebrachten Vorwürfe völlig. ${ }^{377}$ Erwartungsgemäß mobilisierte auch das nationalistische Lager gegen REKOM. Stefan Karganović vom Srebrenica Historical Project warf in einem Artikel auf Nova srpska politička misao REKOM die Produktion einer dem serbischen Staat und Volk schadenden »Lügengeschichte« sowie Inkompetenz, mangelnde Objektivität und mangelnde Wissenschaftlichkeit vor. Weiterhin rief er die Leser zu einer nur mäßig erfolgreichen Petition auf, in der die Bürger Serbiens Präsident Nikolić auffordern sollten, REKOM jegliche offizielle und staatliche Unterstützung zu verweigern. ${ }^{378}$

Im Oktober 2011 erhielt Serbien die Stellungnahme der Europäischen Kommission zum gestellten Mitgliedsantrag. Grundlage hierfür war eine ausführliche Analyse, die nach der Verhaftung von Mladić und Hadzić erwartungsgemäß positiv ausfiel. Im Bereich der politischen Kriterien zeigte sich die Kommission in großen Teilen zufrieden, so habe sich die Zusammenarbeit mit dem ICTY stark verbessert und die Regierung habe auf 46 Aufforderungen des ICTY zur Auslieferung von Angeklagten reagiert. ${ }^{379}$ Auch die polizeilichen Ermittlungen von Kriegsverbrechen seien professioneller geworden. ${ }^{380}$ Besonders betont wurde mit Blick auf die regionale Zusammenarbeit die Wiederaufnahme des Prozesses der Sarajevo-Erklärung zur Flüchtlingsrückkehr bei einer weiteren Ministerialkonferenz in Belgrad 2010. ${ }^{381}$ Trotz dieser positiven Bilanz machte der Bericht auch die Erwartungen der Kommission deutlich: »Further efforts to explain and defend the role of the ICTY and confront the past are essential for a

http://www.b92.net/info/vesti/index.php?yyyy=2011\&mm=10\&dd=23\&nav_category= 12\&nav_id=551703 vom 11.2.2013.

377 Kandić, Nataša: »O inicijativi za REKOM« [Über die Initiative für REKOM], in: Politika vom 1.11.2011, S. 22.

378 Karganović, Stefan: REKOM - stop proizvodnji lažne istorije [REKOM - Stoppt die Produktion der Lügengeschichte], in: Nova srpska politička misao online vom 27.10.2012, http://www.nspm.rs/istina-i-pomirenje-na-ex-yu-prostorima/rekom-stopproizvodnji-lazne-istorije.html vom 11.2.2013.

379 European Commission: Commission Opinion on Serbia's Application for Membership of the European Union. Analytical Report, EU-Dok. SEC (2011) 1208 vom 12.10.2011, S. 33 .

380 Vgl. ebd., S. 41.

381 Vgl. Regional Ministerial Conference on Refugee Returns: Declaration vom 31.1.2005, http://www.kirs.gov.rs/docs/Sarajevo\%20Declaration\%20January\%202020 05.pdf vom 9.4.2013. 
lasting reconciliation. ${ }^{382}$ Abschließend bewertete sie in ihrer Beschlussfassung, dass Serbien auf einem guten Weg sei, die politischen Kriterien zufriedenstellend zu erfüllen. ${ }^{383}$ Die Kooperation mit dem ICTY sei voll zufriedenstellend, wie die Auslieferung von Mladić und Hadzić zeige, auch engagiere sich das Land in der regionalen Zusammenarbeit und »has taken significant steps to foster reconciliation $\aleph^{384}$. Als einzige Schlüsselpriorität zur Verleihung des Kandidatenstatus forderte die Kommission weitere konkrete Schritte zur Normalisierung der Beziehungen mit dem Kosovo gemäß den Bedingungen des Stabilisierungs- und Assoziierungsprozesses.

\section{Seit 2012: „Alte Garde» wieder an der Macht?}

Im Januar 2012 reflektierte der Parteivorsitzende der SPS, Ivica Dačić, dass seine Partei von dem lernen sollte, was vor 2000 passiert sei, damit dies nie wieder geschehe. In einem Interview mit der Zeitung Press räumte er ein, dass sich die Partei in diesem Sinne bei den Bürgern Serbiens für die Probleme der 90er entschuldigen könne, da sie partiell daran und an der Gesamtsituation schuld sei. ${ }^{385}$ Die SPS hatte sich zwar sukzessive von der früheren Politik distanziert, sich aber nie offiziell entschuldigt. Wenn auch nicht im Wortlaut und in einem entsprechend formellen Rahmen kommt die Äußerung Dačić' aber einer Entschuldigung gleich und wurde in der Öffentlichkeit auch so aufgefasst. Während die SPS sich durch »Selbstlustration«, wie ihr von Seiten der serbischen Justizministerin Snežana Malovič bestätigt wurde, ${ }^{386}$ selbst entlastete, fragten sich Aktivisten und Wissenschaftler im Februar 2012 im Rahmen einer vom Fonds Biljana Kovačević Vućo, der Heinrich-Böll-Stiftung und dem Zentrum für kulturelle Dekontamination veranstalteten regionalen Konferenz: Šta dalje? (Wie weiter?) Die Fragen der Aufarbeitung scheinen weitgehend verhandelt, wenn auch nicht immer mit zufriedenstellendem Ergebnis. Nun stehen überregionale Initiativen

382 European Commission: Commission Opinion on Serbia's application for membership of the European Union, EU-Dok. COM (2011) 668/F1 vom 12.10.2011.

383 Ebd, S. 11.

384 Ebd., S. 8.

385 O. V.: »Socialist Leader Says Party Should Apologise for 90s«, in: Balkan Insight vom 4.1.2012, http://www.balkaninsight.com/en/article/serbia-s-socialists-may-appolo gize-for-90s vom 14.5.2013.

386 Zagorac Simonović, Jasna: »Pouka o samolustraciji« [Die Lektion über die Selbstlustration], in: Danas vom 2.2.2012, http://www.danas.rs/danasrs/dijalog/pouka_o_ samolustraciji.46.html?news_id=233222 vom 30.3.2013. 
und Fragen der medialen und edukativen Umsetzung der Einsichten über Kriegsverbrechen und die Rolle der jeweiligen Nation im Mittelpunkt.

Auch im Bericht des Monitoringkomitees 2012 ermutigte die parlamentarische Versammlung des Europarats Serbien, seine Politik des Dialogs, der Versöhnung und der Kooperation fortzuführen, besonders stellte sie die SrebrenicaDeklaration des serbischen Parlaments 2010 heraus. Hinsichtlich der Kooperation mit dem ICTY zeigte sich die parlamentarische Versammlung zufrieden. Darüber hinaus lud sie Serbien ein, in seiner Gesetzgebung die Maßnahmen zu berücksichtigen, die der Europarat 2011 in Resolution $1784 »$ Protection of witnesses as a cornerstone for justice and reconciliation in the Balkans $«{ }^{387}$ festlegte. ${ }^{388}$

Nachdem Serbien am 1. März 2012 den lang ersehnten Status eines EUBeitrittskandidaten erhalten hatte, gewann der nationalpopulistische Tomislav Nikolić von der SNS die Präsidentschaftswahlen. Nikolić sorgte schon am Tag nach seiner Amtseinführung für Empörung. In einem Interview mit der Frankfurter Allgemeinen Zeitung behauptete er, die kroatische Stadt Vukovar sei eine serbische Stadt. ${ }^{389}$ Im montenegrinischen Fernsehen bestritt er die Qualifizierung Srebrenicas als Genozid - und kritisierte implizit das ICTY: »In Srebrenica gab es keinen Genozid. Viele werden dafür vielleicht verurteilt, aber niemandem wurde das bisher bewiesen. $\ll^{390}$

Auch Ivica Dačić (SPS), Ministerpräsident der neuen, aus der Fortschrittspartei, der SPS und den Ujedinjeni Regioni Srbije (Vereinigten Regionen Serbiens, URS) bestehenden Regierungskoalition, behauptete in der Regierungserklärung zu seinem Amtsantritt, man solle sich nicht mit der Vergangenheit, sondern mit der Zukunft befassen. Aleksandar Vučić von der SNS ist stellvertretender Ministerpräsident. Nikolić, Dačić und Vučić bekleideten bereits in den 90er Jahren verantwortungsvolle Positionen in der serbischen Politik: Dačić war ab 1992 Sprecher der Sozialisten, Nikolić stellvertretender Vorsitzender der Ra-

387 Parliamentary Assembly of the Council of Europe: Protection of Witnesses as a Cornerstone for Justice and Reconciliation in the Balkans, Resolution Nr. 1784 vom 26.1.2011.

388 Dies. (Hg.): The Honouring of Obligations and Commitments by Serbia, Report Nr. 12813 vom 9.1.2012.

389 Martens, Michael: »Die Serben durften nicht entscheiden, wo sie leben wollen. Im Gespräch: Tomislav Nikolić«, in: faz.net vom 19.5.2012, http://www.faz.net/aktuell/ politik/ausland/wahl-in-serbien-die-serben-durften-nicht-entscheiden-wo-sie-leben-wol len-11750937.html 20.4.2014.

390 Meyer-Feist, Andreas: Serbien: Protest gegen Äußerungen von Nikolic, in: Deutschlandradio Kultur - Europa heute vom 6.6.2012. 
dikalen Partei, Vučić deren Sprecher. Diese personelle Kontinuität lässt die These der Selbstlustration und die Aussagen von einer Diskontinuität mit der Politik der 90er Jahre wenig glaubhaft erscheinen.

Nach zehn Jahren Kontroverse, drei offenen Wettbewerben und Kosten in Höhe von 60 Millionen Dinar eröffnete der Belgrader Bürgermeister Dragan Đilas am 24. März, dem 13. Jahrestag des Beginns der NATO-Bombardierung Serbiens 1999, eine Gedenkstätte für die Opfer des Kriegs und die Verteidiger des Vaterlands 1990-1999 in der Nähe des Belgrader Hauptbahnhofs. ${ }^{391}$ Obwohl der Zeitpunkt der Enthüllung bewusst geheim gehalten wurde, wurde sie von Protesten begleitet: Vertreterinnen der Frauen in Schwarz kritisierten die Gleichsetzung von Opfern mit Mördern, Eltern von Gefallenen äußerten Unverständnis darüber, dass das Monument weder die Namen der Gefallenen noch ein orthodoxes Kreuz trug, und bemängelten seine kühle, moderne Gestaltung. Đilas betonte in einer kurzen Ansprache, dass man alle Opfer und ihre Eltern ehren müsse, unabhängig davon, ob sie im Recht seien oder nicht. Obwohl man nach Jahren der Kontroverse nun eine gangbare Lösung gefunden zu haben glaubte, war sie für keinen Beteiligten in der Debatte zufriedenstellend. Wie David ausführt, nutzte man diese Sprach- und Formregelung, mit der die Verteidiger des Vaterlands bewusst unter der universalen Opferkategorie subsumiert werden, bewusst, um zwischen den divergierenden innenpolitischen und außenpolitischen Erwartungen zu vermitteln. ${ }^{392}$

Nach dem Erfolg einer Klage vor dem Europäischen Menschengerichtshof Ende April ${ }^{393}$ muss die serbische Regierung nun den Reservisten, die im Kontext des Kosovokonflikts mobilisiert wurden, ihren noch ausstehenden Sold auszahlen. Sie organisieren sich zunehmend, um auf ihre Situation hinzuweisen und um ihre Rechte in Anspruch zu nehmen. In der Folge des Urteils schlossen sich im September im Savez udruženja boraca od 1990. do 1999. Republike Srbije (Rat der Vereinigungen der Kämpfer von 1990 bis 1999) 14 Organisationen zusammen, der mit ca. 140.000 Mitgliedern den nunmehr größten Verband von Kriegsveteranen in Serbien bildete. Zudem sorgte die Ankündigung des Savez

391 David, Lea: »Mediating international and domestic demands: Mnemonic battles surrounding the monument tot he fallen oft he wars oft he 1990s in Belgrade«, in: Nationalities Papers 42 (2014) 4, S. 655-673, hier S. 655. David unterscheidet in der Kontroverse von 2002 bis 2012 drei Phasen, in denen die Opferdefinition den veränderten politischen Umständen entsprechend rejustiert wurde.

392 Ebd., S. 666.

393 European Court of Human Rights: Case of Vučković and others v. Serbia. Judgement, Application Nr. 17153/11 vom 28.8.2012. 
ratnih veterana Srbije (Bund der Kriegsveteranen Serbiens) für Wirbel, die Öffentlichkeit der Pride parade für eine Parada sramna (beschämende Parade) nutzen zu wollen, um auf die Situation der Veteranen aufmerksam zu machen, da sie die marginalisierteste Gruppe im Land darstellen würden. ${ }^{394}$

In ihrem Fortschrittsbericht lobte die Europäische Kommission die Zusammenarbeit mit dem ICTY, lediglich weitere Untersuchungen hinsichtlich des Unterstützungsnetzwerks von flüchtigen Kriegsverbrechern wurden angemahnt. Positiv wird auch die Arbeit des Staatsanwalts für Kriegsverbrechen bewertet, der im Juni 2012 Anklage gegen ein Netzwerk von Personen erhob, die Mladić bei seiner Flucht unterstützt hatten. Auch sei der Austausch von Informationen mit Behörden in Kroatien und mit der EULEX 2012 ermöglicht worden. Allein in Bezug auf den Zeugenschutz gäbe es Nachbesserungsbedarf. ${ }^{395}$

Die Enttäuschung und Wut über drei Freisprüche des ICTY im Herbst für mutmaßliche Kriegsverbrecher, die sich Gewaltverbrechen an serbischen Zivilisten schuldig gemacht haben sollen, griff die Regierung auf. Der stellvertretende Ministerpräsident kritisierte das ICTY vor dem UN-Sicherheitsrat scharf, indem er ihm vorwarf, dass Gesetz und Gerechtigkeit nicht immer seine leitenden Prinzipien gewesen seien. Gerade die aktuellsten Freisprüche des ICTY für die Kroaten Ante Gotovina und Mladen Markać sowie den ehemaligen UÇK-Führer Ramush Haradinaj zeigten, dass einzig die serbische Nation als Täter von Kriegsverbrechen und nur das serbische Volk als verantwortlich für die schreckliche Gewalt herausgegriffen worden seien. Das Tribunal habe es versäumt, Gerechtigkeit herbeizuführen, da es die Schuld nicht adäquat festgestellt habe. So könnten nun die Schulbücher in Kroatien, in Teilen von Bosnien und des Kosovo die Unschuld ihrer Einwohner behaupten. ${ }^{396}$ Nach den Freisprüchen reduzierte Serbien seine Zusammenarbeit mit dem ICTY auf ein technisches Level. Im Februar 2013 kippte das Berufungsgericht am ICTY auch das Urteil gegen den ehemaligen Generalstabschef der JNA, Momčilo Perišić, und sprach ihn umgehend frei. In Serbien wurde dieses Urteil begrüßt.

394 Beta: »Veterani zakazali 〉Paradu srama istog dana kada se održava Parada ponosa« [Veteranen planen >Parade der Schande Stolzes stattfindet], in: Blic online vom 11.9.2012, http://www.blic.rs/Vesti/Drustvo/ 342241/Veterani-zakazali-Paradu-srama-istog-dana-kada-se-odrzava-Parada-ponosa vom 24.4.2013.

395 European Commission: Serbia 2012 Progress Report, EU-Dok. SWD (2012) 333/F1 vom 10.10.2012.

396 Vgl. United Nations Security Council: 6880th Meeting, Agenda: ICTY/ICTR, UNDok. SC/10846 vom 5.12.2012, S. 29 ff. 
Die Kritik am ICTY trug der serbische Außenminister Vuk Jeremić auf die internationale Ebene, als er 2013 der UN-Generalversammlung vorstand. Er brachte im April erstmals eine Debatte über die globale Strafjustiz auf die Tagesordnung des höchsten Gremiums. Der serbische Präsident Tomislav Nikolić drückte in seinem Redebeitrag die Enttäuschung Serbiens über die internationale Strafjustiz aus. Das Land sei eines der ersten gewesen, welches das Tribunal unterstützt habe, um mit der Anwendung der gleichen Normen Gerechtigkeit für alle Opfer des Konflikts zu erreichen. Heute erhärte sich der Eindruck, dass Serbien unberechtigterweise das Tribunal legitimiert hätte. Es sei keine Gerechtigkeit geübt, sondern alte Wunden seien geöffnet worden: »Justice had not been done since the end of the Second World War, when 700.000 Serbs had been murdered in the Jasenovac camp. $\aleph^{397}$ Das Misstrauen präge Generationen von Serben. Das ICTY sei kein Instrument der Strafverfolgung, die Prozesse hätten bewiesen, dass es keine Unvoreingenommenheit gebe. Er erklärte, Serben hätten den Ausdruck haška pravda (Haager Gerechtigkeit), um ungerechte juristische Entscheidungen zu benennen, die auf Unwahrheiten basierten und unter politischem Druck erreicht würden. Die Arbeit des Tribunals würde in Serbien als parteiisch wahrgenommen, was oftmals als Ergebnis eines nationalistischen Ansatzes gewertet würde und auf dem Wunsch beruhend, die Schwere der begangenen Verbrechen herunterzuspielen. Solchen Behauptungen stelle er entgegen, dass keine Personen höheren Rangs aus der kroatischen oder bosnischen Armee oder der UÇK verurteilt worden seien. Ermittlungen gegen die Kriegsverbrechen im Rahmen der NATO-Intervention oder hinsichtlich des Organhandels im Kosovo seien nicht aufgenommen worden. Die Praxis des Tribunals entspreche nicht den Standards der serbischen Justiz. Kooperation entspringe aus dem Wunsch, zur Versöhnung beizutragen. Deshalb erwarte er auch die Verurteilung von Verbrechen der Staaten, in deren Namen Verbrechen gegen das serbische Volk begangen wurden. Alle Straftäter müssten vor Gericht, das Tribunal würde diese Ansicht allerdings nicht teilen. Er halte die anderen Staaten dazu an, Serbien bei seinem Versuch zu unterstützen, die Wahrheit zu enthüllen, da es nie zu spät für Versöhnung sei. Er plädiere gegen die Anwendung selektiver Gerechtigkeit und für die Gleichbehandlung aller Konfliktparteien. ${ }^{398}$

397 United Nations General Assembly: Robust International Criminal Justice System Gives »Much-Needed Voice to Victims« of Serious Crimes, Secretary-General Tells General Assembly, Pressemitteilung http://www.un.org/press/en/2013/ga11355.doc. htm vom 24.4.2013.

398 Ebd. 
Ende April 2013 entschuldigte sich Nikolić in einem Interview im bosnischen Fernsehen für das Verbrechen in Srebrenica:

»Ich knie deswegen, ich knie und bitte um Verzeihung für Serbien wegen des Verbrechens, das in Srebrenica begangen wurde. Ich entschuldige mich für die Verbrechen, die im Namen unserer Landes und Volkes von Einzelnen begangen wurden. ${ }^{399}$

Als er gefragt wurde, ob es sich dabei um einen Genozid gehandelt habe, sagte er, dies sei nicht erwiesen. Alles was sich auf dem Gebiet des ehemaligen Jugoslawien ereignet habe, hätte Charakterzüge eines Völkermordes aufgewiesen, als Beispiel führte er die Vertreibung der serbischen Bevölkerung während der kroatischen Militäraktion Oluja an. Weiterhin kündigte er einen baldigen Besuch in Srebrenica an. ${ }^{400}$ Nikolić knüpft dabei an die Symbolpolitik seines Vorgängers Tadić an und forciert mit der Aussöhnungspolitik den Kurs seines Landes in Richtung EU.

Bis April 2013 fehlte zum Inkrafttreten des Stabilisierungs- und Assoziierungsabkommens nur noch die Ratifizierung durch Litauen, bis dahin gilt ein Interimsabkommen für Handelsfragen. Mit der Regierung des Kosovo konnte ein Normalisierungsabkommen erreicht werden, so dass nun eine Mitgliedschaft in der EU in Aussicht steht.

\section{Zwischenfazit}

Die ersten Jahre nach dem Ende des Milošević-Regimes waren vom Austesten politischer Spielräume und der Konsolidierung der neuen Regierungsparteien geprägt. Um Konflikte zwischen den Lagern zu vermeiden, suchten die Regierungsverantwortlichen möglichst elegante Lösungen im Umgang mit den Unterstützern des Milošević-Regimes und mieden öffentliche Vorwürfe von Machtmissbrauch und Menschenrechtsverletzungen. Aufgrund der Unterstützung, die die neue Regierung von ihnen benötigte, verblieben Lukić, Pavković, die Roten Barette oder die Mitarbeiter der Geheimdienste zunächst in ihren Machtpositionen.

Die Politik war hinsichtlich der Aufarbeitung von Kriegsverbrechen weiterhin in zwei Lager gespalten, die in immer wiederkehrenden Ritualen ihre Positionen für oder gegen Instrumente der Aufarbeitung markierten. Diese charakteristische Kontroverse um alle Bestrebungen, Kriegsverbrechen aufzuklären,

399 Tanjug (Hg.): »Nikolić«.

400 Ebd. 
zeigt, dass es keine klare Distanzierung vom Milošević-Regime und von den Kriegen der 90er Jahre gab, dass die Akteure der nationalistischen Kriegsvergangenheit - zum Teil bis heute - noch immer im politischen System und in Behörden vertreten sind und dass die widerstreitenden Narrative über die Kriegsvergangenheit auch geschichtspolitisch noch einer Einhegung harren.

Die Weigerungshaltung gegenüber einer Kooperation mit dem ICTY konnte wegen der alten Kader in den Schlüsselpositionen von Militär und Geheimdiensten auch nach der Transition nur gegen Widerstände und Obstruktionen oder unter externem Druck allmählich aufgeweicht werden. Während das nationale Recht internationalen Standards gemäß reformiert wurde, versuchte Koštunica mit der Wahrheits- und Versöhnungspolitik eine Aufarbeitung unter nationalen Vorzeichen durchzusetzen. Mit dem Tod Đinđić' verschlechterten sich die Möglichkeiten für die Aufarbeitung von Kriegsverbrechen erneut, da sie als gefährlich und die Stabilität des Landes bedrohend dargestellt wurde und somit innenpolitisch kaum noch vermittelbar war. Als nationale Alternative wurde die Kammer für Kriegsverbrechen eingerichtet, die nur sehr schleppend anlief und der anfangs kaum eine objektive Verfahrensführung zugetraut werden konnte. Auch das verabschiedete Lustrationsgesetz existierte nur auf dem Papier, belastetes Personal wurde nur aus machtpolitischen Interessen, aufgrund von Korruptionsvorwürfen und dank der Professionalisierung der Behörden aus Staatsämtern entfernt. Sowohl die Wahrheits- und Versöhnungskommission als auch die Lustrationskommission scheiterten, da man sich über die Besetzung der Gremien nicht einig wurde. In beiden Fällen kann man davon ausgehen, dass es zur politischen Strategie der serbischen Regierung und besonders des Präsidenten gehörte, symbolisch dem inneren und äußeren Druck auf die Regierung nachzugeben und eine Politik der Aufarbeitung zum Schein zu forcieren, diese aber durch Obstruktionen im Frühstadium zu lähmen. Während die Konditionalitätspolitik der EU und von Drittstaaten deutliche Fortschritte bei der Kooperation mit dem ICTY erreichte, wurde gleichzeitig kein politischer Druck auf das Land hinsichtlich der Aufklärung von Kriegsverbrechen und der Aufarbeitung der Kriegsvergangenheit ausgeübt. Thematisch wurden die Forderungen nach einer Wahrheitsund Versöhnungskommission von den NGOs aufgegriffen, die sich nunmehr selbst für eine regionale Variante einer solchen Kommission engagieren. In der politischen Landschaft Serbiens ist es vor allem Nenad Čanak von der LSV, der weiter unermüdlich eine Implementierung und Verlängerung des Lustrationsge- 
setzes fordert. ${ }^{401} 2010$ brachte seine Partei dazu einen Gesetzesentwurf ein. ${ }^{402}$ Doch bis heute schaffte er es nicht auf die Tagesordnung des Parlaments. Auch die Initiative der SPO und der DHSS, die nach erfolglosen Versuchen 2004 und 2010 im August 2012 erneut einen Gesetzesvorschlag zur Öffnung von Geheimdienstakten in das Parlament einbrachten, wurde bis dato nicht auf die Tagesordnung gesetzt. ${ }^{403}$ Als Unterstützer eines solchen Gesetzes gelten weniger als ein Viertel der Abgeordneten der serbischen Skupština. Eine Zustimmung der bisher die Schritte der institutionellen Aufarbeitung unterstützenden Partei G17, seit 2011 URS, ist ungewiss, seitdem sie in Koalition mit der SPS und der SNS regiert.

Der Milošević-Prozess hatte in drei Punkten signifikanten Einfluss auf die serbische Innenpolitik. Erstens wurde die Ermordung des serbischen Premierministers Zoran Đinđić als direkte Reaktion auf dessen Auslieferungspolitik an das ICTY gewertet. Zweitens stimmten bei den Parlamentswahlen Ende 2003 wieder zunehmend mehr Bürger für die SRS und für die SPS, die der Regierung die Zusammenarbeit mit dem Tribunal und vor allem die Auslieferung Milošević' zum Vorwurf machten. Drittens wurde im März 2004 die Minderheitsregierung des neuen Premierministers Vojislav Koštunica nur durch die SPS möglich, die offiziell immer noch von Milošević angeführt wurde. Als Bedingung für die Tolerierung der Regierung verlangt sie, dass es keine Zusammenarbeit mit dem ICTY gebe und dass diejenigen verhaftet und bestraft würden, die für Milošević' Auslieferung verantwortlich waren. ${ }^{404}$

Das ICTY übergab der Belgrader Kammer für Kriegsverbrechen 2005 drei Fälle (Zvornik, Škorpioni und Ovčara). Noch 2007 bemängelte ein Bericht des

401 Über das parteipolitische Spektrum hinaus thematisieren das Helsinki-Komitee oder die Heinrich-Böll-Stiftung mit Veranstaltungen und Podiumsdiskussionen immer wieder eine Öffnung von Geheimdienstakten und die Lustration von Amtsträgern.

402 Volksversammlung der Republik Serbien: Predlog: Zakon o izmenama i dopunama zakona o odgovornosti za kršenje ljudskih prava [Gesetzesvorschlag über die Änderung und Erweiterung des Gesetzes über die Verantwortung für die Verletzung von Menschenrechten] vom 9.11.2010, http://www.parlament.rs/upload/archive/files/lat/ pdf/predlozi_zakona/2873_10.1at.zip vom 13.8.2012.

403 Volksversammlung der Republik Serbien: Predlog: Zakon o otvaranju dosijea službi bezbednosti u Republici Srbiji [Gesetzesvorschlag über die Öffnung von Geheimdienstakten in der Republik Serbien] vom 29.8.2012, http://www.parlament.gov.rs/ upload/archive/files/lat/pdf/predlozi_zakona/2535-12Lat.zip vom 29.4.2013.

404 Gow, James/Zveržhanovski, Ivan: »The Milošević Trial. Purpose and Performance«, in: Nationalities Papers 34 (2004) 4, S. 897-919, hier S. 903 f. 
International Center for Transitional Justice ein Ressourcendefizit sowie Personalknappheit der Kammer und forderte mehr Unterstützung durch die Politik und die Exekutive. ${ }^{405}$ Weiterhin wurde kritisiert, dass die Urteile der Kammer für Kriegsverbrechen die bis dato verhandelten Kriegsverbrechen als isolierte Taten einzelner Täter deuteten, ohne einen Zusammenhang mit einer möglichen Beteiligung des Staates herzustellen. ${ }^{406}$ Seitdem hat die Kammer für Kriegsverbrechen an ihrer Professionalisierung gearbeitet, weitere Mitarbeiter eingestellt und ist Kooperationsvereinbarungen mit anderen Strafverfolgungsbehörden aus der Region eingegangen. Ein 2006 unterzeichnetes Abkommen ermöglichte eine enge Zusammenarbeit der Anklagebehörde mit dem ICTY und vollen Zugriff auf die Datenbanken des ICTY. Vor allem das entschiedene Auftreten und die Äußerungen des Staatsanwalts der Kammer für Kriegsverbrechen, Vladimir Vukčević, der als Experte in Fragen der Kriegsverbrechen gilt, sorgten in der serbischen Öffentlichkeit für ein breiteres Bewusstsein für die begangenen Straftaten. 2010 wurde die Kammer für Kriegsverbrechen des Bezirksgerichts Belgrad in das Büro des Staatsanwalts für Kriegsverbrechen und in die Abteilung für Kriegsverbrechen am Oberen Gerichtshof in Belgrad transformiert. Totz der immer wieder geäußerten berechtigten Kritik an den Organen konnten die Ermittlungen und Prozesse auf nationaler Ebene beachtliche Erfolge vorweisen: Bis Mitte Februar 2013 wurde gegen 395 Personen ermittelt, insgesamt 151 wurden angeklagt. Alles in allem wurden 31 Fäll abgeschlossen, in denen 61 Personen verurteilt und 13 freigesprochen wurden. Zu diesem Zeitpunkt werden sieben Fälle gegen 28 Angeklagte verhandelt. Weitere sieben Fälle, die 37 bereits verurteilte Personen betreffen, sind im Berufungsverfahren anhängig. In 21 Fällen wird ermittelt, in 100 Fällen gibt es Vorermittlungen. ${ }^{407}$ Vor allem mit Kroatien besteht eine enge Zusammenarbeit bei der Strafverfolgung, aber auch die internationalen Vertreter der kosovarischen Verwaltung, Bosnien-Herzegowina und Montenegro arbeiten bei Fragen der Rechtshilfe mit der serbischen Staatsanwaltschaft für Kriegsverbrechen zusammen. ${ }^{408}$

405 B. Ivanišević: Against the Current.

406 J. Subotić: Hijacked Justice, S. 56, sowie D. Orentlicher: Shrinking the Space, S. $44 \mathrm{ff}$.

407 Vgl. bis zum Ende des Absatzes die Informationen auf der Homepage Tužilaštvo za ratne zločine: Predmeti [Fälle], http://www.tuzilastvorz.org.rs/html_trz/predmeti_lat.htm vom 22.2.2013.

408 Das Büro des Staatsanwalts für Kriegsverbrechen Serbiens hat dazu diverse Abkommen unterzeichnet, so das bilaterale Memorandum of Agreement on Realization and Advancement of Cooperation in the Fight Against All Forms of Serious Criminal Activities mit seinem Gegenpart in Kroatien am 5.2.2005 und das gleiche Ab- 
Die von Koštunica eingeführte Politik der Selbstauslieferung karikierte die Konditionalitätspolitik und auch die Kooperation mit dem ICTY schlussendlich, entfernte aber die mit ICTY-Anklagen belasteten verbliebenen Repräsentanten aus Staat und Politik. Erst die DS-dominierte Regierung 2008 bis 2012 unterstützte mit ihrem EU-Kurs, auf dem es notwendig war, die der von der EU gestellten politischen Bedingungen zu erfüllen, eine Politik der Auseinandersetzung mit Kriegsverbrechen entsprechend den internationalen Erwartungen. Hierzu gehörte, dass inzwischen alle vom ICTY gesuchten Kriegsverbrecher aufgespürt und vor Gericht gestellt wurden und dass Tadić mit symbolischen Entschuldigungen eine Politik der Versöhnung und Wiederannäherung in den Fokus seiner Amtszeit gestellt hat. Darüber hinaus gelang es zivilgesellschaftlichen Initiativen mit ihrer Öffentlichkeitsarbeit, die gesellschaftliche Aufmerksamkeit für Aufarbeitungsthemen zu erhöhen. Ihre internen Zerwürfnisse und die Radikalität der Äußerungen und Handlungen einzelner Aktivisten führten allerdings dazu, dass ihr Image in der breiten Gesellschaft weiterhin negativ besetzt und ihre Reichweite begrenzt bleiben. Aufgrund einer erfolgreichen transnationalen Mobilisierung konnte mit REKOM ein vielversprechendes neues Instrument geschaffen werden, das im Rahmen des Beitrittsprozesses weiter auf Unterstützung aus Brüssel hoffen kann.

Die Debatte innerhalb des »anderen Serbien« offenbarte bereits 2002 die unterschiedlichen ideologischen Ausrichtungen der NGO-Aktivisten mit Blick auf die Aufarbeitung von Kriegsverbrechen. Die verschiedenen Positionen reflektierte auch Margaret Hagan, die die im öffentlichen Diskurs exponierten Aktivisten der »menschenrechtsmotivierten Vergangenheitsaufarbeitung « in zwei Lager einteilte: die Hardliner Nataša Kandić vom Fonds für Völkerrecht und Sonja Biserko vom Helsinki-Komitee für Menschenrechte auf der einen und die "Softliner« Biljana Kovačević-Vučo vom Anwaltskomitee für Menschenrechte und Vojin Dimitrijević vom Beogradski centar za ljudska prava (Belgrader

kommen trilateral mit Bosnien-Herzegowina und Kroatien am 1.7.2005. Mit Kroatien schloss man am 13.10.2006 das Agreement on Cooperation in the Prosecution of Perpetrators of War Crimes, Crimes Against Humantiy, and Genocide, mit Montenegro am 31.10.2007 das Agreement on Cooperation in the Prosecution of Perpetrators of War Crimes, Crimes Against Humanity and Genocide sowie das Agreement on Cooperation in the Prosecution of Perpetrators of Crimes Against Humanity and Other Rights Protected by International Law. Serbien hat mittlerweile mit allen exjugoslawischen Staaten außer dem Kosovo sowie mit der EULEX ein Abkommen über die Kooperation und den Austausch von Dokumenten sowie die Auslieferung von Angeklagten abgeschlossen. 
Zentrum für Menschenrechte) auf der anderen Seite. ${ }^{409}$ Es bestünde die Gefahr, dass die Hardliner durch ihre extremen Äußerungen, Angriffe und Vergleiche die Vergangenheitsaufarbeitung an sich delegitimierten, da sie so ein verzerrtes Bild in der Öffentlichkeit schüfen und nationalistische Interpretationsmuster reaktivierten. Ohne Frage erschwerten die Auseinandersetzungen innerhalb des NGO-Sektors und die provokativen Extrempositionen von Biserko und Kandić es, eine breite gesellschaftliche und politische Basis für einen Prozess der Vergangenheitsaufarbeitung zu mobilisieren und auch gemäßigte Bürger für das Projekt der Aufarbeitung zu gewinnen. Auch das Helsiniki-Komitee unterschied 2005 zwischen drei Wegen der Aufarbeitung in Serbien. Es gäbe zwei radikale Positionen, den einerseits ein Teil des NGO-Sektors und andererseits die SRS, rechtsextreme Gruppen ${ }^{410}$ und Flüchtlingsorganisationen vertreten würden. Sie würden sich für beziehungsweise gegen die Arbeit des ICTY engagieren. Daneben gäbe es einen dritten Weg, der im Bericht des Helsinki-Komitees wegen Relativierung und seiner Staatsnähe harsch kritisiert wurde. Er würde vor allem von der Viktimologischen Gesellschaft Serbiens und ihrer Vorsitzenden Vesna Nikolić-Ristanović vertreten:

"She espouses the thesis that dealing with the past is a process in which all social groups, be they victims or participants and regardless of their national, political and religious hallmarks, should take an active part. ${ }^{411}$

Der kritische NGO-Sektor, der sich mit den Themen Aufarbeitung und Kriegsverbrechen beschäftigte, stand kontinuierlich unter der Kritik der Vertreter des nationalistischen Lagers. Während vor allem Sonja Biserko und Nataša Kandić persönlich angegriffen und auch teilweise schwer bedroht wurden, ${ }^{412}$ stand nach 2005 für einige Jahre der ganze alternative NGO-Sektor im Fokus auch staatlicher Angriffe durch die Behörden unter der Regierung Koštunicas. Nach der These Denisa Kostovicovas stand der alternative NGO-Sektor in diesem Kontext vor einer doppelten Herausforderung, da er sowohl von Seiten der »dunklen Sei-

409 Hagan, Margaret Darin: Facing the Past in Post-Milošević Serbia. The Public Relations of Post-Conflict Human Rights Activism, Masterarbeit, Budapest 2004.

410 Aufgezählt werden hier die Gruppen Justin Popović, Dveri und Svetozar Miletć sowie die Rechtsextremen von Nacionalni stroj. Vgl. Helsinški odbor za ljudska prava u Srbiji (Hg.): Human Rights in an Unfinished State, Belgrad: Zagorac 2000, S. 39.

411 Ebd.

412 Das Extrembeispiel im Bereich der Publikationen war sicher die Schmähschrift des SRS-Führers, vgl. V. Šešelj: Afera Hrtkovci. 
te der Zivilgesellschaft« als auch von Seiten des Staates unter Druck geraten sei. ${ }^{413}$ Einige Organisationen gerieten sogar unter Beobachtung des Geheimdienstes BIA. ${ }^{414}$ Auch Wissenschaftler wirkten an der Diskreditierung von prominenten Akteuren mit, deren Interpretation der Jugoslawienkriege, der jüngeren serbischen und jugoslawischen Geschichte politisch motiviert und interessengeleitet seien. ${ }^{415}$ Exemplarisch sei hier Mirjana Radojičić genannt. Im Fokus ihrer wissenschaftlichen Auseinandersetzung, die mehr einer patriotisch-empörten und denunziativen Richtigstellung ähnelt, stehen Äußerungen von Sonja Biserko, Nataša Kandic, Biljana Kovačević-Vučo, Vesna Pešić (Građanske incijative, Bürgerliche Initiativen) und Vojin Dimitrijević, die in einen harschen Kontrast zur serbischen Gesellschaft gestellt werden. Die Sichtweisen der NGO-Vertreter werden »falsifiziert«, indem die Autorin einzelne Behauptungen und Äußerungen aus dem Zusammenhang reißt und ihnen die »historische Wahrheit« im Sinne einer »richtigen Lesart« der Geschichte entgegenstellt. Abschließend wirft Radojičić den Aktivisten des NGO-Sektors »arrogance and extremism as a style, counterfactuality as a strategy and anti-Serbian nationalism and racism as an ideological strongpoint $\aleph^{416}$ vor. Gerade in der Folge der Unabhängigkeit des Kosovo waren die »Frontfrauen« der alternativen NGOs aufgrund ihrer Unterstützung kosovarischer Positionen besonders gefährdet. ${ }^{417}$

Für die beschriebenen symbolischen Entschuldigungen von serbischer Seite gilt, dass sie relativierende Figuren enthielten, die eine historische Verantwortung individualisierten oder externalisierten. Eine kollektive oder staatliche Verantwortung wies Serbien explizit von sich. Auffällig sind vor allem Passivformulierungen und ein weitgehender Verzicht auf das Agens. Teilweise werden Opfer gegeneinander aufgerechnet, indem auf serbische Tote verwiesen wird, an denen

413 Kostovicova, Denisa: „Civil Society and Post-Communist Democratization. Facing a Double Challenge in Post-Milošević Serbia«, in: Journal of Civil Society 2 (2006) 1, S. 21-37.

414 Vgl. Helsinški odbor za ljudska prava u Srbiji (Hg.): Human Rights.

415 Vgl. Radojičić, Mirjana: »Nevladine organizacije i politika interpretiranja novije južnoslovenske prošlosti« [NGOs und die Interpretationspolitik der neueren südslawischen Vergangenheit], in: Filozofija i društvo 27 (2005) 2, S. 109-125. Die Autorin veröffentlichte zudem: dies.: Istorija u krivom ogledalu. Nevladine organizacije $u$ Srbiji i politika interpretiranja skorije južnoslovenske prošlosti [Geschichte im Zerrspiegel. NGOs in Serbien und die Interpretationspolitik der jüngsten südslawischen Vergangenheit], Belgrad: Institut za političke studije 2009.

416 Dies.: »Nevladine organizacije«, S. 125.

417 Amnesty International (Hg.): Serbia. 
genauso Verbrechen begangen worden seien. Die Verantwortung für die Kriege und die Kriegsverbrechen wurden so stets für alle Konfliktparteien universalisiert. ${ }^{418}$ Aus dieser Figur ergibt sich dann auch eine Legitimität für die Forderung nach Entschuldigung von den anderen Kriegsparteien. Oft ist zudem eine Funktionalisierung zu erkennen, wenn zum Beispiel eine Entschuldigung in den direkten Kontext der nötigen Verpflichtung zur Kooperation mit dem ICTY gestellt wird. Einige Male wird einer Entschuldigung im zweiten Satz anklagend und disziplinierend die Kritik an den unberechtigten Kollektivvorwürfen nachgeschoben, die gegenüber Serben erhoben würden. Uneingeschränkt entschuldigten sich nur montenegrinische Repräsentanten für die Verbrechen in den Jugoslawienkriegen bei anderen Kriegsteilnehmern, während gesamtstaatliche beziehungsweise ab 2004 serbische Repräsentanten nur diese »entleerten « Entschuldigungen vorbrachten. Auffällig ist auch, dass Entschuldigungen nur von den Staatsoberhäuptern geäußert wurden, die in ihrer Rolle als moralische Instanz auch persönliche Meinungen äußern können und mit ihrer repräsentativen Funktion nicht mit den Positionen der Regierung übereinstimmen müssen. Offensichtlich ist nichtsdestotrotz, dass nicht unbedingt die Akzeptanz der Entschuldigungsgesten bei den Adressaten im Vordergrund steht. Jennifer Lind qualifiziert diese Art von Entschuldigungen als »non-apology apologies ${ }^{419}$ - sie sind eine Geste, für die der jeweilige Staatsmann und seine Nation auf internationaler Bühne Anerkennung erlangen. Trotzdem ermöglichen sie durch die ihnen inhärenten Distanzierungen und Relativierungen eine Fortsetzung innenpolitisch populärer Narrative sowie den Erhalt der eigenen Machtposition und laufen damit der eigentlichen Intention von Entschuldigungen, nämlich der Versöhnungsleistung durch eine Akzeptanz beim Adressaten, zuwider. Innenpolitisch sind Entschuldigungsgesten risikobehaftet. Wie Brian Grodsky herausstellte, werden sie als »politische Stunts ${ }^{420}$ gesehen, um dem Westen zu gefallen, auf die aber aus Gründen der Praktikabilität verzichtet würde, um die Wähler nicht zu konsternieren. Dieser Umstand erklärt auch, warum keine politischen Führungsfiguren für Entschuldigungen verantwortlich zeichneten. Popularitätsverlust befürchtend, scheinen die Kosten für unpopuläre Entschuldigungsgesten zu

$418 \mathrm{Zu}$ den Schlüssen der Individualisierung und Universalisierung von Schuld kommt auch Horelt in seiner Analyse der serbischen Entschuldigungen bezüglich Vukovar und Srebrenica, vgl. M.-A. Horelt: »Durch Symbolik und Recht«, S. 150.

419 Lind, Jennifer M.: Sorry States: Apologies in International Politics (= Cornell Studies in Security Affairs), Ithaca: Cornell University Press 2008.

420 B. Grodsky: The Costs of Justice, S. 193. 
hoch. ${ }^{421}$ Zur innenpolitischen Rationalisierung von Entschuldigungen dienten die relativierenden und einschränkenden Formulierungen. So scheint es aus Sicht der Entschuldigenden zentral für das innenpolitische Publikum zu sein, zu vermitteln, dass die Politik der Entschuldigung und der Aufarbeitung einem nationalen serbischen Interesse entspräche und eine unbelastete, positive Zukunft, vorzugsweise in der EU, zum Ziel habe. Dazu sei es zweckdienlich, die Vergangenheit hinter sich zu lassen und zusammenzuarbeiten. Im Fokus steht also ein pragmatisches und funktionales Interesse an einer Wiederannäherung der ehemaligen Kriegsparteien. Besonders wichtig für die nationale Identität scheint es weiterhin zu sein, die Führungsrolle in der Versöhnung und Aufarbeitung der Kriege zu proklamieren und dadurch einen überlegenen moralischen Charakter zu betonen, der als neue nationale Identitätsressource nutzbar gemacht werden kann. Das nationalistische Lager sanktioniert das Verhalten des Präsidenten als unpatriotisch und kritisiert öffentlich, dass er nicht den serbischen Opfern, denen zum Beispiel in Bratunac gedacht wurde, oder den aus der Krajina vertriebenen Flüchtlingen oberste Priorität eingeräumt.

Eine Ausnahme bildet die Entschuldigung von Tomislav Nikolić im April 2013, der auf Knien um Vergebung bittet, was einer vollständigen Entschuldigung gleichkommt. Er erkennt Srebrenica an und verweist lediglich in Bezug auf die Frage nach der Genozidqualifizierung auch auf serbische Opfer. Die Einordnung des Massakers in Srebrenica als Völkermord stellt auch hier wieder eine Grenze des Sagbaren dar, die aus innenpolitischen Gründen gezogen wird. Auffällig ist die Kniefallmetapher, die Nikolić wählt. Schon für das Treffen von Präsident Tadić mit dem kroatischen Präsidenten Josipović in Vukovar bemühte die serbische Presse den Vergleich mit Willy Brandt, um auf die historische Bedeutung des Rituals hinzuweisen. Und Nikolić knüpft in seiner Wortwahl ganz bewusst an Brandt an und verortet seine Bitte um Vergebung in einer Reihe großer Entschuldigungssymbolik.

Die Freisprüche am ICTY auf der Ebene der Befehlshaber zeigen weisen darauf hin, dass die Rechtssprechung des Tribunals mit Blick auf die Befehlsverantwortung zunehmend an Substanz verliert. Obwohl es Serbien nicht gelang, breite Unterstützung für die Sache der serbischen Opfer außerhalb der begrenzten Reichweite serbischer und serbophiler Erinnerungslobbyisten zu gewinnen, konnte es die selektive Wahrnehmung des Konflikts in der internationalen Strafjustiz internationalisieren und in internationalen Gremien die Delegitimierung des Gerichts vorantreiben. Präsident Nikolić zeigte in seiner Rede vor der UNGeneralversammlung eine Interpretation auf, in der er eine Linie internationaler 
Strafjustiz vom Zweiten Weltkrieg bis heute zieht. In dieser Sichtweise haben die serbischen Opfer sowohl nach dem Zweiten Weltkrieg als auch nach den Jugoslawienkriegen weder auf internationaler noch auf jugoslawischer Ebene Gerechtigkeit erfahren. Dieser Empfindung von Ungerechtigkeit liegt auch Nikolić' Symbolpolitik zugrunde. Stattdessen verlangt Nikolić eine Gleichbehandlung aller Kriegsparteien hinsichtlich der Verurteilung der Taten und der Strafverfolgung der Täter, in dem Glauben, dass einzig dadurch ein Engagement aller Kriegsparteien und eine Versöhnung möglich seien. Nur der gemeinsame Akt des sich gegenseitigen Vergebens bildet eine Grundlage, von der aus man sich positiv erinnern kann. Ungerechtigkeit in der Strafverfolgung hingegen bereitet in dieser Vorstellung die Basis für neue ethnonationale Konflikte. Statt auf Wahrheit oder Gerechtigkeit aufzubauen scheint also das Versöhnungsritual selbst als Moment positiver Integration zu gelten.

\subsection{Normativer Wandel: Normübernahme?}

Auf den nächsten Seiten möchte ich der Frage nachgehen, inwieweit Serbien die sich auf internationaler Ebene entwickelnde Norm der Vergangenheitsaufarbeitung übernommen hat und welche Rolle externe Faktoren dabei spielten. Auf Basis der bisherigen Ausführungen soll die Normsozialisation anhand der von Cortell und Davis Jr. vorgeschlagenen Kriterien bewertet werden: strukturelle Faktoren und politische Kultur, cultural match und die Salienz der Norm in nationalen Institutionen und politischer Rhetorik. ${ }^{422}$

Zunächst untersuche ich, welche strukturellen Faktoren der politische Kontext und die politische Kultur für die Vergangenheitsaufarbeitung von Kriegsverbrechen boten. Wie aufgezeigt, galt es im öffentlichen Diskurs Ende der 80er und zu Beginn der 90er Jahre noch als eine Art demokratisches Recht im Prozess der Liberalisierung und Pluralisierung des politischen Systems Jugoslawiens, sich kritisch mit der sozialistischen Vergangenheit und den im Zweiten Weltkrieg begangenen Kriegsverbrechen zu befassen. Nationalistische Intellektuelle, Literaten und Politiker griffen das Thema auf und nutzten es als politische Ressource. Allerdings ging es hierbei nicht darum, einen justiziellen Umgang mit begangenen Verbrechen zu etablieren, aus dem man eine Norm der Aufarbeitung hätte ableiten können, sondern um den Aufbau eines serbischen Gegennarrativs mit Fokus auf die serbischen Opfer, das sich gegen die sozialistische, kroatische oder kosovarische »Wahrheit« richtete, die gleichzeitig relativiert wurde. Diese

422 Cortell/Davis Jr.: »Understanding the Domestic Impact«. 
eingeübte Diskursformation variierte hinsichtlich der Aufarbeitung von Kriegsverbrechen zu Beginn der 90er Jahre nur geringfügig: Die Beschäftigung mit Kriegs- und Völkermordverbrechen wurde weiter institutionalisiert und nunmehr staatliche Politik, blieb aber auf Serben als Opfer dieser Verbrechen begrenzt. Wie deutlich wurde, behandelte die Regierung das Thema Kriegsverbrechen jedoch stiefmütterlich und stellte keine ausreichenden Ressourcen bereit, um umfassende Untersuchungen durchzuführen. Statt um tatsächliche Aufklärung oder Strafverfolgung ging es im Zusammenhang mit der Last der Kriegsgräuel darum, ein Gegennarrativ zur internationalen Wahrnehmung der Jugoslawienkriege zu postulieren, in der sich die serbische Regierung fälschlicherweise beschuldigt sah.

Während der Kriege und danach beschäftigten sich nur wenige zivilgesellschaftliche Organisationen mit der Aufklärung von Kriegsverbrechen, die von Serben begangen wurden. Die wenigen, die auf diesem Feld aktiv waren, präsentierten sich allerdings als extrem und unpatriotisch beziehungsweise wurden in der Öffentlichkeit so dargestellt, wodurch ihre Positionen gesellschaftlich kaum anschlussfähig waren. Nichtserbische Opfergruppen fehlten im innerserbischen Diskurs weiterhin völlig, ihre Äußerungen wurden und werden weiterhin gleichgesetzt mit den Äußerungen der feindlichen Konfliktpartei. Als Stakeholder prägten serbische Opfer- und Flüchtlingsorganisationen sowie NGOs den Diskurs, die sich mit der Erforschung des Leidens und der Verbrechen gegen Serben beschäftigten. Die Aktivisten, die sich für eine umfassende Aufarbeitung der Kriegsverbrechen einsetzten und damit vor allem die von Serben begangenen Taten meinten, wurden trotz transnationaler Unterstützung innenpolitisch marginalisiert, da diese Kriegsgräuel zum einen als Kriegspropaganda und Lüge der Gegner gedeutet wurden und zweitens die Forderung nach Aufarbeitung gerade im Kontext des Kriegs als Verrat an denjenigen betrachtet wurde, die die eigenen Leute verteidigt hatten. Als stilisierte »innere Feinde « waren die Aufarbeitungsaktivisten Angriffen des Milošević-Regimes, der Radikalen und anderer nationaler Kräfte ausgesetzt, doch auch sie selbst waren auf Konfrontation aus. Vor allem Ende der 90er Jahre wurden sie als Verräter beschuldigt, sie seien ein verlängerter Arm der Imperalisten der USA, des Haager Tribunals und des Westens.

Zwar gab es seit 1995 mit dem ICTY, den Staaten und Organisationen (USA, EU, Belgien, Niederlande), die eine Kooperation mit dem ICTY forcierten und Druck auf Serbien ausübten sowie den serbischen Aufarbeitungs-NGOs eine nahezu perfekte advocacy coalition für eine Normdiffusion. All diese Akteure vertraten aber eine Sicht auf die Jugoslawienkriege, die Serbien die Hauptverantwortung für die Kriege anlastete, und verlangten eine radikale Form der 
Aufarbeitung und des Bruchs mit dem Vorgängerregime, die vermutlich nur in einem besetzten Land zu realisieren gewesen wäre. Aufgrund der mangelnden Anschlussfähigkeit an die Erfahrungen in der serbischen Politik und Gesellschaft, mit denen die geforderte Aufarbeitung an Akzeptanz hätte gewinnen können, und da die Beschäftigung mit serbischen Opfern und Leiden ausblieb, gelang es hier nicht, einen unbelasteten Diskurs über die Norm zu eröffnen, der eine umfassende Normübernahme für alle relevanten politischen und gesellschaftlichen Kräfte ermöglicht hätte.

Die Polarisierung angesichts der Frage der Konfrontation mit Kriegsverbrechen kulminierte während der NATO-Bombardierung und der Anklageerhebung des ICTY gegen Slobodan Milošević. Zu dieser Zeit erodierte aber dessen Legitimität zunehmend, was vor allem im intellektuellen Diskurs Raum dafür öffnete, sich deutlicher als bisher für eine Aufarbeitung einzusetzen. Nichtsdestotrotz wurden Fortschritte auf dem Feld der Aufarbeitung nach der Transition nur auf der Basis von Konditionalitätspolitik, vor allem hinsichtlich der Kooperation mit dem ICTY, und unter großem Druck durch die USA und später die EU erreicht. Die Konditionalitätspolitik war einerseits hilfreich für die Normsozialisation, da die Aussicht auf materiellen oder institutionellen Fortschritt eine pragmatische Politik der Auseinandersetzung mit Kriegsverbrechen begünstigte. Allerdings war der externe Druck andererseits auch kontraproduktiv in Bezug auf eine Normübernahme: Er spielte den nationalistischen Kräften in die Hände, die die Politiker, die sich für eine Aufarbeitung engagierten, in der nicht die serbischen Opfer im Mittelpunkt stehen, als Marionetten, als unpatriotisch und Verräter diffamierten. Den Politikern mangelte es an Bereitschaft, die Bürger Serbiens von der Notwendigkeit zu überzeugen, sich mit den von Serben begangenen Kriegsverbrechen auseinanderzusetzen. So fiel es leicht, das Erfüllen von Bedingungen als erzwungenen und rein instrumentellen Tauschhandel zu stilisieren. Die Konditionalitätspolitik trug also zwar dazu bei, Vorstellungen von Vergangenheitsaufarbeitung auszubilden, unterminierte allerdings den normativen Gehalt der Norm im Diffusionsprozess. Stattdessen wurden Begriffe, Rhetorik und Handlungen symbolisch eingesetzt, die inhaltlich aber weitgehend leer blieben.

Weiterhin fehlt gesamtgesellschaftlich und vor allem politisch die Anerkennung der vom ICTY gesprochenen Urteile. Eine höhere Akzeptanz erreichten die Formen einer Aufarbeitung, in der die ownership eindeutig in serbischer Hand lag. So sind beispielsweise die Urteile der Kammer für Kriegsverbrechen weit weniger umstritten.

Während Kriegsverbrechen bis dahin innenpolitisch noch nicht unter dem Stichwort Vergangenheitsaufarbeitung verhandelt wurden, ahmten einzelne Akteure des alternativen NGO-Sektors und Intellektuelle bereits seit 1991 unter 
Verweis auf die Nürnberger Prozesse Konzepte anderer historischer Konstellationen nach. 1998/1999 schließlich nahmen Politiker der Oppositionsparteien einen zivilgesellschaftlichen Diskurs über die Frage der Aufarbeitung der Vergangenheit auf. Fast alle Konzepte wurden dem deutschen Vorbild entlehnt, wie auch die Begriffsverwendungen und direkten Übersetzungen wie suočavanje (Aufarbeitung) oder denazifikacija (Entnazifizierung) zeigen. Für die Wahrheitsund Versöhnungskommission diente die südafrikanische Kommission als Vorbild, bei der Bewältigung der sozialistischen Vergangenheit orientierten sich die Initiatoren an Beispielen aus den ostmitteleuropäischen Ländern. Zwar tauchten all diese konzeptionellen Schlagwörter im öffentlichen und intellektuellen Diskurs auf, allerdings wurde keines der damit verbundenen Konzepte übernommen.

Die Salienz der Norm in Serbien ist deutlich am Wandel der policy, aber auch von Institutionen nachzuvollziehen. Seit 1992 gibt es eine Rechtsgrundlage für die staatliche Dokumentation von Kriegsverbrechen, auf deren Basis eine Kommission eingerichtet wurde. Das Außenministerium hielt in der Frage der Kriegsverbrechen kontinuierlich Kontakt zu den Organen der UN. Von 1996 an machten die jugoslawischen Exekutivorgane auch Teilzugeständnisse in der Kooperation mit dem ICTY und unternahmen erste eigene Strafverfolgungsbemühungen. Nach der Transition 2000 wurde der Kontakt zum ICTY intensiviert, wobei die Kooperation zunächst weiterhin von Obstruktionen blockiert war. 2002 wurde das Rom-Statut, nur wenige Monate darauf auch eine gesetzliche Grundlage zur Auslieferung von Kriegsverbrechern ratifiziert. Ein Rat zur Zusammenarbeit mit dem ICTY wurde geschaffen und der Posten eines eigens für diese Kooperation zuständigen Sonderbeauftragten sowie die Kammer für Kriegsverbrechen eingerichtet. Durch die Konditionalitätspolitik der USA und später der EU konnten alle flüchtigen Kriegsverbrecher an das ICTY ausgeliefert werden. Nach einigen symbolischen Entschuldigungen durch den Präsidenten des Landes verurteilte 2009 auch das serbische Parlament das Massaker von Srebrenica. Was die Ergebnisse angeht, kann also von einer erfolgreichen Normübernahme gesprochen werden: Vergangenheitsaufarbeitung ist Teil der politischen Agenda und staatlicher Institutionen und wird als Leitlinie außenund innenpolitischen Handelns verstanden. Die Norm der Vergangenheitsaufarbeitung ist insofern nachhaltig, als dass mit der Kammer für Kriegsverbrechen, der Initiative REKOM, lokalen und transnationalen NGOs Kräfte vorhanden sind, die eine weitergehende Normsozialisierung in Serbien realistisch erscheinen lassen.

Für die Normübernahmen waren immer externe Faktoren ausschlaggebend. Mit Referenz auf die Notwendigkeit der Aufarbeitung von Kriegsverbrechen er- 
folgte ein institutioneller Wandel, setzte sich aber nicht in allen Politikbereichen durch. Als Negativbeispiel kann hier der Bildungsbereich angeführt werden, in dem keinerlei Berücksichtigung einer veränderten Position gegenüber Kriegsverbrechen und deren Aufarbeitung Eingang gefunden hat. Obwohl es normative Bekenntnisse von offiziellen Vertretern staatlicher Behörden oder von Politikern gibt, sind gleichzeitig gegenläufige Positionen in Politik und staatlichen Institutionen offenbar. Die Salienz der Norm ist damit als moderat einzuschätzen.

Bei allen aufoktroyierten oder auf externen Druck hin eingerichteten Mechanismen der Aufarbeitung war zu beobachten, dass die Norm unterwandert wurde, indem man sie national umdeutete. Das ist nicht nur auf die Einschränkung nationaler Souveränität durch die dem Land gestellten Bedingungen oder auf eine Disqualifizierung dieser Instrumente durch die nationalistische Opposition zurückzuführen, sondern auch auf die Relativierung der Norm durch politische Repräsentanten. Dieses Verhalten konnte in der politischen Kommunikation nachgewiesen werden, sei es bei der Einrichtung nationaler Institutionen wie der Wahrheits- und Versöhnungskommission oder bei der Kooperation mit dem ICTY, sei es bei symbolischen Entschuldigungen oder in den Kommentaren der Repräsentanten zur Arbeit des ICTY. Diese ambivalente politische Kommunikation verhinderte einen grundlegenden normativen Wandel in der Gesellschaft, dem ein universelles Verständnis von Menschenrechten zugrunde liegen würde. Eine selektive Ausgestaltung von Normen bleibt prävalent. Kriegsverbrechen sind nicht durchgängig bekannt, teilweise werden verurteilte Schuldige, trotz ihrer Verurteilung, nicht als solche betrachtet, was die Kontinuitäten des Kriegsund Milošević-Regimes verdeutlichen. Die relativerende und selektive Aufarbeitungspolitik der Regierung hat Folgen: So belegte eine Umfrage 2010, dass dreiBig Prozent der befragten serbischen Bürger nicht wussten, was in Srebrenica passierte. 48 Prozent war unbekannt, was in Ovčara bei Vukovar geschah, zwanzig Prozent behaupteten, Sarajevo sei nie belagert worden. Siebzig Prozent der Befragten gaben an, Serbien hätte immer nur Verteidigungskriege geführt, über die Hälfte war davon überzeugt, Serbien habe auf der Gewinnerseite gestanden. ${ }^{423}$ Die Narrative des Milošević-Regimes scheinen in Teilen der Gesellschaft

423 Vgl. Hrašovec, Ivana Milanović: »Propuštena prva lekcija. Naši građani ne znaju ko je bombardovao Dubrovnik i šta se desilo na Ovčari, u Srebrenici, Sarajevu, ali su složni oko toga da su među narodima za raspad Jugoslavije najviše krivi Hrvati« [Verpasste erste Lektion. Unsere Bürger wissen nicht, wer Dubrovnik bombardierte und was in Ovčara, Srebrenica oder Sarajevo passierte, aber sind sich einig, dass von den Völkern die Kroaten am meisten Schuld für den Zerfall Jugoslawiens haben], in: Vreme vom 28.10.2010, S. 28 ff., sowie Pintar Manojlović, Olga: »Rat i nemir. O 
ungebrochen zu sein. Politische Repräsentanten akzeptieren zwar öffentlich die Urteile des ICTY und eine Leugnung der vom ICTY etablierten »Wahrheit« scheint aus außenpolitischen Erwägungen heraus unsagbar. Über die Prozesse oder Verbrechen konkret äußern sie sich allerdings nicht, auch erhält der strikte Verweis auf individuelle Täter den Mythos staatlicher Unschuld aufrecht. Eine gegen Serben gerichtete Verwendung des Genozidbegriffs ist ohnehin tabuisiert und nicht mehrheitsfähig. Somit muss von einer fehlenden Internalisierung der Norm ausgegangen werden.

Dadurch, dass die Aufarbeitung von Kriegsverbrechen über viele Jahre hinweg Serbiens »most valueable foreign export « ${ }^{424}$ war, ist die politische Rhetorik der Vergangenheitsaufarbeitung und der Menschenrechte bei Politikern gut eingeübt. Die Lücke zwischen der verwandten Rhetorik und der konkreten Politik lässt hingegen eine gewisse Inhaltsleere und eine eher symbolische Übernahme von Normen vermuten. Selbst bei symbolischen Entschuldigungen scheint die Übernahme einer uneingeschränkten Täterrolle, die keinen Verweis auf die eigenen Opfer und die Schuld aller Konfliktparteien erlaubt, eine diskursive Grenze zu markieren.

Die Hindernisse für eine erfolgreiche und nicht nur instrumentelle Normübernahme scheinen die ownership des Prozesses und der mangelnde cultural match zu sein. Vergangenheitsaufarbeitung wurde nie als universeller Prozess betrachtet, sondern selektiv gedeutet - entweder als Privilegierung der serbischen Perspektive in den Jugoslawienkriegen oder als gegen Serben gerichtetes Instrument. Dies schien sich für serbische Politiker und die serbische Öffentlichkeit mit dem ICTY und den dem Land gestellten Bedingungen zu bestätigen. Zwar wurde eine Strafverfolgung einiger Schuldiger vor dem ICTY und nun durch die Kammer für Kriegsverbrechen erreicht, die Effekte der Vergangenheitsaufarbeitung auf Versöhnung, Stabilisierung und Demokratisierung blieben aber limitiert. Der Prozess der Vergangenheitsaufarbeitung war diesbezüglich teilweise sogar kontraproduktiv: Zwischen den ehemaligen Konfliktparteien

viđenjima socijalističke Jugoslavije, drugog svetskog rata u kome je nastala i ratova u kojima se raspala« [Krieg und Unfrieden. Über Sichten auf das sozialistische Jugoslawien, den Zweiten Weltkrieg, in dem es errichtet wurde, und die Kriege, in denen es zerfiel], in: Dubravka Stojanović/Radina Vučetić/Sanja Petrović/Olga Todosijević/Olga Manojlović Pintar/Radmila Radić (Hg.): Novosti iz prošlosti: Znanje, neznanje, upotreba i zloupotreba istorije [Neuigkeiten aus der Vergangenheit. Wissen, Nichtwissen, Gebrauch und Missbrauch der Geschichte], Belgrad: Beogradski centar za ljudska prava 2010, S. 83-106.

424 B. Grodsky: The Costs of Justice, S. 123. 
bleibt der Diskurs über Kriegsverbrechen weiterhin kontrovers und konflikthaft, wie die Protestreaktionen auf Urteile des ICTY, die Srebrenica-Deklaration in Bosnien-Herzgowina oder die Empörung über die Äußerungen von Präsident Nikolić nach seinem Amtsantritt zeigten. Zwei Mal sorgte die erzwungene Kooperation mit dem ICTY für eine Destabilisierung der politischen Situation: $\mathrm{Zu}$ nächst nach der Auslieferung Milošević' 2001, woraufhin Koštunicas DSS aus der Regierung ausscherte, und sodann bei der Ermordung des Premierministers Zoran Đinđić. Da es keinen harten Bruch mit den Eliten des Milošević-Regimes gegeben hat, haben in Politik, Militär, Geheimdiensten und Gesellschaft zum Teil noch die gleichen Kader einflussreiche Positionen inne. Für sie, die naturgemäß einer durchgreifenden Aufklärung der Verantwortlichkeiten für den Krieg und für den in Kriegsverbrechen mündenden Nationalismus entgegenstehen, haben sich lediglich die Spielregeln verändert. Sie haben sich an die neuen Verhältnisse angepasst. Und auch die Vertreter des »anderen Serbien«, die bis heute die stärksten Befürworter einer Aufarbeitung im Land sind, werden als Vertreter einer selektiven Gerechtigkeitsvorstellung verstanden. Durch die Politisierung des Aufarbeitungskonzepts im serbischen Diskurs ist Aufarbeitung nicht nur Gegenstand von Politik. Anstatt für die Gleichheit vor Gesetz und Gericht, Sicherheit und Zivilisierung zu werben und eine universelle Gültigkeit zu erlangen, bleibt die Wirkung einer Norm der Aufarbeitung begrenzt auf die eines politischen Kampfbegriffs, mit dem es partikulare Interessen durchzusetzen gilt.

\section{Die Problematik externer Interventionen und erzwungener Gerechtigkeit}

Ein besonderes Hindernis für die Bereitschaft, eine Aufarbeitungsnorm zu internalisieren, war ohne Frage die grundlegende Skepsis gegenüber extern induzierten und aufoktroyierten Prozessen, die während des Milošević-Regimes als illegitime Angriffe und feindliche Interventionen gedeutet wurden. Wie Victor Peskin aufzeigte, glich der Kampf um Kooperation und Konditionalitätspolitik zwischen dem Tribunal, dem Staat und der internationalen Gemeinschaft einem »virtual trial of their own « ${ }^{425}$. Das ICTY konnte erst arbeiten, als die Unterstützer der Anklagebehörde, die einflussreichen Staaten und Organisationen, sich zu Koalitionen formierten, deren Engagement schon einem Urteil über den Staat gleichkam, der zur Kooperation gezwungen werden sollte.

Diese immanente Vorstrukturierung erlaubte es, dass politische Eliten in Serbien die Frage der Vergangenheitsaufarbeitung zu einer Frage der nationalen 
Loyalität und der politischen Dominanz verwandelten. Der Eindruck, dass eine Aufarbeitung der Kriegsverbrechen dem nationalen Interesse widersprechen würde, setzt sich bis heute fort und wird mit der Logik der Konditionalität rationalisiert. Durch das Zuckerbrot wird Aufarbeitung somit zu einem strategischen Vorteil und als nationales Interesse darstellbar, dementgegen bleibt die Gerechtigkeitsvorstellung aber weiterhin selektiv.

Nach 2000 hieß die Formel hinsichtlich der Konditionalitätspolitik der USA "Geld gegen Kriegsverbrecher«. Sie stellte die handelnden Politiker vor ein Dilemma: Kooperierten sie nicht mit dem ICTY, würden sie durch die damit verbundenen Sanktionen oder die in Aussicht gestellten Nachteile geschwächt, doch auch die Unterstützung des ICTY bedrohte ihre innenpolitische Popularität. Also legten sie ihre Zwangslage offen und arbeiteten mit dem ICTY zusammen - um die Bedingung zu erfüllen und nicht um Kriegsverbrecher zur Verantwortung zu ziehen, Gerechtigkeit walten zu lassen oder die von Krieg und Autoritarismus geprägte staatliche Vergangenheit aufzuarbeiten. So wurden zwar die gesuchten Kriegsverbrecher ausgeliefert und vor Gericht gestellt, eine weitergehende Wirkung auf die serbische Gesellschaft allerdings konnte nicht erreicht werden, da eine überzeugende moralische Rechtfertigung für das Handeln ausblieb. Im Gegenteil, die Glaubwürdigkeit des Tribunals wurde durch die Unfreiwilligkeit des Handelns sogar noch weiter beschädigt. Gleichzeitig erlaubte die Konditionalitätspolitik Anti-ICTY-Kräften, kooperierende Politiker des Verkaufs von Serben gegen Geld oder des Verrats von Serben an das ICTY zu bezichtigen. Das Ablehnen der Serbien gestellten Bedingungen oder der in Aussicht gestellten »Belohnungen« konnte überdies sogar als Zeichen besonderer politischer Potenz und der Verteidigung nationaler Interessen gedeutet werden. Vojislav Koštunica ging noch einen Schritt weiter, als er mit seiner Politik der freiwilligen Selbstauslieferung die EU-Konditionalitätspolitik als eine Art faustischen Pakt mit der EU darstellte, »handing over wartime sheroes« in return for the >empty promise of Europe « ${ }^{426}$. Damit verkehrte er die normativen Bezugspunkte der Konditionalitätspolitik in ihr Gegenteil, die Unterstützung der »serbischen Helden « galt als legitim und gerechtfertigt, wenn sie sich für die Nation opferten und nach Den Haag gingen. Eine negative Einstellung gegenüber dem ICTY war politisch sogar à la mode. Koštunica räumte wiederholt ein, er kooperiere nur aus Gründen des nationalen Interesses mit dem ICTY. Europa galt zwar aus finanziellen und wirtschaftlichen Gründen als notwendig, aber normativ nicht als Vorbild, vielmehr grenzte sich Koštunica davon ab. 
Marlene Spoerri wies auf die Problematik »erzwungener Gerechtigkeit« hin, nach der Konditionalitätspolitik zwar der internationalen Strafjustiz helfe, aber auch gegenteilig wirken könne, indem sie »inadvertently protract the normative shifts required to see truth and reconciliation achieved « ${ }^{427}$. Zwar wurden flüchtige Kriegsverbrecher nach den Haag ausgeliefert und dort vor Gericht gestellt, was zunächst Gerechtigkeit für die Opfer bedeutete. Das Tribunal blieb allerdings in der Rolle eines von allen Parteien anerkannten, unparteiischen Dritten, der über Straftaten und das historische Narrativ der Konflikte entscheiden könne. Durch die fehlende Glaubwürdigkeit und Legitimität des Tribunals erreichen Prozesse und Urteile sowohl in ihrer normativen als auch emotionalen Dimension einen großen Teil der Serben nicht. Gut sichtbar wurde die Leere der Auslieferungspraxis durch die durchgängig kommunizierte Notwendigkeit der Erfüllung externer Bedingungen, als Präsident Tadić im Mai 2011 der Presse die Verhaftung von Ratko Mladić bekannt gab. Svetlana Lukić, die Moderatorin der populären, kritischen Radiosendung Peščanik (Stundenuhr), kommentierte die Äußerung des Präsidenten:

»In einem Satz lobte er, dass es geschafft sei, im zweiten entschuldigt er sich, im dritten verlachte er [ICTY-Chefankläger, D. M.] Brammertz und bemerkte mehrfach, wie Brammertz trübes Wasser in seinem Bericht davontragen wird. Im vierten Satz versuchte er bereits, mit der Europäischen Union zu verhandeln, und im fünften verkündet er, dass mit der Verhaftung von Ratko Mladić auch offiziell das Stigma vom serbischen Volk genommen worden sei. $\ll^{428}$

Tadić kommunizierte nicht die Notwendigkeit von Gerechtigkeit oder der Konfrontation mit Kriegsverbrechen, sondern die Demonstration der Stärke der Regierung, bemerkte schadenfroh, dass Brammertz diesmal zu keinem negativen Urteil über Serbien kommen könne und dass Serbien nun Anspruch auf den Kandidatenstatus bekäme. Wie Lukić weiter feststellte, habe Tadić somit »allen den Ablass erteilt, die im Namen des serbischen Volkes irgendwelche Sünden begangen haben $\ll^{429}$. Mit Erfüllung der an das Land gestellten Konditionalitäten gilt die Aufarbeitung der Kriegsverbrechen von Regierungsseite als beendet, als ein Kapitel, dass man nun hinter sich lassen könne.

427 M. Spoerri: »Justice Imposed«, S. 1847.

428 S. Lukić: Reakcije na hapšenje Ratka Mladić.

429 Ebd. 


\section{Srebrenica erinnern: Narrative und Normen}

Dieses Kapitel untersucht anhand eines konkreten Kriegsverbrechens, des Massakers von Srebrenica, die Narrative und Normen in Deutungsfestschreibungen von internationalen und serbischen Akteuren im Zeitraum 1995-2010. Dazu werden diese Deutungsfestschreibungen auf internationaler und serbischer Ebene dargestellt und in Relation zueinander gesetzt. Für die serbische Ebene wurden zudem deklaratorische Äußerungen auf Regierungs- und Parteiebene untersucht, um der Frage nachzugehen, wie sich das Sprechen in öffentlichen Diskursen beziehungsweise das Schreiben über Srebrenica verändert. So können diskursive Verschiebungen zwischen der Kontroverse um eine Verurteilung von Srebrenica zwischen 2005 und 2010 sichtbar gemacht werden, die Ausdruck normativen Wandels sein und als »Richtungsanzeiger« dienen können. Darüber hinaus stellte sich die Frage, ob hinsichtlich einer Differenzierung nach Opfergruppe unterschiedliche Normvorstellungen vorliegen. Diesen Fragen wurde ebenfalls im Rahmen eines lexikometrischen Vergleichs der Deklarationen zur Verurteilung des Massakers und der Verbrechen an Serben 2010 nachgegangen.

Lexikometrische Verfahren können Hinweise auf die Charakteristika von Korpora geben. Dieses induktive Verfahren erlaubt es, den möglichen blinden Fleck rein theoriegeleiteter Analysen zu erhellen. Computergestützt wurde mit MaxQDA so eine quantitative Analyse der Korpora von 2005 und 2010 vorgenommen, die auf einer Worthäufigkeitssuche beruhte. Statt sämtliche möglichen Wörter zählen zu lassen, wurde die Zählung auf Basis eines Diktionärs entwickelt, das heißt, nur die Wörter in diesem Wörterbuch werden gezählt. ${ }^{1}$ Die Begriffe des Diktionärs wurden nach dem Kriterium der allgemeinen Worthäufigkeit und nach den Erkenntnissen der bisherigen empirischen Arbeit, das heißt aus dem Wortschatz der Vergangenheitsaufarbeitung und von spezifischen Kriegsverbrechen im serbischen Diskurs, ausgewählt. Aufgrund der serbischen

1 Siehe das Diktionär im Anhang dieser Arbeit. 
Grammatik, die ähnlich der deutschen Veränderungen am Wortende je nach verwendetem Kasus vorsieht, musste häufig nach dem Wortstamm mit einem Stern $(*)$ statt nach einem bestimmten Wortende gesucht werden. Dadurch ergeben sich zum Teil ganze Wortfelder hinter nur einem Wort. Die Worthäufigkeit wurde zur Vergleichbarkeit auf einen idealen Durchschnittsartikel heruntergerechnet, also durch die Anzahl der vorliegenden Artikel aus der jeweils zu untersuchenden Periode geteilt. Von den daraus resultierenden Ergebnissen wurde die Differenz ermittelt (Worthäufigkeit 2005 - Worthäufigkeit $2010=$ Differenz). Diejenigen Kategorien mit einer Differenz von mehr als $+/-0,1$ wurden im Rahmen der Auswertung für signifikant erachtet.

Deklarationen, Resolutionen und Berichte stellen in der Regel den Versuch dar, eine bestimmte Deutung festzuschreiben und öffentlichen Debatten und Auseinandersetzungen um einen Sachverhalt ein Ende zu setzen, indem sie, möglicher konkurrierender Deutungen zum Trotz, ein einheitliches Narrativ präsentieren. Sie werden gewöhnlich von höchsten Gremien verabschiedet und haben einen hohen Geltungsanspruch. Juristische Deutungen und Wertungen nehmen im Fall Srebrenica die gleiche Funktion ein, wie sie die Geschichtswissenschaft für andere Erinnerungstopoi ausübt: Sie entscheiden über die »richtigen« Narrative - über »Fakten«, die Frage von (Un-)Schuld und Verantwortung. ${ }^{2}$ Allgemein werden die hier untersuchten Srebrenica-Deutungen aufgrund des verkürzten Charakters von Deklarationen und Berichten ohne eine breitere Berücksichtigung des Konfliktkontexts erzählt. Da die konkreteren Konfliktumstände aber Aufschluss über die Positionen der Akteure in der Deutung und damit über den Hintergrund und die Motivation für die Deutungsfestschreibung gibt, werden die Deutungsfestschreibungen sowohl hinsichtlich der Akteurspositionen während der Jugoslawienkriege als auch in gegenwärtigen Diskursen kontextualisiert.

2 Hier wird auf »forensische«, »faktische« oder »historische« Wahrheit verwiesen. 


\subsection{INTERnationale DekLaRationen UND DEUTUNGSFESTSCHREIBUNGEN 1995-2009³}

\section{Kontext der internationalen Deutungsfestschreibung}

Ein grundlegender bias auf internationaler Ebene in der Wahrnehmung der Jugoslawienkriege ist darauf zurückzuführen, dass das Milošević-Regime und die Vertreter der Republika Srpska vergleichsweise schlecht mit internationalen Medienvertretern und Institutionen kooperierten und nach dem Ausschluss aus den UN isoliert waren. Dadurch blieben die Verbrechen, die im Bosnienkrieg an Serben begangen wurden, in der internationalen Öffentlichkeit weitgehend unbeachtet. Gleichzeitig forcierten bosnisch-muslimische Politiker und von ihnen beauftragte PR-Agenturen ab 1992 eine Zuschreibung der muslimischen Bosnier als unschuldige Opfer, um die Unterstützung der internationalen Öffentlichkeit zu mobilisieren. ${ }^{4}$ Einen entsprechenden Geltungsanspruch bekam diese Deutung, als Bosnien und Herzegowina am 20. März 1993, also mehr als zwei Jahre vor dem Massaker von Srebrenica, Klage vor dem Internationalen Strafgerichtshof gegen die Bundesrepublik Jugoslawien einreichte, um die Anwendung der Genozidkonvention vor dem Internationalen Gerichtshof zu prüfen. Die bosnischmuslimische Führung beabsichtigte damit, den Bosnienkrieg nicht als Bürgerkrieg oder als Konflikt um ein Territorium zu definieren, sondern als entschlossene Anstrengung der serbischen Seite darzustellen, die bosnischen Muslime auf dem von Serben kontrollierten Territorium als Volk zu eliminieren. ${ }^{5}$ Diese Sichtweise wurde breit von den westlichen Medien rezipiert und unterstützte die Konfliktwahrnehmung der Bosniaken. ${ }^{6}$ Ihr Narrativ, in dem Bosnier und Serben als homogene und dichotome Gruppen dargestellt werden - als muslimische, zivile Opfer und bosnisch-serbische, (para-)militärisch organisierte Täter - wurde dadurch in den Deutungen der Vertreter der internationalen Gemeinschaft dominant.

3 Dieses Unterkapitel wurde von der Autorin verändert und erweitert veröffentlicht, vgl. D. Mehler: »Srebrenica und das Problem«.

4 Vgl. zum Engagement von PR-Agenturen in den Jugoslawienkriegen Becker, Jörg/ Beham, Mira: Operation Balkan. Werbung für Krieg und Tod, Baden-Baden: Nomos 2006. Für eine Übersicht über Agenturen, die für die Regierung Bosnien-Herzegowinas tätig waren, siehe ebd., S. 103.

5 J. Subotić: Hijacked Justice, S. 136.

6 Vgl. Beham, Mira: Kriegstrommeln. Medien, Krieg und Politik, München: Deutscher Taschenbuch Verlag 1996. 
Der Fall der UN-Schutzzone Srebrenica wurde nur wenige Tage nach dem Verbrechen international verurteilt. Angeprangert wurde zunächst, dass es den Blauhelmen nicht gelungen war, die Enklave gegen den serbischen Angriff zu schützen oder zu verteidigen, obwohl ein Vorrücken der bosnisch-serbischen Einheiten auf Srebrenica absehbar gewesen sei. Die UN wurden vor allem von der Türkei kritisiert, die während des ganzen Bosnienkriegs diplomatisch und in internationalen Organisationen als Fürsprecher der bosnischen Muslime agierte. ${ }^{7}$ Frankreich forderte eine Rückeroberung der Schutzzone. Erst in der zweiten Julihälfte gab es Gerüchte über ein Massaker. Erste Flüchtende aus der Enklave und später Überlebende des Massakers machten diesbezügliche Aussagen, nachdem sie auf sicherem Territorium angekommen waren. Einzelne Blauhelmsoldaten gaben ähnliche Aussagen zu Protokoll. Am 24. Juli 1995 wurde schließlich der sogenannte Mazowiecki-Bericht des UN-Menschenrechtsbeauftragten veröffentlicht, der eine Woche lang die Ereignisse um Srebrenica untersucht hatte. Demnach gab es klare Anzeichen, die auf Massenexekutionen schließen ließen. Zudem, formulierte Tadeusz Mazowiecki, seien ca. 7000 Einwohner der Enklave offenbar »verschwunden «. ${ }^{8}$ Nur drei Tage später trat er von seinem Amt zurück. Am 10. August wurden die Verbrechen in der Umgebung von Srebrenica im UN-Sicherheitsrat thematisiert. Im Herbst 1995 schoben sich die involvierten Akteure UN, NATO und die einzelnen Staaten gegenseitig die Verantwortung

7 Die Türkei sieht sich als Nachfolger des Osmanischen Reiches bis heute als Schutzmacht der europäischen Muslime. Auch hinsichtlich der finanziellen und humanitären Unterstützung der Muslime im Bosnienkrieg spielte die Solidarität der türkischen Politik und Zivilgesellschaft eine wichtige Rolle: Sowohl die muslimischen Gemeinden als auch der türkische Rote Halbmond sowie bosnische Netzwerke in der Türkei unterstützten die bosnischen Muslime zu Kriegszeiten. Diese Unterstützung reichte von einfachen humanitären Hilfsleistungen bis zur Finanzierung von Waffen. Bis heute wird von den ethnischen und kulturellen »Verwandten« in Südosteuropa gesprochen, vgl. Reljić, Dušan: »Die Türkei weckt alte Lieben und Feindschaften im Westbalkan« (= SWP-Aktuell 2010/A 69), http://www.swp-berlin. org/fileadmin/contents/products/aktuell/2010A69_rlc_ks.pdf vom 16.6.2011, S. 1. Nach dem Fall der Schutzzone gab es in der Türkei Proteste in Form von Demonstrationen, Spendensammlungen und medialer Berichterstattung.

8 United Nations Commission on Human Rights (Hg.): Final Periodic Report on the Situation of Human Rights in the Territory of the Former Yugoslavia, UN-Dok. E/CN.4/1996/9 vom 22.8.1995. 
für den Fall der Schutzzone um Srebrenica zu. ${ }^{9}$ Die Außenministerkonferenz der islamischen Staaten verurteilte in ihrer Sitzung Mitte Dezember 1995 die »serbische Aggression gegen die Republik Bosnien und Herzegowina, Genozid und terroristische Akte, vor allem das Überrennen der sicheren und demilitarisierten Gebiete von Srebrenica und Žepa« aufs Schärfste. ${ }^{10}$ Am 21. Dezember verabschiedete der UN-Sicherheitsrat eine Resolution, um die Menschenrechtsverletzungen im Zusammenhang mit dem Fall von Srebrenica und Žepa - aber auch in anderen Fällen - zu verurteilen. ${ }^{11}$ In den Monaten nach dem Massaker setzte im internationalen Diskurs eine begriffliche Verkürzung ein. Srebrenica wurde zum Symbol für einen irrationalen Exzess von ethnischer Gewalt, der untrennbar mit einer Schuldzuweisung gegenüber »den Serben« verknüpft war.

\section{Anklagen und Prozesse vor dem ICTY}

Von höchster Bedeutung für die Wahrheitsfindung war und ist das seit 1993 bestehende ICTY. Die Bewertung des Massakers von Srebrenica als Völkermord wurde erst durch die Legitimität des ICTY in den internationalen Diskurs über Srebrenica gesetzt, das am 14. November 1995 Ratko Mladić und Radovan Karadžić wegen Genozid, Verbrechen gegen die Menschlichkeit und Verletzungen des Kriegsrechts anklagte. ${ }^{12}$ Weitere Anklagen folgten. Schon im November 1996 wurde mit Dražen Erdemović der erste am Massaker von Srebrenica beteiligte Täter medienwirksam verurteilt. Am Wahrheitsgehalt der im Prozess vorgenommenen Rekonstruktion des Ablaufs des Massakers werden bis heute nach-

9 Semo, Mar: »Srebrenica, retour sur un massacre. Le général Janvier est accusé d'avoir abandonné l'enclave musulmane tombée en juillet«, in: Libération.fr vom 1.11.1995, http://www.liberation.fr/monde/0101160055-srebrenica-retour-sur-un-massa crele-general-janvier-est-accuse-d-avoir-abandonne-l-enclave-musulmane-tombee-enjuillet vom 12.5.2011.

10 Organisation of Islamic Cooperation (Hg.): Final Communiqué 23rd Islamic Conference of Foreign Ministers vom 12.12.1995, Organisation of Islamic Cooperation: Final Communiqué of the 23rd Islamic Conference of Foreign Ministers vom 12.12.1995, http://www.oic-oci.org/english/conf/fm/23/final23.htm\#final vom 21.6.2015. Hier wurde bereits der Begriff Genozid benutzt.

11 United Nations Security Council: Resolution 1034, UN-Dok. S/RES/1034 vom 21.12.1995.

12 International Criminal Tribunal for the Former Yugoslavia: The Prosecutor of the Tribunal Against Radovan Karadzic, Ratko Mladic. Indictment, Fall Nr. IT-95-18-I vom 14.11.1995. 
vollziehbare Zweifel erhoben. ${ }^{13}$ Erst der Prozess gegen den Kommandanten des Drina-Korps der Armee der Republika Srpska, Radislav Krstić, in den Jahren 2000 und 2001 beruhte auf präzisen Ermittlungen und Recherchen, die die Anklage des ICTY unter anderem durch Exhumierungen von 21 primären und sekundären Massengräbern vorgenommen hatte. Im Rahmen dieses Prozesses wurde auch erstmals eine konkrete Opferzahl genannt, die auf konservativen Schätzungen beruhte: Mindestens 7475 Personen seien nach dem Fall der Enklave ermordet worden. ${ }^{14}$ Die Verurteilung von Radislav Krstić vor dem ICTY 2001 wegen Völkermords - dieses Urteil wurde 2004 in Beihilfe zum Völkermord revidiert - legte erstmals eine eindeutige Sichtweise fest und bildete einen Referenzpunkt für alle folgenden Narrationen. Die Reaktionen auf das ICTYUrteil in Serbien und Bosnien-Herzegowina fielen - wie zu erwarten - entsprechend der sich diametral gegenüberstehenden Deutungen sehr gegensätzlich aus. $^{15}$

Das ICTY verhandelte nach der Causa Krstić noch eine Vielzahl weiterer mit Srebrenica in Verbindung stehender Fälle. Besonderes Aufsehen in Serbien und Bosnien-Herzegowina erregte der Prozess gegen Naser Orić, der eine wichtige Symbolfigur ist: Während er für die bosnischen Muslime als Rückeroberer serbischen Territoriums und Verteidiger der Enklave bis zu deren Fall gefeiert wird, nimmt ihn die serbische Seite als brutalen Gewalttäter wahr, der sich mit dem Töten und Foltern serbischer Zivilisten öffentlich brüstet. Der im April 2003 festgenommene ehemalige Kommandant der Enklave wurde vor dem ICTY diverser Vergehen im Zusammenhang mit Verbrechen an serbischen Zivilisten angeklagt. Ihm konnten aber nur leichtere Delikte nachgewiesen werden, alle weiteren Anklagepunkte wurden aus Mangel an Beweisen fallen gelassen. Direkt nach der Verkündung des Urteils von zwei Jahren Haft wurde Orić freigelassen. Im Berufungsverfahren wurde zwar festgestellt, dass es Verbrechen gegen serbische Zivilisten gegeben hatte, allerdings konnte auch hier keine direkte Beteiligung Orić' nachgewiesen werden. Erst schien die Verhandlung des Falls Orić vor dem ICTY durch eine Integration der Verbrechen gegen Serben in der Umgebung von Srebrenica in das hegemoniale Srebrenica-Narrativ eine weniger polarisierte Auseinandersetzung mit Srebrenica zu ermöglichen. Der Vorwurf von bosnisch-muslimischer Seite, das Gericht wolle mit dem Fall eine »false

13 Čivikov, Germinal: Srebrenica. Der Kronzeuge, Wien: Promedia 2009.

14 Brunborg, Helge/Lyngstad, Torkild Hovde/Urdal, Henrik: »Accounting for Genocide. How Many Were Killed in Srebrenica?«, in: European Journal of Population/Revue europenne de Demographie 19 (2003) 3, S. 229-248.

15 J. Subotić: Hijacked Justice, S. 137. 
ethnic balance $~^{16}$ herstellen, führte aber gemeinsam mit dem unglücklichen Prozessverlauf zu einem gegenteiligen Effekt: der Reaktualisierung der jeweiligen nationalen Narrative beider Konfliktparteien und dem erneuten Vorwurf an das ICTY, die Opfer auf serbischer und bosnisch-muslimischer Seite unterschiedlich zu werten. ${ }^{17}$

\section{Untersuchungsberichte von Peacekeeping-Akteuren}

Am 15. November 1999 veröffentlichte UN-Generalsekretär Kofi Annan einen Bericht zum Fall von Srebrenica. ${ }^{18}$ Er räumte ein, dass durch »error, misjudgment and an inability to recognize the scope of the evil confronting us, we failed to do our part to help save the people of Srebrenica from the Serb campaign of mass murder. $\aleph^{19}$ Annan betonte, »Bosnia was as much a moral cause as a military conflict. The tragedy of Srebrenica will haunt our history forever. $\aleph^{20} \mathrm{Er}$ forderte die UN-Mitgliedsstaaten zu einem Prozess der Reflexion und der Analyse auf. Das Versagen des Konzepts der Schutzzonen, das fehlende robuste Mandat für etwaige Kampfeinsätze sowie die Frage der Immunität der unter UN-Mandat Handelnden führten nachhaltig zu einer Diskussion über eine Reform der UNFriedenssicherungsinstrumente.

Im Juli 2000 begann die französische NGO Médecins Sans Frontières, die beim Fall der Enklave und den darauf folgenden Ereignissen den Tod von 22 lokalen Mitarbeiter zu beklagen hatte, sich für die Einsetzung einer parlamentarischen Kommission in Frankreich zu engagieren, um die politische und militärische Verantwortung des eigenen Landes zu untersuchen. ${ }^{21}$ Schließlich versprach der französische General Philippe Morrillon als Kommandant der United Nations Protection Force im März 1993 der Bevölkerung der belagerten Enklave den Schutz durch die UN, was der UN-Sicherheitsrat in einer Resolution auf eine ju-

16 Ebd., S. 130.

17 Ebd., S. 131.

18 United Nations General Assembly: Report of the Secretary-General Pursuant to General Assembly Resolution 53/35 on The Fall of Srebrenica, UN-Dok. A/54/549 vom 15.11.1999.

19 Ebd., S. 108.

20 Ebd.

21 Nettelfield, Lara J.: Courting Democracy in Bosnia and Herzegovina. The Hague Tribunal's Impact in a Postwar State (= Cambridge Studies in Law and Societies), Cambridge, New York: Cambridge University Press 2010, S. 120. 
ristische Grundlage stellte. ${ }^{22}$ Morrillons Nachfolger Bernard Janvier war 1995 verantwortlich für die nichtweitergeleitete Anforderung von NATO-Luftunterstützung, die möglicherweise die vorrückenden serbischen Einheiten hätte aufhalten können. Die aufgrund des öffentlichen Drucks eingesetzte Expertenkommission der französischen Nationalversammlung veröffentlichte im November 2001 ihren Bericht:

»L'échec des Nations unies à Srebrenica est donc avant toute chose l'échec des Etats qui ont pris des engagements, notamment au sein du Conseil de sécurité, qu'ils n'ont pas respectés, faute de s'en donner les moyens. La raison de fond de la chute de Srebrenica est à rechercher dans l'absence de volonté politique affirmée d'intervenir à Srebrenica: de la France, du Royaume-Uni, des Etats-Unis, des autorités bosniaques de Sarajevo ellesmêmes. ${ }^{23}$

Gerade Frankreich fiele als ständigem Mitglied im UN-Sicherheitsrat eine besondere Rolle zu. Der Bericht räumte ein, dass der französische General Bernard Janvier der Anforderung nach Luftunterstützung (früher) hätte nachkommen müssen. ${ }^{24}$ Er habe aber die bosnischen Serben unterschätzt. Den Vermutungen, es hätte einen »Deal« zwischen Janvier und Mladić gegeben, ${ }^{25}$ wurde entgegnet,

22 United Nations Security Council: Resolution 819.

23 »Das Versagen der UN in Srebrenica ist in erster Linie ein Scheitern von Staaten, die Verpflichtungen eingegangen sind, insbesondere im Sicherheitsrat, die nicht erfüllt wurden, für die keine Mittel bereitgestellt wurden. Der wesentliche Grund für den Fall von Srebrenica war, dass man in Abwesenheit des politischen Willens von Frankreich, dem Vereinigten Königreich, Vereinigte Staaten, die bosnischen Behörden in Sarajevo selbst - versuchte, in Srebrenica zu intervenieren«, aus: Assemblée nationale: Mission d'information commune (1) sur les événements de Srebrenica vom 22.11.2001, XI. législature, Rapport d'information no. 3413, S. 187.

24 Aus der Anhörung vor der französischen Nationalversammlung ging hervor, dass das niederländische Bataillon schon ab dem 6. Juli 1995 um Luftunterstützung gebeten hatte, was aber erst am 10. Juli 1995 an die niederländische Regierung weitergeleitet wurde. Das Dutchbat sei von einem Luftangriff am 11. Juli 1995 ausgegangen, während nur ein begrenzter Lufteinsatz geflogen worden sei.

25 Es wurde vermutet, es habe eine Geheimverhandlung zwischen Janvier, Mladić und dem Kommandanten der serbischen Armee, Momčilo Perišić, gegeben. In dieser hätte Janvier versucht, die Freiheit gefangener französischer UN-Soldaten zu erwirken und im Gegenzug zugesagt, im Falle einer Attacke auf Srebrenica keine Luftschläge zu unternehmen. 
dass sich diese Annahmen nicht erhärtet hätten und es keine Beweise dafür gäbe. Aus den Dokumenten im Anhang des Berichts geht aber auch hervor, dass es ebenso keinerlei Beweise gab, die diese Vermutung widerlegten. Der Bericht forderte in seinen Schlussfolgerungen dazu auf, dass Franzosen, Briten und Amerikaner insbesondere die nötigen Mittel wie Gelder für das ICTY bereitstellen sollen, um »diese Verbrecher gegen die Menschlichkeit« zu fassen. ${ }^{26}$ Da die Anhörung von Morrillon und Janvier unter Ausschluss der Öffentlichkeit stattfand, blieben der Bericht und die Beratungen darüber umstritten: Die Wahrheit über Srebrenica und die Verantwortung der internationalen Gemeinschaft sei weiterhin nicht öffentlich gemacht worden.$^{27}$ Bis heute hat es keinerlei Ermittlungen gegen General Janvier gegeben. Zudem weigert sich Frankreich, französische Offiziere vor dem ICTY aussagen zu lassen.

Eine zentrale Rolle für die internationale und europäische SrebrenicaInterpretation spielte die niederländische Perspektive, in der zunächst die Hilflosigkeit der zum Schutz der UN-Schutzzone rund um Srebrenica eingesetzten niederländischen UN-Blauhelmsoldaten zum Ausdruck kommt. Während das niederländische Königshaus die Soldaten des niederländischen Bataillons nach ihrer Rückkehr für den geleisteten Einsatz lobte, wurde in den Monaten darauf die Schuldfrage und die Rolle der Blauhelmsoldaten in den niederländischen Medien breit diskutiert. ${ }^{28}$ Ihnen wurde vorgeworfen, nichts gegen den unter ihren Augen geschehenen Völkermord an tausenden Menschen unternommen zu haben, die Schutz auf ihrem Gelände gesucht hätten. Während die niederländische Gesellschaft durch eine überaus hohe Spendenbereitschaft große Anteilnahme an dem Schicksal der bosnisch-muslimischen Opfer und ihrer Angehörigen zeigte, ${ }^{29}$

26 Assemblée nationale: Mission d'information, S. 194.

27 Sabljaković, Dževad: »Srebrenica Evidence Kept Under Wraps. French Public Barred from Hearing Crucial Evidence at Srebrenica Parliamentary Inquiry« (= BCR Issue 215), Institute for War \& Peace Reporting vom 6.2.2001, http://iwpr.net/ report-news/srebrenica-evidence-kept-under-wraps vom 29.4.2013.

28 Diese Debatte über Srebrenica, das niederländische Militär und die Bedeutung der Geschehnisse in Srebrenica für die niederländische nationale Identität hielt für Jahre an. Die Erfahrung von Srebrenica hat die holländische Außenpolitik nachhaltig beeinflusst. Vgl. Meulen, Jan van der/Soeters, Joseph: »Dutch Courage: The Politics of Acceptable Risk«, in: Armed Forces \& Society 31 (2005) 4, S. 537-558.

29 »Between 1996 and 2002, the Dutch spent 592 million euros in Bosnia. Total assistance to Srebrenica-related projects was 33,769,733 euros. On the list they provided, the Women Srebrenica appeared twice, with 38,000 and 37,000 euro donations respectively, both in 1999. The Dutch were also large donors to the memorial center in 
verwies das niederländische Bataillon selbst in erster Linie auf das eingeschränkte Einsatzmandat, das ihnen von der UN und ihrer Regierung gegeben worden war. Zur Klärung des Sachverhalts gab die niederländische Regierung 1996 eine Untersuchung bei dem unabhängigen Niederländische Institut für Kriegsdokumentation (NIOD) in Auftrag. 2002 wurde die 3875-seitige Studie ${ }^{30}$ veröffentlicht. Das Institut kam zu dem Schluss, dass das niederländische Bataillon aufgrund der Konfliktsituation keinerlei echte Chance gehabt hätte, Frieden zu sichern, »where there was no peace to keep $\aleph^{31}$. Auch wenn der Bericht die niederländischen Soldaten rehabilitierte, wies er eindeutig auf Verfehlungen der niederländischen Regierung hin: »[H]umanitarian motivation and political ambitions drove the Netherlands to undertake an ill-conceived and virtually impossible peace mission ${ }^{32}$. Die Mission sei weder entsprechend vorbereitet und ausgerüstet gewesen, noch hätte es eine angemessene Koordination zwischen dem Verteidigungs- und Außenministerium gegeben. Zudem sei Unterstützung durch NATO-Luftangriffe ausgeblieben. Sowohl die Niederlande als auch die UN seien ihrer Pflicht nicht nachgekommen. ${ }^{33}$ Nach einer außerordentlichen Parlamentsdebatte am 16. April 2002 trat die amtierende Regierung von Premierminister van Kok als Reaktion auf den NIOD-Bericht und das darin konstatierte Versagen zurück. Die Demission der Regierung van Kok war umstritten und wurde sowohl als angemessen hinsichtlich der niederländischen Rolle während des Falls der Enklave als auch als Versuch gewertet, schon früh weitere Diskussionen über die Enthüllungen des NIOD-Reports zu verhindern. ${ }^{34}$ Die kritische Auseinandersetzung mit Srebrenica in der niederländischen Öffentlichkeit war damit beendet. Lediglich NGOs wie der Interkerkelijk Vreedesberaad (Inter-

Potočari and to the ICMP. Some observers commented that donations for things related to the survivors' concerns, like identifiation and the memorial, were sometimes underappreciated by the groups because tose were not directly distributed to them.«, L. Nettelfield: Courting Democracy, S. 117.

30 Blom, Johan C. H./Romijn, Peter (Hg.): Srebrenica. Reconstruction, Background, Consequences and Analyses of the Fall of a \Safe`Area, Amsterdam: NIOD 2002.

31 Ebd., S. 1424.

32 NIOD Institute for War, Holocaust and Genocide Studies (Hg.): Dutchbat had to keep the peace where there was no peace. Humanitarian Motivation and Political Ambitions Drove the Netherlands to Undertake an Ill-Conceived and Virtually Impossible Peace Mission, Presseerklärung vom 10.4.2002, http://www.niod.knaw.nl/ en/srebrenica-report/press-release vom 5.5.2011.

33 J. C. H. Blom/P. Romijn: Srebrenica.

34 L. Nettelfield: Courting Democracy, S. 116. 
kirchliche Friedensrat) sind auf diesem Feld weiterhin aktiv. Die nachfolgende niederländische Regierung hingegen versuchte, den niederländischen UNEinsatz zu rehabilitieren, und zeichnete die Soldaten des niederländischen Bataillons im Dezember 2006 für ihren Einsatz aus. Seit 1995 transformierte sich die niederländische Erinnerung an Srebrenica von einer Position der Hilflosigkeit und des Versagens in eine Position der Verantwortlichkeit für die Bestrafung der Täter und der Unterstützung der Opfer.

\section{Verurteilungen des Völkermords in Srebrenica durch den amerikanischen Kongress und Senat}

Erst die entschiedenen Luftangriffe der NATO, an der die USA maßgeblich beteiligt waren, und die von der amerikanischen Regierung initiierten Verhandlungen zum Abkommen von Dayton führten zu einem Friedensvertrag im Bosnienkrieg. Der Diplomat Richard Holbrooke, der die rivalisierenden Konfliktparteien an einen gemeinsamen Verhandlungstisch brachte, vermittelte auch während der Kosovokrise. Seitdem verstehen sich die USA, vor allem in Bosnien selbst, als Schutzmacht der bosnischen Muslime und der kosovarischen Albaner. Die amerikanische Botschaft in Sarajevo beispielsweise spendete ein Sechstel der Kosten für den Aufbau des Gedenkzentrums in Srebrenica-Potočari, das gleichzeitig Friedhof für die Opfer des Massakers ist. Zudem unterstützen die USA die Souveränität Bosnien-Herzegowinas und des Kosovo.

Anfang Mai 2005 reichten acht Senatoren der Demokraten und der Republikaner im Senat der Vereinigten Staaten von Amerika einen Resolutionsentwurf ein, der eine grundsätzliche Position des Senats zum Massaker von Srebrenica zum Ausdruck bringen sollte. Ohne Änderungen verabschiedete der Senat am 22. Juni 2005 einen Resolutionstext, der die Ermordung von Tausenden Männern und Jungen aus der Enklave und die Gewaltverbrechen gegen die zivile Bevölkerung durch serbische Kräfte verurteilte. Der Senat beschloss, dass

»the thousands of innocent people executed at Srebrenica in Bosnia and Herzegovina in July 1995, along with all individuals who were victimized during the conflict and genocide in Bosnia and Herzegovina from 1992 to 1995, should be solemnly remembered and honored $\aleph^{35}$.

Die Konfliktinterpretation des Kongresses ist stark opferzentriert und verfolgt eine juristische Verurteilung von Verbrechen und Gewalt. Dementsprechend be- 
zog sie sich auf die Genozidkonvention und die Verfahren am ICTY. Mit der Formulierung des zweiten Satzes der Resolution nimmt der Kongress dabei auch das Urteil des Internationalen Gerichtshofs vorweg und weitet die durch die ersten Urteile des ICTY nur für Srebrenica geltende Qualifizierung des Genozids auf ganz Bosnien-Herzegowina aus:

»[T]he policies of aggression and ethnic cleansing as implemented by Serb forces in Bosnia and Herzegovina from 1992 to 1995 meet the terms defining the crime of genocide in Article 2 of the Convention on the Prevention and Punishment of the Crime of Genocide, done at Paris December 9, 1948, and entered into force January 12, 1951 « ${ }^{36}$.

Weiterhin fordert die Resolution, dass die UN und ihre Mitgliedsstaaten ihren Anteil an der Verantwortung dafür akzeptierten, das Massaker in Srebrenica und den Völkermord in Bosnien-Herzegowina zugelassen zu haben. Darüber hinaus schrieben die Senatoren in ihr die Strafverfolgung der Täter und die weitere Unterstützung des ICTY fest und weiteten dieses auch als Imperativ für alle Staaten aus. Darüber hinaus sollten die USA eine Politik der Unabhängigkeit und Integrität Bosnien-Herzegowinas und des Friedens und der Stabilität in Südosteuropa verfolgen. Spezifischer soll sie in den Punkten Flüchtlingsrückkehr, Demokratisierung von Institutionen, Rechtsstaatlichkeit, Aufbau wirtschaftlicher Möglichkeiten sowie Aufklärung über das Schicksal vermisster Personen Hilfestellung leisten. ${ }^{37}$ Fünf Tage später verabschiedete nach dem Kongress auch der Senat eine wortgleiche Resolution, die Anfang Mai von vierzig Abgeordneten über die politischen Lager hinweg eingereicht worden war. ${ }^{38}$

\section{Urteil des Internationalen Gerichtshof}

Im Februar 2007 fällte der Internationale Gerichtshof sein Urteil über die 1993 eingereichte Klage auf Anwendung der Genozidkonvention. Die Richter des Internationalen Gerichtshofs befanden, dass es zwar schwere Verbrechen während des Bosnienkrieges gegen die muslimische Bevölkerung gegeben habe, dass aber außer im Falle von Srebrenica keine Intention zur Auslöschung eines ganzen Volkes nachzuweisen sei. Der serbische Staat habe zwar die bosnischen Serben in hohem Maße finanziell und militärisch unterstützt, aber eine Mittäteroder Komplizenschaft für den Völkermord könne Serbien nicht nachgewiesen

\footnotetext{
36 Ebd.

37 Ebd.

38 United States Senate: A Resolution.
} 
werden. ${ }^{39}$ Zusammenfassend konstatierte der Internationale Gerichtshof, dass Serbien seiner Pflicht nicht nachgekommen sei, den Völkermord in Srebrenica $\mathrm{zu}$ vermeiden sowie für dessen Aufklärung mit dem ICTY zusammenzuarbeiten. ${ }^{40}$ Eine direkte Beteiligung des serbischen Staates am Massaker von Srebrenica hingegen wurde nicht nachgewiesen. Während das Urteil in Serbien weitgehend mit Erleichterung aufgenommen wurde, stieß es unter bosnischen Muslimen überwiegend auf Kritik. Ihr Interesse an einem anders ausfallenden Urteilsspruch zielte auf drei Punkte: Erstens hätte eine Verurteilung Serbiens den Nachweis einer politischen beziehungsweise moralischen Schuld erbracht - in einer kollektiven Dimension, die vor dem ICTY nicht verhandelt wird. Zweitens wären hohe Entschädigungszahlungen die Folge gewesen. Und drittens wollte man den Fall benutzen, um auf das Ausmaß des Leidens der eigenen ethnonationalen Gruppe hinzuweisen. ${ }^{41}$

\section{Resolutionen des Europarats und des Europäischen Parlaments zu Srebrenica}

Anlässlich des zehnten Jahrestags des Massakers von Srebrenica unterschrieben 200937 Abgeordnete der parlamentarischen Versammlung des Europarats, das heißt weniger als neun Prozent aller Parlamentarier, eine Deklaration. Sie beschrieben, dass die Täter des Verbrechens in Srebrenica »had Serbian names and carried the Serbian flag. That is truth which all of us, and Serbian society before all, should confront.« Hinsichtlich der Aufarbeitung des Kriegsverbrechens

39 Auf Grundlage der zensierten Teile der Protokolle des Obersten Verteidigungsrats Jugoslawiens kommt Carla del Ponte zu einer anderen Interpretation, da diese eindeutig belegten, »dass die serbischen Kriegshandlungen in Bosnien-Herzegowina unter Leitung und Kontrolle Serbiens stattfanden. Aus ihnen geht hervor, dass Belgrad diese Kriegshandlungen finanzierte und unterstützte und die bosnisch-serbische Armee, obwohl offiziell seit 1992 von der jugoslawischen Armee unabhängig, dennoch nichts weiter als deren Anhängsel war.« C. Del Ponte: Im Namen der Anklage, S. $458 \mathrm{f}$.

40 International Court of Justice: Application of the Convention on the Prevention and Punishment of the Crime of Genocide (Bosnia and Herzegovina v. Serbia and Montenegro), Judgment.

41 Das Urteil des Internationalen Gerichtshofs verringerte das Vertrauen vieler Bosniaken in internationale Instrumente zur Aufarbeitung von Kriegsverbrechen, stattdessen wurde danach vermehrt auf lokale Instrumente gesetzt. Vgl. J. Subotić: Hijacked Justice, S. 140. 
bezogen die Abgeordneten deutlich Position und konstatierten, dass »[t]hat road of catharsis shall free us from a collective guilt but it requires pointing at commanders and perpetrators of that crime and rapid action on their arrest « ${ }^{42}$

Einen deutlich höheren Stellenwert hatte die auf Initiative der Europäischen Grünen hin verabschiedete Entschließung des Europäischen Parlaments zur "Zukunft des Balkans zehn Jahre nach Srebrenica«. ${ }^{43}$ Mit Verweisen auf den Stabilisierungs- und Assoziierungsprozess, den Gipfel von Thessaloniki, UNResolutionen und den aktuellen Bericht von UN-Chefanklägerin del Ponte wird die Resolution im internationalen und europäischen Kontext verortet und bestätigt diese Instrumente, Institutionen und die von ihnen vorgenommenen Interpretationen. Srebrenica wird als Tragödie beschrieben und die Morde spezifischer als wahllose Hinrichtungen während eines tagelangen Gemetzels. Da die Entschließung im direkten Nachhall der Veröffentlichung des Škorpioni-Videos erfolgte, erweiterte sich der Täterkreis. Benannt werden bosnisch-serbische Einheiten unter dem Kommando Mladić' und paramilitärische Einheiten »einschließlich irregulärer serbischer Polizeieinheiten, die von Serbien aus in bosnisches Gebiet eingedrungen waren « ${ }^{44}$ Zudem werden vielfache Verstöße gegen die Genfer Konventionen genannt. Srebrenica wird als »Symbol für die Ohnmacht der internationalen Gemeinschaft« gewertet, der es nicht gelang, »in den Konflikt einzugreifen und Unschuldige zu schützen $\ll .{ }^{45}$ Explizit wird auf die fehlenden Entscheidungsmechanismen innerhalb der EU und einer gemeinsamen Außen- und Sicherheitspolitik verwiesen, die sich »auf den Ablauf der Ereignisse äußerst negativ ausgewirkt haben $« .{ }^{46}$ Überraschend ist das Eingeständnis, dass es nach wie vor nicht möglich sei, die Ereignisse in und um Srebrenica vollständig zu rekonstruieren. Nichtsdestotrotz wird Gerechtigkeit als erstes Ziel postuliert, als Instrument dazu wird auf das ICTY verwiesen - und auf die Qualifizierung als Genozid im Krstić-Urteil. Schließlich fordert das Europäische Parlament ein Gedenken im Duktus eines »Nie wieder!«,

42 Parliamentary Assembly of the Council of Europe: Srebrenica, Written Declaration Nr. 366 vom 8.7.2005.

43 Europäisches Parlament: Entschließung des Europäischen Parlaments zu der Zukunft des Balkans zehn Jahre nach Srebrenica, EP-Doc. P6_TA(2005)0296 vom 7.7.2005

44 Ebd., S. 1.

45 Ebd, S. 2.

46 Ebd. 
»dass diese unsägliche Schande in Europa das letzte Massaker gewesen sein muss, das im Namen einer auf Volkszugehörigkeit basierenden Ideologie begangen wurde; bekräftigt, dass es alles in seiner Macht Stehende tun wird, um zu verhindern, dass sich eine derartige grauenhafte Barbarei in Europa jemals wieder ereignet «. ${ }^{47}$

In insgesamt drei Paragraphen geht das Parlament auf den politischen Umgang mit dem Škorpioni-Video und dem Gedenken an Srebrenica ein. Während es die vom Präsidenten durchgesetzte schnelle Strafverfolgung und die Zusage des Premierministers lobte, an der Gedenkfeier in Srebrenica teilzunehmen, bedauerte es, dass die vorgeschlagene Resolution zu einer Verurteilung des Massakers nicht angenommen wurde. Weiterhin kritisierten die Volksvertreter die in Serbien dominante Geschichtsaufassung und forderten mehr Engangement der serbischen Regierung auf diesem Feld: Das Europäische Parlament

»verleiht seiner ernsten Sorge darüber Ausdruck, dass immer noch zu einem beträchtlichen Teil in der serbischen öffentlichen Meinung die Kriegsverbrechen gegen muslimische Zivilisten nicht zugegeben werden; ermutigt die serbische Regierung nachdrücklich, Maßnahmen zu ergreifen, um der Nation die Vergangenheit vor Augen zu führen und der Verherrlichung mutmaßlicher Kriegsverbrecher Einhalt $\mathrm{zu}$ gebieten; erkennt, dass die Veröffentlichung des besagten Srebrenica-Videos durch serbische Fernsehsender in den Abendnachrichten ein erster Schritt in diese Richtung ist, unterstreicht jedoch, dass viel mehr getan werden muss, um die Geschichtsklitterungen, die von der Bevölkerung für wahr gehalten werden, zu beseitigen ${ }^{48}$.

Die Universalisierung des Gedenkens an Srebrenica wurde vom Europäischen Parlament weiter vorangetrieben, das seinerseits eine Initiative von bosniakischer Seite aufnahm. Nachdem die Vizepräsidentin des Parlaments Diana Wallis und der slowenische Abgeordnete Jelko Kacin 2008 an der Gedenkveranstaltung in Srebrenica-Potočari teilnahmen, setzten sich mit Munira Subašić und Murat Tahirović zwei Vorsitzende von bosnischen Opfer- und Hinterbliebenenverbänden gemeinsam mit dem Großmufti Reis-ul-ulema Dr. Mustafa Cerić für eine Resolution des Europäischen Parlaments zur Einrichtung eines europaweiten Gedenktags an Srebrenica ein. Am 15. Oktober 2008 übergaben sie einen Resolutionsvorschlag an das Präsidium des Europäischen Parlaments, der weitgehend übernommen wurde. ${ }^{49}$ Während die bosniakischen Vertreter in ihrer Resolution

47 Ebd., S. 3.

48 Ebd., S. 4.

49 Vgl. H. Karge: »Nie wieder Srebrenica«, S. 135. 
nicht auf andere Opfer der Kriege im ehemaligen Jugoslawien verwiesen, warben sie dafür, einen Gedenktag zur Erinnerung »an die unschuldigen Opfer von Genozid« einzurichten. Heike Karge schließt daraus, dass das Europäische Parlament aller Opfer der Kriege gedenken und dabei den Opfern von Srebrenica eine besondere Würdigung zukommen lassen wolle, während die bosniakischen Vertreter beabsichtigten, den Völkermord in Srebrenica zu einem »Symbol für alle Kriegsverbrechen - beziehungsweise tatsächlich generell für Völkermord « ${ }^{50}$ zu stilisieren. Am 15. Januar 2009 verabschiedete das Parlament schließlich die fraktionsübergreifend initiierte Resolution. Darin gedenkt es

»aller Menschen, die während der Kriege im ehemaligen Jugoslawien Opfer von Gewalttaten wurden, und zollt ihnen Respekt; spricht den Angehörigen der Opfer, die oftmals keine endgültige Gewissheit über das Schicksal ihrer Verwandten haben, sein Mitgefühl aus und bekundet seine Solidarität mit ihnen; erkennt an, dass der anhaltende Schmerz noch dadurch vergrößert wird, dass die Urheber dieser Taten bislang nicht vor Gericht gestellt wurden. ${ }^{51}$

Kern der Resolution ist die Initiative, des Jahrestags des Massakers angemessen zu gedenken, indem alle EU-Mitgliedsländer den 11. Juli zum Gedenktag an den Völkermord von Srebrenica erklären und auch die Staaten des westlichen Balkans aufgefordert werden, dasselbe zu tun. Weiterhin betont das Parlament die Relevanz von strafrechtlicher Verfolgung durch das ICTY und mahnt an, dass Verfahren wegen Kriegsverbrechen auf innerstaatlicher Ebene stärkere Beachtung geschenkt werden müsse. Es »hebt die Bedeutung von Aussöhnung als Teil des Europäischen Integrationsprozesses hervor« und formuliert die Erwartung, dass weitere Anstrengungen unternommen werden sollten, um »eine von Problemen und Konflikten geprägte Vergangenheit aufzuarbeiten und zu bewältigen $\aleph^{52}$.

Innerhalb von wenigen Monaten kamen alle EU-Staaten dieser Aufforderung nach. ${ }^{53}$ Damit wurde die Erinnerung an Srebrenica neben anderen Massenver-

50 Ebd., S. $135 \mathrm{f}$.

51 Europäisches Parlament: 11. Juli: Tag des Gedenkens.

52 Ebd.

53 Auch in den USA und in Kanada wird der 11. Juli als Gedenktag für das Massaker von Srebrenica begangen. Maßgeblich für die Einführung von Gedenktagen waren lokale bosniakische Lobbygruppen. 
brechen $^{54}$ in den Kanon einer europäischen negativen Erinnerungskultur eingeordnet. Der europaweite Gedenktag und seine Unterstützung suggerieren eine gemeinsame Deutung der ihn mittragenden Länder.

Der Text der EU-Resolution ist eindeutig in der Darstellung und Bewertung der Ereignisse des Massakers von Srebrenica, das »das schwerste Kriegsverbrechen [...] seit Ende des Zweiten Weltkriegs in Europa« sei und gemäß der Interpretation des ICTY klar als Völkermord klassifiziert wird. ${ }^{55}$ Die Rollen in Srebrenica werden eindeutig zugeschrieben: Als Täter werden »bosnisch-serbische Soldaten unter dem Kommando von General Ratko Mladić und paramilitärische Einheiten, darunter auch irreguläre serbische Polizeieinheiten, die von Serbien aus in bosnisches Hoheitsgebiet eingedrungen waren «, identifiziert. Weiterhin wird auf die Ermittlungen des ICTY und auf General Radislav Krstić, der wegen Beihilfe zum Völkermord schuldig befunden wurde, sowie auf Radovan Karadžić verwiesen, den damaligen Präsidenten der Republika Srpska und Befehlsgeber des Militärführers Mladić. Als Opfer werden 8000 getötete muslimische Männer und Jungen sowie ca. 25.000 zwangsverschleppte Frauen, Kinder und alte Menschen angegeben. Zusätzlich zu den bereits genannten Verbrechen werden Massenvergewaltigungen genannt. ${ }^{56}$ Anders als 2005 benennt das Europäische Parlament 2009 zwar kurz das »Unvermögen der internationalen Gemeinschaft «-in diesem Zusammenhang wird das Massaker euphemistisch als »Tragödie« bezeichnet $^{57}$-, bleibt an dieser Stelle hinsichtlich der eigenen Rolle allerdings vergleichsweise unkritisch, auch wird die Europäische Gemeinschaft nicht mehr erwähnt. ${ }^{58}$

\section{Bewertung internationaler Deutungsfestschreibungen}

Es sind bis heute die Hauptakteure um das Massaker von 1995 sowie die zivilgesellschaftlichen Vertreter der Opfergruppen, die das Gedenken an Srebrenica wachhalten.

54 Wie der 2002 eingerichtete »Tag zum Gedenken an den Holocaust und zur Verhütung von Verbrechen gegen die Menschlichkeit« am 27. Januar, den ebenfalls 2009 eingeführten europäischen Gedenktag an die Opfer von Nationalsozialismus und Kommunismus am 23. August.

55 Ebd., S. 2.

56 Ebd., S. 1.

57 Ebd.

58 Vgl. ausführlich einordnend H. Karge: »Nie wieder Srebrenica«, S. 136. 
Die Erinnerung der am peacekeeping beteiligten Akteure ist geprägt von dem Ringen um die Zuschreibung von Verantwortung für den Völkermord, nachdem Bemühungen, den Konflikt zu regeln und den Frieden zu sichern, das Massaker nicht verhindert hatten. Die Auseinandersetzung und Aufarbeitung wird durch das Einsetzen von Untersuchungskommissionen und das Veröffentlichen entsprechender Berichte deutlich. Während es den Akteuren dabei in erster Linie um eine Selbstreflexion der eigenen Rolle und des eigenen Versagens ging, hat das niederländische NIOD den Bosnienkrieg auch in seiner historischen Dimension untersucht. Mit zunehmendem zeitlichen Abstand scheint eine Art Vergessen oder Verdrängen der eigenen Position während des Bosnienkriegs und der Zeit des Massakers einzusetzen, die bei der Reaktualisierung nunmehr immer unkonkreter wird oder, wie im Fall des Europäischen Parlaments, gar nicht mehr auftaucht. Es ist zu vermuten, dass die eigene Position als Dritter in der Rückschau nicht (mehr) als relevant für die Konfliktdynamik erachtet wird und die Erinnerung an das eigene Versagen nicht zur Identität passt, die die Akteure gegenwärtig von sich konstruieren. Folglich werden die für die eigene Identität problematischen Erinnerungen mehr oder minder systematisch vergessen. Darüber hinaus stellen die internationalen Deklarationen Opfer und Täter beziehungsweise die Ideologien, die die Tat legitimierten, in das Zentrum ihrer Deutungsfestschreibungen.

Die internationalen Deutungsfestschreibungen rekurrieren auf die Akteure von 1995: muslimische Opfer auf bosnischem Territorium, bosnisch-serbische und serbische (para-)militärische Täter sowie eine versagende internationale Gemeinschaft. Mit der Benennung von bosnisch-serbischen, serbischen regulären und paramilitärischen Einheiten nehmen sie eindeutige Täterzuweisungen vor. Weitere Konkretisierungen von Tätern und Tat sind unterschiedlich, immer wird jedoch General Ratko Mladić erwähnt. Oftmals werden klare Wertungen vorgenommen, die an die justiziellen Strafbestände angelehnt sind. Mit dem Verweis auf Tausende oder konkreter 8000 muslimische Männer und Jungen sowie Gewaltverbrechen und Vertreibung der Zivilbevölkerung erfolgt eine komplementäre Opferzuschreibung. Die Opfer werden durchgängig als Zivilisten oder sogar, wie im Fall der amerikanischen Erklärungen, als unschuldig bezeichnet.

Synchrone Deutungskämpfe wurden im Laufe der Zeit von vornehmlich westlich dominierten Narrativen eingehegt und hegemonial festgeschrieben. Eine besondere Rolle spielt dabei die juristische Aufarbeitung durch das ICTY 
und andere Institutionen. ${ }^{59}$ Juristische Wertungen nehmen die gleiche Funktion ein, die die legitimatorische Geschichtsschreibung für andere Erinnerungstopoi erfüllt. Sie entscheiden über die »richtigen« Narrative von Verbrechen, indem sie vermittels des positiven Geltungsanspruchs der Justiz festlegen, was »wahr « ist. ${ }^{60}$ Zwar können internationale Gerichte wie das ICTY nationalistische Mythen über Verbrechen und Krieg dekonstruieren, allerdings urteilen sie in hochpolitisierten Kontexten. So stellt nationalistische Gegenmobilisierung die Legitimität des Gerichts an sich in Frage, wie das serbische Beispiel zeigt. Die komplexitätsreduzierenden, partiellen Darstellungen eines den universalistischen Menschenrechtsnormen verpflichteten Gerichts wie des ICTY kollidieren oftmals mit nationalen oder lokalen Darstellungen; Konflikte sind vorprogrammiert. Zudem bleiben die dichotomen Freund-Feind-Identitäten nach Konflikten durch die erneuten Zuweisungen der bipolaren Kategorien von schuldigen Tätern und unschuldigen Opfern erhalten.

Dies wird mit der Verwendung des Terminus Völkermord unterstützt, die sich noch vor dem Urteil des Internationalen Gerichtshofs als hegemoniale Deutung des Massakers durchgesetzt hat. Der Menschenrechtsdiskurs und das internationale Regime der transitional justice setzten mit Referenz auf die Rechtsprechung des ICTY, des Internationalen Strafgerichtshofs sowie der Genozidkonvention und der politischen Unterstützung der USA eine eindeutige Deutung hegemonial durch, mit welcher sich sowohl Opfergruppen, globale advocacy networks aus internationalen Organisationen und NGOs als auch Beteiligte der international community identifizieren können. Der Prozess der Inanspruchnahme war dabei ein zweiseitiger: Während die Bosniaken mit der Verwendung des Genozidbegriffes eine Anschlussfähigkeit ihres Anliegens und

59 Vgl. Wilson, Richard Ashby: »Judging History. The Historical Record of the International Criminal Tribunal for the Former Yugoslavia«, in: Human Rights Quarterly 27 (2005) 3, S. 908-942, oder breiter diskutiert in: ders.: Writing History in International Criminal Trial, Cambridge/New York: Cambridge University Press 2011. Zur Problematik von Historikern als Zeugen bei Gericht siehe Petrović, Vladimir: Historians as Expert Witnesses in the Age of Extremes, Dissertation, Budapest 2009.

60 Das Verhältnis von Recht und Narrativität ist mehrdimensional, es umfasst »the function and necessity of stories in actual court settings, the fictional and nonfictional representations of legal cases in popular culture, and the repercussion of stories about legal issues on the process of law«, Schwarz, Claudia: »Sentenced to >Storification<. A Trial on Legal Narratives«, in: Gudrun M. Grabher/Anna Gamber (Hg.): Legal Narratives. European Perspectives on U.S. Law in Cultural Context, Wien: Springer 2009, S. 213-238, hier S. 213. 
internationale Unterstützung beabsichtigten, war die internationale Gemeinschaft nach Srebrenica dankbar, diese Deutung aufzunehmen und für ihre Zwecke zu wenden. Der Anschluss an die Praktiken der Holocausterinnerung ist offensichtlich und hält seit den Paralellisierungen Anfang der 90er Jahre auch semantisch an. Eine Zweiteilung des diskursiven Raumes in sich dichotom gegenüberstehende Opfer- und Täterrollen ist dabei implizit.

Die eindeutige Zuweisung der Täter-Opfer-Relation vermied eine weitere Auseinandersetzung mit Fragen des Kontexts, der Schuld und Verantwortlichkeiten. Die Schuldfrage schien eindeutig geklärt. Der Internationale Gerichtshof entlastete zwar in seinem Urteil den serbischen Staat, da sich aber die internationale Position danach nicht änderte und serbische Opfer muslimischer Gewalt weiter eine Leerstelle bleiben, kann das serbische Narrativ, demzufolge die Serben von internationalen Akteuren oder dem Westen oder der EU kollektiv verurteilt und bestraft würden, weitergetragen werden. Die Konditionalisierung der Bereitstellung von Finanzhilfen, der Re-Integration in internationale Organisationen oder des EU-Integrationsprozess mit der Aufarbeitung der Vergangenheit befördern diese Deutung noch.

Auf internationaler Ebene umfassen die Vorstellungen der Aufarbeitung des Massakers von Srebrenica neben der Auseinandersetzung mit dem eigenen institutionellen Versagen immer die Strafverfolgung der Täter durch das ICTY und die Qualifizierung des Verbrechens als Genozid. Darüber hinaus wird eine Wiedergutmachung durch eine politische und finanzielle Unterstützung der Opfer sowie bei der Stabilisierung der Region signalisiert. Einzelne Mitglieder der parlamentarischen Versammlung des Europaparlaments fordern sogar eine Katharsis. Die internationalen Deklarationen dienen nicht nur der Positionierung gegenüber dem Kriegsverbrechen, sondern definieren gleichzeitig die gegenwärtigen Politiken der jeweiligen Staaten und Institutionen. Darin enthalten sind ihre monetäre und politische Unterstützung des ICTY, Versprechen eines institutionellen Lernens aus der Versagenserfahrung und die Unterstützung des Friedensund Stabilisierungsprozesses der Region. Zum Teil werden konkrete Politiken formuliert, wie im Fall der amerikanischen Deklarationen oder der Resolutionen des Europäischen Parlaments, in den meisten Fällen bleiben sie allerdings implizit. Das bedeutet nicht, dass die impliziten Botschaften weniger wirksam wären - wie exemplarisch die Ankündigung, dass der amerikanische Kongress eine Deklaration zur Verurteilung des Massakers von Srebrenica verabschieden würde, im politischen Diskurs Serbiens zeigte. Explizit sind die Verhaltenserwartungen in den Resolutionen des Europäischen Parlaments, die einem Kritierienkata$\log$ einer angemessenen europäischen Erinnerungspolitik nach massiven Menschenrechtsverbrechen entsprechen. Dieser umfasst eine staatliche Verurtei- 
lung von Kriegsverbrechen, die Strafverfolgung von Tätern, eine angemessene, opferzentrierte Gedenkpraxis durch Staatsoberhäupter, ein Verbot der Leugnung der Verbrechen oder einer Verherrlichung der Täter sowie die 2009 nachgelieferte Einführung eines europaweiten Gedenktags.

Gemeinsam bilden die Deklarationen und Deutungsfestschreibungen ein symbolisches transnationales Normregime, das ein hegemoniales Narrativ über die Deutung des Massakers von Srebrenica und des Bosnienkriegs sowie damit verbundene Verhaltenserwartungen umfasst. Dieses Normregime hat klare Grenzen. Da Relativierungen des muslimischen beziehungsweise internationalen Narrativs nicht toleriert und Kontextualisierungen schnell mit dem Vorwurf der "Srebrenica-Leugnung « disqualifiziert werden, mobilisiert eine diskursive Koalition für ein Gegennarrativ zu den internationalen Deutungsfestschreibungen. Die Vielzahl an proserbischen Publizisten, Wissenschaftlern und linken Intellektuellen sehen ihrerseits die Machtverhältnisse eines imperialistischen Westens der 90er Jahre fortgesetzt, der eine Zerschlagung Jugoslawiens aus ökonomischen und imperialistischen Gründen betreibe. Eine weitere Grenze scheint die Auseinandersetzung der internationalen Akteure mit dem eigenen Versagen über die bisherigen deklaratorischen Bekundungen hinaus zu sein. Den Forderungen nach Schadensersatz und Entschuldigungen wurde bislang kaum nachgekommen.

Auf Ebene der globalen und europäischen Politik erfüllt Srebrenica eine symbolische Integrationsfunktion. Durch die negative Erinnerung an den Völkermord wird die Zugehörigkeit zu einer politischen Gemeinschaft ausgedrückt, die mit Bezug auf universelle Normen wie den Menschenrechtsdiskurs und die Genozidkonvention eine besondere moralische Legitimität aufweist. Auf globaler Ebene ist Srebrenica Teil einer variierenden Diskurskoalition, die eine Wiederholung dieser Gräuel in einem drohenden neuen Völkermord suggeriert, wenn keine Intervention erfolge. Schon in den ersten Monaten des Bosnienkrieges stellten amerikanisch-jüdische Lobbyorganisationen eine Analogie zum Holocaust auf. ${ }^{61}$ Gerade das Ausbleiben eines angemessenen Eingreifens zum Schutz der bosnischen Bevölkerung, das Versagen, wird zur Grundlage einer neuen Identität. Aus dem »stain on our collective conscience ${ }^{62}{ }^{2}$ wird eine neue Haltung abgeleitet, die eine Anteilnahme an entfernten Konflikten und einen

61 Vgl. D. Levy/N. Sznaider: Erinnerung im globalen Zeitalter, S. 184-190.

62 Der amerikanische Präsident Barack Obama bei einer Rede an der Universität Kairo in Bezug auf die Konflikte in Bosnien und Darfur, vgl. Obama, Barack: Remarks by the President at Cairo University, Pressemitteilung vom 6.4.2009, http://www.white house.gov/the-press-office/remarks-president-cairo-university-6-04-09 vom 13.5.2013. 
außenpolitischen Imperativ suggeriert. Die Verknüpfung von Srebrenica mit dem Holocaust fiel insbesondere in Europa und vor allem in Deutschland auf fruchtbaren Boden. Erstmals machten Außenminister Joschka Fischer und Verteidigungsminister Rudolf Scharping die Analogie von Srebrenica und Auschwitz während der Debatte über den Auslandseinsatz der Bundeswehr 1999 im Kosovokrieg prominent. ${ }^{63}$ Seitdem wird die Diskurskoalition Srebrenica - Holocaust zunehmend relevant und erfüllt durch ihre normative Aufladung eine wirkmächtige Legitimationsfunktion, um in der öffentlichen Meinung westlicher Gesellschaften Unterstützung für militärische Interventionen in (Bürger-)Kriegen aus humanitären Gründen zu generieren. ${ }^{64}$

Darüber hinaus wurde Srebrenica als negative, gesamteuropäische Erinnerung institutionalisiert. Die Deutung, derzufolge Srebrenica das größte Verbrechen in Europa seit Ende des Zweiten Weltkriegs sei, verweist sowohl auf die Zugehörigkeit zu Europa als auch in einem zweiten Schritt auf das Versagen der internationalen und europäischen Außen- und Sicherheitspolitik. Die Lesart von Srebrenica als negative gesamteuropäische Erinnerung wird sowohl im öffentlichen Mediendiskurs sowie in den symbolischen Gedenkakten der EU fortgesetzt und jährlich reaktualisiert als auch von zukünftigen Mitgliedsstaaten explizit erwartet.

\subsection{DekLarationen Serbischer AKteure 2005-2010}

Die serbische Deutung von Srebrenica hat ganz andere Referenzpunkte als die internationale, sie ist vor allem diachron angelegt. Schon im Zweiten Weltkrieg war die Region rund um Srebrenica Schauplatz zahlreicher Auseinandersetzungen zwischen der lokalen muslimischen und serbischen Bevölkerung gewesen. Angehörige der von Kroaten dominierten, aber auch bosnische und albanische Muslime umfassenden Ustaše und serbische Četnici hatten die jeweils andere Gruppe und ihre Dörfer im Zeitraum von 1941 bis 1943 überfallen und massakriert. ${ }^{65}$ In der serbischen Bevölkerung wurden diese Erinnerungen und Erfah-

63 Vgl. den Wandel der deutschen Rhetorik ausführlich bei M. Schwab-Trapp, Kriegsdiskurse.

64 Beispielhaft ist die Forderung nach einer Intervention in Syrien zur Verhinderung eines Massakers in Homs, vgl. Suljagić, Emir/Bajrović, Reuf: »Keine Schutzzone ohne Schutz«, in: Zeit online vom 2.3.2012, http://www.zeit.de/2012/10/P-opedSuljagic vom 2.3.2012.

65 G. Duijzings: »Commemorating Srebrenica«. 
rungen reaktualisiert: von den lokalen wie den überregionalen Medien, vor allem aber durch die seit 1992 regelmäßig verübten Überfälle von muslimischen Truppen unter Führung von Naser Orić, dem militärischen Kommandanten der Enklave Srebrenica. Schon seit den 1980ern wurden Interpretationen im serbischen Medien- und Wissenschaftsdiskurs populär, die Gegenwart durch die historische Erfahrung - vor allem des Zweiten Weltkriegs - nationalistisch zu deuten. ${ }^{66} \mathrm{Im}$ Kontext des sogenannten Genoziddiskurses, in dem man sich mit den Kroaten um Schuld, Verantwortung und die Höhe der Opferzahl im Zweiten Weltkrieg stritt, wurde der Eindruck erweckt, dass die Serben schon seit der Schlacht auf dem Amselfeld Opfer genozidaler Politik anderer politischer Mächte gewesen seien: der Türken, der Österreicher, der Deutschen und der mit ihnen kollaborierenden Kroaten und Muslime sowie des Vatikans. In diesem Kontext wurde auch die Politik innerhalb Jugoslawiens und dessen Zerfall gedeutet.

\section{Resolutionsvorschläge 2005}

In ihrem Entwurf »Deklaration über die Verpflichtungen des Staates Serbien, alle Maßnahmen zu ergreifen, um die Rechte der Opfer von Kriegsverbrechen zu schützen, besonders der Opfer des Völkermords in Srebrenica ${ }^{67}$, forderten die Frauen in Schwarz, das Zentrum für Regionalismus, das Helsinki-Komitee für Menschenrechte, das Anwaltskomitee für Menschenrechte und der Fonds für Völkerrecht, dass Serbien die eingegangen internationalen Verträge zu Menschenrechten erfülle und die Normen in der eigenen Verfassung einhalte sowie seine Politik ihnen angemessen ausgestalte. Im Zentrum steht Srebrenica, das konsequent als Völkermord oder als Verbrechen qualifiziert wird. Weder Täter noch Opfer werden näher spezifiziert, lediglich Mladić konkret benannt. Immer wieder wird Bezug genommen auf die internationalen vertraglichen Verpflich-

66 Vgl. T. Sindbæk: Usable History?; Hayden, Robert M.: »Recounting the Dead: The Rediscovery and Redefinition of Wartime Massacres in Late- and Post-Communist Yugoslavia«, in: Rubie S. Watson (Hg.): Memory, History and Opposition under State Socialism, Santa Fe/New Mexico: School of American Research Press 1994, S. 167-184.

67 Vgl. bis zum Ende des Absatzes: ljudska prava: »Deklaracija o obavezama države Srbije da preduzme sve mere zaštite prava žrtava ratnih zločina, a posebno žrtava genocida u Srebrenici« [Deklaration über die Pflichten des Landes Serbiens alle Maßnahmen zu ergreifen zum Schutz der Opfer von Kriegsverbrechen, insbesondere der Opfer des Genozids in Srebrenica], in: Peščanik.net vom 31.5.2005, http://pescanik. net/predlog-teksta-deklaracije-o-srebrenici/ vom 21.6.2015. 
tungen Serbiens, die es einzuhalten gelte. Zu Beginn geht die Resolution auf die Völkermordkonvention sowie auf die Verpflichtungen als Mitglied der UN, in der Kooperation mit dem ICTY und im Rahmen des Prozesses der Annäherung an die EU ein. Weiterhin werden im Einzelnen die Regelungen im Internationalen Pakt über bürgerliche und politische Rechte der UN, die Europäische Konvention zum Schutz der Menschenrechte und der bürgerlichen Grundrechte, die Verfassung Serbien-Montenegros, die Charter über Menschen- und Minderheitenrechte und das Gesetz über nationale Minderheiten in Serbien und Montenegro genannt. Konkrete Maßnahmen für eine echte Aufarbeitung, die mit einem fundamentalen Wertewandel einhergehen solle, werden beschrieben. Demnach sollen alle ideologischen Rechtfertigungen für Verbrechen aufgedeckt und bestraft sowie die gefällten juristischen Urteile in Bezug auf das Massaker von Srebrenica respektiert werden. Besonders würdigt der Text den Schutz und die Rechte der Opfer und ihrer Angehörigen. So solle das Eingeständnis, dass das Verbrechen in »unserem Namen « begangen wurde, an Opfer und deren Angehörige klar kommuniziert werden, um sich mit diesem »legitimen und moralischen Handeln« von dem Verbrechen zu distanzieren: »Die Opfer haben ein Recht darauf und erwarten das von uns. $\ll^{68}$

Die SPO verfasste eine sehr emotionale »Deklaration anlässlich des 10. Jahrestages des Kriegsverbrechens in Srebrenica « ${ }^{69}$, in der sie das während des Bosnienkriegs begangene Verbrechen verurteilte. Den Schmerz der Angehörigen teilend, bat sie diese darum,

»in ihren Herzen einen Unterschied zu machen zwischen den Henkern und dem serbischen Volk, das so oft im 20. Jahrhundert, in zwei Weltkriegen, und vor allem im Zweiten, das Opfer von Unvernunft wurde. Wir bitten auch die Familien und Landsleute der in Srebrenica Getöteten anzuerkennen, dass die, die töteten und das Verbrechen begingen, nicht die Serben und nicht Serbien vertreten, sondern eine vom Volk entfremdete Ordnung des Terrors und des Unglücks, welcher die Serben und Serbien kräftigen Widerstand leisteten und und wofür sie den höchsten Preis zahlten. Die Mehrheit Serbiens trug einen schwarzen Trauerflor für Srebrenica und für Sarajevo und für jedes unschuldige Opfer, wo auch immer auf dem Gebiet des ehemaligen Jugoslawien, während es [Serbien, D. M.], am Willen des serbischen Volkes vorbei, in Blut ermordet wurde.«

68 Ebd.

69 Vgl. bis zum Ende des Absatzes SPO: Deklaracija povodom desete godišnjice ratnog zločina u Srebrenici [Deklaration anlässlich des 10. Jahrestags des Verbrechens in Srebrenica], Beograd 2005: SPO. 
Als Täter werden sowohl als »Henker« die direkt Handelnden als auch die indirekt Agierenden benannt, die die Verbrechen organisiert und befohlen haben. Sie seien keine Helden. Da das Verbrechen durch "serbische Hand und Waffen «wenn auch am Willen des serbischen Volks vorbei - begangen worden sei, sei es auch ein Verbrechen am serbischen Volk, welches so oft im 20. Jahrhundert Opfer gewesen sei. Die SPO forderte, einen Unterschied zwischen den Henkern und dem serbischen Volk zu machen. Gleichzeitig verurteilte sie das Massaker, drückte ihr Mitgefühl aus und forderte eine Verfolgung der Täter - nicht ohne unerwähnt zu lassen, dass es viele solcher »Srebrenicas« am serbischen Volk gegeben habe.

Die DSS verurteilte in ihrer »Deklaration $«{ }^{70}$ alle Verbrechen, die in der neuesten Geschichte Jugoslawiens begangen worden sind. Darunter fasst sie insbesondere Massenkriegsverbrechen und "gemeinschaftliches Unglück» während des Bürgerkriegs in den 1990er Jahren, in welchem das serbische Volk das größte Opfer gewesen sei. Sie betont, dass die Täter Einzelne seien und Vor- und Nachnamen hätten. Auch die unschuldigen Opfer hätten Vor- und Nachnamen gehabt. Sie fordern eine Aufklärung und Bestrafung aller nichtaufgeklärten Verbrechen, sowohl der in den 90er Jahren verübten als auch derjenigen, die zu den Massengräbern und Richtstätten des Zweiten Weltkriegs geführt haben. Zur Erforschung der Wahrheit wird eine unabhängige Institution gefordert. Alle Verbrechen, zwischen denen man keinen Unterschied machen dürfe, müssten verurteilt werden - für die Zukunft, Würde und Selbstachtung der Bürger Serbiens. Als Ziel wird kollektive Heilung angestrebt. Die Deklaration scheint widersprüchlich, da die DSS einerseits eine universale Anwendung von Werten wie Wahrheit und der Verurteilung aller Verbrechen proklamiert und damit eine Gleichheit aller Verbrechen suggeriert, aber gleichzeitig betont, dass die Serben die größeren Opfer seien.

Die SRS wiederum verurteilt in ihrem Vorschlag ebenfalls jedes Verbrechen, das während des Kriegsgeschehens auf dem Territorium des ehemaligen Jugoslawien begangen wurde. ${ }^{71}$ Zwar zeige sie sich »überzeugt davon, dass im Krieg Verbrechen vorbei am Wissen und dem Einfluss des Staates Serbien und seiner

70 Vgl. bis zum Ende des Absatzes DSS: Deklaracija o osudi ratnih zločina na prostoru nekadašnje Jugoslavije [Deklaration über die Verurteilung der Kriegsverbrechen auf dem Gebiet des ehemaligen Jugoslawien], Belgrad: DSS 2005.

71 Vgl. bis zum Ende des Absatzes o. V.: »Poigravanje sa zločinima. Svaka stranka pravi svoju deklaraciju o osudi ratnih zločina« [Herumtanzen mit den Verbrechen. Jede Partei macht ihre eigene Erklärung über die Verurteilung von Kriegsverbrechen], in: Blic vom 16.6.2005, S. 2. 
Bürger begangen wurden«, eine Verantwortung des Staates oder die kollektive Schuld seiner Bürger für die im Krieg begangenen Straftaten hingegen lehnt sie ab. Anhand der Vergehen auf dem Gebiet Bratunac, Srebrenica, der serbischen Republik Krajina und Klečka, an denen mit Ausnahme von Srebrenica Taten gegen Serben begangen wurden, verurteilt die SRS Verbrechen gegen die Zivilbevölkerung. Zwar wird hier eine allgemeine Verurteilung signalisiert, durch die Aufzählung von Ortsnamen wird aber eine selektive Wahrnehmung deutlich. Weiterhin verlangt die SRS von den anderen Staaten in der Region eine Verurteilung und weist darauf hin, dass alle Kriegsparteien Verbrechen begangen haben.

Die DS hält ihren Vorschlag sehr knapp. Sie verurteilt alle Verbrechen, die während des Kriegsgeschehens auf dem Territorium des ehemaligen Jugoslawien begangen wurden, und gedenkt deren Opfer und »namentlich das an den Angehörigen des bosniakischen Volks begangene Kriegsverbrechen im Bezirk Srebrenica $\aleph^{72}$.

Parlamentspräsident Predrag Marković versuchte mit einem weiteren Deklarationsvorschlag zwischen den verschiedenen Fraktionen zu vermitteln. In ihm sollten alle Verbrechen verurteilt werden, die während der kriegerischen Ereignisse auf dem Territorium Jugoslawiens begangen wurden, die Marković weiter beschreibt:

»Während und nach dem Zerfall der SFRJ [sozialistisch-föderative Republik Jugoslawien, D. M.], durch die Nichtbeachtung der Grundsätze der Rechtsstaatlichkeit, gegen das Gesetz und versteckt vor der kompletten Öffentlichkeit, wurden individuelle und organisierte Übeltaten begangen. $\ll^{73}$

In seinem Vorschlag wird die Untersuchung von Rechtsbrüchen durch serbische Behörden zugesichert. Besonders Verbrechen gegen Zivilisten wie in Srebrenica und Bratunac dürften nicht nur im Rahmen von Gedenkfeiern Gegenstand der Aufarbeitung sein.

Die Erklärung des Ministerrats, die statt einer parlamentarischen Resolution erfolgte, verurteilte das Verbrechen in Srebrenica auf das Schärfste. Jede Verteidigung eines Verbrechens sei auch ein Verbrechen, und Serbien und Montenegro vergebe und vergesse kein Verbrechen. Außerdem fühle der Ministerrat mit dem

\section{Ebd.}

73 O. V.: »Zločin ne sme biti zaboravljen.« [Verbrechen darf nicht vergessen werden], in: Blic vom 11.6.2005, S. 2. 
Schmerz der Familien der Opfer. Weiterhin forderte er eine Differenzierung und bat auch die Angehörigen der Opfer,

»in ihren Herzen einen Unterschied zu machen zwischen den Verbrechern auf der einen und den Völkern Serbiens und Montengros auf der anderen Seite. Die, die in Srebrenica gemordet haben, und die, die dieses Massaker befohlen und organisiert haben, repräsentieren nicht Serbien und nicht Montenegro, sondern ein undemokratisches Regime des Terrors und des Todes, dem die große Mehrheit der Bürger Serbiens und Montenegros den stärksten Widerstand geboten hat $\aleph^{74}$.

Für die Staatenunion sei Srebrenica ein großes Verbrechen an der Geschichte, Tradition und Kultur des serbischen und montenegrinischen Volks wie auch an all ihren Opfern in den früheren Kriegen auf dem Gebiet des ehemaligen Jugoslawien und in zwei Weltkriegen. Man dürfe nicht ein Verbrechen vergessen, ungeachtet, wer die Verbrecher und wer die Opfer seien. ${ }^{75}$

\section{Resolutionsvorschlag 2007}

Anlässlich des Urteils des Internationalen Gerichtshofs 2007 reichte die LDP einen neuen Resolutionsvorschlag ein. In dieser »Erklärung über die Verpflichtungen der staatlichen Organe der Republik Serbien zur Erfüllung der Entscheidung des Internationalen Gerichtshofs $«{ }^{76}$ wird das Massaker von Srebrenica konsequent als Genozid qualifiziert. Im Deklarationsentwurf wird auf zahlreiche internationale Abkommen und Institutionen verwiesen, denen gegenüber sich Serbien verpflichtet hat. Serbien solle die Verantwortung seiner Staatsorgane und vor allem von Ratko Mladić für die Verletzung der Völkermordkonvention anerkennen, wie es das Urteil des Internationalen Gerichtshofs bestätigt habe. Damit sei auch die Festnahme aller vom ICTY Angeklagten verbunden. Da es nicht möglich sei,

74 R. D./M.T.: »Odbrana zločina je takođe zločin« [Die Verteidigung des Verbrechens ist auch ein Verbrechen], in: Danas vom 16.6.2005, S. 1.

75 Ebd.

76 Vgl. bis zum Ende des Absatzes o. V.: »Inicijative koalicije oko LDP. Predlog Deklaracije o genocidu u Srebrenici« [Initiative der Koalition um die LDP. Vorschlag einer Deklaration über den Völkermord in Srebrenica], in: Helsinška povelja 12 (2007) 103/104, S. 47. 
»eine demokratische, offene und gerechte Gesellschaft in Serbien zu schaffen, ohne die Verbrechen in der Vergangenheit aufzuarbeiten, einschließlich und besonders des auf dem Gebiet der geschützten Enklave Srebrenica begangenen Völkermords « ${ }^{77}$,

werden weitergehende Maßnahmen gefordert. Jede Glorifizierung, Rechtfertigung oder Relativierung des Völkermords und aller anderen Verletzungen des internationalen Rechts stellten Verbrechen dar und bedrohten die verfassungsmäßige Ordnung, die Gegenwart und Zukunft Serbiens. Die Menschenrechte anzuerkennen und Verantwortung dafür zu übernehmen impliziere auch, die Opfer zu achten und alle erforderlichen Maßnahmen zu ergreifen, um dem Recht auf Wahrheit, Gerechtigkeit und symbolische Reparationen nachzukommen und zu garantieren, dass sich die Verbrechen aus der Vergangenheit nicht wiederholen werden. Verbrechen zu vergessen und die Ideen $\mathrm{zu}$ rehabilitieren, die Verbrechen und ihre Täter rechtfertigen, stellten neue Verbrechen dar, die nicht akzeptiert werden dürften und unter Strafe gestellt werden müssten. Zudem erfordere die Notwendigkeit der Aufarbeitung der Vergangenheit ein System von Institutionen, Mechanismen und Prozessen. In einem weiteren Absatz wendet sich die Resolution mit einer aufrichtigen Entschuldigung und tiefstem Beileid an alle Opfer und ihre Angehören von Verbrechen, die »in unserem Namen begangen wurden ${ }^{78}$. Srebrenica wird hier besonders herausgestellt. Darüber hinaus verpflichte sich Serbien, eine Außenpolitik der gutnachbarlichen Beziehungen und der territorialen Integrität von Bosnien-Herzegowina zu betreiben. Zudem sichere die Republik Serbien zu, alle Normen zu achten, die sich aus der Völkermordkonvention ergeben, jede Anstiftung zu nationalem, rassistischem und religiösem Hass und Kriegspropaganda $\mathrm{zu}$ ahnden und $\mathrm{zu}$ bestrafen sowie jeden Versuch klar zu verurteilen, der Verbrechen relativiere, »die in unserem Namen während des Krieges in Bosnien und Herzegowina begangen wurden - insbesondere in der geschützten Enklave Srebrenica « ${ }^{79}$. Der Resolution gemäß solle Serbien umgehend ein Gesetz einführen, das Rechenschaft für die Verletzung von Menschenrechten abverlangt und es Personen verbietet, öffentliche Aufgaben wahrzunehnen, wenn sie für massive Menschenrechtsverletzungen während des Kriegs im ehemaligen Jugoslawien verantwortlich sind. Das Justizsystem solle gestärkt werden, um Straftaten zu ahnden, die Elemente des Völkermords, von Menschenrechtsverletzungen, der Anstiftung zu nationalem, rassistischem und religiösem Hass und Intoleranz der Kriegspropaganda aufweisen oder die zu

$\begin{array}{ll}77 & \text { Vgl. ebd. } \\ 78 & \text { Vgl. ebd. } \\ 79 & \text { Vgl. ebd. }\end{array}$


einem Angriffskrieg aufrufen. Ein politischer und öffentlicher Dialog müsse geschaffen werden, der es nachhaltig verunmögliche, Verbrechen zu rechtfertigen. Dass Verbrechen zu verurteilen sind, solle sich auch im Bildungssystem niederschlagen. Die internationalen moralischen Normen sollten in Zukunft die Grundlage staatlichen Handelns bilden. ${ }^{80}$

Die LSV und der Savez Vojvodjanskih Mađara (Rat der Ungarn der Vojvodina, SVM) schlugen eine gemeinsame Deklaration ${ }^{81}$ zu Srebrenica vor, in der sie betonen, dass das Massaker nicht nur ein auf dem Territorium des früheren Jugoslawien begangenes Kriegsverbrechen sei, sondern das umfassendste, das nach dem Zweiten Weltkrieg in Europa verübt worden sei. In Referenz auf den Internationalen Gerichtshof wird von Völkermord gesprochen. Die Opfer werden als Bosniaken bezeichnet, als wichtiges Attribut wird angeführt, dass sie unbewaffnet gewesen seien. Es wird auf die Schuld der unmittelbaren Täter verwiesen und gleichzeitig betont, dass man auch diejenigen berücksichtigen müsse, die das Verbrechen »anzettelten, genehmigten oder vertuschten «, weiterhin wird deutlich formuliert, dass in die »Vorbereitung, Durchführung und das Verleugnen des Verbrechens in Srebrenica [...] Einzelne mit hohen Funktionen in der Republik Serbien und in den Staatsapparaten der Republik Serbien aktiv involviert « waren. ${ }^{82}$

In der Deklaration wird konstatiert, dass die Beziehung zu Srebrenica die Zukunft des Landes und der kommenden Generationen bestimmen wird und ein klares Bekenntnis zum Urteil des Internationalen Gerichtshofs sowie die Verurteilung des Verbrechens notwendig seien. Die Fraktion fordert, aus dem Leiden der Opfer und ihrer Angehörigen zu lernen, und spricht sich gegen jede Relativierung, Ethnonationalismus und Kriegstreiberei aus. Weiterhin werden weitgehende Maßnahmen für eine gesellschaftliche Aufarbeitung angekündigt, inklusive einer Anpassung von Lehrplänen und Schulbüchern an das Urteil des Internationalen Gerichtshofs.

Nach der vom europäischen Parlament verabschiedeten Resolution, die den 11. Juli zum europaweiten Gedenktag an den Völkermord in Srebrenica einführte, brachte die SDU im Vorlauf des Jahrestags des Massakers von Srebrenica 2009 noch einmal die Deklaration der NGOs von 2005 ins Gespräch. Dieser Initiative wurde allerdings kaum Aufmerksamkeit zuteil, da sie keinerlei politische Unterstützung bei den einflussreicheren Parteien fand. ${ }^{83}$

80 Vgl. ebd.

81 N. Čanak: »Antiratni aktivisti«, die Deklaration wurde im Volltext neben dem Artikel abgedruckt.

82 Ebd.

83 SDU: Deklaracija o obavezama. 


\section{Resolutionsvorschläge 2010}

Bereits nach wenigen Wochen Debatte über eine Resolution zu Srebrenica brachte die DSS den Resolutionsvorschlag erneut ein, den sie bereits 2005 vorgeschlagenen hatte. Die Jugendorganisation der Partei organisierte eine Kampagne unter dem Titel »Srebrenica - Nicht in meinem Namen«, zu der auch ein Youtube-Video gehörte. ${ }^{84}$

Erst drei Tage vor der Sitzung des Parlaments veröffentlichte die Regierungskoalition ihren Resolutionsvorschlag. Darin verurteilte sie das Verbrechen an der bosnischen Bevölkerung und weiterhin

»alle gesellschaftlichen und politischen Prozesse und Erscheinungen, die zur Bildung eines Bewusstseins geführt haben, in welchem man eigene nationale Ziele mit Waffengewalt und physischer Gewalt gegen Angehörige anderer Völker und Religionen verwirklichen könne« ${ }^{85}$.

In ihrem Vorschlag wurde die Zusammenarbeit der serbischen Behörden bei der Untersuchung der Ereignisse und bei der Suche nach Ratko Mladić zugesagt. Zwar wird auf das Urteil des Internationalen Gerichtshofs referiert, trotzdem wurde der Terminus »Völkermord« nicht erwähnt. Um dem Bedürfnis nach Anerkennung der serbischen Opfer nachzukommen, wird die Erwartung ausgedrückt, dass auch die anderen Länder in der Region die Verbrechen an der serbischen Bevölkerung verurteilen.

Die Liberaldemokraten formulierten als Reaktion auf den Vorschlag der Regierungskoalition Ergänzungen wie eine Referenz auf das Urteil des Internationalen Gerichtshofs, in dem die Verbrechen in Srebrenica als Genozid qualifiziert werden, sowie die Einführung des 11. Julis als Gedenktag, die Anführung der Verbrechen, für die Ratko Mladić angeklagt wird, die Garantie der Rechte und

84 DSS Omladina (Hg.): »Srebrenica - Ne u moje ime« [Srebrenica - Nicht in meinem Namen], http://www.youtube.com/watch?v=pCIMTdn-DjM vom 28.4.2013.

85 Volksversammlung der Republik Serbien: Deklaracija Narodne Skupštine Republike Srbije o osudi zločina u Srebrenici [Deklaration der Volksversammlung der Republik Serbien über die Verurteilung des Verbrechens in Srebrenica] vom 31.3.2010, http:// www.parlament.gov.rs/upload/archive/files/lat/pdf/ostala_akta/2010/Rs31-10Lat.zip vom 28.4.2013. 
des Status der Republika Srpska und die Würdigung aller Opfer von Gewalt während der Kriege im ehemaligen Jugoslawien. ${ }^{86}$

Am Tag der Debatte brachte die Fortschrittspartei ihrerseits einen Vorschlag ein. Darin werden nachdrücklich

»alle im Bürgerkrieg im ehemaligen Jugoslawien begangenen Verbrechen, Verbrechen gegen das serbische Volk und die von Angehörigen des serbischen Volkes begangenen Verbrechen gegen Angehörige anderer Nationen, insbesondere das Verbrechen, das gegen die bosniakische Bevölkerung von Srebrenica im Juli 1995 begangen wurde « ${ }^{87}$,

verurteilt. Interessant ist hier die Reihenfolge der Auflistung: »alle - serbische bosniakische«, die eine klare Priorisierung und damit eine Ungleichheit von Opfern ausdrückt. Es folgt das Eingeständnis, dass Serbien und die internationale Gemeinschaft dem Urteil des Internationalen Gerichtshofs gemäß bei besserer Zusammenarbeit »diese Tragödie« hätte verhindern oder ihr Ausmaß deutlich reduzieren können. Die Fortschrittspartei fordert eine konsequente innerstaatliche Strafverfolgung und ein Ende der Prozesse vor dem ICTY. Angestrebt werden Versöhnung und das Fortsetzen des Zusammenlebens in der Region auf Basis der Menschenrechte. Die Verurteilung von Verbrechen durch andere Staaten der Region wird erwartet.

\section{Deklaration für die serbischen Opfer 2010}

In der Resolution zur »Verurteilung der an den Angehörigen des serbischen Volkes begangenen Verbrechen« ist allgemein von Verbrechen gegen Angehörige des serbischen Volkes und Bürger Serbiens während des »brutalen bewaffneten

86 LDP: Amandmani LDP na deklaraciju o Srebrenici. Izjava predsednika Liberalnodemokratske partije Čedomira Jovanovića [Ergänzungen der LDP zur Erklärung über Srebrenica. Äußerungen des Präsidenten der liberaldemokratischen Partei Čedomir Jovanović], Pressemitteilung vom 28.3.2010, http://istina.ldp.rs/Vesti/12752/ Amandmani-LDP-na-deklaraciju-o-Srebrenici.shtml vom 8.8.2014.

87 Vgl. bis zum Ende des Absatzes Nikolić, Tomislav: Predlog Deklaracije Narodne Skupštine Republike Srbije o osudi svih zločina učinjenih u građanskom ratu u bivšoj Jugoslaviji i posebno zločina u Srebrenici. Predlog poslanike SNS-a [Vorschlag einer Erklärung der Nationalversammlung der Republik Serbien über die Verurteilung aller im Bürgerkrieg im ehemaligen Jugoslawien verübten Verbrechen und besonders des Verbrechens in Srebrenica] vom 30.3.2010, Belgrad: Narodna Skupština Republike Srbije 2010. 
Konflikts $\aleph^{88}$ die Rede, konkreter werden im weiteren Wortlaut die an den Serben und Bürgern Serbiens begangenen Verbrechen in Kroatien, Bosnien und Herzegowina sowie des Kosovo verurteilt. Die Täter werden nicht im Einzelnen benannt. Zentral in der Resolution sind Strafverfolgung, Wahrheit, Versöhnung sowie die Gleichbehandlung aller Täter und Opfer. Für innenpolitische Konflikte sorgten die fehlende Erwähnung des EU-Mitglieds Slowenien und der Umstand, dass die Deklaration die Bombardierung Serbiens durch die NATO 1999 aus außenpolitischer Rücksichtnahme nicht verurteilte. Stattdessen wurde eine schwächere Formulierung gewählt, die lediglich »Bedauern und Solidarität« mit den Opfern der Bombardierung zum Ausdruck brachte. Die Opposition warf der Regierungskoalition vor, dass dies einer Amnestierung der NATO gleichkäme, und unterstützte die Deklaration nicht. ${ }^{89}$

Die Deklaration für die serbischen Opfer wurde international kaum thematisiert. Sie diente in erster Linie dazu, sich mit den Gegnern der SrebrenicaResolution und denjenigen im Land auszusöhnen, die sich mit der SrebrenicaDeklaration als »Tätervolk« verunglimpft sahen. Sie war aber nicht weitreichend genug, um wirklich integrativ zu wirken und den Vertretern des "patriotischen" Opferdiskurses nachhaltig ihr Mobilisierungspotential zu nehmen. Eine Integration gelingt nun erst den »Patrioten«, die seit 2012 an der Macht sind und die serbischen Themen diplomatisch, aber ohne Umschweife auch vor die internationalen Organisationen tragen. Ihr Ansatz des Umgangs mit Kriegsverbrechen beinhaltet allerdings auch, von Serben begangene Kriegsverbrechen zu relativieren und zu rechtfertigen.

\section{Analyse und Vergleich serbischer Deklarationen}

Augenscheinlich ist bei der Analyse der serbischen Deklarationsvorschläge, dass der Gegenstand der Resolutionsentwürfe in unterschiedlicher Weise spezifisch

88 Vgl. bis zum Ende des Absatzes Volksversammlung der Republik Serbien: Deklaracija Narodne Skupštine Republike Srbije o osudi zločina učinjenih.

89 Volksversammlung der Republik Serbien: Stenografske beleške. Druga sednica Drugog redovnog zasedanja. Predlog deklaracije Narodne Skupštine Republike Srbije o osudi zločina učinjenih nad pripadnicima srpskog naroda i građanima Srbije [Stenografisches Protokoll. Zweite Sitzung der zweiten regulären Periode. Vorschlag einer Erklärung der Volksversammlung der Republik Serbien über die Verurteilung der an den Angehörigen des serbischen Volkes und den Bürgern Serbiens begangenen Verbrechen] vom 14.10.2010, Belgrad: Narodna Skupština Republike Srbije 2010. 
ist: So wird im serbischen Fall mal nur das Massaker von Srebrenica verurteilt, mal alle Verbrechen - zum Teil noch mit der Einschränkung »gegen die Zivilbevölkerung«. Zudem fällt die große Varianz in den Zuweisungen der Kategorien Verbrechen, Täter, Opfer und der Versöhnungskonzepte ins Auge, die sich teilweise gegenseitig auszuschließen scheinen. Sogar die Frage, wie die Jugoslawienkriege der 90er zu benennen sind, scheint weiterhin umstritten. 2005 benutzten alle Fraktionen technische Formulierungen wie während »des Kriegsgeschehens im Raum des früheren Jugoslawien« oder »Verbrechen, die auf dem Territorium der früheren sozialistisch-förderativen Republik Jugoslawien« begangen wurden. Es wurde vermieden, den Krieg darüber hinaus zu charakterisieren oder zu qualifizieren. In den Folgejahren ist in den unterschiedlichen Deutungen von Bürgerkrieg, Kriegsgeschehen, einem brutalen bewaffneten Konflikt oder den bewaffneten Konflikten auf dem Territorium der früheren sozialistisch-föderativen Republik Jugoslawien die Rede. Srebrenica wird als Verbrechen, Massaker, Völkermord und »das umfassendste Kriegsverbrechen, das seit dem Zweiten Weltkrieg auf europäischem Boden verübt wurde $\ll^{90}$, bezeichnet. Die NGOs, die Liberaldemokraten und die Abgeordneten aus der Vojvodina benutzen sogar die Qualifizierung Völkermord, letztere erweitern den Fokus sogar auf»Verbrechen, die in unserem Namen während des Krieges in Bosnien und Herzegowina begangen wurden ${ }^{91}$. Darüber hinaus erfolgt, anders als in den internationalen Deklarationen, die eine konkretere Situationsbeschreibung vornehmen, keine nähere Darstellung des Verbrechens.

Bei den Opferzuweisungen ist mal von bosnischen oder bosniakischen, mal von unbewaffneten oder gefangenen und zivilen Bosniern und teilweise auch von Serben die Rede. Diese Varianz deutet auf zwei Umstände hin: Erstens ist für die meisten Serben noch nicht endgültig geklärt, ob alle in Srebrenica Ermordeten Zivilisten waren; zweitens ist für viele nicht nachvollziehbar, warum man dem Massaker von Srebrenica eine Sonderstellung verleihen soll, indem man es mit einer gesonderten Deklaration verurteilt. Die Sonderstellung, die dem Massaker von bosniakischen und den internationalen Narrativen zugeschrieben wird, wird nicht geteilt. Dieser Konflikt erinnert, wenn auch natürlich auf einer anderen Ebene angesiedelt, an die Auseinandersetzungen während des Historikerstreits in Deutschland, als die Vergleichbarkeit von Verbrechen und die Singularität des Holocaust diskutiert wurden.

Anders als bei den internationalen Resolutionen findet sich in den serbischen Deklarationen und Entwürfen nur selten eine konkrete Benennung von Tätern.

90 N. Čanak: »Antiratni aktivisti«.

91 Ebd., Herv. D. M. 
Während öfters Ratko Mladić als Kommandoführer angeführt wird, wird die aktive Rolle von serbischen staatlichen Institutionen lediglich von der LDP und der LSV/SVM erwähnt. Interessant sind die Erklärungsversuche und Beschreibungen für die Prozesse in Serbien und der Region in den 90er Jahren. Die NGOs bezeichnen diese als »Politik des Verbrechens « $^{92}$, die LSV/SVM als »Ethnonationalismus, Kriegstreiberei und blinde[n], unkritische[n] Patriotismus « sowie als »Wahnsinn des Krieges, die ethnonationalistische Verdummung und die Einbringung des Unwesens in das Bewusstsein unserer Leute ${ }^{93}$. Auch die verabschiedete Parlamentsdeklaration zu Srebrenica spricht von

»gesellschaftlichen und politischen Prozessen und Erscheinungen, die zur Bildung eines Bewusstseins geführt haben, in welchem man eigene nationale Ziele mit Waffengewalt und physischer Gewalt gegen Angehörige anderer Völker und Religionen verwirklichen könne ${ }^{94}$.

Diesen Schuldeingeständnissen diametral entgegengesetzt stehen die Formulierungen der DSS, der SRS und der SPO, die die Unschuld des serbischen Volkes betonen. Die DSS und die SPO stellen sogar heraus, dass das serbische Volk in den Jugoslawienkriegen das größte, aber auch im Zweiten Weltkrieg und im sozialistischen Jugoslawien Opfer gewesen sei. Mit diesen Selbstviktimisierungen wird eine Art »Opfer-Pole-Position« eingenommen. Darüber hinaus können sie in Kombination mit der von der SPO verwendeten Entlastung, dass das Massaker von Srebrenica »am Willen des serbischen Volkes vorbei« und »verdeckt von der Öffentlichkeit ${ }^{95}{ }^{5}$ verübt wurde, und der Geste, dass man die moralische Größe besäße, die Verbrechen an den anderen zu verurteilen, als Versuch gelesen werden, sich als überlegen zu inszenieren. Dies drückt sich in den Worten der DSS wie folgt aus: »Als Erstes unter den Opfern muss Serbien als Erstes alle Verbrechen verurteilen. ${ }^{96}$

Neben Srebrenica wird auch auf andere Verbrechen referiert: Während die SRS mit Bratunac, Srebrenica, der serbischen Republik Krajina und Klečka ausschließlich auf Orte von Verbrechen an Serben verweist, zählt die DSS neben Bratunac und zwei kroatischen Militäroperationen zur Rückeroberung des von

92 Komitet pravnika za ljudska prava et. al.: Deklaracija o obavezama.

93 N. Čanak: »Antiratni aktivisti«.

94 Volksversammlung der Republik Serbien: Deklaracija Narodne Skupštine Republike Srbije o osudi zločina u Srebrenici.

95 SPO: Deklaracija povodom desete godišnjice.

96 DSS: Deklaracija o osudi. 
Serben besetzten Gebiets mit Tuzla und Sarajevo noch zwei Orte auf, an denen Verbrechen gegen die bosniakische Zivilbevölkerung von serbischen Einheiten verübt wurden. Auch werden indirekt eigene Ansprüche formuliert: Die SRS fordert das Engagement der UN für die Rückkehr in eigene Häuser, was sich im diskursiven Kontext nur auf die Situation der Serben in Kroatien beziehen kann. Indirekt drückt die Fortschrittspartei mit ihrem Bekenntnis zur Achtung des Völkerrechts und zu der territorialen Integrität sowie der Souveränität aller UNMitgliedsstaaten auch ihren Standpunkt gegenüber dem Kosovo in der Srebrenica-Deklaration aus.

In den Deklarationsentwürfen können unterschiedliche diskursive Entlastungsstrategien ${ }^{97}$ identifiziert werden:

- erstens der Individualisierung der Verantwortung, indem Verbrechen als Taten Einzelner dargestellt werden. Dadurch wird das ethnonationale Kollektiv und der Staat entlastet;

- zweitens einer Generalisierung. Da alle Seiten Kriegsverbrechen begangen hätten, wird die eigene Verantwortung relativiert und das Fehlverhalten entexotisiert und legitimiert. Häufig wird dann eine Gleichbehandlung aller Kriegsverbrechen verlangt und sich pauschal entschuldigt, um die eigene Verantwortung nicht sichtbar zu machen;

- drittens der Relativierung Srebrenicas, indem man es in eine Reihe mit anderen Verbrechen stellt;

- viertens einer Externalisierung von Verantwortung, indem andere Täter und Verantwortliche benannt werden. Hierunter fallen auch die Distanzierung vom Täterkreis, der im Zuge einer Schuldabwehr von der SPO als unserbisch markiert wurde;

- fünftens der Seitenwechsel, wie ihn die SPO vornimmt, als sie den kräftigen Widerstand des serbischen Volkes - und nicht nur vergleichsweise marginalen Teilen dessen - gegen die Verantwortlichen betont und auf eine Solidarisierung mit den Bosniaken schon während des Konflikts referiert, oder die SRS, die behauptet, die Verbrechen seien vorbei am Wissen und dem Einfluss des Staates Serbien und seiner Bürger begangen worden; und

97 Der Strategiebegriff ist hier nicht im Sinne der Intentionalität zu verstehen, sondern bezeichnet im Anschluss an Foucault die theoretischen Ordnungs- und Konstitutionsprinzipien der verschiedenen Segmente einer diskursiven Formation, vgl. Foucault, Michel: Archäologie des Wissens (= Suhrkamp-Taschenbuch Wissenschaft 356), Frankfurt am Main: Suhrkamp 2008, S. 96. 
- sechstens einer Schuldübertragung, das heißt eines Ablenkens von der eigenen Verantwortung, indem auf die Schuld anderer an Kriegsverbrechen verwiesen wird. Das kann dadurch erreicht werden, dass andere wie der Westen oder die Bosniaken auch für das gleiche Kriegsverbrechen verantwortlich gemacht werden, wie es manches Mal im innerserbischen Diskurs zu Srebrenica zu finden ist. In der Kommunikation nach außen wird die Schuld der anderen Konfliktparteien für Kriegsverbrechen an Serben zur Ablenkung von der eigenen Verantwortung verwandt.

Des Weiteren konnten Strategien identifiziert werden, die der innenpolitischen Positionierung und Legitimierung dienen:

- die nationalistische Vereinnahmung, indem durch den Verweis auf ein größeres Opfer auf serbischer Seite der Fokus verschoben wird;

- die Überlegenheit im sozialen Vergleich. Beide Strategien werden in der Erklärung der DSS deutlich, die ein besonderes serbisches Interesse an der Aufklärung und Verurteilung von Verbrechen anführt, da Serbien »als erstes unter den Opfern [...] auch erster im Verurteilen aller Kriegsverbrechen sein ${ }^{98}$ müsse; und

- die Rechtfertigung der Verurteilung gegenüber einem innenpolitischen Publikum durch Funktionalisierung, wie von der DSS praktiziert, die die Zukunft, Würde und Selbstachtung der Bürger Serbiens in den Vordergrund stellt.

Unterschiedliche Akteure vertreten verschiedene Konzepte von Aufarbeitung. Allen gemein sind die Identifizierung von Tätern und Opfern sowie die Forderung nach Strafverfolgung. LDP, SDU, GSS und LSV/SVM machen deutlich, dass sie neben der Befolgung der internationalen Verpflichtungen Serbiens eine tiefgehende, opferzentrierte Auseinandersetzung mit Kriegsverbrechen fordern, mit der ein grundlegender Wandel politischer Werte einhergehen soll. Sie entstammen aus dem Umfeld des Konzepts der moralischen Verantwortung einer Gesellschaft für die Taten des Regimes, dass Sonja Biserko während der VremeDebatte 2002 vertrat. Dazu gehört, Kriegsverbrechen deutlich zu benennen, wie Srebrenica als Genozid zu bezeichnen unter Referenz auf das Urteil des Internationalen Gerichtshofs. Die LDP und die NGOs fordern weiterhin die Einführung des 11. Julis als Gedenktag in Serbien. Der Ansatz kollektiver Verantwortung und die Qualifizierung von Srebrenica als Genozid markieren den grundlegenden Unterschied zu allen anderen Parteien. Während die SPO neben Strafverfolgung 
ein »Mitfühlen« mit den Opfern und ihren Angehörigen fordert und damit an eine Grundkategorie menschlichen Verhaltens appelliert, stellt die DSS als Ziel »kollektive Heilung« in Aussicht und Wahrheit als Grundkonzept der Aufarbeitung in den Mittelpunkt. Die SNS legt den Schwerpunkt für die Aufarbeitung auf Versöhnung, wie auch die Regierungskoalition Wahrheit und Versöhnung kombiniert. Während sich die ehemalige Regimepartei SPS bis 2010 gar nicht zur Aufarbeitung von Kriegsverbrechen positionierte, vertritt sie nun mit der DS eine Position der Mitte. Sie galt 2010 als intern gespalten. Ihre Forderung nach einer Gleichbehandlung aller Täter und Opfer ist eine implizite Kritik an der selektiven Gerechtigkeit der internationalen Strafjustiz.

Erstaunlich ist der Wandel der SNS. Das gleiche Personal, das im Rahmen der SRS in den 90er Jahren für die Kriege mobilisierte, 2005 vornehmlich Entlastungsstrategien verwandte und Verbrechen an der Zivilbevölkerung allgemein ächtete, verurteilte als SNS 2010 die Verbrechen an der bosniakischen Bevölkerung und benannte die Täter als Angehörige des serbischen Volkes. Darüber hinaus forderte es eine innerstaatliche Strafverfolgung und ein Ende der Prozesse vor dem ICTY - ein Punkt, in dem sich die Parteiführung durchgängig treu blieb, wie auch die reduzierte Zusammenarbeit mit dem ICTY seit 2012 bestätigt.

Der Blick auf die parlamentarische Deklaration 2010 deutet eine neue Qualität des Umgangs mit den Jugoslawienkriegen in Serbien an, da sich Regierung und Parlament aus Eigeninitiative mit der Verabschiedung einer Deklaration befassen und die mediale Debatte darüber drei Monate anhielt. Obwohl dieser politische Diskurs breit angelegt war und bisweilen sehr hitzig geführt wurde, und trotz der großen medialen Aufmerksamkeit blieb die Debatte erstaunlich technisch. Gerade von Seiten der proeuropäisch geprägten Akteure wurde die diskursive Allianz aus der Verurteilung des Massakers von Srebrenica und dem zukünftigen Beitritt Serbiens zur EU verwendet, um breite Unterstützung zu erhalten. Deutlich kommunizierten Regierungspolitiker, dass die Verurteilung Srebrenicas ein notwendiger Schritt auf dem Weg in die EU sei. Neben der Erfüllung dieser Maßnahme sollte die Verabschiedung auch auf normativer Ebene symbolische Zugehörigkeit zu Europa ausdrücken. Weiterhin diente den Regierungspolitikern die Deklaration als doppelte innenpolitische Ressource, indem sie politische Gegner mit dem Vorwurf einer unmoralischen oder antieuropäischen Haltung innenpolitisch disqualifizierten. ${ }^{99}$ Die Notwendigkeit einer ak-

99 »Europäisch« wird innerhalb Serbiens oftmals damit gleichgesetzt, dass Parteien reformorientiert, Wohlstand versprechend, freiheitlich und nichtnationalistisch orien- 
tiven Auseinandersetzung mit den Kriegsverbrechen während der Jugoslawienkriege geriet hierbei in den Hintergrund.

Die formale Trennung einer Deklaration für die Opfer von Srebrenica von der Monate später verabschiedeten Resolution für die serbischen Opfer war zentral, da sie nicht nur den Opfern des Massakers gegenüber Ehrerbietung zum Ausdruck bringt, sondern auch das Alleinstellungsmerkmal Srebrenicas anerkennt. Im letzten Absatz der Deklaration wurde allerdings doch auf die serbischen Opfer verwiesen und die Erwartung ausgedrückt, dass die anderen Länder des ehemaligen Jugoslawien auch die Verbrechen an Serben verurteilen. Somit separierte die Deklaration die Themenkomplexe zwar nicht konsequent, doch nur indem sie so formuliert wurde, konnte sie auch verabschiedet werden, ohne mit einer Erklärung für alle Kriegsverbrechen eine Relativierung zu riskieren, wie von der Opposition gefordert.

Die Verabschiedung der Deklaration erzielte einen dreifachen Fortschritt: Erstens beschäftigten sich die politischen Organe des Landes unverblümt mit dem Thema Kriegsverbrechen. Zweitens trug mit der SPS auch die ehemalige Milošević-Partei die Verurteilung von Srebrenica 2010 mit. Und drittens erfuhr die Theorie eines gerechtfertigten Verbrechens nun auch offen Kritik. Zudem kann mit der parlamentarischen Erklärung auf ein offizielles Dokument der eigenen Regierung verwiesen werden, das die Position lokaler Normunterstützer stärkt. Trotzdem ist die Deklaration 2010 in erster Linie als politischer Kompromiss zu werten, »that neither sought nor achieved broader political or social legitimacy ${ }^{100}$. Sie diente als außenpolitisches Instrument, ohne Ausdruck eines gesellschaftlichen Wandels zu sein oder als Grundlage für einen solchen zu dienen. Darüber hinaus bestätigte sie die anhaltende ideologische Teilung der Gesellschaft und reflektierte die politischen Verhältnisse zum Zeitpunkt der Verabschiedung. Gleichzeitig offenbarte die Resolution, dass die Kompromissformel des Parlaments recht nah an der Meinung der Öffentlichkeit war: Einer Umfrage des Gallup Balkan Monitors nach der Verabschiedung durch das Parlament gemäß unterstützten 40,8 Prozent der befragten serbischen Bürger diese Deklaration, während sie von 28,9 Prozent gänzlich abgelehnt wurde. 25,7 Prozent votierten zwar für die Verabschiedung der Resolution, gaben aber an, man solle auch über die Verbrechen sprechen, die die anderen begangen haben. 8,7 Prozent befürworteten die Resolution vorbehaltlos, während 6,4 Prozent die Anerkennung von Srebrenica als Genozid forderten. 27,6 Prozent gaben an, nicht zu wis-

tiert sind. Antieuropäische Kräfte werden dementsprechend als rückwärtsgewandt und nationalistisch eingeordnet.

100 Vgl. J. Dragović-Soso: »Apologising for Srebrenica«, S. 173. 
sen, ob sie der Deklaration zustimmten oder nicht, während 2,7 Prozent keine Antwort gaben. ${ }^{101}$

\subsection{LEXIKOMETRISCHE ANALYSE DES NORMWANDELS IN SERBIEN}

Zur Überprüfung der These, dass sich zwischen 2005 und 2010 ein normativer Wandel auf dem Feld der Aufarbeitung vollzogen hat, habe ich auf Grundlage der erhobenen Zeitungsdiskurse über die öffentlichen Debatten eine lexikometrische Diskursanalyse durchgeführt (vgl. Tabelle 1).

Der Vergleich des öffentlichen Diskurses über die Deklarationen zur Verurteilung von Srebrenica in Serbien 2005 und 2010 zeigt Verschiebungen in verschiedenen Wortfeldern auf, die einerseits einen reiferen Aufarbeitungsdiskurs und andererseits eine Anpassung an den internationalen Diskurs widerspiegeln. Sehr auffällig ist die signifikant gestiegene Fokussierung auf das Wortfeld »Strafe« im Zeitungsdiskurs 2010. Die Bestrafung von Tätern, die Kriegsverbrechen begangen haben, scheint sich als gesellschaftliche Norm durchgesetzt $\mathrm{zu}$ haben und wurde auch in den Deklarationen und dem institutionellen und Politikwandel reflektiert. Auch wird häufiger auf konkrete Urteile verwiesen, besonders natürlich auf das Urteil des Internationalen Gerichtshofs, das erst 2007 gesprochen wurde. Die Übernahme der Qualifizierung als Völkermord im öffentlichen Diskurs wird höchst kontrovers verhandelt, was seine Häufung erklärt.

2005 wurde fast ausschließlich von »Verbrechen « gesprochen, um Srebrenica zu bezeichnen. Auch das Wortfeld »Urteil« lässt eine regelmäßige Referenz auf die Urteile des ICTY und des Internationalen Gerichtshofs vermuten. Die öfteren Bezungnahmen auf »international« und »europäisch« deuten auf eine zunehmende Integration in diese sozialen Referenzsysteme hin: Mit internationalen und europäischen Institutionen und Forderungen wird sich - zum Teil auch konfliktiv - auseinandergesetzt, um die eigene Zugehörigkeit, partiell aber auch Abgrenzung, zu demonstrieren. Darauf deutet die häufigere Nennung des Wortfeldes »Westen« sowie des Wortfelds »Bedingung« hin. Hiermit werden aber gleichzeitig Machtverhältnisse benannt. Die signifikante Häufung des Wortfeldes

101 Vgl. Gallup Balkan Monitor: Country Specific Question: Declaration on Srebrenica by the Serbian Parliament: Do you agree or disagree with the Declaration on Srebrenica by the Serbian Parliament?, http://www.balkan-monitor.eu/index.php/ dashboard vom 23.4.2013. 
Tabelle 1: Lexikometrischer Vergleich der Zeitungsdiskurse über die Debatten um eine parlamentarische Verurteilung von Srebrenica 2005 und 2010

\begin{tabular}{|l|l|l|}
\hline \multicolumn{2}{|l|}{ 2005 häufiger als 2010 } \\
\hline Suchwort & Wortfeld & Diff. \\
\hline zločin* & Verbrechen & 2,59 \\
\hline suoč* & Aufarbeitung & 0,34 \\
\hline Milošević* & Milošević & 0,26 \\
\hline optuž* & Angeklage & 0,21 \\
\hline hašk* & Haager & 0,18 \\
\hline ljudsk* & menschlich & 0,18 \\
\hline srb* & Serbien & 0,18 \\
\hline demokrat* & Demokratisch & 0,15 \\
\hline prizna* & Anerkennung & 0,15 \\
\hline odgovorn* & Verantwortung & 0,15 \\
\hline prizna* & Anerkennung & 0,15 \\
\hline režim* & Regime & 0,15 \\
\hline ubistv* & Mord & 0,14 \\
\hline Bratun* & Bratunac & 0,13 \\
\hline ime* & Name & 0,10 \\
\hline Mladić* & Mladić & 0,12 \\
\hline istin* & Sicherheit & 0,10 \\
\hline bezbednost* & \\
\hline moral* & Moral & \\
\hline
\end{tabular}

\begin{tabular}{|l|l|l|}
\hline \multicolumn{2}{|l|}{2010 häufiger als 2005 } \\
\hline Suchwort & Wortfeld & Diff. \\
\hline kazn* & Strafe & $-4,92$ \\
\hline genocid* & Völkermord & $-1,47$ \\
\hline međunarod* & International & $-0,60$ \\
\hline evrop* & europäisch & $-0,49$ \\
\hline žrt* & Opfer & $-0,48$ \\
\hline presud* & Urteil & $-0,44$ \\
\hline kriv* & Schuld & $-0,24$ \\
\hline pravd* & Gerechtigkeit & $-0,23$ \\
\hline izvin* & Entschuldigung & $-0,21$ \\
\hline narod* & Volk & $-0,18$ \\
\hline zapad* & Westen & $-0,17$ \\
\hline pomirenj* & Versöhnung & $-0,13$ \\
\hline naš & Unser & $-0,10$ \\
\hline saučešc* & Beileid & $-0,10$ \\
\hline sopstven* & Eigen & $-0,10$ \\
\hline uslov* & Bedingung & $-0,10$ \\
\hline
\end{tabular}


»Opfer« ist ambivalent, sie wird sowohl auf muslimische, als auch auf serbische Opfer angewendet. Deutlich wird in jedem Fall, dass es eine Zunahme von Opferdiskursen gibt. Dies passt zu den theoretischen Befunden eines zunehmenden globalen Opferdiskurses und zu der These einer Europäisierung des serbischen Diskurses, in dem »Erinnerungsdiskurse, in denen das Leid der Opfer der Geschichte in den Mittelpunkt gerückt werden, [...] zunehmend nationalistische Erinnerungsdiskurse mit der Überhöhung von Helden und Siegen« ${ }^{102}$ ersetzen. 2010 ist eine häufigere Nennung von Worten aus den Wortfeldern »Schuld« und »Gerechtigkeit« festzustellen als 2005. Die Referenz auf »Volk« und auf »wir« hat leicht zugenommen wie auch auf »uns« sowie »eigen«. Diese Befunde können Indikatoren für eine Aneignung des Themas oder eine Nationalisierung des Diskurses sein, welche mit Opferkonkurrenzen und Schulddebatten einhergeht. Die häufigeren Nennungen der Wortfelder »Entschuldigung« und »Anteilnahme/Beileid« weisen gleichzeitig auf eine leichte Bevorzugung symbolischer Praktiken der Vergangenheitsaufarbeitung hin, was sich in konkretem Politikwandel manifestiert.

2005 hingegen wurde deutlich häufiger als 2010 von »Verbrechen« gesprochen, auch wurden klarere Qualifizierungen des Verbrechens mit der Nennung »Massaker« und »Mord « vorgenommen. Interessant ist, dass deutlich häufiger Bezug genommen wurde auf »Aufarbeitung«, »Verantwortung«, »Anerkennung«, »Wahrheit« und »Moral«, was normative Grundpositionen zur Aufarbeitung der Vergangenheit widerspiegelt. Hierzu passen auch die vermehrten Verweise auf die Wortfelder »menschlich« und »demokratisch«. »Milošević« und »Mladić« sowie das »Regime« wurden als konkrete Schuldige häufiger genannt, häufiger als 2010 wurde auch auf »Sicherheit« rekurriert. Zudem verweisen die Wortfelder »Anklage« und »Haager« auf eine strafrechtliche Form der Aufarbeitung.

Einige Befunde von 2005 sind sicher durch den Eindruck des kurz zuvor gezeigten Videofilms erklärbar, die eine Auseinandersetzung an einem konkreten Gegenstand beförderten und unmittelbar Reaktionen von Betroffenheit und Erschütterungen auslösten. Die Strafverfolgung der noch auf freiem Fuß lebenden Täter war einer der Fokusse des Diskurses kurz nach der Ausstrahlung und wurde vor allem von Regierungsseite betont, um sich als verantwortungsvoll Handelnde zu präsentieren. Hier stand neben dem Opfergedenken vor allem die Idee der retributive justice im Vordergrund.

Interessant ist die häufigere Bezugnahme auf Bratunac 2005. Serbische Nationalisten, vor allem in der Republika Srpska, versuchten Bratunac als Symbol

102 S. Bayraktar: Politik und Erinnerung, S. 59. 
für die von Muslimen an Serben begangenen Kriegsverbrechen zu prägen und nachhaltig als Gegenerinnerungsort zu Srebrenica durchzusetzen. Damit gelang es ihnen partiell, die Deutung der eigenen Gruppe als Opfer und der Muslime als Täter aufrechtzuerhalten, was sich in das Deutungsmuster der jugoslawischen Auflösungskriege als serbische Verteidigungskriege fügt. Bratunac wird im Diskurs 2010 seltener genannt, da die meisten Argumente schon 2005 ausgetauscht wurden und 2010 zwei klare Lager bestanden. Mit der Einigung auf zwei Resolutionen zu Beginn der Debatte 2010 wurde der Konflikt weitgehend geregelt. Es gelang der Regierungskoalition mit dem Versprechen einer zweiten Resolution die patriotischen und nationalen Kräfte einzuhegen und sich das Thema der serbischen Opfer mit einer zweiten Resolution zu eigen zu machen. Bratunac selbst aber wurde von Seiten der Regierungskoalition nicht als konkreter Ort angeführt, auch gab es keine Vermittlungsversuche, um dieses Narrativ zu integrieren. Stattdessen nutzten die Vertreter des nationalen Lagers Bratunac, um ihre politische, patriotische Identität zu verteidigen. Dies zeigt sich auch darin, dass genau diese Akteure immer wieder die Symbolpolitik kritisierten, daran Anstoß nehmend, dass Präsident Tadić die Gedenkfeierlichkeiten in Srebrenica und nicht die in Bratunac besuchte. Bratunac wird zum Symbol für die serbischen Opfer und die Loyalität zu den serbischen Opfern zum Indikator für Patriotismus stilisiert. Auffällig ist der Positionswandel der SRS und damit auch der aus ihr 2008 hervorgegangenen SNS. Während sie 2005 diejenigen Akteure waren, die das Thema der serbischen Opfer am stärksten vertraten und auch in der öffentlichen Debatte mit Referenz auf Bratunac offensiv besetzten, tauchen sie 2010 kaum mehr auf. Interessant ist, wie 2010 zunächst auch die SRS mit Aleksandar Vučić, später nur noch die Vertreter der DSS, Dragan Marković Palma von JS, der Präsident der Republika Srpska Milorad Dodik und der Bund der Flüchtlinge versuchen, neben Bratunac auch eine Vielzahl von anderen Orten der Erinnerung an serbisches Leiden im Diskurs einzubringen, ${ }^{103}$ möglicherweise um eine breitere Mobilisierung zu erreichen. Die Liste der Täter umfasste alle Konfliktparteien und die NATO, so dass keine eindeutige Stoßrichtung mehr zu erkennen war und

103 Neben Bratunac wird vor allem auf die kroatischen Operationen Oluja und Bljesak (Blitz) oder allgemeiner auf Verbrechen in der Krajina, im Kosovo oder auf die NATO-Bombardierung rekurriert, darüber hinaus streuen sich die Bezugnahmen auf Klečka, ein kosovo-albanisches Gefangenenlager in der Gemeinde Mališevo im Kosovo, Kravica, wo am orthodoxen Weihnachtsfest 1992/1993 ein Massaker an Serben stattfand, und weitere Verbrechen an Serben in Foča, Međaki đep, Varvarin, Bjelovac, Sikirići, Voljevići, Jugovići, Loznička Rijeka, Vlasenica, Zvornik sowie Tuzla. 
als Ergebnis lediglich die parteipolitische Profilierung durch den Opferdiskurs festgehalten werden muss.

\section{0: Zweierlei Maß? \\ Srebrenica und Verbrechen an Serben verurteilen}

Ein weiterer Vergleich mit der Diktionärshäufigkeitsmethode verdeutlicht die unterschiedlichen Normsysteme und Adressatenkreise der Deklaration zur Verurteilung von Srebrenica und der Verbrechen an Serben. Da die beiden Dokumente in Anlage und Umfang sehr vergleichbar sind, musste nicht auf Koeffizienten zurückgegriffen werden. Die vorliegenden Daten wurden lediglich zur besseren Darstellbarkeit um Kategorien ohne Nennung bereinigt. Einige Nennungen erklären sich durch die Referenz auf die gleichen Rechtsdokumente in der Präambel wie die Menschenrechtspakte und -konventionen sowie die Genozidkonvention. Diese sind in Tabelle 2 grau eingefärbt.

Sehr auffällig ist die deutlich häufigere Nennung des Wortfeldes »Verbrechen « im Kontext der Deklaration zur Verurteilung der Verbrechen an den Serben, wohingegen in der Deklaration zur Verurteilung des Verbrechens in Srebrenica relativierend von »Tragödie« gesprochen wird. Die Häufungen des Wortfeldes »Serbien/serbisch" sowie »Volk« in der Deklaration zur Verurteilung der Verbrechen an den Serben liegt aufgrund ihrer Intention auf der Hand, ihre hohen Werte zeigen aber auch eine gewisse Relevanz der Nennung dieser Wörter als Diskursregeln nach innen: Das patriotische Bekenntnis gehört noch immer zu einer der wertvollsten politischen Ressourcen. Auch ist hinsichtlich der Serbendeklaration häufiger von Opfern und Trauern die Rede. Auffällig ist, dass Schlagwörter aus dem Vokabular der retributive justice bei der zweiten Deklaration öfter beziehungsweise überhaupt fallen wie »Strafe/Schuld" oder "Gesetz« beziehungsweise »Verantwortung «. Dies ist in erster Linie auf die Forderung nach Untersuchung und Strafverfolgung der an Serben begangenen Verbrechen zu erklären, welche aber nicht nur an einem konkreten Ereignis festgemacht, sondern auf die gesamten 90er Jahre bezogen wird. Die Deklaration zur Verurteilung der Verbrechen an den Serben ist mit seinen zahlreichen Verweisen auf internationales Recht und die entsprechenden Organe auch als Ausdruck des Versuchs einer nachholenden Internationalisierung ihres Anliegens zu verstehen, mit der zumindest eine gleiche Opferbehandlung durch internationales Recht und Organe eingefordert werden soll. Der Eindruck der Ungleichbehandlung und der Fehlperzeption der Geschehnisse durch die internationale Gemeinschaft wird auch zweifach durch die Referenz auf die »Wahrheit« ausgedrückt. In der Srebrenica-Deklaration wird häufiger auf schon gesprochene Urteile 
internationaler Gerichte Bezug genommen, gleichsam wird mit emotionalsymbolischer Rhetorik (»Entschuldigung«, »Anteilnahme/Beileid«) auf ein moralisch angemessenes Verhalten verwiesen.

Tabelle 2: Lexikometrischer Vergleich der serbischen Deklaration zur Verurteilung von Srebrenica und der Deklaration zur Verurteilung der Verbrechen an den Serben

\begin{tabular}{|c|c|c|c|c|}
\hline Suchwort & Wortfeld & Srebrenica & Serben & Diff. \\
\hline narod* & Volk & 11 & 21 & -10 \\
\hline $\mathrm{srb}^{*}$ & Serbien & 13 & 23 & -10 \\
\hline zločin* & Verbrechen & 5 & 13 & -8 \\
\hline srp* & Serbisch & 2 & 7 & -5 \\
\hline žrt* & Opfer & 4 & 8 & -4 \\
\hline kriv* & Schuld & 4 & 7 & -3 \\
\hline međunarod* & International & 10 & 13 & -3 \\
\hline zakon* & Gesetz & 0 & 3 & -3 \\
\hline istin* & Wahrheit & 0 & 2 & -2 \\
\hline žaljenj* & Trauer & 0 & 2 & -2 \\
\hline bombardovanj* & Bombardierung & 0 & 1 & -1 \\
\hline humanitar* & Völkerrechtlich & 0 & 1 & -1 \\
\hline interes* & Interesse & 0 & 1 & -1 \\
\hline istorij* & Historisch & 0 & 1 & -1 \\
\hline kazn* & Strafe & 0 & 1 & -1 \\
\hline ljudsk* & Menschlich & 4 & 5 & -1 \\
\hline NATO & NATO & 0 & 1 & -1 \\
\hline odgovorn* & Verantwortung & 0 & 1 & -1 \\
\hline
\end{tabular}




\begin{tabular}{|c|c|c|c|c|}
\hline Suchwort & Wortfeld & Srebrenica & Serben & Diff. \\
\hline osu* & Verurteilung & 3 & 4 & -1 \\
\hline pomirenj* & Versöhnung & 1 & 2 & -1 \\
\hline prošlo* & Vergangenheit & 0 & 1 & -1 \\
\hline svets* & Welt & 0 & 1 & -1 \\
\hline vrednost* & Wert & 0 & 1 & -1 \\
\hline dostojan* & Würde & 1 & 1 & 0 \\
\hline evrop* & Europa & 1 & 1 & 0 \\
\hline genocid* & Völkermord & 1 & 1 & 0 \\
\hline poštovanj* & Respekt & 3 & 3 & 0 \\
\hline stradanj* & Leiden & 1 & 1 & 0 \\
\hline uslov* & Bedingung & 1 & 1 & 0 \\
\hline Mladić* & Mladić & 1 & 0 & 1 \\
\hline obavez* & Verpflichtung & 1 & 0 & 1 \\
\hline pošt* & Respekt & 1 & 0 & 1 \\
\hline sopstven* & Eigenen & 1 & 0 & 1 \\
\hline tragedi* & Tragödie & 1 & 0 & 1 \\
\hline zapad* & Westen & 1 & 0 & 1 \\
\hline izvin* & Entschuldigung & 2 & 0 & 2 \\
\hline pravd* & Gerechtigkeit & 3 & 1 & 2 \\
\hline saučešće* & Beileid & 2 & 0 & 2 \\
\hline Presud* & Urteil & 3 & 0 & 3 \\
\hline
\end{tabular}


Anders als eventuell zu erwarten gewesen wäre, wurden bei den Deklarationen 2010 weder mannigfaltig Referenzen auf Verbrechen an Serben noch der Slogan »nicht in unserem Namen« benutzt. Stattdessen blieb die Semantik der Deklarationen im Rahmen der international akzeptierten Regeln und Narrative mit Ausnahme der Referenz auf die NATO-Bombardierung. Lediglich anhand der Häufung bestimmter Termini sind bestimmte Tendenzen aus den Dokumenten ablesbar: Aussagekräftig in diesem Kontext ist auch die doppelt so häufige Nennung des Begriffs »Opfer« in der Serbendeklaration, was doch eine deutliche Gewichtung zeigt und darauf verweist, dass von serbischer Seite eben doch zwischen Opfern unterschieden wird - zumindest in der Behandlung der eigenen und anderer Opfer.

\section{Unterschiedliche politische Rationalitäten}

Aus der Erinnerung an Srebrenica, dem eigenen institutionellen Versagen und der späten militärischen Intervention in den Bosnienkrieg erwächst bei den internationalen Akteuren eine besondere Verpflichtung und Verantwortung hinsichtlich der Strafverfolgung der Täter und der Unterstützung der Opfer. Darüber hinaus legitimieren sie ihre Institutionen wie das ICTY und ihre Handlungen wie die Einrichtungen der Schutzzonen und die Bombardierungen durch die NATO 1995 und 1999 ex post. Mit ihrem Verhältnis zu Srebrenica können sie weiterhin ihre Verpflichtung gegenüber universellen Normen wie den Menschenrechten und der Völkermordkonvention bekunden und zukünftige militärische Handlungen rechtfertigen.

Eine serbische Positionierung zu Kriegsverbrechen, vor allem zu Srebrenica, umfasst neben der moralischen Komponente mindestens vier weitere Funktionen: Sie drückt erstens das Verhältnis zur autoritären Vergangenheit aus, zweitens markiert sie das Bekenntnis zur Nation und der Republika Srpska, drittens definiert sie die außenpolitische Richtung und die Zukunft des Landes und viertens symbolisiert sie die Unterordnung oder den Widerstand gegenüber externen Mächten wie den USA und der EU. All diese Punkte bezeichnen ein Verhältnis zur Nation, was verdeutlicht, dass Nationalismus in der gegenwärtigen Politik noch immer eine der zentralen politischen Ressourcen aller Parteien ist. Denen gelang es seit der Transition kaum, inhaltlich und normativ differenzierte Profile zu entwickeln, weiterhin scheinen die Parteien weitgehend austauschbare Politikansätze zu vertreten. Darüber hinaus sind die Positionen auf dem Feld der Aufarbeitung von Kriegsverbrechen, die weitgehend internationalen Erwartungen der Aufarbeitung entsprechen, innenpolitisch unpopulär. Sie werden von nationalistischen und patriotischen Kräften als Verrat gewertet und treffen auch bei 
Flüchtlingen und Veteranen aufgrund ihrer Wahrnehmung der Kriege häufig auf Missfallen. Das erklärt auch, warum symbolträchtige Kategorien wie Genozid eine Grenze des Sagbaren darstellen und warum eine Positionierung ohne Verweis auf die serbischen Opfer politisch nicht durchzusetzen ist.

\subsection{EINE WAHRHEIT?}

Roger Duthie beschreibt die Spannung zwischen den Konfliktnarrativen auf unterschiedlichen Ebenen wie der internationalen, der nationalen oder lokalen als eine der unbeabsichtigten Folgen von transitional justice. ${ }^{104}$ Dieses $»$ Problem der einen Wahrheit« entsteht nicht nur grundsätzlich durch den konstitutiven Pluralismus von Erinnerung ${ }^{105}$, sondern ist gerade nach komplexen Konfliktdynamiken, an denen mehrere Akteure auf verschiedenen Ebenen beteiligt waren, zentral: In diesen Fällen ist es nahezu unmöglich, ein gemeinsames Narrativ zu finden. Das Konstruieren einer bestimmten Vergangenheitsinterpretation, wie der Wahrheit des ICTY und der internationalen Organisationen, behindert dadurch oftmals die Inklusion der komplexeren Konfliktdynamiken auf lokaler Ebene. Im Kontext von internationalisierten Konflikten und extern induzierter Aufarbeitung ist diese unbeabsichtigte Folge sehr wahrscheinlich, da sich das internationale Narrativ aufgrund der Machtasymmetrie hegemonial durchsetzen können wird. Das so konstruierte und durch Konditionalität implementierte neue Vergangenheitsnarrativ wird als einseitig oder als anderen Narrativen gegenüber konflikthaft wahrgenommen. So kann die Aufarbeitung der Vergangenheit konfliktfördernde Effekte haben, wenn unterschiedliche Narrative aufeinander treffen - sowohl innerhalb des Landes als auch zwischen nationaler und internationaler Ebene.

Mit Blick auf Serbien ist es nicht nur der unterschiedliche Schärfegrad der Linse, um eine photographische Metapher zu strapazieren, sondern vor allem die Partikularität der unterschiedlichen Narrative, also die Perspektive oder gar das ganze Motiv, die eine Konflikthaftigkeit bedingen. Dabei ist einerseits die institutionalisierte Täter-Opfer-Zuweisung in den Srebrenica-Deklarationen problematisch andererseits die Völkermordkategorie. Sie delegitimieren die Anliegen

104 R. Duthie: »Afterword «, S. $250 \mathrm{ff}$.

105 Zur konstitutiven Pluralität von Erinnerung vgl. Feindt, Gregor/Krawatzek, Félix/ Mehler, Daniela/Pestel, Friedemann/Trimçev, Rieke: »Entangled Memory. Toward a Third Wave in Memory Studies«, in: History and Theory 53 (2014) 1, S. 24-44, hier S. $31 \mathrm{f}$. 
der serbischen Opfer sowie die Frage nach bosniakischer Täterschaft und danach, inwieweit die Opfer des Massakers von Srebrenica ausschließlich Zivilisten waren.

\section{Sich gegenüberstehende Ordnungen?}

Auf Grundlage der vorliegenden Untersuchung kann die von Natalija Bašić aufgeworfene Frage beantwortet werden, ob der von der

»internationalen Staatengemeinschaft beschlossenen Verfahrens- und Normenordnung lokale und nationale Ordnungen gegenüber[stehen, D. M.], die die juristisch behandelten Sachverhalte in gänzlich anderer Weise wahrnehmen und bewerten « ${ }^{106}$.

Wie die Analysen der Deklarationen bestätigen, sind auf internationaler und serbischer Ebene Konfliktbeschreibungen, Norm- und Verhaltenserwartungen formuliert, die sich auch diachron im Wandel befinden. Deutlich sind Unterschiede auf den beiden Ebenen festzustellen, allerdings beziehen sie sich nicht unbedingt auf die Normenordnung, sondern vielmehr auf die Konfliktwahrnehmung und die Frage des Verfahrens. Die Grenze verläuft aber nicht entlang der Ebenen national/international, sondern zwischen politischen Lagern, die entweder eine Anerkennung der serbischen Verantwortung für den Völkermord in Srebrenica oder allgemein formuliert: für die Jugoslawienkriege fordern oder ablehnen. Internationale Akteure wie auch einige NGOs und Parteien (LDP, SDU, LSV/SVM) ergreifen in ihren Deklarationen Partei für die bosniakischen Opfer und für das ICTY, wie Tabelle 3 zeigt.

Die von ihnen vertretene Genozidqualifizierung und die dadurch entstehende dichotome Konfliktbeschreibung, die sich in ihren Deklarationen ausdrückt, finden auf innenpolitischer und lokaler Ebene nur geringe Zustimmung. Zudem spiegeln sie nicht die serbische Opferschaft wider, die aber einerseits angesichts des Erfahrungshorizonts der serbischen Gesellschaft und andererseits aufgrund des Opferthemas als nationalistischer Ressource nach Integration verlangt. Die Frage $A$ šta je s njihovim zločinima? (Und was ist mit ihren Verbrechen?) entspricht der lokalen Konfliktwahrnehmung und kaum mit der Perspektive der sich vornehmlich auf Srebrenica fokussierenden Akteure übereinzubringen, die das

106 Bašić, Natalija: »Völkermord vor Gericht. Kriegsverbrecherprozesse, Emotionen und der Umgang damit in Serbien«, in: Südosteuropa 59 (2011) 4, S. 396-411, hier S. 336 . 
Tabelle 3: Politische Positionierung zu Srebrenica $2010 \mathrm{ff}$.

\begin{tabular}{|l|c|c|c|}
\hline & $\begin{array}{c}\text { bosniakische/ } \\
\text { ICTY- } \\
\text { Interpretation }\end{array}$ & $\begin{array}{c}\text { universelles } \\
\text { Opfernarrativ }\end{array}$ & $\begin{array}{c}\text { serbisches, } \\
\text { partikulares } \\
\text { Opfernarrativ }\end{array}$ \\
\hline $\begin{array}{l}\text { auf } \\
\text { internationaler } \\
\text { Ebene }\end{array}$ & $\begin{array}{c}\text { UN, USA, ICTY, } \\
\text { Internat. Gerichts- } \\
\text { hof, F, NL, Europäi- } \\
\text { sches Parlament }\end{array}$ & & \\
\hline $\begin{array}{l}\text { auf } \\
\text { nationaler } \\
\text { Ebene }\end{array}$ & $\begin{array}{c}\text { NGOs, LDP, SDU, } \\
\text { LSV/SVM }\end{array}$ & $\begin{array}{c}\text { DS, G17plus, } \\
\text { SPO, SPS, PUPS, } \\
\text { seit 2013: SNS }\end{array}$ & $\begin{array}{c}\text { DSS, SRS, JS, } \\
\text { Veteranen, } \\
\text { Flüchtlings- und } \\
\text { Opfergruppen }\end{array}$ \\
\hline
\end{tabular}

ICTY unterstützen und oftmals auch die NATO-Bombardierung befürworteten. Diese lokalen Narrative können als bewusstes Instrument des Widerstandes gegen die hegemoniale »westliche Sicht« auf den Krieg verstanden werden, gleichzeitig können sie aber auch eine Strategie der Verarbeitung von Gewalterfahrung darstellen, deren Politizität nicht intendiert ist. ${ }^{107}$ In Serbien treffen beide Fälle zu, wobei analytisch nicht zwischen den verschiedenen Motivationen für die Gegennarrative unterschieden werden kann, wenn sie nicht explizit gemacht werden.

Diese Zweiteilung des diskursiven Raums wird in der serbischen Öffentlichkeit von nationalistischen Akteuren oftmals äquivalent gesetzt mit patriotisch oder unpatriotisch, richtig oder falsch, Freund oder Feind, wahr und unwahr sowie Opfer oder Täter. Diese Polarisierung und Teilung des gesellschaftlichen und internationalen Raums hat ihre Wurzeln in der sozialistischen Geschichtsschreibung und Propaganda, die durch Satanisierung und Heroisierung in beiden Referenzsystemen idealtypische Zuschreibungen vornahm und Gegner im Äußeren als Nazis oder Imperialisten, im Inneren als Verräter oder Volksfeinde disqualifizierte. Folglich deuten nationalistische Kräfte die Aufarbeitung von Kriegsverbrechen, soweit sie von außen mitgestaltet wird oder serbische Opfer nicht anspricht, als ungerecht. Die internationale Strafverfolgung und die nunmehr hegemoniale Konfliktwahrnehmung erscheinen ihnen als Beweis dafür. Aufgrund dieser Polarisierung ist bis heute kein offener Diskurs über Vergangenheitsaufarbeitung möglich, in dem diese Vorstrukturierung nicht dominant wird. Doch erst ein Überkommen dieser Dichotomien kann einen gesellschaftlichen Dialog 
eröffnen, der sich kritisch und produktiv mit der Vergangenheit auseinandersetzt, auch Graustufen, auch die Doppelrollen von Akteuren als Täter-Opfer sowie Opfer-Täter und Sprecher mit einer anderen Position zulässt, ohne sie sofort als illegitim zu disqualifizieren.

\section{Agieren im Dazwischen: Universalisierung und symbolische Praktiken}

Wie bereits vermutet, konnte im gegenwärtigen serbischen Diskurs keine Ablehnung der Norm der Aufarbeitung gefunden werden. Im Gegenteil, es wird in allen Deklarationen und von sämtlichen politischen Fraktionen gefordert, Kriegsverbrechen unabhängig der ethnischen Zugehörigkeit von Täter oder Opfer zu verurteilen und Täter und Opfer beim Namen zu nennen. Wie der diachrone Wandel der serbischen Deklarationen aufzeigt, wird der Konflikt zwischen den unterschiedlichen partikulären Narrativen durch einen Kompromiss aufzulösen versucht.

Die Deutungsoffenheit der Vergangenheitsaufarbeitung ebnet den Ausweg, sich mit Hilfe universalistischer Rhetorik und symbolischer Praktiken den international geforderten Normerwartungen anzupassen, diese aber auch in Teilen zurückzuweisen. Sie ermöglicht dabei beiden Narrativen und Normsystemen eine weitgehend friedliche Koexistenz. Die Universalisierung des Opfers integriert die eigene partikuläre Opferschaft und schließt auch die Opferschaft anderer Konfliktparteien mit ein, wie auch die Verurteilung von Kriegsverbrechen die Täterschaft aus dem eigenen Kollektiv genauso wie die der anderen miteinbezieht, was es ermöglicht, dem nationalistischen Lager und der lokalen Konfliktwahrnehmung gerecht zu werden. Die Offenheit und Wagheit dieser universalistischen Normbezüge lässt auch die Angriffe derer ins Leere laufen, die ein partikuläres Narrativ vertreten, da es in ihnen aufgeht und integrativ wirkt.

Die sich zu der Deklaration komplementär verhaltende religiös anmutende Kultur öffentlicher Entschuldigung kommt einem Bußritual gleich. Staatsmännische Gesten wie Entschuldigungen und Gedenkakte sind ein probates Mittel der Versöhnung. Der außenpolitische Nutzen solcher symbolischen Handlungen, die ein Einzelner für ein ganzes Kollektiv vollzieht, ist offenkundig. Auf einer solchen Grundlage können Verhältnisse neu definiert und Verträge geschlossen werden. Serbische Repräsentanten haben die Symbolpolitik als neue Staatsdoktrin offenbar akzeptiert, sie soll die Grundlage regionaler Zusammenarbeit und europäischer Integration bieten.

Die relativierenden Wendungen in den Entschuldigungen, die Weigerung, Srebrenica als Genozid anzuerkennen, die weiterhin ausbleibende offizielle An- 
erkennung der Verwicklung staatlicher Organe oder die fehlende Anpassung der Bildungspolitik treten in der internationalen Beurteilung der Gesten in den Hintergrund. In der serbischen Gesellschaft können somit serbische Opfer »gleicher« sein als bosnische, und somit dürfen mit Verweis auf die Meinungsfreiheit Diskurse über Opfer- und Tätersymmetrien weitergeführt werden, die international nicht toleriert würden. Innenpolitisch hingegen kollidieren diese Positionen.

Gleichzeitig soll aus Sicht der Mehrheit der serbischen Akteure das Kapitel der Aufarbeitung der Vergangenheit beendet sein, und mit Blick auf den Druck durch die Konditionalitätspolitik sind zumindest mit einiger Wahrscheinlichkeit in Zukunft weniger internationale Interventionen zu erwarten. Denn formal verhielt sich Serbien mit der parlamentarischen Verurteilung von Srebrenica, dem Besuch des Präsidenten in Srebrenica und Vukovar, mit Entschuldigungen und schließlich den nicht verhandelbaren Auslieferungen der letzten flüchtigen Kriegsverbrecher den internationalen Erwartungen angemessen. 



\section{Fazit}

Im Folgenden werden die Ergebnisse der Studie mit Blick auf die bestehende Literatur und Theorie reflektiert. Ziel der Studie war es, die Aufarbeitung von Kriegsverbrechen in Serbien vor dem Hintergrund externer Induzierung und transnationaler Normsozialisationsprozesse am Fallbeispiel Serbien zu untersuchen. Konkret wurden der Politikwandel auf dem Feld der Vergangenheitsaufarbeitung und die Ambivalenzen zwischen innenpolitischer und außenpolitischer Politikformulierung in den Fokus genommen. Ausgehend von der Literatur zu transnationaler Normsozialisation wurde vermutet, dass sich die Interpretation der Norm der Vergangenheitsaufarbeitung auf gesellschaftlicher Ebene in Serbien den Vorstellungen auf internationaler Ebene angleicht. Die zweite These besagte, dass die Norm nach außen befolgt wird und auch im Inneren unbestritten ist, obgleich im Inneren weiterhin Kämpfe darüber ausgetragen werden, was mit ihr gemeint ist und wie sie ausgestaltet werden soll.

\section{Historische Erfahrungen}

In Jugoslawien bildete sich nach dem Zweiten Weltkrieg ein Umgang mit Kriegsverbrechen aus, der seinem rechtsstaatlichen Anstrich entgegen politisch motiviert und selektiv war. Diese Form der Siegerjustiz diente dem Machtausbau der sozialistischen Partisanen, die einige Praktiken des Umgangs mit Kriegsverbrechen dem sowjetischen Vorbild entlehnten. Ein Wissenstransfer auf die jugoslawische Ebene war auch mit der Zusammenarbeit mit der United Nations War Crimes Commission verbunden. Deutliche Bezugnahmen auf internationale Normen wie die Völkermordkonvention erfolgten in der geschichtswissenschaftlichen Umdeutung des Zweiten Weltkriegs. Durch biographische Zeugnisse und schriftstellerische Verarbeitung pluralisierten sich parallel Kriegsnarrative, was im Kontrast zur sozialistischen Deutung des Kriegs stand. Die innerjugoslawische Auseinandersetzung mit Kriegsverbrechen wandelte sich zu einem hege- 
monialen Diskurs nationaler Opfer. Die Mobilisierung des Völkermordtopos nahm der Frage nach Tätern innerhalb der serbischen Nation jede Relevanz und externalisierte sie. Die Dynamik, mit der andere Länder zeitgleich Formen der transitional justice eruierten, kam in Jugoslawien nicht zum Tragen. Stattdessen deuteten die gleichen Akteure die Jugoslawienkriege, die sich zuvor für eine nationale Deutung des Zweiten Weltkriegs engagiert hatten, und beschrieben sie in den gleichen Narrativen des nationalen Opfers und des Völkermords. Darüber hinaus konnte die Persistenz historischer Bezugsrahmen in der serbischnationalistischen Deutung aufgezeigt werden. In der nationalistischen Wahrnehmung blieben die Vorstellungen von äußeren und inneren Feinden der nationalen und politischen Gemeinschaft über die Zeit weitgehend stabil, sie wurden lediglich den politischen Transformationen gemäß variiert. National gesinnte Akteure stellten den Niedergang und die Auferstehung des serbischen Volkes seit der Jahrhundertwende in den Kontext der Dominanz durch Großmächte. Die beschriebene historische Kontinuität reicht je nach Ansatz bis zur Zeit des Osmanischen Reichs zurück. Der innere Feind oder Verräter wurde bereits im Kosovomythos etabliert, fand sein Äquivalent im Sozialismus im Volksfeind und erweiterte ab Mitte der 70er Jahre sukzessive den äußeren Feind um die ebenso »genozidalen« innerjugoslawischen Gegner. Der Eindruck einer bewusst unterlassenen Strafverfolgung von Verbrechen am serbischen Volk durch antiserbisch gesinnte Verschwörungen oder Großmächte fügt sich hier ein.

\section{Spezifika des serbischen Umgangs mit Kriegsverbrechen der Jugoslawienkriege}

Die serbische Aufarbeitung der während der Jugoslawienkriege verübten Kriegsverbrechen ist von mindestens sechs Spezifika geprägt: Erstens waren die während der Jugoslawienkriege begangenen Kriegsverbrechen, besonders das Massaker von Srebrenica, aufgrund der Beteiligung internationaler Organisationen und Akteure an der Konfliktregelung von Beginn an auch Gegenstand internationaler Politik. So wurde zweitens die Strafverfolgung von Kriegsverbrechen und damit ihre Bearbeitung extern induziert. Das Alleinstellungsmerkmal Genozid in Bezug auf das Massaker von Srebrenica impliziert drittens für die serbische Vergangenheitsaufarbeitung, sich mit der Täterrolle auseinanderzusezten und Schuld anzunehmen. Die Essentialisierung der Serben als »Tätervolk« in den internationalen Zuschreibungen kontrastiert mit der Opferrolle, die sich serbische Nationalisten spätestens seit den 80ern zuschreiben und die in der serbischen Politik bis heute eine Mainstreamposition darstellt. Gleichzeitig gelang es der serbischen Politik viertens nicht, die Frage der serbischen Opfer und Flücht- 
linge zu internationalisieren. Fünftens ist in der Akteurskonstellation in Serbien eine problematische personelle legacy des Vorgängerregimes zu erkennen. Aus diesem Grund mangelt es an einer Vergangenheitsaufarbeitung sowie wegen der Abwesenheit von nichtserbischen Opfergruppen und der Schwäche des lokalen Protests gegenüber den relevanten gesellschaftlichen Trägern. Die Konditionalitätspolitik erforderte sechstens weitere Schritte einer Aufarbeitung, ohne eine breite gesellschaftliche Basis zu haben. In allen Fällen wurde Wandel von außen induziert oder von Seiten des Staats als Reaktion auf äußere Prozesse eingeleitet. Lediglich die zivilgesellschaftliche Initiative für eine regionale Kommission sticht als Ausnahme hervor.

\section{Der öffentliche Diskurs in Serbien: Positionen und soziale Mobilisierungen}

Im öffentlichen Diskurs in Serbien konnte eine dichotome Zweiteilung der Zivilgesellschaft festgestellt werden, die auch nach 2000 weitgehend den Konfliktlinien der 90er Jahre entsprach und konstant blieb. Seit 1990 stehen sich Menschenrechts-NGOs und "patriotische« zivilgesellschaftliche Organisationen gegenüber. Sie reagieren feindlich aufeinander und mobilisieren in der Öffentlichkeit gegen die Aktivitäten und Initiativen der anderen. Die MenschenrechtsNGOs schwächten sich mit inneren Fraktionierungen selbst und waren aufgrund ihrer als extrem wahrgenommenen Positionen gesellschaftlich wenig anschlussfähig. Diese ermöglichten allerdings gleichermaßen eine inhaltliche Erweiterung des Diskurses über die Aufarbeitung von Kriegsverbrechen, da sie durch ihre Differenz zu bestehenden Positionen große Öffentlichkeit erhielten, und unterstützen somit die sozietale Normsozialisation.

Eine ähnliche Zweiteilung wie auf dem Feld der Zivilgesellschaft war lange in der serbischen Parteienlandschaft zu finden, wobei diese angesichts der Volatilität der Orientierungen der Parteien weniger statisch ist und hier keine Partei eine offen antinationalistische Position vertritt. Betrachtet man das Verhältnis zu den Kriegsverbrechen ist trotz der staatlicherseits nach außen vertretenen adäquaten Symbolpolitik festzustellen, dass es üblich ist, von Serben begangene Kriegsverbrechen zu relativieren und diese oft in größere Zusammenhänge gestellt werden. Es gibt aber keine offen ethnonationalistische Rechtfertigung von Seiten der Parteien, nicht einmal mehr von der SRS. Im Rahmen der offiziellen Politik hat sich ein solches Verhalten weitgehend als Tabu etabliert, universalistische Opferbezüge stellen ein Substitut für partikulare Narrative dar. 


\section{Normdiffusion}

Es konnte gezeigt werden, dass jugoslawische beziehungsweise serbische Institutionen seit der Etablierung der Expertenkommission im Oktober 1992 mit den entsprechenden Organen der UN zusammenarbeiteten. Je nach Intensität des außenpolitischen Drucks auf die Regierung kooperierten sie mehr oder weniger umfangreich mit dem ICTY und führten sogar auf nationaler Ebene erste Prozesse durch. Ideen, Instrumente und Praktiken der Vergangenheitsaufarbeitung aus anderen Ländern wie Deutschland oder Südafrika wurden in Serbien übernommen. Mit der von der Konditionalitätspolitik erzwungenen Kooperation mit dem ICTY wurden internationale Erwartungen befriedigt. Während die Urteilssprüche des Tribunals in Serbien umstritten bleiben, adaptierte man die justizielle Aufarbeitung von Kriegsverbrechen auch auf nationaler Ebene. Die politische Rhetorik und symbolischen Praktiken der Aufarbeitung passten sich den gegenwärtigen westeuropäisch-amerikanischen Standards an. Die Frage, ob sich die Normvorstellungen über die Vergangenheitsaufarbeitung dabei auch angleichen, muss differenzierter beantwortet werden. Die Aufarbeitung von Kriegsverbrechen gilt als politischer und gesellschaftlicher Konsens und wird formal umgesetzt. Damit kann die erste These als bestätigt gelten. Allerdings sind immer wieder inhaltliche Einschränkungen festzustellen, die diskursive Grenzen bei der Anpassung an die internationale Norm markieren: die Zuweisung einer eindeutigen Täter-Opfer-Relation im Zusammenhang mit dem Genozidbegriff, eine Nichterwähnung serbischer Opfer oder eine Privilegierung anderer Opfer. So besteht zwar ein gesellschaftlicher Konsens darüber, dass Kriegsverbrechen aufgearbeitet werden müssen, die Frage, ob diese Aufarbeitung serbischen, antiserbischen oder universellen - und hierbei die Frage, ob damit möglicherweise relativierenden - Charakter haben soll, bleibt innenpolitisch umstritten. Anhand der Analyse der Debatten bei der Einführung von Aufarbeitungsinstrumenten und besonders des öffentlichen Diskurses über die Srebrenica-Deklarationen konnte gezeigt werden, dass die politische Landschaft wie auch die Zivilgesellschaft mindestens zweigeteilt ist in der Frage, was Aufarbeitung von Kriegsverbrechen bedeutet. Hier deutet sich eine diskursive Polarisierung an, die das Verhältnis zum partikulären serbischen Opfertum und damit die Frage der nationalen Loyalität bestimmt. Entscheidend ist also, wie mit den Verbrechen »der anderen" an den Serben umgegangen wird. Dementsprechend ist das Wie der Aufarbeitung ausschlaggebend im innenpolitischen Diskurs, wie in der zweiten These vermutet, und nicht die Befürwortung oder Ablehnung der Norm. Eine universelle Aufarbeitung erscheint als relativierende Ausweichstrategie. 
Darüber hinaus ist der Diskurs über Aufarbeitung auch eine Auseinandersetzung mit der Souveränität und der Frage, wie viel externe Einmischung mit der Legitimität der jeweiligen Regierungsparteien vereinbar ist. Aufgrund der machtpolitischen Durchsetzung einer Aufarbeitung von Kriegsverbrechen nach internationalen Vorstellungen in Form von externer Induzierung und Konditionalitätspolitik wurde die Frage der Aufarbeitung zu einer außenpolitischen Loyalitätsbekundung, zur Praxis der machtpolitischen Unterordnung und als Bedingung für einen EU-Beitritt auch zum innenpolitischen Argument gegen politische Gegner.

\section{Probleme externer Induzierung}

Vergleichsfälle zeigten, dass der zeitliche Abstand und die Generationenfolge zentral für die Aufarbeitung der Vergangenheit sind. So gab es nach einer Verurteilung von Führungsfiguren einer abgesetzten Herrscherriege selbst in besetzten Ländern längere Perioden des Beschweigens von Verbrechen dieses autoritären Vorgängerregimes oder von Kriegsverbrechen. Der temporäre Faktor wurde Serbien durch die externen Erwartungen an das Land genommen, der Kosovokonflikt wurde aufgearbeitet, noch während die Kriege andauerten. Die Aufarbeitung wurde damit zum Gegenstand der Kriegspropaganda und der Konflikt auf das Recht und internationale Institutionen ausgedehnt. Das kann im Falle einer Konflikttransformation zwar auch einen konfliktregelnden Effekt haben, aber gerade bei einer asymmetrischen Privilegierung bestimmter Konfliktparteien und deren Opfergruppen auch nachhaltig zur Institutionalisierung des Konflikts beitragen. Aufgrund der seit seiner Etablierung vorstrukturierten »einen Wahrheit« des bosniakisch-internationalen Narrativs, das das ICTY und die es unterstützenden Akteure beibehielten, war eine Harmonisierung mit nationalen und lokalen serbischen Konfliktdeutungen unmöglich. Besonders die Aufrechterhaltung des Genozidtopos war einem gemeinsamen Narrativ abträglich. Weiterhin fehlte im serbischen Beispiel die notwendige gesellschaftliche und politische Unterstützung der Norm und ihrer Institutionen, weshalb eine Kooperation mit dem ICTY auch erzwungen werden musste. Diese Ergebnisse unterstreichen die von Roger Duthie herausgestellten unbeabsichtigten Konsequenzen extern induzierter Aufarbeitung. ${ }^{1}$ 


\section{Probleme transnationaler Normsozialisationsprozesse}

Eine zentrale Hürde für eine erfolgreiche Normsozialisation sind die Glaubwürdigkeit der Institutionen und Unterstützer einer Norm an sich. So lange auf horizontaler und vertikaler Ebene politische Selektivität in der vermeintlich universellen Anwendung des Völkerstrafrechts herrscht ${ }^{2}$ und die Normanwendung global inkonsistent bleibt, ist eine erfolgreiche und umfassende Normsozialisation im internationalen System unwahrscheinlich. Stattdessen erlernen Zielländer, dass politische Interessen und Doppelmoral eine höhere Geltung haben und dass Normen nicht aus idealistischen Gründen und Überzeugung befolgt werden sollten, sondern in erster Linie, um sich einem machtpolitischen Gefüge unterzuordnen. Die Legitimität von Institutionen wie dem ICTY, das gleichzeitig den Anspruch von Neutralität erhebt, wird dadurch ausgehöhlt und in Verbindung mit der Konditionalitätspolitik noch verstärkt. Die Konsequenz der Konditionalitätspolitik, wenn nationale Eliten in ein Dilemma zwischen nationalen und internationalen Erwartungen hinsichtlich der Aufarbeitung der Vergangenheit geraten, beschrieb Brian Grodksy als »compromise justice ${ }^{3}$ : Der zu findenden Kompromiss über den Umgang mit der Vergangenheit ist abhängig von der Verhandlungsmacht und den Präferenzen der sich gegenüberstehenden pressure groups sowie der Einstellung der lokalen Eliten. Das Ergebnis ist eine Politik, die unterhalb dessen bleibt, was internationale Akteure bevorzugen, doch über das hinausgehen, was lokal unterstützt wird. Die Aufarbeitung von Kriegsverbrechen impliziert innenpolitische Destabilisierung und nationalistische Gegenreaktion, wie das Beispiel Serbiens anschaulich demonstriert. Somit werden im Fall von compromise justice zwar formal die Prozeduren und Normen der Vergangenheitsaufarbeitung übernommen, sozialer Wandel bleibt aber weitgehend aus. Wie das Fallbeispiel Serbien gezeigt hat, ist eine Vergangenheitsaufarbeitung, in der die nationalen Eliten zum Handeln gezwungen werden, dann erfolgreich, wenn sie den nationalen Interessen entspricht. Diese Begründung kommunizierten die serbischen Regierungschefs gerade bei Zugeständnissen in der Kooperation mit dem ICTY aufgrund internationaler Erwartungen nach innen. Die so offensichtliche Funktionalisierung der Aufarbeitung von Kriegsverbrechen stand einer Norminternalisierung auf gesellschaftlicher Ebene im Weg. Nach außen nutzten serbische Politiker eine universalistische Rhetorik, die auch

2 Vgl. Kaleck, Wolfgang: Mit zweierlei Maß. Der Westen und das Völkerstrafrecht (= Schriftenreihe des Österreichischen Ost- und Südosteuropa-Instituts 1312), Bonn: Bundeszentrale für politische Bildung 2012.

3 B. Grodsky: »International Prosecutions«, S. 692. 
national partikulare Deutungen mit einschloss, um externe Erwartungen zu bedienen. Der externe Druck unterminierte das Potential reformorientierter Parteien und den normativen Gehalt der Vergangenheitsaufarbeitung. Dadurch, dass Aufarbeitungspolitik von außen erzwungen werden konnte, wurde anstelle einer Auseinandersetzung mit Kriegsverbrechen kontinuierlich ein Konflikt über die compliance geführt. Die Politik der Durchsetzung half zwar dem ICTY, war aber für die serbische Aufarbeitung von Kriegsverbrechen schädlich, indem sie den Fokus von den Kriegsverbrechen und der Auseinandersetzung mit Verantwortung und Schuld nahm und dessen normatives Potential unterminierte. Für serbische Akteure gilt das Kapitel der Aufarbeitung der Kriege nunmehr als weitgehend geschlossen.

\section{Lessons learned}

Aus dem serbischen Fallbeispiel kann abgeleitet werden, dass eine internationale Strafgerichtsbarkeit nur dann anerkannt wird, wenn sie die Neutralität und die Gleichbehandlung vor dem Recht einhält, die sie beansprucht. Dies muss für alle Konfliktparteien, aber auch für intervenierende Dritte gelten. Eine Politisierung des Rechts durch die Pflege von double standards ermöglicht sonst statt seiner Konflikt regelnden Funktion neues Konfliktpotential. Wie gezeigt wurde, ist für die Verankerung einer Norm die Frage von ownership und cultural match zentral. Nur wenn möglichst viele gesellschaftliche Kräfte hinter einer Norm stehen, kann sie verankert werden. In Serbien war das Gegenteil der Fall: Indem die Aufarbeitung von Kriegsverbrechen auf mehreren Ebenen als antinationales Projekt verhandelt und verstanden wurde, wurde sie hochgradig politisiert. Nicht nur in der Beziehung zu den anderen Konfliktparteien und zum ICTY, sondern auch innenpolitisch blieb die Fraktionsbildung bestimmend, statt gemeinsam ein Modell der Aufarbeitung, auch zum Zweck der nationalen Aussöhnung, zu entwickeln. Es wäre zentral gewesen, auch gemäßigte serbische Kräfte für die Aufarbeitung zu gewinnen, die dann sowohl eine Aufarbeitung von Kriegsverbrechen als auch die Lustration von belasteten Personen aus öffentlichen Ämtern hätten vorantreiben können. Dazu wäre es notwendig gewesen, das Primat des Rechts über die Politik zu etablieren und zudem in der Konfliktwahrnehmung und in der Strafverfolgung eine Gleichbehandlung aller Konfliktparteien zu ermöglichen. Das hätte entweder eine Integration eines »serbischen Narrativs« oder, was sinnvoller scheint, den Versuch einer konsequenten Deethnisierung des Rechts bedeutet, damit keine nationalen Vereinnahmungen möglich gewesen wären. Für die Legitimität des Tribunals wäre es hilfreich gewesen, auf die nationalen und lokalen Konfliktnarrative einzugehen und ein Outreach-Programm 
frühzeitig einzusetzen und breit aufzustellen. Generell scheint es problematisch, auf die nachhaltige Wirkung von entfernten Tribunalen während eines laufenden Konflikts als Mittel der Abschreckung zu setzen. Sinnvoller wäre es, so ist zu vermuten, erst nach Konfliktende unter Einbezug aller politischen Kräfte eine hybride Gerichtsbarkeit zu etablieren. Mit Blick auf die Zeitperspektive sollten generationellen Dynamiken mehr Aufmerksamkeit gewidmet werden.

\section{Stärken und Schwächen des gewählten Vorgehens}

Der Rückgriff auf die historischen Erfahrungen im Umgang mit Kriegsverbrechen ermöglichte es, die Kontinuitäten von Deutungsmustern, Personen und Institutionen über die Jahrzehnte und politischen Systeme hinweg aufzuzeigen. Erst auf Grundlage einer Untersuchung der politischen Debatte anhand der wichtigsten Printmedien konnten die vorgebrachten Argumente, Widerstände und Mobilisierungszyklen dicht rekonstruiert werden. Auch das lexikometrische Verfahren lieferte wichtige Einsichten, indem es anhand des induktiven Vorgehens semantische Schwerpunkte aufzeigte, welche die Veränderungen im Umgang mit Kriegsverbrechen deutlich sichtbar machten. Neben dem Wandel zwischen 2005 und 2010 konnte auch aufgezeigt werden, dass es unterschiedliche Regeln im Umgang mit serbischen und anderen Opfern von Kriegsverbrechen gibt. Aus den Problemen bei der qualitativen diskursanalytischen Analyse ergeben sich wichtige Einsichten, aus denen sich zugleich Forschungsdesiderate ableiten. So kann eine qualitative Diskursanalyse zur Untersuchung der konkreten Gebrauchsregeln des Sprechens über Kriegsverbrechen nicht sinnvoll auf ein solch extensives Korpus angewandt werden, wie es in diesem Fall erhoben wurde. Zudem schien die qualitative Analyse überaus kleinteilig und nach der quantitativen Analyse und ersten qualitativen Testungen keine neuen Erkenntnisse mehr $\mathrm{zu}$ liefern.

\section{Forschungsdesiderate}

Eine vergleichende Untersuchung der lokalen Effekte internationaler Strafgerichtsbarkeit scheint dringend geboten. Eine erste Studie, die Medien, politische Diskurse und institutionellen Wandel einiger betroffener Länder in den Blick nehmen soll, erhielt vom Polnischen Wissenschaftsrat 2013 den Zuschlag für eine Förderung über fünf Jahre. Federführend koordinieren Klaus Bachmann aus Wroclaw, Irena Ristić aus Belgrad und Gerhard Kemp aus Stellenbosch das Projekt, das den Sudan, Libyen, Kenia, Ruanda und die ehemaligen jugoslawischen Republiken untersuchen wird. Auch der in der UN-Generalversammlung 
begonnene internationale Diskurs über die internationale Strafgerichtsbarkeit sollte wissenschaftlich eng begleitet werden, um auf die daraus entstehenden Probleme auf staatlicher Ebene aufmerksam zu werden und die normativen Verheißungen von transitional justice damit kontrastieren zu können. Darüber hinaus erscheint es sinnvoll, weitere Studien über die grundsätzliche Notwendigkeit von Aufarbeitung durchzuführen, die aufgrund ihrer historischen Kontingenz und aufgrund der der Norm inhärenten Politizität problematisiert werden sollte. Besonders großangelegte, vergleichende quantitative Forschungen über Vergangenheitsaufarbeitung stellen noch eine Leerstelle in der Literatur dar. So zeigte eine erste quantitative Überblicksstudie von Tricia D. Olsen, Leigh A. Payne und Andrew G. Reiter, dass kein einzelnes der untersuchten Aufarbeitungsinstrumente einen positiven Effekt auf die Stärkung der Demokratie und die Reduktion von Menschenrechtsverletzungen hat. ${ }^{4}$ Damit stellt sich, gerade vor dem Hintergrund der Gefahr von Rückschlägen auf innenpolitischer Ebene, grundsätzlich die Frage nach den Vorteilen einer Aufarbeitung für Staaten. Mit Blick auf die Wirkung auf zwischenstaatliche Beziehungen hat Jennifer Lind eine erste anregende Studie durchgeführt. ${ }^{5}$ Diese Fragestellung sollte allerdings systematisiert und auf mehrere Fälle ausgedehnt werden. Im Rahmen der Analyse von sozialen Diskursen nach Kriegs- und Gewaltverbrechen mutet der Ansatz vielversprechend an, über Schweigen und Nichterwähnen bestimmter Themen den Regeln des Sagbaren und Unsagbaren angesichts begangener Verbrechen auf den Grund zu kommen. ${ }^{6}$ Hier scheint die Entwicklung einer methodischen Systematik geboten, um Leerstellen zu untersuchen.

4 Vgl. T. D. Olsen/L. A. Payne/A. G. Reiter: Transitional Justice in Balance, S. 153161.

5 Vgl. J. M. Lind: Sorry States.

6 Vgl. Gordana Đerić: »O čemu govorimo kada čutimo i o čemu čutimo kada govorimo? Polazne pretpostavke za antropologiju čutanja o najbližnoj prošlosti« [Worüber reden wir, wenn wir schweigen, und worüber schweigen wir, wenn wir reden? Ausgangsannahmen für eine Anthropologie des Schweigens über die jüngste Vergangenheit], in: Filozofija i društvo 34 (2007) 3, S. 43-57. 



\section{Literatur/Quellen}

A.A.: »Nepoznat broj tela. MUP Srbije potvrdio da se grobnica nalazi kod Batajnice« [Unbekannte Zahl Körper. Innenministerium bestätigt Massengrab bei Batajnica], in: Blic online vom 14.6.2001, http:/www.blic.rs/stara _arhiva/hronika/4180/Nepoznat-broj-tela vom 22.4.2013.

Adorno, Theodor W.: »Was bedeutet: Aufarbeitung der Vergangenheit«, in: ders.: Eingriffe. Neun kritische Modelle, Frankfurt am Main: Suhrkamp 1963, S. 125-146.

Agentur Politikum: »Istraživanje stavova građana Srbije na temu Haga i rezolucije o Srebrenici« [Untersuchung der Standpunkte der Bürger Serbiens zum Thema ICTY und Srebrenica-Resolution], in: Nova srpska politička misao vom 18.3.2010, http://www.nspm.rs/istrazivanja-javnog-mnjenja/agencijapolitikum-istrazivanje-stavova-gradjana-srbije-na-temu-haga-i-rezolucije-osrebrenici-januar-2010.html?alphabet=1 vom 23.4.2013.

Akçam, Taner: Armenien und der Völkermord: Die Istanbuler Prozesse und die türkische Nationalbewegung, Hamburg: Hamburger Edition 2004.

Amnesty International: Serbia: Human Rights Defenders at Risk, Bericht vom 14.9.2009, https://www.amnesty.org/download/Documents/48000/eur700142009 en.pdf vom 22.8.2011.

Anastasakis, Othon: »The EU's Political Conditionality in the Western Balkans.

Towards a More Pragmatic Approach«, in: Southeast European and Black Sea Studies 8 (2008) 4, S. 365-377.

Anastasijević, Dejan: »Bombaški procesi« [Bombenprozesse], in: Vreme vom 31.7.1995, S. $16 \mathrm{f}$.

Anastasijević, Dejan: »Srebrenica za početnike« [Srebrenica für Anfänger], in: Vreme vom 2.6.2005, S. 18.

Assemblée nationale: Mission d'information commune (1) sur les événements de Srebrenica vom 22.11.2001, XI. législature, Rapport d'information no. 3413. 
Ast, Slobodanka: »Istina-odgovornost-pomirenje. Da li su Srbi krivi?« [Wahrheit - Verantwortung - Versöhnung. Sind die Serben schuld?], in: Vreme vom 25.3.2000, S. 11-14.

Außenministerium der Republik Serbien: Daily Survey vom 26.3.2005, http://www.mfa.gov.rs/Bilteni/Engleski/b260303_e.html\#N11 vom 6.2.2013.

B92: Istina, odgovornosti i pomirenja: Srbija pred izazovom suočavanja s prošlošću [Wahrheiten, Verantwortungen und Versöhnungen. Serbien vor der Herausforderung der Vergangenheitsaufarbeitung], Homepage der Konferenz vom 17.-19.3.2000 in Ulcinj, http://www.b92.net/trr/trr.html vom 11.5.2013.

B92: »Marović i Mesić razmenili izvinjenja građanima Hrvatske i SCG« [Marović und Mesić tauschen Entschuldigungen bei den Bürgern Kroatiens und Serbien-Montenegros aus], in: b92.net vom 10.9.2003, http://www.b92.net/ info/vesti/index.php?yyy $=2003 \& \mathrm{~mm}=09 \& \mathrm{dd}=10 \&$ nav_category $=11 \&$ nav_id= 119131 vom 4.4.2013.

B92: »Srebrenica: 10 godina od zločina« [Srebrenica: zehn Jahre seit dem Verbrechen], in: b92.net vom 11.7.2005, http://www.b92.net/info/vesti/ind ex.php?yyyy $=2005 \& \mathrm{~mm}=07 \& d d=11 \&$ nav_category $=12 \&$ nav_id $=172392$ vom 21.2.2013.

B92: »Tadić: Svi dugujemo izvinjenje« [Tadić: Alle schulden eine Entschuldigung], in: b92.net vom 6.12.2004, http://www.b92.net/info/vesti/ind ex.php?yyyy $=2004 \& m m=12 \& d d=06 \&$ nav_category $=11 \&$ nav_id $=157274$ vom 21.2.2013.

B92/Beta: »Tadić se izvinio građanima Hrvatske« [Tadić entschuldigt sich bei den Bürgern Kroatiens], in: b92.net vom 24.6.2007, http://www.b92.net/ info/vesti/index.php?yyy $=2007 \& \mathrm{~mm}=06 \& \mathrm{dd}=24 \&$ nav_category $=11 \&$ nav_id $=$ 252551 vom 23.2.2013.

Bačević, Batić: »Ko če se kome izviniti?« [Wer wird sich bei wem entschuldigen?], in: NIN vom 30.11.2000, S. $16 \mathrm{f}$.

Bašić, Natalija: »Völkermord vor Gericht. Kriegsverbrecherprozesse, Emotionen und der Umgang damit in Serbien«, in: Südosteuropa 59 (2011) 4, S. 396411.

Bass, Gary Jonathan: Stay the Hand of Vengeance. The Politics of War Crimes Tribunals (= Princeton Studies in International History and Politics), Princeton: Princeton University Press 2000.

Batt, Judy/Obradović-Wochnik, Jelena (Hg.): War Crimes, Conditionality and EU Integration in the Western Balkans (= Chaillot Paper 116), Paris: EU Institute for Security Studies 2009. 
Bayraktar, Seyhan: Politik und Erinnerung. Der Diskurs über den Armeniermord in der Türkei zwischen Nationalismus und Europäisierung (= Global Studies), Bielefeld: transcript 2010.

Becker, Jörg/Beham, Mira: Operation Balkan. Werbung für Krieg und Tod, Baden-Baden: Nomos, 2006.

Beham, Mira: Kriegstrommeln. Medien, Krieg und Politik, München: Deutscher Taschenbuch Verlag 1996.

Bekan, Milan: »Dekontaminacija vredne dokumentacije« [Dekontaminierung einer wertvollen Dokumentation], in: Pravda u tranziciji 5 (2009) 13, http:// www.tuzilastvorz.org.rs/html_trz/\%28casopis\%29/srp/srp13/2191.pdf vom 10.9.2010.

Beta: »Del Ponte submits negative report«, in: b92.net vom 10.12.2007, http:// www.b92.net/eng/news/crimes-article.php?yyyy $=2007 \& \mathrm{~mm}=12 \& \mathrm{dd}=10 \& \mathrm{nav}_{-}$ $\mathrm{id}=46080$ vom 19.4.2013.

Beta: »Marović se u Sarajevu izvinio za zla počinjena BIH«, in: b92.net vom 13.11.2003, http://www.b92.net/info/vesti/index.php?yyyy=2003\&mm=11\&dd $=13 \&$ nav_category $=11 \&$ nav_id=124553 vom 4.4.2013.

Beta: »Veterani zakazali >Paradu srama< istog dana kada se održava Parada ponosa« [Veteranen planen 〉Parade der Schande` am gleichen Tag, an dem die Parade des Stolzes stattfindet], in: Blic online vom 11.9.2012, http://www.blic.rs/ Vesti/Drustvo/342241/Veterani-zakazali-Paradu-srama-istog-dana-kada-se-od rzava-Parada-ponosa vom 24.4.2013.

Beta: »Vlada izjednačeno osudila zločine« [Regierung verurteilte Verbrechen ausgeglichen], in: b92.net vom 7.7.2005, http://www.b92.net/info/vesti/inde x.php?yyyy $=2005 \& \mathrm{~mm}=07 \& d d=07 \&$ nav_category $=11 \&$ nav_id $=172193$ vom 25.8.2011.

Bieber, Florian: »Serbien zwischen Europa und Kosovo. Politische Entwicklungen seit der Unabhängigkeitserklärung«, in: Südosteuropa 56 (2008) 3, S. 318-335.

Bieber, Florian: »The Role of the Yugoslav People's Army in the Dissolution of Yugoslavia«, in: Jasna Dragović-Soso/Lenard Cohen (Hg.): State Collapse in South-Eastern Europe. New Perspectives on Yugoslavia's Disintegration (= Central European Studies), West Lafayette: Purdue University Press 2007, S. 301-332.

Bilbija, Bojan: »Poklonjenje žrtvama na Ovčari« [Das Ehren der Opfer in Ovčara], in: Politika vom 5.11.2010, S. A5.

Biserko, Sonja (Hg.): Milošević vs. Jugoslavija [Milošević gegen Jugoslawien] (= Biblioteka Svedočanstva 20), 2 Bd., Belgrad: Zagorac 2004. 
Biserko, Sonja: »Reporting from the Writing Fields, or: How to Prepare Genocide in Five Years «, Vortrag an der University of California in Berkeley bei der Konferenz »Reporting from the Killing Fields" vom 11.4.1997, http://www.nettime.org/Lists-Archives/nettime-1-9705/msg00066. html vom 5.4.2013.

Blom, Johan C. H./Romijn, Peter (Hg.): Srebrenica. Reconstruction, Background, Consequences and Analyses of the Fall of a $>$ Safe $<$ Area, Amsterdam: NIOD 2002.

Boarov, Dimitrije: »Intervju: prof. dr. Momčilo Grubač, minister pravde SRJ: Samo se zakonu može robovati« [Interview: Prof. Dr. Momčilo Grubač, Justizminister: Nur dem Gesetz kann man frönen], in: Vreme vom 9.11.2000, S. $12 \mathrm{ff}$.

Bock, Petra/Wolfrum, Edgar: »Einleitung«, in: dies. (Hg.): Umkämpfte Vergangenheit. Geschichtsbilder, Erinnerung und Vergangenheitspolitik im internationalen Vergleich (= Sammlung Vandenhoeck), Göttingen: Vandenhoeck \& Ruprecht 1999, S. 7-14.

Boeck, Katrin: Von den Balkankriegen zum Ersten Weltkrieg (= Südosteuropäische Arbeiten 97), München: Oldenbourg 1996.

Boekh, Katrin: »Zur Religionsverfolgung in Jugoslawien 1944-1953. Stalinistische Anleihen unter Tito«, in: Konrad Clewing/Oliver Jens Schmitt (Hg.): Südosteuropa. Von vormoderner Vielfalt und nationalstaatlicher Vereinheitlichung, München: Oldenbourg 2005, S. 431-462.

Boekle, Henning/Rittberger, Volker/Wagner, Wolfgang: Normen und Außenpolitik. Konstruktivistische Außenpolitiktheorie (= Tübinger Arbeitspapiere zur Internationalen Politik und Friedensforschung 34), Tübingen: Institut für Politikwissenschaft 1999.

Boekle, Henning/Rittberger, Volker/Wagner, Wolfgang: »Soziale Normen und normgerechte Außenpolitik. Konstruktivistische Außenpolitiktheorie und deutsche Außenpolitik nach der Vereinigung «, in: Zeitschrift für Politikwissenschaft 11 (2001) 1, S. 71-103.

Bogdanović, Dušan/Kovačević-Vučo, Biljana: Zloupotrebljene institucije. Ko je bio ko u Srbiji 1987-2000. godine [Mißbrauchte Institutionen. Wer war wer in Serbien 1987-2000], Belgrad: Fond Biljana Kovačević-Vučo 2011.

Bogdanović, Srboljub: »Kolektivno nevini« [Kollektiv unschuldig], in: NIN vom 31.10.2002, S. 22-25.

Bonacker, Thorsten: »Inklusion und Integration durch Menschenrechte. Zur Evolution der Weltgesellschaft«, in: Zeitschrift für Rechtssoziologie 24 (2003) 2, S. 121-149. 
Bonacker, Thorsten/Brodocz, André: »Im Namen der Menschenrechte. Zur symbolischen Integration der internationalen Gemeinschaft durch Normen«, in: Zeitschrift für Internationale Beziehungen 8 (2001) 2, S. 178-208.

Božić, Ivan/Cir-Kovit, Sima/Ekmetić, Milorad/Dedijer, Vladimir (Hg.): Istorija Jugoslavije [Geschichte Jugoslawiens], Belgrad: Prosveta 1972.

Bremer, Thomas/Stobbe, Heinz-Günther (Hg.): Serbiens Weg in den Krieg. Kollektive Erinnerung, nationale Formierung und ideologische Aufrüstung, Berlin: Berlin-Verlag Spitz 1998.

Brunborg, Helge/Lyngstad, Torkild Hovde/Urdal, Henrik: »Accounting for Genocide. How Many Were Killed in Srebrenica?«, in: European Journal of Population/Revue europenne de Demographie 19 (2003) 3, S. 229-248.

Bugarski, Ranko: Jezik od mira do rata [Die Sprache vom Frieden zum Krieg] (= Biblioteka XX vek 81), Belgrad: Slovograf 1995.

Bulajić, Milan/Samardžić, Radovan (Hg.): Ratni zločini i zločini genocida 19911992. Naučno savetovanje Odbora SANU za sakupljanje građe o genocidu protiv srpskog naroda i drugih naroda Jugoslavije u XX veku i Državne komisije za ratne zločine i zločine genocida, održano od 6. do 8. avgusta 1992. godine u Beogradu [Kriegsverbrechen und Verbrechen des Genozids 19911992. Wissenschaftliche Beratung des SANU-Komitees zur Sammlung von Materialien über den Genozid am serbischen Volk und anderen Völkern Jugoslawiens im 20. Jahrhundert und der Staatskommission für Kriegsverbrechen und Verbrechen des Genozids, abgehalten 6.-8.8.1992], Belgrad: Srpska akademija nauka i umetnosti 1993.

Bundesparlament der Bundesrepublik Jugoslawien: Zakon o osnivanju Komisiju za prikupljanje podataka radi utvrđivanja zločina genocida i drugih zločina protiv čovečnosti i međunarodnog prava koji su počinjeni nad stanovništvom srpske i drugih nacionalnosti u vreme oružanih sukoba u Hrvatskoj i drugim delovima zemlje [Gesetz über die Errichtung einer Kommission zur Sammlung von Daten zur Feststellung der Verbrechen des Völkermords und anderer Verbrechen gegen die Menschlichkeit, begangen an Bevölkerung serbischer und andere Nationalitäten in der Zeit des bewaffneten Konflikts in Kroatien und in anderen Teilen des Landes], in: Službeni list SRJ 18 (1992).

Bundesparlament der Bundesrepublik Jugoslawien: Zakon o prikupljanju i dostavljanju podataka o izvršenim zločinima protiv čovečnosti i međunarodnog prava [Gesetz über das Sammeln und Dokumentieren von Informationen über begangene Verbrechen gegen die Menschlichkeit und das internationale Recht], in: Službeni list SRJ 37 (1993). 
Bundesparlament der Bundesrepublik Jugoslawien: Zakon o saradnji Srbije i Crne Gore sa međunarodnim tribunalom za krivično gonjenje lica odgovornih za teška kršejna međunarodnog humanitarnog prava počinjena na teritoriji bivše Jugoslavije od 1991. godine [Gesetz über die Zusammenarbeit Serbien und Montenegros mit dem Internationalen Tribunal für die Strafverfolgung von verantwortlichen Personen für auf dem Territorium des ehemaligen Jugoslawien seit 1991 begangene schwere Verletzungen des Internationalen Völkerrechts], in: Službeni list SRJ 18 (2002) sowie in: Službeni list SCG 16 (2003).

Bundesregierung der Republik Jugoslawien: Četvrti izveštaj vlade SRJ o počinjenim zločinima protiv čovečnosti i međunarodnog prava na području bivše SFRJ [Vierter Bericht der Regierung der Bundesrepublik Jugoslawien über begangene Verbrechen gegen die Menschlichkeit und das internationale Recht auf dem Boden der ehemaligen SFRJ], 1995, http://www.slobodanmilosevic.org/documents/reports/Serbian/4-izv-u.htm vom 17.1.2013.

Bundesregierung der Republik Jugoslawien: Deveti izveštaj Vlade SRJ o izvršenim ratnim zločinima na području prethodne Jugoslavije pripremljen od strane Komiteta za prikupljanje podataka o izvršenim zločinima protiv čovečnosti i međunarodnog prava [Neunter Bericht der Regierung der SRJ über begangene Kriegsverbrechen auf dem Gebiet des früheren Jugoslawien, angefertigt vom Kommittee für die Sammlung von Daten über begangene Verbrechen gegen die Menschlichkeit und das internationale Recht] vom 2.4.1998, http://www.slobodan-milosevic.org/documents/reports/Serbian/9-uvod. htm vom 21.1.2013.

Bundesregierung der Republik Jugoslawien: Drugi izveštaj komisiji eksperata ustanovljenoj na osnovi rezolucije Saveta Bezebdnosti 780 (1992) [Zweiter Bericht an die Expertenkommission auf Grundlage der Resolution des Sicherheitsrates 780 (1992)], http://www.slobodan-milosevic.org/documents/ reports/Serbian/2-izv-u.htm vom 3.1.2013.

Bundesregierung der Republik Jugoslawien: Izveštaj komisiji eksperata ustanovljenoj na osnovi rezolucije Saveta Bezbednosti 780 (1992) [Bericht an die Expertenkommission auf Grundlage der Resolution des Sicherheitsrates 780 (1992)], 1992, http://www.slobodan-milosevic.org/documents/reports/Serbian/ 1-izv.htm vom 3.1.2013.

Bundesregierung der Republik Jugoslawien: Odgovornost Alije Izetbegovića za ratne zločine u logoru Čelebići i na području Konjica [Die Verantwortung Alija Izetbegović' für Kriegsverbrechen im Lager Ćelebići und auf dem Gebiet Konjic], 1998, http://www.slobodan-milosevic.org/documents/reports/ Serbian/alija.htm vom 21.1.2013. 
Bundesregierung der Republik Jugoslawien: Treći izveštaj vlade SRJ o počinjenim ratnim zločinima na prodručju bivše SFRJ 1994 [Dritter Bericht der Regierung Jugoslawiens über begangene Kriegsverbrechen auf dem Territorium der ehemaligen SFRJ 1994], April 1994, http://www.slobodan-milosevic. org/documents/reports/Serbian/3-izv.htm vom 16.1.2013.

Cakić, Milan: »Lustracija u Evropi i Srbiji. Motivacija za donošenje zakona o lustraciji i njihove društvene funkcije« [Lustration in Europa und in Serbien. Motivation für die Gesetzgebung zu Lustration und ihre gesellschaftlichen Funktionen], in: Sociologija. Časopis za sociologiju, socijalnu psihologiju i socijalnu antropologiju 52 (2010) 3, S. 285-306.

Calic, Marie-Janine: Geschichte Jugoslawiens im 20. Jahrhundert (= Europäische Geschichte im 20. Jahrhundert), München: C.H. Beck 2010.

Čanak, Nenad: »Antiratni aktivisti su jedini pravi heroji« [Antikriegsaktivisten sind die einzigen wahren Helden], in: Slobodna Vojvodina 10 (2007) 19, S. 2.

Čavoški, Kosta: Hag protiv pravde [Haag gegen die Gerechtigkeit], Belgrad: Centar za srpske studije 1996.

Čavoški, Kosta: Haški minotaur tom drugi. Hag protiv istine [Haager Minotaurus Teil 2. Haag gegen die Gerechtigkeit], Belgrad: Beoknjiga 2007.

Čekerevac, Mirjana: »Usvojena deklaracija o Srebrenici« [Deklaration zu Srebrenica verabschiedet], in: Politika vom 31.3.2010, S. A1.

Ćerović, Stojan: »Haški pitomci« [Haager Zöglinge], in: Vreme vom 17.10.1994, S. 8 f.

Ćirić, Aleksandar: »Ratni zločini. Balkanska arheologija« [Kriegsverbrechen. Balkanische Archäologie], in: Vreme vom 15.11.1993, S. 26 f.

Čivikov, Germinal: Srebrenica. Der Kronzeuge, Wien: Promedia 2009.

Clark, Janine Natalya: „Collective Guilt, Collective Responsibility and the Serbs«, in: East European Politics and Societies 22 (2008) 3, S. 668-692.

Cohen, Roger: »Serbs Put a Serb On Trial for War Crimes«, in: The New York Times vom 12.7.1994, http://www.nytimes.com/1994/06/12/world/serbs-puta-serb-on-trial-for-war-crimes.html vom 8.4.2011.

Čolak, Jasmina: »Mnoge patriote pokazaće se kao zločinci« [Viele Patrioten werden sich als Verbrecher herausstellen], in: Danas vom 18.6.2005, S. 7.

Čongradin, Snežana: »Izvinjenje zbog zločina, uz skrivanje grobnica žrtava: Nakon posete Borisa Tadića u Vukovaru« [Entschuldigung wegen der Verbrechen, nebst dem Verstecken von Opfergräber. Nach dem Besuch Boris Tadić' in Vukovar], in: Danas online vom 6.11.2010, http://www.danas.rs/ dodaci/nedelja/plave_strane/izvinjenje_zbog_zlocina_uz_skrivanje_grobnica_z rtava.45.html vom 3.12.2013. 
Cortell, Andrew P./Davis Jr., James W.: »Understanding the Domestic Impact of International Norms. A Research Agenda«, in: International Studies Review 2 (2000) 1, S. 65-87.

Ćosić, Dobrica: »Kriza i krivci« [Krise und Schuldige], in: NIN vom 9.4.1993, S. $51 \mathrm{ff}$.

Crocker, David A.: »Transitional Justice and International Civil Society. Toward a Normative Framework«, in: Constellations 5 (1998) 4, S. 492-517.

Cvetićanin, Radivoj: »Kraj rata« [Ende des Kriegs], in: Danas vom 5.11.2010, S. 6.

Cvijanović, Željko: »Del Ponte in Belgrade. Hague Tribunal Prosecutor Carla Del Ponte Storms out of Meeting with President Kostunica«, in: Institute for War \& Peace Reporting online vom 23.1.2001, http://iwpr.net/print/reportnews/del-ponte-belgrade vom 15.9.2010.

David, Lea: »Mediating international and domestic demands: Mnemonic battles surrounding the monument to the fallen of the wars of the 1990s in Belgrade«, in: Nationalities Papers 42 (2014) 4, S. 655-673.

Dedijer, Vladimir: Vatikan i Jasenovac. Dokumenti [Der Vatikan und Jasenovac. Dokumenti], Belgrad: Izdavačka radna organizacija $>\operatorname{Rad}<1987$.

Dedijer, Vladimir/Miletić, Antun: Genocid nad Muslimanima 1941-1945. Zbornik dokumenata i svedočenja [Genozid an den Muslimen 1941-1945. Sammlung von Dokumenten und Bezeugungen] (= Biblioteka $>$ Refleksi $<$ ), Sarajevo: Svjetlost 1990.

Dedijer, Vladimir/Miletić, Antun: Proterivanje Srba sa ognjišta 1941-1944. Svedočanstva [Die Verbannung der Serben von der Feuerstelle 1941-1944. Zeugnisse], Belgrad: Prosveta 1989.

Dedijer, Vladimir/Miletić, Antun: Protiv zaborava i tabua. Jasenovac 1941-1991 [Gegen das Vergessen und das Tabu. Jasenovac 1941-1991], Sarajevo: Pregres 1991.

Del Ponte, Carla: Im Namen der Anklage. Meine Jagd auf Kriegsverbrecher und die Suche nach Gerechtigkeit, Frankfurt am Main: S. Fischer 2009.

Đerić, Gordana: »O čemu govorimo kada čutimo i o čemu čutimo kada govorimo? Polazne pretpostavke za antropologiju čutanja o najbližnoj prošlosti« [Worüber reden wir, wenn wir schweigen, und worüber schweigen wir, wenn wir reden? Ausgangsannahmen für eine Anthropologie des Schweigens über die jüngste Vergangenheit], in: Filozofija i društvo 34 (2007) 3, S. 43-57.

Deutsche Welle/AFP : „EU Welcomes Serbia War Crimes Action Plan, Awaits Results«, in: Deutsche Welle online vom 18.7.2006, http://www.dw.de/eu-wel comes-serbia-war-crimes-action-plan-awaits-results/a-2099346 vom 28.4.2013. 
Dević, Ana: »Anti-war Initiatives and the Unmaking of Civic Identities in the Former Yugoslav Republics«, in: Journal of Historical Sociology 10 (1997) 2, S. 127-156.

Diamandouros, Nikiforos P./Larrabee, Stephen F.: Democratization in Southeastern Europe. Theoretical Considerations and Evolving Trends (= Working Paper 129), Madrid: Juan March Institute 1999.

Đilas, Milovan: Der Krieg der Partisanen. Memoiren, 1941-1945, Weinheim: Fritz Molden 1978.

Dimitrijević, Bojan B.: »Slučaj likvidacije zarobljenika posle zauzimanja Srebrenice jula 1995. Problemska pitanja« [Der Fall der Liquidierung Gefangener nach der Einnahme Srebrenicas im Juli 1995. Problemstellungen], in: Istorija 20. veka 22 (2004) 1, S. 131-156.

Dimitrijević, Nenad: »Apology Instead of Reconciliation. A View from Serbia«, in: Peščanik.net vom 12.11.2011, http://pescanik.net/2011/11/apology-instead -of-reconciliation-a-view-from-serbia vom 24.11.2011.

Dimitrijević, Nenad: »Prošlost, odgovornost, budućnost« [Vergangenheit, Verantwortung, Zukunft], in: Reč. Časopis za književnost, kulturu i društvena pitanja 57 (2000) 9, S. 5-16.

Dimitrijević, Nenad: »Serbia after the Criminal Past. What Went Wrong and What Should be Done«, in: The International Journal of Transitional Justice 2 (2008) 1, S. 5-22.

Dimitrijević, Vojin: „Domestic War Crimes Trials in Serbia, BosniaHerzegovina and Croatia«, in: Judy Batt/Jelena Obradović-Wochnik (Hg.): War Crimes, Conditionality and EU Integration in the Western Balkans (=Chaillot Paper 116), Paris: EU Institute for Security Studies 2009, S. 8399.

Dimitrijević, Vojin: »Izgledi za utvrđivanje istine i postizanje pomirenja u Srbiji« [Perspektiven auf die Feststellung der Wahrheit und das Erreichen von Versöhnung in Serbien], in: Reč. Časopis za književnost, kulturu i društvena pitanja, 62 (2001) 8, S. 69-74.

Dimitrijević, Vojin: »Justice Must be Done and Been Seen to Be Done. The Milosevic Trial«, in: East European Constitutional Review 11 (2002) 1-2, S. 5962. 
Dimitrijević, Vojin: »Od pijanca i plota do devete rupe na svirali. Ljudska prava u Jugoslaviji i Srbiji, pre i posle novembra 1989. godine« [Vom Betrunkenen, der Umzäunung bis zum neunten Loch auf der Flöte. Menschenrechte in Jugoslawien und Serbien, vor und nach November 1989], in: Ivan Čolovićv (Hg.): Zid je mrtav, živeli zidovi! Pad Berlinskog zida i raspad Jugoslavije [Die Mauer ist tot, es leben die Mauern! Der Fall der Berliner Mauer und der Zerfall Jugoslawiens], Belgrad: Biblioteka XX vek 2009, S. 107-128.

Dimitrijević, Vojin: »Ostareli zlikovci i zli starci« [Greise Schurken und böse Alte], in: Reč. Časopis za književnost, kulturu i društvena pitanja 57 (2000) 3, S. $25 \mathrm{ff}$.

Dimitrijević, Vojin: »The War Crimes Tribunal in the Yugoslav Context«, in: East European Constitutional Review 5 (1996) 4, S. 85-92.

Dimitrijević, Vojin/Hadži-Vidanović, Vidan/Ivanović, Ivan/Marković, Žarko/ Milanović, Marko: Haške nedoumice. Poznato i nepoznato o Međunarodnom krivicnom tribunalu za bivšu Jugoslaviju [Haager Ratlosigkeiten. Bekanntes und Unbekanntes über das ICTY], Belgrad: Beogradski centar za ljudska prava 2010.

Dobbels, Mathias: Serbia and the ICTY. An Analysis of EU Conditionality, Masterarbeit, Brügge 2009.

Dobromirović, Milan/Šaronjić, Ivana: »Jaja i grafiti ispred Skupštine« [Eier und Grafitti vor dem Parlament], in: Kurir vom 2.4.2010, S. 2

Đorđević, Đorđe: Summary Report Regarding Local, Regional and International Documentation of War Crimes and Human Rights Violations in the Former Yugoslavia, New York: International Center for Transitional Justice 2002.

Dragović-Soso, Jasna: »Apologising for Srebrenica. The Declaration of the Serbian Parliament, the European Union and the Politics of Compromise«, in: East European Politics and Societies 28 (2012) 2, S. 163-179.

Dragović-Soso, Jasna/Gordy, Eric D.: »Coming to Terms with the Past. Transitional Justice and Reconciliation in the Post-Yugoslav Lands«, in: James Ker-Lindsay/Dejan Djokić (Hg.): New Perspectives on Yugoslavia. Key Issues and Controversies, Milton Park/New York: Routledge 2011, S. 193213.

DSS: Deklaracija o osudi ratnih zločina na prostoru nekadašnje Jugoslavije [Deklaration über die Verurteilung der Kriegsverbrechen auf dem Gebiet des ehemaligen Jugoslawien], Belgrad: DSS 2005.

DSS Omladina: „Srebrenica - Ne u moje ime« [Srebrenica - Nicht in meinem Namen], http://www.youtube.com/watch?v=pCIMTdn-DjM vom 28.4.2013. 
Dudek, Peter: »Sozialwissenschaften und Nationalsozialismus. Zum Stand der disziplingeschichtlichen >Vergangenheitsbewältigung««, in: Neue Politische Literatur 35 (1990), S. 407-442.

Dudek, Peter: »' Vergangenheitsbewältigung<: Zur Problematik eines umstrittenen Begriffs«, in: Aus Politik und Zeitgeschichte 42 (1992) 1-2, S. 44-53.

Duijzings, Ger: »Commemorating Srebrenica. Histories of Violence and the Politics of Memory in Eastern Bosnia«, in: ders. / Xavier Bougarel/Elissa Helms (Hg.): The New Bosnian Mosaic. Identities, Memories and Moral Claims in a Post-War Society, Farnham/Burlington: Ashgate 2007, S. 141-166.

Dulović, Jovan: »Šabačka posla« [Šabačker Angelegenheiten], in: Vreme vom 26.12.1994, S. 23.

Đuretić, Veselin: Saveznici i jugoslovenska ratna drama [Die Alliierten und das jugoslawische Kriegsdrama], Belgrad: Narodna knjiga/Balkanološki institut SANU 1985.

Đurić, Silvija/Stevanović, Vidosav: Golgota i vaskrs Srbije 1914-1918 [Golgatha und Auferstehen Serbiens 1914-1918] (= Istorijsko-memoarska dela [Historisch-autobiographische Werke), 2 Bd., Belgrad: Beogradski izdavačko-grafički zavod/Partizanska knjiga 1986.

Duthie, Roger: »Afterword. The Consequences of Transitional Justice in Particular Contexts«, in: Alexander Laban Hinton/Stephen E. Bronner/Nela Navarro (Hg.): Transitional Justice. Global Mechanisms and Local Realities after Genocide and Mass Violence, New Brunswick: Rutgers University Press 2010, S. 249-256.

Dveri srpske: »Skupštinska deklaracija o Srebrenici« [Die parlamentarische Deklaration über Srebrenica], März 2010, http://www.dverisrpske.com/tekst/ 1791741 vom 4.3.2011.

Dyrberg, Torben Bech: »Diskursanalyse als postmoderne politische Theorie«, in: Oliver Marchart (Hg.): Das Undarstellbare der Politik. Zur Hegemonietheorie Ernesto Laclaus, Wien: Turia + Kant 1998, S. 23-65.

Elster, Jon: »Coming to Terms with the Past. A Framework for the Study of Justice in the Transition to Democracy«, in: Archives Européennes de Sociologie 39 (1998) 18, S. 7-48.

Engert, Stefan/Jetschke, Anja: »Transitional Justice 2.0. Zur konzeptionellen Erweiterung eines noch jungen Forschungsprogramms«, in: Die FriedensWarte. Journal of International Peace and Organization 86 (2011) 1-2, S. 15 43.

Erjavec, Karmen/Volčič, Zala: »Rehabilitating Milošević. Posthumous Coverage of the Milošević Regime in Serbian Newspapers«, in: Social Semotics 19 (2009) 2, S. 125-143. 
Europäisches Parlament: 11. Juli: Tag des Gedenkens an die Opfer des Massakers von Srebenica. Entschließung des Europäischen Parlaments EP-Dok. P6_TA(2009)0028 vom 15.1.2009.

Europäisches Parlament: Entschließung des Europäischen Parlaments zu der Zukunft des Balkans zehn Jahre nach Srebrenica, EP-Dok. P6_TA(2005)0296 vom 7.7.2005.

European Commission: Commission Opinion on Serbia's Application for Membership of the European Union. Analytical Report, EU-Dok. SEC (2011) 1208 vom 12.10.2011.

European Commission: Commission Opinion on Serbia's Application for Membership of the European Union, EU-Dok. COM (2011) 668/F1 vom 12.10.2011.

European Commission: Federal Republic of Yugoslavia: Country Strategic Paper 2002-2006, http://ec.europa.eu/enlargement/pdf/financial_assistance/ cards/publications/fry_strategy_paper_en.pdf vom 11.4.2013.

European Commission: Report on the Preparedness of Serbia and Montenegro to negotiate a Stabilisation and Association Agreement with the European Union. Commission Staff Working paper, EU-Dok. SEC (2005) 478 final vom 12.4.2005

European Commission: Serbia 2005 Progress Report, EU-Dok. SEC (2005) 1428 vom 9.11.2005.

European Commission: Serbia 2006 Progress Report, EU-Dok. SEC (2006) 1389 vom 8.11.2006.

European Commission: Serbia 2007 Progress Report, EU-Dok. SEC (2007) 1435 vom 6.11.2007.

European Commission: Serbia 2008 Progress Report, EU-Dok. SEC (2008) 2698/F vom 5.11.2008.

European Commission: Serbia 2009 Progress Report, EU-Dok. SEC (2009) 1339 vom 14.10.2009.

European Commission: Serbia 2010 Progress Report, EU-Dok. SEC (2010) 1330 vom 9.11.2010.

European Commission: Serbia 2012 Progress Report, EU-Dok. SWD (2012) 333/F1 vom 10.10.2012.

European Council: Council Common Position on Further Measures in Support of the Effective Implementation of the Mandate of the International Criminal Tribunal for the Former Yugoslavia (ICTY), Dok. 2004/694/CFSP, in: Official Journal of the European Union L 315/52 vom 14.10.2004. 
European Council: Council Decision of 14 June 2004 on the principles, priorities and conditions contained in the European Partnership with Serbia and Montenegro including Kosovo as defined by the United Nations Security Council Resolution 1244 of 10 June 1999, in: Official Journal of the European Union L 227 vom 26.6.2004.

European Court of Human Rights: Case of Vučković and others v. Serbia. Judgement, Application Nr. 17153/11 vom 28.8.2012.

Fatić, Aleksandar/Bulatović, Aleksandra: »Justice and Reconciliation in the International Criminal Tribunal for the Former Yugoslavia«, in: Međunarodni problemi 60 (2008) 1, S. 31-46.

Federal Ministry of Foreign Affairs of the Federal Republic of Yugoslavia: NATO crimes in Yugoslavia. Documentary evidence, 25 April - 10 June 1999, Bd. 2, Belgrad: Federal Ministry of Foreign Affairs of the Federal Republic of Yugoslavia 1999.

Feindt, Gregor/Krawatzek, Félix/Mehler, Daniela/Pestel, Friedemann/Trimçev, Rieke: »Entangled Memory. Toward a Third Wave in Memory Studies«, in: History and Theory 53 (2014) 1, S. 24-44.

Feindt, Gregor/Krawatzek, Félix/Mehler, Daniela/Pestel, Friedemann/Trimçev, Rieke: Europäische Erinnerung als verflochtene Erinnerung. Vielstimmige und vielschichtige Vergangenheitsdeutungen jenseits der Nation (= Formen der Erinnerung 55), Göttingen: V \& R unipress 2014.

Ferhadbegović, Sabina: »Von >Volksfeinden schen Kriegsverbrecherprozesse nach dem Zweiten Weltkrieg und heute«, Vortrag an der Humboldt-Universität Berlin am 8.6.2011.

Finnemore, Martha/Sikkink, Kathryn: »International Norm Dynamics and Political Change«, in: International Organization 52 (1998) 4, S. 887-917.

Fischer, Martina: Friedens- und Versöhnungsprozesse im westlichen Balkan. Von den Schwierigkeiten des Umgangs mit gewaltsamer Vergangenheit (= Berghof Working Paper 4), Berlin: Berghof Conflict Research 2008.

Fond za humanitarno pravo (Hg.): Škorpioni. Od zločina do pravde [Die Skorpione. Vom Verbrechen zur Gerechtigkeit] (= Edicija: Dokumenti), Belgrad: Publikum 2007.

Fonet: »Mladić u kasarnama u Srbiji« [Mladić in Kasernen in Serbien], in: b92.net vom 3.1.2006, http://www.b92.net/info/vesti/index.php?yyyy=2006 $\& m m=01 \& d d=03 \& n a v \_i d=184139$ vom 16.4.2013.

Foucault, Michel: Archäologie des Wissens (= Suhrkamp-Taschenbuch Wissenschaft 356), Frankfurt am Main: Suhrkamp 2008. 
Freeman, Mark: Serbia and Montenegro. Selected Developments in Transitional Justice, International Center for Transitional Justice Briefing Paper vom 1.10.2004, http://www.ictj.org/images/content/1/1/117.pdf vom 16.9.2010.

Frei, Norbert: Vergangenheitspolitik. Die Anfänge der Bundesrepublik und die NS-Vergangenheit, München: Beck 1996.

Freyburg, Tina/Richter, Solveig: National Identity Matters. The Limited Impact of EU Political Conditionality in the Western Balkans (= NCCR Working Paper 19), Zürich: National Centre of Competence in Research Challenges to Democracy in the 21st Century 2008.

Friedensvertrag von Versailles, 28.6.1919, http://www.documentarchiv.de/wr/vv. html vom 14.9.2012.

Fuchs, Ruth/Nolte, Detlef: »Politikfeld Vergangenheitspolitik. Zur Analyse der Aufarbeitung von Menschenrechtsverbrechen in Lateinamerika«, in: Lateinamerika Analysen 3 (2004) 9, S. 59-92.

Gallup Balkan Monitor: Country Specific Question: Declaration on Srebrenica by the Serbian Parliament: Do you agree or disagree with the Declaration on Srebrenica by the Serbian Parliament?, http://www.balkan-monitor.eu/index. php/dashboard vom 23.4.2013.

Glasze, Georg: »Vorschläge zur Operationalisierung der Diskurstheorie von Laclau und Mouffe in einer Triangulation von lexikometrischen und interpretativen Methoden«, in: Historical Social Research 33 (2008) 1, S. 185-223.

Gojković, Drinka: Istine, odgovornosti i pomirenja [Wahrheiten, Verantwortungen und Versöhnungen], in: Republika XII (2000) 235, http://www.yurope. com/zines/republika/arhiva/2000/235/235_21.html vom 30.1.2013.

Gojković, Drinka: Za početak, skica [Für den Anfang, eine Skizze], in: Reč. Časopis za književnost, kulturu i društvena pitanja 35 (1998) 2, S. 135-141.

Gordy, Eric D.: »Accounting for a Violent Past by Other than Legal Means«, in: Southeast European and Black Sea Studies 3 (2003) 1, S. 1-24.

Gordy, Eric D.: »Confronting the Past in Serbia. Obstacles and Opportunities«, in: Wolfgang Petritsch/Goran Svilanović/Christophe Solioz (Hg.): Serbia Matters. Domestic Reforms and European Integration (= Southeast European Integration Perspectives 1), Baden-Baden: Nomos 2009, S. 137-141.

Gordy, Eric D.: Guilt, Responsibility, and Denial. The Past at Stake in PostMilošević Serbia (=Pennsylvania Studies in Human Rights), Philadelphia: University of Pennsylvania Press 2013. 
Gordy, Eric D.: »Postwar Guilt and Responsibility in Serbia: The Effort to Confront It and the Effort to Avoid It«, in: Sabrina P. Ramet/Vjeran Pavlaković (Hg.): Serbia since 1989. Politics and Society under Milosević and after (= Jackson School Publication in International Studies), Seattle: University of Washington Press 2005, S. 166-191.

Gow, James/Zveržhanovski, Ivan: »The Milošević Trial. Purpose and Performance«, in: Nationalities Papers 34 (2004) 4, S. 897-919.

Grodsky, Brian: »International Prosecutions and Domestic Politics. The Use of Truth Commissions as Compromise Justice in Serbia and Croatia«, in: International Studies Review 11 (2009) 4, S. 687-706.

Grodsky, Brian: The Costs of Justice. How New Leaders Respond to Previous Rights Abuses (=Contemporary European Politics and Society), Notre Dame: University of Notre Dame Press 2010.

Grubanović, Saša: »Serbia \& Montenegro. Helping and Unhelpful«, in: Transitions online vom 6.4.2004, http://www.tol.org/client/article/11840-helpingand-unhelpful.html.

Grujić, Dragoslav: »Godina bombardovanja, heroja i izdajnika« [Die Jahre der Bombardierungen, Helden und Verräter], in: Vreme vom 27.11.1999, S. $18 \mathrm{f}$.

Haas, Peter: »Introduction. Epistemic Communities and International Policy Coordination«, in: International Organization 46 (1992) 1, S. 1-35.

Hagan, John: Justice in the Balkans. Prosecuting War Crimes in the Hague Tribunal, Chicago: University of Chicago Press 2003.

Hagan, Margaret Darin: Facing the Past in Post-Milošević Serbia. The Public Relations of Post-Conflict Human Rights Activism, Masterarbeit, Budapest 2004.

Hankel, Gerd: Die Leipziger Prozesse. Deutsche Kriegsverbrechen und ihre strafrechtliche Verfolgung nach dem Ersten Weltkrieg, Hamburg/Bremen: Hamburger Edition 2003.

Hartmann, Florence: »The ICTY and EU conditionality«, in Judy Batt/Jelena Obradović-Wochnik (Hg.): War Crimes, Conditionality and EU Integration in the Western Balkans (= Chaillot Paper 116), Paris: EU Institute for Security Studies 2009, S. 67-82.

Hayden, Robert M.: »Recounting the Dead. The Rediscovery and Redefinition of Wartime Massacres in Late- and Post-Communist Yugoslavia«, in: Rubie S. Watson (Hg.): Memory, History and Opposition under State Socialism, Santa Fe/New Mexico: School of American Research Press 1994, S. 167-184.

Hazan, Pierre: Judging War, Judging History. Behind Truth and Reconciliation (= Stanford Studies in Human Rights), Stanford: Stanford University Press, 2010. 
Hečimović, Joseph: In Tito’s Death Marches and Extermination Camps, New York: Carlton Press 1962.

Helsinški odbor za ljudska prava u Srbiji (Hg.): Helsinški odbor. Misija i strategija [Helsinki-Komittee. Mission und Strategie], http://www.helsinki.org.rs/ serbian/onama.html vom 11.4.2013.

Helsinški odbor za ljudska prava u Srbiji (Hg.): Human Rights in an Unfinished State, Belgrad: Zagorac 2000.

Helsinški odbor za ljudska prava u Srbiji (Hg.): Kovanje antijugoslovenske zavere [Das Schmieden der antijugoslawischen Verschwörung] (= Biblioteka Svedočanstva 26), 2 Bd., Belgrad: Helsinški odbor za ljudska prava u Srbiji 2006.

Helsinški odbor za ljudska prava u Srbiji (Hg.): Tačka razlaza. Povodom polemike vođene na stranicama lista Vreme od 1. avgusta do 21. novembra 2002 [Punkte der Trennung. Anlässlich der auf den Seiten der Zeitung Vreme geführten Polemik vom 1. August bis zum 21. November 2002] (= Helsinške sveske 16), Belgrad: Zagorac 2003.

Hinton, Alexander Laban: »Introduction. Toward an Anthropology of Transitional Justice«, in: ders./Stephen E. Bronner/Nela Navarro (Hg.): Transitional Justice. Global Mechanisms and Local Realities after Genocide and Mass Violence, New Brunswick: Rutgers University Press 2010, S. 1-22.

Höpken, Wolfgang: »Jasenovac - Bleiburg - Kočevski rog. Erinnerungsorte als Identitätssymbole in (Post-)Jugoslavien«, in: Angela Richter/Barbara Beyer (Hg.): Geschichte (ge-)brauchen. Literatur und Geschichtskultur im Staatssozialismus: Jugoslavien und Bulgarien, Berlin: Frank \& Timme 2006, S. 401432.

Höpken, Wolfgang: »Vergangenheitspolitik im sozialistischen Vielvölkerstaat. Jugoslawien 1944-1991«, in: Petra Bock/Edgar Wolfrum (Hg.): Umkämpfte Vergangenheit. Geschichtsbilder, Erinnerung und Vergangenheitspolitik im internationalen Vergleich (= Sammlung Vandenhoeck), Göttingen: Vandenhoeck \& Ruprecht 1999, S. 210-243.

Horelt, Michael-André: »Durch Symbolik und Recht zur Versöhnung? Ein Vergleich der Versöhnungswirkung des Internationalen Strafgerichtshofs für das ehemalige Jugoslawien (ICTY) und politischer Entschuldigungen im ehemaligen Jugoslawien«, in: Die Friedens-Warte. Journal of International Peace and Organization 86 (2011) 1-2, S. 131-154. 
Hrašovec, Ivana Milanović: »Propuštena prva lekcija. Naši građani ne znaju ko je bombardovao Dubrovnik i šta se desilo na Ovčari, u Srebrenici, Sarajevu, ali su složni oko toga da su među narodima za raspad Jugoslavije najviše krivi Hrvati« [Verpasste erste Lektion. Unsere Bürger wissen nicht, wer Dubrovnik bombardierte und was in Ovčara, Srebrenica oder Sarajevo passierte, aber sind sich einig, dass von den Völkern die Kroaten am meisten Schuld für den Zerfall Jugoslawiens haben], in: Vreme vom 28.10.2010, S. $28 \mathrm{ff}$.

Human Rights Watch: Council of Europe: Hold Serbia to Account, Pressemitteilung vom 6.5.2007, http://www.hrw.org/news/2007/05/06/councileurope-hold-serbia-account vom 16.4.2013.

Human Rights Watch: War Crimes Trials in the Former Yugoslavia, Report vom 1.6.1995, http://www.unhcr.org/refworld/docid/3ae6a7ed0.html vom 16.8.2011.

Huntington, Samuel P.: The Third Wave. Democratization in the Late Twentieth Century (= Julian J. Rothbaum distinguished lecture series 4), Norman/ London: University of Oklahoma Press 1991.

Ilić, Dejan: »The Yugoslav Truth and Reconciliation Commission. Overcoming Cognitive Blocks«, in: Eurozine vom 23.4.2004, http://www.eurozine.com/ articles/2004-04-23-ilic-en.html vom 30.8.2010.

Ilić, Dejan: »Zašto »Reč«, ponovo?« [Warum erneut 〉Reč‘?], in: Reč. Časopis za književnost, kulturu i društvena pitanja, Online-Ausgabe vom Mai/Juni 1999, http://www.b92.net/casopis_rec/arhiva/ilic.html vom 29.1.2013.

Ilić, Dejan/Matić, Veran: Truths, Responsibilities, Reconciliations. The Example of Serbia, Belgrad: Samizdat Free B92 2000.

Ilić, Saša: »Danak konzervativnoj metodi« [Tribut den konservativen Methoden], in: Peščanik.net vom 29.7.2011, http://pescanik.net/2011/07/danak-konzer vativnoj-metodi vom 13.5.2013.

Inicijativa građana za istinu o Srebrenici: »Apel više od 80 srpskih nevladinih organizacija povodom tvz. Rezolucije o Srebrenici« vom 11.2.2010 [Appell von mehr als achtzig serbischen NGOs anlässlich der sogenannten Resolution über Srebrenica], http://inicijativagis.wordpress.com/2010/02/11/апелвише-од-80-српских-невладиних-орган vom 6.7.2011.

Inicijativa za REKOM: Prilozi u medijima. Reagovanja na navode o trošenju donacija i propasti procesa REKOM [Medienbeiträge. Reaktionen auf die Vorwürfe der Ausgaben von Spenden und des Zerfalls von REKOM], http://www.zarekom.org/press/Reagovanja-na-navode-o-trosenju-donacija-i-pro pasti-procesa-REKOM/index.sr.html vom 11.5.2013. 
International Commission on Intervention and State Sovereignty: The Responsibility to Protect, Dezember 2001, http://responsibilitytoprotect.org/ICISS Report.pdf vom 13.5.2013.

International Court of Justice: Application of the Convention on the Prevention and Punishment of the Crime of Genocide (Bosnia and Herzegovina v. Serbia and Montenegro), Judgment vom 26.2.2007.

International Court of Justice: Application of the Convention on the Prevention and Punishment of the Crime of Genocide (Bosnia and Herzegovina v. Yugoslavia). Application Instituting Proceedings vom 20.3.1993.

International Court of Justice: Application of the Convention on the Prevention and Punishment of the Crime of Genocide (Bosnia and Herzegovina v. Yugoslavia). Counter-Memorial of the Federal Republic of Yugoslavia vom 23.7.1997.

International Court of Justice: Application of the Convention on the Prevention and Punishment of the Crime of Genocide (Bosnia and Herzegovina v. Yugoslavia). Rejoinder of the Government of the Federal Republic of Yugoslavia vom 22.2.1999.

International Court of Justice: Application of the Convention on the Prevention and Punishment of the Crime of Genocide (Bosnia and Herzegovina v. Yugoslavia). Request for the Indication of Provisional Measures made by the Federal Republic of Yugoslavia vom 10.8.1993.

International Court of Justice: Application of the Convention on the Prevention and Punishment of the Crime of Genocide (Bosnia and Herzegovina v. Yugoslavia). Withdrawal of Counter-claims by the Federal Republic of Yugoslavia vom 20.4.2001.

International Criminal Tribunal for the Former Yugoslavia: ICTY Weekly Press Briefing vom 15.11.2000, http://www.icty.org/sid/3448 vom 15.11.2010.

International Criminal Tribunal for the Former Yugoslavia: The Prosecutor of the Tribunal Against Radovan Karadzic, Ratko Mladic: Indictment, Fall Nr. IT-95-18-I vom 14.11.1995.

International Criminal Tribunal for the Former Yugoslavia: The Prosecutor v. Jovica Stanišić and Franko Simatović. Third Amended Indictment, Fall Nr. IT-03-69-PT vom 10.7.2008.

Ivanišević, Bogdan: Against the Current: War Crimes Prosecutions in Serbia (= Prosecution Case Studies Series), Brüssel: International Center for Transitional Justice 2007.

Ivanišević, Milivoje (Hg.): Srebrenica july 1995. In Search of Truth, Belgrad: Hrišćanska misao 2008. 
Ivanji, Andrej: »Sa Ovčara do Kablara« [Vom Ovčar zum Kablar], in: Vreme vom 11.11.2010, http://www.vreme.com/cms/view.php?id=960456 vom 12.7.2014.

Jansen, Stef: »Victims, Underdogs and Rebels. Discursive Practices of Resistance in Serbian Protest«, in: Critique of Anthropology 20 (2000) 4, S. 393-420.

Jevremović, Pavle: »An Examination of War Crimes Comitted in the Former Yugoslavia«, in: Međunarodni problemi 46 (1994) 1, S. 39-73.

Jovanović, Igor/Alić, Anes: »Serbia sentences its Scorpions«, in: ISN Security Watch vom 17.5.2007, http://www.isn.ethz.ch/Digital-Library/Articles/Detail? lng=en\&id=53124 vom 22.4.2013.

Jovanović Cupa, Zoran: »Željko Ražnatović Arkan: Zločin je ne braniti svoj narod« [Željko Ražnatović Arkan: Es ist ein Verbrechen, sein Volk nicht zu verteidigen], in: NIN vom 5.11.1993, S. $30 \mathrm{f}$.

Kadijević, Veljko: Moje viđenje raspada [Meine Sicht auf den Zerfall], Belgrad: Politika 1993.

Kadijević, Veljko: »Neonacisti na radu u Hrvatskoj« [Neonazis am Werk in Kroatien], in: Narodna armija vom 5.10.1991, S. 5.

Kaleck, Wolfgang: Mit zweierlei Maß. Der Westen und das Völkerstrafrecht (= Schriftenreihe des Österreichischen Ost- und Südosteuropa-Instituts 1312), Bonn: Bundeszentrale für politische Bildung 2012.

Kandić, Nataša: »O inicijativi za REKOM « [Über die Initiative für REKOM], in: Politika vom 1.11.2011, S. 22.

Kant, Immanuel: Zum ewigen Frieden. Ein philosophischer Entwurf, Nachdr., Stuttgart: Reclam 1981.

Karapandžić, Bor: Kočevje: Tito's Bloodiest Crime, Cleveland 1965.

Karganović, Stefan: REKOM - stop proizvodnji lažne istorije [REKOMStoppt die Produktion der Lügengeschichte], in: Nova srpska politička misao online vom 27.10.2012, http://www.nspm.rs/istina-i-pomirenje-na-ex-yu-pro storima/rekom-stop-proizvodnji-lazne-istorije.html vom 11.2.2013.

Karganović, Stefan (Hg.): Srebrenica. Falsifikovanje istorije [Srebrenica. Fälschung der Geschichte], Belgrad: Pekograf 2012.

Karganović, Stephen/Simić, Ljubiša/Herman, Edward/Pumphrey, George/Maher, J. P./Wilcoxson, Andy: Deconstruction of a Virtual's Genocide. An Intelligent Persons Guide to Srebrenica, Den Haag/Belgrad: Srebrenica Historical Project 2011.

Karge, Heike: »Nie wieder Srebrenica. Eine Dokumentation der SrebrenicaErklärungen und ihrer Wirkungen«, in: Südosteuropa 59 (2011) 1, S. 128167. 
Karge, Heike: Steinerne Erinnerung - versteinerte Erinnerung? Kriegsgedenken in Jugoslawien (1947-1970) (= Balkanologische Veröffentlichungen 49), Wiesbaden: Harrassowitz 2010.

Kastner, Fatima: »Trojanische Pferde. Universalistische Normen und globaler Wahrheits- und Versöhnungsdiskurs. Zur Evolution der Weltgesellschaft«, in: Hauke Brunkhorst (Hg.): Demokratie in der Weltgesellschaft (= Soziale Welt 18), Baden-Baden: Nomos 2009, S. 259-276.

Keck, Margaret E./Sikkink, Kathryn: Activists Beyond Borders. Advocacy Networks in International Politics, Ithaca: Cornell University Press 1998.

Keller, Reiner: Wissenssoziologische Diskursanalyse. Grundlegung eines Forschungsprogramms, Wiesbaden: VS Verlag 2005.

Ker-Lindsay, James/Djokić, Dejan (Hg.): New Perspectives on Yugoslavia. Key Issues and Controversies, Milton Park/New York: Routledge 2011.

Kiel, Sören: State Bonus und Social Credit. Zwei frühe Grundeinkommensvorschläge in diskurstheoretischer Perspektive, Diplomarbeit, Hamburg 2008.

Klarin, Mirko: »Nirnberg sada!« [Nürnberg jetzt], in: Borba vom 16.5.1991, S. 3.

Knezević, Darko: »Why Did the >War in Albania〈 First Erupt in Hollywood?«, in: Politika vom 13.10.1998 (Übersetzung des serbischen Informationsministeriums: vgl. http://www.ex-yupress.com/politika/politika7.html vom 8.5.2012).

Koalicija za REKOM: Predlog statuta regionalne komisije za utvrđivanje činjenica o ratnim zločinima i drugim kršenjima ljudskih prava na području nakadašnje SFRJ [Vorschlag eines Statuts der regionalen Kommission zur Feststellung von Tatsachen über Kriegsverbrechen und andere Verletzungen der Menschenrechte auf dem Gebiet der ehemaligen SFRJ] vom 26.3.2011, http://www.recom.link/wp-content/uploads/2012/01/Predlog-Statuta.pdf vom 11.2.2015.

König, Helmut: »Von der Diktatur zur Demokratie oder Was ist Vergangenheitsbewältigung «, in: ders./M. Kohlstruck/A. Wöll (Hg.): Vergangenheitsbewältigung (1998), S. 371-392.

König, Helmut/Kohlstruck, Michael/Wöll, Andreas: »Einleitung «, in: dies. (Hg.): Vergangenheitsbewältigung (1998), S. 7-10.

König, Helmut/Kohlstruck, Michael/Wöll, Andreas (Hg.): Vergangenheitsbewältigung am Ende des zwanzigsten Jahrhunderts (= Leviathan Sonderhefte 18), Opladen: VS Verlag 1998. 
Komisija za prikupljanje podataka radi utvrđivanja zločina protiv čovječnosti i međunarodnog prava koji su počinjeni nad stanovništvom srpske i drughi nacionalnosti u vrijeme oružanij sukoba u Hrvatskoj i drugim djelovima zemlje [Kommission zur Sammlung von Informationen hinsichtlich der Feststellung von Verbrechen gegen die Menschlichkeit und gegen das internationale Recht, begangen an der Bevölkerung serbischer und anderer Nationalität während des bewaffneten Konflikts in Kroatien und in anderen Teilen des Landes] (Hg.): Zbornik o radu državne komisije za ratne zločine i zločine genocida (od 20. marta 1992 do 23. jula 1993) [Sammlung über die Arbeit der Staatskommission für Kriegsverbrechen und Verbrechen des Genozids (20.3.1992-23.7.1993)], Belgrad: Muzej žrtava genocida 1995.

Komitet pravnika za ljudska prava, Centar za kulturnu dekontaminaciju, Građanske inicijative, Helsinški odbor za ljudska prava u Srbiji, Žene u crnom, Beogradski krug, Fond za humanitarno pravo i Inicijativa mladih za ljudska prava: »Deklaracija o obavezama države Srbije da preduzme sve mere zaštite prava žrtava ratnih zločina, a posebno žrtava genocida u Srebrenici« [Deklaration über die Pflichten des Landes Serbiens alle Maßnahmen zu ergreifen zum Schutz der Opfer von Kriegsverbrechen, insbesondere der Opfer des Genozids in Srebrenica], in: Peščanik.net vom 31.5.2005, http://pescanik.net/predlog-teksta-deklaracije-o-srebrenici vom 21.6.2015.

Kostić, Slobodan: »Zaboravljeno vojvodstvo. Film Srpske radikalne stranke« [Vergessenes Herzogtum. Film der Serbischen Radikalen Partei], in: Vreme vom 13.7.2005, http://www.vreme.com/cms/view.php?id=421886 vom 12.7.2013.

Kostovicova, Denisa: »Civil Society and Post-Communist Democratization. Facing a Double Challenge in Post-Milošević Serbia«, in: Journal of Civil Society 2 (2006) 1, S. 21-37.

Koštunica, Vojislav: Predlog Deklaracije o osudi ratnih zločina na prostoru nekadašnje Jugoslavije. Predlog 30 poslanike DSSa i Nove Srbije [Deklarationsvorschlag über die Verurteilung von Kriegsverbrechen im Raum des ehemaligen Jugoslawien. Vorschlag von dreißig Abgeordneten der Fraktionen der DSS und Nova Srbija] vom 1.2.2010, Belgrad: Narodna Skupština Republike Srbije 2010.

Krestić, Vasilije: »O genezi genocida nad Srbima u NDH « [Über die Genese des Völkermords an den Serben im Unabhängigen Staat Kroatien], in: Književne novine vom 15.9.1986, S. 1-4.

Kron, Ana: »Determining the Fate of Missing Persons in Post-Conflict Society. Role of Judiciary, ad hoc Bodies, and International Actors. Case study«, in: Justice in Transition 2 (2006) 7, http://www.tuzilastvorz.org.rs/html_trz/\%28 casopis\%29/eng/eng07/1620.pdf vom 3.3.2013. 
Laclau, Ernesto: »Was haben leere Signifikanten mit Politik zu tun?«, in: ders.: Emanzipation und Differenz, Wien/München: Turia + Kant 2007, S. 65-78.

Laclau, Ernesto/Mouffe, Chantal: Hegemonie und radikale Demokratie. Zur Dekonstruktion des Marxismus, Wien/München: Passagen Verlag 2006.

Lamont, Christopher K.: Coercion, Norms and Atrocity. Explaining State Compliance with International Criminal Tribunal for the former Yugoslavia Arrest and Surrender Orders, Dissertation, Glasgow 2008.

LDP: Amandmani LDP na deklaraciju o Srebrenici. Izjava predsednika Liberalno-demokratske partije Čedomira Jovanovića [Ergänzungen der LDP zur Erklärung über Srebrenica. Äußerungen des Präsidenten der liberaldemokratischen Partei Čedomir Jovanović], Pressemitteilung vom 28.3.2010, http://is tina.ldp.rs/Vesti/12752/Amandmani-LDP-na-deklaraciju-o-Srebrenici.shtml vom 8.8.2014.

Levy, Daniel/Sznaider, Natan: Erinnerung im globalen Zeitalter: der Holocaust (= Suhrkamp Taschenbuch 3870), Frankfurt am Main: Suhrkamp 2007.

Levy, Daniel/Sznaier, Natan: Human Rights and Memory. Essays on Human Rights, University Park: Pennsylvania State University Press 2010.

Lind, Jennifer M.: Sorry States. Apologies in International Politics (= Cornell Studies in Security Affairs), Ithaca: Cornell University Press 2008.

Lukić, Svetlana: Reakcije na hapšenje Ratka Mladić [Reaktionen auf die Verhaftung von Ratko Mladić], Radiosendung Peščanik vom 27.5.2011, http:// pescanik.net/2011/05/reakcije-na-hapsenje-ratka-mladica vom 14.2.2013.

Magliveras, Konstantinos D.: »The Interplay between the Transfer of Slobodan Milosevic to the ICTY and Yugoslav Constitutional Law«, in: European Journal of International Law 13 (2002) 3, S. 661-677.

Marić, Boro: »Dodik: Srebrenica nije jedino mesto zločina u BiH« [Dodik: Srebrenica ist nicht der einzige Ort eines Verbrechens in Bosnien-Herzegowina], in: Politika vom 22.3.2005, S. 1.

Marijan, Davor: »The Yugoslav National Army Role in the Aggression Against the Republic of Croatia 1990 to 1992 «, in: National Security and the Future 2 (2001) 3-4, S. 143-178.

Marković, Zoran M.: »Sudbina poraženog. Telefonska anketa: Šta sa Slobodanom Miloševićem?« [Das Schicksal des Besiegten. Telefonumfrage: Was wird aus Slobodan Milošević?], in: NIN vom 19.10.2000, S. $12 \mathrm{ff}$.

Martens, Michael: »Die Serben durften nicht entscheiden, wo sie leben wollen. Im Gespräch: Tomislav Nikolić«, in: faz.net vom 19.5.2012, http://www. faz.net/aktuell/politik/ausland/wahl-in-serbien-die-serben-durften-nicht-entschei den-wo-sie-leben-wollen-11750937.html 20.4.2014. 
McMahon, Patrice C./Forsythe, David P.: »The ICTY's Impact on Serbia. Judicial Romanticism Meets Network Politics«, in: Human Rights Quarterly 30 (2008) 2, S. 412-435.

Medijska arheologija: Glasačka mašina [Die Wahlmaschine], http://www.you tube.com/watch?v=ucBVRRk4tcc vom 11.5.2013.

Mehler, Daniela: »Srebrenica und das Problem der einen Wahrheit«, in: Feindt, Gregor/Krawatzek, Félix/Mehler, Daniela/Pestel, Friedemann/Trimçev, Rieke (Hg.): Europäische Erinnerung als verflochtene Erinnerung. Vielstimmige und vielschichtige Vergangenheitsdeutungen jenseits der Nation (= Formen der Erinnerung 55), Göttingen: V \& R unipress 2014, S. 205-234.

Mehler, Daniela: »Understanding Normative Gaps in Transitional Justice. The Serbian Discourse on the Srebrenica Declaration 2010«, in: Journal on Ethnopolitics and Minority Issues in Europe 11 (2012) 4, S. 127-156.

Meier, Christian: Das Gebot zu vergessen und die Unabweisbarkeit des Erinnerns. Vom öffentlichen Umgang mit schlimmer Vergangenheit, München: Siedler 2010.

Meulen, Jan van der/Soeters, Joseph: »Dutch Courage: The Politics of Acceptable Risk«, in: Armed Forces \& Society 31 (2005) 4, S. 537-558.

Meyer-Feist, Andreas: Serbien: Protest gegen Äußerungen von Nikolic, in: Deutschlandradio Kultur - Europa heute vom 6.6.2012.

Miladinović, Veljko: »Veliko izvinite i mala isprika« [Große Entschuldigung und kleine Ausreden], in: Press vom 5.11.2010, S. 3.

Miljković, Maja/Hoare, Marko Attila: „Crime and the Economy under Milošević and his Successors«, in: Sabrina P. Ramet/Vjeran Pavlaković (Hg.): Serbia since 1989. Politics and Society under Milosević and after (= Jackson School Publication in International Studies), Seattle: University of Washington Press 2005, S. 192-226.

Milošević, Milan: »Haški sud. Između Unprofora i Interpola« [Das Haager Gericht. Zwischen Unprofor und Interpol], in: Vreme vom 14.11.1994, S. 22 f.

Milošević-Ristić, Katarina: Media Discourses on War Crimes Trials in Serbia (=Working papers series 4), Graz: Centre for South East European Studies 2012, http://www.suedosteuropa.uni-graz.at/sites/default/files/publications/ $/ \%$ 20Ristic\%20WP\%204\%20sept\%202012.pdf.

Minić, Miloš: »Who Caused Kosovo Tragedy. Open letter from Milos Minic to Slobodan Milosevic«, in: Pobjeda vom 24.6.1999, http://www.ex-yupress. com/pobjeda/pobjeda3.html vom 6.5.2013.

Misztal, Barbara A.: »Collective Memory in a Global Age. Learning How and What to Remember«, in: Current Sociology 58 (2010) 1, S. 24-44. 
Mitrović, Momčilo: »Narodni i državni neprijatelji u Srbiji posle Drugoga svetskog rata « [Volks- und Staatsfeinde in Serbien nach dem Zweiten Weltkrieg], in: Hans-Georg Fleck/Igor Graovac (Hg.): Dijalog povjesničara - istoričara 4 [Dialog kroatischer und serbischer Historiker 4], Zagreb: Friedrich Naumann Stiftung 2000, S. 249-266.

Nadjivan, Silvia: Wohl geplante Spontaneität. Der Sturz des Milošević-Regimes als politisch inszenierte Massendemonstration in Serbien, Frankfurt am Main: Lang 2008.

Nagy, Rosemary: »Transitional Justice as Global Project. Critical Reflections«, in: Third World Quaterly 29 (2008) 2, S. 275-289.

Nakarada, Radmila: Raspad Jugoslavije. Problemi tumačenja, suočavanja i tranzicije [Zerfall Jugoslawiens. Probleme der Interpretation, der Aufarbeitung und der Transition] (= Vreme Jugoslavije 5), Belgrad: Službeni glasnik 2008.

Nedić, Aleksandra/Jeremić, Milovan (Hg.): Da li je bilo sve tako u Srebrenici? [War das alles so in Srebrenica?], Belgrad: Srpska liberalna stranka 2005.

Nešić, Branimir: »Uvodna reč. O sirenama, preciznosti i pečenom mesu [Einleitende Worte. Von Sirenen, Genauigkeiten und verbranntem Fleisch], in: ders./Boško Obradović (Hg.): 1999-2000. NATO genocid nad srpskim narodom: Deset godina od bombardovanja Srbije [1999-2000. NATOGenozid am serbischen Volk: Zehn Jahre seit der Bombardierung Serbiens] (= Dveri srpske 41), Belgrad: Dveri srpske 2009, S. 2-3.

Nešović, Slobodan: Stvaranje nove Jugoslavije 1941-1945. Jubilarno izdanje povodom 40-godišnjice narodnog ustanka i revolucije 1941-1945 [Die Schaffung des neuen Jugoslawien 1941-1945. Jubiläumsausgabe anlässlich des 40. Jahrestags des Volksaufstands und der Befreiung 1941-1945], Belgrad: Beogradski izdavačko-grafički zavod 1981.

Nettelfield, Lara J.: Courting Democracy in Bosnia and Herzegovina. The Hague Tribunal's Impact in a Postwar State (= Cambridge Studies in Law and Societies), Cambridge/New York: Cambridge University Press 2010.

Nikolić, Kosta/Dimitrijević, Bojan B.: »Formiranje OZN-e u Srbije i Beogradu i likvidacije >narodnih neprijatelja 1944« [Die Bildung der OZNA in Serbien und Belgrad und die Liquidierung der »Volksfeinde« 1944], in: Istoria 20. veka (2010) 2, S. 9-28. 
Nikolić, Tomislav: Predlog Deklaracije Narodne skupštine Republike Srbije o osudi svih zločina učinjenih u građanskom ratu u bivšoj Jugoslaviji i posebno zločina u Srebrenici. Predlog poslanike SNS-a [Vorschlag einer Erklärung der Volksversammlung der Republik Serbien über die Verurteilung aller im Bürgerkrieg im ehemaligen Jugoslawien verübten Verbrechen und besonders des Verbrechens in Srebrenica] vom 30.3.2010, Belgrad: Narodna Skupština Republike Srbije 2010.

Nikolic-Ristanovic, Vesna: »Truth and Reconciliation in Serbia«, in: Dennis Sullivan/Larry Tifft (Hg.): Handbook of Restorative Justice: A Global Perspective, London, New York: Routledge 2006, S. 369-386.

Ninčić, Roksanda: »Intervju: Sonja Biserko: O vlasti, opoziciji, crkvi i denacifikaciji« [Interview: Sonja Biserko: Über die Regierung, die Opposition, die Kirche und Denazifizierung], in: Vreme vom 12.2.2000, S. $23 \mathrm{ff}$.

Ninčić, Roksanda: »Po slovu zakona. Balkanski Nirnberg « [Dem Gesetz nach. Balkanisches Nürnberg], in: Vreme vom 1.3.1993, S. 22 f.

NIOD Institute for War, Holocaust and Genocide Studies (Hg.): Dutchbat had to keep the peace where there was no peace. Humanitarian Motivation and Political Ambitions Drove the Netherlands to Undertake an Ill-Conceived and Virtually Impossible Peace Mission, Presseerklärung vom 10.4.2002, http:// www.niod.knaw.nl/en/srebrenica-report/press-release vom 5.5.2011.

Nonhoff, Martin: »Chantal Mouffe und Ernesto Laclau. Konfliktivität und Dynamik des Politischen «, in: Ulrich Bröckling/Robert Fenstel (Hg.): Das Politische denken. Zeitgenössische Positionen, Bielefeld: transcript 2010, S. 3357.

Nonhoff, Martin: »Diskurs«, in: Gerhard Göhler/Matthias Iser/Ina Kerner (Hg.): Politische Theorie. 22 umkämpfte Begriffe zur Einführung (= Politische Theorie 2594), Wiesbaden: VS Verlag 2004, S. 65-82.

Nonhoff, Martin: Politischer Diskurs und Hegemonie. Das Projekt >Soziale Marktwirtschaft< (= Sozialtheorie), Bielefeld: transcript 2006.

Nosov, Andrej (Hg.): Srbija i Srebrenica 1995-2005. Serbia and Srebrenica 1995-2005, Belgrad: Inicijativa mladih za ljudska prava 2006.

Noutcheva, Gergana: »Fake, Partial and Imposed Compliance. The Limits of the EU's Normative Power in the Western Balkans«, in: Journal of European Public Policy 16 (2009) 7, S. 1065-1084.

Novak, Viktor: Magnum crimen. Pola vijeka klerikalizma u Hrvatskoj [Magnum crimen. Ein halbes Jahrhundert des Klerikalismus in Kroatien], Belgrad: Nova knjiga 1986. 
Novaković, Stojan: Vaskrs Države Srpske. Političko-istorijska studija o prvom srpskom ustanku 1804-1813 [Die Wiedergeburt des serbischen Staates. Politisch-historische Studie über den ersten serbischen Aufstand 1804-1813], Belgrad: Državna štamparija Kraljevine Srbije 1903.

Obama, Barack: Remarks by the President at Cairo University, Pressemitteilung vom 6.4.2009, http://www.whitehouse.gov/the-press-office/remarks-presidentcairo-university-6-04-09 vom 13.5.2013.

Obradović, Boško/Nešić, Branimir (Hg.): 1999-2009. NATO genocid nad srpskim narodom. Deset godina od bombardovanja Srbije [1999-2009. NATO-Genozid am serbischen Volk: Zehn Jahre seit der Bombardierung Serbiens] (= Dveri Srpske 41), Belgrad: Dveri srpske 2009.

Obradović-Wochnik, Jelena: Ethnic Conflict and War Crimes in the Balkans. The Narratives of Denial in Post-Conflict Serbia (= International Library of War Studies), London: IB Tauris 2013.

Obradović-Wochnik, Jelena: »Knowledge, Acknowledgment and Denial in Serbia's Responses to the Srebrenica Massacre«, in: Journal of Contemporary European Studies 17 (2009) 1, S. 61-74.

Obradović-Wochnik, Jelena: »Strategies of Denial. Resistance to ICTY Cooperation in Serbia«, in: J. Batt/dies. (Hg.): War Crimes, Conditionality and EU Integration in the Western Balkans (= Chaillot Paper 116), Paris: EU Institute for Security Studies 2009, S. 29-47.

O'Donnell, Guillermo A./Schmitter, Philippe C.: Transitions from Authoritarian Rule. Tentative Conclusions about Uncertain Democracies, Baltimore: Johns Hopkins 1986.

Olsen, Tricia D./Payne, Leigh A./Reiter, Andrew G.: Transitional Justice in Balance. Comparing Processes, Weighing Efficacy, Washington: United States Institute of Peace Press 2010.

Orentlicher, Diane: Shrinking the Space for Denial. The Impact of the ICTY in Serbia, New York: Open Society Institute 2008.

Organisation of Islamic Cooperation: Final Communiqué of the 23rd Islamic Conference of Foreign Ministers vom 12.12.1995, http://www.oic-oci.org/ english/conf/fm/23/final23.htm\#final vom 21.6.2015.

OSCE Mission to Serbia and Montenegro: War Crimes Before Domestic Courts. OSCE Monitoring and Empowering of the Domestic Courts to Deal with War Crimes, Belgrad: OSCE 2003.

Osland, Kari M.: »The Trial of Slobodan Milošević«, in: Sabrina P. Ramet/ Vjeran Pavlaković (Hg.): Serbia since 1989. Politics and Society under Milosević and after (= Jackson School Publication in International Studies), Seattle: University of Washington Press 2005, S. 227-251. 
O. V.: »Ako neće Srbija hoće Vojvodina. Bojan Kostreš o Deklaraciji o Srebrenici« [Wenn nicht Serbien, will die Vojvodina. Bojan Kostreš über die Deklaration über Srebrenica], in: Večernje Novosti vom 10.6.2005, S. 4.

O. V.: »Apel lekara, republičkih i saveznik poslanika, rukovodstvu Republike Srbije i Savezne Republike Jugoslavije, medicinskoj i najširoj javnosti za adekvatno lečenje Slobodana Miloševića i za obezbedivanje ambijenta u kom će se ono realizovati. Sprečite fatalan ishod Miloševićeve bolesti i ne budite saučesnici u njegovom tihom ubistvu« [Appell an die Ärzte, die Republiksund Bundesabgeordneten, die Regierung der Republik Serbien und der Bundesrepublik Jugoslawien, die medizinische und weiteste Öffentlichkeit für eine adäquate Behandlung Slobodan Milošević' und für die Bereitstellung einer Umgebung, in der die sich realisieren lässt. Vermeiden Sie einen fatalen Ausgang der Krankheiten Milošević' und seien Sie keine Komplizen an seinem leisen Mord], in: P. Raljić (Hg.): Bela knijga (2001), S. 165-170.

O.V.: »Apel svetu da zaštiti Srbe. Deklaracija protiv genocida nad srpskim narodom« [Appell an die Welt um die Serben zu schützen. Erklärung gegen den Genozid am serbischen Volk], in: Blic vom 22.4.1997, S. 3.

O. V.: »Čula se samo antisrpska istina« [Man hört nur die antiserbische Wahrheit], in: Glas Javnosti vom 13.6.2005, S. 2.

O. V.: »Deklaracija o pomirenju DS-a i SPS-a« [Versöhnungserklärung der DS und der SPS], in: Politika online vom 21.10.2008, http://www.politika.rs/rub rike/Politika/Deklaracija-o-pomirenju-DS-a-i-SPS-a.lt.html vom 11.5.2013.

O. V.: »Dragan Čavić osudio zločin« [Dragan Čavić verurteilt Verbrechen], in: Glas Javnosti vom 11.6.2005, S. 4.

O. V.: Evidence on Mladić by mid-September, in: b92.net vom 21.8.2006, http://www.b92.net/eng/news/politics.php?yyyy=2006\&mm=08\&dd=21\&nav $\_\mathrm{id}=36235$ vom 16.4.2013.

O. V.: »Inicijative koalicije oko LDP: Predlog Deklaracije o genocidu u Srebrenici« [Initiative der Koalition um die LDP. Vorschlag einer Deklaration über den Völkermord in Srebrenica], in: Helsinška povelja XII (2007) 103-104, S. 47.

O. V.: »Izjave godine« [Äußerungen des Jahres], in: Vreme vom 2.1.1999, S. $34 \mathrm{f}$.

O. V.: »Ključni potez za pomirenje u čitavom regionu« [Entscheidender Zug für die Versöhnung in der ganzen Region], in: Večernje Novosti vom 1.4.2010, S. 2.

O. V.: »Kostunica admits Kosovo guilt«, in: BBC News online vom 24.10.2000, http://news.bbc.co.uk/2/hi/europe/988602.stm vom 13.2.2013. 
O. V.: Let Civility Prevail. A Statement of Concerned Serbian Citizens, in: balkansnet.org vom 16.4.1999, http://balkansnet.org/wib/stats/civility.html vom 30.1.2013.

O. V.: »Poigravanje sa zločinima. Svaka stranka pravi svoju deklaraciju o osudi ratnih zločina« [Herumtanzen mit den Verbrechen. Jede Partei macht ihre eigene Erklärung über die Verurteilung von Kriegsverbrechen], in: Blic vom 16.6.2005, S. 2.

O. V.: »Rasim Ljajić«, in: Blic vom 3.6.2005, S. 5.

O. V.: »REKOM osuđen na propast« [REKOM zum Untergang verurteilt], in: Politika vom 24.10.2012, S. 5.

O. V.: Slucaj Strpci - za Haski tribunal [Fall Strpci - für das Haager Tribunal], in: Naša Borba vom 14.2.1998, http://www.yurope.com/nasa-borba/arhiva/ Feb98/1402/1402_8.htm vom 25.1.2013.

O. V.: »Socialist Leader Says Party Should Apologise for 90s«, in: Balkan Insight vom 4.1.2012, http://www.balkaninsight.com/en/article/serbia-s-socialistsmay-appologize-for-90s vom 14.5.2013.

O. V.: »SPC osudila zločin Škorpiona« [Serbisch-orthodoxe Kirche verurteilt das Verbrechen der Skorpione], in: Glas Javnosti vom 11.6.2005, S. 2.

O. V.: »Srbija hapsi ubice iz 〉Škorpiona<: Srebrenica, deset godina posle: součavanje sa zločinom« [Serbien verhaftet die Mörder der »Skorpione«. Srebrenica, zehn Jahre danach: Auseinandersetzung mit dem Verbrechen], in: Dnevnik vom 3.6.2005, S. 14.

O. V.: Svilanović u poseti u Hrvatskoj [Svilanović auf Besuch in Kroatien], in: b92.net vom 14.12.2001, http://www.b92.net/info/vesti/index.php?yyyy=2001 $\& m m=12 \& d d=14 \&$ nav_category=1\&nav_id=54979 vom 13.2.2013.

O. V.: To the Governments of the FRY, Serbia and Montenegro; To the Parliaments of the FRY, Serbia and Montenegro, in: balkansnet.org vom 10.5.1999, http://balkansnet.org/wib/stats/tofry.html vom 30.1.2013.

O. V.: »Ubijeno 3.277 Srba!« [3.277 Serben getötet!], in: Večernje Novosti vom 13.6.2005, S. 7.

O. V.: »Vidovdanski masakr« [Vidovdan-Massaker], in: NIN vom 12.7.2001, S. 20 .

O. V.: »Zločin ne sme biti zaboravljen« [Verbrechen darf nicht vergessen werden], in: Blic vom 11.6.2005, S. 2.

Pantelić, Željko: »Osuda zločina zbog suda u Hagu. Eksklusivno: Kako EU vidi pokušaj suočavanja Srbije s genocidom u Srebrenici« [Verurteilung der Verbechen wegen des Gerichts in Den Haag. Exklusiv: Wie die EU den Versuch Serbiens sieht, den Genozid in Srebrenica aufzuarbeiten], in: Dnevnik vom 1.2.2010, S. 2. 
Parliamentary Assembly of the Council of Europe: Consequences of the Referendum in Montenegro, Resolution Nr. 1514 vom 29.6.2006.

Parliamentary Assembly of the Council of Europe: Functioning of Democratic Institutions in Serbia and Montenegro, Resolution Nr. 1397 vom 5.10.2004.

Parliamentary Assembly of the Council of Europe: Prosecution of offences falling within the jurisdiction of the International Criminal Tribunal for the former Yugoslavia (ICTY), Resolution Nr. 1564 vom 28.6.2007.

Parliamentary Assembly of the Council of Europe: Protection of Witnesses as a Cornerstone for Justice and Reconciliation in the Balkans, Resolution Nr. 1784 vom 26.1.2011.

Parliamentary Assembly of the Council of Europe: Reconciliation and political dialogue between the countries of the former Yugoslavia, Resolution $\mathrm{Nr}$. 1786 vom 26.1.2011.

Parliamentary Assembly of the Council of Europe: Srebrenica, Written Declaration Nr. 366 vom 8.7.2005.

Parliamentary Assembly of the Council of Europe: The Honouring of Obligations and Commitments by Serbia, Report Nr. 11701 vom 15.9.2008.

Parliamentary Assembly of the Council of Europe: The Honouring of Obligations and Commitments by Serbia, Report Nr. 12813 vom 9.1.2012.

Parliamentary Assembly of the Council of Europe: The Honouring of Obligations and Commitments by Serbia, Resolution Nr. 1661 vom 28.4.2009.

Pavić, Aleksanda: Zabranjena istina o Srebrenici. Priručnik zasnovan isključivo na stranim izvorima [Die verbotene Wahrheit über Srebrenica. Handbuch basierend ausschließlich auf ausländischen Quellen], Čačak: Legenda 2007.

Pavićević, Borka/Drakulić, Slavenka: »Sučeljavanja. Dželati i žrtve« [Die Debatten. Henker und Opfer], in: Vreme vom 29.5.1999, S. 10.

Pavlaković, Vjeran: „Serbia Transformed?«, in: Sabrina P. Ramet/Vjeran Pavlaković (Hg.): Serbia since 1989. Politics and Society under Milosević and after (= Jackson School Publication in International Studies), Seattle: University of Washington Press 2005, S. 13-54.

Pearl, Elizabeth L.: »Punishing Balkan War Criminals. Could the End of Yugoslavia Provide an End to Victors' Justice?«, in: American Criminal Law Review 30 (1992/1993) 4, S. 1373-1414.

Pešić, Vesna: »Facing the Past. The Prerequisite for Creating a Modern Serbian State«, in: Dragica Vujadinović/Vladimir Goati (Hg.): Between Authoritarianism and Democracy Vol. III. Serbia at the Political Crossroads, Belgrad: Friedrich-Ebert-Stiftung/Centar za demokratsku tranziciju 2009, S. 179-195. 
Pešić, Vesna: »Revolucija ili puč. Rekonstrukcija petooktobarskih zbivanja na osnovu memoarske i stručne literature « [Revolution oder Putsch. Rekonstruktion des Geschehens am 5. Oktober auf der Grundlage von Erinnerungsund Forschungsliteratur], in: Republika XXII (2010) 490-491, http://www. republika.co.rs/490-491/20.html\#f16 vom 13.5.2013.

Peskin, Victor: International Justice in Rwanda and the Balkans. Virtual Trials and the Struggle for State Cooperation, Cambridge: Cambridge University Press 2008.

Petrović, Duško M. (Hg.): NATO i Hag [Die NATO und das ICTY] (= Edicija Tribina 1), Belgrad: Udruženje Srba iz BiH u Srbiji 1999.

Petrović, Vladimir: Gaining the Trust through Facing the Past? Prosecuting War Crimes Committed in the Former Yugoslavia in National and International Legal Context (= CAS Working Paper Series 4), Sofia: Centre for Advanced Study 2008.

Petrović, Vladimir: Historians as Expert Witnesses in the Age of Extremes, Dissertation, Budapest 2009.

Pintar Manojlović, Olga: »Rat i nemir. O viđenjima socijalističke Jugoslavije, drugog svetskog rata u kome je nastala i ratova u kojima se raspala « [Krieg und Unfrieden. Über Sichten auf das sozialistische Jugoslawien, den Zweiten Weltkrieg, in dem es errichtet wurde, und die Kriege, in denen es zerfiel], in: Dubravka Stojanović/Radina Vučetić/Sanja Petrović/Olga Todosijević/Olga Manojlović Pintar/Radmila Radić (Hg.): Novosti iz prošlosti. Znanje, neznanje, upotreba i zloupotreba istorije [Neuigkeiten aus der Vergangenheit. Wissen, Nichtwissen, Gebrauch und Missbrauch der Geschichte], Belgrad: Beogradski centar za ljudska prava 2010, S. 83-106.

Polónyi, Carl: Heil und Zerstörung. Nationale Mythen und Krieg am Beispiel Jugoslawiens 1980-2004, Berlin: Berliner Wissenschafts-Verlag 2010.

Popov, Nebojša/Gojković, Drinka (Hg.): Srpska strana rata. Trauma i katarza u istorijskom pamćenju [Die serbische Seite des Kriegs. Trauma und Katharsis im historischen Gedächtnis], Belgrad: Republika 1996.

Popov, Nebojša/Gojković, Drinka (Hg.): The Road to War in Serbia. Trauma and Catharsis, Budapest/New York: Central European University Press 2000.

Popović, Đorđe: Savet za nacionalnu bezbednost Republike Srbije, http:// www.bezbednost.org/upload/document/popovic_2009_savet_za_nacionalnu_bez bednost.pdf vom 13.5.2013. 
Portmann, Michael: Kommunistische Abrechnung mit Kriegsverbrechern, Kollaborateuren, »Volksfeinden « und »Verrätern « in Jugoslawien während des Zweiten Weltkriegs und unmittelbar danach (1943-1950), Diplomarbeit, München/Ravensburg: Grin 2002.

Präsident der Republik Serbien Boris Tadić: Obraćanje naciji povodom desete godišnjice zločina u Srebrenici [Ansprache an die Nation anlässlich des zehnten Jahrestags des Verbrechens in Srebrenica], http://www.predsednik.rs/ $\mathrm{mwc} / \mathrm{pic} / 50 / 20061224125233 /$ srebrenica_256_Stream.wmv vom 13.5.2013.

Präsident der Republik Serbien Vojislav Koštunica: Odluka o osnivanju Komisije za istinu i pomirenje [Entschließung über die Errichtung einer Kommission für Wahrheit und Versöhnung], in: Službeni list SRJ 15 (2001).

Prcela, John/Guldescu, Stanko (Hg.): Operation Slaughterhouse. Eyewitness Accounts of Postwar Massacres in Yugoslavia, Philadelphia: Dorrance Publications 1970.

Preneto: »Ameri zgroženi« [Amerika angewidert], in: Kurir vom 3.6.2005, S. 4.

Preneto: »Izvinjenje i Podgorice« [Entschuldigung auch aus Podgorica], in: Večernje Novosti vom 15.6.2005, S. 15.

Preneto: „Grafit o genocidu nad Srbima« [Graffitti über den Genozid an den Serben], in: Glas Javnosti vom 15.1.2010, S. 3.

Preneto: »SRS: Antisrpska histerija « [SRS: Antiserbische Hysterie], in: Politika vom 12.6.2005, S. A7.

Preneto: »Šteti državnim interesima. SPS protiv izjave Saveta ministara« [Schadet staatlichen Interessen. SPS gegen die Äußerung des Ministerrats], in: Politika vom 17.6.2005, S. A5.

Preneto: »Tadić: Rezolucija o Srebrenici je naša obaveza« [Tadić: Die Erklärung über Srebrenica ist unsere Verpflichtung], in: Politika vom 11.1.2010, S. 2.

Putnam, Robert: »Diplomacy and Domestic Politics. The Logic of Two-Level Games«, in: International Organization 42 (1988) 3, S. 427-460.

Radojičić, Mirjana: Istorija u krivom ogledalu. Nevladine organizacije u Srbiji i politika interpretiranja skorije južnoslovenske prošlosti [Geschichte im Zerrspiegel. NGOs in Serbien und die Interpretationspolitik der jüngsten südslawischen Vergangenheit], Belgrad: Institut za političke studije 2009.

Radojičić, Mirjana: »Nevladine organizacije i politika interpretiranja novije južnoslovenske prošlosti« [NGOs und die Interpretationspolitik der neueren südslawischen Vergangenheit], in: Filozofija i društvo 27 (2005) 2, S. 109125.

Rajković, Nikolas Milan: »The Limits of Consequentialism. ICTY Conditionality and (Non)Compliance in Post-Milosevic Serbia«, in: Review of European and Russian Affairs 4 (2008) 1, S. 27-72. 
Rakić-Vodinelić, Vesna: »An Unsuccessful Attempt of Lustration in Serbia«, in: Vladimira Dvořáková/Anđelko Milardović (Hg.): Lustration and Consolidation of Democracy and the Rule of Law in Central and Eastern Europe (= Series of Political Science Research Centre Forum 5), Zagreb: Political Science Research Centre 2007, S. 169-182.

Raljić, Prvoslav (Hg.): Bela knijga. Istina o Haškom tribunalu. Apel za ukidanje Haškog tribunala [Weißbuch. Die Wahrheit über das Haager Tribunal. Appell zur Abschaffung des Haager Tribunals], Belgrad: Sova 2001.

Ramet, Sabrina P.: »Martyr in his own Mind. The Trial and Tribulations of Slobodan Milošević«, in: Wolfgang Höpken/Holm Sundhausen (Hg.): Serbia, Croatia and Slovenia at Peace and at War. Selected Writings, 1983-2007 (= Studien zur Geschichte, Kultur und Gesellschaft Südosteuropas 7), München/Zürich: LIT 2008, S. 111-134.

Ramet, Sabrina P.: »The Denial Syndrome and its Consequences. Serbian Political Culture since 2000«, in: Communist and Post-Communist Studies 40 (2007) 1, S. 41-58.

Ramet, Sabrina P./Pavlaković, Vjeran (Hg.): Serbia since 1989. Politics and Society under Milosević and after (= Jackson School Publication in International Studies), Seattle: University of Washington Press 2005.

Ratiu, Camelia Elena: EU Soft Power at Its Best. Zur Leistungsfähigkeit der Europäischen Union als Demokratieförderer in Transformationsstaaten, Hamburg: Dr. Kovač 2011.

Reckwitz, Andreas: »Ernesto Laclau. Diskurse, Hegemonien, Antagonismen«, in: Stephan Moebius/Dirk Quadflieg (Hg.): Kultur. Theorien der Gegenwart, Wiesbaden: VS Verlag 2006, S. 339-349.

Regierung der Republik Serbien: Odluka o osnivanju nacionalnog saveta za saradnju sa međunarodnim tribunalom za krivično gonjenje lica odgovornih za teška kršenja međunarodnog humanitarnog prava počinjena na teritoriji bivše Jugoslavijie od 1991. godine [Entschließung über die Einrichtung eines nationalen Rats für die Zusammenarbeit mit dem Internationalen Tribunal für die Strafverfolgung von verantwortlichen Personen für auf dem Territorium des ehemaligen Jugoslawien begangene schwere Menschenrechtsverbrechen seit 1991], in: Službeni glasnik RS 50 (2007).

Regional Ministerial Conference on Refugee Returns: Declaration vom 31.1.2005, http://www.kirs.gov.rs/docs/Sarajevo\%20Declaration\%20January\%20202005. pdf vom 9.4.2013.

Reljić, Dušan: Die Türkei weckt alte Lieben und Feindschaften im Westbalkan (= SWP-Aktuell 2010/A 69), http://www.swp-berlin.org/fileadmin/contents/ products/aktuell/2010A69_rlc_ks.pdf vom 16.6.2011 
Renner, Judith: »»Versöhnung` als leerer Signifikant im Kontext politischer Transformationen. Eine diskursanalytische Konzeptualisierung «, in: Die Friedens-Warte. Journal of International Peace and Organization 86 (2011) 1-2, S. 245-270.

Republik Serbien: Answers to Additional Questions vom 22.4.2011, http://www. seio.gov.rs/upload/documents/upitnik/answers_to_additional_questions.zip vom 22.4.2013.

Republik Serbien: Answers to the European Commission's Questionnaire vom 31.1.2011, http://www.seio.gov.rs/upload/documents/upitnik/answers_ro_the_ ec_questionnaire.zip vom 17.4.2013.

Risse, Thomas/Sikkink, Kathryn: »The Socialization of International Human Rights Norms into Domestic Practices. Introduction«, in: dies./Stephen C. Ropp (Hg.): The Power of Human Rights. International Norms and Domestic Change (= Cambridge Studies in International Relations), Cambridge/New York/Melbourne: Cambridge University Press 1999, S. 1-38.

Ristić, Katarina: Imaginary Trials. War Crimes and Memory in Former Yugoslavia (= Global History and International Studies 9), Leipzig: Leipziger Universitätsverlag 2014.

Rovčanin, Snzežana/Babović, Milan: »Osuđeni i zločini nad Srbima« [Auch Verbrechen an Serben verurteilt], in: Večernje Novosti vom 15.10.2010, S. 3.

RTV, RTS, Beta, Tanjug, Fonet: Hadžić se neće žaliti na izručenje Hagu [Hadžić wird sich nicht über Auslieferung nach den Haag beklagen], in: rtv.rs vom 20.7.2011, http://www.rtv.rs/sr_lat/hronika/pocelo-saslusanje-hadzica-u-specijal nom-sudu_264597.html vom 20.7.2011.

Sabatier, Paul: »Advocacy-Koalitionen, Policy-Wandel und Policy-Lernen. Eine Alternative zur Phasenheuristik«, in: Adrienne Héritier (Hg.): PolicyAnalyse. Kritik und Neuorientierung (= Politische Vierteljahresschrift Sonderheft 24), Opladen: Westdeutscher Verlag 1993, S. 116-148.

Sabljaković, Dževad: »Srebrenica Evidence Kept Under Wraps. French Public Barred from Hearing Crucial Evidence at Srebrenica Parliamentary Inquiry « (= BCR Issue 215), Institute for War \& Peace Reporting vom 6.2.2001, http:// iwpr.net/report-news/srebrenica-evidence-kept-under-wraps vom 29.4.2013.

Salamurović, Aleksandra: Wie viele Gesichter hat Deutschland? Das Deutschlandbild in der serbischen Presse, Wiesbaden: Harrassowitz 2013.

Sandner, Günther: »Hegemonie und Erinnerung. Zur Konzeption von Geschichts- und Vergangenheitspolitik«, in: Österreichische Zeitschrift für Politikwissenschaft 30 (2001) 1, S. 5-17. 
Savić, Obrad: »Parallele Welt. Die Belgrader NGO-Szene«, in: Šlosar, Irina (Hg.): Verschwiegenes Serbien. Stimmen für die Zukunft?, Klagenfurt/ Salzburg: Wieser 1997, S. 41-54.

Savić, Obrad: »Srebrenica. Between Denial and Recognition«, in: Eurozine vom 8.7.2005, http://www.eurozine.com/articles/2005-07-08-savic-en.html vom 26.5.2010.

Schaber, Thomas/Ulbert, Cornelia: »Reflexivität in den Internationalen Beziehungen. Literaturbericht zum Beitrag kognitiver, reflexiver und interpretativer Ansätze zur dritten Theoriedebatte«, in: Zeitschrift für Internationale Beziehungen 1 (1994) 1, S. 139-169.

Schwab-Trapp, Michael: Kriegsdiskurse. Die politische Kultur des Krieges im Wandel 1991-1999. Opladen: Leske + Budrich 2002.

Schwarz, Claudia: »Sentenced to `Storification<. A Trial on Legal Narratives«, in: Gudrun M. Grabher/Anna Gamber (Hg.): Legal Narratives. European Perspectives on U.S. Law in Cultural Context, Wien: Springer 2009, S. 213238.

SDU: Deklaracija o obavezama države Srbije da preduzme sve mere zaštite prava žrtava ratnih zločina, a posenbno žrtava genocida u Srebrenici [Deklaration über die Verpflichtungen des Staates Serbien zur Ergreifung aller Maßnahmen zum Schutz der Rechte der Opfer von Kriegsverbrechen, besonders des Völkermords in Srebrenica] vom 10.7.2009, http://www.sdo.org.rs/cms/ documents/SDU\%20\%20deklaracija\%20o\%20srebrenici.pdf vom 26.8.2011.

Semo, Mar: „Srebrenica, retour sur un massacre. Le général Janvier est accusé d'avoir abandonné l'enclave musulmane tombée en juillet«, in: Libération.fr vom 1.11.1995, http://www.liberation.fr/monde/0101160055-srebrenica-retoursur-un-massacrele-general-janvier-est-accuse-d-avoir-abandonne-l-enclave-mu sulmane-tombee-en-juillet vom 12.5.2011.

Šešelj, Vojislav: Afera Hrtkovci i ustaška kurva Nataša Kandić [Die Affäre Hrtkovci und die Ustaša-Hure Nataša Kandić], Belgrad: SRS 2007.

Šešelj, Vojislav: Suočavanje za haškim inkvizitorima [Konfrontation mit den Haager Inquisitoren], Belgrad: SRS 2003.

Shaw, Emily: The Role of Social Identity in Resistance to International Criminal Law. The Case of Serbia and the ICTY (= Berkeley Program in Soviet and Post-Soviet Studies Working Paper Series), Berkeley: University of California 2003.

Shentov, Ognian/Todorov, Boyko/Stoyanov, Aleksander: »Partners in Crime. The Risk of Symbiosis between the Security Sector and Organized Crime in Southeast Europe« (= CSD Report 13), Sofia: Center for the Study of Democracy 2004. 
Simeunović, Dragan: Srpska kolektivna krivica. Srbi i tradicija kolektivne krivice [Die serbische kollektive Schuld. Die Serben und die Tradition kollektiver Schuld], Belgrad: Nolit 2007.

Simić, Ljubiša: The Martyrdom of Serbian Srebrenica 1992-1995, Belgrad: Istorijski projekat Srebrenice 2010.

Simović, Tomislav: »Strategija domina« [Domino-Strategie], in: Narodna armija vom 2.10.1991, S. 10.

Sindbæk, Tea: Usable History? Second World War Massacres and the Theme of Genocide in Yugoslav Historical Culture, 1945-2002, Aarhus: University Press 2013.

Škrbić, Ratko P.: Srebrenica. Genocid nad istinom [Genozid an der Wahrheit] (=Edicija Dokumenti), Belgrad: Svet knjige 2011.

Smajlović, Liljana: »Srebrenica kao sudbina« [Srebrenica als Schicksal], in: NIN vom 2.6.2005, S. 16.

SPO: Deklaracija povodom desete godišnjice ratnog zločina u Srebrenici [Deklaration anlässlich des 10. Jahrestags des Verbrechens in Srebrenica], Beograd 2005: SPO.

Spoerri, Marlene: »Justice Imposed. How Policies of Conditionality Effect Transitional Justice in the Former Yugoslavia«, in: Europe-Asia Studies 63 (2011) 10, S. 1827-1851.

Spoerri, Marlene/Freyberg-Inan, Annette: »From Prosecution to Prosecution: Perceptions of the International Criminal Tribunal for the former Yugoslavia (ICTY) in Serbian domestic politics«, in: Journal of International Relations and Development 11 (2008) 4, S. 350-384.

Srebrenica Historical Project (Hg.): »Appeal to President Boris Tadić and the Serbian Parliament. Do Not Gamble With Your Country's Future! No to the Srebrenica Resolution!« vom 6.2.2010, http://www.srebrenica-project. $\mathrm{com} /$ index.php?option=com_content\&view=article\&id=83:appeal-to-presidentboris-tadi-and-the-serbian-parliament-do-not-gamble-with-your-countrys-futureno-to-the-srebrenica-resolution\&catid=12:2009-01-25-02-01-02 vom 20.3.2013.

Srebrenica Research Group: Srebrenica and the Politics of War Crimes vom 11.7.2005, http://www.srebrenica-report.com vom 12.11.2010.

Sriram, Chandra Lekha: »Revolutions in Accountability. The Approaches to Past Abuses«, in: American University International Law Review 19 (2003) 21, S. 301-429.

Staatsamt für Äußeres in Wien (Hg.): Die Österreichisch-Ungarischen Dokumente zum Kriegsausbruch, Wien: Europäischer Geschichtsverlag 2012. 
Stahl, Bernhard: »Perverted Conditionality. The Stabilisation and Association Agreement between the EU and Serbia«, in: European Foreign Affairs Review 16 (2011) 4, S. 465-487.

Stefanov, Nenad: »Geschichte als Religion. Anmerkungen zur gesellschaftlichen Genese der historisierenden Opfermythologie im serbischen Ethnonationalismus«, in: Ulf Brunnbauer/Andreas Helmedach/Stefan Troebst (Hg.): Schnittstellen. Gesellschaft, Nation, Konflikt und Erinnerung in Südosteuropa: Festschrift für Holm Sundhaussen zum 65. Geburtstag (= Südosteuropäische Arbeiten 133), München: Oldenbourg 2007, S. 449-460.

Stefanov, Nenad: Wissenschaft als nationaler Beruf. Die Serbische Akademie der Wissenschaften 1944-1992. Tradierung und Modifizierung nationaler Ideologie (= Balkanologische Veröffentlichungen Geschichte - Gesellschaft - Kultur 52), Wiesbaden: Harrassowitz 2011.

Stojanović, Dubravka: »Demokratska opozicija Srbije - otvaranje traumatičnog kruga? (2000-2002)« [Die Demokratische Opposition Serbiens - Öffnen eines traumatischen Kreises?], in: dies.: Ulje na vodi. Ogledi iz istorije sadašnjosti Srbije [Ö1 auf dem Wasser. Ansichten aus der Zeitgeschichte Serbiens], Belgrad: Čigoja štampa 2010, S. 212-255.

Štrbac, Savo: »Pitanje izbeglih važnije od izvinjenja« [Die Flüchtlingsfrage ist wichtiger als Entschuldigungen], in: Pravda vom 5.11.2010, S. 4.

Subotić, Jelena: Hijacked Justice. Dealing with the Past in the Balkans, Ithaca: Cornell University Press 2009.

Subotić, Momčilo: »Politika (zlo)upotreba zločina« [Politik des Gebrauchs/ Missbrauchs von Verbrechen], in: Politička revija 4 (2005) 3, S. 813-828.

Sučurlija, Jelena/Pavlović, Biljana/Jovanović Padejski, Đurđa: Mapping Digital Media: Serbia, London: Open Society Foundations 2011.

Suljagić, Emir/Bajrović, Reuf: »Keine Schutzzone ohne Schutz«, in: Zeit online vom 2.3.2012, http://www.zeit.de/2012/10/P-oped-Suljagic vom 2.3.2012.

Supreme Commander for the Allied Powers at Tokyo: Special proclamation: Establishment of an International Military Tribunal for the Far East Charter, 19.1.1946, http://www.loc.gov/law/help/us-treaties/bevans/m-ust000004-0020. pdf vom 23.3.2012.

Tanjug: »Nikolić se izvinio zbog zločina i najavio posetu Srebrenici« [Nikolić hat sich wegen des Verbrechens entschuldigt und kündigt Besuch in Srebrenica an], in: politika.rs vom 25.4.2013, http:/www.politika.rs/rubrike/Poli tika/Nikolic-se-izvinio-zbog-zlocina-i-najavio-posetu-Srebrenici.lt.html vom 25.4.2013. 
Tanjug: »RTS traži odštetu od Skupštine« [RTS verlangt Schadenersatz vom Parlament], in: Glas Javnosti online vom 1.4.2010, http://www.glas-javnosti.rs/ clanak/politika/glas-javnosti-01-04-2010/rts-trazi-odstetu-od-skupstine vom 1.4.2014.

Tanjug: »Statut REKOM-a protiv dobre ideje« [Das Statut von REKOM gegen eine gute Idee], in: b92.net vom 23.10.2011, http://www.b92.net/info/vesti/in dex.php?yyyy=2011\&mm=10\&dd=23\&nav_category $=12 \&$ nav_id $=551703$ vom 11.2.2013.

Tašić, Jelana: »Gospode, ne ponovilo se« [Herr, lass es nicht wieder geschehen!], in: Danas vom 11.6.2005, S. 4.

Tašić, Jelana: »Poziv savesti (celog sveta): Šta sadrži Deklaracija protiv genocida nad srpskim narodom« [Aufruf an das Gewissen (der ganzen Welt). Was die Erklärung gegen den Genozid am serbischen Volk enthält], in: Naša Borba vom 25.4.1997, http://www.yurope.com/nasa-borba/arhiva/Apr97/2504/25 04_25.htm vom 12.7.2014.

Teitel, Ruti G.: »Transitional Justice Genealogy«, in: Harvard Human Rights Journal 69 (2003) 16, S. 69-94.

Tepavac, Mirko: »Srbija na kori od banane« [Serbien auf der Bananenschale], in: ders. (Hg.): Države, državnici i stradalnici. Ogledi iz Republike (1991-2008) [Länder, Staatsmänner und Verunglückte. Ansichten aus der Republik (19912008)] (= Edicija PUBLIKUS 18), Belgrad: Službeni glasnik 2009, S. 167170 .

Todorović, Dragan: »Zaostale i ostale snage« [Verbliebene und andere Kräfte], in: Vreme vom 6.11.1995, S. 13.

Todorović, Kosta/Velimirović, Milutin (Hg.): Golgota i vaskrs Srbije 19161918 [Golgatha und Auferstehung Serbiens 1916-1918], Belgrad: Udruženje nosilaca albanske spomenice 1915-1916/Beogradski izdavačko-grafički za$\operatorname{vod} 1971$.

Tolstoy, Nikolai: The Minister and the Massacres, London: Hutchinson 1986.

Tončić, Bojan: »Dok predsednik Tadić ne prizna zločin ne možemo dalje. Konferencija 〉Srebrenica: Van osnovane sumnje«« [Solange Präsident Tadić das Verbrechen nicht anerkennt, können wir nicht weiter. Konferenz »Srebrenica: Ohne grundlegende Zweifel«], in: Danas vom 13.6.2005, S. 4.

Torov, Ivan: »Zatrpavani zločini« [Verschüttete Verbrechen], in: Politika vom 12.6.2005, S. A8.

Torov, Milica: »Odbrana zločina je takođe zločin« [Die Verteidigung des Verbrechens ist auch ein Verbrechen], in: Danas vom 16.6.2005, S. 1. 
Trkulja, Jovica: »Uvodne napomene« [Einführende Bemerkungen], in: Hereticus. Časopis za preispitivanje prošlosti 1 (2003) 2, http://www.hereticus.org/ arhiva/2003-2/uvodne-napomene.html vom 6.2.2013.

Tužilaštvo za ratne zločine: Predmeti [Fälle], http://www.tuzilastvorz.org. rs/html_trz/predmeti_lat.htm vom 22.2.2013.

Ulbert, Cornelia: »Konstruktivistische Analysen der internationalen Politik: Theoretische Ansätze und methodische Herangehensweisen«, in: dies./ Christoph Weller (Hg.): Konstruktivistische Analysen der Internationalen Politik, Wiesbaden: VS Verlag 2005, S. 9-34.

United Nations: Agreement for the prosecution and punishment of the major war criminals of the European Axis (»London Agreement«) vom 8.8.1945, 82 U.N.T.C. 280, http://www.refworld.org/docid/47fdfb34d.html vom 5.2.2012.

United Nations: United Nations Approach to Transitional Justice: Guidance Note of the Secretary-General vom März 2010, http://www.unrol.org/files/TJ_ Guidance_Note_March_2010FINAL.pdf vom 25.10.2010.

United Nations Commission on Human Rights: Final Periodic Report on the Situation of Human Rights in the Territory of the Former Yugoslavia, UN-Dok. E/CN.4/1996/9 vom 22.8.1995.

United Nations General Assembly: Affirmation of the Principles of International Law recognized by the Charter of the Nürnberg Tribunal, UN-Dok. A/RES/I/95 vom 11.12.1946.

United Nations General Assembly: Convention on the Prevention and Punishment of the Crime of Genocide, UN-Dok. A/RES/III/260 vom 9.12.1948.

United Nations General Assembly: Human Rights Questions: Human Rights Situation and Reports of Special Rapporteurs and Representatives. Letter dated 24 May 1993 from the Chargé d'affaires a.i. of the Permanent Mission of Yugoslavia to the United Nations addressed to the Secretary-General, 48th session, Annex, Agenda item 115c, 2.6.1993.

United Nations General Assembly: Letter dated 20 September 1996 from the Chargé d'affaires a.i. of the Permanent Mission of Yugoslavia to the United Nations addressed to the Secretary-General, UN-Dok. A/51/397 vom 24.9.1996.

United Nations General Assembly: Letter dated 22 May 1995 from the Chargé d'affaires a.i. of the Permanent Mission of Yugoslavia to the United Nations addressed to the Secretary-General, UN-Dok. A/50/187 vom 12.6.1995.

United Nations General Assembly: Letter dated 26 January 1996 from the Chargé d'affaires a.i. of the Permanent Mission of Yugoslavia to the United Nations addressed to the Secretary-General, UN-Dok. A/51/61 vom 30.1.1996. 
United Nations General Assembly: Letter dated 28 February 1997 from the Chargé d'affaires a.i. of the Permanent Mission of Yugoslavia to the United Nations addressed to the Secretary General, UN-Dok. A/52/83 vom 3.3.1997.

United Nations General Assembly: Letter dated 29 August 1998 from the Chargé d'affaires a.i. of the Permanent Mission of Yugoslavia to the United Nations addressed to the Secretary-General, UN-Dok. A/53/300 vom 31.8.1998.

United Nations General Assembly: Report of the Secretary-General Pursuant to General Assembly Resolution 53/35 on The Fall of Srebrenica, UN-Dok. A/54/549 vom 15.11.1999.

United Nations General Assembly: Robust International Criminal Justice System Gives »Much-Needed Voice to Victims« of Serious Crimes, Secretary-General Tells General Assembly, Pressemitteilung, http://www.un.org/press/en/2013/ga 11355.doc.htm vom 24.4.2013.

United Nations Security Council: 6880th Meeting, Agenda: ICTY/ICTR, UNDok. SC/10846 vom 5.12.2012.

United Nations Security Council: Letter dated 24 May 1994 from the SecretaryGeneral to the President of the Security Council, UN-Dok. S/1994/674 vom 27.5.1994.

United Nations Security Council: Resolution 1034, UN-Dok. S/RES/1034 vom 21.12.1995.

United Nations Security Council: Resolution 1160, UN-Dok. S/RES/1160 vom 31.3.1998.

United Nations Security Council: Resolution 1820, UN-Dok. S/RES/1820 vom 19.6.2008.

United Nations Security Council: Resolution 780, UN-Dok. S/RES/780 vom 6.10.1992.

United Nations Security Council: Resolution 808, UN-Dok. S/RES/808 vom 22.2.1993.

United Nations Security Council: Resolution 819, UN-Dok. S/RES/819 vom 16.4.1993.

United Nations Security Council: Resolution 827, UN-Dok. S/RES/827 vom 25.5.1993.

United Nations Security Council: Resolution 836, UN-Dok. S/RES/836 vom 4.6.1993.

United States House of Representatives: Expressing the Sense of the House of Representatives Regarding the Massacre at Srebrenica in July 1995, HRES 199 EH vom 27.6.2005.

United States Senate: A Resolution Expressing the Sense of the Senate Regarding the Massacre at Srebrenica in July 1995, S.Res. 134 vom 22.6.2005. 
Urban, George: Gespräche mit Zeitgenossen, Weinheim: Beltz 1982.

Vasilijević, Vladan: »Pravo na zločin« [Recht auf Verbrechen], in: Vreme vom 12.6.1993, S. $34 \mathrm{f}$.

Vasilijević, Vladan: »Sveti princip pravde. Međunarodni krivični sud: zablude i fakta [Das internationale Gerechtigkeitsprinzip. Das Internationale Strafgericht: Missverständnisse und Fakten], in: Vreme vom 8.3.1993, S. 26 ff.

Vilić, Dušan/Todorović, Boško: Zašto su optuženi [Warum sie beschuldigt sind], Belgrad: Grafomark, 2001.

Völkl, Ekkehard: »Abrechnungsfuror in Kroatien«, in: Klaus-Dietmar Henke/Hanns Woller (Hg.): Politische Säuberung in Europa. Die Abrechnung mit Faschismus und Kollaboration nach dem Zweiten Weltkrieg, München: Deutscher Taschenbuch Verlag 1991, S. 358-394.

Vojinović, Svetlana.: »Opozicija tvrdi da je Tadić morao da ode i u Bratunac« [Die Opposition behauptet, Tadić hätte auch nach Bratunac gehen müssen], in: Press vom 14.7.2010, http://www.pressonline.co.rs/sr/vesti/vesti_dana/ story/125434/Opozicija+tvrdi $+\mathrm{da}+\mathrm{je}+$ Tadi $\% \mathrm{C} 4 \% 87+$ morao $+\mathrm{da}+$ ode $+\mathrm{i}+\mathrm{u}+\mathrm{Br}$ atunac.html vom 22.8.2010.

Volksversammlung der Republik Serbien: Deklaracija Narodne Skupštine Republike Srbije o osudi zločina učinjenih nad pripadnicima srpskog naroda i građanima Srbije [Deklaration der Volksversammlung der Republik Serbien über die Verurteilung der an den Angehörigen des serbischen Volkes und den Bürgern Serbiens begangenen Verbrechen] vom 14.10.2010, Belgrad: Narodna Skupština Republike Srbije 2010, http://www.parlament.gov.rs/upload/ar chive/files/lat/pdf/ostala_akta/2010/Rs31-10Lat.zip vom 28.4.2013.

Volksversammlung der Republik Serbien: Deklaracija Narodne Skupštine Republike Srbije o osudi zločina u Srebrenici [Deklaration der Volksversammlung der Republik Serbien über die Verurteilung des Verbrechens in Srebrenica] vom 31.3.2010, Belgrad: Narodna Skupština Republike Srbije 2010, http://www.parlament.gov.rs/upload/archive/files/lat/pdf/ostala_akta/2010/ Rs31-10Lat.zip vom 28.4.2013.

Volksversammlung der Republik Serbien: Predlog: Zakon o izmenama i dopunama zakona o odgovornosti za kršenje ljudskih prava [Gesetzesvorschlag über die Änderung und Erweiterung des Gesetzes über die Verantwortung für die Verletzung von Menschenrechten] vom 9.11.2010, http://www.parlament.rs/upload/ archive/files/lat/pdf/predlozi_zakona/2873_10.lat.zip vom 13.8.2012. 
Volksversammlung der Republik Serbien: Predlog. Zakon o otvaranju dosijea službi bezbednosti u Republici Srbiji [Gesetzesvorschlag über die Öffnung von Geheimdienstakten in der Republik Serbien] vom 29.8.2012, http://www.parlament.gov.rs/upload/archive/files/lat/pdf/predlozi_zakona/253512Lat.zip vom 29.4.2013.

Volksversammlung der Republik Serbien: Stenografske beleške. Druga sednica Drugog redovnog zasedanja. Predlog deklaracije Narodne skupštine Republike Srbije o osudi zločina učinjenih nad pripadnicima srpskog naroda i građanima Srbije [Stenografisches Protokoll. Zweite Sitzung der zweiten regulären Periode. Vorschlag einer Erklärung der Volksversammlung der Republik Serbien über die Verurteilung der an den Angehörigen des serbischen Volkes und den Bürgern Serbiens begangenen Verbrechen] vom 14.10.2010, Belgrad: Narodna Skupština Republike Srbije 2010.

Volksversammlung der Republik Serbien: Zakon o odgovornosti za kršenje ljudskih prava [Gesetz über die Verantwortung für die Verletzung der Menschenrechte], in: Službeni glasnik RS 58 (2003).

Volksversammlung der Republik Serbien: Zakon o organizaciji i nadležnosti državnih organa u postupku protiv učinilaca ratnih zločina [Gesetz über die Organisation und Kompetenzen von Staatsorganen im Verfahren gegen Täter von Kriegsverbrechen], in: Službeni glasnik RS 67 (2003).

Volksversammlung der Republik Serbien: Zakon o osnovama uređenja službi bezbednosti [Gesetz über die grundlegende Ordnung der Sicherheitsdienste], in: Službeni glasnik RS 116 (2007).

Volksversammlung der Republik Serbien: Zakon o pravima optuženog u pritvoru međunarodnog krivičnog tribunala i članova njegove porodice [Gesetz über die Rechte Angeklagter im Arrest des Internationalen Strafgerichtshofs und ihrer Familienmitglieder], in: Službeni glasnik RS 35 (2004).

Vujadinović, Željko: »Fenomenologija Srebrenice« [Phänomenologie Srebrenicas], in: Istorija 20. veka 24 (2006) 2, S. 147-161.

Vukčević, Vladimir: »Jedinstvena prilika za poruku pomirenja« [Einzigartige Möglichkeit für eine Botschaft der Versöhnung], in: Vreme vom 11.2.2010, S. 14.

Vuković, Slobodan: Etika zapadnih medija. Antisrpska propaganda devedesetih godina XX veka [Die Ethik der westlichen Medien. Antiserbische Propaganda in den Neunziger Jahren des 20. Jahrhunderts], Sremski Karlovci: Izdavačka Knjižarnica Zorana Stojanovića 2009.

Vuković, Slobodan: Kako su nas voleli. Antisrpska propaganda i razbijanje Jugoslavije [Wie sie uns liebten. Antiserbische Propaganda und die Zerschlagung Jugoslawiens], Novi Sad: Stylos 2007. 
Vuković, Slobodan: »Ulica Vase Mickina, Markale, Račak. Događaji s obarčem« [Die Vasa Mickina-Straße, Markale, Račak. Ereignisse mit Auslöser], in: Teme. Časopis za društvene nauke 33 (2009) 1, S. 201-214.

Vuković-Birčanin, Momčilo/Vuković, Dragoljub T.: Golgota i vaskrs Srbije. Očev dnevnik I. Svetskog rata [Golgatha und Auferstehung Serbiens. Vaters Tagebuch des Ersten Weltkriegs], München: Izdanje pisca 1979.

Watson, Rubie S. (Hg.): Memory, History and Opposition under State Socialism, Santa Fe, New Mexico: School of American Research Press 1994.

Werkmeister, Christian: »Johannes Lepsius und die Verbrechen an den Armeniern. Die Vorgeschichte der UN-Genozidkonvention«, in: Fritz Bauer Institut/Sybille Steinbacher (Hg.): Holocaust und Völkermorde. Die Reichweite des Vergleichs (= Jahrbuch zur Geschichte und Wirkung des Holocausts Bd. 16), Frankfurt am Main: Campus Verlag 2012, S. 83-104.

Wilson, Richard Ashby: »Judging History. The Historical Record of the International Criminal Tribunal for the Former Yugoslavia«, in: Human Rights Quarterly 27 (2005) 3, S. 908-942

Wilson, Richard Ashby: Writing History in International Criminal Trial, Cambridge/New York: Cambridge University Press 2011.

Wöll, Andreas: »Vergangenheitsaufarbeitung in der Gesellschaftsgeschichte der Bundesrepublik: Zur Konfliktlogik eines Streitthemas«, in: Schaal, Gary S./ Wöll, Andreas (Hg.): Vergangenheitsbewältigung. Modelle der politischen und sozialen Integration in der bundesdeutschen Nachkriegsgeschichte, Baden-Baden: Nomos 1997, S. 29-42.

YUCOM: Attitudes in Serbia Regarding the Demand by one Hundred NGOs for July 11 to be Proclaimed as Remembrance Day of the Srebrenica Genocide, Human Rights and Democracy Violation Early Warning Weekly Newsletter 41 vom 24.7.2009, http:/www.yucom.org.rs/upload/vestgalerija_61_18/12537 90310_GS0_EWS41-English-24072009.pdf vom 12.7.2015.

Zagorac Simonović, Jasna: »Pouka o samolustraciji« [Die Lektion über die Selbstlustration], in: Danas vom 2.2.2012, http://www.danas.rs/danasrs/dijalog/ pouka_o_samolustraciji.46.html?news_id=233222 vom 30.3.2013.

Žarković, Dragoljub: »Dehelsinkizacija gospođe Biserko« [Die Dehelsinkisierung von Frau Biserko], in: Vreme vom 1.8.2002, http://www.vreme.com/ /cms/view.php?id=319354 vom 15.7.2014.

Živojinović, Dragoljub R./Lučić, Dejan V.: Varvarstvo u ime Hristovo. Prilozi za Magnum crimen [Barbarbei im Namen Christi. Beiträge zum Magnum crimen], Belgrad: Nova knjiga 1988. 
Zgonjanin, Dragan: »Istina o zločinima u Vukovaru« [Die Wahrheit über die Verbrechen in Vukovar], in: Milan Bulajić/Radovan Samardžić (Hg.): Ratni zločini i zločini genocida 1991-1992. Naučno savetovanje Odbora SANU za sakupljanje građe o genocidu protiv srpskog naroda i drugih naroda Jugoslavije u XX veku i Državne komisije za ratne zločine i zločine genocida, održano od 6. do 8. avgusta 1992. godine u Beogradu [Kriegsverbrechen und Verbrechen des Genozids 1991-1992. Wissenschaftliche Beratung des SANU-Komitees zur Sammlung von Materialien über den Genozid am serbischen Volk und anderen Völkern Jugoslawiens im 20. Jahrhundert und der Staatskommission für Kriegsverbrechen und Verbrechen des Genozids, abgehalten 6.-8.8.1992], Belgrad: Srpska akademija nauka i umetnosti 1993, S. 205-208.

Zveržhanovski, Ivan: „Watching War Crimes. The Srebrenica Video and the Serbian Attitudes to the 1995 Srebrenica Massacre«, in: Southeast European and Black Sea Studies 7 (2007) 3, S. 417-430. 



\section{Verwendetes Diktionär}

In der lexikometrischen Analyse mit MaxQDA benutzte Suchwörter (token):

$$
\begin{aligned}
& \text { agres* - Aggression, Angriff } \\
& \text { ambas* - Botschaft } \\
& \text { ameri* - amerika* } \\
& \text { anti* - anti } \\
& \text { bezbednost* - Sicherheit }
\end{aligned}
$$$$
\text { Bljes* - Blitz. Hier: kroatische }
$$

Gegenoffensive im Mai 1995, bei der Polizei und Armee innerhalb von etwa 31 Stunden 500 Quadratkilometer der seit 1992 von serbischen Truppen besetzten Teile Westslawoniens zurückeroberten. Ca. 15.000 Serben wurden vertrieben, 283 Zivilisten ermordet bzw. sind bis heute vermisst.

bombardovanj* - Bombardierung Bratun* - Bratunac. B. ist ein kleiner Ort, der nur wenige Kilometer von Srebrenica entfernt liegt und in dem und in dessen Umgebung 1992-1995 ca. 3500 Serben von den Einheiten Naser Orić', dem Kommandanten der

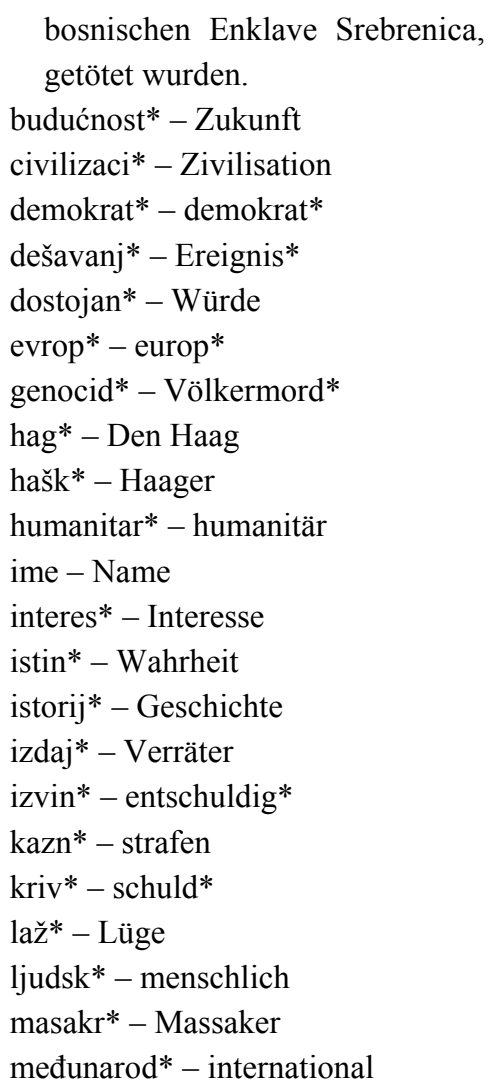




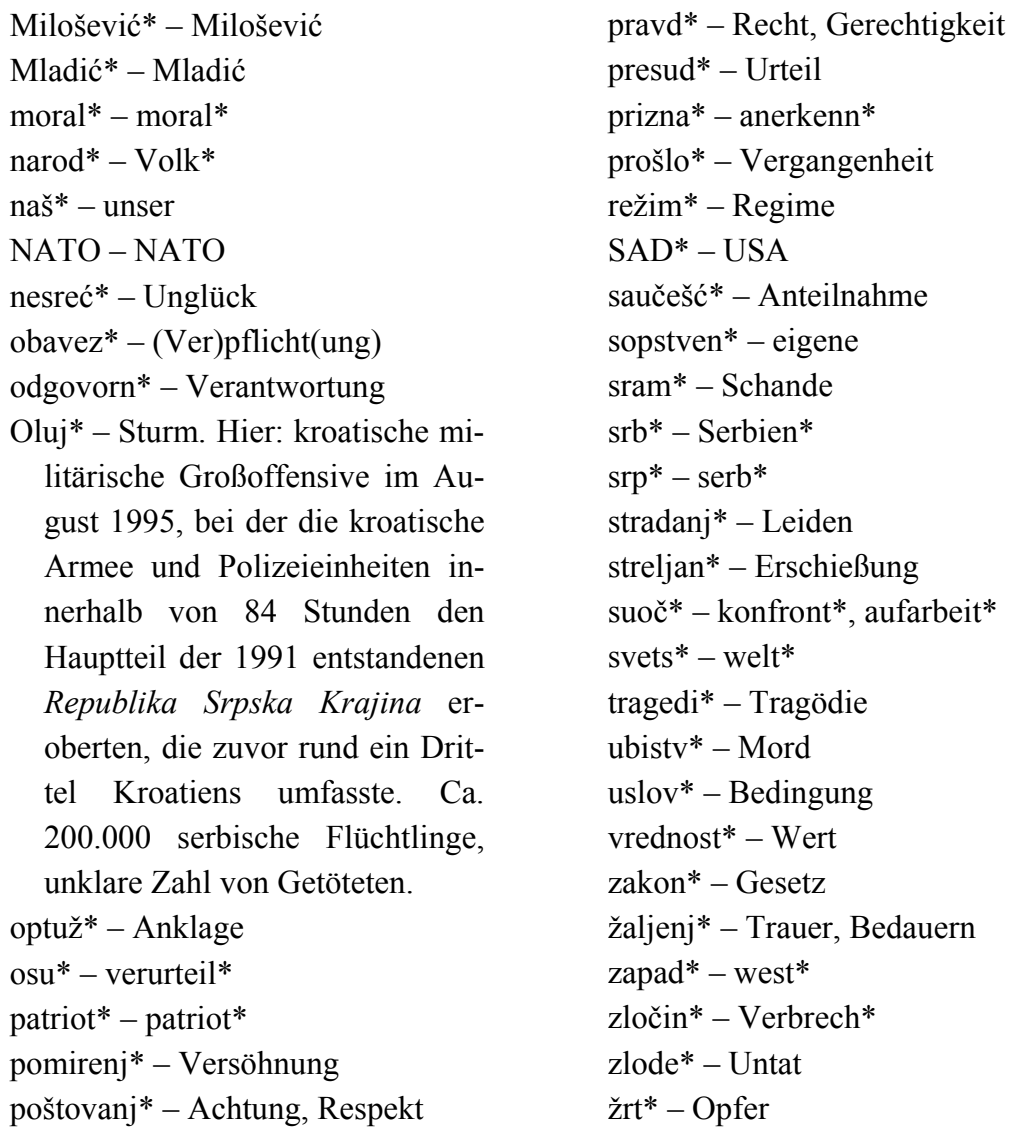




\section{Serbische Auslieferungen an das ICTY}

Vor dem ICTY wurden Prozesse gegen 161 Personen eingeleitet, davon 109 »ethnische« Serben, wovon 57 Bürger der Republik Serbien waren. Das Tribunal forderte von der Republik Serbien schließlich die Auslieferung von insgesamt 46 Personen. Einer von ihnen starb. 14 von ihnen wurden in der Republik Serbien verhaftet, vier in Kooperation mit den Geheimdiensten anderer Länder, 27 stellten sich freiwillig. Unter den Ausgelieferten befanden sich zwei ehemalige Staatspräsidenten, ein ehemaliger Premierminister und ein Vizepremier, drei Generalstabschefs der JNA und der Leiter des Staatssicherheitsdienstes. Die folgende Liste umfasst in chronologischer Reihenfolge der Verhaftungen Namen, Stellung während der Jugoslawienkriege, die Daten der Verhaftung und der Auslieferung an das ICTY sowie die Bezeichnung des Verfahrens.

14 der vom ICTY Angeklagten wurden in der Republik Serbien verhaftet:

Dražen Erdemović, Soldat des 10. Sabotage-Stoßtrupps der bosnischserbischen Armee. Verhaftet am 2.3.1996, Transfer am 30.3.1996. Prozess 1996: Er wurde des Mordes an etwa siebzig Personen im Massaker von Srebrenica für schuldig befunden und mit zehn Jahren Haft bestraft. Im Berufungsprozess 1998 wurde die Strafe auf fünf Jahre Haft reduziert.

Milomir Stakić, Vorsitzender des Krisenstabs der Gemeinde und Vorsitzender des nationalen Verteidigungsrates in Prijedor. Verhaftung und Transfer am 23.3.2001. Prozess 2003: in fünf von acht Anklagepunkten, unter anderem des Mordes, der Verfolgung und der Auslöschung schuldig gesprochen und zu lebenslanger Haft verurteilt. Die Haftstrafe wurde in der Revision 2006 auf vierzig Jahre reduziert.

Slobodan Milošević, Präsident Serbiens ab 1990, 1997-2000 Präsident Jugoslawiens. Festnahme am 1.4.2001, Transfer am 29.6.2001. Starb noch während des ICTY-Prozesses 2006. 
Predrag Banović, Wachmann im bosnisch-serbischen Lager Keraterm. Verhaftung am 8.11.2001, Transfer am 9.11.2001. 2003 wegen Verfolgung zu achtn Jahre Haft verurteilt.

Nenad Banović, Zwillingsbruder von Predrag, ebenfalls Wachmann im Lager Keraterm. Verhaftung am 8.11.2001, Transfer am 9.11.2001. 2002 wurde die Anklage aus Mangel an Beweisen aufgehoben und Nenad Banović freigelassen.

Ranko Ćešić, Mitglied der bosnisch-serbischen Territorialverteidigung in Grčica, Gemeinde Brčko. Verhaftung am 25.3.2002, Transfer am 17.6.2002. Er bekannte sich in allen zwölf Anklagepunkten, darunter Morde und sexuelle Nötigung, schuldig und wurde 2004 zu 18 Jahren Haft verurteilt.

Franko Simatović, Chef der serbischen Geheimpolizei und Kommandant der Einheit für Sondereinsätze. Verhaftung am 13.5.2003, Transfer am 30.5.2003. 2013 wurde er von allen Anklagepunkte freigesprochen.

Jovica Stanišić, Chef des Staatssicherheitsdienstes des Innenministeriums Serbiens. Verhaftung am 13.5.2003, Transfer am 16.6.2003. 2013 wurde er von allen Anklagepunkte freigesprochen.

Veselin Šljivančanin, Major der JNA, in der militärischen Führung während der Schlacht um Vukovar. Verhaftung und Transfer am 13.6.2003. Er wurde gemeinsam mit Milan Mrkšić und Miroslav Radić im Fall »Vukovar Hospital« wegen des Massakers von Vukovar der Kriegsverbrechen und der Verbrechen gegen die Menschlichkeit angeklagt. 2007 verurteilte die Strafkammer ihn zu fünf Jahren Haft. 2009 wurde das Urteil in 17 Jahre Haft revidiert: Das Gericht sprach ihn der Verfolgung und der Unterstützung von Folter im Kontext des Massakers von Vukovar schuldig, von der Komplizenschaft des Mordes wurde er freigesprochen.

Vladimir Kovačević, Kommandeur des 3. Bataillons der Trebinje-Brigaden der JNA, die Dubrovnik bombadierte. Verhaftung am 25.9.2003, Transfer am 23.10.2003. Aufgrund seines Gesundheitszustandes war er nicht prozessfähig, wurde zur medizinischen Behandlung nach Serbien entlassen. Der Fall wurde 2007 an die Belgrader Kammer für Kriegsverbrechen zur weiteren Strafverfolgung im Falle einer Besserung des Gesundheitszustands gegeben.

Stojan Župljanin, Leiter der Sicherheitsdienste in Banja Luka. Verhaftung am 11.6.2008, Transfer am 21.6.2008. 2013 zu 22 Jahren Haft verurteilt.

Radovan Karadžić, Präsident der Republika Srpska. Verhaftung am 21.7.2008, Transfer am 30.7.2008. Prozess läuft.

Ratko Mladić, Oberbefehlshaber und General der bosnisch-serbischen Armee. Verhaftung am 26.5.2011, Transfer am 3.6.2011. Prozess läuft.

Goran Hadžić, 1992/1993 Präsident der Republika Srpska Krajina. Verhaftung am 20.11.2011, Transfer am 22.11.2011. Prozess läuft. 
Vier Festnahmen und Überstellungen in Zusammenarbeit mit den Geheimdiensten anderer Staaten:

Milan Lukić, Anführer der bosnisch-serbischen paramilitärischen Einheit Beli Orlovi (Weiße Adler) in Višegrad. Verhaftung am 8.8.2005 in Buenos Aires, Argentinien. Transfer am 21.2.2006. 2009 der Verfolgung, des Mords, der Vernichtung und anderer unmenschlicher Handlungen und Verbrechen gegen die Menschlichkeit sowie des Mords und der grausamen Behandlung in sechs Fällen schuldig gesprochen und zu lebenslanger Haft verurteilt. 2012 wurde das Urteil im Berufungsprozess bestätigt.

Dragan Zelenović, Militärpolizist in Foča. Verhaftung 2005 in Russland, Transfer am 10.6.2006. 2007 der Folter und Vergewaltigung als Verbrechen gegen die Menschlichkeit und Verletzung des Kriegs-(gewohnheits-)rechts für schuldig befunden und zu 15 Jahren Haft verurteilt.

Zdravko Tolimir, Vize-Kommandeur des Geheimdienstes des Generalstabs der bosnisch-serbischen Armee, verhaftet am 31.5.2007 in BosnienHerzegowina. 2012 in sechs von acht Anklagepunkten, unter anderem des Völkermordes mit Blick auf das Massaker von Srebrenica schuldig gesprochen und zu lebenslanger Haft verurteilt.

Vlastimir Đorđević, stellvertretender Innenminister Serbiens und Leiter der Abteilung für öffentliche Sicherheit im Innenministerium 1997-2001. Verhaftung und Auslieferung am 17.6.2007 in Montenegro. 2011 der Deportationen, des Zwangstransfers, Mordes und der Verfolgung aus politischen, rassistischen oder religiösen Gründen im Zuge der Beteiligung an einer gemeinsamen kriminellen Unternehmung mit Blick auf die serbischen Verbrechen an KosovoAlbanern im Kosovokrieg schuldig gesprochen und zu 27 Jahren Haft verurteilt. 2014 reduzierte das Gericht die Strafe auf 18 Jahre Haft.

27 vom ICTY Angeklagte stellten sich im Rahmen der »freiwilligen Selbstauslieferungen«:

Blagoje Simić, Vorsitzender des Gemeinderats der Serbischen Demokratischen Partei in Bosanski Šamac (Bosnien-Herzegowina) und des serbischen Krisenstabs. Stellte sich freiwillig am 12.3.2001 und wurde am selben Tag an das ICTY überstellt. Wurde der Verbrechen gegen die Menschlichkeit für Verfolgung im Kontext von illegalen Inhaftierungen von bosnisch-muslimischen und -kroatischen Zivilisten, grausamer und inhumaner Behandlung und Unterbringung von Gefangenenen, Deportation und der Zwangsumsiedlung zunächst 2003 zu 17 Jahren Haft verurteilt, die 2006 in 15 Jahre revidiert wurden. 
Pavle Strugar, Kommandeur der 2. Operationsgruppe der JNA, stellte sich am 21.10.2001 freiwillig. Aufgrund des Angriffs auf Zivilisten und der Zerstörung beziehungsweise der absichtlichen Beschädigung historisch-kulturellen Erbes bei der Bombardierung der Altstadt von Dubrovnik wurde er $2005 \mathrm{zu}$ acht Jahren Haft verurteilt. Im Rahmen eines Berufungsprozesses 2009 wurde das Urteil bestätigt, seine Haftstrafe aber aufgrund der Verschlechterung seines gesundheitlichen Zustands um ein halbes Jahr reduziert.

Miodrag Jokić, Vizeadmiral und Kommandeur des 9. militärischen Marinesektors der JNA, kommandierte 1991 den schwerwiegenden Beschuss der Altstadt von Dubrovnik. Er stellte sich am 12.11.2001 freiwillig, legte 2003 ein vollumfängliches Schuldgeständnis ab und wurde 2004 zu einer Gefängnisstrafe von sieben Jahren verurteilt.

Dragoljub Ojdanić, Generalstabschef der Vojska Jugoslavije ab 1998, ab Februar 2000 Verteidigungsminister der Bundesrepublik Jugoslawien. Ojdanić wurde gemeinsam mit Milan Milutinović, Nikola Šainović, Nebojša Pavković, Vladimir Lazarević und Sreten Lukić einer gemeinsamen kriminellen Unternehmung gegen die kosovo-albanische Bevölkerung von Oktober 1998 bis Juni 1999 beschuldigt. Er stellte sich und wurde am 25.4.2002 an das ICTY ausgeliefert. 2009 wurde er der Deportationen und der erwzungenen Vertreibung schuldig gesprochen und zu 15 Jahren Haft verurteilt.

Nikola Šainović war 1994-2000 stellvertretender Premierminister der Bundesrepublik Jugoslawien. Šainović wurde gemeinsam mit Milan Milutinović, Dragoljub Ojdanić, Nebojša Pavković, Vladimir Lazarević und Sreten Lukić im Fall »Milutinović et al.« einer gemeinsamen kriminellen Unternehmung gegen die kosovo-albanische Bevölkerung von Oktober 1998 bis Juni 1999 beschuldigt. Am 2.5.2003 wurde er an das ICTY überstellt. 2009 verurteilte das Gericht ihn aufgrund von Verbrechen gegen die Menschlichkeit und Kriegsverbrechen im Kosovokrieg zu 22 Jahren Haft. Im Berufungsurteil 2014 wurde die Strafe auf 18 Jahre Haft festgesetzt.

Momčilo Gruban stellte sich freiwillig und wurde am 2.5.2002 an das ICTY überstellt. Er war Schichtführer im Lager Omarksa bei Prijedor. Sein Fall wurde gemeinsam mit Željko Mejakić, Dušan Fustar und Duško Knežević als »Mejakić et al.« verhandelt und 2005 an die Kammer für Kriegsverbrechen in BosnienHerzegowina übergeben. Hier wurde Gruban 2008 zu elf Jahren Haft wegen Verbrechen gegen die Menschlichkeit verurteilt.

Milan Martić war vor dem Krieg Polizeichef in der Stadt Knin, 1991-1995 bekleidete er diverse politische Ämter in der Republika Srpska Krajina, unter anderem Außen- und Verteidigungsminister sowie Präsident. Er stellte sich am 15.5.2002 den Behörden. 2007 wurde er vom ICTY zu 35 Jahren Haft verurteilt, 
das ihn in 16 von 19 Anklagepunkten schuldig sprach und ihm die Mitverantwortung für von paramilitärischen Verbänden verübte Taten nachwies. Vom Vorwurf des Völkermords wurde er freigesprochen.

Mile Mrkšić, Oberst der JNA, führte die Einheit, die 1991 für den Angriff auf Vukovar verantwortlich zeichnete. Er stellte sich am 15.2.2002 und wurde am selben Tag nach Den Haag überstellt. Gemeinsam mit Veselin Šlivančanin und Miroslav Radić wurde er im Fall »Vukovar Hospital« wegen des Massakers von Vukovar der Kriegsverbrechen und der Verbrechen gegen die Menschlichkeit angeklagt. 2007 wurde er der Beihilfe bei Mord und Folterung in Bezug auf das Massaker von Vukovar schuldig gesprochen und zu zwanzig Jahren Haft verurteilt.

Milan Milutinović war 1998-2002 Präsident Serbiens und Mitglied des Obersten Verteidigungsrates der Bundesrepublik Jugoslawien 1997-2002. Er stellte sich dem ICTY am 20.1.2003. Anders als seine Mitangeklagten im Prozess »Milutinović et al.«, in dem das ICTY den Angeklagten eine gemeinsame kriminelle Unternehmung gegen die kosovo-albanische Bevölkerung nachweisen wollte, wurde Milutinović 2009 freigesprochen, da seine Schuld als nicht hinreichend erwiesen galt.

Vojislav Šešelj gründete 1990 die Serbische Erneuerungsbewegung (später: Srpski četnički pokret, Serbische Tschetnikbewegung) und ist seit 1991 Vorsitzender der SRS. Šešelj gilt als Anführer mehrerer paramilitärischer Einheiten während des Kroatien- und Bosnienkriegs. Obwohl er das Tribunal als illegitim bezeichnete, stellte er sich am 24.2.2003 dem ICTY, wo er für seine Mitverantwortung für zahlreiche Verbrechen von paramilitärischen Verbänden angeklagt wird. 2006 trat er in einen Hungerstreik, 2009 wurde er wegen Missachtung des Gerichts zu einer 15-monatigen Haftstrafe verurteilt, da er geschützte Informationen veröffentlichte. Das Schlussplädoyim Hauptverfahren er wurde 2012 gehalten, allerdings noch kein Urteil verkündet. Im November 2014 wurde der schwerkranke Šešelj zur medizinischen Behandlung nach Serbien entlassen, in Belgrad von seinen Anhängern jubelnd empfangen und kündigte seine Rückkehr in die Politik und Neuwahlen an. Im März 2015 entschied der Berufungssenat des ICTY, Šešelj müsse nach Den Haag zurückkehren. Dieser weigerte sich, auch mit Verweis auf die Verletzung seiner Grundrechte und die unverhältnismäßige Länge des Prozesses. Der serbische Ministerpräsident schloss zunächst eine erneute Verhaftung und Überstellung Šešeljs an das ICTY aus. Im Mai 2015 verbrannte Šešelj die kroatische Flagge und löste damit diplomatische Spannungen zwischen Kroatien und Serbien aus.

Miroslav Radić war Hauptmann der JNA und nahm an der Schlacht um Vukovar teil. Er stellte sich am 21.3.2003 freiwilig dem ICTY. Gemeinsam mit 
Milan Mrkšić und Veselin Šlivančanin wurde er im Fall »Vukovar Hospital« wegen des Massakers von Vukovar der Kriegsverbrechen und der Verbrechen gegen die Menschlichkeit angeklagt. 2007 wurde er von allen Anklagepunkten aufgrund von mangelnden Beweisen für eine direkte Beteiligung freigesprochen.

Željko Mejakić, Polizist, Sicherheitschef und ab Juni 1992 Leiter des Lagers Omarska bei Prijedor. Er stellte sich am 4.7.2003 freiwillig und wurde im Fall »Mejakić et al.« gemeinsam mit Dušan Fustar, Duško Knežević und Momčilo Gruban angeklagt. Mejakić war Schichtführer im Lager Omarksa bei Prijedor. 2008 wurde er von der Kammer für Kriegsverbrechen in Sarajevo des Morders, der Folter, der Vergewaltigung und anderer unmenschlicher Verbrechen gegen Gefangene in Omarska zu 21 Jahren Haft verurteilt. Das Berufungsurteil bestätigte das verhängte Strafmaß.

Mitar Rašević war Kommandeur der Wachen im Gefängnis »KP Dom« in Foča von April 1992 bis Oktober 1994. Rašević stellte sich dem ICTY am 15.8.2003. Sein Fall wurde gemeinsam mit dem von Savo Todović verhandelt und 2006 an die Kammer für Kriegsverbrechen Bosnien-Herzegowinas überführt, die ihn 2008 der Verbrechen gegen die Menschlichkeit für schuldig sprach und zu acht Jahren und sechs Monaten Haft verurteilte.

Ljubiša Beara, Oberst und Sicherheitschef des Generalstabs der Armee der Republika Srpska. Er gilt als Hauptkoordinator des Plans, der zum Massaker von Srebrenica führte. Er stellte sich am 9.10.2004 dem ICTY und wurde mit sechs weiteren Offizieren des bosnisch-serbischen Militärs und der Polizei im Verfahren »Popović et al.« angeklagt. ${ }^{1} 2010$ wurde er wegen seiner Beteiligung am Massaker von Srebrenica wegen Völkermords zu lebenslanger Haftstrafe verurteilt. Im Urteil des Berufungsprozesses 2015 wurde der Tatbestand um »Verschwörung zum Völkermord « erweitert und das Strafmaß bestätigt.

Dragomir Milošević, General der Armee der Republika Srpska, Stabschef des Kommandeurs und später Kommandeur des Sarajevo-Romanija-Korps, das Sarajevo 1992-1995 belagerte. Im Dezember 2004 stellte Milošević sich freiwillig den serbischen Behörden und wurde an das ICTY überstellt. 2007 wurde er vor dem ICTY wegen Kriegsverbrechen und Verstößen gegen das Kriegs(gewohnheits-)recht zu 33 Jahren Haft verurteilt. Im Berufungsverfahren 2007 wurde die Strafe auf 29 Jahre reduziert.

Vladimir Lazarević war ab 1998 Generalstabschef und wenig später Kommandeur des Priština-Korps, ab 1999 Generalstabschef der dritten Armee der ju-

1 Die Anklage ging hierbei von zwei Tatkomplexen aus: einerseits der gemeinsamen kriminellen Unternehmung des Mordes und andererseits der gemeinsamen kriminellen Unternehmung des Zwangstransfers der Bevölkerung von Srebrenica und Žepa. 
goslawischen Streitkräfte. Lazarević stellte sich nach Beratungen mit Ministerpräsident Koštunica am 3.2.2005 den serbischen Behörden und wurde an das ICTY überstellt. Patriach Pavle und Koštunica lobten ihn für diese schwierige Entscheidung im Interesse seines Heimatlandes. Das ICTY klagte ihn gemeinsam mit Nikola Šainović, Milan Milutinović, Dragoljub Ojdanić, Nebojša Pavković und Sreten Lukić im Fall »Milutinović et al.« einer gemeinsamen kriminellen Unternehmung gegen die kosovo-albanische Bevölkerung von Oktober 1998 bis Juni 1999 an. Im Februar 2009 wurde er wegen Deportationen und anderen unmenschlichen Verbrechen wie der erzwungenen Verteibung zu 15 Jahren Gefängnis verurteilt. Im Berufungsprozess 2014 wurde das Strafmaß auf 14 Jahre reduziert.

Milan Gvero, stellvertretender Befehlshaber im Generalstab der bosnischserbischen Armee, zuständig für moralische, juristische und religiöse Angelegenheiten. Er stellte sich freiwillig am 24.2.2005. Er wurde gemeinsam mit sechs weiteren Offizieren des bosnisch-serbischen Militärs und der Polizei im Verfahren »Popović et al.« wegen seiner Mitverantwortung für das Massaker in Srebrenica angeklagt. 2010 wurde er zu fünf Jahren Haft wegen der Verhinderung humanitärer Hilfe für die vom Tode bedrohten Menschen in Srebrenica verurteilt. Aufgrund seines schlechten Gesundheitszustandes wurde er vorzeitig aus der Haft entlassen, er verstarb 2013.

Radivoje Miletić, Operations- und Ausbildungleiter des stellvertretenden Generalstabschefs der bosnisch-serbischen Armee. Er stellte sich am 24.2.2005 freiwillig und wurde gemeinsam mit sechs weiteren Offizieren des bosnischserbischen Militärs und der Polizei im Verfahren »Popović et al.« angeklagt. Miletic wurde der Verhinderung humanitärer Hilfe für die vom Tode bedrohten Menschen in Srebrenica für schuldig befunden und 2010 zu 19 Jahren Haft verurteilt, im Revisionsurteil 2015 auf 18 Jahre reduziert.

Momčilo Perišić, Generalstabschef der jugoslawischen Armee 1993-1998. Umgehend nach der Anklageerhebung durch das ICTY stellte er sich am 7.3.2005. 2011 wurde er für seine Mitverantwortung für die Belagerung Sarajevos, einen Raktenangriff auf Zagreb und seine Mitverantwortung am Massaker von Srebrenica zu 27 Jahren Haft verurteilt. Im Berufungsverfahren 2013 wurde er von allen Anklagepunkten freigesprochen, da nicht zweifelsfrei erwiesen werden konnte, dass Perišić die Truppen der kroatischen und bosnischen Serben bei den begangenen Verbrechen unterstützt hatte.

Mićo Stanišić war Innenminister in der Republika Srpska. Er stellte sich am 11.3.2005 freiwillig, nachdem er vom ICTY gemeinsam mit Stojan Župljanin für Verbrechen gegen die bosnisch-muslimische und bosnisch-kroatische Bevölkerung angeklagt wurde. 2013 sprach ihn die Strafkammer der Vertreibung, Folter, 
Ausrottung, Zwangsumsiedlung sowie des Mordes schuldig und verurteilte ihn zu 22 Jahren Haft.

Gojko Janković war Unterbefehlshaber der bosnisch-serbischen Militärpolizei in Foča. Er stellte sich freiwillig, am 14.3.2005 Transfer an das ICTY. Sein Fall wurde im November 2005 an die Kammer für Kriegsverbrechen BosnienHerzegowinas überführt. 2007 verurteilte ihn das Gericht wegen Verbrechen gegen die Menschlichkeit, vor allem wegen Gewalt und Verbrechen gegen Zivilisten, zu 34 Jahren Haft.

Drago Nikolić war Sicherheitschef der Zvornik-Brigade der bosnischserbischen Armee. Am 17.3.2005 wurde er an das ICTY überführt, nachdem er sich freiwillig gestellt hatte. Er wurde gemeinsam mit sechs weiteren Offizieren des bosnisch-serbischen Militärs und der Polizei im Verfahren »Popović et al.« wegen seiner Mitverantwortung für das Massaker in Srebrenica angeklagt. 2010 wurde er wurde wegen Beihilfe zum Völkermord sowie zur Vertreibung und Vernichtung von Menschen zu 35 Jahren Haft verurteilt. Der Berufungsprozess ist noch anhängig.

Vinko Pandurević war Kommandeur der Zvornik-Brigade des Drina-Korps der bosnisch-serbischen Armee, er stellte sich am 23.5.2005. Er wurde vom ICTY gemeinsam mit sechs weiteren Offizieren des bosnisch-serbischen Militärs und der Polizei im Verfahren »Popović et al.« wegen seiner Mitverantwortung für das Massaker in Srebrenica angeklagt. 2010 wurde er wegen Beihilfe zum Mord sowie zur Verfolgung und Vernichtung von Menschen zu 13 Jahren Gefängnisstrafe verurteilt. Der Berufungsprozess 2015 bestätigte das Strafmaß. Im April 2015 wurde Pandurević vorzeitig aus der Haft entlassen.

Ljubomir Borovčanin war 1990-1992 Leiter der Polizeistation von Kladanj, 1992-1995 der Polizeistation von Bratunac und ab dem 10.7.1995 stellvertretender Kommandeur der Sonderpolizeibrigade des Innenministeriums der Republika Srpska. Er stellte sich am 1.4.2005 dem ICTY, wo er gemeinsam mit sechs weiteren Offizieren des bosnisch-serbischen Militärs und der Polizei im Verfahren »Popović et al.« wegen seiner Mitverantwortung für das Massaker in Srebrenica angeklagt wurde. 2010 verurteilte ihn das Gericht wegen der gezielten Vernichtung von Menschenleben, Mordes und gewaltsamer Vertreibung zu 17 Jahren Haft.

Sreten Lukić war ab Mai 1998 Beauftragter des serbischen Innenministeriums für Kosovo und Metohija und ab 1999 Chef der Abteilung für öffentliche Sicherheit und der Grenzschutzbehörde. Er stellte sich am 4.4.2005 dem ICTY, wo er gemeinsam mit Milan Milutinović, Nikola Šainović, Nebojša Pavković, Vladimir Lazarević und Dragoljub Ojdanić wegen einer gemeinsamen kriminellen Unternehmung gegen die kosovo-albanische Bevölkerung von Oktober 1998 
bis Juni 1999 angeklagt wurde. Die Strafkammer befand ihn der Vertreibung, der Zwangsumsiedlung, der Verfolgung und des Mordes für schuldig und verurteilte ihn zu 22 Jahren Haft. Das Strafmaß wurde im Berufungsprozess auf zwanzig Jahre reduziert.

Vujadin Popović war Oberstleutnant und Sicherheitsoffizier des DrinaKorps der bosnisch-serbischen Armee. Am 14.4.2005 wurde er an das ICTY ausgeliefert, wo er gemeinsam mit sechs weiteren Offizieren im nach ihm benannten Verfahren »Popović et al.« wegen seiner Mitverantwortung für das Massaker in Srebrenica angeklagt wurde. Die Anklage konnte darlegen, dass Popović am Tag des Massakers in Potočari an fast allen Schauplätzen der Verbrechen anwesend und voll über die Massenmorde informiert war. 2010 wurde er des Völkermordes, der Massenvernichtung, des Mordes und der Verfolgung schuldig gesprochen und zu lebenslanger Haft verurteilt. Im Berufungsprozess wurde der Tatbestand um »Verschwörung zum Völkermord« erweitert, das Urteil 2015 bestätigte das Strafmaß.

Nebojša Pavković war 1998-2000 Kommandeur der dritten Armee der jugoslawischen Streitkräfte und 2000-2002 Generalstabschef der Jugoslawischen Armee. Er wurde am 25.4.2005 überstellt. Pavković wurde gemeinsam mit Milan Milutinović, Dragoljub Ojdanić, Nikola Šainović, Vladimir Lazarević und Sreten Lukić im Fall »Milutinović et al.« einer gemeinsamen kriminellen Unternehmung gegen die kosovo-albanische Bevölkerung von Oktober 1998 bis Juni 1999 angeklagt. 2009 verurteilte die Strafkammer ihn zu 22 Jahren Haft, 2014 wurde dieses Urteil bestätigt. 

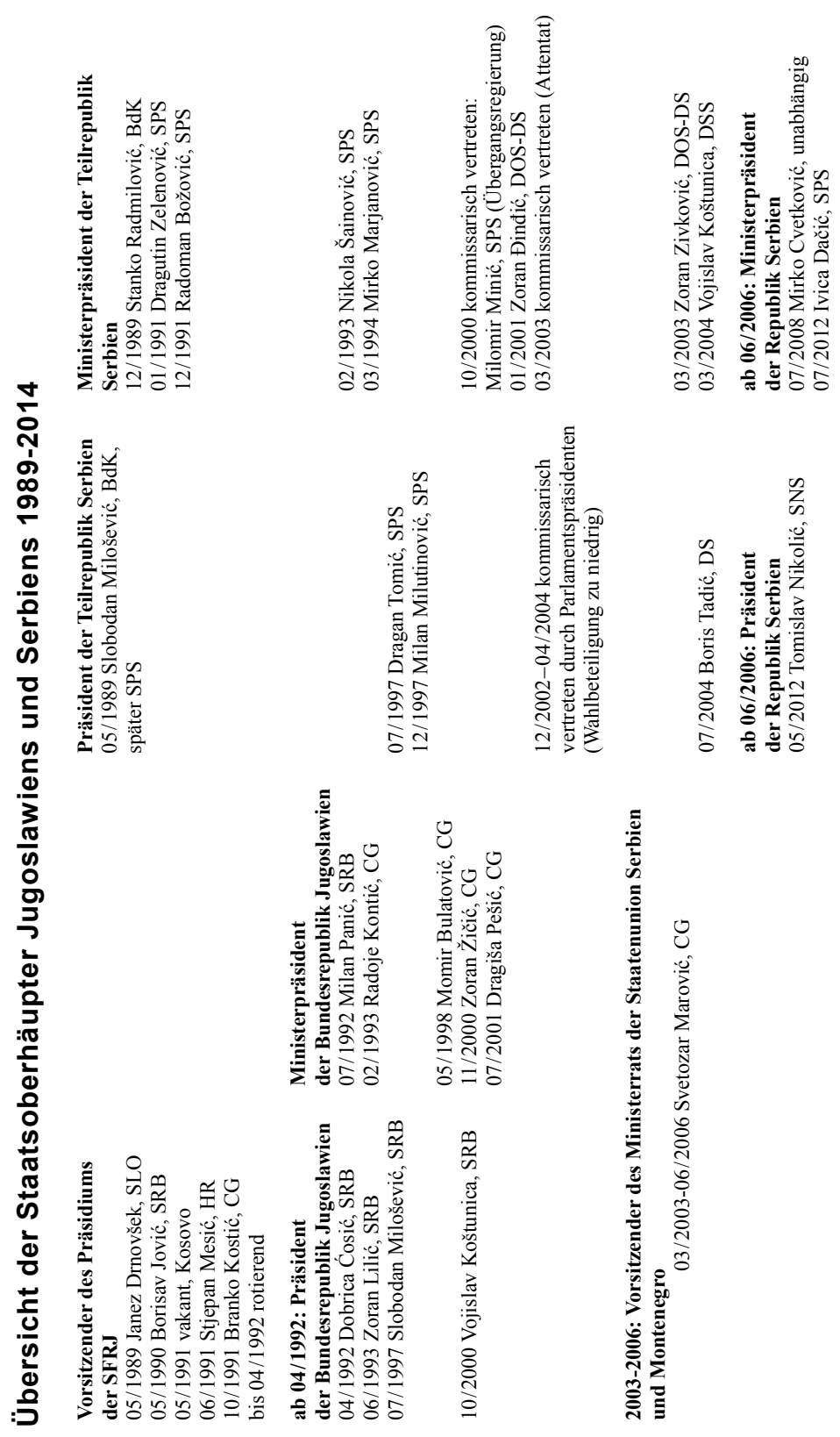


\section{Global Studies}

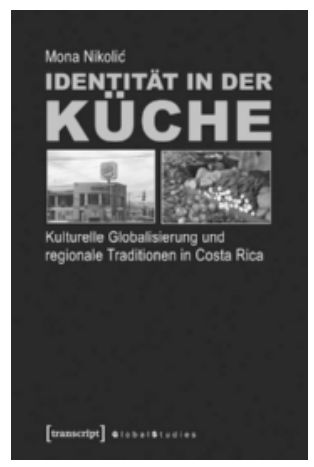

Mona Nikolic

Identität in der Küche

Kulturelle Globalisierung und regionale

Traditionen in Costa Rica

April 2015, 374 Seiten, kart., zahlr. z.T. farb. Abb., 49,99€, ISBN 978-3-8376-2979-8

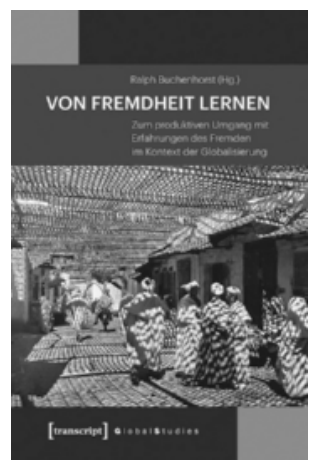

Ralph Buchenhorst (Hg.)

Von Fremdheit lernen

Zum produktiven Umgang mit Erfahrungen

des Fremden im Kontext der Globalisierung

April 20I5, 306 Seiten, kart., 34,99€,

ISBN 978-3-8376-2656-8

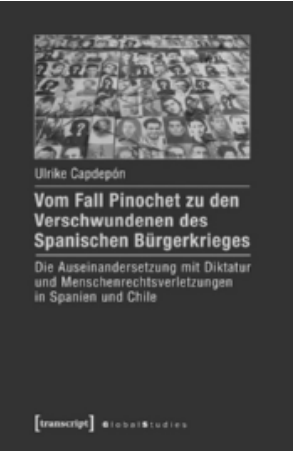

Ulrike Capdepón

Vom Fall Pinochet zu den Verschwundenen des Spanischen Bürgerkrieges

Die Auseinandersetzung mit Diktatur und Menschenrechtsverletzungen in Spanien und Chile

März 20I5, 376 Seiten, kart., 34,99€, ISBN $978-3-8376-2347-5$ 


\section{Global Studies}
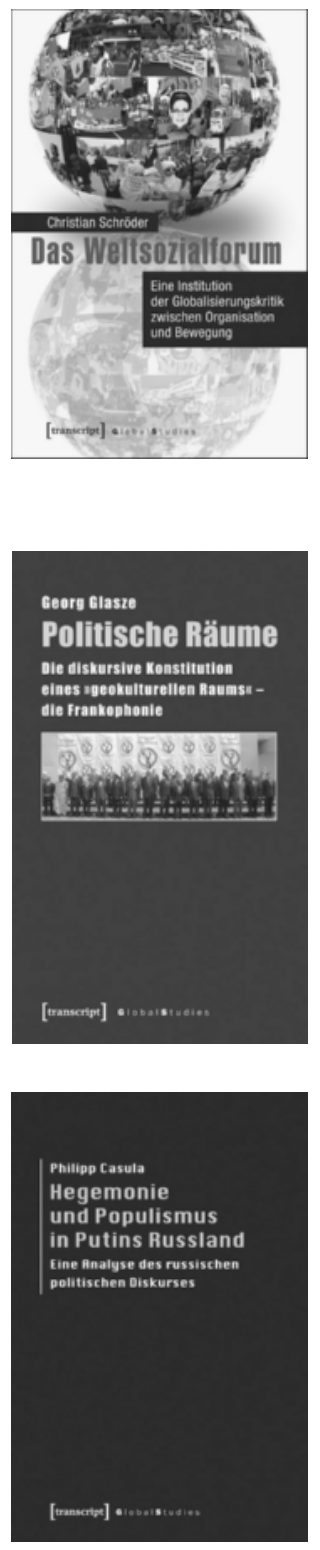

\section{Christian Schröder}

Das Weltsozialforum

Eine Institution der Globalisierungskritik

zwischen Organisation und Bewegung

März 2015, 298 Seiten, kart., zahlr. z.T. farb. Abb., 34,99€, ISBN 978-3-8376-2967-5

\section{Georg Glasze}

\section{Politische Räume}

Die diskursive Konstitution eines

»geokulturellen Raums« - die Frankophonie

2013, 272 Seiten, kart., 29,80€,

ISBN 978-3-8376-I232-5

\section{Philipp Casula}

Hegemonie und Populismus in Putins Russland Eine Analyse des russischen politischen Diskurses

20I2, 350 Seiten, kart., 33,80€,

ISBN 978-3-8376-2105-I 